\title{
D. Grab und Kloster - Basin und Liutwin Zwei heilige Bischöfe - Rezeption und Wirkung von Hinkmars Geschichtsbildern in Trier
}

Im 10. Jahrhundert fanden Erzbischof Hinkmars (845-882) Reimser Geschichtsbilder also Eingang in Trier. Doch wie gelangten sie dorthin? Wie entfalteten sie ihre Wirkung? Welches eigene Wissen hatten die Trierer dem entgegenzusetzen? Über was verfügten sie? Wie war es in Trier überhaupt um die Vergangenheit bestellt? Dies soll im folgenden an Milos vermeintlichem Vater Bischof Liutwin von Trier und dessen Onkel, dem Bischof Basin, genauer untersucht werden. Wie bestimmten Hinkmars Bilder die Trierer Bilder von diesen beiden?

\section{Zwei Bischöfe und der Einfall der Normannen}

1. Als Trier sein Gedächtnis verlor - Der Normannenüberfall von 882

„Als die Normannen den Tod des Königs [Ludwig III., des Jüngeren von Ostfranken (876-882)] vernahmen, überlassen sie sich ungemessenem Jubel und denken jetzt nicht mehr an Kampf, sondern nur an Beute. Sie brechen also mit allen ihren Streitkräften aus ihrem befestigten Lager hervor und erobern Trier, die berühmteste Stadt Galliens am 5. April, dem Tage des heiligsten Abendmahles des Herrn. Hier ruhten sie bis zum heiligen Ostertage die vom Marsche ermüdeten Glieder aus und verwüsteten das ganze Gebiet der Stadt ringsumher von Grund aus; dann lassen sie die Stadt in Flammen aufgehen und führen ihre Scharen nach Metz. Als dies der Bischof dieser Stadt erfuhr, vereinigte er sich mit dem Bischof Bertulf [von Trier] und dem Grafen Adalhard und rückt jenen aus eigenem Entschlusse zur Schlacht entgegen. Es kam zum Kampf und die Normannen blieben Sieger. Jener Bischof Wala [von Metz] fiel in der Schlacht, die übrigen flohen. Die Heiden geben den Zug, den sie begonnen hatten, auf und kehren mit unermeßlicher Beute in größter Schnelligkeit zu ihrer Flotte zurück. "1

1 Vgl. Regino, Chronik, ed. Rau, S. 263. Vgl. dazu Regino, Chronicon ad a. 882, ed. Kurze, S. 119: Nortmanni audita morte regis nimio exultant tripudio et iam non de conflictu, sed de preda cogitant. Igitur cum omnibus viribus a munitione exiliunt et Trevirorum nobilissimam civitatem Galliarum Nonas Apr. die sacratissimae cęnae Domini occupant. In qua usque sancto die paschae fessa ab itinere corpora recreantes omne territorium urbis circumquaque usque ad solum demoliti sunt; deinde civitatem flammis exurentes Mediomatrico dirigunt aciem. Quod cum comperisset eiusdem urbis antistes, adiuncto sibi 
Mit diesen Worten beschreibt Regino von Prüm (†915) in seiner Chronik eines der wohl einschneidendsten Ereignisse für die Trierer Geschichte des frühen Mittelalters: die Plünderung und erhebliche Zerstörung Triers im Jahr 882. Regino lebte zunächst als Mönch im Kloster Prüm - vielleicht schon unter Abt Ansbald (†886) - und war ab 892 selbst dort Abt. ${ }^{2}$

Auch Prüm plünderten die Normannen: an Epiphanias 882. Noch vor ihrem Beutezug nach Trier hielten sie sich drei Tage im Kloster auf, verwüsteten es, beraubten die dortige Umgebung und steckten es schließlich in Brand. Die Wasserwege von Prüm, Sauer, Saar und Mosel ermöglichten den Drachenbooten große Mobilität. Die Klöster Echternach an der Sauer und Mettlach an der Saar lagen als weitere Opfer in unmittelbarer Reichweite. Regino wußte von den Ereignissen in Prüm wahrscheinlich aus den Erzählungen seiner Mitbrüder und vermerkte: „Als sie abzogen, verzehrte das Feuer, welches in verschiedenen [Wohn-]Gebäuden brennend zurückgeblieben war, das Kloster, weil niemand zum Löschen da war. “3 Dieser Überfall und ein weiterer 892 - dann während

Bertulfo episcopo et Adalardo comite ultro illis obviam ad pugnam procedit. Inito certamine Nortmanni victores extiterunt. Isdem Wala episcopus in prelio cicidit, ceteri fugerunt. Pagani iter, quod ceperant, deserentes cum ingenti preda summa celeritate ad classem revertuntur. Vgl. zu den weiteren Quellen BM ${ }^{2}$ 1627a, S. 683 f. DüMmLER, Jahrbücher 3, S. $161 \mathrm{f}$. Vgl. ferner unten Anm. 6. Zum Erzbistum Trier vgl. hier noch zusammenfassend Germ. Pont. 10, ed. Bosнof, S. 1 ff. - Weiterführend zu den in Kap. D. vorgestellten Überlegungen ist auch die Dissertation von KRÖNERT, La construction du passé de la cité de Trèves VIIIe-XIe siècle, zu nennen, die allerdings nicht mehr berücksichtigt werden konnte. Deren Manuskriptfassung ist derzeit als "Thèse à la carte“ bestellbar. Doch ergänzen sich die Studie Krönerts und die hier vorliegende Arbeit in ihren Ergebnissen wechselseitig. Krönert hat die Trierer Hagiographie des 8. bis 11. Jahrhunderts untersucht und zeigt, daß hagiographische Texte in Trier überhaupt erst seit den 960er Jahren verstärkt einsetzen. Da jedoch über die behandelten Heiligen und die Trierer Vergangenheit zur Abfassungszeit dieser Texte kaum mehr Quellen vorlagen, handle es sich bei der beschriebenen Vergangenheit der Stadt um eine Rekonstruktion bzw. überwiegend um eine ,Konstruktion im quellenfreien Raum', die in der Folge sogar noch aus- und weitergeschrieben worden sei. Eine kurze Zusammenfassung der Dissertation in Aufsatzform liegt inzwischen vor als KRÖNERT, Trierer Heiligenviten. Die endgültige Fassung KRöNERT, L'exaltation de Trèves. Eciture hagiographique et passé historique de la métropole mosellane (VIIIe-XIe siècle), ist in Vorbereitung. Erste Reaktionen auf die Manuskriptfassung finden sich bereits in Anton, Neue Studien zu Trier im frühen und hohen Mittelalter, und auf diesen wiederum in KRÖNERT, Erwiderung.

2 Vgl. zu Regino, auch im folgenden, Regino, Chronik, ed. Rau, S. 6-10. WattenbachLevison-Löwe, Geschichtsquellen 6, S. 897-904. Weber, Moral, S. 231 ff. Sanderson, Archbishop Radbod, Regino of Prüm. Vgl. zuletzt Laudage, Regino. WisplingHOFF, Geschichte des Klosters Prüm an der Wende vom 9. zum 10. Jahrhundert, S. 439 ff., der den Sturz Reginos aufgrund innerklösterlicher Auseinandersetzungen vermutet. Vgl. ferner Regino, Sendhandbuch, ed. Hartmann, S. 3-17. - Zu Prüm vgl. hier zudem Germ. Pont. 10, ed. Boshof, S. 268 ff. Vgl. auch unten Anm. 5.

3 Regino, Chronik, ed. Rau, S. 263. Vgl. dazu Regino, Chronicon ad a. 882, ed. Kurze, S. 118: Illis discedentibus ignis, qui in diversis habitaculis accensus remanserat, cum nullus 
Reginos Abbatiat (892-899) - veranlaßten diesen, wohl wegen jetzt vernichteter und verlorener Besitzurkunden in umfangreicher Arbeit die Prümer Besitzungen und Güter rekonstruieren zu lassen. Das bekannte Prümer Urbar entstand. ${ }^{4}$ Durch eine Intrige verlor Regino 899 jedoch sein Amt und floh zu Erzbischof Radbod (883-913) nach Trier, der ihn zum Abt von St. Martin am Moselufer vor der Stadt machte und wohl mit dem Wiederaufbau dieses Klosters beauftragte. Hier arbeitete er nun an seinem Hauptwerk: der Chronik. Er verwendete dazu auch die knappen Einträge der Prümer Annalen. Vielleicht hatte er eine Abschrift mit nach Trier gebracht. Die Chronik schloß er $908 \mathrm{ab}$ und widmete sie Bischof Adalbero von Augsburg (887-909), dem Erzieher Ludwigs des Kindes (893-911), des damaligen ostfränkischen Königs. Regino starb 915 und wurde wohl in der Trierer Abtei St. Maximin bestattet. ${ }^{5}$ Er kannte das niedergebrannte Trier also aus eigener Anschauung.

Die Zerstörungen waren beträchtlich. Kultgegenstände, Reliquien, Kirchenausstattungen, Kodizes mit wertvollen Einbänden, all dies dürfte Beute der Nordmänner geworden sein. Die außerhalb Triers gelegenen Klöster St. Maximin im Norden und St. Eucharius im Süden traf es besonders hart. Nicht nur sie selbst, auch ihre Vergangenheit wurde ausgelöscht, ihre Bibliotheken, ihre Archive. Was nicht in Sicherheit gebracht werden konnte, verbrannte. Nur eine einzige echte Urkunde ist für St. Maximin noch aus der Zeit vor dem Überfall überliefert und diese lediglich abschriftlich im 13. Jahrhundert (MRUB I 83); eine für St. Eucharius (MRUB I 7a) dagegen ist verdächtig. Ähnliches gilt für die Stadt selbst. Nur wenig ist noch erhalten, gerade einmal zwei im Original vorliegende Urkunden für die Trierer Bischofskirche (BMㄹ 626 u. DLoI. 67), keine einzige echte für die dortigen Klöster wie das berühmte St. Maria beim alten Kornspeicher, der ihm den Namen Oeren gab. Trier und wohl auch sein Umland verloren damit ihr Gedächtnis. Die Schwierigkeiten, später Informationen über die eigene Geschichte vor dem Normanneneinfall zusammenzu-

esset, qui eum extingueret, monasterium consumpsit. - Vgl. insgesamt zu den Quellen und weiteren Ereignissen BM ${ }^{2}$ 1573a, S. 668 f. DümmLER, Jahrbücher 3, S. 159-161. - Zu einer möglichen Plünderung Mettlachs vgl. Wattenbach-Levison-Löwe, Geschichtsquellen 6, S. 894.

4 Vgl. zum Prümer Urbar hier nur Seibert, Prümer Urbar, Sp. 291 f. WattenbachLevison-Löwe, Geschichtsquellen 6, S. 898 f. Anno verbi incarnati DCCCXCIII conscriptum, ed. Nolden. Willwersch, Grundherrschaft. - Vgl. zu Prüm auch Haubrichs, Abtei Prüm, S. $34 \mathrm{f}$. Wisplinghoff, Gründungsgeschichte. Wisplinghoff, Geschichte des Klosters Prüm an der Wende vom 9. zum 10. Jahrhundert.

5 Vgl. zu Bischof Radbod unten S. 179, 218 f., 347 ff., 372 u. Anm. 245, 378-380, 727 ff., 796 f., sowie bes. Kap. D.IV.4.-5. - Vgl. zur Chronik und deren Entstehung auch Boschen, Annales Prumienses, bes. S. 183 ff. u. 210-226. Ann. Prum. ad a. 882, ed. Holder-Egger, S. 1291, sowie oben Anm. 2. Zu Reginos Beisetzung in St. Maximin vgl. seine dort 1581 aufgefundene, fragmentarisch erhaltene Grabinschrift in: Regino, Chronicon, ed. Kurze, S. VI. 
tragen, belegen dies mehr als deutlich. ${ }^{6}$ Allerdings ist es wahrscheinlich, daß man im Wissen um die anrückenden Nordmänner noch einiges in Sicherheit brachte. Es wird ebenso diskutiert, ob nicht doch Trierer Bestände unberührt blieben. ${ }^{7}$ Die Frage stellt sich dennoch, wie z. B. die Prümer Annalen und die zahlreichen im Prümer Urbar aufgezeichneten Nachweise Bestand haben konnten.

Einige Informationen zu Trier vor 882 erhielten sich in außerhalb der Stadt verfaßten oder aufbewahrten Quellen: Annalen, Geschichtswerken, Viten, Briefsammlungen, Synodalprotokollen etc. Doch dazu gehörte ebenso eine von Hinkmar geprägte Reimser Tradition, die sich über Trier äußerte. Letztlich starb auch Hinkmar als alter und geschwächter Mann im Jahr dieses Überfalls, als er

$6 \mathrm{Zu}$ den Zerstörungen insgesamt vgl. Anton, Trier im frühen Mittelalter, S. 173 f., 180 f., mit weiterer Literatur. Anton, Trier in der hohen und späten Karolingerzeit, S. 78 f. Anton, Raumbestimmende Voraussetzungen, S. 186. Zuletzt auch den Ausstellungskatalog Wikinger am Rhein, ed. Willemsen. - Zu St. Maximin und der einzig erhaltenen Urkunde vgl. MRUB I 83, S. 88 f. Es handelt sich um die Schenkung der Erkanfrida vom 1. April 853. Wisplinghoff, St. Maximin bei Trier, S. 5 ff., zeigt, daß man in späteren Jahren förmlich nach Erklärungsmustern im Kloster suchte, warum man keine Informationen über die Frühzeit mehr fand. Gießmann, Besitzungen, S. 23-28, zur Zerstörung des Archivs und den ersten Kopiarbüchern. Vgl. ferner auch Germ. Pont. 10, ed. Boshof, S. 185 ff. Zuletzt Heyen u.a., Trier, St. Maximin, mit einer umfassenden Geschichte des Klosters, sowie Neyses, Baugeschichte, der die dortigen Grabungen dokumentiert hat. - Vgl. zu St. Paulin Heyen, St. Paulin, S. 89. Vgl. zu St. Paulin insgesamt auch Germ. Pont. 10, ed. Boshof, S. $231 \mathrm{ff} .-\mathrm{Zu}$ St. Eucharius vgl. zunächst insgesamt Germ. Pont. 10, ed. Boshof, S. $214 \mathrm{ff}$. Vgl. hier sodann Becker, St. Eucharius, S. 1-6, bes. S. 6 u. S. 78 f., 245 f. Nochmals zusammenfassend Becker, Trier, St. Eucharius-St. Matthias. Bei der womöglich einzigen erhaltenen Urkunde handelt es sich mindestens um eine Teilfälschung. Vgl. dazu MRUB I 7a, S. 9 f., sowie PAulY, Älteste Urkunde, schließlich ausführlicher unten Kap. D.III.1., wo sie dann klar als Fälschung nachgewiesen wird. - Im Original sind zwei Trierer Urkunden erhalten: die Immunitätsbestätigung Ludwigs des Frommen für die Trierer Kirche unter Erzbischof Hetti vom 27. August 816 sowie die Restitution Mettlachs an Trier durch Kaiser Lothar I. am 29. August 842. Vgl. dazu MRUB I 50, 69, S. 55-57, 77 f., sowie DLoI. 67, S. 178-180. In Teilen echt könnte auch die Bestätigung der Trierer Kirche unter Erzbischof Weomad (762-791) durch Karl den Großen vom 1. April 772 sein. Vgl. MRUB I 24, S. 28 f. DKarol. I 66, S. 95-97. - Zu den frühen Prümer Urkunden allerdings mit dem Glauben an deren Echtheit - vgl. nochmals Wisplinghoff, Gründungsgeschichte.

7 Vgl. dazu nur Laufner, Klosterbibliothek St. Maximin, S. 17-30, der die These vertritt, daß ein Teil der Klosterbibliothek erhalten blieb. Man finde noch heute zahlreiche Handschriften aus dem Klosterbestand, die vor 882 entstanden seien. Es handle sich um etwa 30 Bände bzw. Teilbände (ebd., S. 20 ff.). - Dabei sollte man allerdings bedenken, $\mathrm{da}$ diese auch andernorts nach 882 erworben worden sein könnten. - Zur Bibliothek und deren Verlusten vgl. schließlich Кловцісн, Bibliothek, S. 16 ff. u. $80 \mathrm{ff}$. 
sich auf der Flucht aus Reims vor den Normannen mit den Reliquien des hl. Remigius befand. Doch blieb Reims das Trierer Schicksal erspart. ${ }^{8}$

Triers Vergangenheit aus diesen wenigen Zeugnissen und Spuren zu rekonstruieren, gleicht einem komplexen Puzzle. Nicht anders stellte es sich für die Verfasser der ersten Trierer Geschichtswerke des 11. Jahrhunderts dar. Vor allem der in dessen drittem Viertel geschriebene Libellus de rebus Treverensibus sammelte viele Versatzstücke. Über Seiten werden ältere, noch greifbare Quellen und Werke zu Trier zitiert und um eigene Kommentare ergänzt. Manche davon stammen aus Reims und sind von Hinkmar beeinflußt. Viel mehr erhaltenes Material, als der Libellus zusammentrug, kann es kaum mehr gegeben haben. Doch verfolgte dieser Text, den KöLzER eine „mehr schlecht als recht geratene Stoffsammlung für die Interessen des Trierer Erzbischofs" nennt, auch ein politisches Ziel: Aus den erhaltenen Vorlagen sollte die Trierer Vergangenheit so rekonstruiert bzw. konstruiert werden, wie sie der Auftraggeber des Libellus' der Trierer Erzbischof Eberhard (1047-1066) - für wahr hielt, nicht so, wie sie tatsächlich verlaufen sein dürfte. Hier wurden also die noch erhaltenen situativen Geschichtsbilder zu einem neuen situativen Bild zusammengefügt, ohne auch nur die Bilder berücksichtigen zu können, die es einmal gab und die längst verloren waren. Ähnlich gingen der oder die Autoren der Trierer Redaktion A der Gesta Treverorum (1101) vor. Sie konnten allerdings zusätzlich auf weitere, inzwischen neu hinzukonstruierte Quellen zurückgreifen. ${ }^{9}$ Und ganz ähnlich hat auch die moderne Forschung - wie beim bereits untersuchten Fall Milos - alles, was sich zur frühen Trierer Geschichte nur fassen ließ, gleichwertig zusammengetragen, um auf diese Weise überhaupt ein erkennbares Bild dieser Zeit zu erhalten. Doch vergaß man oft, das dürftige Material genauer zu gewichten, die gefundenen Belege jeweils zu kontextualisieren, zu historisieren, um damit zum eigentlichen Kern der wenigen fragmentarischen Einzelbilder vorzudringen. ${ }^{10}$

Was also bleibt vom Trier der Jahre vor 882? Was wußte man sich dort später noch zu erzählen? Vermochte man noch etwas zu sichern? Der Feuersturm raubte nicht nur Materielles, sondern auch die eigene Vergangenheit. Er

8 Wisplinghoff, St. Maximin bei Trier, S. 5, geht davon aus, daß sich die beiden St. Maximinsviten aus dem 8. und 9. Jahrhundert in der Stadt erhalten haben dürften. Vgl. zu den Viten unten Kap. D.III.3. Zu Hinkmar vgl. ausführlich oben u. a. Kap. B.I. und auch Kap. A.I. sowie insgesamt Kap. B. u. C. - Zu Hinkmars Flucht vgl. oben Kap. B.II. bei Anm. 16.

9 Vgl. zu beiden Texten ausführlich oben Kap. C.I., C.IV.3 u. C.IV.5. sowie unten Kap. D.IX.3. u. DIX.6. Vgl. schließlich KöLzer, Studien, S. 260, mit seiner Bemerkung zum Libellus.

10 Vgl. dazu nur die Arbeiten zur Stadtgeschichte, die die Trierer Geschichte der Merowingerzeit an wenigen Quellenbelegen entlangschreiben: EwIG, Trier. ANTON, Trier im frühen Mittelalter. - Einen ersten allmählichen Wandel stellt der seit kurzem vorliegende Band: Geschichte des Bistums Trier 1, ed. Heinen/Anton/Weber, dar. 
zwang nun dazu, sich auf das, was blieb, das kulturelle Gedächtnis der Stadt, zu besinnen. Hieraus ließen sich die auswärts erhaltenen Texte deuten und eine wenigstens wahrscheinliche Vergangenheit rekonstruieren. An was erinnerte man sich dabei vor Ort? Was wußten andere? Wie gelangte man an das Auswärtige? Jetzt war man noch mehr auf orale Traditionen angewiesen als ohnehin in dieser von Mündlichkeit dominierten Epoche. ${ }^{11}$ Man schaffte es, die eigenen Traditionen zu retten, indem man sie neu schuf. Bewußt entstanden diese Traditionen vielleicht, auch aus ,alten“ Erzählungen, die in den Köpfen der Menschen oder getragen durch Gedächtnisorte - einem Grab oder Ruinen weiterlebten. Langsam wuchsen sie zusammen, wurden weitergetragen, ergänzt, wandelten sich ständig. Man kreierte, erfand und spekulierte, wenn alte Vorlagen nicht weiterhalfen. Nicht ohne Grund ist Trier eines der einschlägigen Beispiele für Konstruktions- bzw. Fälschungsprozesse im frühen Mittelalter. Man konstruierte auf die Zeit vor der großen Zerstörung, aber auch danach, um beispielsweise vorgebliche, aber für berechtigt gehaltene eigene Besitzrechte nachzuweisen, zu denen es keine Urkunden (mehr) gab. Hätte jemand ein echtes Gegenstück vorlegen können? Ja, denn auch dieses entstand nun durch die verprellte Partei als neue Konstruktion im Dienste der guten Sache. Es entwickelte sich bei diesem Phänomen geradezu eine Eigendynamik. Zuletzt hat das Theo Kölzer minutiös an der Überlieferung zu den Trierer Klöstern St. Maximin und Oeren gezeigt, die im 10. und 11. Jahrhundert um ihre Position der Reichsunmittelbarkeit gegen den Besitzanspruch des Erzstiftes kämpften und diesen Kampf schließlich verloren. ${ }^{12}$

Dies ist die stets zu vergegenwärtigende Situation, in der jetzt die Spuren zu Trier im frühen 8. Jahrhundert sowie die von Hinkmars Erinnerungsbildern weiterverfolgt werden sollen. Sie erklärt, warum man in Trier nichts Zeitgenössisches mehr zu Milo fand, deshalb auf das Reimser Material Hinkmars sowie Flodoards zurückgriff und gegen vielleicht noch bestehende mündliche Traditionen abwog. So setzte sich das stimmige Bild von Milos Doppelamt und seiner Schlechtigkeit zunehmend durch. Es hatte jedoch weitere Konsequenzen - wie wir schon sahen. Denn die Trierer Überlieferung verbindet Milo dann mit zwei weiteren Personen: einmal mit einem Liutwin, der Bischof von Trier (705$721 / 2$ ?), Reims sowie Laon und zudem Milos Vater gewesen sein soll; zum anderen einem Trierer Bischof namens Basin (697/8-705?), dem angeblichen Onkel des Liutwin. ${ }^{13}$ Welches alte Wissen hatte sich in Trier tatsächlich noch über sie erhalten? Mußte sich das aus Reims aufgenommene Milobild nicht zwangsläufig darauf auswirken? Schuf es gar erst deren eigenes Bild? Unsere

11 Vgl. zum späten 9. Jahrhundert u.a. Fried, Weg, S. 383 ff.

12 Vgl. insgesamt Kölzer, Studien. Vgl. neuerdings auch Gießmann, Besitzungen, S. 38 45.

13 Vgl. dazu bereits oben Kap. C.VI. 
heutigen Informationen zu den beiden basieren ohnehin fast ausschließlich auf handschriftlichen Belegen weit nach dem Normannensturm von 882, auch wenn diese dann viel ältere Zeugnisse zu übermitteln vorgeben. ${ }^{14}$

\section{Basin und Liutwin - Der Forschungsstand}

a. Die Ausgangslage

Die auffällig enge Verbindung von Milo, Liutwin und Basin in der Trierer Überlieferung nach 882 weckt in der Tat deutliche Zweifel. Die Vermutung liegt nahe, daß bei diesen Personen auch mehrere unterschiedliche Traditionen und Bilder aufeinander gestoßen sein könnten, die man nachträglich zu harmonisieren suchte - in Trier wie auch in der späteren Forschung. Unübersehbar ist zudem - wie wir gleich zeigen werden -, daß sich die Quellenbelege zu Basin zunächst nahezu völlig mit denen zu Liutwin decken, während Liutwin darüber hinaus häufiger noch allein zu finden ist. All dies deutet auf manche begründeten Abhängigkeiten dieser Personen in der Überlieferung hin. Es macht die erneute genauere Analyse des Materials zu Basin und Liutwin dringend erforderlich. Aufgrund des verwobenen Quellenbefundes empfiehlt es sich, die beiden im folgenden gemeinsam zu untersuchen.

Auch die bisherigen Studien zu Liutwin und Basin gingen den schon bei Milo beobachteten Weg, alle verfügbaren Belege gleichwertig und monoperspektivisch zu einem kohärenten Bild zusammenzutragen. Schnell herrschte hier relative Einigkeit. ${ }^{15}$ Die eigentliche Grundlage der Überlegungen war dabei der älteste erhaltene Prosatext, in dem die beiden gemeinsam auftreten. Auch Milo findet sich darin. Es handelt sich um die bereits oben kurz besprochene, vermutlich im späten 10. oder frühen 11. Jahrhundert in Mettlach entstandene älteste Liutwin-Vita (Vita I). ${ }^{16}$ Sie soll auch am Anfang dieser Untersuchung stehen. Denn an ihrer Kernaussage hat man - bei Zweifeln an einigen Details festgehalten.

Diese Vita berichtet, Liutwin sei durch Zustimmung eines Königs Childerich und des Majordomus Grimoald Bischof von Trier geworden (cap. 11). Die Forschung vermutet dabei berechtigterweise eine Verwechslung mit Childebert III. (694-711). ${ }^{17}$ Liutwin sei ferner von senatorischem Rang sowie königlicher Herkunft gewesen. Seine Eltern hätten Gerwin und Gunza geheißen.

14 Vgl. dazu den kurzen Überblick unten in Kap. D.I.2.b.-c.

15 Vgl. dazu die beiden sich anschließenden Kapitel.

16 Zur älteren Vita Liutwini I vgl. bereits oben Kap. C.IV.2. sowie noch ausführlicher unten Kap. D.IX.2. Zu Mettlach vgl. hier zusammenfassend BEcker, Mettlach, der sich an der älteren Literatur orientiert.

17 Vgl. Vita Liutwini I cap. 17, ed. Perier, S. 171B. Vgl. dazu unten S. 322 u. Anm. 656. 
Liutwin habe geheiratet und schließlich den Rang eines Herzogs totius regni Francorum erhalten. ${ }^{18}$ In Mettlach habe er nach einer Vision - ihm erschien ein Adler im Traum - zunächst ein Dionysiusoratorium gebaut, das er auch mit weiteren Reliquien ausstattete. Noch heute - also zur Abfassungszeit - finde eine Dionysiuswallfahrt zu dieser Kirche statt. Danach begann Liutwin mit dem Klosterbau: Es entstanden ein Petrusoratorium und eine Marienbasilika. Maria sollte die Schutzpatronin der Gesamtanlage sein. Das Kloster erhielt eine Ausstattung, Mönche und einen eigenen Abt, eingesetzt durch Liutwin. Das $\mathrm{Zu}-$ sammenleben sollte iuxta regularis vitae instituta erfolgen. ${ }^{19}$ Sein Vermögen vermachte er Christus. Schließlich trat er dem Konvent selbst bei. Nach dem Tod des Trierer Erzbischofs Basin, Liutwins Onkel, an einem 4. März wählte man ihn dann selbst an einem 20. November zum Erzbischof, später sogar zum Bischof der vakanten Bistümer Reims und Laon. Er übertrug das Kloster dem hl. Petrus in Trier. Es sollte unter dem Recht der Trierer Bischöfe stehen. Liutwin starb schließlich an einem 29. November in Reims. Die Trierer holten seinen Leichnam in Begleitung seines Sohnes und Nachfolgers Milo aus Reims in ihre eigene Stadt zurück. Es folgen in der Vita die bereits oben besprochenen Bemerkungen zu Milo. ${ }^{20}$ Doch stellten sich Liutwins dortiger Bestattung Schwierigkeiten entgegen. So beschloß man, seinen Körper einem steuerlosen Schiff anzuvertrauen und dies treiben zu lassen. Es bewegte sich die Mosel und Saar aufwärts bis nach Mettlach, dessen Glocken zu läuten begannen. In Mettlach habe Liutwin ein Grab erhalten. In seinem Umfeld erfolgten dann zahlreiche Wunder. Soweit der hier kurz wiedergegebene Inhalt der Vita. ${ }^{21}$

Schon auf den ersten Blick fallen die legendenhaften Züge des Berichtes auf, ebenso der nicht korrekte Merowingerkönig. Aus den Überlegungen zu Milo dürfte ferner in Erinnerung geblieben sein, daß Liutwins hier beschriebene Bistumsanhäufung kaum glaubwürdig sein kann, sondern von Milos angeblichem Doppelbistum in Reims und Trier übernommen sein dürfte. Was für den Sohn galt, mußte auch für den Vater zutreffen. ${ }^{22}$ Erinnert sei zudem nochmals daran, daß der Verfasser der Vita I ja in seinem Vorwort selbst angibt, keine Schriftquellen über Liutwin vorgefunden zu haben. Er scheint sich vielmehr auf mündliche Angaben zu beziehen, die er vor dem Vergessen bewahren will. Auffälligerweise fordert er den Leser sogar auf, nicht aus Neugier nach ihm selbst zu forschen. ${ }^{23}$ Insgesamt erregt also einiges Zweifel an der grundsätzlichen

18 Vgl. Vita Liutwini I cap. 3, ed. Perier, S. 169F.

19 Vgl. Vita Liutwini I cap. 7, S. 170D.

20 Vgl. dazu oben Kap. C.IV.2., aber auch nochmals grundsätzlich unten Kap. D.IX.2.

21 Vgl. Vita Liutwini I, ed. Perier, S. 169-172.

22 Vgl. dazu oben Kap. C.IV.2. bei Anm. 111-113.

23 Vgl. Vita Liutwini I cap. 2, ed. Perier, S. 169D-E: Unde quoddam narrandi operis inicium aggrediens lectorem prius consulente commoneo, omnesque, in quorum manus vel aures haec forte pervenerint, rogo, ne a quo vel qualiter haec eadem sint dicta, curiosi 
Glaubwürdigkeit dieses Textes. Wie zuverlässig können die vom Autor erwähnten Traditionen gewesen sein? Gab es sie überhaupt, oder handelt es sich dabei schlichtweg um Topoi? Muß man die Vita vielleicht ganz anders lesen?

Als Martin Klewitz in der Mitte der fünfziger und zu Beginn der sechziger Jahre des vergangenen Jahrhunderts Grabungen in Mettlach vornahm, fand er keinen sicher nachweisbaren Ort eines Liutwin-Grabes, ebensowenig Spuren eines Dionysiusoratoriums. Ja, bei den freigelegten Vorgängerbauten der Petrusund Marienkirche fielen gerade die für die Merowingerzeit beachtlichen Ausmaße der ersten, vielleicht schon dreischiffigen Peterskirche mit drei Ostapsiden auf. Dagegen fanden sich zunächst nur mehrere kleine einschiffige Anlagen im Bereich der Marienkirche. ${ }^{24}$ Der Ausgräber hat in persönlichen Auskünften darauf hingewiesen, daß er inzwischen von einer sukzessiven Entstehung des Klosterkomplexes über mehrere Jahre ausgehe und die Kirchen kaum gleichzeitig, sondern nacheinander entstanden seien. In welcher Reihenfolge dies geschah, sei aufgrund der archäologischen Funde schwer zu sagen. Einige der Bauten könnten auch erst nach Liutwins Tod fertiggestellt worden sein. ${ }^{25}$

Betrachtet man nun aber den beschriebenen Befund, liegt es näher, daß die deutlich kleinere Marienkirche die ältere der beiden gewesen sein dürfte und die

inquirant; sed quid in se aedificationis habeant, vel cujus meritorum praeconia sint, videant. Inest namque mihi animus de specialis patris nostri Lutwini vita, quasi de quodam viridissimae amoenitatis prato, varii generis floribus referto, quaedam virtutum ejus excerpere insignia, ne tanti Viri facta taceantur... Quamvis ergo libro vitae inserta sit perhenniter illius memoria, nondum tamen ad nos usque pervenire contigit de ejus vita aliquam librorum relationem, quae factorum ejus certam daret noticiam. Sed quaedam nobis de eo ex solertia primorum nobis tradita, quaedam populari rumore hactenus vulgata, ipsius auxilio confisus, narrare incipiam, ne oblivionis modius talis Viri celet lucernam.

24 Vgl. Klewitz, Baugeschichte, S. 81-94, bes. S. 82-85. Klewitz, Mettlach an der Saarschleife, S. 3-7. Beim Dionysiusoratorium besteht immerhin die Möglichkeit, daß sich die Kirche an anderer Stelle befunden hat. Vgl. zu Mettlach nochmals zusammenfassend BECKER, Mettlach, der sich u. a. an der Liutwin-Vita orientiert. Zum Baubefund vgl. ebd., S. 537 f., wobei er überwiegend den Ergebnissen Klewitz' folgt.

25 Vgl. hierzu die mir vorliegenden Schreiben des Saarländischen Landeskonservators i. R. Dr. Martin KLewitz vom 15. Juni, 3. Juli, 10. August und 14. September 2004 sowie 3. Mai 2005, in denen er freundlicherweise u.a. darauf hinweist, daß die vollständige Publikation seiner Grabungsergebnisse nach jetzigem Stand in Kürze zu erwarten sei. Im Umfeld der ersten Marienkirche, die teilweise über die Maße des heute erhaltenen Oktogons deutlich hinausragte, fanden sich zudem noch Sarkophage, die in die Merowingerzeit zu gehören scheinen. Vgl. aber auch unten S. 200, 311, 327 f. u. Anm. 314, 614, 671. - Heute steht in Mettlach noch die Marienkirche in Form des oktogonalen sog. ,Alten Turmes'. Die baufällige Peterskirche wurde Anfang des 19. Jahrhunderts abgerissen. Einige Jahre später entstand ein Kirchneubau, in den man die zuvor in der Peterskirche aufbewahrten Liutwinreliquien überführte. Vgl. zu dieser Kirche St. Lutwinus neuerdings JöckLe, Kath. Pfarr- und Wallfahrtskirche St. Lutwinus Mettlach. 
auffällig große Peterskirche mit einiger Verzögerung hinzukam. ${ }^{26} \mathrm{Muß} \mathrm{man}$ vielleicht insgesamt von Interpretationsmustern ausgehen, die der Vitenverfasser auf der Grundlage des Mettlacher Baubestandes seiner eigenen Zeit anzubieten hatte? Doch wie läßt sich dann erklären, daß die Vita ein Petrusoratorium und eine Marienbasilika nennt? Die tatsächlichen Größenverhältnisse sind nämlich umgekehrt! ${ }^{27}$ Verlief die Gründung Mettlachs überhaupt so, wie in Liutwins ältester Vita beschrieben? Gründete Liutwin Mettlach? Wer war Liutwin? War Basin wirklich sein Onkel? Was haben beide tatsächlich mit Milo zu tun? Um diese Fragen und aufgeworfenen Unstimmigkeiten zu klären, bleibt nur der Weg, die Quellen und Literatur zu den beiden noch einmal gemeinsam zu überprüfen und dabei ihre Verbindung mit Milo zu berücksichtigen.

\section{b. Bischof Basin von Trier}

Das Material zu Basin ist überschaubar. Seine Amtszeit meint man, mit den Jahren 697/8-705 annäherungsweise angeben zu können. Die Grundlage für diese Berechnungen bilden zunächst mehrere scheinbar zeitgenössische Urkunden einer Äbtissin Irmina von 697/8 bis 704 (WАмрасн I 2, Nr. 3, 4, 6 u. 9). Diese Irmina wird gewöhnlich für die Äbtissin des Trierer Frauenklosters Oeren gehalten. Die Urkunden stehen im Zusammenhang mit der Gründung des Klosters Echternach im heutigen Luxemburg unter seinem ersten Abt Bischof Willibrord von Utrecht (†739). Sie nennen merkwürdigerweise Basin und Liutwin mehrere Male zusammen und zeitgleich als Bischöfe, u.a. als Zeugen. Diese Stücke sind jedoch erst durch Texte des späteren 11. und des 12. Jahrhunderts sicher überliefert, wie wir gleich genauer sehen werden. ${ }^{28}$ Nur das im Original noch vorliegende Kalendarium des Willibrord enthält einen zeitgenössischen Nachtrag mit dem Todestag eines Bischofs Basin ohne genaue Ortsangabe zum 4. März. Dies belegt immerhin die Existenz und Bedeutung eines Basin für das beginnende 8. Jahrhundert im Echternacher Umfeld. ${ }^{29}$ Die letzte der sog. Irmina-Urkunden, in denen Basin erscheint, stammt vom 8. Mai 704 (Wамрасн I 2, Nr. 9). Diese sowie eine verdächtige, im Kern aber von der Forschung bislang für glaubwürdig gehaltene Urkunde seines vorgeblichen Nachfolgers Liutwin vom 1. Februar 706 (MRUB I 7a) führten zu einer ein-

26 Natürlich sind hierzu aber noch genauere Prüfungen und Abwägungen des archäologischen Befundes erforderlich. Einstweilen handelt es sich um eine Hypothese.

27 Zur Größe der Mettlacher Kirchen vgl. die u. a. bei Junges, Pfarrei Mettlach, S. 306 f., wiedergegebene Karte Mettlachs aus dem Jahr 1810, die zeigt, daß die - hier noch erhaltene - Peterskirche größer als die Marienkirche war.

$28 \mathrm{Vgl}$. zu diesen ausführlich unten Kap. D.II.4.a.-c. - Zur darin überwiegend übereinstimmenden Forschungsliteratur vgl. unten Anm. 34-39.

29 Vgl. The Calendar of St. Willibrord, ed. WILsON, S. 5. 
helligen Datierung von Basins Todestag auf den 4. März 705. ${ }^{30}$ All diese Urkunden werden im weiteren Verlauf noch genauer behandelt. Von nun an schweigen die Quellen zu Basin, bis sie wieder ganz langsam im Trier des 10. und 11. Jahrhunderts zu sprudeln beginnen. Wann genau er seinem Vorgänger Numerian (646/7-vor 697/8?) folgte, muß offen bleiben. Denn erst die unter Erzbischof Egbert (977-993) entstandenen Trierer Bischofslisten nennen beide hintereinander. ${ }^{31}$ Die sich den Listen anschließenden weiteren Trierer Quellen erwähnen Basin dann jeweils nur knapp, meist als Onkel Liutwins. Den Anfang macht die eben paraphrasierte ältere Liutwin-Vita. ${ }^{32}$ Auch diese Quellen werden noch ausführlich besprochen.

Bereits BRower und MASEN trugen die ihnen bekannten Quellen über die Zeit Basins 1670 zusammen. ${ }^{33}$ Erich Winheller erfaßte dann erstmals 1935 das gesamte Material zu ihm. ${ }^{34}$ Er ergänzte es noch um eine Vita Basini. Bei ihr folgt er jedoch dem Urteil Albert PonCELETs: Dieser veröffentlichte 1912 deren zuvor kaum berücksichtigten Widmungsbrief und wies aufgrund des darin genannten Verfassers nach, daß die Vita im Trierer Kloster St. Maximin während des beginnenden 16. Jahrhunderts entstand. ${ }^{35}$ Die Basin-Vita benutzte u. a. auch die älteste Liutwin-Vita sowie zeitlich nach dieser manipuliertes Trierer Material. Für die im folgenden beabsichtigte Untersuchung verliert sie deshalb ihren Quellenwert. Sie erwähnt ihren Protagonisten vor seinem Trierer Episkopat als Abt von St. Maximin. Das dürfte jedoch auf St. Maximiner Fälschungen seit dem 11./12. Jahrhundert beruhen, die dem Verfasser vorlagen. ${ }^{36}$ Schließlich sei

30 Vgl. zu dieser Urkunde auch schon oben Kap. C.II.1, Anm. 15, sowie nochmals unten den Beginn von Kap. D.II.1. Anton, Liutwin, S. 31 f., 36 u. Anm. 28, 45. Zur Datierung des Todestages vgl. nochmals die Literatur in Anm. 34-39.

31 Vgl. zu Numerian, für den es darüber hinaus nur wenige Belege gibt, hier nur GAUTHIER, Évangélisation, S. 356 f. Bauer, Spätmerowingische Zeit, S. 231 ff. Zur entsprechenden Passage der Trierer Bischofsliste vgl. Duchesne, Fastes 3, S. 33 u. 39, der zu Basin nur Angaben in Verbindung mit Liutwin macht. Vgl. auch unten Kap. D.VI.

32 Vgl. zu diesen Quellen die Ausführungen unter Liutwin S. 122 u. Anm. 51-57 sowie Kap. D.VI.3.ff.

33 Vgl. Brower/Masen, Antiquitates, S. 356-360.

34 Vgl. Winheller, Lebensbeschreibungen, S. 167-174. Vita Basini, ed. Henschen, S. 315-321.

35 Vgl. Poncelet, Vie de S. Basin. Es handelt sich dabei um den St. Maximiner Mönch Johannes Scheckmann, der sie seinem Abt Vinzenz von Cochem (1514-1525) überreichte. Vgl. dazu auch WINHELLER, Lebensbeschreibungen, S. 169.

36 Vgl. Winheller, Lebensbeschreibungen, S. 169-174. - Zu diesen St. Maximiner Fälschungen gehört eine angebliche Schenkung Papst Gregors II. (715-731) an St. Maximin unter einem Abt Basin aus dem Jahr 729. Vgl. dazu MRUB I †9, S. 12 f., sowie genauer unten Kap. D.III.2. - Dazu paßt, daß sich Basin im St. Maximiner Totenbuch des 10./11. Jahrhunderts erst als Nachtrag des 12. Jahrhunderts zum 4. März findet: Depositio Basini epi. Vgl. dazu Miesges, Trierer Festkalender, S. 9, Anm. 4, sowie Kraus, Necrologium, S. 111. 
Basin - so die Vita - auch in St. Maximin begraben. Dazu allerdings fehlt jeder zeitgenössische Nachweis. ${ }^{37}$

Die weitere Forschung hat im wesentlichen W INHELLERs Grundlagenarbeit übernommen. Dennoch erscheint Basins St. Maximiner Abbatiat immerhin als möglich. Aufgrund seines wohl später noch existenten Grabes im Kloster habe man ihn für einen dortigen Abt gehalten und deshalb in ein Abtsverzeichnis eingetragen. So lautet zumindest ein Erklärungsversuch Erich Wisplinghoffs (1970). Dieses Verzeichnis lasse sich aber nur noch aus erhaltenen frühneuzeitlichen Quellen rekonstruieren, wie der Autor zugibt. ${ }^{38}$ Nancy GauthiER hat sich dann (1980) noch einmal intensiver mit Basin beschäftigt, wiederholt jedoch allein die bekannten Ergebnisse. ${ }^{39}$ Zuletzt hat Thomas BAUER (2003) die vorhandenen Quellen mit deutlicher und berechtigter Vorsicht behandelt. ${ }^{40}$ Einige Studien wollen in Basin endlich das älteste noch zurückverfolgbare Glied der Sippe der sog. ,Widonen-Lambertiner-Miloniden' erkennen. Sie soll über Basins Neffen Liutwin und dessen Sohn Milo ihren Ausgang genommen haben. ${ }^{41}$

Insgesamt dürfte hier erkennbar geworden sein, wie wenig Genaues über Basin tatsächlich bekannt ist und daß deshalb einige Forschungsergebnisse in manchen Teilen spekulativ bleiben müssen. Den Schlüssel zu möglichen neuen Erkenntnissen könnte Liutwin bieten.

\section{c. Bischof Liutwin von Trier}

$\mathrm{Zu}$ Liutwin liegt ein deutlich umfangreicheres Quellenmaterial vor, das hier kurz umrissen sei. Zunächst müssen nochmals die erwähnten sog. Echternacher Irmina-Urkunden seit 697/8 genannt werden, in denen Liutwin neben Basin auftritt (Wамрасн I 2, Nr. 3, 4, 6 u. 9). Hinzu kommt die schon genannte, verdächtige Liutwin-Urkunde von 706 (MRUB I 7a). Durch diese Urkunden

37 Vgl. dazu Gierlich, Grabstätten, S. 50 f.

38 Vgl. nur Ewig, Trier, S. 95, 130, 140, 229, der an ein Abbatiat glaubt; ebenso Pauly, Geschichte des Erzbistums Trier 2, S. 39. - Vgl. ferner Anton, Trier im frühen Mittelalter, S. 155-157. Anton, Liutwin, S. 46-48. Anton, Trier vom Beginn des 6. bis zum Ende des 8. Jahrhunderts, S. 49 u. 66. Er bezieht zum Abbatiat keine Stellung. Wisplinghoff, St. Maximin bei Trier, S. 7-13, ist insgesamt kritischer, hält aber am Abbatiat fest. Er weist (ebd., S. 8) darauf hin, daß es sich um Abhandlungen des 16. und 17. Jahrhunderts zur Geschichte des Klosters handelt, die sich auf ältere Abtlisten berufen.

39 Vgl. Gauthier, Évangélisation, S. 357-359.

40 Vgl. Bauer, Spätmerowingische Zeit, S. 238 f. Bauer, Verehrung heiliger Trierer Bischöfe, S. 397 f., zu Basins späterer Verehrung.

41 Vgl. dazu z. B. Ewig, Milo, S. 413-415. Zuletzt Hlawitschka, Widonen (Lambertiner), Sp. 72-74, mit der neuesten Literatur. Vgl. dazu ferner auch unten Anm. 316, $402,441,448$. 
sieht die Forschung den Beginn von Liutwins mit Basin gemeinsamem (ab 697/ 8), dann alleinigem (706) Trierer Episkopat markiert. ${ }^{42}$ Dessen Ende nimmt man zwischen 715 und $722 / 3$ an. Diese beiden Daten beruhen wiederum auf zwei Nachrichten zum vermuteten Beginn der Amtszeit seines vermeintlichen Nachfolgers Milo. ${ }^{43}$ Sie sind im Zusammenhang mit Milo bereits besprochen worden: Zunächst handelt es sich um eine Schenkungsurkunde eines sacerdos Hugo, seines Bruders Herzog Arnulf, Pippins und Godefridus' an das Apostelkloster in Metz vom 24. oder 25. Juni 715, in der ein Milo ohne Bischofstitel in einer später interpolierten Zeugenliste auftaucht. ${ }^{44}$ Ferner wird ein Bischof Milo ohne aufgeführtes Bistum in einem Eintrag der Gesta abbatum Fontanellensium aus dem frühen 9. Jahrhundert bei einer Versammlung Karl Martells ( $\dagger$ 741) von $722 / 3$ erwähnt. ${ }^{45}$ Es ist nicht sicher, um welchen Milo es sich bei ihnen handelt. Denkbar sind auch spätere Rückprojektionen oder Verfälschungen. Ergebnisse aber, die sich auf Milo stützen, müssen nach den neu gewonnenen umfangreichen Erkenntnissen zu ihm fragwürdig sein.

Diesen Dokumenten folgen drei Urkunden zum Kloster Mettlach an der Saar, die allerdings erst kopial im 14. Jahrhundert überliefert sind. In der ersten, schon bei Milo kurz besprochenen, überträgt Karl der Große (768-814) 782 das Kloster an Trier (DKarol. I 148). Sie nennt einen Bischof Liutwin, der Mettlach an Trier geschenkt habe und Vater eines Milo und Wido gewesen sei. ${ }^{46}$ Zwei weitere Diplome, die Kaiser Karl der Dicke (†888) 884 (DKIII. 102) und König Arnulf (888-899) 888 (DArn. 39) für den Trierer Bischof Radbod (883-913) ausstellten, bezeichnen Liutwin ebenfalls als Schenker Mettlachs. ${ }^{47}$ Eine vierte, im Original erhaltene Urkunde, durch die Kaiser Lothar I. (817/ 840-855) 842 Mettlach an den Trierer Bischof Hetti (814-847) zurückgibt (DLoI. 67), nennt dagegen einen oder mehrere Vorfahren des Wido von Spoleto (†ca. 859) als Klosterschenker. ${ }^{48}$ Damit boten diese Diplome die Basis zu Studien, die in Liutwin den Stammvater der Sippe der, Widonen-LambertinerMiloniden“ sehen wollen. ${ }^{49}$ Der Name „Liutwin“ selbst mit seinen Varianten war häufig in dieser Zeit. ${ }^{50}$

42 Vgl. dazu nochmals oben S. 118 f. u. Anm. 28-30.

43 Vgl. dazu nochmals insgesamt oben Kap. C.

44 Vgl. dazu genauer oben Kap. C.II.1.

45 Vgl. dazu genauer oben Kap. C.III.1.

46 Vgl. DKarol. I 148, S. 200-202. Vgl. dazu schon ausführlicher oben Kap. C.II.1. sowie umfassend unten Kap. D.IV.6.

47 Vgl. DKIII. 102, S. 165 f. DArn. 39, S. 57 f.

48 Vgl. DLoI. 67, S. 178 f. Vgl. hier beispielsweise Hlawitschka, Widonen (Lambertiner). RaAch, Mettlach, S. 25 ff., bes. S. 25 f. Wüstenfeld, Spoleto.

$49 \mathrm{Zu}$ Liutwin als möglichem Stammvater der, Widonen-Lambertiner-Miloniden' vgl. die Ausführungen bei sowie die Anm. 41, 316, 402, 441, 448. Vgl. zu dieser Familie auch unten Kap. D.IV.6.c.

50 Vgl. hier nur Förstemann, Personennamen, Sp. 1049 f., sowie unten S. 248 f. u. Anm. 448. 
Seit der Mitte des 10. Jahrhunderts schließen sich beständig wachsende Trierer Bischofslisten an, die Liutwin als heiligen Bischof der Stadt aufführen. ${ }^{51}$ Seit dieser Zeit etwa - so zumindest die langjährige Forschungsmeinung - seien einige Lebensbeschreibungen Liutwins entstanden. Am Anfang dürfte der Sermo de proprio patrono Liutwino des Mettlacher Abtes Remigius aus dem späten 10. Jahrhundert stehen, dessen Text jedoch nicht überliefert ist. ${ }^{52}$ Die älteste Vita (die anfangs paraphrasierte Vita I) entstand in literarisch anspruchsvoller Reimprosa am Ende des 10. oder zu Beginn des 11. Jahrhunderts, spätestens jedoch 1077, vermutlich in Mettlach. Sie macht Liutwin nicht nur zum Schenker, sondern erstmals auch zum Gründer Mettlachs. Eine ausführlichere zweite (Vita II) schrieb der spätere Abt Thiofrid von Echternach (1083-1110) zwischen 1072 und $1077 .^{53}$ Etwa zur gleichen Zeit (bis 1090) wurden in Mettlach die Wundergeschichten Liutwins verfaßt, die Miracula s. Liutwini, die die Klostergeschichte vom Beginn bis zur eigenen Gegenwart zusammenfassen. ${ }^{54}$ Eine dritte Vita (Vita III) folgt am Anfang des 12. Jahrhunderts. ${ }^{55}$

Auch in der Trierer Stadtgeschichtsschreibung wird Liutwin mehrfach genannt, einmal im schon bekannten kürzeren Libellus de rebus Treverensibus aus dem dritten Viertel des 11. Jahrhunderts; ${ }^{56}$ schließlich in den ausführlichen Gesta Treverorum, die ab und nach 1101 in mehreren aufeinanderfolgenden Redaktionsstufen vorliegen. ${ }^{57}$ Liutwins Todestag am 29. September findet sich erstmals in der Vita I sowie in liturgischen Handschriften seit dem späten 10. Jahrhundert. ${ }^{58}$ Für die Viten sowie die Geschichtsschreibung gilt, daß deren

51 Vgl. dazu genauer unten Kap. D.IV.ff.

52 Vgl. Winheller, Lebensbeschreibungen, S. 94 u. Anm. 44. Nach ihm finde sich der Sermo, den die Miracula s. Liutwini erwähnen, in der Handschrift Trier, Priesterseminar, 4, S. 15-23, aus dem 12. Jahrhundert. Vgl. dazu, aber auch zu Abt Remigius RAACH, Mettlach, S. 59-61, bes. S. 59 u. Anm. 130, der Winheller einen Fehler nachweist. Der Text liege nicht handschriftlich vor. Zwar wiesen die Miracula auf den Sermo hin. Winheller verwechsle aber einen Anmerkungshinweis der Edition auf die „Homilie zur Geschichte von Eucharius, Valerius und Maternus“ des Remigius. Vgl. dazu insgesamt die Miracula s. Liutwini auct. Monacho Mediolacensi cap. 16, ed. SAuerland, S. 1266 u. Anm. 2. - Zur erwähnten Handschrift vgl. unten Anm. 532. - Vgl. zum Sermo, bei dem es sich vermutlich um die Vita Liutwini I handelt, auch ausführlich unten zu Beginn von Kap. D.IX.2. mit weiterer Literatur.

53 Vgl. zur Vita Liutwini I schon genauer oben S. 115 f. u. Anm. 16-21. Zur Vita II vgl. unten S. 123 f. u. Anm. 64, sowie nochmals unten Kap. D.IX.5.

54 Vgl. dazu oben Kap. C.IV.4. sowie unten Kap. D.IX.4.

55 Vgl. dazu WinhelLER, Lebensbeschreibungen, S. $105 \mathrm{f}$.

56 Vgl. dazu oben Kap. C.IV.3. sowie unten Kap. D.IX.3.

57 Vgl. dazu oben Kap. C.IV.5. sowie unten Kap. D.IX.6.

58 Vgl. Vita Liutwini I cap. 15, ed. Perier, S. 171E: [...] ad laborum praemia cum Sanctis possidenda tertio Kalendas Octobris migravit. - Vgl. zu den erwähnten Handschriften unten Kap. D.VI.3.b. u. D.VII. 
kodikologische Überlieferung nicht vor dem 12. Jahrhundert, in den meisten Fällen danach, einsetzt. ${ }^{59}$

Faßt man diesen Quellenbefund zusammen, fällt schnell auf, daß kein originaler Beleg, der Liutwin namentlich nennt, vor der Mitte des 10. Jahrhunderts erhalten ist. Von nun an und im 11. Jahrhundert erwachte ein massives Interesse an seiner Person. Die überwiegenden Forschungsergebnisse beruhen somit auf einer meist späten Überlieferung zu Liutwin und Hilfsberechnungen zu Milo.

Schon 1670 trugen Brower und MASEN von ihnen geordnetes Material über die Trierer Zeit Liutwins zusammen. Dabei benutzten sie u.a. Texte und Inschriften, die heute verloren sind.$^{60}$ Erstmals genauer nahm sich Jacob Marx in der Mitte des 19. Jahrhunderts Liutwins an. Allerdings standen ihm dazu noch nicht alle vorhandenen Quellen zur Verfügung. ${ }^{61}$ Intensiver beschäftigte sich Constantin vON BRIESEN 1863 mit dem Liutwin-Stoff, der eine Teilübersetzung der Vita I sowie der Miracula anfertigte. ${ }^{62}$ Johann Christian LAgER berücksichtigte 1875 neben diesen Texten auch das Urkundenmaterial intensiver und setzte sich in einigen Punkten kritisch damit auseinander. So bemerkte er schon aufgrund der Reimser Parallelüberlieferung, daß Liutwin wohl kaum Bischof in Reims und Laon gewesen sein könne. ${ }^{63}$ WINHELLER legte schließlich 1935 auch zu Liutwin die umfangreichste und vollständigste Materialsammlung vor und ging den Entstehungszeiten der Liutwin-Viten nach. Die Vita I datierte er an die Wende vom 10. zum 11. Jahrhundert. Er maß ihr geringe Glaubwürdigkeit bei, weil er einige inhaltliche Fehler erkannte. Die Vita II paraphrasierte er. LAMPEN konnte zuvor schon die erwähnte Verfasserschaft Thiofrids von Echternach für sie nachweisen. ${ }^{64}$

59 Vgl. dazu hier nur Winheller, Lebensbeschreibungen, S. $84 \mathrm{f}$.

60 Vgl. Brower/Masen, Antiquitates, S. 359-363.

61 Vgl. Marx, Erzstift Trier 1,1, S. 85-87 u. ebd. 2,1, S. 388-423.

62 Vgl. von Briesen, Urkundliche Geschichte, S. 72-91. Dort folgt (ebd., S. 91) noch der Druck der Urkunde Erzbischof Alberos von Trier aus dem Jahr 1147 zur Wallfahrt nach Mettlach.

63 Vgl. Lager, Urkundliche Geschichte, S. 1-12, auch S. 9, zur Unmöglichkeit eines Episkopats in Reims und Laon. Lager bietet eine umfangreiche Geschichte Mettlachs, wobei seine Darstellung bis zum Ende des 11. Jahrhunderts (ebd., S. 13-47) überwiegend den Miracula s. Liutwini folgt. Auf den Arbeiten Marx', von Briesens sowie Lagers basieren auch zwei Publikationen zu Liutwin und Mettlach aus den 1920er Jahren: Kolt, Wallfahrt. Conrath, Mettlach. Eine allgemeine und geraffte Geschichte des Klosters Mettlach bietet Zimmermann, Mettlach.

64 Vgl. WinhelLer, Lebensbeschreibungen, S. 84-106; dort S. 88-96, zur Kritik insgesamt; S. 94 f., zum Stil und der Reimprosa der Vita. Ihm fiel auf, daß Liutwin eben nicht unter einem König Childerich Bischof geworden sein könne (ebd., S. 88 f.). Ebd., S. 93 u. 96-105, zur Vita II. - Vgl. ferner Lampen, Thiofrid, S. 7-11. - Anton, Liutwin, S. 34 f., datiert die Vita I wieder ins späte 10. Jahrhundert. Er beruft sich dabei 
Doch Ewig vertraute dann (1954) wieder fast allen Quellen zu Liutwin und stellte auf ihrer Grundlage weitere Überlegungen zur Geschichte des Trierer Raums an. Während er bei Basin ein enges Verhältnis zu Echternach vermutet, sieht er bei Liutwin eher eine gewisse Distanz zu diesem Kloster und zu Willibrord. ${ }^{65}$ KLEwiTz verwandte bei seinen erwähnten Grabungen in Mettlach die Vita I sowie die Miracula als Interpretationsgrundlage für seinen Befund. ${ }^{66}$ Auch PAuly berief sich 1969 in seiner "Geschichte des Bistums Trier" auf beide Texte. ${ }^{67}$ Im Rahmen einer umfangreichen Untersuchung zum Kloster Mettlach, die Theo RaAch 1974 vornahm, benutzte er ebenfalls dieses Material als überwiegend verläßliche Basis für die Frühgeschichte des Klosters sowie zur Herkunft der, Widonen-Lambertiner-Miloniden' ${ }^{68}$ GaUTHIER hat 1980 erneut alle Belege versammelt, zeigt aber deutlich, daß sie sich inhaltlich zum Teil erheblich widersprechen. ${ }^{69}$ ANTON hingegen bezweifelt in seinen Trierer Arbeiten deren grundsätzlichen Wahrheitsgehalt nicht. Im Jahr 1991 widmet er Bischof Liutwin sogar einen umfassenden Aufsatz, in dem er ihn nochmals als Gründer Mettlachs, Förderer Echternachs und Stammvater der ,WidonenLambertiner-Miloniden' betont. ${ }^{70}$ Ulrich NONN sieht Liutwin 1995 sogar immer noch als Bischof von Reims. ${ }^{71}$ BECKER trägt 1999 schließlich erneut die gesamte Forschung zu Mettlach zusammen und ist dem Urteil der ihm vorausgehenden Literatur gefolgt. ${ }^{72}$

Die bisherige, geradezu traditionelle Interpretation wird erstmals von der Kölner Dissertation Hildegard Schmals „Die Gründung des Klosters Mettlach und der ,Alte Turm“" (2000) in Frage gestellt. ${ }^{73}$ Sie sichtet das Material noch-

auf Junges, Mettlacher Gotteshäuser, S. 81, Anm. 8, der meint, die Vita müsse vor dem Neubau der Grabkirche unter Egbert von Trier und Abt Lioffin Ende des 10. Jahrhunderts entstanden sein. - Doch kann das ebenso während oder nach dem Bau geschehen sein.

65 Vgl. Ewig, Trier, S. 133-143. Ewig, Milo, S. 413-417. Er glaubt auch an ein Doppelepiskopat Liutwins in Reims und Trier.

66 Vgl. Klewitz, Baugeschichte. Klewitz, Mettlach an der Saarschleife.

67 Vgl. Pauly, Geschichte des Erzbistums Trier 2, S. 39-41.

68 Vgl. RaAch, Mettlach, S. 6-36. Junges, Mettlacher Gotteshäuser, S. 81-85, 90-100, hielt an der Beschreibung der Vita I für die Mettlacher Patrozinien fest.

69 Vgl. Gauthier, Évangélisation, S. 359-362. - 1983 porträtierte Heinz, Liutwin, Liutwin auf diesem Kenntnisstand für die Saarländischen Lebensbilder essayistisch.

70 Vgl. Anton, Trier im frühen Mittelalter, S. 157-159. Anton, Trier vom Beginn des 6. bis zum Ende des 8. Jahrhunderts, S. 49 f., 66 f. Anton, Trier in der hohen und späten Karolingerzeit, S. 74 f. Anton, Liutwin, bes. S. 30 ff. Anton, Klosterwesen und Adel, S. 113 ff. Schließlich Anton, Raumbestimmende Voraussetzungen, S. 119 ff., bes. S. 161-163, wo er eine knappe Zusammenfassung der Trierer Bistumsgeschichte bietet und auch kurz auf Liutwin eingeht. Er greift aber vor allem seine alten Überlegungen wieder auf.

71 Vgl. Nonn, Rigobert.

72 Vgl. BeCKer, Mettlach.

73 Vgl. Schmal, Mettlach. 
mals, unterzieht es einer scharfen Kritik und deutet es völlig neu. Ihr frappierendes Ergebnis: Liutwin könne Mettlach nicht gegründet haben, vielmehr sei das Kloster wohl erst später in karolingischer Zeit entstanden. $\mathrm{Zu}$ dieser These gelangt sie, weil sie alle schon genannten Urkunden, die mit Liutwin verbunden sind, aufgrund von deren Überlieferungssituation vollständig als Fälschungen oder durch verfälschende Passagen interpoliert verwirft (WАмрасн I 2, Nr. 3, 4, 6, 9; MRUB I 7a; DKarol. I 148; DLoI. 67; DKIII. 102; DArn. 39). Aufgrund eines Stilvergleichs der Miracula s. Liutwini mit der Vita II des Thiofrid von Echternach kommt sie zum Schluß, Thiofrid müsse auch die Miracula verfaßt haben. Da ferner die Vita I über Informationen verfüge, die die Miracula noch nicht böten, sei die Vita I erst nach den Miracula entstanden. Die Vita I schöpfe sogar aus den Miracula. Bei diesen Wundergeschichten handle es sich deshalb um die erste ausführliche Quelle zu Liutwin überhaupt. Allein der sehr kurze Eintrag zu Liutwin im Libellus de rebus Treverensibus gehe ihnen vorraus. Daher seien diese Texte in folgender Reihenfolge entstanden: 1. Libellus, 2. Miracula, 3. Vita I, 4. Vita II. Thiofrid als Autor der Miracula und Vita II habe also - so Schmals zentrales Ergebnis - die Tradition zu Liutwin erheblich mitgeprägt und konstruiert. Es liege daher nahe, daß Thiofrid auch einen Teil des erwähnten manipulierten Urkundenmaterials zu Liutwin (und Basin) zu verantworten habe, das er wohl einfach an Miracula und Vita II anpaßte.

Die scharfe Quellenkritik Schmals ist insgesamt berechtigt. Doch konzentriert sich ihre Untersuchung aufgrund ihrer Themenwahl verständlicherweise auf Liutwins Rolle als Gründer Mettlachs. Deshalb bezieht sie zusätzliche Quellen zu Liutwin nicht mit ein. So fehlt beispielsweise eine Weihenotiz aus dem Kloster St. Maximin von 952, die eine Bischofsliste mit Liutwins Namen enthält. ${ }^{74}$ Ferner fehlen die vielleicht älteste Stufe der „Mettlacher Güterrolle“ aus der gleichen Zeit, die ein Fest eines hl. Liutwin nennt, sowie die erwähnten Trierer Bischofslisten des ausgehenden 10. Jahrhunderts mit mehrfachen Einträgen eines Liutwin. ${ }^{75}$ Auf diese Quellen wird noch zurückzukommen sein. Schmal berücksichtigt nur am Rande, daß die Urkunde Lothars I. zu Mettlach von 842 (DLoI. 67) noch als fragmentarisch erhaltenes Original im Landeshauptarchiv Koblenz unter der Bestandsnummer „1 A Nr. 4“ aufbewahrt wird. ${ }^{76}$ Ist das Diplom also tatsächlich eine Fälschung? Die von SchmaL vorgeschlagene Umdatierung der Vita I in die Zeit nach den Miracula scheint auf den ersten Blick plausibel. Sie beschränkt sich bei ihren Argumenten allerdings fast ausschließlich auf die inhaltlichen Abhängigkeiten der Angaben zu Liutwin und Mettlach in beiden Texten. Doch die ebenfalls darin enthaltenen Belege zu Milo und Basin berücksichtigt sie kaum, obwohl diese beiden in den Trierer Quellen

74 Vgl. dazu unten Kap. D.VI.1.

75 Vgl. dazu unten Kap. D.V. u. D.VI.3.ff.

76 Vgl. dazu Мӧтsсн, Balduineen, S. 91, Nr. 10. 
seit etwa 1000 nahezu immer verbunden mit Liutwin auftreten. Auch geht sie auf die jeweiligen Quellenkontexte als einmal Trierisch und einmal Mettlachisch nicht ein. Die sehr enge zeitliche Abfolge der genannten Texte, die sich durch ihre These ergibt (drittes Viertel des 10. Jahrhunderts bis spätestens 1077), müßte ebenfalls ausführlicher erklärt werden. Denn wenn Thiofrid die Vita I (die nach „seinen“ Miracula entstanden sein soll) als Vorlage für seine Vita II verwendete, dann unterliefen ihm innerhalb weniger Jahre einige schwer verständliche inhaltliche Fehler. ${ }^{77}$ Warum gibt die Vita I an, über keine Schriftquellen verfügt zu haben, während die Miracula - wie wir noch sehen werden solche verwenden und sogar zitieren? Die Miracula erwecken zudem nicht den Eindruck, Liutwin erstmals intensiver zu behandeln. Ohne eine ausgeprägte und als bekannt vorauszusetzende Liutwintradition hätten sie wohl kaum begonnen, die Geschichte des Klosters Mettlach zu erzählen. Den Einfluß der Reimser Milo-Quellen auf das Liutwinbild im Trierer Raum berücksichtigt Sснмal auch nicht. ${ }^{78}$ Ohne diesen Einzelpunkten nachzugehen, können ihre Ergebnisse aber nicht als gesichert gelten.

Zuletzt hat sich Thomas BAUER Liutwins angenommen und folgt wieder der traditionellen Sichtweise der Forschung, wobei er allerdings erstmals den Kult und die Verehrung der frühen Trierer Bischöfe in seine Überlegungen miteinbezieht. $^{79}$

\section{d. Zur Vorgehensweise}

All dies bietet Anlaß, die Quellen zu Liutwin und Basin nun noch einmal umfassend und ausführlich zu prüfen. Die Überlegungen Schmals weisen die Richtung. Doch sind die von ihr nicht berücksichtigten, auch unscheinbaren Belege miteinzubeziehen. Schmals Thesen müssen dabei kritisch hinterfragt werden. Wer also waren Liutwin und Basin? Woher und was wußte man von ihnen? Welche Spuren hinterließen sie tatsächlich?

Für Basin und Liutwin lassen sich die zunächst dürftigen, dann immer präziseren und umfangreicheren Quellenbelege kaum übersehen. Auffälligerweise erfolgt erst nach der Zäsur des Normannenüberfalls von 882 eine allmähliche, Wissensexplosion' der Informationen zu ihnen. Die daher anzunehmenden Verluste früherer Texte müssen jedoch Zweifel am später so schillernden Gesamtbild erregen. Dieser Befund legt vielmehr nahe, daß sich das Bild beider Personen im kulturellen Gedächtnis des Trierer Raums langsam aufge-

77 So wird aus dem Märtyrer Dionysius der Areopagit Dionysius. Aus Liutwins Titel eines dux totius regni Francorum macht Thiofrid einen dux Belgicae Galliae. Vgl. dazu WINHELLER, Lebensbeschreibungen, S. 102.

$78 \mathrm{Vgl}$. dazu insgesamt bereits oben Kap. C.IV.

79 Vgl. dazu Bauer, Spätmerowingische Zeit, S. 239-242. Bauer, Verehrung heiliger Trierer Bischöfe, S. 398-400. 
baut und verändert haben muß und dabei immer farbiger wurde. Doch an wen oder was erinnerte man sich jeweils und warum? Und worauf beruhte der Wandel der Einzelbilder?

Die für diese Arbeit gewählte methodische Vorgehensweise wird hier deshalb weiterverfolgt. Da Liutwin und Basin meist eng miteinander verbunden auftreten, empfiehlt es sich, die Quellen zu ihnen gemeinsam in der chronologischen Abfolge ihres Entstehens zu untersuchen. Dazu ist es notwendig, sowohl den von einer Quelle vorgegebenen als auch ihren womöglich viel späteren Entstehungszeitpunkt zu berücksichtigen. Hinzu kommt der Ort der frühesten kopialen Überlieferung, falls kein Original mehr vorliegt. Aus diesem Grund werden einige Texte mehrfach in verschiedenen Kontexten ausführlicher besprochen, nicht zuletzt, um gegebenenfalls ihren tatsächlichen Abfassungsumständen auf die Spur zu kommen. Dies macht es manches Mal unerläßlich, sich von Liutwin und Basin etwas weiter zu entfernen, um den erforderlichen Verständnishorizont überhaupt herstellen zu können. Wichtig ist schließlich - soweit möglich -, einige Gegenproben vorzunehmen: Warum findet sich Liutwin beispielsweise nicht in unabhängigen zeitgenössischen oder zeitnahen Quellen, obgleich er dort zu erwarten wäre? Die entsprechende Literatur und die Thesen Schmals sind im jeweiligen Zusammenhang dann genauer zu diskutieren.

$\mathrm{Da}$ man Liutwin und Basin in mehreren zusammenhängenden Quellengruppen findet, erscheint es sinnvoll, in einzelnen inhaltlichen und zu kontextualisierenden Blöcken vorzugehen. Am Anfang steht die Gruppe der sog. Irmina-Urkunden aus der vorgeblichen Gründungszeit des Klosters Echternach um 700 (u.a. Wampach I 2, Nr. 3, 4, 6, 9 u. auch 10). Deren Überlieferung muß genau geklärt und auf Verformungen geprüft werden (vgl. II.). Ist den Urkunden zu trauen? Jede Urkunde ist getrennt zu analysieren und im Echternacher Umfeld einzuordnen. Es stellen sich dabei folgende Fragen: Ist diese Irmina mit der später heiligen Äbtissin des Trierer Klosters Oeren identisch? Wie verlief die Gründung Echternachs? Welche Rolle nahmen Willibrord und Irmina, welche Basin und Liutwin dabei ein?

Es folgen weitere Quellen, die in den Bereich des 8. und frühen 9. Jahrhunderts zu gehören angeben oder gehören (vgl. III.). Zunächst sind dies zwei vermeintliche Liutwin-Urkunden, von denen eine schon erwähnte (MRUB I 7a) den Irmina-Urkunden formal auffällig nahe steht, ferner eine falsche Urkunde für Basin (MRUB I †9). Die beiden erhaltenen Viten des hl. Maximin, deren frühere vor 800 in Trier entstand, dienen einer unabhängigen Gegenprobe.

Anschließend wird die Gruppe der Mettlacher Urkunden besprochen, die vom späten 8 . bis ins späte 9. Jahrhundert datieren und von denen einige Liutwin als Schenker dieses Klosters an Trier nennen (vgl. IV.). Ausgehend vom einzigen im Original vorliegenden Diplom (DLoI. 67) sollen die nur kopial im 14. Jahrhundert überlieferten Stücke (DKIII. 112, DArn. 39 u. DKarol. I 148) auf ihre grundsätzliche Glaubwürdigkeit untersucht werden. 
Nach dem Normannenüberfall 882 bietet die sog. Mettlacher Güterrolle, deren älteste Vorlagen man bisher in der Mitte des 10. Jahrhunderts annimmt, vielleicht neue Hinweise zu Liutwin und Mettlach. Die Rolle selbst entstand erst Ende des 11. Jahrhunderts (vgl. V.). Danach müssen die ab 952 einsetzenden Trierer Bischofslisten schrittweise darauf geprüft werden, seit wann sie Liutwin und Basin aufnehmen (vgl. VI.). Diese Listen sind verschiedenartig: in Form der St. Maximiner Weihenotiz von 952, in Form einer Urkunde Papst Johannes' XIII. (965-972) von 969 sowie zahlreicher Listen, die während des Episkopats Egberts von Trier (977-993) entstanden (darunter liturgische Handschriften, der Trierer Petrusstab und der Egbert-Psalter). Seitdem wachsen die liturgischen Nachweise an (vgl. VII.).

Von zwei Urkunden, die ins späte 10. Jahrhundert weisen, bietet eine endlich eine knappe Lebensbeschreibung Liutwins, die andere nennt sein Grab in Mettlach (vgl. VIII.). Seitdem setzten ausführliche Trierer Texte zu Liutwin, Basin und auch Milo ein. Sie sollen in der bisher angenommenen Chronologie und nicht in der von Schmal vorgeschlagenen Reihenfolge behandelt werden, was auch erläutert wird. Es gilt dabei, die Liutwin-Vita I, den Libellus de rebus Treverensibus, die Miracula s. Liutwini, die Vita II sowie die Redaktion A der Gesta Treverorum vor allem auf verwendete Vorlagen, ihre Abhängigkeiten untereinander sowie ihren Trierer oder Mettlacher Entstehungskontext zu untersuchen (vgl. IX.). Wie weit wirkten auf sie Reimser Bilder ein, die von Hinkmar beeinflußt waren? Diese Quellen bieten einigen Aufschluß über das Verhältnis zwischen Trier und Mettlach in dieser Zeit, wobei Liutwin eine besondere Rolle zukommt.

Am Ende stehen zahlreiche neue Bilder mit erheblichen Konsequenzen für Liutwin und einigen für Basin, aber auch für den schon behandelten Milo (vgl. $\mathrm{X}$.). Es sind dies Bilder, die Trier selbst vom frühen 8. bis ins 11. Jahrhundert betreffen, aber ebenso die außerhalb gelegenen Klöster Mettlach und Echternach sogar bis ins 12. Jahrhundert. Ein neues stimmiges Gesamtbild ermöglichen sie nicht mehr. Vielmehr sollen diese mannigfachen Bilder dazu anregen, bisherige Forschungsergebnisse zu diesen Orten innerhalb dieses langen Zeitraums noch einmal zu überdenken und auf dieser Basis zu weiteren Erkenntnissen vorzudringen.

\section{Die Rolle Liutwins und Basins bei der Gründung Echternachs}

\section{Die Irmina-Urkunden - Der Forschungsstand}

Erstmals finden sich die Namen Basins und Liutwins gemeinsam als Zeugen in vier der sog. Irmina-Urkunden von 697/8-704 (WАмрасн I 2, Nr. 3, 4, 6 u. 9) im Umfeld der Gründung des Klosters Echternach, wo der hl. Friesenapostel 
Willibrord als erster Abt wirkte und schließlich 739 bestattet wurde. ${ }^{80}$ In einer fünften Irmina-Urkunde (WАмрасн I 2, Nr. 10) sowie einem knappen Regest, das eine Ymena und ihre Töchter Attala und Crodelindis nennt (WAмpach I 2, Nr. 12*), tauchen Liutwin und Basin hingegen nicht auf. Alle diese Donationen richten sich an das Kloster Echternach oder an Bischof Willibrord von Utrecht selbst. Bis auf eine Ausnahme wird Irmina in den Schenkungen sogar als Äbtissin genannt, im abweichenden Fall nur als Nonne. In den meisten dieser Urkunden behauptet sie zudem, Echternach neu gegründet zu haben. Ja, von einem von ihr zuvor errichteten Klösterlein ist die Rede. ${ }^{81}$

Schnell stellte die Forschung deshalb eine Verbindung mit der bekannten, in Trier wirkenden Äbtissin Irmina vom Kloster Oeren/St. Marien her und schloß, daß Irmina Echternach gegründet und Willibrord es sodann übernommen habe. Die Trierer Bischöfe Basin und Liutwin hätten dabei mitgewirkt. Einige Studien wollten daneben jedoch auch Willibrords eigenständige Rolle bei der Gründung stärker betont wissen. ${ }^{82}$ HALBEDEL sah Irmina auf der Basis des angesprochenen Ymena-Regests erstmals als Mutter der Äbtissin Adela von Pfalzel ( $†$ ca. 735) und - aufgrund weiterer genealogischer Überlegungen - ebenso als Mutter von Pippins des Mittleren (†714) Gattin Plektrud. ${ }^{83}$ Camille Waмpach entwickelte

$80 \mathrm{Zu}$ Echternach vgl. hier Germ. Pont. 10, ed. Boshof, S. 252 ff., sowie zuletzt den Sammelband: Die Abtei Echternach, ed. Ferrari u.a., sowie den Echternacher Tagungsband zum Klosterjubiläum: L'évangélisation des régions entre Meuse et Moselle, ed. Polfer. Vgl. ferner die Tagungsbände: Willibrord. Apostel der Niederlande, ed. Kiesel/Schroeder. Willibrord, zijn wereld en zijn werk, ed. BANGe/Weiler. Vgl. aber auch Brower/Masen, Metropolis ecclesiae Trevericae, quae metropolitanae ecclesiae originem, jura, decus, officia 1, ed. von Stramberg, S. 517-556. Allgemein zu Willibrord vgl. auch ANGENENDT, „Er war der erste ...", S. 13-34.

81 Zur Diskussion der Urkunden vgl. unten Kap. D.II.4.

$82 \mathrm{Zu}$ Irmina vgl. zuletzt zusammenfassend mit der Literatur Schroeder/Trauffler, Anfänge, S. 8-24. Knichel, Irmina. Knichel, Trier (-Oeren), St. Irminen, S. $938-$ 941, 957, mit umfangreicher weiterer Literatur. - Zahlreiche Autoren sehen in Irmina die Klostergründerin. Vgl. dazu Sauer, Fundatio, S. 249-251. Anton, Liutwin, S. 47 u. Anm. 84 f. Schroeder/Trauffler, Anfänge, S. 18 f., gekürzt nochmals Trauffler, Gründung, S. 49-52. Sie alle glauben an eine Gründung durch Irmina (jedoch nicht in einer Einöde). Es handle sich dabei um die Oerener Äbtissin Irmina. Die genauen Besitzverhältnisse jedoch seien unklar. - Vgl. dagegen aber auch SEmmLer, Episcopi potestas, S. 313, der Willibrord als Gründer sieht, welcher auf Bitten Irminas handelt. Gauthier, Évangélisation, S. 292-294, 316-328, folgt diesem Bild. Werner, Adelsfamilien, S. 60 ff., bes. S. 69-74, hält Willibrord wenigstens für den geistigen Gründer.

83 Vgl. Halbedel, Fränkische Studien, S. 16-24. - Die These funktioniert aber nur, wenn man Plektruds Vater Hugobert und Irminas angeblichen Vater Dagobert, wie ihn die spätere Trierer Tradition sehen will, aufgrund einer Verlesung bzw. Verwechslung für identisch hält, so die Grundüberlegung. - Doch scheint das unglaubwürdig, wenn man allein die auffällig massive Trierer Dagoberttradition berücksichtigt. Vgl. zu dieser Tradition in Trier WeHrLI, Überlieferungen von Dagobert, S. 292-301. Es spricht gegen ein Verlesen und vielmehr für bedachte Absicht. Vgl. zu Dagobert als möglichem Vater 
diesen Ansatz in seiner grundlegenden Echternacher Klostergeschichte 1929 weiter und versuchte, Irminas Familie zu rekonstruieren. WАмрасн widmete Willibrord dann 1953 noch eine umfangreiche Biographie und wiederholte darin seine Ausführungen. Eduard Hlawitschka benutzte diese Ergebnisse seit 1962 für seine umfangreichen Überlegungen zu einer „Hugobert-IrminaSippe “ ${ }^{84}$ Man sah folglich Basin und Liutwin durch die Irmina-Urkunden in enger Verbindung mit bedeutenden merowingischen Adligen und den Karolingern selbst. Matthias Werner hat jedoch 1982, nachdem er die Quellen erneut geprüft hatte, zu erheblicher Vorsicht gemahnt gegenüber diesem ausgesprochen konstruierten Modell. ${ }^{85}$

Sickel hielt die Irmina-Urkunden zunächst für echt. Doch Pertz erkannte in ihnen 1872 Konstruktionen des 12. Jahrhunderts. WAмPACH wies dann aber auf schon im 11. Jahrhundert bestehende Irminatraditionen hin, die für die Echtheit der Urkunden sprächen. Damit wirkte er so überzeugend, daß sein Urteil lange Zeit nicht mehr in Zweifel gezogen wurde. ${ }^{86}$ Selbst die jüngst erschienenen Veröffentlichungen zum Echternacher Klosterjubiläum 1998 halten daran fest. ${ }^{87}$ Doch der archäologische Befund der von 1949-1951, 1982 und 1989-1992 in Echternach durchgeführten Grabungen widerspricht den Angaben der Urkunden, daß Irmina Klostergründerin sei. Denn man fand nur ein Kloster und einen Kirchbau Willibrords mit dessen erstem Grab, aber keinen nachweisbaren Vorgängerbau der Irmina, auch kein davon unabhängiges

der Irmina, wie er in Trier erst seit dem 11. Jahrhundert erscheint, unten S. 132 u. Anm. 91.

84 Vgl. Wampach I 1, S. 111 -135. Wampach, Willibrord, bes. S. 249 ff., 421 ff. Zimmer, Oeren, S. 35, glaubt an eine Übereinstimmung der Personen. Hlawitschka, Merowingerblut, bes. S. 76 ff., hier S. 79. Hlawitschka, Herkunft, S. 8 ff. Unter anderem werden dabei Pippins Frau Plektrud und Bertrada d. Ä. als Kinder Hugoberts und Irminas genannt.

85 Vgl. dazu insgesamt Werner, Adelsfamilien, der alle möglichen, von der Forschung durchgespielten Varianten nochmals intensiv überprüft hat. - Schon ZImmer, Oeren, S. 34 ff., war gegenüber dem Sippenkonstrukt skeptisch und wies auf zahlreiche problematische Schlüsse hin. Hlawitschka, Grundlagen des Aufstiegs, bes. S. 12 ff., 28 ff., hat dem entschieden widersprochen, ist aber nicht in der Lage neue Argumente beizubringen.

86 In Diplomata spuria $\$ 55-59$, ed. Pertz, S. 173-177, verwarf Pertz die Irmina-Urkunden komplett als Fälschungen des Mönchs Theoderich von Echternach im 12. Jahrhundert. Theoderich verfaßte den Liber aureus von Echternach, der die Urkunden erstmals vollständig überliefert. - Sickel, Beiträge zur Diplomatik III., S. $34 \mathrm{ff.}$, 208 f., 224, 234, zeigte aber, daß sich die Urkunden schon Ende des 11. Jahrhunderts in Viten des Abtes Thiofrid von Echternach finden. Vgl. dazu unten S. 132-134 u. Anm. 91-96. Vgl. schließlich Wамрасн I 1, S. 113-116. - So hält die neuere Literatur die Urkunden für echt. Vgl. dazu nur Zimmer, Oeren, S. 19, 28-30. Krier, Epternus, S. 39, sowie auch die oben in Anm. 82 aufgeführte Literatur.

87 Vgl. Schroeder/Trauffler, Anfänge, S. 16-19. Die Abtei Echternach, ed. Ferrari u.a. 
Klösterchen. Es gab in Echternach jedoch spätestens seit der zweiten Hälfte des 6. Jahrhunderts eine größere fränkische Siedlung mit einer Villa und einer ersten Kirche, die vom Kloster abgelöst worden sein dürfte. Man hat allerdings überlegt, ob sich Irminas Klösterchen nicht im Bereich eines in der Nähe gelegenen Felskegels befunden haben könnte, auf dem einmal ein Römerkastell lag. Dort steht inzwischen die frühromanische Pfarrkirche St. Peter und Paul. Doch sprechen 1997 ausgeführte Grabungen dagegen. Zwar ist man auf einen kleinen Vorgängerkirchbau mit römischen Kryptenresten und ein nahes Gräberfeld gestoßen. Der ältere Bau datiert aber eher ins 5. oder 6. Jahrhundert und bietet keinerlei Spuren weiterer Klosteranlagen. ${ }^{88}$

So läßt es aufhorchen, wenn Schmal in einigen der Irmina-Urkunden neuerdings wieder Fälschungen oder Verfälschungen sehen will. Abt Thiofrid von Echternach (1083-1110) habe die Urkunden an der Wende vom 11. zum 12. Jahrhundert konstruiert, wozu von ihm in seinem Kloster wohl noch vorliegende Regesten benutzt und ausgeschrieben worden seien. Gleich wird darauf noch genauer zurückzukommen sein. $^{89}$ Schmals Argumente beruhen überwiegend auf der Überlieferungslage der Irmina-Urkunden. Diese Überlieferung muß deshalb zunächst erörtert werden, bevor Schmals Thesen und deren Folgen für Basin und Liutwin kritisch geprüft werden können (vgl. dazu das ausführliche Schaubild im Anhang).

\section{Die Überlieferung der Irmina-Urkunden}

Der älteste erhaltene erzählende Text, der sich mit Willibrord und dem Kloster Echternach beschäftigt, ist die Willibrord-Vita Alkuins, die zwischen 785 und 797 entstand. Doch erwähnt diese weder die Urkunden einer Irmina, deren Rolle in der Frühzeit Echternachs noch den Einfluß eines Basin oder Liutwin.

88 Vgl. Krier, Epternus, S. 36-45. Diese frühe fränkische Kirche wurde allerdings nicht lokalisiert. Doch deutet eine entdeckte fragmentarische frühchristliche Grabinschrift auf deren Existenz hin (ebd., S. 38). Auffällig ist auch die unterschiedliche Ausrichtung von Kirche und Konventsgebäude beim Willibrordkloster (ebd., S. 39). Vgl. ferner KRIER, Echternach. - Vgl. Trauffler, Gründung, S. 50, zur möglichen Lage des Klösterleins auf dem Felskegel. Doch bleibt dies umstritten. Schroeder/Trauffler, Anfänge, S. 8, $10-16,19$ f., 40. Die ältere Forschung vermutete es am Fuße des Felskegels, am Ort des späteren St.-Georg-Spitals. Danach ging man von einem Umbau eines Irminabaus durch Willibrord zu seinem Kloster aus (ebd., S. 19 f.). Ein Plan der ersten beiden Kirchen in Echternach findet sich ebd., S. 40. - Zu den Grabungen 1997 vgl. Bis-Worch, Kirchenbauten, S. 116-121. Das Kastel auf dem Berg sei etwa bis zum Ende des 5. Jahrhunderts genutzt worden. Die erste Kirche auf dem Berg müsse lange vor Irmina entstanden sein. Auch die Ruine der römischen Villa in Echternach habe man nachweisbar nicht für eine Kirche oder ein Kloster verwendet.

89 Vgl. Schmal, Mettlach, S. 44-54, sowie unten Kap. D.III.3. 
Die stark legendenhafte Vita weiß nur von der Klostergründung durch Willibrord selbst zu berichten. Irmina kommt überhaupt nicht zur Sprache. ${ }^{90}$

Die sog. Irmina-Urkunden sind erst danach in drei Stufen überliefert (vgl. dazu das Schaubild im Anhang), jedoch immer nur in der Tradition des Klosters Echternach. Zum ersten Mal finden sich zwei davon als jeweils regestenhafter Satz in der Vita sanctae Irminae, die der schon erwähnte Abt Thiofrid von Echternach (1083-1110) vor 1081 im Auftrag der Oerener Nonnen über eine Irmina verfaßte, die in deren Kloster verehrt wurde. In der Vita beschreibt Thiofrid diese Irmina als Gründerin des Klosters Oeren und Tochter König Dagoberts I. († 638/9). Dieser Zeitansatz läßt sich aber mit der angeblich 697/8-704 in Echternach tätigen Irmina kaum in Einklang bringen. Thiofrid folgt in der Vita sanctae Irminae insgesamt einer sich ab dem späten 10. Jahrhundert allmählich in Trier neu herausbildenden Dagobert-Irmina-Tradition, die später noch genauer zu diskutieren ist. ${ }^{91}$ In einem eigenen Kapitel des Textes geht er auch knapp auf die angebliche Unterstützung dieser Irmina für Willibrord und Echternach ein, die Willibrord - so das erste der beiden ,Urkundenregesten ' - ihren Anteil an Echternach übertragen habe (ähnlich WАмрасн I 2, Nr. 4). Den restlichen Teil an Echternach habe dieser von Pippin (dem Mittleren) und seiner Frau Plektrud erhalten, was auf einer anderen, später zu besprechenden Urkunde basiert (WАмрасн I 2, Nr. 14). Willibrord habe dann - so die Vita weiter - an diesem Ort eine Kirche gebaut und dorthin Mönche

90 Vgl. Alkuin, Vita Willibrordi archiepiscopi Traiectensis cap. 24, ed. Levison, S. 134 f.: Die sexta Novembri mensis, id est octavas Idus, ex hac peregrinatione ad perpetuam migrabat patriam et sepultus est in monasterio Aefternaco, quod ipse Deo, ut praefati sumus, construxerat. Die ältesten Handschriften stammen noch aus dem 9., viele aus dem 11. und 12. Jahrhundert (ebd., S. 97 ff.). - Zu deren Entstehung vgl. Willibrord - Apostel der Friesen. Seine Vita nach Alkuin und Thiofrid, ed. Reischmann, S. 11-42, bes. S. $14 \mathrm{f}$. Vgl. zu dieser Vita zuletzt auch Schroeder, Willibrord, S. 349-352, der von einer Entstehung im Echternacher Umkreis spricht, den Informationsgehalt dennoch anzweifelt. Berschin, Biographie 3, S. 113-139, datiert (ebd., S. 115 f.) auf 796. Alkuin habe für Abt Beornrad von Echternach, zugleich Erzbischof von Sens († 797), geschrieben. Es handle sich um die erste karolingische Biographie. Vgl. zur Vita schließlich allgemein ELm, Macht der Weisheit, S. 228 f.

91 Vgl. zur Dagobert-Irmina-Tradition unten Kap. D.II.6. - Vgl. zur schon vor Thiofrid erfolgenden Wandlung Irminas zur Königstochter und Thiofrids Verfasserschaft der Irmina-Vita Wampach I 1, S. 114-116 u. Anm. 4. Im bei Thiofrid, Vita sanctae Irminae, ed. Weiland, nicht edierten Prolog der Vita nenne sich Thiofrid als deren Verfasser im Auftrag der Nonnen, aber noch nicht als Abt, was er jedoch ab 1081 war. Vgl. den Prolog der Vita bei Krusch, Reise nach Frankreich, S. 620 f. - Zur Irmina-Vita vgl. auch Lampen, Thiofrid, S. 5-7. Zu den Vorlagen der Vita vgl. Poncelet, Fontibus, S. 285 f., der zeigen kann, daß alle verwendeten Quellen heute noch erhalten sind. Vgl. zuletzt nochmals Kölzer, Studien, S. 255-257 u. Anm. 28, der erneut auf die Entstehung vor 1081 hinweist. 
gebracht. ${ }^{92}$ Der zweite regestenhafte Vermerk einer Donation Irminas ist dann eine kleine Landschenkung der Villa Berg im Zülpichgau, die noch kurz nachgeschoben wird (WАмРАCH I 2, Nr. 6). ${ }^{93}$ Insgesamt kann man sich jedoch nicht des Eindrucks erwehren, als ob Thiofrid in der Vita die ihm bekannten Echternacher Irmina-Donationen in die aufgegriffene Oerener Irminatradition nachträglich einflocht: ein Analogieschluß. In der Oerener Irmina glaubte er wohl, die Echternacher Irmina wiederzuerkennen. Die chronologischen Unstimmigkeiten fielen nach fast 400 Jahren nicht mehr auf. ${ }^{94}$ Um es nochmals zu betonen: Gemäß der vom Echternacher Thiofrid verfaßten Vita sanctae Irminae gründete diese Irmina zwar das Kloster Oeren, doch ist Willibrord dagegen ganz allein der Gründer Echternachs.

Ein zweites Mal finden sich just diese beiden gerade erwähnten Schenkungen Irminas (Wамрасн I 2, Nr. 4 u. 6) in der Vita Willibrordi desselben Abtes Thiofrid, die er aber erst um 1103/4 schrieb. Er erwähnt die zwei erneut regestenhaft mit zahlreichen anderen wiedergegebenen frühen Schenkungen an Willibrord, die aus der Gründungszeit des Klosters Echternach stammen sollen. Sie alle sind als knappe Inhaltsnotizen in cap. 12 der Willibrord-Vita aufgenommen. Die Schenkung von Pippins und Plektruds Teil an Echternach steht jetzt ganz zu Anfang, ihr wird Priorität eingeräumt (WАмрасн I 2, Nr. 14). Erst dann folgt Irminas Gabe, die diesmal aber als gemeinsames Regest mit der Landschenkung der Villa Berg im Zülpichgau unter dem Einheitsdatum des 1. Dezember 697/8 verbunden ist (Wampach I 2, Nr. 4 u. 6). Thiofrid bemerkt, nachdem er alle Donationsregesten aufgeführt hat, daß es darüber hinaus noch weitere Urkunden gebe, die für ihn jedoch unlesbar seien. ${ }^{95}$ Das könnte bedeuten, daß ihm noch merowingische Originale auf brüchigem Papyrus oder frühe Abschriften vorgelegen haben. Vielleicht erstellte er sogar überhaupt erstmals aus dem für ihn noch lesbaren Material diese Regestensammlung. Insgesamt aber sieht auch diese Vita natürlich ihren Protagonisten Willibrord als Gründer Echternachs. Als Vorlage verwendete Thiofrid die Gliederung der Willibrord-Vita Alkuins (785/97) und schrieb diese aus. Die älteste erhaltene Handschrift von Thiofrids Vita Willibrordi stammt aus dem frühen 12. Jahr-

92 Vgl. Thiofrid, Vita sanctae Irminae cap. 6, ed. WeIland, S. 49: Qui construxit ibi aecclesiam et imposuit viros qui vitam exercerent monachicam.

93 Vgl. zu diesen Urkunden ausführlicher unten Kap. D.II.4.a.-b. u. D.II.5.

94 Vgl. Thiofrid, Vita sanctae Irminae cap. 6, ed. WeILAnd, S. 49.

95 Vgl. Thiofrid, Vita S. Willibrordi, Vita prosa cap. 12, ed. Poncelet, S. 468 A: [...]; et plura alia que consulto praetereo propter barbara et hominum et locorum vocabula. Vgl. zu dieser Passage zuletzt Schroeder, Willibrord, S. 352-355, der von einer intensiven Archivbenutzung durch Thiofrid spricht. Die Vita sei mehr um die Wahrheit bemüht, als die Alkuins. Heidrich, Urkunden der frühen Karolinger, S. 455 u. Anm. 3, bemerkt: „Thiofrid ist nur am Besitz des Klosters, nicht an dessen Rechtsstatus interessiert." Vgl. ferner WАмрасн, Willibrord, S. $135 \mathrm{ff} ., 410 \mathrm{f}$. 
hundert, in unmittelbarer zeitlicher Nähe zum Autor also. Über Willibrord verfaßte Thiofrid auch noch einen kurzen Miracula-Text. Neben Thiofrids schriftstellerischem Werk, das auf erheblichen literarischen Kenntnissen beruht, sowie seinem Abbatiat ist über ihn nur wenig bekannt: Er stand wohl in einem guten Verhältnis zu Kaiser Heinrich IV. (†1106), aber auch zu den Trierer Erzbischöfen Egilbert (1079-1101) und Bruno (1102-1124). Vielleicht mußte er sich bereits mit den Übergriffen der Vögte der Reichsabtei Echternach - den Luxemburger Grafen - sowie deren Untervögten auf das Klostergut auseinandersetzen. ${ }^{96}$ Dies könnte womöglich einen Anlaß für das Schenkungsregest geboten haben.

Thiofrids vor 1081 entstandene Vita sanctae Irminae findet sich heute allerdings handschriftlich zum ersten Mal in der nunmehr dritten Überlieferungsstufe der Irmina-Urkunden tradiert: dem Liber aureus Epternacensis, dem großen Echternacher Kopiarbuch aus dem späten 12. Jahrhundert. In Echternach trug im Jahr 1191/2 zunächst ein Mönch Theoderich unter seinem Abt Gottfried II. (1181-1210) die Besitztitel des Klosters im ersten Teil dieses Kopiarbuchs in Form einer Chartularchronik bis zum Jahr 727 zusammen. Es handelt sich dabei um in ihrem Text meist vollständige, chronologisch angeordnete Urkunden, die von historischen Erläuterungen umgeben sind. Unter Gottfrieds Nachfolger Bartholomäus (ca. 1210-1231) wurde dann das von Theoderich begonnene Werk endgültig zum Abschluß gebracht. ${ }^{97}$ Theoderich

96 Vgl. Thiofrid, Vita S. Willibrordi, Vita prosa, ed. Poncelet. - Zu Thiofrids WillibrordVita vgl. WАмрасн, Willibrord, S. 135 ff., 410 f. Willibrord - Apostel der Friesen. Seine Vita nach Alkuin und Thiofrid, ed. Reischmann, S. 91-93. Schmal, Mettlach, S. 49. Trauffler, Gründung, S. 51. Zu Thiofrid vgl. Lampen, Thiofrid, S. 1-5, zu seinem Leben; ebd., S. 12-16, zur Willibrord-Vita und den Miracula Willibrordi; ebd., S. 21 24, zur handschriftlichen Überlieferung. WAмPACH I 1, S. $241-251$, bes. S. 241 f., weist die Quellen nach. Thiofrid könne in Lüttich ausgebildet worden sein. Er folgte Abt Reginbert in Echternach und stand in der Politik des Reiches 1101 auf Seiten Heinrichs IV. Auch die Übergriffe auf das Klostergut werden (ebd., S. 251-266) geschildert. Doch ist die Quellenlage dünn. Vgl. zu Thiofrid, seinem literarischen Werk und der handschriftlichen Überlieferung auch Worstвrock, Thiofrid. - Thiofrid nennt die Namen der Vögte und Untervögte, die das Klostergut bedrohten, in seiner Vita S. Willibrordi cap. 33, S. 479 f. Zu den Vogteiproblemen vgl. auch Kölzer, Studien, S. 263-266. Margue, Libertas, S. 241, ist da vorsichtiger und hält dies für Vorwürfe des späten 12. Jahrhunderts. - Vgl. ferner Thiofrid, Miracula S. Willibrordi, ed. Poncelet, S. 458 f. Zum Trierer Erzbischof Bruno von Lauffen vgl. Goerz, Regesten der Erzbischöfe zu Trier, S. 13-15. Bönnen, Trier zwischen dem 10. und dem 12. Jahrhundert, S. 229, $234-237$.

97 Vgl. dazu Theoderich, Chronicon Epternacense, ed. Weiland, S. 38-64. Die Edition folgt den Seitenangaben der Handschrift (Gotha, Forschungs- und Landesbibliothek, Memb. I 71). - Vgl. zum Liber und dessen Überlieferung WАмрасн I 1, S. 67-79, bes. S. 67-70. Der Mönch Theoderich ist auch selbst erster Schreiber des Kodex'. Ausführlich zu den Entstehungsumständen vgl. SAUER, Fundatio, S. 246-273 u. 354-359, 
verfaßte das Kopiarbuch auf der Basis von vermutlich in irgendeiner Form in Echternach erhaltenen Urkunden. Er bezweckte damit, der 1192 drohenden Mediatisierung des Klosters durch Kaiser Heinrich VI. (1191-1197) und den Trierer Erzbischof Johannes I. (1189-1212) sowie dem damit verbundenen Verlust der Position als Reichsabtei entgegenzuwirken. Johannes beabsichtigte, für das Kloster die Burg Nassau einzutauschen. Der Liber aureus sollte dagegen mit seinem Material zeigen, daß Echternach seit seiner Gründung schon immer reichsunmittelbar war. Auch wollte man durch die vielen aufgeführten Besitznachweise das Klostergut zurückbekommen, das der Luxemburger Graf Echternachs Vogt - in der Mitte des 12. Jahrhunderts an seine Leute als Lehen vergeben hatte. Schon Wampach hat das in seiner umfangreichen Arbeit zu Echternach deutlich herausgearbeitet. MARGUE spricht gar von einer Neuschreibung der Echternacher Gründung. Bei Theoderich lassen sich dabei auch gezielte Fälschungen nachweisen. ${ }^{98}$ Dem Liber ist also nicht blind zu vertrauen.

In zwei Prologen in Form einer Herrscher- und Abtliste wies der Mönch Theoderich zu Beginn des goldenen Buches auf die alte und lange Geschichte Echternachs hin. Es gehe auf eine Gründung der hl. Irmina, des hl. Willibrord und Pippins des Mittleren mit seiner Frau Plektrud zurück. ${ }^{99}$ Danach folgt der Text von Thiofrids Vita sanctae Irminae, die in gewisser Weise prägend auf den Liber gewirkt zu haben scheint. Denn sogleich schließen sich jetzt hinterein-

auch zu den Prologen. Heidrich, Titulatur, S. 172-176. Margue, Libertas, S. $241 \mathrm{f}$. Heidrich, Urkunden der frühen Karolinger, S. 455-460, 465-470, betont nochmals den besonderen Charakter der Chartularchronik und die damit verbundene Urkundenproblematik. Zur Handschrift vgl. auch Hopf, Die abendländischen Handschriften 1, S. 52 f. - Vgl. zu Abt Gottfried, der auch Abt von St. Eucharius war, Becker, St. Eucharius, S. 595-598.

98 Vgl. Waмpach I 1, S. 80-110, hier S. 104 f., der Fälschungen Theoderichs in zwei Urkunden Pippins III. im Liber nachweist. Doch ein schlimmer Fälscher sei er nicht gewesen. Wampach bietet (ebd., S. 266-292) einen Überblick über die Verhältnisse im 12. Jahrhundert in der Abtei sowie zum Streit mit Trier (ebd., S. 280-290). - Vgl. zu den Fälschungen auch MüHLbacher, Urkundenfälschungen, S. 350. - Vgl. ferner Werner, Adelsfamilien, S. 100-102, zur Arbeitsweise Theoderichs. Margue, Libertas, S. 230-245, bes. $241 \mathrm{ff}$, der auch (ebd., S. 230) darauf hinweist, daß Wampach teils den tendenziösen Klosterquellen gefolgt ist. Theoderichs Leitmotiv sei die Libertas ecclesiae von fremden Einflüssen (ebd.). Er wolle Echternachs frühe Geschichte neu schreiben. „Aus dem Reichskloster des karolingischen Hauses wird hier ein Reichskloster, das dem jeweiligen Herrscher unmittelbar untersteht" (ebd., S. 243). - Vgl. zum Geschehen auch Corsten, Erzbischof Johann I., S. 152 f., und Csendes, Heinrich VI., S. 138 f. Vgl. zu Johann I. auch Goerz, Regesten der Erzbischöfe zu Trier, S. 26-31. Pundt, Erzbischof und Stadtgemeinde, S. 259 ff. Hirschmann, Civitas Sancta, S. 412 u. 445.

99 Vgl. Theoderich, Chronicon Epternacense, ed. Weiland, S. 38 f. u. 47 f. Zwischen beiden Prologen befindet sich eine Genealogie der Frankenfürsten von der Frühzeit bis zu den Tagen Willibrords und der Gründung Echternachs. Vgl. ferner WАмрасн I 2, S. 3-11. - Zu den Prologen vgl. auch oben Anm. 97. 
ander alle fünf bekannten Irmina-Urkunden im kompletten Wortlaut an (Waмpaсн I 2, Nr. 3, 4, 6, 9 u. 10) und nicht mehr nur die beiden, die sich als Regesten bei Thiofrid finden (WАмрасн I 2, Nr. 4 u. 6). Die Irmina-Urkunden eröffnen also ganz gezielt den Urkundenteil des Liber. Es ist - wie erwähnt - die erste und einzige Volltextüberlieferung dieser Stücke überhaupt, 500 Jahre nach ihrem angegebenen Ausstellungsdatum. Den Irmina-Urkunden folgen zwei Urkunden Pippins und Plektruds (Wampach I 2, Nr. 14 u. 15), darunter die Schenkung eines Teils von Echternach an das Kloster, die wir schon aus Thiofrids Viten kennen. Andere, teils noch früher datierende Urkunden werden erst danach aufgeführt, in einigen wenigen Fällen auch nur in knapper Regestenform. ${ }^{100}$

Theoderich räumte Irmina also absolute konzeptionelle Priorität ein. Der Liber visualisiert die herausragende Rolle Irminas in zwei Traditionsbildern. Das erste zeigt Irmina und Willibrord gemeinsam, wie beide Irminas Schenkungsurkunde über Echternach (Wampach I 2, Nr. 4) mit den Händen fassen. Irmina trägt - gemäß ihrer Vita - als Tochter König Dagoberts I. (†638/9) gar eine Krone. In einem zweiten späteren Bild halten Irmina - wieder mit Krone - und Pippin - als Hausmeier ohne Krone - gemeinsam die Kirche von Echternach in die Höhe. ${ }^{101}$ Die Bedeutung Irminas verstärkt sich damit im Bezug auf die Gründung Echternachs gegenüber Willibrord sowie Pippin und Plektrud im Gegensatz zu Thiofrids Irmina- und Willibrord-Vita erheblich, ja dramatisch.

Der Mönch Theoderich ergänzte seine Argumentation noch um eine Streitschrift, den Libellus de libertate Epternacensi, die sich am Ende der Handschrift des Liber aureus nachgetragen findet. Auch darin hob Theoderich erneut die so alte und weit zurückreichende Geschichte des Klosters hervor. Echternach hatte mit dem Konzept des Liber Erfolg. Heinrich VI. gab schließlich sein Vorhaben auf und sicherte dem Kloster seine Freiheit urkundlich zu. ${ }^{102}$

Zusammengefaßt ist die Botschaft des Liber aureus und damit die seines Verfassers Theoderich schon auf den ersten Blick eindeutig, ohne den genauen

100 Vgl. Theoderich, Chronicon Epternacense, ed. Weiland, S. $48 \mathrm{ff}$.

$101 \mathrm{Zu}$ den Bildern vgl. Gotha, Forschungs- und Landesbibliothek, Memb. I 71, fol. $28^{\mathrm{r}} \mathrm{u}$. $32^{\mathrm{v}}$. Abbildungen davon finden sich bei WaмpaCH I 1, S. 64 f., sowie WaмpaCH I 2, S. 48 f., ebenso bei Trauffler, Gründung, S. 49 u. 51. Irmina wird dabei als Heilige behandelt, sie trägt einen Heiligenschein. SAUER, Fundatio, S. 260-263, interpretiert die beiden Bilder und weist auch auf die doppelte Ansippung an Merowinger wie Karolinger durch sie hin. Man habe die Gründertradition zugunsten der Angehörigen beider Königsgeschlechter verschoben.

102 Zum Freiheitsprivileg Heinrichs VI. vom 26. August 1192 und dessen Gesinnungswandel vgl. die Edition der Urkunde bei Wampach I 2, Nr. 216, S. 382-384. - Vgl. ferner Theoderich, Libellus de libertate Epternacensi, in: WАмрасн I 2, Nr. 215, S. 360-382. - Vgl. dazu insgesamt Margue, Libertas, S. 241-245, der seine Überlegungen anhand des Libellus' anstellt. 
Wortlaut der Irmina-Urkunden zu kennen: Irmina steht jetzt primär am Anfang der Klostergeschichte, wo alle bisher besprochenen früheren Texte ohne jeden Zweifel vielmehr Willibrord sehen. Deshalb muß es um so stutziger machen, daß sich plötzlich gleich fünf - statt zuvor zwei - Irmina-Urkunden in Vollversion an so herausgehobener Stelle im Liber präsentiert finden, die bis auf eine auch Basin und Liutwin nennen. Theoderich ging also sehr durchdacht und gezielt bei der redaktionellen Arbeit vor. Wie weit aber reichte diese? Griff er womöglich auch in die Urkundentexte ein? Die gerade beschriebene Überlieferungssituation dieser Urkunden weckt jedenfalls begründete Zweifel an Schmals Überlegungen, die ja Abt Thiofrid 100 Jahre zuvor für Manipulationen daran verantwortlich machen will.

3. Die Irmina-Urkunden und der Zustand des Echternacher Klosterarchivs

Die ersten Belege der Irmina-Urkunden finden sich also (frühestens etwa 380 Jahre, nachdem Echternach gegründet wurde) bei Abt Thiofrid von Echternach (1083-1110); Basin und Liutwin tauchen erst in den einzigen Volltextversionen im Liber aureus nach knapp 500 Jahren auf. Ob die Normannen 882 die Bestände des Klosters dezimierten, ist unklar, aber möglich. Im Jahr 1016 gab es einen größeren Klosterbrand, dem ein Teil des Archivs zum Opfer gefallen sein könnte und dem ein Kirchenneubau folgte. ${ }^{103}$ Älteres Material kann also verlorengegangen sein.

Kommen wir dazu nochmals auf Schmals Thesen zurück. Sie berücksichtigt bei ihren Überlegungen vor allem die Formalia der Urkunden und kaum deren inhaltliche Aussagen. ${ }^{104}$ Wie die erwähnten Urkundenregesten in cap. 12 der Willibrord-Vita $(1103 / 4)$ des Thiofrid zeigten, seien ihm einige Echternacher Urkunden bekannt gewesen, die sich später auch im Liber aureus (1191/2) wiederfänden. (Schmal übersieht dabei die beiden Irmina-Schenkungsregesten in Thiofrids Vita sanctae Irminae vor 1081.) Für Thiofrid müßten diese in einer älteren Urkundensammlung bzw. Regesten greifbar gewesen sein, vermutet Schmal. ${ }^{105}$ In der angenommenen kopialen Form hätten sich die Urkunden allerdings nur in einer absichtlich verkürzten Fassung befunden, die auf die Datums-, Signums- und Rekognitionszeile sowie die Zeugenliste verzichtete. Das gelte auch für die Irmina-Urkunden. Da diese Urkunden jedoch - wie viele

103 Vgl. zu einem möglichen Normannenüberfall Wampach I 1, S. 177 f. Margue, Libertas, S. 231. Zum Klosterbrand vgl. Waмpach I 2, S. 101.

104 Vgl. Schmal, Mettlach, S. $44 \mathrm{f}$.

105 Die ältere regestenartige Sammlung könnte nach dem Klosterbrand von 1016 angelegt worden sein. - Zum Klosterbrand als Anlaß für die Regestensammlung vgl. SchmaL, Mettlach, S. 53, Anm. 338. 
andere - im Liber aureus in Vollversionen stünden, müßten sie zuvor „durch Interpolationen wieder, vervollständigt"“ worden sein. Man hätte also die fehlenden Zeilen und Zeugen neu ergänzt. An den Irmina-Urkunden lasse sich das sogar noch erkennen. Denn an deren Textende fänden sich die Schreibervermerke cum testibus firmavit. Bei Anlage der Regestensammlung habe man dies eingefügt, um auf die jetzt ausgelassenen Zeugennamen hinzuweisen. In den vollständigen Urkunden mit Zeugen habe sich ursprünglich nämlich nur firmavit befunden. Im Liber aureus lasse sich das noch an zwei Urkunden desselben Ausstellers (eines Grafen Ebroin) zeigen, die unmittelbar aufeinanderfolgten. Die erste enthalte Zeugen (also firmavit), die zweite nicht (also cum testibus firmavit). ${ }^{106}$ Als die Irmina-Urkunden wieder vervollständigt worden seien, habe man also schlicht vergessen, das cum testibus wieder zu streichen. Hätten noch Originale existiert, wäre das kaum passiert. Die Zeugennamen sowie einige weitere Teile der fünf Irmina-Urkunden seien deshalb frei erfunden. Das teilweise übereinstimmende Namensgut belege das nur zusätzlich. ${ }^{107}$

Nach Schmal habe schon Abt Thiofrid die Urkundenregesten, also auch die der Irmina-Urkunden, wieder vervollständigt. Man finde in den Echternacher Urkunden nämlich Thiofrids typische Stilmerkmale, die schon LAMPEN herausarbeitete. ${ }^{108}$ - Darauf wird später noch genauer einzugehen sein. - Thiofrid habe also Liutwin und Basin in die Irmina-Urkunden interpoliert. Beide seien ihm ja aus seiner Liutwin-Vita (der Vita II, 1072/7) bekannt gewesen. Ihre gleichzeitigen Bischofstitel müsse man deshalb als Bischof Basin und der spätere Bischof Liutwin lesen. ${ }^{109}$ Thiofrid habe für seine Irmina-Vita wohl Irminas Verdienste noch mehren wollen. Das Regest, in dem Irmina ihren Teil an Echternach an das dortige Kloster schenkte, habe Thiofrid zuerst wieder vervollständigt (Wамрасн I 2, Nr. 4). Dann habe er nach dessen Vorlage eine zweite neue Urkunde gefälscht (WАмрасн I 2, Nr. 3), in der Irmina das Kloster jetzt sogar erst auf eigenem Grund erbaut und dann an Willibrord schenkt. Dieses konstruierte Bild einer Klostergründerin habe Thiofrid anschließend noch in die anderen vervollständigten Irmina-Urkunden interpoliert (WАмРАCH

106 Vgl. Schmal, Mettlach, S. 46 u. 299 f. Als Beispiele führt sie zwei entsprechende Urkunden eines Ebroin im Liber aureus auf, einmal mit Zeugennamen und ohne das cum testibus nur mit firmavit (WAмpach I 2, Nr. 31, S. 72-75, bes. S. 75) sowie einmal ohne Zeugennamen, dafür aber mit dem Vermerk cum testibus firmavit (WАмрасн I 2, Nr. 32*, S. 76).

107 Vgl. Schmal, Mettlach, S. 45-49. Schmal bietet für den Vergleich des Namensgutes eine tebellarische Aufstellung.

108 Vgl. Schmal, Mettlach, S. 49-51. Lampen, Thiofrid, S. 61-82.

109 Vgl. Schmal, Mettlach, S. 50, 53. Deshalb erscheine Liutwin denn auch in einer der Urkunden nur als presbiter (ebd., Anm. 340). Zum Doppelepiskopat vgl. ebd., S. 44 f. Auf den Doppelepiskopat hat auch schon Werner, Adelsfamilien, S. 67, hingewiesen. Dieser könne nur kurz gedauert haben. 
I 2, Nr. 6, 9 u. 10), ${ }^{110}$ was deren teils übereinstimmenden Wortlaut erkläre. Wieweit die Urkunden noch über einen echten Kern verfügten, läßt SchmaL offen. ${ }^{111}$ Der häufig zu beobachtende Wechsel von der 1. zur 3. Person Singular in deren Text belege die Manipulation. ${ }^{112}$

Gegen diese nicht widerspruchsfreie Argumentation läßt sich Grundsätzliches einwenden: Wie kann der Liber aureus von 1191/2 als Beleg dafür dienen, wie Echternacher Urkunden irgendwann einmal aussahen, bevor sie zu Regesten verkürzt wurden, die zur Zeit des Liber ja schon wieder vervollständigt waren? Das ist ein Zirkelschluß. Die von Schmal dazu als Beispiel angeführten aufeinanderfolgenden (Ebroin-)Urkunden lassen sich auch ganz anders erklären: Denn der Kopist des Liber könnte bei der zweiten Urkunde auch deshalb auf die Zeugen verzichtet haben, weil sich schlicht die der ersten wiederholten. Weshalb hätte man überhaupt viele Jahre vor der Abfassung des Liber in großem Stil kopial verkürzt überlieferte Urkunden plötzlich mit frei erfundenen Zeugen versehen sollen? Wenn überhaupt, dann wäre ein solches Motiv doch eher dem Verfasser des Liber aureus, dem Mönch Theoderich, zu unterstellen. Ferner führt der Liber bei einigen weiteren Urkunden keine Zeugen auf, ${ }^{113}$ aber nirgendwo steht stattdessen cum testibus firmavit, was es nach Schmal doch müßte. Auch die im Liber als solche zu findenden Regesten enthalten kein solches cum testibus firmavit, ${ }^{114}$ ebensowenig die regestenhaft wiedergegebenen Schenkungen in Thiofrids Vita Willibrordi. Diese Zahlen wiegen die beiden Beispiele Schmals bei weitem auf. Der erwähnte Terminus dürfte deshalb fester Formularbestandteil der Corroboratio einiger Urkunden gewesen sein, die dem Mönch Theoderich bei der Anlage des Liber (1191/2) noch vorlagen. Abt Thiofrid nennt ja in cap. 12 seiner Vita Willibrordi (1103/4) alte Urkunden, die er nicht mehr lesen konnte. Ebenfalls zählt er dort regestenhaft auch Schenkungen auf, die sich später im Liber nicht wiederfinden. ${ }^{115}$ Es muß also noch Originale gegeben haben, von denen einige inzwischen verloren gingen oder die nun der Mönch Theoderich vielleicht selbst nicht mehr lesen konnte. Ob diese aber tatsächlich zeitgenössisch waren oder ihre Existenz früheren Abschriften oder

110 Vgl. oben S. 133 u. Anm. 95.

111 Vgl. Schmal, Mettlach, S. 49, 52 f.

112 Vgl. Schmal, Mettlach, S. 46, 53 u. Anm. 301, 336.

113 Vgl. nur die folgenden Urkunden bei Wамрасн I 2, Nr. 21, 23, 27 f., 33-35, 41, $44-$ 46 , S. 52-57, 65-70, 76-81, 98-102, 107-110 usw.

114 Vgl. dazu nur die Regesten bei Waмpaсн I 2, Nr. 1*, 2*, 5*, 7*, 12*, 19*, 29*, 38*, S. 15-17, 23, 27 f., 36 f., 49 f., 70, 83, die allesamt keinen Vermerk über cum testibus firmavit verfügen.

115 Vgl. Wampach I 2, Nr. 22*, 37*, 38*, S. 54, 82 f. 
Verformungen verdankten, muß freilich offen bleiben. ${ }^{116}$ Dann allerdings können auch die Zeugennamen der Irmina-Urkunden teilweise durchaus glaubwürdig sein. Warum hätte aber ausgerechnet Thiofrid Basin und Liutwin gemeinsam zu Bischöfen machen sollen, wenn er es doch aufgrund seiner Willibrord-Vita wirklich besser wußte. ${ }^{17}$ An einer Irmina als Gründerin Echternachs kann Thiofrid im Gegenteil kaum etwas gelegen haben, denn für ihn war - wie wir sahen - sowohl in seiner Irmina- wie in der Willibrord-Vita doch nur Willibrord ganz allein der Gründer des Klosters.

Ingrid Heidrich hat sich schließlich zeitgleich mit Schmal dem Liber aureus und dessen frühen Urkunden gewidmet. Sie betont die aus der Form der Chartularchronik für die Urkunden resultierende Problematik und weist auf die teilweise unsaubere Redaktionsarbeit sowie die Lückenhaftigkeit des Liber hin. Diese mache sich aufgrund des Fehlens von im Original noch erhaltenen Urkunden bemerkbar. Für die Frühzeit könnten aufgrund der Regestenvermerke noch archivalische Verzeichnisse vorgelegen haben. Als Ursache für Dopplungen im Liber vermutet sie thematische „Dossiers“, bei denen dieselbe Urkunde in mehr als einem habe auftauchen können. ${ }^{118}$ Auch das spricht in gewisser Weise gegen Schmal. Diese Dossiers sind denkbar. Archivalische Notizen über die Frühzeit müssen nicht erhaltene Originale aus diesen Jahren aber grundsätzlich ausschließen, wie man an Thofrids Bemerkung sieht. Vielleicht sind die Regesten im Liber auch Inhaltsangaben kaum lesbarer alter Urkunden. Womöglich waren auf denen knappe Zusammenfassungen notiert, die dann in den Liber übernommen wurden.

\section{Der Inhalt der Irmina-Urkunden - Eine Analyse}

Hier sollen die Irmina-Urkunden deshalb nochmals einer genauen Prüfung unterzogen werden, um neue Erkenntnisse über ihre Echtheit, die Rolle Irminas, Basins und Liutwins bei der Klostergründung sowie mögliche originale Vorlagen zu gewinnen. Schmals Thesen sind dabei jeweils zu berücksichtigen. Es erscheint dazu sinnvoll, die fünf bekannten Volltexturkunden (WАмрасн I 2, Nr. 3, 4, 6, 9 u. 10) sowie das Ymena-Regest (Wampach I 2, Nr. 12*) in der nicht ganz chronologischen - Reihenfolge zu untersuchen, in der sie ihre einzige Überlieferungsquelle bietet: der Liber aureus (1191/2) und damit der Mönch

116 Auch läßt sich nicht ganz klären, ob einige der Urkunden als Original und andere durch die Vorlage von Regesten erhalten blieben, man es also mit einer Art Mischüberlieferung $\mathrm{zu}$ tun hat.

117 Schmal, Mettlach, S. 44 f., gibt selbst zu, daß auch die Liutwin-Vita I und die Gesta Treverorum das Bild zweier aufeinanderfolgender Bischöfe zeichnen.

118 Vgl. Heidrich, Urkunden der frühen Karolinger, S. 455-460, 465-470. 
Theoderich. WampaCH hat sie dagegen in seine Edition chronologisch aufzunehmen versucht. ${ }^{119}$

\section{a. Das Testament Irminas vom 1. Dezember 697/8 (WАмpach I 2, Nr. 4)}

Im Liber aureus wird der Anfang der Gruppe der fünf Irmina-Urkunden, die dort der Vita sanctae Irminae folgen, wie schon erwähnt, visuell klar hervorgehoben. Irmina und Bischof Willibrord halten gemeinsam in einer Illustration zwischen sich das Dokument jeweils mit einer Hand, in dem Irmina ihren Besitz in Echternach an das dortige Kloster unter seinem Vorsteher Willibrord überträgt. ${ }^{120}$ Diese Urkunde scheint in großen Teilen echt, aber auch leicht interpoliert worden zu sein, wie wir im folgenden sehen werden.

Am 1. Dezember, im 4. Jahr der Herrschaft König Childeberts (III., 678/9711), 697/8 verfaßte die Gott geweihte Äbtissin Irmina in Trier ihr Testament, womit sie als Schreiber den Priester Huncio beauftragte. Darin schenkt sie der in ihrer Villa Echternach an der Sauer errichteten Basilika, an der Bischof Willibrord rector et gubernator sei, ihren gesamten elterlichen Teil an Echternach. Die Basilika sei der Hl. Dreifaltigkeit, der Maria, den Aposteln Peter und Paul sowie weiteren Heiligen geweiht. Der erwähnte elterliche Teil beinhalte auch alles in Baidelingo (Badelingen, heute Echternacherbrück auf der anderen Sauerseite gleich gegenüber), Matholfingo (Matzen bei Rittersdorf) sowie ihren Anteil in Oxinvillare (Osweiler) - alles Liegenschaften im näheren Umkreis von Echternach. Diese Besitzungen schenkt sie den Orten/Altären der Heiligen (ad sepefata loca sanctorum) und dem dort gebauten Klösterlein. Ausgenommen davon sind elf namentlich genannte Freigelassene, die dafür eine jährliche Wachsspende zu Weihnachten an die Orte/Altäre der Heiligen leisten sollen. Ebenso schenkt sie einen Weinberg in monte Viennense (Vianden) mit dem Winzer Alithfred und seinem Besitz. Schließlich folgt eine eigenwillige geistliche Poenformel, die sich aber noch in zwei weiteren bekannten merowingischen Testamenten findet. ${ }^{121}$ Huncio erwähnt, daß er das Testament geschrieben und

119 Vgl. Theoderich, Chronicon Epternacense, ed. Weiland, S. 50 ff. Wampach I 2, S. $15 \mathrm{ff}$.

120 Vgl. zur Illustration oben S. 136 u. Anm. 101.

121 Vgl. Wampach I 2, Nr. 4, S. 21-23: Anno quarto regni domini nostri Childeberti regis, sub die Kalendas Decembris. I In nomine Patris et Filii et Spiritus Sancti. / Ego Irmina, in Christi nomine Deo sacrata acsi indigna gratia Domini abbatissa, sana quidem, Deo propitio, mente sanoque consilio testamentum meum fieri rogavi, idque fratri in Christo meo Huncione presbitero scribendum commisi. I Idcirco dono a die presenti pro remedio anime mee vel pro mercedis mee augmento in ęterna beatitudine vel retributione ad basilicam que est in nomine sancte Trinitatis vel in honore sancte Marie genitricis Domini nostri Ihesu Christi vel beatorum apostolorum Petri et Pauli seu cęterorum sanctorum in villa nostra Epternaco constructa, sita super fluvium Sura, ubi dominus et pater noster in Christo Willibrordus episcopus rector et gubernator esse videtur, donatumque esse volo, hoc est in ipsa 
gemeinsam mit Zeugen bestätigt habe. Deren Namen lauten: Basinus episcopus. Ego Leotwinus episcopus. Ego Theodefridus. Gundebertus. Bertwinus. Adelbertus. Trasebrictus. Garibertus. Gazebertus. Audobertus. Waltharius.

Schmal hält die Urkunde im Kern zwar für echt, doch seien die Zeugennamen - wie oben bereits genauer ausgeführt - interpoliert und frei erfunden. Dies erkennt sie irrigerweise daran, daß auch die Datumszeile der Urkunde anders als bei Originalurkunden am Anfang stehe und nachträglich ergänzt sei. Sie gibt aber zu, daß wenn Originale vorgelegen hätten, diese sicherlich verwendet worden wären. Die Urkunde weise zudem Interpolationen auf, die sie Abt Thiofrid von Echternach $(† 1110)$ zuweist, die aber wohl eher Indizien für die Echtheit des Textes sind. Es fänden sich nämlich Thiofrids typische Stilmerkmale, wie z. B. zahlreiche griechische Begriffe, Superlative und biblische Vergleiche. Gerade der Schlußteil des Testamentes mit dem griechischen Wort caraxaturae, die Formel anathema maranatha sowie der biblische Hinweis auf den leprösen Naaman belegten das. ${ }^{122}$

villa Epternacon, quantumcumque ibidem ex successione paterna vel materna michi obvenit ad integrum, tam domibus quam ędificiis, casis, mansis, mancipiis, vineis, campis, pratis, silvis, pascuis, aquis aquarumque decursibus, cum appenditiis vel omnibus adiacentiis suis, Baidelingo, Matholfingo vel portione mea in Oxinvillare. Omnia ista cum adiacentiis eorum, una cum pastoribus vaccariis, porcariis, bervicariis, cum gregibus eorum vel omni peculio promiscuo ad sepefata loca sanctorum vel ad monasteriolum ibidem constructum in Dei nomine volo esse donatum, exceptis hominibus illis quos per epistolas nostras ingenuos relaxavi, quorum vocabula sunt: Garario, Cumloaldo, Achilde, Theodfrido filio, Aldfrido, Clodoare, Raocare, Warinlinde, Bacelinde, Grauceleba, Gundulfo. Isti toti denominati annis singulis unusquisque eorum in luminaribus unam libram cerę ad supradicta loca sanctorum in ipsa villa Epternaco constructa ad nativitatem Domini reddere vel dissolvere studeant. Similiter dono ad iam dicta loca sanctorum vinee pedeturam unam in monte Viennense, cum vinitore nomine Alithfredo cum omni peculiari suo. Ista omnia, ut superius intimavi, ad memorata loca sanctorum a die presenti per presentem paginam testamenti nostri tradimus atque transfundimus perpetualiter in Dei nomine possidendum. Hęc sunt que huic testamento meo annectere volui. Si que liturę vel caraxaturę adiectionis factę sunt, ego feci fierique iussi, dum michi mea sepius recensetur voluntas. Nam si quis contra hoc meum testamentum venire temptaverit, aut aliquid irrumpere voluerit, sit anathema maranatha, indissolubili vinculo in ęternum dampnatus, et sit lepra percussus Naaman Siri, et insuper inferat fisco auri libram unam, argenti pondo duo, et nichilominus presens testamentum firma stabilitate permaneat. I Actum Treberi die et regno suprascripto. / Ego Huncio, in Christi nomine presbiter, rogante et iubente domina mea Irmina abbatissa, hoc testamentum perscripsi et ipsa subter manu propria una cum testibus firmavit. / Ego Irmina hoc testamentum meum relegi. Es folgen die oben genannten Zeugen. - Zu den in der Urkunde genannten Ortsnamen vgl. zunächst die Anmerkungen zum Editionstext, sodann auch WАмрасн I 1, S. 117-120. Trauffler, Epternacus, S. 249. Zur Poenformel vgl. Nonn, Merowingische Testamente, S. $100-104$, hier S. 102, wo er darauf hinweist, daß der erwähnte lepröse Naaman auch in den Testamenten des Bertram und der Burgundafora erscheine.

122 Vgl. Schmal, Mettlach, S. 47 f. u. Anm. 308. Zum Stil Thiofrids vgl. nochmals oben Anm. 108. 
Doch die von Schmal angesprochenen Zweifel rütteln nicht an der Glaubwürdigkeit der Urkunde. Zunächst ist der Inhalt logisch und weist keinerlei Widersprüche auf. Ja, er deckt sich sogar mit dem archäologischen Befund in Echternach. Bei den Ausmaßen der ergrabenen Anlage handelt es sich tatsächlich um ein kleines Kloster mit nur einer Kirche. ${ }^{123}$ Für die Echtheit spricht, daß Irmina ihre Schenkung an die Heiligen der Kirche vornimmt, wie es üblicherweise geschieht, und nicht an Willibrord als Vorsteher derselben, wie es in anderen Echternacher Urkunden - wie wir gleich sehen - anzutreffen ist. ${ }^{124}$ Ebenso belegt die Echtheit, daß die Urkunde dem Aufbau des fränkischen Testamentformulars folgt, was NonN betont hat. ${ }^{125}$ Gerade einmal zwölf dieser merowingischen Testamente sind zusammen mit dem der Irmina noch erhalten. Das letzte aus dem Jahr 739. ${ }^{126}$ Daß aber Irminas Testament vom 1. Dezember die Datierung am Anfang vornimmt, stimmt genau mit diesem Formular überein. Eine nachträgliche Interpolation Abt Thiofrids oder eines anderen Kompilators dürfte das kaum sein. ${ }^{127}$ Die drei genannten Orte könnten zwar nachträglich interpoliert sein, doch müssen sie es nicht. Baidelingo erscheint im Liber aureus nur bei den Irmina-Urkunden. In Matzen war immerhin auch eine Ava begütert, die 832/3 ihren dortigen Besitz Echternach zur Nutznießung überließ. Beide Orte erwecken hier somit kein Mißtrauen. Zumindest haben sich keine Quellen mehr erhalten, die Anlaß dazu gäben. ${ }^{128}$ Nur in Osweiler wird 835/6 in zwei weiteren Urkunden soviel Besitz an Echternach geschenkt, daß man zweifeln mag, ob Irmina hier tatsächlich einmal begütert gewesen sein

123 Vgl. dazu oben S. 130 f. u. Anm. 88.

124 Vgl. zur Schenkung an Kirchen und deren Heilige Angenendt, Heilige, S. 193-206. Grundlegend: STUTz, Eigenkirche, S. 19-41, 66-84, bes. S. 38 ff. Ebd., S. 69, nennt er eine solche Eigenkirche eine "Sachfirma“, die der Heilige des Patroziniums schaffe. Im Zentrum stehe dessen Altar, zu dem gleichsam alles gehöre. Für Eigenklöster gelte dasselbe. - Die bei ihm vorgenommenen Projektionen in die Germanenzeit dürften allerdings überholt sein. Vgl. dazu ferner Borgolte, Mittelalterliche Kirche, S. 98-100, mit aktueller Literatur, sowie unten bei u. Anm. 430.

125 Vgl. dazu auch Werner, Adelsfamilien, S. 68 u. Anm. 166. Nonn, Merowingische Testamente, S. 32, sieht deutliche Parallelen zum Testamentformular, äußert aber Bedenken, weil es sich nach dem Rechtsinhalt um eine Schenkung handle. Ja, es sei bei einer einfachen Schenkung sogar das umständlichere Formular verwendet, das volle römische Testamentformular aber nicht mehr ganz durchgehalten worden. Das genaue Formular eines fränkischen Testamentes arbeitet er zudem (ebd., S. 58-110) aus.

126 Vgl. dazu Nonn, Merowingische Testamente, S. 25-58.

127 Vgl. dazu Nonn, Merowingische Testamente, S. 58-62. Vgl. dagegen Schmal, Mettlach, S. 48 u. Anm. 308.

128 Vgl. dazu noch Wampach I 2, Nr. 140, S. $208-210$ (832/3, im 19. Jahr der Herrschaft Kaiser Ludwigs). Darin überläßt der Trierer Erzbischof Hetti und Abt von Echternach der Ava den von ihr zur Nutznießung an Echternach geschenkten Besitz. 
konnte. Im 12. Jahrhundert scheint der dortige Besitz auch für einige Zeit verpfändet gewesen zu sein. ${ }^{129}$

Freilassungen erscheinen in jedem Fall in solchen Testamenten. Die hier elf namentlich genannten Freigelassenen machen ohnehin nur bei einer zeitgenössischen Abfassung Sinn. ${ }^{130}$ Warum hätte man ihre Namen erfinden sollen? Freilich sind spätere Interpolationen nicht auszuschließen. Der von Schmal monierte Wechsel der grammatischen Person der Schenkerin, der im Testament selbst jedoch nur zwei Mal auftritt, läßt sich erklären. Ein Blick in die Formularvorlagen Markulfs aus dem späten 7. Jahrhundert für Privaturkunden mit den dortigen Beispielen für Schenkungen an Kirchen sowie für ein Testament zeigt, daß solche Fehler auch schon den Zeitgenossen unterliefen. ${ }^{131}$ Ja, im

129 Vgl. dazu hier nur Wampach I 2, Nr. 141, S. 210-212 (Januar 835/Januar 836, im 22. Jahr der Herrschaft Kaiser Ludwigs). Das Formular folgt dem der Hetti-Urkunde für Ava in der vorausgehenden Anm. Erzbischof Hetti überläßt darin als Abt von Echternach dem Wintarius die dem Kloster zur Nutznießung übertragenen Güter (einen Herrenhof, Herrenland und Wiesen) in Ossewilre. Ferner: Waмpach I 2, Nr. 142, S. 212 f. (ebenfalls im 22. Jahr der Herrschaft Kaiser Ludwigs). Darin überträgt eine Irmintrud ihr Heiratsgut in Oszuwilre (Herrenland und zwei Hörigenmansen). Schließlich: WАмрасн I 2, Nr. 204, S. 335-337 (zwischen 1140 und 1179), worin der Mönch Hazzo, der über ein größeres Vermögen verfügt zu haben scheint, u.a. verpfändete Echternacher Güter wieder einlöst, darunter IIII marcas bei Oswilre. - Danach ist der Besitz nicht mehr umstritten. Die dortigen Einkünfte werden sogar für Baumaßnahmen in Echternach eingesetzt. Vgl. dazu noch Wамрасн I 2, Nr. 214, S. 359 f. (19. Januar 1185).

$130 \mathrm{Zu}$ den Freilassungen vgl. Nonn, Merowingische Testamente, S. 77. Angenendt, Heilige, S. $194 \mathrm{f}$, geht auf die freigelassenen Wachszinser ein. Schließlich Borgolte, Freigelassene im Dienst der Memoria, der die Breite dieses Phänomens aufzeigt. Die Freilassung und die durch die Freigelassenen zu erbringende Leistung diene auch dem Gebetsgedächtnis des Freilassenden. Folgt man seinen Überlegungen (ebd., S. 241 u. Anm. 31), müßte man gar eine Bestattung Irminas in Echternach selbst annehmen: „Die Kerzengabe konnte nur für die Kirche bestimmt gewesen sein, in oder bei der das Freilassergrab lag." Dazu verweist er auf die Handschrift A3 der Marculfi Formulae II,34, ed. Zeumer, S. 96. Vgl. ferner Marculfi Formularum libri duo, ed. Uddholm, S. 280. - Spinnt man den Gedanken weiter, spricht die Freilassung dagegen, daß Irmina eine Äbtissin war. Hier hätte der Konvent die Memoria übernommen. Es spricht vielmehr dafür, in Irmina eine einfache Adlige zu sehen, die kurz vor ihrem Tod stand und Vorsorge für die Zeit danach treffen wollte.

131 Vgl. Schmal, Mettlach, S. 53 u. Anm. 336. - Im Testament sind dies aber nur zwei Stellen, wo Irmina in den Plural übergeht. Einmal weist Irmina im Zusammenhang mit den Freigelassenen auf Briefe hin, die sie diesbezüglich formuliert haben will (epistolas nostras). Bei der zweiten Stelle handelt es sich um die zusammenfassende Formulierung der Schenkung: per presentem paginam testamenti nostri tradimus atque transfundimus. Diese Stelle erweckt den Eindruck, als ob hier etwas aus dem Testament herausgenommen worden sein könnte und man deshalb nach einem Überleitungssatz suchte. Vgl. hier nur die Marculfi Formulae II,2-4 u. 17, ed. Zeumer, S. 74-77, 86-88. Marculfi Formularum libri duo, ed. UdDholm, S. 176-199, 232-241. Vgl. dazu auch Heidrich, Titulatur, S. 171-195. Nonn, Merowingische Testamente, S. 110-121. Die 
Testamentformular bei Markulf findet sich sogar das von Schmal als Interpolation beanstandete caraxaturae wieder, was folglich nicht von Thiofrid stammt. Ähnliches gilt für den biblischen Vergleich des leprösen Naaman, der auch bei weiteren merowingischen Testamenten in der Poenformel steht. ${ }^{132}$

NONN hat angemerkt, daß das Eschatokoll solcher Testamente aufgrund einer Kopiarüberlieferung in vielen Fällen gekürzt sein kann. ${ }^{133}$ Irminas Testament verfüge mit elf Namen über die höchste Zeugenzahl eines derartigen Rechtstextes. Vorgeschrieben seien lediglich sieben. Ein Schreiber - wie hier Huncio - finde sich üblicherweise bei allen Privat- und Hausmeierurkunden. Allerdings unterzeichne er nur im Irmina-Testament vor der Schenkerin und den Zeugen. ${ }^{134}$ So ist der Verdacht nicht völlig unberechtigt, daß die Zeugenreihe nachträglich hinzugefügt wurde. Sie muß es aber nicht. Auch könnte sie aus einer anderen Urkunde übernommen worden sein. Interpolationen in diese Namensreihe lassen sich ebensowenig ausschließen.

In diesem Zusammenhang muß auffallen, daß Bischof Leotwinus/Liutwin und dem bezeichnungslosen Theodefridus ein Ego voransteht, während dieses für den an erster Stelle erwähnten Bischof Basinus sowie die anderen Zeugen fehlt. Deutet das Ego in diesem Fall vielleicht eine spätere Interpolation in eine noch erhaltene Reihe an? Ein solches Ego wenigstens ist für die Zeugenreihen der frühen Echternacher Urkunden absolut ungewöhnlich und tritt nur dieses eine Mal hier auf, wenn es auch in anderen Urkundenteilen durchaus zu finden ist. ${ }^{135}$ Der noch zeitgenössische Nachtrag des Todestages eines Bischofs Basin

Datierungen schwanken allerdings von der Mitte des 7. bis zum Beginn des 8. Jahrhunderts.

132 Vgl. Marculfi Formulae II,17, ed. Zeumer, S. 88. - Vgl. zur Verwendung des Begriffs charaxatura und den weiteren abgeleiteten Wortbildungen die entsprechenden Artikel im Mittellateinischen Wörterbuch 2, Sp. 520 f., mit den entsprechenden Nachweisen. So findet er sich auch in Theoderichs, Translatio S. Celsi cap. 13, ed. Wartz, S. 207 f., die in Trier im frühen 11. Jahrhundert entstand. Vgl. dazu unten S. 286 f. u. Anm. 541. Auch Hinkmar von Reims (Vita Remigii cap. 32, ed. Кrusch, S. 339, Z. 25, im kürzeren Testament des Remigius) überliefert ihn. - Zu Naaman vgl. nochmals NonN, Merowingische Testamente, S. 100-104, bes. S. $101 \mathrm{f}$. - Die Formulierung, die den Vorstand Willibrords in einer Kirche beschreibt (ubi episcopus/gubernator etc. esse videtur/ videor), scheint zudem vielmehr formelhaft und weniger eine Interpolation Thiofrids. Sie findet sich auch mehrfach in den Privaturkunden der Marculfi Formulae. Vgl. dazu noch Schmal, Mettlach, S. 51, Anm. 325. - Die Drohung mit dem anathema ist eine schlicht biblische und in vielen Urkunden verbreitet. Vgl. dazu Gal. 1,8 u. 1. Kor. 5,5.

133 Vgl. Nonn, Merowingische Testamente, S. 79 ff.

134 Vgl. NonN, Merowingische Testamente, S. 85-88. Sieben Zeugen seien seit spätrömischer Zeit vorgeschrieben gewesen. Tatsächlich aber schwanke die Zeugenzahl. Vielleicht habe man zunächst die Unterschrift des Schreibers mit zu den Zeugen gerechnet. Zum Schreiber vgl. ebd., S. 88-92, auch mit dem Hinweis auf die vorgezogene Unterschrift des Schreibers.

135 Die gehäufte Verwendung des Ego ist aber noch in der Zeugenreihe der gefälschten Liutwin-Urkunde von 706 (MRUB I 7a) zu finden, die ja eine starke formale Ver- 
zum 4. März im Kalendar Willibrords zeigt zumindest, daß Willibrord einen solchen Basin tatsächlich gekannt haben dürfte und seinem Erscheinen an der ersten Position der Liste wenig Ungewöhnliches anhaftet. ${ }^{136}$ Dagegen schweigt derselbe Kalender seltsamerweise über einen Liutwin völlig. ${ }^{137}$ Wenig spricht zudem für einen unkanonischen Doppelepiskopat der beiden. Da liegt es näher, eine gemeinsame Interpolation des Leotwinus und Theodefridus anzunehmen. Warum findet sich nämlich unter den elf Namen der Freigelassenen einer ausnahmsweise als Theodfrido filio bezeichnet, ohne dessen Namen zu nennen? Die ihm vorausgehende Achilde kann damit nicht gemeint sein. Hängen beide Namensnennungen miteinander zusammen? Wurden sie beide nachträglich gemeinsam interpoliert? Doch warum sollte der Vater eines Freigelassenen als Zeuge unterschreiben? Die beiden Egos ließen sich auch erklären, wenn in einer Vorlage ursprünglich andere Zeugennamen an dieser Stelle überschrieben worden wären. Man hätte dann entsprechende Lücken überdeckt oder gefüllt. Wenn jedenfalls Basin allein als Trierer Bischof unterschrieben hätte, wäre nur wenig an diesem Testament auszusetzen und die Zeugenzahl mit neun Personen erheblich glaubwürdiger.

In der Vita sanctae Irminae des Thiofrid von Echternach (vor 1081) findet sich ein kurzer, schon erwähnter regestenhafter Eintrag, der wahrscheinlich diesen Text meint: Eine beata virgo Irmina habe die Hälfte Echternachs mit allem Besitz an Willibrord geschenkt. In der Vita Willibrordi Thiofrids (1103/4) wird diese Urkunde dann in einem Kurzregest auch auf den 1. Dezember datiert und mit einer weiteren Donation Irminas (der Villa Berg im Zülpichgau) verbunden, die wir gleich in der Schenkung vom 1. Juli 699 (WАмрасн I 2, Nr. 6) wiederfinden werden. ${ }^{138}$ Im Kontext des Eintrages erwähnt diese Willibrord-Vita - wie wir sahen - mehrere weitere persönliche Schenkungen verschiedenen Inhalts an den Heiligen, verliert dabei aber kein einziges Wort über die genaue Gründung Echternachs. Doch wird an anderer Stelle ausschließlich

wandtschaft mit den Irmina-Urkunden aufweist. Vgl. zu diesem Stück ausführlicher unten Kap. D.III.1.

136 Vgl. oben Anm. 29.

137 Doch schweigt er auffälligerweise auch über Irmina, nennt aber die Oerener Äbtissin Anastasia. Vgl. dazu die ausführlicheren Überlegungen unten bei Anm. 213.

$138 \mathrm{Vgl}$. Thiofrid, Vita sanctae Irminae cap. 6, ed. WeILAND, S. 49: Huic sanctissimo viro beata virgo dedit medietatem fisci Epternacensis cum omnibus suis appendiciis. - Thiofrid, Vita S. Willibrordi, Vita prosa cap. 12, ed. Poncelet, S. 467E: [...]; Hirmina vero, Dagoberti regis filia, hereditario iure possessam cum omnibus appendiciis et adiacentiis suis cum villa Montis, sita in pago Tulbiacensi, in calendis decembris addidit partem alteram. Wамрасн I 2, Nr. 3 u. 4, S. 18, 21, schreibt Thiofrids Regest jedoch erst der nächsten hier zu besprechenden Urkunde vom 1. November desselben Jahres zu. - Zur zweiten in der Willibrord-Vita genannten Schenkung vgl. WАмрасн I 2, Nr. 6, S. 24-26, die unten in Kap. D.II.4.c. behandelt wird. 
Willibrord als Gründer genannt. ${ }^{139}$ Der Text nennt Irmina im entsprechenden Eintrag Tochter König Dagoberts, worauf der eben vorgestellte Volltext des Testaments keinen Hinweis bietet. Merkwürdigerweise unterbleibt in den beiden Regesten der Viten Thiofrids aber jede Anspielung auf die im Volltext zu findende Selbstbezeichnung Irminas als Deo sacrata acsi indigna gratia Domini abbatissa. Warum? Hatte Thiofrid eine völlig andere Urkunde vor Augen? Oder war ihm die postulierte königliche Herkunft wichtiger? Verstand sich das alles ohnedies von selbst? Thiofrid übernahm hier - wie oben schon gesehen - durch seine Arbeit an der Vita sanctae Irminae eine Oerener bzw. Trierer Irminatradition, die eine Königstochter Irmina als Gründerin Oerens und erste dortige Äbtissin sah. Thiofrid stülpte diese Tradition nachträglich über das ihm vorliegende Echternacher Irminadokument, wobei er sich von der Namensanalogie leiten ließ. ${ }^{140}$

Dann aber stellt sich eine ganz andere Frage: Bezeichnete sich Irmina in der Urform ihres Testamentes überhaupt als Äbtissin? Wurde sie womöglich erst in einer Abschrift dazu, weil man sie jetzt - nach Thiofrids Analogiebildung - mit der Dagoberttochter und Oerener Äbtissin verband? War sie vielleicht nur eine einfache Nonne oder keines von beidem? Man hätte sie in diesem Fall aufgrund der inzwischen starken Oerener Irminatradition in ihrem Testament nachträglich zu einer Äbtissin gemacht, spätestens als der Mönch Theoderich den Liber aureus (1191/2) zusammenstellte. Der Konzeption seines Werkes hätte es entsprochen. Weshalb sonst bezeichnet sich Irmina zu Beginn des Testamentes selbst sowohl als Nonne wie auch (acsi) als Äbtissin, während sie im Eschatokoll nur als domina und abbatissa agiert? Wozu diese doppelte Eigenbezeichnung, die sich gleich mehrfach auf Gott beruft? Warum wird die Anfangsformel nicht wieder aufgegriffen? Um es vorweg zu nehmen: In den übrigen Irmina-Urkunden wird der Terminus dann zu Deo sacrata abbatissa zusammengezogen oder nur noch von einer abbatissa gesprochen. Daneben findet sich in den Echternacher Urkunden eigenständig der Begriff einer Deo sacrata oder consecrata Deo für eine Nonne. Eine Äbtissin dagegen wird nur als domna und abbatissa verbunden mit dem zugehörigen Kloster aufgeführt. ${ }^{141}$ So entsteht tatsächlich der Eindruck, daß Irmina zunächst nur Nonne gewesen sein könnte und durch einen nachträglichen Einschub in das Testament zur Äbtissin wurde, was sich in den anderen ihr zugeschriebenen Urkunden durchsetzte. Allerdings

139 Vgl. Thiofrid, Vita S. Willibrordi, Vita prosa cap. 12, S. 467. Da die in den Regesten erwähnten Schenkungen alle direkt an Willibrord gehen, spricht einiges dafür, daß diese Einträge so nicht zeitgenössisch sind.

140 Vgl. dazu ausführlich unten Kap. D.II.6.

141 Vgl. nur Wampach I 2, Nr. 2*, 12*, 17, 33, 48, 52, S. 16, 37, 48, 77, 113, 118. Auch findet sich ein Titel wie illustri femina atque Deo consecrata virgine (Nr. 17). - Zum Titel der Äbtissin vgl. ebd., Nr. 19, S. 49 f., hier S. 50: domna Anastasia, abbatissa puellarum in Horreo. - Zur weiteren Verwendung von Irminas Titel vgl. die folgenden Kapitel. 
bleibt auch anzumerken, daß sich die Bezeichnung einer Deo sacrata abbatissa in einigen wenigen Merowingerurkunden und einer König Karlmanns (768-771) von 769 findet. ${ }^{142}$

An der Existenz eines nahezu noch vollständig erhaltenen Irmina-Testament-Textes zu Zeiten des Liber aureus jedenfalls besteht kaum Zweifel. Doch sind kleinere Interpolationen erkennbar, andere jedoch, als sie S nimmt.

\section{b. Die Schenkung Irminas vom 1. November 697/8 (WАмрасн I 2, Nr. 3)}

Das insgesamt glaubwürdige Formular des Irmina-Testaments widerspricht dem Inhalt der zweiten Irmina-Urkunde, die sich im Liber aureus unmittelbar anschließt.

Schon am 1. November desselben Jahres will die Gott geweihte Äbtissin Irmina nämlich eine Schenkung ähnlichen Inhalts an Bischof Willibrord gemacht haben. Irmina handelt nun plötzlich auf den Rat der Bischöfe Basin und Liutwin hin und unter Zustimmung ihrer versammelten Mitschwestern. Sie überträgt darin die [wohl zwei] Basiliken, [1.] die der Hl. Dreifaltigkeit und Maria sowie [2.] dem Petrus, Paulus und weiteren Heiligen geweiht seien, auf ihrem Besitz in der Villa Echternach an der Sauer. Willibrord solle diese leiten. Ein Klösterlein komme hinzu, von ihr gebaut zur Fürsorge für pilgernde Mönche und zur Armenspeisung sowie für ihr eigenes Seelenheil. Ganz offenbar geschieht das, weil Willibrord sein heiliges Wesen und seine Liebe ihr und ihrem Kloster gegenüber gezeigt habe und sie sich verpflichtet fühle, ihn damit zu trösten. Doch scheint hier mit der Satzkonstruktion etwas nicht zu stimmen. Für diese Kirchen überträgt Irmina Willibrord ihren gesamten elterlichen Besitz in Echternach mit Gebäuden, Ländereien, Wäldern etc.; dies beinhalte auch das Zubehör in Baidalingo, Mathulfovillare und ihren Teil in Oxinvillare, ausgenommen die von ihr Freigelassenen, die aber weder namentlich noch mit Zahl genannt werden. Ferner schenkt sie Willibrord sowie an die genannten Basiliken [der Kasus ist hier falsch] einen Weinberg in monte Viennense mit dem Winzer Alitfrid und all seinem Eigentum. Die Poenformel besteht gerade einmal aus einem Satz. Huncio will diese Urkunde auf Anordnung Irminas ausgestellt und mit Zeugen unterzeichnet haben. ${ }^{143}$ Als Unterzeichner werden - wieder erst am

142 Vgl. dazu DMerowinger I 118, S. 302-304, hier S. 303, Z. 9. Es handelt sich um ein interpoliertes Diplom Theuderichs III. vom 6. Dezember 677, dessen älteste Überlieferung sich in einer Handschrift des 12. Jahrhunderts befindet. Ebd. I 150, S. 376-378, hier S. 378, Z. 2, ist eine im Original noch vorliegende Urkunde Childeberts III. vom 3. April 697. Das Karlmann-Diplom findet sich ediert als DKarol. I 49, S. 68, dort Z. 37 f.

143 Wамрасн I 2, Nr. 3, S. 19 f.: Domino sancto ac venerabili in Christo patri Willibrordo episcopo Ermina in Christo Deo sacrata abbatissa. I Dum ab omnibus non habetur incognitum, quod ego, inspirante misericordia Christi, pro consilio virorum apostolicorum patrum 
Ende und nach dem Schreiber - Basinus episcopus. Leodowinus episcopus. I Theodefridus presbiter. Waltarius diaconus. Garibertus presbiter. Audobertus presbiter genannt. ${ }^{144}$

Die in Thiofrids Irmina- und Willibrord-Vita genannten regestenhaften Einträge zu einer Schenkung Echternachs durch Irmina an Willibrord können diese Urkunde wohl kaum meinen oder wiedergeben, auch wenn WАмрасн diese zu erkennen glaubt. Denn von mehreren Kirchen ist bei Thiofrid keine Rede. Er bietet also keinen Nachweis für dieses Dokument. ${ }^{145}$

Man ging nun u.a. davon aus, diese Urkunde solle Irminas Testament womöglich noch präzisieren. ${ }^{146}$ Doch Schmal plädiert wegen des scheinbar fast gleichen Inhaltes beider Rechtstexte für eine Fälschung. Diese Urkunde schöpfe aus dem Testament und verkürze seine Botschaft. Man erkenne erneut Thiofrids Stilmerkmale. Er verwende mehrere Superlative für die Personen, und auch das

nostrorum, domni Basini et domni Leotwini episcoporum seu et pro consensu sororum nostrarum Christo servientium, que nobiscum sunt congregate, basilicas in nomine sancte Trinitatis vel in honore gloriosissime virginis Marie, genitricis Domini nostri Ihesu Christi, seu et beatissimorum apostolorum Petri et Pauli vel ceterorum sanctorum in villa mea propria que vocatur Epternacus, sita super fluvio Sura, seu et monasteriolum ibidem ad monachos peregrinos conversandum vel pauperes ibidem alimoniam petendum pro divino respectu vel pro anime mę remedio construxi, ut dum sanctitas et dilectio vestra erga me vel monasterium meum assidue agitur, ideo decrevi apud animum meum, ut vos de rebus meis propriis in aliquo consolari deberem. Quod ita spontanea voluntate feci. I Idcirco dono vobis donatumque esse volo memoratas basilicas sanctorum ad gubernandum vel dominandum. Itemque dono vobis ad supradicta loca sanctorum portionem meam in ipsa villa Epternaco, hoc est quantumcumque ex successione paterna vel materna michi obvenit, tam domibus quam edificiis, mansis, mancipiis, vineis, terris, campis, pratis, silvis, pascuis, aquis aquarumque decur ibus, seu et pastores vaccarios, porcarios, verbecarios cum gregibus eorum vel cum appendiciis suis, id sunt: Baidalingo, Mathulfovillare vel portionem nostram in Oxinvillare, exceptis hominibus illis quos per epistolas ingenuos relaxavimus. Similiter dono vobis vel ad supradictas basilicas vinee pedeturam unam in monte Viennense cum vinitore nomine Alitfrido cum omni peculiari suo. I Ista omnia, ut dixi, ad ipsa loca sanctorum vel vobis a die presenti tradimus atque transfundimus ad gubernandum vel dominandum, ea ratione ut quicquid de re superius memorata in Deo nomine facere volueritis, liberam et firmissimam in omnibus habeatis potestatem. Nam si quis contra hanc cartulam donationis mee venire temptaverit, inferat fisco auri libras $X$, argenti pondo XX, manente nichilominus firmitate. I Actum Treberi sub die Kalendas Novembris. Anno IIII regni domini nostri Childeberti regis. I Ego Huncio in Christi nomine presbiter hanc cartulam donationis iubente domina mea Irmina perscripsi, et ipsa subter manu propria una cum testibus firmavit, vel qui subscipserunt in presenti rogavit. / Ego Irmina in Christi nomine hanc donationem relegi. Es folgen die oben genannten Zeugen.

144 Vgl. Wampach I 2, Nr. 3, S. 20.

145 Vgl. dazu oben Anm. 138.

146 Vgl. dazu nur Werner, Adelsfamilien, S. 68. Krier, Epternus, S. 39. Wagner, Gründung, S. 130-141, der alle Urkunden für echt hält, von dem von Irmina vorausgesehenen Tod ausgeht, aber die Ergebnisse Schmals noch nicht berücksichtigt hat. Vielmehr möchte er die späteren Irmina-Urkunden auch ins Jahr 699 datieren. 
Motiv der Pilgermönche bzw. Pilgerschaft finde sich häufig bei ihm. Letztlich beabsichtige er, Irmina zur Klostergründerin zu machen, indem sie nun direkt an Willibrord schenke. Basin und Liutwin seien seine Zutat aufgrund von Thiofrids Liutwin-Vita. Der Text wirke zudem so, als ob er aus mehreren Irmina-Urkunden zusammengesetzt sei. ${ }^{147}$

Tatsächlich wird Irmina hier allein zur Klostergründerin gemacht. Darüber hinaus stellt sich aber die Frage, warum denn Basin und Liutwin nun auch noch als Ratgeber Irminas in den Text aufgenommen werden. Warum müssen hier zwei Trierer Bischöfe gemeinsam intervenieren? Diese Schenkung verfügt keinesfalls über einen Inhalt, der mit dem Testament identisch ist. Denn, daß mit dieser Urkunde etwas nicht stimmen kann, fällt sofort auf. Nicht nur die Datierung exakt einen Monat vor dem Testament ist verräterisch. Diese Urkunde krempelt förmlich den gesamten Rechtsinhalt des Testamentes um, nutzt dazu aber das vorgefundene Vokabular. Sie macht aus einer Schenkung von Besitz in Echternach durch Irmina an das dortige Kloster und seine Heiligen eine Schenkung von mindestens zwei Kirchen (mit einer denkbaren Klosterkirche käme eine dritte hinzu), die nun die Patrozinien der ehemals einen Kirche des Testamentes jeweils übernehmen. Und diese Schenkung erfolgt unmittelbar an die Person Willibrords, aber mehr oder weniger zur Betreuung. Auch ein Klösterlein will Irmina selbst gegründet haben. Die Schreibung des Ortsnamens von Matzen verändert sich zudem von Matholfingo zu Mathulfovillare. Da der Ort im Liber aureus nur noch einmal zu 832/3 als Machonvillare genannt ist, hilft das nicht, zu gesicherten neuen Erkenntnissen zu gelangen. ${ }^{148}$ Diese Urkunde muß also nicht aufgrund des gleichen, sondern des erheblich veränderten Inhalts eine Fälschung sein! Die hier zusätzlich geschaffenen Kirchen kann es nicht gegeben haben. Man tut besser daran, am Grabungsergebnis von nur einer Kirche festzuhalten.

Irmina wird aber nicht nur zur Klostergründerin gemacht, ihr Besitz wird um ein Vielfaches vergrößert. Aus etwas Land in Echternach werden nun zwei Kirchen. Welch ein Unterschied! Die noch verhältnismäßig einfache Irmina des Testaments wandelt sich in eine viel bedeutendere reiche und einflußreichere Person. Das Formular eines Testaments verschwindet. Es fällt zudem auf, daß Irmina jetzt auch mit Zustimmung ihrer Mitschwestern schenkt. Warum war das im Testament aber nicht notwendig? Daß Irmina dem Willibrord für Wohltaten an ihr und ihrem Kloster dankt, hat wohl nichts mit dem angeblich von ihr begründeten Klösterlein in Echternach zu tun. Diese Passage meint wohl Irminas Kloster Oeren. Doch welche Wohltaten könnten das gewesen sein?

147 Vgl. Schmal, Mettlach, S. 49-53, bes. auch die Anm. 320, 326, 334.

148 Vgl. dazu nochmals oben Anm. 128. 
Auch in diesem Zusammenhang scheint die schon erwähnte Oerener Irminatradition eingeflossen zu sein. ${ }^{149}$ Noch Ende des 8. Jahrhunderts erzählt Alkuin in einem legendenhaften Kapitel seiner Willibrord-Vita, Willibrord habe ein Trierer Nonnenkloster von einer Pest gerettet. Doch spricht er dabei weder vom genauen Namen des Klosters noch von einer dasselbe leitenden Äbtissin. Vielmehr handeln die Nonnen gemeinschaftlich und bitten ihn um Hilfe. ${ }^{150}$ Es lag durch die Anspielung auf das Nonnenkloster für den Leser nahe, darin Oeren zu erkennen. Wohl deshalb verband diese Legende dann spätestens Thiofrid in seiner Vita sanctae Irminae (vor 1081) zaghaft mit der Oerener Irmina: im selben Kapitel, in dem er auch die Schenkung einer Irmina an Echternach erwähnt. ${ }^{151}$ In seiner Willibrord-Vita findet sich das neu geformte Legendenbild dann schon wesentlich lebendiger, ausführlicher und facettenreicher in einer längeren Passage wieder. ${ }^{152}$ Die Geschichte wuchs allmählich. Fragmente des kulturellen Gedächtnisses wurden mit anderen Bildern weiter angereichert und neu geformt in dieses wieder aufgenommen. Auf diese Wohltat Willibrords an ihrem angeblichen Kloster könnte also die vorliegende IrminaUrkunde anspielen. Dann wäre sie aber erst nach der Vita sanctae Irminae entstanden.

All das erklärt, warum Irmina hier als bedeutende und besitzreiche Äbtissin aus dem Kreis ihrer Mitschwestern und ihres Klosters heraus handelt. Irmina erscheint fast wichtiger als Willibrord selbst. In ihrem Testament vom 1. Dezember war das alles noch nicht erforderlich. Man versteht nun, weshalb diese Schenkung um einen Monat vor dem Testament datieren mußte. Folgte sie ihm

149 Vgl. dazu oben S. 132 u. Anm. 91, sowie ausführlicher unten Kap. D.II.6.

150 Vgl. Alkuin, Vita Willibrordi archiepiscopi Traiectensis cap. 21, ed. Levison, S. 132: Est in Treveris civitate monasterium puellarum, quod temporibus beati Wilbrordi episcopi pestis acerrima invassit. Cuius acervitate multae ex ancillis Dei moriebantur, [...]. Et quia prope est praedictae civitati sancti viri monasterium, quod appellatur Aefternaco, in quo usque hodie sanctus ille requiescit corpore, et eius posteri traditione ex legitima patris et piissimorum pietate regum tenere noscuntur, antedicti vero monasterii faeminae, audientes sanctum virum venire illuc, statim miserunt lagationem, postulantes eum non tardare venire. Die Nonnen holten Willibrord zu Hilfe, und er heilte sie durch heiliges Wasser. - Doch besteht die Vita aus zahlreichen Wundergeschichten. Alkuin konnte sicher nur auf wenige historische Fakten zurückgreifen.

151 Vgl. Thiofrid, Vita sanctae Irminae cap. 6, ed. WeIland, S. 49: Hanc quodam tempore visitatum de Traiecto venerat, cum ecce pestis lętifera sanctimoniales de Horreo invaserat. Es folgt dann der Heilungsbericht nach Alkuin. Schließlich habe Willibrord dort eine St. Paulskirche geweiht, wo die hl. Jungfrau, also Irmina, zwölf Brüder zum Dienst am Herrn ordiniert habe. Werner, Anfänge, S. 19, Anm. 75, hält das für unglaubwürdig. ZImmer, Oeren, S. 38 f., glaubt zwar die Meldung, weist aber darauf hin, daß diese Kirche urkundlich erstmals um 1200 genannt wird. Vgl. dazu MRUB II 292, S. 326 f.

152 Vgl. Thiofrid, Vita S. Willibrordi, Vita prosa cap. 20, ed. Poncelet, S. 471 f. Auch hier wird regię virginis Hirmine kurz (ebd., S. 472 A) genannt. Irmina wird also nicht explizit als Äbtissin bezeichnet. 
später, wäre sie absolut unglaubwürdig. Das dürftiger ausfallende Testament verschwindet so hinter der voluminösen Schenkung vom 1. November. Doch warum schweigt das Testament von alledem und auch von Basins und Liutwins motivierendem Rat bei der Schenkung? Es kann darauf nur eine Antwort geben: die Irmina des Testaments war keinesfalls so besitzreich, ja, auch nicht die eigentliche Gründerin Echternachs und wahrscheinlich auch keine Äbtissin.

Die weiteren Irmina-Urkunden, vor allem das Testament, mußten nun nachträglich noch an die neu geschöpfte Irmina-Urkunde vom 1. November 697/8 angepaßt werden. Ähnlich formuliert es ja schon Schmal. Nur so ließ sich ein kohärentes Bild erzielen, das weder die Neuschöpfung noch die anderen Urkunden in Frage stellte. Und so dürfte erst jetzt der Titel der Äbtissin in die weiteren Irmina-Urkunden Eingang gefunden haben, auch in das Testament. Seltsamerweise erwähnt das Eschatokoll dieser konstruierten Schenkung vom 1. November Irmina gerade nicht als Äbtissin. Sah so womöglich an dieser Stelle einmal die für die Fälschung verwendete Vorlage aus, also das ursprüngliche Irmina-Testament? Auf dem Weg über die Novemberurkunde müssen auch Basin und Liutwin nachträglich als Paar in die Zeugenreihen der anderen Irmina-Urkunden gelangt bzw. wenigstens Liutwin noch neben Basin ergänzt worden sein. Wampach I 2, Nr. 3 steht damit am Anfang aller weiteren Auffälligkeiten in den noch zu besprechenden Dokumenten.

Warum aber finden sich die beiden gemeinsam in der Schenkung vom 1. November? Dafür könnte es eine Erklärung geben. Im Testament oder an anderer Stelle stieß man zwar auf Basin, über den man allerdings nur wenig wußte. In der Trierer Tradition seit dem späten 10. Jahrhundert erschien er aber immer - wie wir inzwischen wissen - gemeinsam mit Liutwin, über den letztlich Thiofrid von Echternach ja eine zweite Vita verfaßt hatte. Während man sich an Basin kaum genauer erinnerte, verfügte man mittlerweile um so mehr Informationen über diesen Liutwin, der inzwischen als Heiliger und Gründer Mettlachs verehrt wurde. Lag es da nicht nahe, die beiden nun ganz einfach miteinander zu verbinden? Basin allein verfügte in dieser Zeit wohl kaum über Liutwins Wirkmächtigkeit. Wie Liutwin seit dem späten 10. Jahrhundert plötzlich rasant als heiliger Trierer Bischof aufstieg, werden wir weiter unten noch genau verfolgen. ${ }^{153}$

Wann und warum könnten beide für Echternach so wichtig geworden sein? Nur einmal griff ein Trierer Bischof nachweislich nach Echternach aus: zur Zeit, als sich der Mönch Theoderich Ende des 12. Jahrhunderts unter Abt Gottfried (1181-1210) dazu veranlaßt sah, den Liber aureus zu verfassen. Denn 1192 wollte Erzbischof Johannes (1189-1212) - wie gesehen - das Reichskloster an das Trierer Erzstift ziehen. Er beabsichtigte, es bei Kaiser Heinrich VI. (11911197) gegen die Burg Nassau einzutauschen. Was lag da näher, als nicht nur an

153 Vgl. dazu bes. unten Kap. D.VI.3.ff. 
Irminas und Pippins Rolle bei Echternachs Gründung zu erinnern, wie oben erläutert, sondern auch daran, daß zwei inzwischen bekannte Trierer Bischöfe an der Wende vom 7. zum 8. Jahrhundert Irmina zuvorderst dazu bewogen, ihre Kirchen an Willibrord zu geben? Was für eine Gründung! Welch ein Besitz! Konnte man Echternach da einfach 1192 wieder einem Amtsnachfolger dieser beiden überlassen?

In der Schenkung findet sich auch wieder der im Testament gemeinsam mit Leodwinus mit einem Ego versehene Theodefridus, der nun als presbiter auftritt. Auch er könnte den nachträglichen Weg von der Schenkung ins Testament gefunden haben. Handelt es sich vielleicht um einen versteckten Hinweis auf Thiofrid von Echternach und seine Irmina-Vita, die beim Entwurf dieser Urkunde zum Einsatz kam? Die Titel der anderen Zeugen mögen auf einer anderen Vorlage beruhen oder frei ergänzt sein. Thiofrids Stil findet sich - im Gegensatz zu Schmals These - eher nicht in diesem Dokument. Der Gebrauch des Superlativs bei Personen oder Heiligen, wie hier anzutreffen, ist nicht ungewöhnlich und erscheint in zahlreichen Urkunden; ${ }^{154}$ ebensowenig, daß Pilger im Umfeld eines angelsächsischen Missionars auftreten. Für den Konstrukteur bzw. Fälscher gab es noch eine andere Vorlage, auf die er zurückgreifen konnte: eine Urkunde Karl Martells und Plektruds für Echternach. Sie wird später noch behandelt. ${ }^{155}$ Letztlich müßte ein Stilvergleich mit den Eigenheiten Thiofrids ohnehin auf einer umfangreicheren Basis erfolgen und die Gegenprobe beinhalten, ob die jeweils herausgegriffenen Elemente nicht auch zeitgenössisch sein könnten, was sie, wie zumindest Stichproben zeigen, auch sind. ${ }^{156}$

\section{c. Die Schenkung Irminas vom 1. Juli 699 (WАмрасн I 2, Nr. 6)}

Die Urkunde eröffnet zunächst mit dem Vermerk, daß eine Äbtissin Irmina an den hl. Herrn und Vater in Christo Bischof Willibrord schenkt. Eine kurze Passage, die die Hoffnung auf späteren Lohn für eine freiwillige Gabe an die Heiligen Gottes ausdrückt, schließt sich an. Darauf folgt der eigentliche Inhalt: Am 1. Juli des fünften Herrschaftsjahres König Childeberts (699) ${ }^{157}$ schenkt die

154 Vgl. dazu Marculfi Formulae II,7, 9-12, 16 f., ed. Zeumer, S. 79-83, 85, 87, mit dem dortigen Gebrauch von dulcissimus/a. Weitere Superlative in Verbindung mit Personen finden sich ebd. II,46f., 50 f., S. 102 f., 105, ebd. I,9 f., 34, S. 48, 64, mit dem Gebrauch von gloriosissimo und einem weiteren Beispiel, das sich noch um zahlreiche aus anderen Urkunden ergänzen ließe. - Vgl. dazu nochmals Schmal, Mettlach, S. 50, Anm. 320.

155 Vgl. dazu unten S. 169-171 u. Anm. 205 u. 209.

156 Vgl. dazu nochmals oben Anm. 154.

157 Vgl. Wampach I 2, Nr. 6, S. 24-26: Domino sancto et in Christo patri Willibrordo episcopo Ermina abbatissa donatrix. / Quicquid unusquisque homo de rebus suis propriis ad loca sanctorum aut servorum Dei spontanea voluntate aliquid condonaverit, hoc sibi credit mercedis premium recipere in futuro. I Idcirco dono ad monasterium vestrum in villa 
Äbtissin Irmina dem Kloster Willibrords in der Villa Echternach an der Sauer, das sie von neuem auf ihrem Grund und Boden erbaut haben will, und den dortigen Orten/Altären der Heiligen, die zu Ehren der Hl. Dreifaltigkeit, der hll. Apostel Peter und Paul sowie weiterer Heiliger errichtet worden seien, ausführlich beschriebene liturgische Geräte und Gewänder. Dies möge ihr vor Gott helfen. Ebenfalls schenkt sie Willibrord für dasselbe Kloster in Echternach die Villa Berg im Zülpichgau mit allen Besitzungen, die sie von ihrer Cousine Irmintrud, der Tochter des Pantinus, erworben habe. ${ }^{158}$ - Diese Villa taucht im

Epternaco constructo super fluvio Sura, quod ego a novo de fundo proprio ędificavi, vel ad illa loca sanctorum que sunt in honore sancte Trinitatis et sanctorum Petri et Pauli apostolorum cęterorumque sanctorum constructa, donatumque esse volo a die presenti, hoc est quantumcumque in ministeria ipsorum sanctorum locorum condonavi vel in quęlibet presidia dedi tam auro quam argento, gemmis, vestimentis, altarium velis, cortinis, utensilia tam erea quam ferrea, seu et ligna operis, quantumcumque in ipsa loca sanctorum vel in predicto monasterio ponere iussi aut in antea Christo presule addere potuero. Volo ut hoc ex nostra munificentia in Dei nomine proficiat perpetualiter in augmentis. / Similiter dono vobis a die presenti ad ipsum monasterium vestrum Epternacense villam, cuius vocabulum est Montis, sitam in pago Tulpiacensi, quam de dulcissima consobrina mea Erminitrude, filia Pantini, dato precio comparavi, hoc est: tam domibus quam ędificiis, mansis, casis, mancipiis, campis, silvis, pratis, pascuis, adiacentiis, aquis aquarumque decursibus, omnia et ex omnibus ad integrum vel quantumcumque in memorata villa Montis tempore presenti possidere videor, seu et peculii promiscuo utriusque generis nationum, vobis vel ad sepefatum monasterium vestrum Epternacense a die presenti, ut superius dixi, de potestate mea in iure et dominatione vestra vestrique monasterii per presentem paginam donationis meę manu mea firmata trado atque transfundo perpetualiter in Dei nomine possidendum, ea ratione ut quicquid ex hoc tam vos quam fratres ipsius monasterii elegeritis, faciendi, habendi, tenendi, commutandi liberam et firmissimam in omnibus Christo propitio habeatis potestatem et nullius ex hoc calumpniam habere pertimescatis. Nam si quis contra hanc cartam donationis, quam ego spontanea voluntate fieri decrevi, temptare conaverit aut aliquid repetere voluerit, inprimitus iram Dei omnipotentis incurrat, et inferat fisco auri libras tres, argenti pondo VIII, et hoc quod repetit nullatenus valeat evendicare. I Facta est hęc cartula donationis sub die Kal(endas) Iulias anno V regni domni nostri Childeberti regis. / Ego Huncio, in Christi nomine presbiter, rogante et iubente Ermina abbatissa, hanc cartulam donationis prescripsi, et ipsa subter manu propria una cum testibus firmavit. / Ego Irmina hoc testamentum a me factum relegi. Es folgen die auf S. 155 genannten Zeugen.

158 Diese Irmintrud taucht dann 710 nochmals in einem Tauschvorgang der Oerener Äbtissin Anastasia mit dem hl. Willibrord auf. Willibrord überträgt Anastasia zwei Weinberge am Rhein, die er von Irmintrud erhalten hat. Dafür erhält er von Anastasia zwei Weinberge an der Mosel. Irmintrud wird hier aber in keine Verbindung mit Irmina gebracht. Vgl. dazu Theoderich, Chronicon Epternacense, ed. Weiland, S. 58. WamPACH I 2, Nr. 19, S. 49 f., hier S. 50: Eodem anno XVI Childeberti regis sanctus Willibrordus et domna Anastasia, abbatissa puellarum in Horreo, fecerunt inter se commutacionem vinearum, et dedit domnus W(illibrordus) domne Anastasie vinee petituras duas in monte Paginse super flumen Rheni cum vinitore et omni peculio suo, que sibi illustris fęmina dederat Irmintrudis, filia Pantini quondam, et recepit ab ea alias petituras duas in monte Cabracense super flumen Moselle cum vinitore et omni peculio suo. - Vielleicht handelt es sich dabei um das in Wамрасн I 2, Nr. 12*, S. 36 f., genannte Köwerich (villa Cabriaco). 
Echternacher Liber aureus nur hier auf. - Die Poenformel ist kurz. Wieder stellt Huncio die Urkunde aus. Irmina unterzeichnet als Äbtissin. Als Zeugen erscheinen - erneut am Ende nach Schreiber und Ausstellerin: Basinus episcopus. Leodowinus episcopus. Waltharius diaconus. Bertuinus diaconus. Farobertus diaconus. Ethberictus presbiter. Garberictus. Transberictus. Bosa. Audobertus. ${ }^{159}$

Thiofrid erwähnt diese Urkunde in seiner Vita sanctae Irminae (vor 1081) nur in einem knappen Satz und spricht darin lediglich von der Schenkung der Villa Berg. Die liturgischen Geräte fehlen, auch Hinweise auf Zeugen. In seiner Vita Willibrordi (1103/4) findet sich der regestenhafte Hinweis auf diese Urkunde, der wieder nur die Villenschenkung Bergs beinhaltet, jedoch verbunden mit dem Inhalt des Irmina-Testaments vom 1. Dezember (WАмpach I 2, Nr. 4). Beide Rechtshandlungen scheinen danach in einem einzigen Dokument, das auf den 1. Dezember 697/8 datiert, vorgenommen worden zu sein. Der 1. Juli wird nicht erwähnt. ${ }^{160}$ Die Frage ist also, was Thiofrid tatsächlich vorlag: nur eine Urkunde, die die beiden Rechtshandlungen gemeinsam beinhaltete, oder zwei Urkunden, die Thiofrid im Regest zu einer zusammenfaßte? Irgendetwas mit dem beschriebenen Rechtsinhalt muß ihm vorgelegen haben. Doch war es der Text der 1191/2 in den Liber aureus aufgenommenen Urkunde vom 1. Juli 699?

Schmal glaubt an die Echtheit von Wampach I 2, Nr. 6. Sie vermutet allerdings Interpolationen, die u.a. Irmina zur Gründerin Echternachs sowie Basin und Liutwin zu Zeugen machen. ${ }^{161}$

Es fällt in der Tat auf, daß diese Urkunde Bezug auf die gefälschte Schenkung vom 1. November (Wамрасн I 2, Nr. 3) und deren Konstrukt nimmt, Irmina habe das Kloster Echternach gegründet bzw. schon vor Willibrord besessen. Die entsprechende Stelle in Waмpach I 2, Nr. 6 spricht deutlich von einem neuen, auf eigenem Besitz gebauten Kloster. Die Urkunde ist also mindestens einmal interpoliert. Die starke Betonung Irminas als Gründerin mutet wie eine Rechtfertigung an, die das der Wahrheit entsprechende Gegenteil verdeckt. Das Irmina-Testament (WАмрасн I 2, Nr. 4) kann dafür nicht als Vorlage gedient haben, weil von einer Irmina als Gründerin darin keine Rede ist. Auch verschleiert Waмрасн I 2, Nr. 6 das genaue Verhältnis zwischen dem Kloster und den loca sanctorum. Das Marienpatrozinium fehlt. Irmina ist nur abbatissa. Weitere konkretisierende Bezeichnungen erscheinen bei ihr nicht. Auch das legt Interpolationen oder Eingriffe nahe.

Basin und Liutwin sind gemeinsam bischöfliche Zeugen. Wenigstens Liutwin muß - folgt man den vorausgehenden Überlegungen - nachträglich ergänzt

159 Vgl. WAMpach I 2, Nr. 6, S. 26.

160 Vgl. Thiofrid, Vita sanctae Irminae cap. 6, ed. WeIland, S. 49: Dedit quoque ei Montis villam in Zulpiaco pago sitam. - Zur entsprechenden Stelle aus der Willibrord-Vita vgl. oben Anm. 145.

161 Vgl. Schmal, Mettlach, S. 49 u. 52. 
sein. Daß den weiteren Zeugen ihre Titel als presbiter bzw. diaconus beigegeben sind, kann so in der Vorlage gestanden haben, aber auch nachträglich hinzugefügt oder aus einer anderen Urkunde übernommen worden sein. Vielleicht bildeten die Namen auch die Grundlage für die Fälschung vom 1. November (Wampach I 2, Nr. 3). Fast alle stimmen jedenfalls mit dem Testament (Wampach I 2, Nr. 4) überein, ein paar weniger mit der Fälschung. Bei einem überwiegend echten Testament spricht das für die Glaubwürdigkeit der meisten in Wамрасн I 2, Nr. 6 aufgeführten Personen. Lediglich ein Name fehlt am 1. Juli 699 im Gegensatz zu den beiden vorausgehenden Dokumenten: Theodefridus. Er taucht in keiner weiteren der Irmina-Urkunden mehr auf. Das macht es tatsächlich wahrscheinlich, daß er auf den Konstrukteur der Urkunde vom 1. November zurückging und darüber dann verspätet in das Testament Eingang fand.

Es bleibt die Frage, warum Thiofrid in seiner Vita Willibrordi den Eindruck erweckt, als handle es sich bei dem Testament vom 1. Dezember 697/8 und der Schenkung der Villa Berg um ein Dokument? Warum fehlt die Kirchenausstattung in Thiofrids Regest? Spaltete man nachträglich einen Text in zwei auf? Daß Irmina in Wampach I 2, Nr. 6 ihr zunächst selbst gegründetes, dann an Willibrord übertragenes Kloster (so die Interpolation) nach ein paar Monaten noch mit reichhaltigem und wertvollem liturgischen Gerät ausstattete, deutet weniger auf die Irmina des Testaments (WАмpach I 2, Nr. 4), sondern auf die einflußreiche und wohlhabende Äbtissin der Schenkung vom 1. November hin (WАмрасн I 2, Nr. 3). Ihr wies man damit eine zusätzliche bedeutende Wohltat zu. Es läßt sich also eine weitere Interpolation fassen.

Folgender Verdacht entsteht: Wenn Thiofrid 1103/4 nichts Anderes vorlag, als das, was er wiedergab, dann dürfte das ursprüngliche Irmina-Testament noch etwas länger gewesen sein und auch die Schenkung Bergs beinhaltet haben (Wampach I 2, Nr. $4+2$. Teil von Nr. 6). Man muß also ein „Ur-Testament“ annehmen, das aufgespalten wurde. Die abgetrennte Schenkung der Villa Berg verband man dann mit der Stiftung liturgischer Geräte und datierte sie nach: auf den 1. Juli 699. Da in diesem konstruierten WАмрасн I 2, Nr. 6 das Marienpatrozinium fehlt, das die beiden vorausgehenden Rechtstexte (WАMPACH I 2, Nr. 3 u. 4) nennen, hat vielleicht das Fomular einer anderen Urkunde als Ersatzvorlage gedient, um die Lücke am Anfang der neu geschaffenen Urkunde zu schließen. Denn das äußere Formular des Testaments ließ sich kaum für diese abgezweigte Schenkung wiederverwenden. Und die Fälschung vom 1. November bot durch ihre umständliche Konstruktion schon gar keine brauchbare Hilfe.

Treffen die vorausgehenden Überlegungen zu, wäre diese Irmina um einiges weniger bedeutend gewesen, als es die Forschung bislang aufgrund der Urkunden vermutet hat. Die erheblichen Konsequenzen für Basin und Liutwin lassen sich erahnen. 


\section{d. Die erste Schenkung Irminas vom 8. Mai 704 (Wampach I 2, Nr. 9)}

Die Urkunde eröffnet ähnlich wie die vom 1. Juli 699 (WАмрасн I 2, Nr. 6). Am 8. Mai des 10. Herrschaftsjahres Childeberts (704) schenkt die hier wieder als Gott geweihte Äbtissin bezeichnete Irmina dem Willibrord für sein Kloster, das sie von neuem gebaut haben will (sie wechselt jetzt in die 1. Person Plural), zu Ehren der Hl. Dreifaltigkeit und Heiliger die Villa Steinheim an der Sauer aus ihrem Besitz mit aller Ausstattung. Die Poenformel ist länger sowie floskelnreicher als in den vorausgehenden Urkunden und weicht von ihnen ab. Huncio ist wieder der Schreiber, der mit den folgenden Zeugen bestätigt: $B a$ sinus episcopus. Radobertus. Dagoinus. Leodoinus presbiter. Gaucebertus. Garibertus. Magnobertus. Quitario. Trasebertus. Waltarius diaconus. Bobo. ${ }^{162}$

Thiofrid jedoch erwähnt eine Schenkung Steinheims weder in der Vita sanctae Irminae (vor 1081) noch in seiner Vita Willibrordi (1103/4), ${ }^{163}$ was er auch nicht mußte, denn Echternacher Besitz in Steinheim wurde erst im 12. Jahrhundert angefochten. Folgt man den weiteren Nachweisen dieses Ortes im Liber aureus, dürften sogar vielmehr die Karolinger Steinheim an Echternach geschenkt haben - wie wir in Kürze sehen -, wahrscheinlich im späten 8. oder dem 9. Jahrhundert. ${ }^{164}$

Schmal hält es für wahrscheinlich, daß diese Urkunde unter Verwendung von Wampach I 2, Nr. 4 vom 1. Dezember 697/8 sowie Wampach I 2, Nr. 6 vom 1. Juli 699 gefälscht wurde. Die Passage, in der sich Irmina als Klostergründerin bezeichnet, sei auch hier nachträglich interpoliert. Die Zeugenliste

162 Vgl. Wampach I 2, Nr. 9, S. 31 f.: Domino sancto et in Christo apostolico patri Willibrordo episcopo Ermina in Christo Deo sacrata abbatissa donatrix. / Quicquid unusquisque homo de rebus suis ad loca sanctorum et servorum Dei spontanea voluntate condonaverit, hoc sibi apud Deum mercedis premium credit recipere in futuro. I Idcirco ego Irmina dono vobis ad monasterium vestrum Epternaco, quod nos a novo construximus, situm super fluvio Sura, in honore sancte Trinitatis vel sanctorum [Petri et Pauli apostolorum cęterorumque sanctorum], donatumque in perpetuum esse volo ad possidendum, hoc est, quantumcumque a die presenti in villa Staneheim, sita super Suram, mea possessio vel dominatio est, tam domibus quam edificiis, mansis, mancipiis, vineis, pratis, pascuis, silvis, aquis aquarumque decursibus, sub ea conditione ut quicquid a die presenti vos vel pars monasterii exinde facere voluerit, liberam et firmissimam in omnibus habeatis potestatem faciendi et nullius repeticiones ex hoc habere vereamini. I Si quis vero, quod fieri non credimus, tam ego quam aliquis de heredibus aut coheredibus meis vel quelibet opposita persona contra hanc nostre donationis cartulam venire conatus fuerit aut eam irrumpere voluerit, primitus iram Dei omnipotentis incurrat et insuper inferat fisco auri libram unam, argenti pondo duo, nec sic quod repetit ullatenus possit evindicare, manente nichilominus firmitate. I Actum Treveri VIII Idus Maias. Anno X Childeberti regis. I Ego Huncio, in Christi nomine presbiter, rogante domna Irmina abbatissa, hanc cartulam donationis perscripsi, et ipsa subter manu propria [una] cum testibus firmavit. / Ego Irmina [hoc testamentum a me factum] relegi et subscripsi. Es folgen die oben aufgeführten Zeugen.

163 Vgl. dazu unten Anm. 186.

164 Vgl. dazu genauer unten S. $160 \mathrm{f}$. 
setze sich aus dem Testament sowie aus der gleich zu besprechenden zweiten Irmina-Urkunde vom selben Tag (Wамрасн I 2, Nr. 10) zusammen. Der Kopist habe das als falsch erkannte Doppelepiskopat Basins und Liutwins schließlich korrigiert und Leodoinus als presbiter eingetragen. Beide Male müsse aber derselbe Liutwin gemeint sein. ${ }^{165}$ Matthias Werner folgt der Literatur und geht von einer echten Urkunde aus. Er hält den seiner Meinung nach unpassenden Priestertitel Liutwins für eine Verschreibung des Kopisten. ${ }^{166}$

Die Urkunde ist verhältnismäßig kurz. Nicht nur der veränderte neue Titel Liutwins fällt auf. Sein Name rückt zudem noch um einige Stellen von Basin und seinem Platz in den anderen Urkunden fort. Ist das wirklich ein Kopistenfehler oder eine spätere Korrektur? Hätte man Liutwin dann nicht konsequent in allen Irmina-Urkunden nachträglich zum Priester machen müssen? Ein Trierer Bischof ist allerdings wesentlich glaubwürdiger als zwei gemeinsam.

Auch diesmal muß man von einer Interpolation der Stelle ausgehen, die Irmina im Sinne der gefälschten Urkunde vom 1. November 697/8 (WАмрасн I 2, Nr. 3) zur Gründerin Echternachs macht, zumal sie diese Selbstaussage hier sogar im Plural vornimmt. ${ }^{167}$ Schon Wampach ist die Ähnlichkeit des Formulars mit der Urkunde vom 1. Juli 699 (WАмрасн I 2, Nr. 6) aufgefallen. ${ }^{168}$ Irminas Bezeichnung als in Christo Deo sacrata abbatissa entspricht gar der Fälschung vom 1. November (Wampach I 2, Nr. 3). Doch ist die Kongruenz mit der Urkunde vom 1. Juli tatsächlich so groß? Zwar stimmt der Beginn beider Stücke miteinander überein, beim Schenkungsinhalt häufen sich aber bereits die Auffälligkeiten. Aus der Gabe an das Kloster Willibrords in WAMРАСН I 2, Nr. 6 wird nun sogar eine an Willibrord für sein Kloster. Das klingt so, als ob Willibrord hier schon als Heiliger behandelt wird. Es folgt der Hinweis Irminas auf ihre Gründung, anschließend das Trinitätspatrozinium. Alle weiteren Patrozinien fehlen. WАмрасн plädiert für einen Zeilensprung des Kopisten, dem Peter und Paul sowie die übrigen Heiligen zum Opfer gefallen seien. ${ }^{169}$ Das wäre möglich. Dann aber schließt sich der Text zu Steinheim an, der nichts mehr mit dem Formular von Waмpach I 2, Nr. 6 gemein hat. Gleiches gilt - bis auf wenige Worte - für die Poenformel. Die erwähnt sogar Erben und Miterben Irminas. Das entspricht zwar einem ähnlich lautenden Formular Markulfs, ${ }^{170}$ Irmina erwähnt jedoch weder in ihrem Testament

165 Vgl. Schmal, Mettlach, S. 45, Anm. 291 u. S. 47-49, 52.

166 Vgl. Werner, Adelsfamilien, S. 92, Anm. 268.

167 Der Wechsel in den Plural kann ein Indiz für eine Manipulation sein, findet sich aber wie gesagt - auch in einigen Markulf-Formularen. Vgl. dazu schon oben S. $144 \mathrm{u}$. Anm. 131.

168 Vgl. Wampach I 2, Nr. 9, S. 31.

169 Vgl. Wampach I 2, Nr. 9, S. 32, Anm. c.

170 Vgl. hier erneut Marculfi Formulae II,3 f., 6, ed. Zeumer, S. 76-79. Schmal, Mettlach, S. 49, Anm. 316, weist darauf hin, daß sich die anderslautende Poenformel auch in 
(Wampach I 2, Nr. 4) noch am 1. Juli (Wampach I 2, Nr. 6) irgendwelche Nachkommen. Die anschließende Datierung zum 8. Mai erscheint exakt in dieser Form nochmals in der folgenden Urkunde (Waмpaсн I 2, Nr. 10). Die Schreiberzeile Huncios stimmt dann wortwörtlich, die Unterschrift Irminas in Teilen mit dem Testament überein. Die Zeugenreihe bietet, verglichen mit den Vorgängerurkunden, auch neues Namensgut.

Da Thiofrid diese Irmina-Schenkung nicht kennt, kann sie frühestens nach dessen Vita Willibrordi (1103/4) entstanden sein. Insgesamt vermittelt WAMPACH I 2, Nr. 9 den Eindruck, daß sie aus mehreren Teilen zusammengesetzt ist. Die Abweichungen lassen sogar für ihren Schluß mindestens einen weiteren, noch unbekannten Text als Vorlage vermuten. Darüber hinaus ist es möglich, daß diese Urkunde selbst wieder als Vorlage für weitere Urkunden diente. Vielleicht läßt sich die Ähnlichkeit mit der Urkunde vom 1. Juli 699 auch so erklären, daß nämlich umgekehrt für sie WАмрасн I 2, Nr. 9 als Vorlage benutzt wurde.

Fehlende Patrozinien, Liutwin als presbiter, mehrere Erben Irminas und Willibrord selbst als Empfänger sprechen nicht für Korrekturen eines Kopisten, die einem solchen spätestens bei der Abfassung des Liber aureus unterlaufen wären. Sie deuten vielmehr auf ausgesprochen unsaubere Arbeit, als man mehrere Vorlagen zusammenfügte. Es gelang nicht, deren Widersprüchlichkeiten zu harmonisieren. Man bemerkte das wohl gar nicht. Deshalb dürfte eine erste Fassung von Wамрасн I 2, Nr. 9 oder dürften wenigstens Teile davon bereits einige Zeit älter sein als das gefälschte WАмрасн I 2, Nr. 3 und die Interpolationen sowie Veränderungen in WАмPACH I 2, Nr. 4 u. 6.

Es gibt noch eine andere Erklärung: Man könnte versucht haben, ein Kurzregest einer Schenkung aufgrund erhaltener Urkunden mit Leben zu füllen. Vielleicht machte man sogar aus der Schenkung Steinheims an Echternach durch eine andere Person eine Schenkung Irminas. Oder: Man schuf erst eine solche Schenkung Steinheims durch Irmina an Echternach. Versatzstücke anderer Echternacher Urkunden der Zeit fanden sich schnell als Grundlage, ebenso Irminas „Ur-Testament“ (WАмрасн I 2, Nr. $4+2$. Teil von Nr. 6).

Die Zeugenliste der Steinheim-Urkunde könnte aus dieser ursprünglichen Testamentsfassung übernommen sein. Liutwins abweichende Position darin und seine Bezeichnung als presbiter sprechen nämlich für eine Frühform der Zeugenliste und deren Echtheit. ${ }^{171}$ Dann hätte man Liutwins Namen später im

späteren Urkunden des Liber aureus wiederfinde. Dies seien die Urkunden WAмpach I 2 , Nr. 80, 94, 101, 153. - Zwar gibt es Ähnlichkeiten, aber auch Abweichungen. Im übrigen weisen die Markulf-Formulare, die Urkunde Pippins und Plektruds sowie weitere frühe Urkunden des Liber eine ähnliche Poenformel auf. Vgl. Wамрасн I 2, Nr. 11, 15 f., S. 36, 43, 45.

171 Vgl. dagegen aber Schmal, Mettlach, S. 48, Anm. 307, die die Urkunde und Zeugenzeile deshalb für falsch hält, weil diese Zeugen nicht vollständig mit der nächsten Ur- 
verkürzten Testament (Wampach I 2, Nr. 4) in die Zeugenliste direkt neben Bischof Basin interpoliert und mit dem Bischofstitel versehen. Von Liutwin wußte man genaueres aus seinen Viten. Vielleicht diente das zweimal nachträglich eingefügte Ego in der Zeugenreihe des verkürzten und interpolierten Testaments dann - wie oben angedeutet - dazu, eine Veränderung zu kaschieren, womöglich, um dabei überschriebene Namen oder entstandene Lücken zu füllen.

In jedem Fall liegt in Waмpach I 2, Nr. 9 die für Basin und Liutwin glaubwürdigste Zeugenliste der Irmina-Urkunden vor. Das bedeutet, daß die beiden eben nicht zeitgleich Bischöfe waren. Auch ein Adliger oder Mönch wie es die Trierer Überlieferung seit dem späten 10. Jahrhundert berichtet könnte Liutwin dann schlechterdings nicht gewesen sein, weil er als presbiter bezeugt ist.

Für eine Konstruktion der Steinheim-Urkunde (vermutlich noch vor der Fälschung oder Verfälschung der anderen Irmina-Urkunden) spricht auch die Rolle Steinheims im Liber aureus selbst. Denn sechs weitere Male taucht der Ort darin auf. Waмрасн weist darauf hin, daß der Liber Steinheim zu jeder Zeit als Echternacher Besitz behandle. ${ }^{172}$ Der scheint allerdings nicht unumstritten gewesen zu sein. Außer in dieser gefälschten Irmina-Steinheim-Urkunde findet sich Steinheim in einer wohl echten Urkunde des Trierer Erzbischofs und Echternacher Abtes Hetti (814-847) von 835/6 zur geographischen Bezeichnung der Lage von Weinbergen. Von einem konkreten Besitz ist keine Rede. ${ }^{173}$ Dann bestätigte König Zwentibold (895-900) in einem Diplom, das im Original noch erhalten ist, den Echternacher Mönchen auf Bitten seines Erzkanzlers und Trierer Erzbischofs Radbod (883-913) am 28. Oktober 895 Steinheim und weitere Orte, die Zwentibolds Vorgänger oder Vorfahren ihnen geschenkt hätten. ${ }^{174}$ War Steinheim also keine Gabe Irminas, sondern eine der Karolinger? Karl der Einfältige (893/898-923) erneuerte am 16. Januar 915 diese Urkunde neben anderen Besitzungen. ${ }^{175}$ Viel später restituierte Graf Heinrich III. (1070-1096), Sohn Konrads von Luxemburg (†1086), Echternach am 12. April 1095 die entrissenen Vogteirechte. In Zusammenhang mit einigen Regelungen wird Steinheim gemeinsam mit anderen Orten erwähnt.

kunde vom selben Tag übereinstimmen. Doch wenn beide Urkunden erst nachträglich zusammengefügt wurden, ist dies kein Widerspruch mehr. Vielmehr kann dann durchaus eine in Teilen glaubwürdige Zeugenliste herangezogen worden sein.

172 Vgl. Wampach I 1, S. 350.

173 Vgl. Wampach I 2, Nr. 141, S. 210-212, hier S. 211.

174 Vgl. DZw. 5, S. 25-27. Wampach I 2, Nr. 159, S. 242-244, hier S. 243. Vgl. dazu Wampach I 1, S. 205. Eine Abbildung findet sich bei Schieffer, Lothringische Kanzlei, S. 16 f., sowie Erläuterungen ebd., S. 49-55.

175 Vgl. DKdE 76, S. 170-172. Wampach I 2, Nr. 166, S. 257-259, hier S. 258. Vgl. ferner Schieffer, Lothringische Kanzlei, S. 131-139. 
Diese seien alle dem Zugang der Vögte entzogen. ${ }^{176}$ Dann verzeichnet eine Schenkungsnotiz, die die Jahre zwischen 1140 und 1173 rückblickend zusammenfaßt, daß ein Mönch Hazzo unter Abt Gerhard II. (1156-1173) verpfändete Klostergüter wieder eingelöst habe, allein bei Steinheim sei das nicht erforderlich gewesen. Es wäre also bei Echternach geblieben. ${ }^{177}$

Damit böte sich ein erster Datierungsansatz für unsere gefälschte IrminaSteinheim-Urkunde. Man muß allerdings bedenken, daß diese Schenkungsnotiz über Hazzo erst in die zweite Redaktionsstufe des Liber aureus ab 1210 aufgenommen wurde. Papst Viktor IV. (1159-1164, Gegenpapst Alexanders III. [1159-1181]) bestätigte schließlich am 9. Juni 1161 in einem Privileg, das im Original noch erhalten ist, namentlich genannte Besitzungen Echternachs darunter Steinheim - und unterstellte auf Bitten des Abtes Gerhard II. das Kloster dem päpstlichen Schutz. ${ }^{178}$ Hatte die auf Irmina gefälschte Urkunde also Wirkung gezeigt? Von nun an wird der Ort nicht mehr erwähnt.

Steinheim dürfte also zunächst eine karolingische Schenkung gewesen sein. Erst aufgrund ihrer gewachsenen Bedeutung für Echternach wäre Irmina nachträglich zu dessen Schenkerin konstruiert worden. Der Besitz war bedroht. Man wollte ihn sichern. Die hervorgehobene Rolle des Ortes in den Aufzeichnungen zu Hazzo bietet ein mögliches Indiz, die Fälschung um die Mitte des 12. Jahrhunderts oder etwas später anzunehmen. ${ }^{179}$ In etwa diese Zeit gehört auch der zweite Echternacher Abtkatalog, der die Echternacher Irmina als Äbtissin und Tochter König Dagoberts nennt. ${ }^{180}$ Dabei bezieht sich der Katalog

176 Vgl. Wampach I 2, Nr. 197, S. 321-324, hier S. 323. Vgl. dazu Wampach I 1, S. 261 264. Unter Thiofrid beginne der Verlust von Klostergut. In seiner Willibrord-Vita mache er dafür als ersten Kaiser Arnulf verantwortlich. Vgl. dazu Thiofrid, Vita S. Willibrordi, Vita prosa cap. 33, ed. Poncelet, S. 479.

177 Vgl. Wampach I 2, Nr. 204, S. 335-337, hier S. 337. Vgl. dazu auch Wampach I 1, S. 87 f., $272-274$.

178 Vgl. JL 14451. Wampach I 2, Nr. 208, S. 345-349, hier S. 348. Germ. Pont. 10, Echternach 10, ed. Boshof, S. 267 f. Vgl. dazu Wampach I 1, S. 275-280. Die päpstlichen Pontifikatsjahre sind hier und im folgenden entnommen der Papstliste bei Funrmann, Päpste, S. $301 \mathrm{ff}$.

179 Allerdings wäre auch der umgekehrte Weg denkbar, daß man nämlich - nachdem die Irmina-Urkunden entstanden waren - bei der Verfassung des zweiten Teils des Liber meinte, Hazzo hätte Steinheim wegen der Irmina-Urkunde nicht mehr auslösen müssen. Doch dann hätte man auch noch andere Gaben in der Hazzo-Notiz berücksichtigen können.

180 Vgl. Catalogus abbatum Epternacensium II, ed. WAItz, S. 737 f., der diesen Katalog aufgrund der darin genannten Äbte in die Zeit Abt Gottfrieds bzw. Abt Gerhards II. im 12. Jahrhundert datiert. Es handelt sich um die Handschrift Paris, BN, lat. 8996 (Suppl. lat. 1059). Ebd., S. 740, Z. 39-43: [...], nomenque ei Clemens est impositum, ac non multo post, id est quarto anno Childeberti regis, cooperantibus domna Irmina abbatissa, Dagoberti regis filia, et eodem Pippino necnon uxore sua Plittrude atque filio suo Karolo Martello multisque aliis principibus, Epternacense coenobium construxit, ibique primus 
wohl auf die Angaben in Thiofrids Irmina- und Willibrord-Vita. Der erste unter Abt Gerhard I. (1110-1123) oder kurz nach seinem Tod verfaßte Echternacher Abtkatalog, der dem zweiten als Vorlage diente, nennt Irmina allerdings noch nicht. ${ }^{181}$ Das spricht gegen Thiofrid als Fälscher von WАмрасн I 2, Nr. 9, wie ja auch, daß er diese Urkunde weder in seiner Irmina- noch in der Willibrord-Vita nennt. Irmina scheint in Echternach im beginnenden 12. Jahrhundert erst allmählich an Bedeutung zu gewinnen.

Der Scholaster und Verfasser des Liber aureus, der Echternacher Mönch Theoderich, ist urkundlich erstmals sicher 1175 und 1179 nachweisbar. ${ }^{182}$ Er sagt von sich selbst in seiner oben schon erwähnten Kampfschrift, dem Libellus de libertate Epternacensi, daß er von Kindheit an im Kloster lebte. ${ }^{183}$ Wurde er womöglich aufgrund der desolaten Besitzverhältnisse Echternachs schon vor dem Liber aureus tätig? Da die Urkunde WAMPaCH I 2, Nr. 9 nicht von zwei bis drei verschiedenen Kirchen in Echternach ausgeht und Liutwin nur presbiter ist, ist anzunehmen, daß sie einige Zeit vor der Schenkungsfälschung zum 1. November 697/8 (Wampach I 2, Nr. 3) entstand. Wenn Thiofrids neues Irminabild für Echternach im Kloster immer wirkmächtiger wurde, kam man bei Wамрасн I 2, Nr. 9 vielleicht erstmals auf die Idee, Irmina aufgrund ihres erhaltenen „Ur-Testaments“ als legitimierende Schenkerin auch an anderer Stelle einzusetzen. Es könnte sich um einen frühen Versuch Theoderichs gehandelt haben, dem bald weitere folgen sollten. Zwei Verformungsstufen würden dann Waмpaсн I 2, Nr. 9 prägen: 1. die Stufe ihrer eigentlichen Entstehung auf der Basis des „Ur-Testaments" mit mindestens einer weiteren Vorlage, 2. eine

abbas extitit; [...]. - Fälschlicherweise datiert WАмPach I 1, S. 114, Anm. 3, diesen Katalog bereits ins 11. Jahrhundert. Ihm folgt dann Zimmer, Oeren, S. 30. - Die Handschrift verwendet den bereits vorliegenden kürzeren Vorgängerkatalog als Grundlage, der bis Thiofrid reicht, nimmt aber weitere Ergänzungen vor: u. a. diese Passage zu Irmina sowie den Hinweis, daß Pippin und Plektrud bei der von Willibrord vorgenommenen Klostergründung mitwirkten. Dies zeigt, daß man nun beide Irminas miteinander verband, Thiofrid die Irmina aber keinesfalls zur Gründerin Echternachs machte und er deshalb auch noch nicht die Irmina-Urkunden verfälscht haben dürfte. Vgl. zu den Abtkatalogen auch unten Anm. 181, 245.

181 Vgl. Catalogus abbatum Epternacensium I, ed. WArtz, S. 737-740. Der Katalog nennt noch Thiofrids Nachfolger Abt Gerhard I., aber nicht mehr dessen Todestag. Vgl. zu Gerhard I. WАмрасн I 1, S. 267-269.

182 Vgl. Wampach I 2, Nr. 211 f., S. 352-356, hier S. 353 u. 355. Die Urkunden der davor liegenden Jahre weisen nur selten aussagekräftige Zeugenlisten auf, so daß Theoderich hier durchaus schon aktiv gewesen sein dürfte. So erscheint bereits in einer Urkunde von 1156 (ebd. Nr. 206, S. 343) dreimal der Name Theoderich.

183 Vgl. Waмpach I 2, Nr. 215, S. 360-382, hier S. 367: Erat tunc temporis Theodericus unus ex ecclesie illius discipulis, a puero fere usque ad provectam etatem claustralibus institutus disciplinis, qui pro eo quod multa audierat, viderat et legerat, statum ecclesie et eventum a principio optime noverat, et quod sepe variis fortune iactata proventibus, numquam a ditione regum et imperatorum alienata fuerat. - Vgl. dazu oben Kap. D.II.2. 
nachträgliche Anpassung an die später entstandene Fälschung vom 1. November 697/8. Eine solche erste Vorstufe der Irmina-Steinheim-Urkunde macht dann verständlich, weshalb der Liber aureus $1191 / 2$ innerhalb kürzester Zeit mehrere Irmina-Urkunden schaffen konnte, die das Bild einer Oerener Äbtissin Irmina als Echternacher Klostergründerin aufgriffen. Sichere Antworten sind allerdings nicht möglich, vielleicht aber eine auf die noch ungeklärte Herkunft einiger Teile des Formulars.

\section{e. Die zweite Schenkung Irminas vom 8. Mai 704 (WАмрасн I 2, Nr. 10)}

Die nächste Urkunde vom selben Tag übernimmt das Formular der Vorgängerurkunde vollständig und damit auch deren Beginn und das Schenkungsmotiv. Die Gott geweihte Äbtissin Irmina schenkt Willibrord für dessen Kloster Echternach, das sie von neuem erbaut haben will (wieder formuliert in der 1 . Person Plural), einen Weinberg innerhalb der Trierer Mauern, den ihr die Gott geweihte Engela als Schenkung übertragen habe. Ausgenommen davon sind (plus minus) drei centua ${ }^{184}$, die außer 1. vom geschenkten Weinberg, 2. vom Besitz eines Folcobertus, 3. dem Besitz der Erben des Mummolittus und schließlich 4. einer via publica umschlossen werden. Die Poenformel folgt exakt der anderen Urkunde dieses Datums (WAмpACH I 2, Nr. 9), nennt also auch wieder Erben. Ein Warenbertus presbiter behauptet, diese Urkunde auf Bitten der Gott geweihten Äbtissin Irmina mit der Erlaubnis des Huncio geschrieben zu haben. Als Zeugen erscheinen: Dagoinus. Radobertus. Gaucebertus. Quiltarius. Magnobertus. Huncio, in Christi nomine presbiter. ${ }^{185}$

184 Bei diesem Wort handelt es sich wohl um ein Flächenmaß. Es findet sich nur in dieser Urkunde. Vgl. dazu Mittellateinisches Wörterbuch 2, Sp. 467.

185 Vgl. Wampach I 2, Nr. 10, S. 33 f.: Domino sancto et in Christo apostolico patri Willibrordo episcopo Ermina in Christo Deo sacrata abbatissa donatrix. / Quicquid unusquisque homo de rebus suis ad loca sanctorum vel servorum Dei spontanea voluntate condonaverit, hoc sibi apud Deum mercedis premium creditur in Dei nomine recipere in futuro. I Idcirco ego Irmina dono vobis ad monasterium vestrum Epternacum, quod nos a novo construximus, situm super fluvio Sura, donatumque esse volumus in perpetuum ad possidendum, hoc est vineam infra muros Treveris civitatis ad crucem, quod nobis Engela Deo sacrata per cartulam donationis condonavit, plus minus centuas tres, ab uno latere Folcobertus et ab alio heredes Mummolitti, et de tercia parte via publica; sub ea conditione ut quicquid a die presenti vos vel pars monasterii exinde decreverit, faciendi liberam et firmam in omnibus habeatis potestatem, et nullius ex hoc repeticionem vereamini. / Si quis vero, quod fieri non credimus, tam ego quam aliquis de heredibus aut coheredibus meis vel quelibet opposita persona contra hanc cartulam donationis venire conatus fuerit aut eam irrumpere voluerit, primitus iram omnipotentis Dei incurrat, et insuper inferat fisco auri libram unam, argenti pondo duo, nec sic quod repetit, ullatenus valeat evindicare, manente nichilominus firmitate. / Actum Treberi sub die VIII Idus Maias. Anno X regni domini nostri Childeberti regis. I Ego Warenbertus presbiter, rogante in Christo Deo sacrata Ermina abbatissa et ex permisso senioris mei Huncionis presbiteri et ammanuense, hanc cartulam donationis perscripsi, et ipsa subter 
Thiofrid erwähnt diese Urkunde weder in seiner Vita sanctae Irminae (vor 1081) noch in seiner Vita Willibrordi (1103/4). ${ }^{186}$

Schmal hält sie für aus Wampach I 2, Nr. 4 u. 6 zusammengesetzt und geht bei der Irmina-Gründungspassage von einer Interpolation gemäß WАмрАсн I 2, Nr. 3 aus. Die Urkunde könne aufgrund der kurzen Zeugenliste die Vorlage für die vorausgehende gewesen sein. Beide seien fast identisch, doch die Namen der Zeugen frei erfunden. ${ }^{187}$ Nach WeRner läßt sich dieser Besitz nicht lokalisieren. ${ }^{188}$

Daß Irmina das Kloster Echternach gegründet haben will, ist auch diesmal sicher eine Interpolation. Für die Urkunde oder zumindest eine ihr vorausgehende echte Vorlage sprechen aber die neben dem Weinberg namentlich erwähnten Nachbarn der drei centua. Warum aber fehlen Bischof Basin und presbiter Liutwin, obwohl sie bei WАмрасн I 2, Nr. 9 noch mitwirkten? Die wenigen Namen dürften auf einer glaubwürdigen Grundlage basieren und kaum frei erfunden sein. Die auffällige und für eine Irmina-Urkunde einmalige Schreiberzeile, die den Priester Warenbertus in Vertretung Huncios nennt, deutet zunächst auf eine Originalvorlage irgendeiner Art hin. Wieso sollte man das erfinden? Huncio hätte sich doch allemal eher als Schreiber - wie schon in den Vorgängerurkunden - angeboten. ${ }^{189}$

Seltsam ist dennoch, daß zwei Urkunden des gleichen Tages bei Zeugen und Schreiber derart variieren. Warum tauchen in Wampach I 2, Nr. 10 keine Echternacher Patrozinien auf, während das in WАмрасн I 2, Nr. 9 wenigstens fragmentarisch geschieht? Auch wechselt die Urkunde nicht nur für Irminas Hinweis auf die Gründung Echternachs, sondern ebenso für die Ausführung zur Schenkung Engelas an Irmina in den Plural. Das vermittelt den Eindruck, daß diese Schenkung nicht unbedingt auf Irmina selbst zurückging, sondern sie erst nachträglich zur Schenkerin gemacht wurde. Wahrscheinlich war sie auch nicht an Willibrord gerichtet. Womöglich wirkte Warenbert ursprünglich als Schreiber, dem man später Huncio durch eine Interpolation an die Seite stellte, um den Inhalt an die Irmina-Vorlagen anzupassen. Die mit ihrer Schenkungsurkunde zitierte Engela Deo sacrata könnte als eigentliche Geberin tätig gewesen sein, was auch die geringe Zeugenzahl sowie das Fehlen eines Bischofs

manu propria [una] cum testibus firmavit, et qui subscriberent vel signarent, in presenti rogavit. / Ego Ermina subscripsi. Es folgen die auf S. 163 aufgeführten Zeugen.

186 Vgl. dazu Thiofrid, Vita sanctae Irminae cap. 6, ed. WeILAnd, S. 49, sowie Thiofrid, Vita S. Willibrordi, Vita prosa cap. 12, ed. Poncelet, S. 467 f., wo diese fehlen.

187 Vgl. Schmal, Mettlach, S. 48 f., 52 f., Anm. 307, 316, 331, 337.

188 Vgl. Werner, Adelsfamilien, S. 80, Anm. 220. Schmal, Mettlach, S. 53, Anm. 337, vermutet, die Urkunde könne auch den Trierer Mauerbering meinen. Dieser sei aber nicht vor dem 10. Jahrhundert entstanden.

189 Vgl. dazu Wampach I 1, S. 305-307. Immer erscheint Huncio. Hinzu kommt noch die umstrittene Liutwin-Urkunde von 706 (MRUB I 7a), die auch den Priester Warenbert als Schreiber in Gegenwart Huncios nennt. Vgl. dazu unten Kap. D.III.1. 
erklärte. Die Vorlage wäre in einem unbedeutenderen Kontext entstanden. Dann hätte Warenbert zunächst auf Engelas Bitte und mit Zustimmung von deren nicht mehr bekannten Äbtissin geschrieben. Auf eine solche Lesart deutet ebenfalls die Schreiberzeile in der verdächtigen Liutwin-Schenkung an St. Eucharius (MRUB I 7a) hin, die formal eng mit den Irmina-Urkunden zusammenhängt und die weiter unten besprochen wird. ${ }^{190}$

Diese Urkunde könnte die schon gesuchte Formularvorlage für die Steinheim-Schenkung (Wampach I 2, Nr. 9) vom selben Tag sein. Vielleicht wurde die Datierung übernommen. Diese Weinberg-Schenkung wäre ebenso selbst oder über die Steinheim-Schenkung in die von Irminas „Ur-Testament“ abgespaltene Urkunde (WАмрасн I 2, Nr. 6) eingegangen. Man sieht also auch hier, wie authentische Bilder verwendet wurden, um neue Bilder zu schaffen.

Auch diese zweite Urkunde vom 8. Mai 704 dürfte mehrere Verformungsstufen durchlaufen haben. Doch läßt sich schwer klären, wann genau das geschah: 1. wurde aus der Schenkung einer Engela u. a. eines der Vorbilder für die Steinheim-Schenkung Irminas; 2. machte man später aus der WeinbergSchenkung ebenfalls eine Irmina-Urkunde. Vielleicht bot die Übertragung der Villa Berg durch Irmina an Echternach (im „Ur-Testament“, jetzt Wampach I 2, Nr. 6), die sie ja zuvor von Irmintrudis erhalten haben wollte, dafür die Anregung. Ob Irmina in der ersten konstruierten Version von WАмрасн I 2, Nr. 10 schon gleich als Gründerin Echternachs wirkte oder erst in einem 3. Schritt dazu gemacht wurde, muß offen bleiben. Eine sichere und eindeutige Lösung wird es wohl nie geben.

\section{f. Das Urkundenregest einer Ymena aus dem Jahr 704 (WАмpach I 2, Nr. 12*)}

Der Liber aureus schließt dann seine Irmina-Passage ab und bemerkt: So habe die seelige Jungfrau Irmina den hl. Willibrord bei der Einrichtung der Kirche in Echternach unterstützt. Sie sei am Nikolaustag des Jahres 700 gestorben. ${ }^{191}$ Von einer Äbtissin ist keine Rede. Das angegebene Todesjahr spricht eindeutig gegen die Glaubwürdigkeit von Wамрасн I 2, Nr. 9 u. 10 zumindest als IrminaUrkunden von 704 und für eine Fälschung als Irmina-Urkunden wohl noch vor Anlage des Liber aureus. Warum nahm der Mönch Theoderich diese Diskrepanz einfach hin und integrierte das widersprüchliche Datum in sein Goldenes Buch, als ob er eine längere Irmina-Erzählung beende? War er denn nicht in der Lage,

190 Einen Hinweis, daß anstelle Huncios einmal der Name einer Frau gestanden haben könnte, bietet auch eine Verschreibung an dieser Stelle in der Liutwin-Schenkung an St. Eucharius in Trier (MRUB I 7a). Vgl. dazu genauer unten S. 192 u. Anm. 285.

191 Vgl. Theoderich, Chronicon Epternacense, ed. WeILand, S. 53, Z. 20-22: Sic beata virgo Irmina sancto Willibrordo in institutione Epternacensis aecclesiae cooperabatur et in omnibus quae ad cultum eius pertinebant promptissima devotione suffragabatur. Sanctus Nicholaus 700. anno incarnationis Domini de hoc mundo transivit. 
die Herrschaftsjahre wenigstens einiger Merowingerkönige aufzulösen, wie doch einige Bemerkungen $\mathrm{zu}$ den frühen Echternacher Urkunden zeigen? ${ }^{192}$ Beim Nikolaustag des Jahres 700 muß es sich um eine eigenständige Echternacher Lokalüberlieferung handeln, die von der Oerener Irminatradition unabhängig ist. In Trier dagegen gedachte man nämlich seit dem 11. Jahrhundert dem Geburtstag einer Irmina am 24. Dezember. ${ }^{193}$

Zwei Urkunden Pippins II., die im nächsten Kapitel noch kurz zu besprechen sein werden (Urkunden der Arnulfinger 4 u. 5), schließen den Block der Echternacher Gründerurkunden im Liber ab. ${ }^{194}$ Ihnen folgen noch fünf kurze Quellenregesten. ${ }^{195} \mathrm{Im}$ letzten der Regesten zum Jahr 704 (dem 10. Jahr Childeberts) schenkt eine Gott geweihte Ymena mit ihren Töchtern Attala und Crodelindis dem hl. Willibrord ihren elterlichen Anteil an den Villen Cabriaco und Bedelinga. ${ }^{196}$ In den beiden von Thiofrid verfaßten Viten erscheint auch dieser Beleg nicht.

Die Frage ist, ob es sich bei Ymena um die Echternacher bzw. Oerener Irmina handelt. In der Forschung wird das inzwischen angezweifelt. Einige haben in diesem Regest einen Beleg dafür sehen wollen, daß die vorgebliche Äbtissin Irmina die Mutter der Adela war, die das Kloster Pfalzel gründete. ${ }^{197}$

192 Vgl. Theoderich, Chronicon Epternacense, ed. Weiland, S. 53, Z. 32-34: Quorum descriptionem ipsimet anno 12. Childeberti gloriosi regis Francorum, qui est annus incarnationis Domini 706, [...].

193 Vgl. dazu Miesges, Festkalender, S. 112 f.

194 Vgl. Theoderich, Chronicon Epternacense, ed. Weiland, S. 53-55. Es wird dann nochmals die gemeinsame Rolle Irminas, Pippins und Plektruds, aber auch die der weiteren Schenker bei der Klostergründung betont. Willibrord habe im dritten Jahr seiner Ordination das Kloster gegründet. Es schließen sich die Herrschaftsjahre der Merowingerkönige seit der Klostergründung an.

195 Es handelt sich zunächst um Schenkungen aus den Jahren 694, 696, 698 und 699. Vgl. Theoderich, Chronicon Epternacense, ed. Weiland, S. 55. Vgl. dazu Wampach I 2, Nr. 1*, 2*, 5*, 7*, S. 15-17, 23 f., 26 f. Es sind dies eine Kirchenschenkung Rohings von Antwerpen an Willibrord, die Schenkung der väterlichen Güter des Grafen Gerbert und seiner Schwester an Willibrord, die Schenkung eines Weinbergs mit Winzer in monte Clotariense an Willibrord sowie die Schenkung der väterlichen Erbgüter eines Haderich an den hl. Willibrord. - Auffällig ist dabei, daß sie sich alle an Willibrord und nicht an das Kloster Echternach richten. Diese Regesten wurden also erst längere Zeit nach Willibrords Tod erstellt.

196 Vgl. Theoderich, Chronicon Epternacense, ed. Weiland, S. 55. Vgl. dazu Wampach I 2, Nr. 12*, S. 36 f.: Anno X Childeberti Ymena, Deo sacrata, et Attala atque Crodelindis, filie ipsius, dederunt viro Dei [sancto Willibrordo] portionem suam in villa Cabriaco et in villa Bedelinga, que eis a parentibus suis provenit. - Die Schenkung unmittelbar an Willibrord erklärt sich dabei entweder als Schenkung an Willibrord, dessen Patrozinium das Kloster inzwischen übernommen hatte, oder an Willibrord als Bischof selbst.

197 Vgl. dazu bereits oben S. 129 f. u. Anm. 82-85. 
Inzwischen ist man vorsichtiger geworden, glaubt aber noch an die Möglichkeit, daß es sich um die Irmina der Echternacher Urkunden handeln könnte. ${ }^{198}$

In jedem Fall hat der Mönch Theoderich 1191/2 darin wohl nicht Irmina erkannt oder erkennen wollen. Sonst hätte er das Regest nicht viel später folgen lassen. War es nicht spektakulär genug? In Irminas Testament erscheint Baidelingo (Wамрасн I 2, Nr. 4) und hier Bedelinga. Handelt es sich um denselben Ort? Gibt es einen Bezug? Immerhin verfügen beide Ortsnamen nicht über dasselbe Genus. ${ }^{199}$ Wäre Ymena jedoch Irmina, die Schenkerin von Echternach, dann belegte dies, daß Irmina eben keine Äbtissin war, sondern nur eine schlichte Nonne. Hatte Theoderich das Regest deshalb an anderer Stelle plaziert? Die Trierer Tradition seit dem 11. Jahrhundert kannte neben der Dagoberttochter Irmina auch ihre Schwester Adela, wie wir gleich sehen werden. Ordnete Theoderich das Regest (Wampach I 2, Nr. 12*) deshalb nicht den anderen Schenkungen zu, weil im Regest im Widerspruch zu diesen eine Attala Irminas Tochter war? ${ }^{200}$

Beides würde jedenfalls die These stützen, daß die Echternacher Irmina zunächst keine Äbtissin war, sondern es sich bei dieser Bezeichnung um eine nachträgliche Interpolation aufgrund der späteren Trierer Tradition handelt. Ermöglichte dieses Regest vielleicht erst die Idee zu den gefälschten IrminaUrkunden vom 8. Mai 704 (WАмрасн I 2, Nr. 9 u. 10)? Es erklärte dann, warum in deren Poenformeln Verwandte und Erben Irminas erscheinen. Handelte es sich bei Ymena womöglich gar nicht um die Echternacher Irmina, sondern um das Vorbild der Dagoberttochter der Oerener Tradition in Trier? Was geschah in Echternach? Es wird sich wohl niemals mehr genau rekonstruieren lassen. Eines aber zeigt sich: Die Texte und Urkunden sind von starken Widersprüchen durchzogen. Und offenbar konnte man diese dem Leser des Liber aureus problemlos zumuten. In diesem Geflecht erscheinen Basin und Liutwin gemeinsam. Deshalb empfiehlt es sich, gleich noch einen genauen Blick auf die Trierer Irminatradition zu werfen. Zuvor aber muß die Rolle Pippins

198 Vgl. dagegen und ausführlich Werner, Adelsfamilien, S. 98 ff., der die Namensform, den geistlichen Titel und die Verwandtschaftsbeziehungen einer grundlegenden Prüfung unterzieht.

199 Wäre vielleicht an Beßlingen zu denken? Vgl. WАмрасн I 1, S. 125, 441, der hierin Badelingen erkennt, aber an anderer Stelle (ebd., S. 120 u. Anm. 3, S. 123) „Bettelingas“ nennt und darin Beßlingen bzw. Ober- und Niederbeßlingen im Kanton Clerf in Luxemburg sehen will. Doch handle es sich dabei um die germanische Form, die romanische laute (nach dem Testament der Adela von Pfalzel) „Beslanc“. - Dies würde dann aber seine einzige Verbindung der Echternacher Irmina mit Adela in Frage stellen. - Vgl. dazu auch Werner, Adelsfamilien, S. 112-118, der nicht an die Übereinstimmung glaubt. Er nennt als Möglichkeiten auch Beilingen (Kr. Bitburg) oder Beidlingen bei Trier. Es müsse sich dann zudem um eine Schenkungswiederholung gehandelt haben, was ein innerer Widerspruch wäre.

200 Vgl. dazu unten S. 175 f. u. Anm. 232. 
und Plektruds bei der Gründung Echternachs erläutert werden, um die Angaben zur Echternacher Irmina durch ein „Gegenzeugnis“ zu prüfen.

\section{Die Rolle Pippins und Plektruds bei der Gründung Echternachs}

Der Liber aureus widmet sich unmittelbar nach Irmina der bedeutenden Rolle Pippins des Mittleren $(† 714)$ und seiner Frau Plektrud $(\dagger 717)$ bei der Klostergründung, die beide chronologisch nach Irmina in Erscheinung treten. Es folgen zwei Urkunden (Urkunden der Arnulfinger 4 u. 5), datiert auf Christi Himmelfahrt, den 13. Mai 706, deren Inhalt kurz für die Überlegungen zu Irmina, Basin und Liutwin betrachtet werden soll. ${ }^{201}$

In der ersten schenken Pippin und Plektrud ihrem Kloster, das der Hl. Dreifaltigkeit, den Aposteln Peter und Paul sowie Johannes dem Täufer geweiht und auf ihrem Eigentum errichtet worden sei und wo sie den eifrigen Mann, Verehrer Gottes und apostolischen Herrn Bischof Willibrord gemeinsam mit einer Schar Mönche unter seiner Leitung für ein heiliges und nach der Regel geführtes Leben einsetzten, die Hälfte Echternachs. Es handle sich um den Teil, den Herzog Theothar dort hatte und den später dessen Sohn Theodardus an Pippin übertrug, außer dem Besitz, den Irmina in Echternach hielt. Ferner sichern beide noch $\mathrm{zu}$, daß das Kloster immer unter ihrem Schutz und dem ihrer Erben und Verwandten bleiben werde. Unterzeichnet ist die Urkunde auffälligerweise von mehreren Bischöfen und weiteren Zeugen: Chuchobertus episcopus. Garebaldus episcopus. Bernarius episcopus. Constantinus episcopus. Josephus. Winetaharius episcopus. Chariganto. Agione. Crodebaldus. Cardimus. Remedius. Bainingus. ${ }^{202}$

201 Zur Datierung auf Christi Himmelfahrt vgl. Angenendt, Willibrord, S. $74 \mathrm{f}$.

202 Vgl. Urkunden der Arnulfinger 4, ed. Heidrich, S. 61-64, hier S. 63 f.: Ego in Dei nomine illuster vir Pippinus filius Ansgisili quondam, necnon et illustris matrona mea Plectrudis filia Huogoberti quondam, cogitantes casum humane fragilitatis, qualiter peccata nostra possimus abluere, et donante domino ad eterna gaudia pervenire. Idcirco ob honorem domini nostri Jhesu Christi donamus donatumque in perpetuum esse volumus, ad monasterium nostrum quod est in honore sancte Trinitatis, et apostolorum Petri et Pauli, et sancti Johannis baptiste, in loco cognomento Epternaco, in pago Bedensi super fluvio Sura, in re proprietatis nostre edificatum, ubi decrevimus et constituimus virum strenuum et Dei cultorem apostolicum dominum Willibrordum episcopum una cum turma monachorum sub sua gubernatione, vita sancta et regulari degere et conversari, hoc est illam medietatem de ipso Epternaco quam Theotharius quondam dux ibidem tenuit, et postea filius suus Theodardus quondam nobis tradidit, preter illam rem quam Ermina in ipso Epternaco tenuit, quantumcumque in ipsa medietate nostra in ipso Epternaco a die presenti nostra videtur esse possessio vel donatio, cum terris, cum domibus, edificiis, acolabus mancipiis, litis, silvis, campis, pratis, pascuis, aquis, aquarumque decursibus, mobilibus et immobilibus farinariis, pecoribus utriusque sexus, quantum in ipsa medietate in ipso Epternaco presenti tempore 
Thiofrid erwähnt die Urkunde mit Angabe des genauen Datums in seiner Willibrord-Vita (1103/4), allerdings nur die Schenkungen. Die Schutzbestimmungen fehlen. ${ }^{203}$ Das spricht für die Echtheit zumindest der Schenkungspassage. Ebenso findet sich das Formular des Diploms ähnlich in den Marculfi Formulae für Schenkungen an Kirchen, ${ }^{204}$ was dieses Urteil unterstützt.

Auch wenn man dieser Urkunde folgt, kann Irmina Echternach kaum gegründet haben. Vielmehr scheint es so etwas wie ein karolingisches Eigenkloster gewesen zu sein, sonst hätte Pippin Willibrord dort kaum als Abt eingesetzt. Zudem ist nur die Rede von einem und nicht mehreren Klöstern. Für Irmina fehlt jeder Titel, sowohl der einer Nonne wie auch der einer Äbtissin. Doch belegt die Urkunde, daß eine Frau mit diesem Namen dort über Besitz verfügte. Vor allem unterzeichnen - wenn die Unterschriften glaubhaft sind - mehrere Bischöfe entfernter Diözesen, doch seltsamerweise kein Trierer.

Die zweite Urkunde, die in einigen Formularteilen von der ersten erheblich abweicht, stellen Pippin und Plektrud dem Bischof Willibrord für das Kloster

possidemus, cum omni integritate de iure et domnatione nostra in iure et domnatione predicti monasterii vel rectoribus suis seu successoribus et omni congregationi ibidem consistenti tradimus atque delegamus, perpetualiter in Dei nomine ad possidendum, ut ibidem omni tempore pro mercede nostra proficiat in augmentis, ea ratione ut ipsum monasterium in nostra vel heredum nostrorum domnatione vel defensione in antea semper permaneat. I Et illud nobis placuit inserendum, si fuerit ullus de heredibus vel propinquis nostris seu quelibet ulla extranea aut opposita persona que contra hanc donationem quam nos plena et integra devotione pro anime nostre remedio fieri et affirmare rogavimus, venire aut agere temptaverit, et ipsa carta ei ad relegendum ostensa fuerit, et se ex hoc compescere noluerit, primitus iram Dei incurrat, et a liminibus sanctorum efficiatur extraneus, et inferat partibus ipsius monasterii, vel cui litem intulerit tantum, et aliud tantum, quantum res ipse eo tempore emeliorate valuerint, et inferat una cum socio fisco, auri libras. $X$. argenti pondo XX coactus exsolvat, et quod repetit evindicare non valeat, sed presens donatio ad instar testamenti cum stipulatione adnixa omni tempore firma stabilitate capiat firmitatem. Actum Gaimundas publice sub die. III. idus maias, anno XII regni domni nostri Childeberti gloriosissimi regis. Pippinus et coniunx eius Plectrudis. Drogo. Es folgen die oben auf S. 168 aufgeführten Zeugen. Vgl. auch Wampach I 2, Nr. 14, S. 38-41. - Vgl. zur Zeugenliste AngenendT, Willibrord, S. 74 f. Semmler, Episcopi potestas, S. 314 f. Gauthier, Évangélisation, S. 428. - Chuchobertus und Constantinus dürften Bischöfe in Lüttich und Beauvais gewesen sein, Garebaldus vielleicht in Toul oder Bayeux. Bernarius läßt sich nicht identifizieren. Wамрасн I 1, S. 53, Anm. 2, hält Josephus und Winetaharius für Chorbischöfe. - Vgl. zur Urkunde zuletzt nochmals Heidnich, Urkunden der frühen Karolinger, S. 461-463, 470. Mit Drogo ist der Sohn von Pippin und Plektrud gemeint. Die Urkunden seien hochoffizielle Akte.

203 Vgl. Thiofrid, Vita S. Willibrordi, Vita prosa cap. 12, ed. Poncelet, S. 467D-E: Denique dux excellentissime generositatis Pipinus cum Blitrude contectali sua, eque generosis orta natalibus, tertio idus mai, anno duodecimo Childiberti gloriosissimi regis, dedit ei [Willibrord] Efternacensis fisci medietatem integram, a Theodardo, egregii ducis. Theotharii filio, sibi traditam, [...]. Es folgt dann der Hinweis auf Irminas Teil. Vgl. oben Anm. 138.

204 Vgl. Marculfi Formulae II,3, ed. Zeumer, S. 74-76. 
Echternach aus, das er auf ihrem Eigentum gebaut habe, um Gott zu dienen, und weil er selbst eine Schenkung vorgenommen habe, damit sie es unter ihrem und ihrer Erben Schutz halten. Sie bestätigen ihm das Kloster und tun dies auch, damit er dort pilgernde und andere Gott fürchtende Brüder versammle und diese nach der hl. Ordnung lebten. Ebenso garantieren sie die Wahl eines Nachfolgeabtes, wenn dieser ihnen und ihren Nachkommen treu bleibe, dort nach der hl. Regel lebe und sie unter ihrem Schutz blieben. Es erscheinen beinahe dieselben Zeugen. ${ }^{205}$

Thiofrid erwähnt diese Urkunde nicht in seiner Willibrord-Vita (1103/4). An anderer Stelle bemerkt er darin aber, Willibrord habe das Kloster dem ius et mundiburdium der Könige und Kaiser übertragen, weil er u. a. nicht wollte, daß

205 Vgl. Urkunden der Arnulfinger 5, ed. Heidrich, S. 64-66, hier S. 65 f.: Semper humana fragilitas casus inevitabiles debet perpendere, ut quandoquidem repentina supervenerit transpositio, non habeat in nobis quod puniat, sed inveniat quod coronet, iuxta mandatum domini date et dabitur vobis, et illud, facite elemosinam et omnia munda sunt vobis. / Idcirco ego in Dei nomine illuster vir Pippinus filius Ansgisili quondam, necnon et illustris matrona mea Plectrudis filia Hugoberti quondam cogitantes casum humane fragilitatis qualiter peccata nostra possemus abluere, et Deo donante ad eterna gaudia pertingere, concedimus domino patri nostro viro apostolico Willibrordo episcopo de monasterio Epternaco sito in pago Bedense super fluvio Sura, quod ipse donante Deo edificavit in rebus proprietatis nostre, et unde ipse beatus Willibrordus testamentum confirmavit ut sub nostra defensione haberemus ac heredum nostrorum. Unde placuit nobis ut apostolico patri nostro Willibrordo ipsum monasterium confirmaremus, quod ita et fecimus eo modo ut ibidem fratres peregrinos vel alios Deum timentes congregent, ut ibidem secundum ordinem sanctum degere et conversari debeant. et illud ibidem nobis placuit inserendum, ut cum ipse beatus Willibrordus de hac luce migraverit, ipsi fratres quem ex semetipsis elegerunt sibi constituant abbatem ea ratione ut heredibus nostris in omnibus fidelis appareat, et ibidem secundum ordinem sanctum degat, et sub nostro mundiburdio vel defensione persistant. Et si quis Deum timens tam de parte nostra quam et de reliquis hominibus de suis rebus ad ipsum monasterium condonare et confirmare deliberaverint vel quicquid ibidem deo inspirante de collatis bonis obvenerit Deo propitio eis proficiat in augmentis. Si quis vero quod minime credimus esse futurum si fuerit ullus de heredibus aut propinquis nostris, seu quelibet extranea aut opposita persona que contra hanc nostram confirmationem quam nos pro divino intuitu vel anime nostre remedio fieri aut firmare rogavimus venire voluerit, aut infringere, et ista carta ei ostensa fuerit ad relegendum et se ex hoc compescere noluerit, inprimitus ire Dei omnipotentis incurrat offensam, et a liminibus sanctorum efficiatur extraneus, et insuper inferat partibus eiusdem loci et fratribus tunc tempore ibidem servientibus aut cui litem intulerit, tantum, et aliud tantum quantum res ipse eo tempore emeliorate valuerint, et insuper inferat cum socio fisco auri libras $X$, argenti pondo.XX. coactus exsolvat, et quod repetit evindicare non valeat, sed presens confirmatio ad instar testamenti cum stipulatio adnixa omni tempore firma stabilitate capiat firmitatem. Actum Gamundias publice, sub die .IIIo. idus maias, anno.XIIo. regni domini nostri Childeberti gloriosi regis. I Pippinus et Plectrudis. Droda. Chugobertus. Gerbaldus. Bernarius. Constantinus. Josefus. episcopi. Wintharius. Agione. Remedius. Bainingus iussus a Pippino et Plectrude, scripsi. Hardoino. Vgl. auch Waмpach I 2, Nr. 15, S. $41-43$. 
es vom Trierer Bistum abhängig sei. ${ }^{206}$ Ingrid Heidnich hält sie für echt, ${ }^{207}$ doch scheinen nicht alle Zweifel gegen dieses Dokument ausgeräumt.

Immerhin betont der Inhalt klar Willibrords Gründerrolle in Echternach, für das hier merkwürdigerweise die Patrozinien fehlen. ${ }^{208}$ Von Irmina und einem Trierer Bischof fehlt wieder jedes Wort. Darüber hinaus kommen hier Pilgerbrüder zur Sprache, die Willibrord in sein Kloster aufnehmen soll. Und damit wäre eine Vorlage für das von Irmina gegründete Klösterlein für Pilgerbrüder in der gefälschten Schenkung vom 1. November 697/8 (Wampach I 2, Nr. 3) gegeben. In einer weiteren Urkunde Pippins für Echternach über Süsteren vom 2. März 714 (WАмрасн I 2, Nr. 24), die auch in Thiofrids Willibrord-Vita genannt wird, tauchen diese Pilgerbrüder in wortgleicher Formulierung nochmals auf. ${ }^{209}$ Man konnte also in jedem Fall zu ihnen auf Echternacher Vorlagen zurückgreifen. Die Irmina-Urkunden verwenden somit schlechterdings das ihnen in Pippins Urkunden bereits vorliegende Material.

\section{Willibrord, Irmina und die Äbtissin Anastasia von Oeren}

Nach diesen Texten des späten 7. und beginnenden 8. Jahrhunderts verschwindet Irmina zunächst aus der Geschichte. Deshalb ist man allgemein von ihrem Tod in dieser Zeit ausgegangen. Ebenso hätten Pippin und Plektrud kein Interesse mehr daran gehabt, Irminas Rolle bei Echternachs Gründung weiter zu betonen. Für 710 läßt sich eine Oerener Äbtissin Anastasia nachweisen. Erst in Trierer Kalendaren des späten 10. Jahrhunderts finden sich wieder Spuren einer Irmina. ${ }^{210} \mathrm{Um}$ die Tragweite dieser langen Unterbrechung und ihre Konsequenzen für Basin und Liutwin zu verdeutlichen, ist noch ein Exkurs erforderlich. Er soll in erster Linie die Problematik des späteren, neuartigen Irminabildes

206 Vgl. Wамрасн I 2, Nr. 13*, S. 38 f., hier S. 38: [...], neque vicinae [Trevirensi], neque longinquae suae sedi Traiectensi voluit esse in rebus materialibus subditum, sed rata concessione ac firma testamenti conscriptione et astipulatione tradidit in ius et mundiburdium regum et imperatorum in ordine sibi legali iure succedentium. Vgl. ebenso Thiofrid, Vita S. Willibrordi, Vita prosa cap. 22, ed. Poncelet, S. 473D.

207 Vgl. oben Anm. 205, sowie zuletzt Heidrich, Urkunden der frühen Karolinger, S. 461 $463,470$.

208 In diesen Urkunden wird Willibrord als Erbauer genannt. Und so muß es auch gewesen sein. Vgl. Werner, Adelsfamilien, S. 69. Schroeder/Trauffler, Anfänge, S. 19.

209 Vgl. Wampach I 2, Nr. 24, S. 57-60, bes. S. 59. Thiofrid, Vita S. Willibrordi, Vita prosa cap. 12, ed. Poncelet, S. 467.

210 Vgl. dazu zuletzt nur Trauffler, Gründung, S. 51, der auf fehlende Quellen zu Irmina seit der Klostergründung bis ins 11. Jahrhundert hinweist. Nach der Gründung werde sie geradezu verschwiegen, was wahrscheinlich auf die politische Intention Pippins zurückzuführen sei. Knichel, Irmina, S. 185 f. Werner, Adelsfamilien, S. 35-39, 69-74, 84-90, bes. S. 74. Vgl. ferner unten S. 173 f. u. Anm. 220-222. 
herausarbeiten und prüfen, ob die Echternacher und Oerener Irmina tatsächlich identisch sind.

Um Willibrord bildete sich bald nach seinem Tod 739 ein Kult. Das zeigt die Form seiner Grabstätte, die schnell für einen größeren Pilgerandrang hergerichtet wurde, aber auch die von Alkuin über ihn verfaßte Vita. ${ }^{211}$ Sein Patrozinium rückte in Echternach allmählich neben das von Petrus. Die folgenden Schenkungsurkunden belegen das. ${ }^{212}$

Warum aber wird nicht mit Willibrord ebenso die Erinnerung an Irminas Rolle bei der Klostergründung sowie die Basins und angeblich ja auch Liutwins wachgehalten? Abgesehen von den problematischen Irmina-Urkunden bieten die zeitgenössischen Quellen keine Verbindung mehr zwischen Willibrord und einer Irmina. In seinem erwähnten, als Original erhaltenen Kalender ist zwar ein Bischof Basin im frühen 8. Jahrhundert nachgetragen, Irmina sucht man jedoch vergeblich. Dagegen wird darin einer Äbtissin Anastasia zum 9. Dezember gedacht, die wohl die Oerener Vorsteherin meint und die die Forschung bisher für Irminas dortige Amtsnachfolgerin gehalten hat. ${ }^{213}$ Mit dieser Anastasia tauschte Willibrord 710, so ein Urkundenregest im Liber aureus von Echternach, zwei Weinberge, die sie von Irmintrud, der Tochter des Pantin, erhalten haben will. Anastasia wird darin explizit als Oerener Äbtissin bezeichnet. ${ }^{214}$ Nach dem Teil der Irmina-Urkunde vom 1. Juli 699 (WАмрасн I 2, Nr. 6), der auf das „UrTestament" zurückgehen dürfte, war diese Irmintrud eine Base Irminas. ${ }^{215}$ Hätte aber Irmina in Willibrords Kalender eigentlich nicht viel mehr Beachtung als Anastasia verdient? Wir erinnern uns an die von Willibrord bekämpfte Pest im Trierer Nonnenkloster und daran, daß Thiofrid das Ereignis in seiner Vita sanctae Irminae zaghaft mit seiner Protagonistin Irmina in Verbindung brachte. ${ }^{216}$ Hätte dieser Bezug ursprünglich nicht ebensogut, ja noch besser auf Anastasia zutreffen können, wenn der Bericht nicht nur einfach Legende ist? Dies erklärte dann nämlich, warum Anastasia in den Kalender aufgenommen wurde.

211 Vgl. dazu Krier, Epternus, S. 38-46, sowie zur Vita Alkuins oben S. 131 f. u. Anm. 90.

212 Vgl. Wамрасн I 2, Nr. 45, S. 109. Die auf 757/8 datierende Urkunde spricht von basilica sancti Petri vel sancti Willibrordi in monasterio Epternaco. Ebd., Nr. 46, S. 109 f., von 758/9 nennt nur noch Willibrord als Heiligen. Ebd., Nr. 48, S. 113 f., von 761/2 nennt ein Kloster des hl. Willibrord und die übrigen Heiligen, ebd., Nr. 49, S. 114 f., von 767/8 wieder Petrus und Willibrord als Heilige. Die weiteren Urkunden führen dies fort, sprechen allein von Willibrord als Heiligem oder davon, daß er in Echternach begraben liege. Vgl. dazu ebd., Nr. 50 ff., S. $115 \mathrm{ff}$.

213 Vgl. The Calendar of St. Willibrord, ed. Wilson, S. 14 u. 44: anastasiae abbatissae (ebd., S. 14). Zu Anastasia vgl. auch Zimmer, Oeren, S. 45-47. Werner, Anfänge, S. 29.

214 Vgl. oben Anm. 158.

215 Vgl. dazu oben S. 153 f. u. Anm. 157 f.

216 Vgl. oben S. 151 u. Anm. 150-152. 
Daß Irmina nicht Oerens Gründerin gewesen sein kann, wie es ihre Vita und die Oerener Tradition berichten, ist seit den Arbeiten Zimmers und Werners bekannt. Doch halten beide Irmina für Oerens zweite Äbtissin. ${ }^{217}$ Wie und warum aber rief sich Irmina nach langer Zeit wieder in Erinnerung, und welche Tradition, welche Bilder herrschten währenddessen vor? Martina KNICHEL hat die einzelnen Stufen eines allmählich wachsenden Irminakultes zusammenfassend einmal genauer herausgearbeitet und dessen Dynamik nachvollziehbar gemacht. Er führt soweit, daß Irminas Gebeine im späten Mittelalter bis ins Kloster Weißenburg gelangten und dort verehrt wurden. ${ }^{218}$

Was jedoch ist über die ersten Oerener Äbtissinnen tatsächlich bekannt? Als früheste Trägerin dieses Amtes ist auf der Basis von annähernd zeitgenössischem Material eine Modesta für das Jahr 659 in den Virtutes Gertrudis am Ende des 7. Jahrhunderts überliefert. Modesta wurde im Trier des 9. und in der Mitte des 10. Jahrhunderts ohne Erwähnung irgendeiner Irmina als Heilige verehrt. Doch bleibt diese Gestalt wegen der hagiographischen Überlieferung legendenhaft. ${ }^{219}$ Irmina erscheint dann ganz plötzlich am Ende des 10. Jahrhunderts direkt neben Modesta im sog. Trierer Egbert-Psalter in einer Heiligenlitanei, die mit wenig Verzögerung nachgetragen wurde, unter den virgines. ${ }^{220}$ Wohl aus der-

217 Vgl. Zimmer, Oeren, S. 13-15, 28-45. Werner, Anfänge, bes. S. 13-15, 48 f.

218 Vgl. Knichel, Irmina, S. 191 f., mit der Weißenburger Tradition, auf deren spätere Entstehung auch schon Werner, Adelsfamilien, S. 49-60, hingewiesen hat. KNICHEL, Trier (-Oeren), St. Irminen, S. 939 ff., hat zuletzt die Forschungsliteratur zur Gründung Oerens nochmals zusammengefaßt. Vgl. dazu auch die frühen Ausführungen bei Brower/Masen, Metropolis ecclesiae Trevericae, quae metropolitanae ecclesiae originem, jura, decus, officia 1, ed. von Stramberg, S. $556 \mathrm{ff}$.

219 Vgl. dazu die Ende des 7. Jahrhunderts entstandenen Virtutes Gertrudis cap. 2, ed. Krusch, S. 465. Sie sprechen von einer Äbtissin eines Trierer Marienklosters namens Modesta, der die sterbende Gertrud von Nivelles im Traum erschienen sei. Zu den Virtutes vgl. auch Zimmer, Oeren, S. 19 u. Anm. 40-42. Fouracre, Merovingian Hagiography, S. 6 f. u. Anm. 10, hält bei unklaren Erzählungen eine metaphorische Lesart für dringend geboten, auch für die Virtutes. - Zur frühen Verehrung der Modesta in Trier vgl. Zimmer, Oeren, S. 20-28. Knichel, Irmina, S. 185. Werner, Anfänge, S. 1 f., $14-18,27-36,39-42$, bes. S. 15 f. u. Anm. 59. Ältestes Zeugnis für ihre Verehrung sei eine St. Maximiner Litanei des 9. Jahrhunderts im sog. Maximiner Psalter, die Modesta neben anderen Lokalheiligen Triers aufführt. Modesta habe zudem auch zum Konvent von Remirement gehört, wo unter den vor 817 verstorbenen Schwestern auch eine Modesta im Memorialbuch eingetragen sei (ebd., S. 31 f.). Vgl. zur St. Maximiner Litanei Coens, Recueil, S. 213-215, Nr. 10, hier S. 215. Neben Modesta tauchen dort schon Anastasia und selbst Willibrord auf, nur Irmina fehlt. Selbst die spätere Äbtissin Basilissa erscheint. Vgl. BöHne, Erzbischof Egbert, S. 108. - In einer St. Maximiner Weihenotiz eines Altars hl. Jungfrauen von 952 findet sich wieder Modesta, jedoch noch keine Irmina. Vgl. dazu Notae dedicationum s. Maximini Treverensis, ed. SAUERLAND, S. 1271, Z. 7: [...], sanctae Walgisgae, sanctae Modestae, sanctae Brigidae, [...].

220 Zur Litanei des Egbert-Psalters vgl. Sauerland/Haseloff, Psalter, S. 10-15 u. 192. Der Name Willibrords erscheint auch, allerdings unmittelbar nach den Trierer Bischö- 
selben Zeit und vielleicht dem Umkreis Erzbischof Egberts (977-993) findet sich ein Trierer Nachtrag im Kalender eines Sakramentars der Kölner Dombibliothek des ausgehenden 10. Jahrhunderts, der zum 24. Dezember den Geburtstag einer hl. Jungfrau Irmina aus Oeren nennt. ${ }^{221}$ Weitere Kalendarien und Weihenotizen folgen nun. ${ }^{222}$

Einiges deutet darauf hin, daß Irmina im Kontext des Streits von Oeren mit dem Trierer Erzstift um seine Reichsunmittelbarkeit auftaucht, der unter Erzbischof Egbert einen Höhepunkt erreichte. ${ }^{223}$ Doch sah dieser Konflikt anders aus und dauerte länger, als die Forschung bisher geglaubt hat. Theo KöLzer hat das nachgewiesen. ${ }^{224}$ Gemäß seinen Ergebnissen war das reichsunmittelbare Oeren durch einen Tausch mit Kaiser Otto I. (936-973) 966 an das Erzstift Trier gekommen, welches das bis dahin zu Trier gehörende Servatiusstift in Maastricht an den Kaiser gab. ${ }^{225}$ Die Oerener Nonnen versuchten, dem etwas später erfolglos mit einer Urkundenfälschung auf Otto II. (961-983) zu begegnen, in der man sich wörtlich auf eine echte ältere Besitzbestätigung Ottos I. für Oeren von 953 berief. Dieses ältere Diplom sicherte noch zu, das Kloster solle stets in königlicher Gewalt bleiben. ${ }^{226} 993$ habe Erzbischof Egbert unter Otto III. (983-1002) Oeren dann im erneuten Tausch gegen Maastricht zurückgeben müssen. Egbert sei wohl ein Verhandlungsfehler bei dem Versuch unterlaufen, zusätzlich auch St. Servatius an Trier zu ziehen. Denn eigentlich

fen. Vgl. ferner Coens, Recueil, S. 204-213, Nr. 9, hier S. 210. Die beiden werden innerhalb anderer hl. Jungfrauen genannt: Savina, Irmina, Modesta, Waldpurga.

221 Vgl. Köln, Dombibliothek, 88, fol. 8v : Eod. d. Nat. s. yrmine virg. horreacs. eclę. (oder horrea cs. eclę.). Die Kürzungen sind hier beibehalten. Der Kalender befindet sich auf fol. $3^{\mathrm{r}}-8^{\mathrm{v}}$. Vgl. zur Handschrift und dem Nachtrag Irminas Hoffmann, Buchkunst 1, S. 156-158, bes. S. 157 f., sowie ausführlich den Kommentar zur digitalisierten Handschrift unter http://www.ceec.uni-koeln.de [01.06.2005]. Der Nachtrag könnte im Zusammenhang der Schreiber des Egbert-Kodex' stehen. BöHnE, Erzbischof Egbert, S. 102 f., 106-108, glaubt aufgrund noch weiterer Nachträge von Trierer Bischöfen, die Zeit Egberts zu erkennen. Er sieht sogar diesen Irmina-Eintrag als Versuch, Trierer Besitzansprüche auf Oeren zu erheben. Vgl. dazu auch noch genauer unten Anm. 559 u. Kap. D.VI.3.b.

$222 \mathrm{Zu}$ den weiteren Litaneien vgl. Werner, Anfänge, S. 17, mit den entsprechenden Nachweisen. Miesges, Festkalender, S. 112 f. u. Anm. 2, der nur auf Sauerland verweist.

223 Vgl. dazu unten Anm. 230 u. 238.

224 Vgl. KöLzer, Studien, S. 118-149. Er gelangt zu dieser Sichtweise, weil er die auf Egbert ausgestellte Restitutionsurkunde Oerens an Trier vom 30. Mai 1000 (DOIII. $\nmid 368$, S. 796 f.) u. a. aufgrund paläographischer Überlegungen als Fälschung aus der Zeit von um 1065 nachweisen kann (ebd., S. 118-121, 132-137).

225 Vgl. DOI. 322, S. $436 \mathrm{f}$.

226 Vgl. DOII. †55, S. 65 f. Vgl. dazu KöLzer, Studien, S. 122-126, der es eine „Teilrevision" nennt. Er betont die Konzeption der Fälschung anhand des für Oeren als Besitzbestätigung von Otto I. ausgestellten echten DOI. 168, S. 249 f., von 953. 
habe er beide Klöster für das Erzstift beansprucht. ${ }^{227} 997$ wurde Oeren wieder reichsunmittelbar. ${ }^{228}$ Erst zu Beginn der Regierungszeit Heinrichs III. (nach 1039-1056) sei dies alles wieder im Wechsel mit St. Servatius in Maastricht rückgängig gemacht worden. Oeren sei erneut an Trier und St. Servatius an das Reich gegangen. ${ }^{229}$

Die Oerener Nonnen könnten als Argument für Oerens Reichsunmittelbarkeit die Tradition einer Klostergründerin konstruiert haben, die eine Tochter König Dagoberts I. (ca. 608-638/9) und seiner Frau Nanthild war, eine Königstochter also. Irmina firmiert zudem als Witwe eines gallischen Grafen Hermann. Die von ihm geerbten Güter habe sie an Oeren gegeben. ${ }^{230}$ Wann genau diese Fama entstand, ist schwer zu bestimmen. Eine dem Trierer Erzstift nahestehende Überlieferung, die Oeren zumindest als Gründung der Zeit Dagoberts nennt, ist im frühen 11. Jahrhundert greifbar. ${ }^{231}$ Erst in der Vita sanctae Irminae Thiofrids von Echternach (vor 1081) sowie im dazu zeitnahen Libellus de rebus Treverensibus (drittes Viertel des 11. Jahrhunderts) läßt sich die Oerener Tradition zum ersten Mal schriftlich greifen. Der Libellus dürfte sogar nach der Vita entstanden sein. Ob er sie direkt benutzte, ist umstritten. Im Libellus wird Irmina jedenfalls ergänzend zur Vita auch noch als Schwester einer Attala genannt, die vermutlich das Kloster Pfalzel gründete. Irmina sei ferner - so der Libellus - der schon ausführlicher behandelten Modesta in Oeren als Äbtissin vorausgegangen. ${ }^{232}$ Irmina sollte damit also vor die ältere Modestatradition in Oeren gerückt werden.

227 Vgl. dazu DOIII. 119, S. 530-532, vom 18. Juni 993. Vgl. dazu Kölzer, Studien, S. $126-130$.

228 Vgl. De rebus Treverensibus saec. VIII-X libellus cap. 14, ed. WAitz, S. 104 f. Vgl. dazu Kölzer, Studien, S. 130-132.

229 Vgl. dazu abschließend die ausführliche Argumentation bei Kölzer, Studien, S. $132-$ 137.

230 Vgl. dazu Werner, Anfänge, S. 25 f.

231 Vgl. Theoderich, Miracula S. Celsi, ed. Waitz, S. 207: Est namque in eadem Treverica urbe quoddam monasterium situm, quod antiquitus Horrei vocabulum accepit, reginae coeli consecratum; in quo a tempore orthodoxi regis Dagoberti sanctimoniales semper feminae Deo consueverant devotius deservire. Vgl. dazu auch KöLzer, Studien, S. $256 \mathrm{f}$.

232 Vgl. dazu erstmals Thiofrid, Vita sanctae Irminae, ed. Weiland, S. 48-50, bes. cap. 1-4, S. 48 f. Zur Vita vgl. oben S. 132 u. Anm. 91. Vgl. ferner De rebus Treverensibus saec. VIII-X libellus cap. 12 f., ed. Wartz, S. 104. Der Libellus gibt auch die einzelnen Stufen des Streits zwischen dem Erzstift Trier und dem Kloster Oeren wieder, indem er die relevanten Urkunden zitiert. Er beendet den Streit aber mit dem gefälschten DOIII. $\dagger 368$ von angeblich 1000 . Der Libellus nennt allerdings Hermann nicht. - Die Entstehungszeit des Libellus' war lange Zeit umstritten und wurde im frühen und späten 11. Jahrhundert angesetzt. Gleiches galt für seine Abhängigkeit von der Irmina-Vita, deren inhaltliche Parallelen sich nicht leugnen lassen. Vgl. dazu nur zusammenfassend Werner, Anfänge, S. 10-13, bes. S. 12. Werner, Adelsfamilien, S. 180, vermutet endlich eine Verwendung der Vita durch den Libellus. - In die Vita sanctae Irminae (vor 
Im frühen 12. Jahrhundert nahm eine in Oeren konstruierte Schenkung auf König Dagobert II. (675-679) das Bild der Dagoberttochter dann nochmals, aber schon leicht mißinterpretierend, wieder auf. Das Diplom datiert vorgeblich auf den 26. August 646 und überträgt Besitzungen an Oeren (DMerowinger 1 $\dagger 65){ }^{233}$ Vielleicht bemerkte man im Kloster die unglaubwürdige temporäre Diskrepanz der Oerener und Echternacher Irmina und entschied sich jetzt für Dagobert II. statt Dagobert I. als Vater, um dies stimmiger zu machen. Irmina

1081) wird Nanthild als Mutter Irminas nämlich erst vom Mönch Theoderich (1191/2) in der Vitenfassung des Liber aureus nachgetragen, wie schon $\mathrm{KRUSCH}$, Reise nach Frankreich, S. 620 f., zeigte. Im Libellus wird Nanthild also im Gegensatz zur Ur-Fassung der Vita sanctae Irminae genannt. - Kölzer, Studien, S. 252-260, weist schließlich insgesamt darauf hin, daß die älteste Handschrift des Libellus' zwar aus dem erzbischöflichen Trierer Kloster St. Eucharius stammt, die Handschrift aber von Oerener Nonnen verfaßt wurde. Der Libellus verfüge über zwei Teile. Cap. 1-10 widmen sich der Trierer Frühzeit unter Karl Martell, Milo und Bonifatius, während cap. 11-18 die Nonnenklöster Oeren und Pfalzel in den Blick nehmen. Da der Libellus das um 1065 gefälschte DOIII. $\$ 368$ verwende, könne er erst danach entstanden sein. Er folgt dabei Poensgen (Geschichtskonstruktionen, S. 95 ff.), die einen erzbischöflichen Bezug des Werkes sieht. Dieser erkläre sich auch aufgrund der Vielfalt der zitierten Quellen. - Vgl. zur Verwendung Dagoberts allgemein und in Trier WehrLI, Überlieferungen von Dagobert, S. 154, 157-159, 161 (zu Adela von Pfalzel und Irmina), 211 f. (Irmina), 215217 (Irmina, Adela, Chlothilde), 292-301 (Trier). - Ob das Verhältnis zwischen Irmina und Adela von Pfalzel tatsächlich auf einer noch erhaltenen Oerener Tradition beruhte, wie ein Teil der Forschung annimmt, oder erst hier ausformuliert wurde, läßt sich schwerlich sagen. Vgl. dazu nur die vielfältigen Überlegungen zur „Hugobert-IrminaSippe“ oben S. 129 f. u. Anm. 83-85, sowie Werner, Anfänge, S. 15 ff., zu einer möglichen Oerener Tradition. Vgl. zu Adela zuletzt und ausführlich die Forschung diskutierend Werner, Adelsfamilien, S. 176-325, der sich ausgesprochen kritisch zu einer möglichen Verwandtschaft Adelas mit Irmina äußert; zur „Hugobert-IrminaSippe“ vgl. ebd., S. 25-34. Zusammenfassend vgl. auch KöLzer, Studien, S. 256 f.

233 Vgl. MRUB I 7, S. 8 f. Diplomata spuria †52, ed. Pertz, S. 169 f. DMerowinger I $† 65$, S. 163-166. Wамрасн I 1, S. 115 f. Es handelt sich um eine ein Original fingierende Fälschung. Eigentlicher Sinn der Urkunde scheint es aber zu sein, darin einzeln aufgeführten Landbesitz zu sichern. - Ob Urkunde oder Libellus zuerst entstanden, war zunächst noch umstritten. Vgl. dazu Zimmer, Oeren, S. 18 f. Werner, Anfänge, S. 5 f. Schieffer datierte sie in seinen Vorbemerkungen zu DLdK $† 80$, S. 219, aber schon ins späte 11. bzw. frühe 12. Jahrhundert, was KöLzer, Studien, S. 138-141, 144 f., aufgrund des paläographischen Befundes schließlich auf das frühe 12. Jahrhundert präzisierte (ebd., S. 139). Es handelt sich bei der Urkunde um zwei Nachzeichnungen, deren Abbildungen sich bei KöLzer, Studien, Taf. 28 f., finden. - Das in unmittelbarer zeitlicher Nähe entstandene und gefälschte DLdK †80, S. 218-221, das KöLzer, Studien, S. 135 f., 138-145 u. Taf. 30, überzeugend ins beginnende 12. Jahrhundert setzt, verbindet zudem die Äbtissin Anastasia mit Ludwig dem Kind und Erzbischof Radbod von Trier (883-915). Das ist natürlich völlig unmöglich, zeigt aber, daß man in Oeren die noch bekannten eigenen Äbtissinnen kaum mehr zeitlich korrekt einzuordnen verstand. 
hatte Modesta jedenfalls inzwischen an Bedeutung übertroffen, obwohl Irminas liturgische Verehrung jünger war. ${ }^{234}$

Für das Trierer Erzstift findet sich bereits zuvor eine Gegentradition über die Gründung Oerens in einer auf König Zwentibold (895-900) datierenden Urkunde, die aber frühestens 993 unter Erzbischof Egbert oder seinem Nachfolger Liudolf (994-1008) gefälscht wurde. Sie nennt den Trierer Bischof Modoald (nach 614/626/7-vor 646/7?) als Gründer Oerens auf Trierer Besitz. ${ }^{235}$ In späteren Verformungsstufen dieses Bildes, die die Gesta Treverorum seit 1101 sukzessive in ihren verschiedenen Redaktionen bieten, agiert Modoald sogar gemeinsam mit König Dagobert. Modesta firmiert dann einmal als Tochter Dagoberts sowie gemeinsam neben ihrer „Schwester“ Irmina als Äbtissin Oerens, endlich als Modoalds Nichte und Mitgründerin Oerens. ${ }^{236}$ Die Bilder gerieten in einen schnellen und variablen Fluß.

Vielleicht reagierte man beim Erzstift schon früh auf die Oerener Irminabilder, nahm sie auf und entgegnete mit der eigenen Überlieferung zu Oeren. Die erst später auftretenden Irminatexte legen jedoch genau den umgekehrten Weg nahe, den auch KöLzer annimmt: Die Irmina-Gründerlegende für Oeren habe sich erst im „mittleren Drittel“ des 11. Jahrhunderts ausgeformt. ${ }^{237}$ Die jeweiligen Traditionen sollten die jeweiligen Ansprüche auf das Kloster als

234 Vgl. Knichel, Irmina, S. 186.

235 DZw. †4, S. 22-25, hier S. 24 f.: [...] inter cetera monasterium sanctae Mariae, quod domnus Modoaldus eiusdem urbis praesul magnificus in territorio sancti Petri a fundamento construxerat, vocatum Orrea sub iure et potestate sancti Petri Treuerensis ecclesiae eiusdemque pontificis per regum praedecessorum videlicet nostrorum sub perpetuae stabilitatis munificentiam mancipatum ac confirmatum. Quae olim quoque patri nostro venerande memoriae Arnulfo restituenda nec ne roboranda petiit, quia per incuriam quorundam antecessorum suorum violata perstiterant. Vgl. dazu KöLzer, Studien, S. 128-130, 147 f. Schieffer, Lothringische Kanzlei, S. 80-92. Doch nicht nur die Urkunde Zwentibolds enthält dieses Bild, sondern auch zwei zeitgleich mit ihr entstandene Diplome: DDKarol. I †36, $\dagger 226$. Es handelt sich bei ihnen um eine manipulierte Urkunde Pippins von 760 für Bischof Weomad von Trier (762-791) sowie eine Karls des Großen ebenso für Weomad von 774 . Vgl. zu dieser Urkundengruppe und deren Entstehung auch noch ausführlicher unten Kap. D.IV.1., bes. ab Anm. 325 ff., sowie S. 204 f. u. Anm. 335, schließlich Anm. 391, 436, 487. Zu Modoald vgl. WinhelLER, Lebensbeschreibungen, S. $145-$ 158. Werner, Anfänge, S. 36-39, 50. Werner, Verwandtschaft. Gauthier, Évangélisation, S. 347-356, mit den wenigen Quellen. AnTon, Trier im frühen Mittelalter, S. 143-149. Doch verdient deren Darstellung nochmals eine Überprüfung. - Vgl. in diesem Zusammenhang zu Oeren auch Germ. Pont. 10, ed. Boshof, S. $169 \mathrm{ff}$.

236 Vgl. Gesta Treverorum cap. 24, ed. Wartz, S. 160. Zur Dagoberttradition in Verbindung mit Modoald vgl. auch WehrLI, Überlieferungen von Dagobert, S. 228-230.

237 Vgl. Kölzer, Studien, S. 257. Werner, Anfänge, S. 13, plädiert für ein Aufkommen der Gründungstradition in Oeren. 
reichsunmittelbar oder Besitz des Erzstiftes unterstreichen und in die Vergangenheit zurückprojizieren. ${ }^{238}$

Doch verbindet weder der Libellus noch die im frühen 12. Jahrhundert gefälschte Oerener Dagobert-Urkunde (DMerowinger 1 †65) Irmina mit Echternach. Sie ist allein Tochter Dagoberts. Lediglich Thiofrid stellte diese Verbindung erstmals nachweisbar in seiner Vita sanctae Irminae (vor 1081) her, wie wir oben gesehen haben. Ja, man könnte meinen, er interpretierte die Schenkung einer Irmina an das Kloster in Echternach, die ihm in deren oben nachgewiesenem "Ur-Testament" vorlag, als den konsequent zu folgernden Dank dafür, daß Willibrord ein Trierer Nonnenkloster von der Pest errettete. Davon berichtet nämlich nebulös Alkuins Willibrord-Vita (zwischen 785 und 797). Dieses Kloster deutet Thiofrid rund 300 Jahre später wohl als Oeren. In seiner späteren Willibrord-Vita (1103/4) nahm er diese Konstruktion erneut auf. ${ }^{239}$ So läßt sich dem Eindruck nicht wehren, daß Thiofrid die ihm bekannte Oerener Dagobert-Irmina-Traditon aufgriff und sie erstmals mit seinen Echternacher Materialien (dem „Ur-Testament" Irminas und der Willibrord-Vita Alkuins) verband. Er vollzog eine Analogiebildung beider Irminas. Wäre er jedoch der Logik seiner Vorlagen gefolgt, hätte ihm auffallen müssen, daß eine Tochter Dagoberts I. (ca.608-638/9) kaum noch eine Zeitgenössin Willibrords gewesen sein konnte. Als Echternacher Klostergründerin sah Thiofrid Irmina dagegen nicht. Das Kloster hatte nach seinem Dafürhalten der hl. Willibrord selbst errichtet. ${ }^{240}$ Vom Bild des Liber aureus (1191/2), nach dem Irmina dann das Kloster Echternach erbaute, findet sich bei Thiofrid noch keine Spur.

Thiofrids Vita sanctae Irminae scheint keine starke Wirkung entfaltet zu haben, wie sich an der Handschriftenverbreitung erkennen läßt. Neben der Fassung im Goldenen Buch Echternachs ist gerade noch ein zweiter Text in einer Pariser Handschrift aus dem 13. Jahrhundert mit dem Januarband des großen Trierer Legendariums auf uns gekommen. Die Vita fügte man jedoch erst im 15. Jahrhundert hinzu. ${ }^{241}$ In die Trierer Redaktion A der Gesta Treverorum (1101) ging beim Gründungsgeschehen Oerens das Bild einer Irmina, die Echternach und Willibrord unterstützte, in keiner Form ein. In der B-Fassung um 1132 wird jedoch plötzlich Modesta zur möglichen Schwester Willi-

238 Vgl. Werner, Anfänge, S. 19-27, der dies deutlich und überzeugend herausgearbeitet hat.

239 Vgl. dazu nochmals oben S. 151 f. u. Anm. 150-152. Knichel, Irmina, S. 187 f.

240 Vgl. dazu auch oben S. 132 f. u. Anm. 92.

241 Vgl. dazu Lampen, Thiofrid, S. 5-7. Es handelt sich um die Handschrift Paris, BN, lat. 9741 (Suppl. lat. 496), fol. 139 f. Vgl. ferner Worstвrock, Thiofrid, Sp. 803 f. 
brords. ${ }^{242}$ Dies deutet vielleicht eine erste Reaktion auf die von Thiofrid geschaffene Verbindung an.

Um es abschließend zu betonen: Für eine konkrete Gründung Oerens durch eine der genannten Personen hat sich keinerlei zeitgenössische Tradition erhalten. ${ }^{243}$ Auch über sichere Angaben zum Wirken einer Oerener Irmina verfügen wir vor dem 11. Jahrhundert nicht. Wenn es sie tatsächlich gegeben haben sollte, müssen ihre Vorgängerin Modesta und Nachfolgerin Anastasia um einiges bedeutender gewesen sein als sie. Sonst hätte man sich nicht noch an diese erinnert, während Irmina zunächst aus dem kulturellen Gedächtnis verschwand.

Worauf gründete der Kern der neuen Irminaüberlieferung in Oeren? WerNER will seinen Ursprung in den Echternacher Irmina-Urkunden erkennen. ${ }^{244}$ Deren oben vorgenommene Analyse hat aber ergeben, daß Ende des 10. Jahrhunderts wahrscheinlich nur das „Ur-Testament“ einer Irmina (WАмpACH I 2, Nr. $4+2$. Teil von $\mathrm{Nr}$. 6) sowie vielleicht noch eine Urkunde der Nonne Ymena oder ein Regest von dieser (Waмpach I 2, Nr. 12*) existierten. Brachten Trierer Bischöfe wie Hetti (814/6-847) oder Radbod (883-915), die in Echternach auch zeitweise als Äbte fungierten, das Wissen darum mit nach Trier? ${ }^{245}$ Hatte die Oerener Irmina womöglich einen ganz anderen Ursprung, vielleicht im wiedergefundenen Grab einer dort bestatteten Nonne? Oder bietet die Geschichte um die Tochter König Dagoberts, die auch Witwe des gallischen Grafen Hermann gewesen sein soll, ein Indiz dafür, daß man in Trier noch über andere Quellen verfügte? Wir wissen es nicht. An kaum einem anderen Ort gab es aber derart massive Dagoberttraditionen wie im Trier dieser Zeit. Das legt

242 Vgl. Gesta Treverorum cap. 24, ed. WAitz, S. 160, mit den entsprechenden Anmerkungen.

243 Oeren könnte mit einiger Wahrscheinlichkeit als ein Eigenkloster entstanden sein, das bald reichsunmittelbar wurde. Doch bleibt das nur Vermutung. Vgl. dazu EwIG, Trier, S. 120. Werner, Adelsfamilien, S. 39 f. Werner, Anfänge, S. 42-48, hält eine Gründung unter Modoalds Nachfolger Numerian für denkbar. Vgl. ferner Gauthier, Évangélisation, S. 291 f., 353. Anton, Trier im frühen Mittelalter, S. 148, 152. KNICHEL, Irmina, S. 185. Sie gehen ebenso eher von Numerian aus.

244 Vgl. Werner, Anfänge, S. $18 \mathrm{f}$.

245 Vgl. dazu die Echternacher Abtlisten in: Catalogi abbatum Epternacensium, ed. Wartz, S. $738-742$, bes. S. 738 , Z. 33 f. (zu Hetti), S. 741, Z. 7-9, 25-27 (zu Hetti und Radbod). Radbod findet sich erst in der zweiten Abtliste aus der Mitte des 12. Jahrhunderts. Radbod sei für vier Jahre Abt gewesen, vom fünften Regierungsjahr Kaiser Arnulfs bis zum ersten Jahr König Zwentibolds 898. Vgl. dazu auch die jüngere und auf jüngeren Handschriften basierende Edition Catalogus abbatum Epternacensium I u. II, ed. Weiland, S. 20, 30-38. Zu Hetti und Radbod vgl. zuletzt auch Anton, Trier im frühen Mittelalter, S. 167-171, 175-178, 199-201, 204-207. Anton, Trier in der hohen und späten Karolingerzeit, S. 72-75, 80-83, 86, 97-101, 103-105, 107, 109, 112 f., 116. Aspner, Hoch- und spätkarolingische Zeit, S. 261-266, 276 ff. Zu den beiden vgl. auch Goerz, Regesten der Erzbischöfe von Trier, S. 1-3. Zu Hetti vgl. zudem Depreux, Prosopographie, Nr. 150, S. 244-246. 
den Verdacht nahe, daß solches Dagobertisches Traditionsgut in irgendeiner Form im kulturellen Gedächtnis existiert haben könnte, auf das man sich bezog. ${ }^{246}$ Eine völlig freie Erfindung scheint unwahrscheinlich.

Kommen wir nun wieder zurück zu den Trierer Bischöfen Basin und Liutwin. Für sie hat das erhebliche Konsequenzen. Denn erst durch das erstarkte Oerener Irminabild des 11. Jahrhunderts, das Thiofrid dann mit dem der Echternacher Irmina verband, bot sich dieses neue Irminabild als Fundament an, auf das sich bauen und mit dem sich weitere einschlägige Personen der Trierer Geschichte verbinden ließen. Deshalb fand der seit dem ausgehenden 10. Jahrhundert in Trier als heilig verehrte Bischof Liutwin seinen späten Platz in den Irmina-Urkunden neben dem farblosen Basin, um ein noch stärkeres und überzeugenderes neues Echternacher Bild davon zu schaffen, wie dieses Kloster einmal entstanden war.

\section{Ergebnis}

Die Analyse der Irmina-Urkunden sowie der Irminatradition ergibt ein völlig neues Bild zu Irmina und damit auch zu den mit ihr bisher in Verbindung gebrachten Bischöfen Basin und Liutwin (vgl. dazu auch das ausführliche Schaubild im Anhang).

Die einzige alte und zunächst nachweisbare Irmina-Urkunde ist das „UrTestament" einer Irmina, die vermutlich nur eine einfache Nonne war, vom 1. Dezember 697/8. Es findet sich belegt bei Abt Thiofrid von Echternach (1083-1110). Der Liber aureus (1191/2) gibt es allerdings nicht mehr in seiner ursprünglichen Form wieder. Irmina übertrug darin vielmehr noch ihren Teil an Echternach sowie zudem die Villa Berg an das dortige Kloster unter Willibrord (Wampach I 2, Nr. $4+2$. Teil von Nr. 6). Als Zeugen unterzeichneten darin u. a. ein Bischof Basin und mit ihm ein presbiter Liutwin.

Mit der in Trier im 11. Jahrhundert allmählich aufkommenden Tradition einer Gründung Oerens, die durch König Dagoberts I. (†638/9) Tochter Irmina erfolgt sein sollte, setzte eine neue Dynamik ein. Thiofrid von Echternach verband erstmals in seiner Vita sanctae Irminae (vor 1081) die Irmina des „UrTestaments", das ihm noch vorlag, mit der Oerener Irminaüberlieferung. Eine legendenhafte Szene aus Alkuins Willibrord-Vita (785/97), in der Willibrord

246 Zur auffällig stark ausgeprägten Trierer Dagoberttradition vgl. nochmals WeHrLI, Überlieferungen von Dagobert, S. 292-301. Es gibt auch eine Dagobertüberlieferung, die Liutwin mit Dagoberts Hof verbindet (ebd., S. 222), doch findet sich die erst bei Coccius, Dagobert, S. 210, im frühen 17. Jahrhundert in Trier. Dort ist ein Lutwin genannt, ein „Heiliger zur Zeit von Dagobert, ein austrasischer ,princeps`, der ins Kloster eingetreten sei." Doch könnte Liutwin erst nachträglich mit Dagobert in Verbindung gebracht worden sein. Vielleicht mißverstand Coccius auch seine Quellen. 
ein Trierer Nonnenkloster von einer Pest befreite, legte für Thiofrid diese Analogiebildung nahe. Von nun an entfaltete sein geschöpftes neues Irminabild langsam und vor allem in Echternach seine Wirkraft. Doch noch im frühen 12. Jahrhundert betrachtete man dort Willibrord allein als Klostergründer.

Erst etwa in der Mitte des 12. Jahrhunderts bediente man sich in Echternach dann dieses neuen Irminabildes, um den Klosterbesitz in Steinheim gegen Verluste zu sichern. Denn Luxemburger Grafen, die als Echternacher Vögte wirkten, vergaben Klostergüter als Lehen. Auf diese Irmina wurde jetzt (vielleicht schon als Äbtissin) eine Schenkung über diesen Ort gefälscht: die erste Stufe der Urkunde vom 8. Mai 704 (WАмpach I 2, Nr. 9). Ursprünglich muß Steinheim aber eine Karolingergabe gewesen sein, wie sich aus Einträgen im Liber aureus erschließen läßt. Als Formularvorlage für die Fälschung kamen das "Ur-Testament" - u.a. mit einem Teil der dortigen Zeugen - sowie eine zweite Urkunde zum Einsatz (WАмрасн I 2, Nr. 10): eine noch in ihrer Urfassung vorliegende Weinberg-Schenkung vom 8. Mai 704, die jedoch zunächst nicht von Irmina, sondern der darin genannten Nonne Engela getätigt wurde. Der Fälscher könnte der noch junge Mönch Theoderich gewesen sein, der bald den Liber aureus bearbeitete. Etwas später wurde dieses Stück dann ebenfalls zu einer Irmina-Urkunde umkonstruiert. Dabei erhielt Warenbert, der Schreiber der Engela-Urkunde, noch Huncio als Vorgesetzten interpoliert. So wurde der Inhalt des ursprünglichen Originals nicht aufgegeben, sondern behutsam in den neuen Irmina-Rahmen eingepaßt. Wohl deshalb blieb auch die kurze alte Zeugenliste erhalten. Den Anstoß für die Konstruktion (Wамрасн I 2, Nr. 9) bzw. Umwidmung (WАмрасн I 2, Nr. 10) der beiden Urkunden von 704 in Irmina-Schenkungen mag das Ymena-Regest von 704 gegeben haben (WAMрасн I 2, Nr. 12*). Die Nonne Ymena schenkt darin gemeinsam mit ihren Töchtern Attala und Crodelindis an Echternach.

Spätestens als der Trierer Erzbischof Johannes I. (1189-1212) Echternach 1192 ans Erzstift zu ziehen versuchte und dies mithilfe des Liber aureus abgewehrt werden sollte, konstruierte dessen Verfasser Theoderich ein noch umfangreicheres Irminabild: Er machte Irmina anstelle Willibrords zur Gründerin bzw. Erbauerin des Klosters und zur Schenkerin mehrerer dort gelegener Kirchen. Dazu fälschte Theoderich anhand des „Ur-Testaments“ eine diesem vorausgehende Urkunde auf den 1. November 697/8 (WАмрасн I 2, Nr. 3), die dieses neue Bild beinhaltete. Darin ließ er Irmina zudem auf Bitten von Trierer Bischöfen handeln: Basin und Liutwin nämlich, wobei man Liutwin erst seit dem späten 10. bzw. frühen 11. Jahrhundert aus Viten als heiligen Bischof kennen konnte. Diese beiden Bischöfe sollten deutlich zeigen, daß die Ansprüche, die ihr Nachfolger auf Echternach erhob, völlig unberechtigt waren.

Um Irminas neue Rolle weiter zu betonen, nahm Theoderich auch die Schenkung Bergs aus dem „Ur-Testament“ heraus und verband sie mit der erfundenen Stiftung einer liturgischen Ausstattung zur Urkunde vom 1. Juli 699 
(Wampach I 2, Nr. 6). Für deren formalen Rahmen zog er die bereits vorhandene ältere Irmina-Fälschung zu Steinheim (Wampach I 2, Nr. 9) in ihrer ersten Stufe als Vorlage heran sowie die Engela-Schenkung, die inzwischen vielleicht schon zu einer Irmina-Urkunde umkonstruiert worden war (WAMPACH I 2, Nr. 10).

Abgesehen vom verbliebenen Rest des „Ur-Testaments“ (WАмрасн I 2, Nr. 4) paßte Theoderich die Irmina-Urkunden nun noch an das neue Bild der Klostergründerin durch entsprechende Interpolationen an. WАмрасн I 2, Nr. 3 , 4 u. 6 erhielten dazu durchgehend die Bischöfe Basin und Liutwin als gemeinsame Zeugen. Nur bei den beiden früher entstandenen Irmina-Konstrukten (Wampach I 2, Nr. 9 u. 10) ließ Theoderich die Zeugenlisten unberührt. Vielleicht erschienen sie ihm authentisch genug, zumal sie einige Jahre nach der Gründung datierten. Das Ymena-Regest von 704 wußte Theoderich entweder nicht genau einzuordnen, oder er ließ es absichtlich beiseite, weil es Attala als Ymenas Tochter erwähnt. Das widersprach nämlich dem Bild, das in Trier im 12. Jahrhundert vorherrschte, nach dem Attala Irminas Schwester war.

Woher die plötzlich aufkommende Oerener Irminatradition rührte, muß hier nicht geklärt werden. Wichtig ist vielmehr, daß sich im Echternacher Umfeld für die Zeit um 700 ein Bischof Basin nachweisen läßt. Ein Bischof Liutwin dagegen kann erst in die Irmina-Urkunden interpoliert worden sein, als der Liber aureus 1191/2 in Echternach angelegt wurde. Einiges spricht immerhin dafür, daß ein presbiter Liutwin im frühen 8. Jahrhundert in Trier wirkte (vgl. die Zeugenliste in WАмрасн I 2, Nr. 9). Dieser Priester widerspricht aber dem Bild, das die schon erwähnten Liutwin-Viten von ihrem Protagonisten entwerfen. Die Irmina-Urkunden bieten also keinerlei Belege für die Existenz eines Trierer Bischofs Liutwin im frühen 8. Jahrhundert. ${ }^{247}$

\section{Liutwin und Basin in der weiteren Überlieferung zum 8. Jahrhundert}

\section{Die Urkunden Liutwins aus dem 12. Herrschaftsjahr König Childeberts}

Deutliche formale Übereinstimmungen mit den Irmina-Urkunden weist die schon deshalb verdächtige Schenkung der Villa Stain (Étain bei Verdun) durch den Trierer Erzbischof Liutwin am 1. Februar des 12. Herrschaftsjahrs König Childeberts (III., 678/9-711) (706) auf, die er an das südlich vor Trier gelegene

247 Der Verfasser plant, noch einmal gesondert die Genese bzw. den Konstruktionsprozeß der Irmina-Urkunden ausgehend vom echten „Ur-Testament“ zu beschreiben. Dabei soll auch die im folgenden Kapitel behandelte, vermeintliche Liutwin-Urkunde von 706 (MRUB I 7a) berücksichtigt werden. 
Kloster St. Eucharius richtete (MRUB I 7a). Die Forschung hat darin einen eindeutigen Bezug erkannt. Zwar sei die Urkunde in einigen Punkten verfälscht, doch verfüge sie über einen glaubwürdigen echten Kern. ${ }^{248}$ Da die Analyse der Irmina-Urkunden jedoch gezeigt hat, daß die meisten von ihnen gefälscht sind, läßt es sich nicht vermeiden, auch diese Urkunde nochmals kritisch zu prüfen. Dazu muß eine weitere Liutwin-Urkunde herangezogen werden, die als Regest in den schon erwähnten Miracula s. Liutwini zu finden ist. Sie wird gleich behandelt. Doch zunächst zum Inhalt von MRUB I 7a (vgl. dazu auch das Schaubild im Anhang).

Im Namen der Hl. und unteilbaren Dreifaltigkeit will die Urkunde ausgestellt sein. Liutwin, von Gottes Gnaden Trierer Erzbischof, macht eine Schenkung an das Kloster des hl. Eucharius in der Trierer Vorstadt zum Unterhalt der dort Gott dienenden Brüder. Dabei handelt es sich um die Villa Stain mit einem genau beschriebenen Bannbezirk: zum einen Teil bis Longeau, zum anderen bis Alehne, zum dritten bis Herméville, zum vierten bis Warcq im Gau Uufranse. Aus väterlichem Erbe sei das auf ihn gekommen. Dies überträgt er mit Häusern, Gebäuden, Mansen etc. - hier übernimmt der Text das gängige Formular - für immer an das Kloster St. Eucharius. ${ }^{249}$ Dergestalt solle es geschehen, daß welchen Teil des Klosters auch immer man davon zu nehmen beschließe, man es im ganzen in freier und dauerhafter Herrschaft halten möge. Es folgen die Poenformel und als Schluß:

Actum publice Treueris sub die Kal. Febr. anno. XII. regni domni Childeberti regis. Ego Uuarembertus presbiter iubente domno meo Leodeano archiepiscopo. et ex permissa seniae meo [sic!] Hunione presbitero et admanuense. hanc donationem prescripsi et ipse manu propria subtus roboraui. Ego Leodoanus hanc donationem a me factam relegi et signaui. signo. Ego Bertinus signo. Uuido comes signo. Adelbertus comes signo. Ego Milo diaconus in Christi nomine signo. Ego Gansbertus in Christi nomine diaconus. s. Uualterinus diaconus. s. Maurus presbiter. s. Ego Ermiribaldus s. Bertilinus. s. Dodo in Christo nominandi. s. Ego Ruotfridus. s. Ego Hunio presbiter in Christi nomine et admanuens scripsi et roboraui. ${ }^{250}$

248 Vgl. die Forschung unten S. 184 ff. u. Anm. 251-260.

249 Zum Formular vgl. oben S. 169 u. Anm. 204.

$250 \mathrm{Vgl}$. MRUB I 7a, S. 9 f.: In nomine sanctae et indiuiduae trinitatis. ego Leodoinus dei gratia Treuirorum archiepiscopus. dono ad monasterium s. Eucharii. quod est situm in suburbio treuirensi ad uictum fratrum ibidem deo seruientium donatum. que esse uolo. hoc est. uillam quae nocatur Stain cum banno sibi debito ex una parte usque Longauna. ex altera parte usque Alehne. ex tercia parte usque Hermeinuille. ex quarta parte usque Uuarch sita in pago Uufranse. quae ex successione paterna mihi euenit. cum domibus. aedificiis. mansis. casis. mancipiis. ac colonibus. appendiciis. adiacentiis. terris. pratis. uineis. aquis aquarumue decursibus. et ex omnibus. scilicet peculio promiscuo utriusque sexus. genere. nacione. a die praesenti ad partem ipsius monasterii s. Eucharii trado atque transfundo a die praesenti perpetualiter possidenda. ea ratione. ut quicquid pars monasterii s. Eucharii inde facere decreuerit. liberam et firmam in omnibus habeat potestatem. Et si quis contra hanc liberam donationem uenire tentauerit. iram dei omnipotentis incurrat. et insuper inferat ad partem 
Schon Perrin schien die Urkunde 1935 verdächtig. Eine erste Fassung könne nicht vor dem 10. Jahrhundert entstanden sein, weil Originalurkunden aus St. Eucharius davor fehlten. Vielleicht habe man eine Liutwin-Urkunde aus Mettlach als Vorlage verwandt. Die Gesta episcoporum Virdunensium aus dem 10. Jahrhundert zeigten zudem, daß die Villa im 8. Jahrhundert im Besitz von Verdun gewesen sein müsse. ${ }^{251}$ OpPERMANN zweifelte an den auffällig präzisen Angaben zum Bannbezirk. Die formale Nähe zu den Irmina-Urkunden belege aber die grundsätzliche Glaubwürdigkeit. Eine Verfälschung der Urkunde dürfte im Zusammenhang mit dem Übergang der Güter in Stain an das MariaMagdalenen-Stift in Verdun 1221 entstanden sein. ${ }^{252}$ Das angebliche Original der Urkunde mit Liutwins gelbfarbenem Siegel habe sich nämlich noch $1787 \mathrm{im}$ dortigen Stiftsarchiv befunden. Allerdings wäre das Siegel dann 300 Jahre älter als das erste bekannte bischöfliche Trierer Siegel Erzbischof Egberts (977-993). Ebensowenig bieten die früheren Trierer Bischofsurkunden einen Hinweis darauf, daß sie überhaupt gesiegelt wurden. ${ }^{253}$ PArdessus edierte den Verduner Text und hing ihm ein erhaltenes Zinsverzeichnis der dazu zu erbringenden Leistungen an. ${ }^{254}$ Die Version von BEYER im Mittelrheinischen Urkundenbuch gibt eine in der Pariser Nationalbibliothek aufbewahrte Kopie des Verduner Stücks wieder. Der Subprior des Stifts fertigte sie 1787 an. Sie verweist ausdrücklich auf ein Siegel an der Vorlage. ${ }^{255}$

PAuly griff die Kritik auf und wies zudem darauf hin, daß auch der Erzbischofstitel, den Liutwin führe, für diese Zeit anachronistisch sei. Allerdings liege eine entsprechende Gegenurkunde mit weiteren Stücken, die die Besitz-

ipsius monasterii una cum socio fisco auri libras. X. argenti pondo. I. et hoc quod repetit. nullatenus ualeat emendicare. sed praesens donatio circa praefatam ecclesiam omni tempore firma stabilitate permaneat. - Die Auflösung der Ortsnamen findet sich bei Becker, St. Eucharius, S. 501.

251 Vgl. Perrin, Recherches, S. 323-338, ausführlich mit dem Gesamtkontext, älterer Literatur, Editionen sowie Angaben zum angeblichen Original und dessen neuzeitlichen Kopien. Zwar hält er auch eine doppelte Eigentümerschaft für möglich, doch ist das unwahrscheinlich. Vgl. auch die Gesta episcoporum Virdunensium cap. 10 u. 13, ed. Waitz, S. 43 f.: 10. Post hunc Bertalamius episcopus. Huius studio et industria Mactigisilus et uxor eius Hechia Tilliacum fiscum et Stagnum et Casam Petriam nostrae aecclesiae, Frumisiacam villam fratribus nostris, et alia quam plurima pro remedio animae suae dedit. (c. 710) [...] 13. Post hunc episcopatus istius aecclesiae per duodecim annos vacuus extitit. Sed quidam servus Dei Amalbertus nomine, iuxta morem illius temporis corepiscopus factus, ipsam regebat aecclesiam, et in quodam oratorio sub honore omnium apostolorum quasi solitariam vitam ducebat. Et tunc perdidit ista aecclesia Waslogium et Tilliacum et Stagnum et Merlam et Casam Petriam et alia quam plurima. Fuit enim hoc sub tempore Karoli Magni (c. 770). Zur Zeit Karls des Großen soll Verdun das Gebiet wieder verloren haben. 252 Vgl. Oppermann, Rheinische Urkundenstudien 2, S. 260.

253 Vgl. ebd. und Ewald, Rheinische Siegel II, S. 3.

254 Vgl. Pardessus, Diplomata 2, Nr. 464, S. 268 f. Die einzelnen Zahlungen und Abgaben sind mit dem jeweiligen Fälligkeitstag genau aufgelistet.

255 Vgl. Ewald, Rheinische Siegel II, S. 3 f. 
sache Stain-Verdun-Trier betreffen, in einem Chartular der Abtei St. Eucharius vor. ${ }^{256}$ GaUthIER äußert wieder deutliche Zweifel. ${ }^{257}$ Werner sieht durch die Ähnlichkeit mit den Irmina-Urkunden Verbindungen zum Trierer Domklerus. ${ }^{258}$ Haubrichs hält zwar die Datierung für falsch, doch versucht er, die Verduner und Trierer Überlieferung zu harmonisieren. Er vermutet, daß die Besitzzugehörigkeit zu Verdun und St. Eucharius aufeinanderfolge und die Urkunde deshalb über einen wahren Kern verfüge. ANTON kann ihm zwar nicht ganz folgen, geht aber von der Echtheit der Grundaussage aus. ${ }^{259}$

Auch Petrus Becker hält daran fest, datiert aber auf 707 und folgt damit Goerz. Es sei die erste Schenkung von Fernbesitz an St. Eucharius überhaupt, der sich erst im 10./11. Jahrhundert andere anschlössen. Für Stain vermutet er gemeinsamen Besitz von St. Eucharius und Verdun. „Der Besitz der Abtei [St. Eucharius] wurde samt Kirche und Zehnten bestätigt von Papst Eugen III. [1145-1153] am 6. Februar 1148 und nochmals von Papst Hadrian IV. [1154-1159] am 29. April 1155 [...]. Um 1200 war diese Grundherrschaft durch Bedrückungen einiger Laien, die wahrscheinlich als Vögte anzusprechen sind, gefährdet.“ 1222 tauschte St. Eucharius schließlich Stain mit dem Magdalenenstift in Verdun gegen den Hof Koenigsmacker. ${ }^{260}$

256 Vgl. Pauly, Älteste Urkunden, S. 12 f. Zum Wiederaufkommen des erzbischöflichen Titels bzw. der Metropolitansitze Ende des 8. Jahrhunderts vgl. schon oben Kap. C.III.1. bei Anm. 35 sowie Kap. C.III.2. bei Anm. 46. Zur Trierer Gegenurkunde vgl. die Handschrift Trier, Stadtbibliothek, 1657a/362, S. 701-706, aus dem 16. Jahrhundert, sowie nochmals Pauly, S. 13, Anm. 8: „(Urkunden des Verduner Stiftes, der Trierer Abtei, des Bischofs von Verdun, des Domkapitels von Verdun und des Papstes Honorius III. [1216-1227] aus den Jahren 1221-1225). “ Zur Handschrift vgl. auch Keuffer/ Kentenich, Beschreibendes Verzeichnis 8, S. 131-134.

257 Vgl. Gauthier, Évangélisation, S. 359 u. Anm. 97, S. 418 f.

258 Vgl. Werner, Adelsfamilien, S. 92 f. u. Anm. 273; S. 127 u. Anm. 415. Auch fänden sich Ähnlichkeiten zum frühmittelalterlichen Formular.

259 Vgl. Haubrichs, Urkunden Pippins, S. 18 f. u. Anm. 123. Schon Karl Martell habe das an Verdun übertragene Gut diesem wieder entzogen. So sei es an den Vater Liutwins gelangt. Anton, Liutwin, S. 31 f. u. Anm. 28, hält einen Bezug zu Verdun im 13. Jahrhundert für durchaus möglich.

260 Vgl. Becker, St. Eucharius, S. 244, 249, 255, 345, 355, 478, 501, 551, 600, bes. S. 501. Goerz, Mittelrheinische Regesten I 118, S. 53. Zu den Papstbestätigungen vgl. zunächst JL 9181. MRUB I 545, S. 604: Stann c. eccl. et dec. et omnibus earum appendiciis. Germ. Pont. 10, St. Eucharius 4, ed. Boshof, S. 223. Vgl. ferner JL 10042. MRUB I 589, S. 647: Stagnum uillam cum ęcclesia. Germ. Pont. 10, St. Eucharius 9, ed. Boshof, S. $224 \mathrm{f}$. Die Bestätigungen erfolgten neben anderem Besitz an St. Eucharius. - Zum Tausch mit Verdun vgl. MRUB III 169, 190, S. 146, 162. Merkwürdigerweise handelt es sich bei der ersten Urkunde von 1221 lediglich um eine Schenkung von Königsmacker an St. Eucharius, während dann die zweite 1222 den Tausch zum beiderseitigen Nutzen nennt. Zur Grundherrschaft Königsmacker vgl. BeCKer, St. Eucharius, S. 502-504. 
Die Ähnlichkeit von MRUB I 7a mit den Irmina-Urkunden stößt erstmals bei Schmal auf Skepsis. ${ }^{261}$ Vor allem mit der Urkunde vom 1. Dezember 697/8 (Wampach I 2, Nr. 4) und der vom 1. Juli 699 (Wамрасн I 2, Nr. 6) fänden sich teilweise wörtliche Übereinstimmungen, die sie tabellarisch auflistet. Gleiches gelte - wie gesehen - für das Eschatokoll der zweiten Urkunde von 704 über den Trierer Weinberg (Waмpach I 2, Nr. 10). Diese nenne auch Warenbert als Schreiber. Vier Zeugennamen von MRUB I 7a fänden sich schon bei Irmina, die anderen seien allerdings neu. Schmal zeigt durch die Abhängigkeitsverhältnisse, daß die Liutwin-Urkunde nicht vor den Irmina-Urkunden entstanden sein kann. Das Dokument sei also formal und inhaltlich gefälscht. Doch habe ihm noch eine andere falsche Liutwin-Urkunde als Vorlage gedient, die schon früher aus den Irmina-Urkunden hervorgegangen sei. Diese befinde sich als Regest am Beginn der Miracula s. Liutwini, die in der zweiten Hälfte des 11. Jahrhunderts in bzw. für Mettlach entstanden. Liutwin schenkt darin sein Vermögen an die Mönche des Klosters Mettlach und nicht an die Trierer Kirche, wie seine Viten berichten. ${ }^{262}$ Sie datiert auch auf das 12 . Herrschaftsjahr König Childeberts (706), zusätzlich jedoch auf das Jahr 696 nach Christi Geburt. Einige Formulierungen wiesen auf Ähnlichkeiten mit MRUB I 7a hin. ${ }^{263}$ Folglich bilde also kein echter Kern die Basis für die Stain-Schenkung (MRUB I 7a), sondern eine Mettlacher Fälschung aus den Miracula - so Schmal. Man habe MRUB I 7a absichtlich so früh datiert, damit es in die Zeit falle, bevor Verdun über Stain verfügte. Zusätzliche Zeugennamen - wie Milo und Wido gehörten als Bestandteil dazu.

Das Formular der Stain-Urkunde ist in der Tat fragwürdig. Schon StumpF hat 1865 darauf hingewiesen, daß die unteilbare Dreifaltigkeit frühestens ab 800 in den Kaiserdiplomen Karls des Großen angerufen werde. ${ }^{264}$ Auch das

261 Vgl. Schmal, Mettlach, S. 55-60.

262 Vgl. Miracula s. Liutwini auct. Monacho Mediolacensi cap. 2, ed. SAuerland, S. $1261 \mathrm{f}$ : In episcopatu igitur positus digne memorandus pater Liutwinus, de rebus, que sibi hereditario iure obvenerant vel pretio comparaverat, testamenti cartulam fecit, per quam Mediolacensi loco fratribusque ibidem Deo servientibus easdem res contradidit; ac apostolica auctoritate in iudicio promulgarat damnandos, si quos in his rebus paterentur molestos. Duodecimo ergo anno Childiberti regis hec facta est traditionis conscriptio et incarnationis Domini sexcentesimo nonagesimo sexto. Huius temporis articulo declaratur, quo sanctus Liutwinus floruerit annorum curriculo.

263 Vgl. Schmal, Mettlach, S. 58 f. u. Anm. 376 f. So werde z. B. beide Male an die im Kloster Gott dienenden Brüder geschenkt. - Doch ist diese Formulierung völlig formelhaft und findet sich auch in anderen Urkunden. Vgl. nur Marculfi Formulae II,1, ed. Zeumer, S. 72, Z. 3 f., oder den Registereintrag in DKarol. I, S. 558, sowie ähnliche Registereinträge in weiteren Urkundeneditionen.

264 Vgl. Stumpf-Brentano, Reichskanzler 1,1, S. 83. 
Gottesgnadentum erscheint erst seit der Königserhebung Pippins III. (751768) 751 in den Urkunden. ${ }^{265}$

Fassen wir kurz zusammen, so haben wir es hier mit vier Ebenen zu tun: 1. erneut den Echternacher Irmina-Urkunden (WАмpach I 2, Nr. 4, 6 u. 10), 2. einer konstruierten Liutwin-Urkunde als Regest in den Mettlacher Miracula s. Liutwini aus der zweiten Hälfte des 11. Jahrhunderts, 3. der vorliegenden gefälschten Fassung von Liutwins Stain-Schenkung für St. Eucharius (MRUB I 7a), wie sie in Verdun und St. Eucharius überliefert ist, 4. einem angeblich echten Kern dieser Urkunde. So kristallisieren sich Echternach, Mettlach und St. Eucharius als mögliche Handlungsorte heraus.

Schmal weist durch die erheblichen Übereinstimmungen mit den IrminaUrkunden nach, daß ein echter Kern einer Liutwin-Schenkung um 706 unglaubwürdig ist. Zwar spricht nichts gegen begründete Ansprüche von St. Eucharius auf Stain. Wann sie aber entstanden, läßt sich nicht mehr klären. Mit einiger Wahrscheinlichkeit dürfte dies erst um einiges später geschehen sein. Es wäre ohnehin merkwürdig, warum ausgerechnet diese Liutwin-Urkunde über Fernbesitz oder wenigstens eine ihr vorausgehende Urkunde die Zerstörung des Klosters vor der Trierer Stadtmauer durch die Normannen 882 überdauert haben sollte. Da liegt es näher, daß man in St. Eucharius den Fernbesitz später sichern wollte, die Urkunde dort konstruierte und an das Magdalenenstift nach Verdun gab, um die fälligen Steuerzahlungen abzusichern. Bischof Liutwin erfreute sich in Trier ja - wie gesehen - seit dem späten 10. Jahrhundert einer allmählich wachsenden Beliebtheit als Heiliger. Seine Lebensdaten schienen zudem geeignet. Deshalb berief man sich auf ihn als weit zurückliegenden Schenker. Doch wann könnte das geschehen sein? Schon im 10. Jahrhundert?

Der Bezug zu den Irmina-Urkunden legt eine enge Verbindung mit Echternach nahe. Wenn Schmal Recht hat mit ihrer These, der spätere Abt Thiofrid von Echternach (1083-1110) habe die Mettlacher Miracula s. Liutwini verfaßt, so ließe sich das darin überlieferte Liutwin-Regest erklären. Wie weiter unten noch genauer zu zeigen ist, trifft dies auch aus anderen Gründen tatsächlich zu. ${ }^{266}$ Den Liutwin-Stoff kannte Thiofrid bestens. Liutwins bedeutende Rolle stand für ihn außer Zweifel. Ins Echternacher Archiv hatte er Einblick. Warum sollte er nicht eine aus Archivalien konstruierte Urkunde an den Anfang der Miracula stellen? Die von Schmal dazu erwogenen Vorlagen wären ja lediglich Irminas sog. Testament vom 1. Dezember 697/8 (WАмpaсH I 2, Nr. 4) sowie der zweite Teil der Urkunde vom 1. Juli 699 (WАмрасн I 2, Nr. 6). Wir haben gesehen, daß beide zusammen den einzig ursprünglichen Kern des Irminabestandes in Form eines „Ur-Testaments“ bildeten. ${ }^{267}$ Die an-

265 Vgl. Anton, Gottesgnadentum, Sp. 1592 f. Wolfram, Intitulatio 1, S. 206 ff.

266 Vgl. zu Schmals These oben S. 124 f. u. Anm. 73 sowie unten S. 341 f. u. Anm. 705.

267 Vgl. dazu oben Kap. D.II.4. 
gegebene Datierung des Liutwin-Regests hätte sich ganz einfach aus den beiden Schenkungen Pippins des Mittleren und Plektruds an Echternach (Urkunden der Arnulfinger 4 u. 5) entnehmen lassen, die beide im 12. Herrschaftsjahr Childeberts erfolgten. Die dem Regest hinzugefügte Jahresangabe 696 zeigt jedoch, daß die Einordnung erhebliche Schwierigkeiten bereitete und man die genaue Chronologie nicht mehr überschaute. Die Behauptung, Liutwin habe sein Eigentum an die Mönche von Mettlach geschenkt, fügt sich in die Gesamttendenz der Miracula ein, die eine gewisse Unabhängigkeit Mettlachs vom Trierer Bistum betonen. Dem steht zwar die Tradition der älteren Liutwin-Vita (von der Wende des 10. zum 11. Jahrhundert) entgegen, nach der Liutwin das von ihm gegründete Mettlach an St. Peter in Trier übertrug, es würde aber immanent Sinn machen. Denn Thiofrid griff mit seinem Echternacher Material ja schon den Nonnen von Oeren in der Vita sanctae Irminae (vor 1081) unter die Arme, in der er deren Haustradition und Selbständigkeit betonte. So hat Schmals These eine gewisse und unten noch präziser nachzuweisende Überzeugungskraft. Die erste konstruierte Liutwin-Urkunde aus den Miracula bzw. deren Regest könnte sich demnach also in Mettlach und/oder Echternach befunden haben.

Doch warum hätte Thiofrid auch für St. Eucharius aktiv werden sollen? Bat man ihn um Hilfe? Verfügte er über Beziehungen dorthin? Indizien finden sich keine. Gab es darüber hinaus eindeutige Kontakte zwischen Echternach und St. Eucharius, die hier weiterhelfen könnten? Die bestanden in der Tat, und sie fügen sich in die Überlegungen ein, wie die gefälschten Irmina-Urkunden entstanden. Es sei erneut daran erinnert, daß noch 1148 und 1155 päpstliche Besitzbestätigungen an St. Eucharius unter seinem Abt Bertulf II. (1135-1159, $\dagger 1162)$ erfolgten, die Stain nennen. Die erste wurde wohl in Gegenwart des Papstes selbst ausgestellt. ${ }^{268}$ Der Tausch mit Verdun kam 1221/2 unter Abt Jakob von Lothringen $(1212-1257)$ zustande. $^{269}$ In den dazwischenliegenden Jahren folgte Abt Gerwich (1162-1168) nach einer nicht ganz zu erklärenden Übergangszeit seinem Vorgänger und stieß im Kloster auf Widerstand. ${ }^{270}$ Seit 1168 läßt sich dann Ludwig $(1168-1186, \uparrow 1188 / 9)$ als Abt in St. Eucharius nachweisen, den man 1173 zusätzlich zum Abt von Echternach wählte. Doch muß die Doppelbelastung zu schwer gewogen haben. 1181 resignierte er in

$268 \mathrm{Zu} \mathrm{Abt} \mathrm{Bertulf} \mathrm{II.} \mathrm{vgl.} \mathrm{Becker,} \mathrm{St.} \mathrm{Eucharius,} \mathrm{S.} \mathrm{590-592.}$

$269 \mathrm{Zu}$ Abt Jakob von Lothringen vgl. Becker, St. Eucharius, S. 598-602.

$270 \mathrm{Zu}$ Abt Gerwich vgl. Becker, St. Eucharius, S. 592 f. Einiges deute darauf hin, daß Bertulf II. schon vor seinem Tod resignierte. Vier Briefe Hildegards von Bingen an einen Mönch Gerwin von St. Eucharius, der Gerwich meinen könnte, weisen auf Unmut im Kloster hin. Gerwich scheint für das Amt des Abtes vorgesehen, doch Hildegard rät ihm ab. In einem anderen Brief spricht sie vom unruhigen Wandel im Kloster. Vgl. Hildegard, Epistolarivm 2, 210-213, ed. van ACKer, S. 468-471. Hildegard, Briefwechsel, ed. FüHrкÖтTER, S. 156 f. 
Echternach und gab die dortige Abtwürde an seinen Kaplan Gottfried ab. Unter diesem entstand als Abt Gottfried II. (1181-1210) der mehrfach erwähnte Liber aureus von Echternach 1191/2. Nach Ludwigs Tod erscheint für 1189 kurz ein electus Johannes in St. Eucharius. ${ }^{271}$ Doch schon 1190 folgt diesem Johannes der Abt Gottfried II. aus Echternach im Doppelamt bis zum Tod (1210). ${ }^{272}$ Unter Ludwig und Gottfried dürften also die konstruierten IrminaUrkunden in Echternach entstanden sein. ${ }^{273}$

Beide Äbte waren eng mit Hildegard von Bingen verbunden. Sie veranlaßten den Mönch und Scholaster Theoderich von Echternach, der den ersten Teil des Liber aureus verfaßte, die Hildegard-Vita zu beenden, die der Mönch Gottfried von Disibodenberg bereits begonnen hatte. Theoderich widmete diese Vita Ludwig und Gottfried. ${ }^{274}$

In diesen Kontext paßt Liutwins vermeintliche Stain-Schenkung (MRUB I 7a) nun bestens. Liegt es nicht nahe, daß man sich Liutwins nicht nur für die Irmina-Urkunden bediente, sondern ihn auch für St. Eucharius einsetzte? Beide Äbte bilden das Verbindungsstück. Es würde nicht einmal verwundern, wenn der Scholaster Theoderich von Echternach selbst den Auftrag ausführte. ${ }^{275}$

Es läßt sich auch erklären, warum Milo und Wido als Zeugen in der StainUrkunde auftreten. Daß Milo Liutwins Sohn gewesen sein sollte, war in Trier längst aus den Liutwin-Viten bekannt. Widos Name erscheint zudem gemeinsam mit den beiden im Kontext des Klosters Mettlach, was unten noch genauer behandelt wird. ${ }^{276}$ Daß Milo in der Urkunde als Diakon unterzeichnet, mag auf einer realen Grundlage beruhen oder Erfindung sein. Ein engeres Verhältnis der beiden unterstreicht jedenfalls auch eine andere problematische Urkunde vom 24./25. Juni 715 aus Metz, die weiter oben schon einmal bei Milo besprochen worden ist. Der sacerdos Hugo, sein Bruder Herzog Arnulf, Pippin und Godefridus machen darin eine Schenkung an das dortige Apostelkloster (später St. Arnulf). Es beglaubigen: S. Milonis. S. Uuidonis comitis. S. Eremberti comitis. signum † Lamtberti comitis. signum †Uuarnarii comitis. HEIDRICH weist darauf hin, daß dieses Dokument in zwei Einzelabschriften in Urkundenform aus dem 12. Jahrhundert überliefert ist sowie in zwei Chartularabschriften des 13 . Jahrhunderts. Dabei enthalten die Urkundenabschriften gegenüber den späteren Chartularfassungen, die jedoch der ursprünglichen Version des Stückes näher ständen, einige Interpolationen, u. a. die genannten Zeugennamen. ${ }^{277}$ Auch hier

$271 \mathrm{Zu}$ Ludwig vgl. Becker, St. Eucharius, S. 593-595.

$272 \mathrm{Zu}$ Gottfried vgl. Becker, St. Eucharius, S. 595-598.

273 Vgl. dazu oben S. 134 f. u. Anm. 97-99, im Text vor Anm. 154.

274 Vgl. Becker, St. Eucharius, S. 594, 597 u. Anm. 1. Zur Vita vgl. Theoderich, Vita sanctae Hildegardis, ed. KlaEs, S. 3 f., mit der Widmung an Ludwig und Gottfried.

275 Vgl. dazu oben S. 134 ff. u. Anm. 97 ff.

276 Vgl. dazu unten die Ausführungen in Kap. D.IV.

277 Vgl. dazu genauer und mit den weiteren Angaben oben Kap. C.II.1. 
deutet somit einiges ins 12. Jahrhundert. KöLzer hat gezeigt, daß der Maximiner Abt Berengoz, der vor seinem Tod 1125 zugleich einige Jahre Abt von St. Arnulf in Metz war, einige Fälschungen für beide Klöster vornahm. ${ }^{278}$ Auf diese Weise läßt sich diese trierisch anmutende Zeugenliste in einer Metzer Urkunde erklären.

Warum hätte man diese Liutwin-Schenkung (MRUB I 7a) ausgerechnet jetzt konstruieren sollen? Betrachtet man die überlieferten Urkunden zu Stain, so scheint dessen Besitz für St. Eucharius nicht sehr umstritten gewesen zu sein. Doch zielt die Urkunde im wesentlichen auch gar nicht darauf, den Besitz für St. Eucharius zu erhalten. Vielmehr will sie ja einen klar umrissenen Bannbezirk legitimieren. Es gab wohl Streit um die präzisen Abgaben oder genauen Besitzrechte. Um das alles klar und unzweifelhaft zu sichern, brauchte es ein altes, ehrwürdiges Dokument. Da bot sich Liutwin als Donator an. Dann wird auch verständlich, weshalb die Urkunde in Verdun gemeinsam mit einer Steuerliste vorlag: St. Eucharius wollte den eingeforderten Leistungen mit dem manipulierten Liutwindokument Nachdruck verschaffen.

Gibt es dazu weitere Indizien? Von Abt Ludwig ist ein Siegel mit folgender Umschrift erhalten: $L V D O W I C(V) S \cdot D(E) I \cdot G R(A C I) A \cdot A B B A S \cdot E P T(E R)$ $N A C(E N S I S) \cdot C E N O B I I \cdot E T \cdot S(A N) C(T) I \cdot$ EVCHARII (ca. 1173-1183). ${ }^{279}$ Die Betonung des Gottesgnadentums fällt besonders auf. Das Siegel von Gottfried lautet dagegen lediglich: + GODEFRIDVS - ABBAS - S(AN)C(T)I . EVCHARII (ca. 1190-1210). ${ }^{280}$ Kein weiteres nachweisbares Siegel aus St. Eucharius bietet die Deo gratia-Formel nochmals. Bereits Ludwig kann der Auftraggeber gewesen sein, denn Liutwin verwendet in MRUB I 7a ebenfalls diese Formel.

Allerdings fand sie seit dem 11. Jahrhundert auch Eingang in die bischöflichen Siegel Triers. Ebenso kann sie hieraus entlehnt sein. Erstmals erscheint sie auf Siegeln Erzbischof Poppos $(1016-1047){ }^{281}$ Eine vermeintliche, auf Erzbischof Liudolf (994-1008) im Jahr 1000 ausgestellte Urkunde trägt sogar ein gefälschtes Siegel aus dem 12. Jahrhundert mit der erstaunlichen Umschrift: +

278 Vgl. zuletzt Kölzer, Ein Fälscher bei der Arbeit.

279 Vgl. Becker, St. Eucharius, S. 595. Es findet sich an zwei Urkunden von 1175 sowie einer vom 27. November 1179 in Trier, Stadtarchiv, Urk. M 20, M 20a, N 16. Eine Abbildung bietet Ewald, Rheinische Siegel IV, Taf. 91, Nr. 1.

280 Vgl. Becker, St. Eucharius, S. 598. Zu weiteren erhaltenen Siegeln vgl. insgesamt die Darstellung zu den Äbten von St. Eucharius ebd., S. 582-659.

281 Vgl. Ewald, Rheinische Siegel II, S. 12-14 u. Taf. 1-7, mit den Bischöfen, ihren Siegeln und den Siegelaufschriften. Zu Poppo vgl. ebd., S. 12 f. u. Taf. 2, Nr. 2-5. Goerz, Regesten der Erzbischöfe zu Trier, S. 8 f. Jacobi, Poppo. Bienert, Besiedlung Triers, S. 125, 136. Clemens, Umgang mit der Antike, S. 183, 195, 198-200. Bönnen, Trier zwischen dem 10. und dem beginnenden 12. Jahrhundert, S. 208, 222-228. Hirschmann, Civitas Sancta, S. 403 f., 406, 417, 439, 442. 
LVTWINVS · DEI · GRAC[IA] · TREVerensis · ARCHIEPiscopuS. ${ }^{282}$ Wie konnte man die Namen verwechseln? Oder stand Lutwin synonym für Liudolf? Verfügte man vielleicht über ein solches konstruiertes Siegel und brachte es wegen der Namensähnlichkeit an der Liudolf-Urkunde an? Wo ein solches Siegel war, befanden sich auch noch mehr. Sah also das Siegel auf der in Verdun im 18. Jahrhundert noch erhaltenen Stain-Urkunde so aus? Immerhin muß es irgendwo einen Prägestempel gegeben haben. Es verdeutlicht jedenfalls, daß man Liutwin seit dem 11./12. Jahrhundert professionell für Fälschungen instrumentalisierte.

Nun kann die falsche Liutwin-Urkunde, deren Regest sich in den Miracula s. Liutwini befindet, als Vorlage für MRUB I 7 a gedient haben. Sie mag es ebenso für die Irmina-Urkunden gewesen sein und dazu inspiriert haben, Liutwin aufgrund der zeitlichen und räumlichen Nähe mit aufzunehmen bzw. zu integrieren. Ganz ausschließen läßt sich aber auch eine völlige Neuschöpfung der Stain-Urkunde aus den in Echternach vorhandenen Stücken nicht. Denn MRUB I 7a bezieht sich nicht auf das Jahr 696.

Schließlich sind die Übereinstimmungen des Eschatokolls dieser Urkunde mit der zweiten Irmina-Schenkung von 704 (WАмpach I 2, Nr. 10) nicht zu übersehen. Als Schreiber unterzeichnet in MRUB I 7a nämlich der Priester Warenbert, der auf Befehl seines Herrn, Erzbischof Liutwins, gehandelt haben will. Sein ,Vorgesetzter', der Priester und Sekretär Hunio/Huncio, hätte dem zugestimmt. ${ }^{283}$ Es stellt sich allerdings die Frage, warum denn Huncio noch einwilligen mußte, wenn Erzbischof Liutwin doch Warenbert selbst aufgefordert hatte, zu schreiben. Das ist unlogisch und weist auf eine formal übernommene Vorlage, die man damit inhaltlich entstellte. Doch was könnte in dieser Vorlage ursprünglich gestanden haben?

Die Erlaubnis einer Person zu Warenberts Handeln hat sie sicher beinhaltet. Schließlich wäre es nicht aufgefallen, wenn Warenbert alleine geschrieben hätte. Das mußte man nicht erfinden. Doch war es Huncio? Folgt man der zweiten Irmina-Schenkung von 704 in der Fassung des Liber aureus (WАмрасн I 2, Nr. 10), dann tritt hier an Liutwins Stelle die Gott geweihte Äbtissin Irmina. Sie bittet (rogante) Warenbert um seine Tätigkeit und befiehlt nicht. Bei der Annahme, Irmina bediene sich des Trierer Domklerus', wird das Einverständnis

282 Vgl. Ewald, Rheinische Siegel II, S. 12 u. Taf. 2, Nr. 1. Ewald gibt als Fälschungszeit ca. 1140 an, nennt aber keine genaueren Argumente. Vgl. dazu Goerz, Mittelrheinische Regesten I 1148, S. 326. MRUB I 276, S. 330 f. Darin beurkundet Liudolf die Schenkung eines Herimannus und seiner Gattin Ada an das Marienkloster am Ufer der Mosel. Wegen Kinderlosigkeit übereignen sie ihren Besitz zu Taberna. Die genaue Aufteilung wird genannt. Abt Warinarius gibt den beiden als Gegenleistung eine Ausstattung für ihren Altenteil. Schließlich gesteht der Bischof dem Kloster freie Abtwahl aus dem Konvent zu.

283 Vgl. den Text oben S. 163 f. u. Anm. 185. 
Huncios für Warenberts Tun immerhin nachvollziehbarer. Die Liutwin-Urkunde könnte sich also schlicht daran orientiert haben.

Wir haben allerdings gesehen, daß diese Irmina-Urkunde in der vorliegenden Form bereits verändert wurde. Zunächst lag die Schenkung einer Nonne Engela vor, die nachträglich in eine an Irmina und damit in eine von Irmina an Echternach umgewandelt wurde. ${ }^{284}$ BeYERs Edition von MRUB I 7a bietet einen Hinweis dazu. Ex permissa seniae [sic!] meo Hunione presbitero et admanuense heißt es da zu Huncios Rolle. Die merkwürdige Verschreibung legt nahe, daß an dieser Stelle einmal der Name einer Frau stand: der Äbtissin, die einst der Nonne Engela zustimmte, als sie ihre Schenkung vornahm. ${ }^{285}$

Da lediglich Wampach I 2, Nr. 10 und das „Ur-Testament“ der Irmina (Wамрасн I 2, Nr. $4+2$. Teil von Nr. 6) verwendet wurden, deutet dies darauf hin, daß MRUB I 7a im Zuge der ersten Stufe der Irmina-Fälschungen entstandt - also noch vor denen im Liber aureus. Die inzwischen stark ausgeprägte Liutwinverehrung in Form seiner Viten und der Miracula bot in jedem Fall Material genug, einen solchen Text zu entwerfen. Von da an war es nur noch ein kleiner Schritt, Liutwin ins direkte Umfeld von Irmina und Basin zu rücken. Bedenkt man das in MRUB I 7a den Zeugen meist vorangestellte Ego, könnte dies die Spur zur verkürzten Fassung des Irmina-Testaments (WАмpach I 2, Nr. 4) weisen, wo Liutwin eben gemeinsam mit Theodefridus verbunden mit einem solchen Ego interpoliert wurde.

Zusammenfassend ist also festzustellen: Die Liutwin-Schenkung von 706 an St. Eucharius (MRUB I 7a) wurde gefälscht, während zunächst Abt Ludwig (seit 1173) und danach Abt Gottfried II. (†1210) über längere Zeit den Klöstern St. Eucharius und Echternach gemeinsam vorstanden. Die erste Fälschungsstufe der Echternacher Irmina-Urkunden diente dabei als Vorlage. Fälscher war vermutlich der Echternacher Mönch und Scholaster Theoderich, der auch den ersten Teil des Liber aureus 1191/2 verfaßte. MRUB I 7a sollte gegenüber dem Maria-Magdalenen-Stift in Verdun die Steuereinnahmen in Stain sichern. Als weitere Vorlage kann das Regest einer Liutwin-Urkunde aus den Miracula s. Liutwini gedient haben, das Abt Thiofrid von Echternach fälschte, indem er die ihm vorliegenden Echternacher Urkunden benutzte.

284 Vgl. dazu oben Kap. D.II.4.e.

285 Bei Pardessus, Diplomata 2, S. 269, lautet diese Stelle: ex permissu seniore meo Huncione presbitero et admanuense. Bietet sie den korrekten Text oder eine nachträgliche Verbesserung von Pardessus? - Sich als Erklärung allein auf korruptes Latein zurückzuziehen, wie dies Wampach I 1, S. 307 u. Anm. 2, tut, überzeugt nicht. Auch seine Vermutung, Huncio sei Eigenpriester der Irmina gewesen, leuchtet nicht ein. Einzig eine Verschreibung könnte diesen Fehler noch erklären. 


\section{Eine Urkunde für Basin aus St. Maximin}

In einer angeblichen Urkunde Papst Gregors II. (715-731) bestätigt dieser im Januar 729 dem ehrwürdigen Abt Basin vom Kloster des hl. Apostels und Evangelisten Johannes und des heiligsten Bekenners Christi, Maximin, dessen Körper dort ruht, die freie Abtwahl (MRUB I †9).

„Niemals dürfe das Kloster irgendeinem Bischofssitz oder einer anderen Kirche unterstellt werden, sondern solle sich solcher Freiheit und Immunität wie die anderen Königsklöster erfreuen und immer unter Königsschutz bleiben. Überdies erhält der Abt das Recht zum Tragen von Mitra, Dalmatika und Sandalen an den hohen Kirchenfesten. Die Errichtung von Befestigungsanlagen auf Klostergrund wird allen verboten. ${ }^{2886}$

Überliefert ist diese Urkunde im St. Maximiner Chartular des beginnenden 13. Jahrhunderts, gleich zweimal in zwei leicht verschiedenen Versionen. Die hier wiedergegebene Edition Beyers bietet eine Mischversion aus beiden an. ${ }^{287}$

Die Urkunde nennt Basin als St. Maximiner Abt, obwohl er zu dieser Zeit längst verstorben war. Erst spätere Quellen sehen in St. Maximin seine Ruhestätte, ohne daß zeitgenössische Nachweise dazu vorliegen. ${ }^{288}$ Vielleicht existierte dort ja tatsächlich ein Grab, aus dem man schloß, daß er einmal Abt des Klosters war. Bei den im 20. Jahrhundert vorgenommenen Grabungen fand sich davon allerdings keine Spur. ${ }^{289}$ BREsslau vermutete, daß das falsche Dokument in der Mitte des 11. Jahrhunderts in St. Maximin entstand. Es beruhe auf einer verlorenen Urkunde Papst Gregors V. (996-999) vom Januar 999. Denn MRUB I $\dagger 9$ stimme mit dem Urkundenformular Gregors V. aus dieser Zeit überein. Die Gregor-Urkunde wiederum basiere auf Trierer Freiheitsprivilegien Papst Johannes' XIII. (965-972) von 968 sowie Johannes' XV. (985-996) von 987. Spätestens 1140 müsse MRUB I $\dagger 9$ vorgelegen haben, weil es als Vorlage in einer echten Bulle Innozenz' II. (1130-1143) erwähnt werde. ${ }^{290}$ WINHELLER

286 Vgl. JE †2179. MRUB I †9, S. 12 f. Germ. Pont. 10, St. Maximin †1, ed. Boshof, S. 199 f. Das Zitat und die Zusammenfassung bei KöLzer, Studien, S. 89. Zu Basin vgl. auch oben Kap. D.I.2.b.

287 Vgl. Kölzer, Studien, S. 92 f., mit der genauen Handschriftenangabe und dem Hinweis (Anm. 348) auf die Mischversion Beyers. Getrennt seien beide Fassungen im Chartular durch DKarol. I $† 276$, S. 410 f. und DKIII. 133, S. 212 f. In der ersten, falschen bestätigt Karl der Große dem Kloster St. Maximin die freie Abtwahl sowie die Freiheit von übergeordneter Herrschaft, Zoll und Gericht. In der zweiten, echten erneuert Karl III. St. Maximin das Schutz- und Wahlprivileg. - Zum Chartular selbst vgl. KunN, Liber aureus von St. Maximin.

288 Vgl. dazu Gierlich, Grabstätten, S. 50 f. Heyen, Grabkirchen, S. 598 f. u. 602. Dem folgt noch Gießmann, Besitzungen, S. $360 \mathrm{f}$.

289 Vgl. dazu Neyses, Baugeschichte, S. 77 ff.

290 Vgl. Bresslau, St. Maximin, S. 60-62. Als Beispiele führt er eine Urkunde Gregors V. vom Januar 999 (JL 3898; Zimmermann, Papsturkunden II 363, S. 708-710) sowie 
übernahm diese Einschätzung. ${ }^{291}$ WisplinghofF ging von einer Entstehung im Zuge der St. Maximiner Fälschungsaktionen des 12. Jahrhundert aus. ${ }^{292}$

KöLzer hat die Urkunde auf der Basis der bisherigen Forschungsergebnisse erneut intensiv und kritisch geprüft und dazu weitere St. Maximiner Stücke herangezogen. Sein Ergebnis: Nicht nur das Deperditum Gregors V. sei eingegangen, sondern auch St. Maximiner Spurien des frühen 12. Jahrhunderts. Doch müsse man hier differenzieren, weil es eben zwei Fassungen des Textes gebe. Die erste berufe sich nämlich lediglich auf Rechtsinhalte, die sich bereits in den drei erwähnten Papsturkunden bis einschließlich der verlorenen von Gregor V. 999 fänden. Nur diesen Inhalt habe Papst Innozenz II. 1140 erneut bestätigt. Dessen Bulle nenne jedoch nicht das Recht der Pontifikalien und das Verbot des Mauerbaus auf Klostergrund. Und eben diese beiden Rechte fehlten auch in der ersten Version der falschen Urkunde Gregors II. Die zweite Fassung allerdings, die zwar gegenüber der ersten einige Auslassungen aufweise, enthalte nun diese Passagen. So müsse man von zwei verschiedenen Vorlagen für das St. Maximiner Chartular ausgehen. Die erste könne bereits unmittelbar nach der Urkunde Gregors V. 999 entstanden, die zweite auf der Basis inzwischen vorliegender St. Maximiner Spurien etwa 1116 um die entsprechenden Passagen ergänzt worden sein. Man habe 1140 dann aber nicht gewagt, dem Papst diese

eine weitere vom 28. Juni 997 (JL 3877; Zimmermann, Papsturkunden I 345, S. 669673) an. Vgl. ähnlich auch Oppermann, Rheinische Urkundenstudien 2, S. 70 f. Vgl. zu den Urkunden MRUB I 231, 258, 516, S. 286 f., 315, 572-574. Johannes XIII. bestätigt 968 St. Maximin die Privilegien sowie die freie Abtwahl (JL 3722; Zimmermann, Papsturkunden I 185, S. 362-364; Germ. Pont. 10, St. Maximin 7, ed. Boshof, S. 202 f.). Johannes XV. wiederholt das 987 (JL 3827; Zimmermann, Papsturkunden I 291, S. 565 f.; Germ. Pont. 10, St. Maximin 8, ed. Bosнof, S. 203). Innozenz II. bestätigt 1140 die Rechte, die umfangreichen namentlich aufgeführten Besitzungen sowie die Reichsunmittelbarkeit (JL 8093; Germ. Pont. 10, St. Maximin 33, ed. Boshof, S. 210 f.). Vgl. schließlich Kölzer, Studien, S. 89 u. Anm. 322.

291 Vgl. WinhelLER, Lebensbeschreibungen, S. $171 \mathrm{f}$. Er zeigt auch, wie diese Urkunde Eingang in die Vita Basins aus dem 16. Jahrhundert gefunden hat.

292 Vgl. Wisplinghoff, St. Maximin bei Trier, S. 143-176, bes. S. 150, 171-173. Die St. Maximiner Fälschungen hatten auch schon Bresslau, St. Maximin, S. 20-65, Oppermann, Rheinische Urkundenstudien 2, S. 1-120, sowie zuletzt und ausführlich KöLzer, Studien, aufgearbeitet. Kölzer kam dabei zum Ergebnis (ebd., S. 305-310), $\mathrm{da}$ in St. Maximin mehr Fälschungen vorliegen, als bisher vermutet. Die dortigen Fälschungen setzten erst im letzten Jahrzehnt des 10. Jahrhunderts parallel zum Oerener Konflikt mit dem Erzstift ein. Sie sollten den reichsunmittelbaren Rechtsstatus des Klosters sichern. Die frühen Spuria gehörten vielmehr ins dritte Viertel des 11. Jahrhunderts. In den ersten Jahren des 12. Jahrhunderts begannen Fälschungen zur Absicherung gegen die Untervögte. Ihnen folgte eine größere Fälschungsaktion um 1116 gegen erste Angriffe des Erzbischofs. Vgl. neuerdings zusammenfassend KöLzer, Fälscher bei der Arbeit, der darin nochmals betont, daß die Fälschungen 1116 vom Maximiner Abt Benzo vorgenommen wurden. 
erweiterte Version zur Bestätigung vorzulegen. ${ }^{293}$ Beide seien deshalb parallel ins Chartular eingegangen.

Einen genauen Entstehungszeitpunkt für die erste Fassung kann KöLzER nicht aufzeigen, nur einen terminus post quem von 999. GIEßMANN datiert sie denn auch vorsichtiger etwa zwischen 1050 und $1084 .^{294}$ Nun interessiert hier weniger der Inhalt, der den Wunsch St. Maximins nach Freiheit und Unabhängigkeit vom Trierer Bistum, eben Reichsunmittelbarkeit, ausdrückt. St. Maximin sollte sie um 1139/40 durch die Übertragung König Konrads III. (1138-1152) an Erzbischof Albero (1131-1152) endgültig verlieren. ${ }^{295}$ Vielmehr geht es um die Berufung auf Basin als Abt. Man wollte damit nachvollziehbar weit in die Vergangenheit zurück, so weit, daß sich keine Gegenargumente von anderer Seite mehr anführen ließen. Dabei wird deutlich, daß man zwar um eine wichtige Rolle Basins in der Vergangenheit wußte, ihn aber chronologisch nicht mehr korrekt einzuordnen verstand. Oder man setzte ihn einfach in die Herrschaftszeit Gregors II., der sich ja als Papst auf der Grundlage der Vorlage Gregors V. anbot. Warum also sollte ausgerechnet Basin St. Maximiner Abt gewesen sein?

Zwei Quellen liegen auf der Hand: Zum einen entstanden Ende des 10. Jahrhunderts die ersten ausführlichen Trierer Bischofslisten. ${ }^{296}$ Da bot sich die Wahl eines Bischofs der gesuchten Zeit auf dieser Basis an. Erst hier scheint Basin ins Trierer Bewußtsein zurückgekehrt zu sein. Zum anderen gab es schon zwei weitere Trierer Bischöfe des 8. Jahrhunderts, die mit einem Kloster in Verbindung gebracht wurden: Liutwin, der Mettlach gegründet haben sollte, und sein Sohn Milo, der ihn dort habe bestatten lassen. Um sie wußte man: Wenigstens die Vita Liutwini I (um die Wende vom 10. zum 11. Jahrhundert) und der Libellus de rebus Treverensibus (aus dem dritten Viertel des 11. Jahrhunderts) berichteten davon. Und sie erwähnten auch einen Bischof Basin als Onkel Liutwins. Von Basins tatsächlicher, oben behandelter Beziehung zu Echternach und Willibrord wissen sie jedoch nichts. ${ }^{297}$ Aufgrund der Liutwintradition bot es sich an, nun auf Basin als St. Maximiner Abt zurückzugreifen. Gegen eine zu frühe Datierung der ersten Fassung von MRUB I $\uparrow 9$ unmittelbar nach 999 spricht ohnehin, daß Basins Name ins St. Maximiner Totengedenkbuch des 10./11. Jahrhunderts erst als Nachtrag des 12. Jahrhunderts Eingang

293 Vgl. Kölzer, Studien, S. 89-94.

294 Vgl. Gießmann, Besitzungen, S. 42.

295 Vgl. dazu Wisplinghoff, St. Maximin bei Trier, S. 33-61, bes. S. 59-61. Boshof, Papsturkunde. Pundt, Erzbischof und Stadtgemeinde, S. 245. Vgl. zu Albero auch Goerz, Regesten der Erzbischöfe zu Trier, S. 17-20, bes. S. 19.

296 Vgl. dazu bereits oben S. 119, 122 u. Anm. 31 u. 51 sowie ausführlicher unten Kap. D.VI.3.e.

297 Vgl. dazu nochmals oben Kap. D.I.2.b. u. D.II. 
fand. ${ }^{298}$ Vielleicht läßt sich das aber auch damit erklären, daß man diese Urkunde zu Beginn des 12. Jahrhunderts erneut verwandte und eine zweite Fassung konstruierte.

So paßt Basins Erscheinen in dieser Urkunde in die Zeit des 11. und 12. Jahrhunderts in Trier und zeigt einmal mehr, daß man dürftige und unzuverlässige Informationen über die eigene Vergangenheit und deren Personen benutzte, um Rechte der Gegenwart zu legitimieren. Was zählte, war, daß die Namen, die man jetzt einsetzte, authentisch schienen, nicht daß die mit ihnen ehemals verbundenen Personen einmal das getan hatten, was man jetzt von ihnen behauptete.

Zusammengefaßt liegt die gefälschte Basin-Urkunde MRUB I †9 in zwei Fassungen vor: eine aus der zweiten Hälfte des 11. Jahrhunderts und eine von etwa 1116. Dazu wurde in St. Maximin entweder das Basinbild der Trierer Bischofslisten oder das der Liutwintradition aufgegriffen und daraus das neue Bild eines St. Maximiner Abtes konstruiert. Damit weisen die bisher für zeitgenössisch gehaltenen Spuren von Basin und Liutwin fast alle in einen viel späteren Trierer Kontext.

\section{Die frühen Viten des hl. Maximin von Trier}

Einer der wenigen Trierer Texte, die sich aus der Zeit vor dem Normannensturm von 882 erhalten haben, ist die ältere Vita des hl. Maximin. ${ }^{299}$ Man hat sie bisher immer in die zweite Hälfte des 8. Jahrhunderts datiert. Zwar wisse sie von ihrem Protagonisten, dem Bischof Maximin von Trier im 4. Jahrhundert, überwiegend Legendenhaftes zu berichten, böte aber einige Angaben über das 8. Jahrhundert. So reichten die darin aufgeführten Wunderberichte bis in die Zeit König Pippins (nach 751). Ja, da man keine Erinnerung mehr an seine Herrschaftsübernahme von den Merowingern finde und Karl Martell sogar als König genannt werde, müsse die Vita in dieser Zeit verfaßt worden sein. Die Sprache wirke altertümlich und passe nicht in die karolingische Renaissance. Entstanden sei sie wohl im Kloster St. Maximin. Man benötigte dort einen Vitentext für das Fest des Heiligen, so der Prolog. ${ }^{300}$ Gerade einmal in drei

298 Vgl. dort zum 4. März: Depositio Basini epi.f. Vgl. dazu Miesges, Trierer Festkalender, S. 9, Anm. 4, sowie die Edition von Kraus, Necrologium, S. 111. Weitere Eintragungen finden sich dann erst wieder ab dem 13. Jahrhundert. Vgl. dazu Miesges, S. 34 f. Zu den Totenbüchern aus St. Maximin vgl. ausführlicher Wisplinghoff, St. Maximin bei Trier, S. 39-45, der aber den Eintrag Basins nicht behandelt.

299 Vgl. Vita sancti Maximini episcopi Trevirensis, ed. Henschen, S. 20-25.

300 Vgl. zusammenfassend zu Maximin und zur Vita WinhelLer, Lebensbeschreibungen, S. 10-27, bes. S. 14-19. Zur Vita und zum Prolog vgl. Vita sancti Maximini episcopi Trevirensis cap. 1, ed. Henschen, S. 20 f., zur karolingischen Zeit bes. cap. 12 f., S. 24. 
Handschriften ist sie überliefert. Die älteste stammt aus dem 11. Jahrhundert sowie jeweils eine weitere aus dem 12. und 15. Jahrhundert. ${ }^{301}$

Zwar berührt die Vita auch die Karolinger im 8. Jahrhundert und die damals geschehenen Wunder Maximins, verliert aber keine konkreten Worte über die Trierer Bischöfe ihres Entstehungsjahrhunderts. Wären diese so einprägsam gewesen, warum fehlen sie dann? ${ }^{302}$ Die Namen viel früherer heiliger Trierer Bischöfe wie Paulinus, Eucharius, Valerius, Maternus und Agricius nennt sie sehr wohl. Ferner kommt ein Bischof Hildulf ohne Bistum zur Sprache, der neben anderen bei einer Umbettung der sterblichen Überreste des hl. Maximin etwa um 700 mitwirkte und den erst spätere Quellen als Trierer Bischof bezeichnen. Sein Name mit dem Bischofstitel findet sich aber auch als zeitgenössischer Nachtrag in Willibrords Kalendar. War vielleicht Hildulf für die ältere Maximin-Vita der wichtigste Trierer Bischof dieser Zeit? ${ }^{303}$ Eine mögliche

In cap. 12 wird Karl Martell als Princeps und einmal als Rex genannt. Zur Vita vgl. auch Ewig, Trier, S. 33-38. Berschin, Biographie 3, S. 64-70. Gauthier, Évangélisation, S. 45 f., 51 f., spricht von einem nur beschränkten Wert der Vita für ihre Abfassungszeit. Vgl. zur „Bischofsvita bis zum Beginn des 9. Jahrhunderts“ seit dem frühen Mittelalter zusammenfassend Elm, Macht der Weisheit, S. 201-238, die auch den oftmals geringen historischen Wert solcher Viten behandelt.

301 Vgl. Winheller, Lebensbeschreibungen, S. 10. Die beiden frühesten handschriftlichen Überlieferungen finden sich in Paris, BN, lat. 15029 (St-Victor 803), fol. 14 ${ }^{\mathrm{r}}-21^{\mathrm{v}}$, sowie in Trier, Stadtbibliothek, 137/50, fol. 192v, aus St. Matthias/St. Eucharius. Der entsprechende Teil des Pariser Kodex' stamme aus dem 12. Jahrhundert, das entsprechende Folio des Trierers aus dem 11. Jahrhundert, wobei diese (Sammel-)Handschrift selbst Überlieferungen des 9. bis 11. Jahrhunderts enthält. In der Trierer Handschrift findet sich der Prolog, „der Anfang der Vita ist ausradiert, der Rest mit den folgenden Blättern verloren“ (Winheller, S. 10). Vgl. zur Pariser Handschrift auch Delisle, Inventaire (1869), S. 67. Der Kodex datiere insgesamt aus dem 12.-14. Jahrhundert. Zur Trierer Handschrift vgl. auch Keuffer, Beschreibendes Verzeichnis 2, S. 32 f. Coens, Catalogus, S. 159. Hoffmann, Buchkunst 1, S. 508. Becker, St. Eucharius, S. 107, Nr. 11.

302 Man hat in der darin erwähnten Bekämpfung des häretischen Kölner Bischofs Eufchrates durch St. Maximin einen Hinweis auf den Konflikt zwischen Bonifatius, der einmal Metropolit in Köln werden sollte, und Milo von Trier gesehen. Doch wirklich sicher ist der Bezug nicht. - Die Akten des angeblich dazu abgehaltenen Kölner Konzils von 346 sind wohl gefälscht und tauchen nicht vor dem 9. Jahrhundert auf. Vgl. dazu WINHeller, Beschreibungen, S. 12 u. Anm. 12 f. Gauthier, Évangélisation, S. 447-453. Man habe sich Ende des 8. Jahrhunderts gegen Kölner Ansprüche durchsetzen wollen. Die Teilnehmerliste könne aber auf einer echten Grundlage beruhen. Vgl. ferner noch zu Milo und Bonifatius ausführlich oben Kap. C.

303 Vgl. Vita sancti Maximini episcopi Trevirensis cap. 5-7, ed. Henschen, S. 22. - Im Zusammenhang mit einer Umbettung des Körpers werden drei weitere Namen genannt. Vgl. ebd. cap. 9, S. 23E: Hidulphus videlicet, Clemens, \& Lothbertus. HeYen u. a., Trier, St. Maximin, S. 1012, nennen die Translation zu 698 und halten Hildulf wohl für einen Trierer Bischof. - Ein Bischof Hildulf erscheint als Nachtrag in Willibrords Kalendar. Vgl. The Calendar of St. Willibrord, ed. Wilson, S. 7 u. 34. War er Trierer Bischof? Erst die späteren Fassungen der Trierer Bischofslisten nehmen ihn als solchen auf. Clemens meint vielleicht Bischof Clemens-Willibrord. Vgl. dazu Vita sancti Maximini 
andere Erklärung für die fehlenden Bischofsnamen wäre, daß die Vita später entstand, als bisher vermutet. Daß Karl Martell (†741) als König auftritt, spräche dafür. Es deckt sich mit Angaben zu Karl, wie sie die Annales Mettenses priores nach 805 machen. ${ }^{304}$ Dann läge das frühe 9. Jahrhundert als Abfassungszeit näher. Doch mag es sich beim Königstitel auch um eine nachträgliche Interpolation handeln.

Eine zweite Maximin-Vita will ein Lupus nach eigener Angabe 839 auf Bitten eines Waldo geschrieben haben. ${ }^{305}$ WinhelLer trug nochmals die Argumente für Lupus von Ferrières als Autor dieser Vita zusammen. Auftraggeber sei wohl Abt Waldo von St. Maximin gewesen. Beide Viten hingen voneinander $\mathrm{ab}$ und böten den gleichen Inhalt in ähnlicher Abfolge. Es gebe wörtliche Übereinstimmungen. Garenfeld ging von einer Entstehung der Vita II vor der Vita I aus. Winheller argumentiert aber mit einem dezidierten Textvergleich dagegen, arbeitet die größere Strukturiertheit der Lupus-Vita mit manchen präzisierenden Ergänzungen gegenüber der ersten Vita heraus und hat sich damit in der Forschung durchgesetzt. ${ }^{306}$ Ganz offenbar dominierte dieser jüngere Text dann die Rezeption. Schon seit dem 11. Jahrhundert finden sich zahlreiche Handschriften. ${ }^{307}$ Auch Lupus geht in keiner Form auf die Trierer Bischöfe des frühen 8. Jahrhunderts ein.

Dennoch bietet die ältere Vita z.B. die genauen Jahre der Bischofszeit Maximins, die sich nicht bei Lupus finden. WinHELLER schließt deshalb nicht aus, daß es sich dabei um nachträgliche Trierer Interpolationen handelt. ${ }^{308}$ Die späte Handschriftenüberlieferung der Vita I und die zahlreichen anderen Trierer Konstruktionen im zeitlichen Umfeld von deren Kodizes machen das nicht unwahrscheinlich.

Zusammenfassend läßt sich also feststellen, daß beiden Viten nichts Genaues über die Trierer Bischöfe des 8. Jahrhunderts berichten und die Namen Basins und Liutwins, aus welchen Gründen auch immer, verschweigen. Die Darstellung der beiden Viten zeigt ferner, wie schnell sich über die Erinnerung an die Tage Karl Martells und Pippins der Schleier der Legende legte.

episcopi Trevirensis, S. 24 f. u. Anm. a-b, vor allem Winheller, Lebensbeschreibungen, S. $17 \mathrm{f}$. Doch erinnerte man sich nicht an Trierer Bischöfe in deren Umfeld. Vgl. genauer auch unten Anm. 427.

304 Vgl. dazu schon genauer oben Kap. B.II. bei Anm. 27 ff.

305 Vgl. Lupus, Vita Maximini episcopi Trevirensis, ed. Krusch, S. 71 -82, hier S. 74.

306 Vgl. dazu Winheller, Lebensbeschreibungen, S. 10, 19-27. Garenfeld, Trierer Bischöfe, S. 26-30. Vgl. zuletzt nochmals Anton, Trier im frühen Mittelalter, S. 210. $\mathrm{Zu}$ Lupus von Ferrières vgl. hier nur Depreux, Prosopograhie, Nr. 193, S. 322 f.

$307 \mathrm{Zu}$ den Handschriften vgl. Lupus, Vita Maximini episcopi Trevirensis, ed. Krusch,

S. 73, sowie auch WinHELLER, Lebensbeschreibungen, S. 10 u. 22.

308 Vgl. WinhelLER, Lebensbeschreibungen, S. 20 f. 


\section{Die Karolingerurkunden für das Kloster Mettlach an der Saar}

\section{Urkunden und Forschungsstand}

Daß Liutwin Beschenker und Gründer des Klosters Mettlach sowie dann Trierer Erzbischof gewesen sein soll, der Mettlach schließlich an die Trierer Kirche übertrug, hat die bisherige Forschung aus den Trierer Quellen seit dem frühen 11. Jahrhundert übernommen: Die beiden ersten Liutwin-Viten (Vita I und II), die Miracula s. Liutwini, der Libellus de rebus Treverensibus und die Gesta Treverorum berichteten davon. ${ }^{309}$ Sie boten damit ein festes Deutungsmuster, um alle weiteren verstreuten Quellen daran $\mathrm{zu}$ messen, in ihnen gleichsam die Bestätigungen für die so überzeugende Legende zu suchen.

$\mathrm{Zu}$ diesen Quellen gehören auch vier Karolingerdiplome, die alle das Kloster Mettlach an der Saar betreffen. Drei davon nennen einen Liutwin. Einen Basin erwähnen sie gar nicht. Es handelt sich um:

1. die schon in Verbindung mit Milo kurz besprochene Urkunde Karls des Großen (768-814) für Bischof Weomad von Trier (762-791), die allgemein auf 782 datiert wird. Sie bestätigt als Rechtsspruch eines Grafengerichtes in Diedenhofen den Besitz Mettlachs für die Trierer Kirche. Schon Bischof Liutwin habe es dorthin gegeben. Sein Sohn und Nachfolger Milo, mit dem Kloster von den Karolingern belehnt, habe dann Äbte dafür bestimmt. Die Söhne eines Lambert, nämlich Wido und seine Brüder, setzten sich mit ihren Besitzansprüchen dagegen nicht durch (DKarol. I 148); ${ }^{310}$

2. eine Urkunde Kaiser Lothars I. (817/40-855) für die Trierer Kirche von 842, in der er Mettlach an sie zurück gibt, nachdem es zuvor Lothars Anhänger Wido I. von Spoleto (842-ca. 859) in Besitz hatte, dessen origo es ursprünglich an Trier geschenkt habe (DLoI. 67);

3. eine Urkunde Kaiser Karls III. (876-888), des Dicken, von 884, der dem Trierer Erzbischof Radbod (883-915) bestätigt, daß einst Erzbischof Liutwin das Kloster der Trierer Kirche übertrug (DKIII. 102);

4. eine Urkunde König Arnulfs (887-899) von 888, in der er Erzbischof Radbod die Urkunde seines Vaters nochmals bestätigt (DArn. 39).

In ihnen erkannte man weitere Belege dafür, daß Mettlach in engem Zusammenhang mit Liutwin stand. Zurecht weist Schmal aber auf den Normannenüberfall von 882 hin, dessen Opfer auch Mettlach gewesen sein könnte. Unterstützt wird ihre These durch die erste Liutwin-Vita (Vita I) sowie die Miracula s. Liutwini. Sie geben an, über kein frühes Schriftmaterial aus Mettlach

309 Vgl. dazu oben Kap. D.I.2.a. u. D.I.2.c.

310 Vgl. dazu schon oben Kap. C.I.3. 
mehr zu verfügen. ${ }^{311}$ Einzige Ausnahme wäre die zu Beginn der Miracula als Regest wiedergegebene Liutwin-Urkunde. Die ist aber - wie gesehen - gefälscht. ${ }^{312}$ Der Teilungsvertrag von Meersen von 870 erwähnt für den Trierer Raum nur die Abteien St. Maximin, Echternach, Oeren und Prüm als Reichsklöster. Sie fallen darin Ludwig dem Deutschen zu $(† 876) .{ }^{313}$ Da Mettlach fehlt, dürfte es zu dieser Zeit nicht über einen solchen Status verfügt haben. Weiteres zeitgenössisches Material, aus dem sich Schlüsse über die Rechtsverhältnisse des karolingischen Mettlach ableiten ließen, gibt es nicht parallel zu diesen Urkunden.

Nur wenige Arbeiten haben sich intensiver mit der Bedeutung dieser Urkunden für Mettlachs Frühzeit beschäftigt. Sie seien hier kurz angesprochen, bevor sie bei der genaueren Einzeluntersuchung der Diplome dezidiert herangezogen werden. Die älteren Studien stützten sich fast ausschließlich auf die erzählenden Berichte und behandelten die Urkunden - wenn überhaupt - nur am Rande. ${ }^{314}$

Erst RAACH befaßte sich 1974 in seiner Dissertation „Kloster Mettlach/Saar und sein Grundbesitz" intensiver mit den Urkunden. Die erzählenden Quellen bilden jedoch auch für ihn die Ausgangsbasis. Da aber eine Stiftungsurkunde oder ein Testament Liutwins verloren sei, müsse man zudem die voneinander abhängigen Karolingerurkunden genauer untersuchen, besonders die Karls des Großen. Die Urkunde weise erhebliche inhaltliche Widersprüche auf, die Informationen seien dürftig. Seine Deutung: Mettlach sei durch Liutwin von einem adligen Eigenkloster mit königlichen Belehnungsrechten zum bischöfli-

311 Vgl. Schmal, Mettlach, S. 36.

312 Vgl. dazu oben Kap. D.III.1.

313 Vgl. dazu Ann. Bert. ad a. 870, ed. Waitz, S. 110 f.

314 Vgl. Brower/Masen, Metropolis ecclesiae Trevericae, quae metropolitanae ecclesiae originem, jura, decus, officia 1, ed. von Stramberg, S. 501-509. Lager, Urkundliche Geschichte, S. 1-12. Von Briesen, Urkundliche Geschichte, S. 73 ff. Marx, Erzstift Trier 2,1, S. $388-423$, bes. S. 388-393. Lediglich LEONARDY, Rückgabe, geht intensiver auf DKarol. I 148 ein. Vgl. sodann Koll, Wallfahrt. Conrath, Mettlach. Winheller, Lebensbeschreibungen, S. 87. Zimmermann, Mettlach, S. 123. - Vgl. ferner Ewig, Trier, S. 133 f., 140-142, 186 f., 229-231, 233, 285-290, 315, der Mettlach in den räumlichen Kontext der Zeit einzuordnen versucht. PAuly, Landkapitel Merzig, S. $82-$ 93, untersucht die Pfarrorganisation im Mettlacher Raum und geht den frühen Baustufen des Klosters nach. Er glaubt (ebd., S. 84) an einen echten Kern in der Legende. Auch Martin Klewitz verwendete für die Deutung seines Mettlacher Grabungsbefundes in den fünfziger Jahren zunächst die Liutwin-Viten. Vgl. Klewitz, Baugeschichte. KLEwitz, Mettlach. Der Grabungsbericht steht inzwischen kurz vor der Publikation. Martin Klewitz geht zwar von einer Gründung durch Liutwin aus, wie in den erzählenden Quellen berichtet, nimmt aber aufgrund des Befundes eine sukzessive Entstehung der Bauten über mehrere Jahrzehnte an. Vgl. dazu die freundlicherweise mitgeteilten Überlegungen von Herrn Dr. Martin Klewitz im mir vorliegenden Schreiben vom 14. September 2004. 
chen Kloster geworden, über das zuletzt aber nochmals Lothar I. verfügen konnte. ${ }^{315}$ Zweifel aufgrund der Widersprüche sind ihm nicht gekommen. RAACH verfolgt dann noch Liutwins mögliche Verbindung zu den Saliern. Er geht dabei der Forschungshypothese nach, die Liutwin als Stammvater der Familie der sog. ,Widonen-Lambertiner-Miloniden' sieht. Auch der später in Italien ansässige Wido I. von Spoleto der Lothar-Urkunde sei mit ihm verwandt. Das im Karls-Diplom zu findende vorgeblich widonische Namensgut, auf dem viele der genealogischen Annahmen beruhten, weise darüber hinaus auf Verbindungen zu den Gründern des salischen Hausklosters Hornbach und damit zu deren Familie hin. RAACH hält den geschlagenen Bogen zum späteren Kaisergeschlecht aber zurecht für nicht beweisbar und spekulativ. ${ }^{316}$

Eine Festschrift zum vermuteten 1300jährigen Bestehen Mettlachs 1976 arbeitet in mehreren Einzelstudien die gesamte Klostergeschichte auf. ${ }^{317}$ Doch außer in einer kurzen Chronologie sowie einigen Überlegungen BECKERs über die Mettlacher Äbte werden die Karolingerurkunden darin nicht behandelt. ${ }^{318}$ Das gilt auch für die Literatur der 1980er Jahre. ${ }^{319}$

315 Vgl. Raach, Mettlach, S. 6-22, bes. S. 12 ff. Ebd., S. 18-20, meint Raach, eine Erwähnung in der Notitia de servitio monasteriorum Ludwigs des Frommen von 819 könnte sogar dafür sprechen, daß Mettlach Reichskloster war. Die Passage laute: Monasterium Prub... Mediolano. Prüm und Mettlach könnten gemeint sein. Diese Variante fände sich aber nur in der Edition von Lesne, Les ordonnances monastiques, bes. im Anh. S. 489493, hier S. 490. Die ältere Edition: Notitia de servitio monasteriorum (817), ed. Boretius, S. 349-352, Nr. 171, sowie die neueste Ausgabe: Notitia de servitio monasteriorum (819), ed. BeCKer, S. 493, enthielten diese Stelle nicht. - Raach übersieht allerdings, daß Becker darauf durchaus in seinem Anmerkungsapparat hinweist. Die Passage wird darin als ein Einschub in der von ihm als B bezeichneten Fassung erwähnt (ebd., S. 490, 493 u. Anm. zu Z. 21). Es handelt sich dabei um die Edition von Leon Menard von 1750. Doch ist eine gleich doppelte Verschreibung von Klosternamen in einem so kurzen Abschnitt nicht gerade wahrscheinlich. Mediolano wird denn meist für Mailand gehalten. Aber auch das überzeugt nicht, weil den Kontext ausschließlich westfränkiche Klöster bilden. Zudem wird üblicherweise je Eintrag nur ein Kloster aufgeführt. Deshalb dürfte es sich eher um einen Heiligen mit Ortsangabe handeln. Auch Anton, Liutwin, S. 45 u. Anm. 72, lehnt eine Verbindung zu Mettlach hier ab. Vgl. zur Notitia zuletzt WAGNER, Notitia.

316 Vgl. RaAch, Mettlach, S. 23-36. Die Verbindung Liutwins zu den Widonen beruht auf umfangreichen älteren Forschungen. Der Großteil der älteren Literatur findet sich bei Raach zusammengefaßt. Vgl. hier nur die wesentlichen Titel Doll, Piminskloster Hornbach, S. 108-142. Metz, Miszellen, S. 1-27. Zur neueren Literatur vgl. HLAwiтschka, Widonen (Lambertiner), Sp. $72-74$.

317 Vgl. 1300 Jahre Mettlach.

318 Vgl. Becker, Mettlacher Äbte, bes. S. 43 f. Junges, Mettlach - eine Gründung Liutwins, S. $13 \mathrm{f}$., stellt sie noch chronologisch-tabellarisch zusammen, geht allerdings ausgesprochen unkritisch mit dem Material um.

319 Vgl. dazu nur Gauthier, Évangélisation, S. 360 f. u. 365, der ganz kurz die Urkunde Karls des Großen für Mettlach streift. 
Anton will 1991 in der Karls-Urkunde dann erneut wesentliche Angaben zur Gründung Mettlachs sowie zu den Verwandtschaftsverhältnissen Liutwins erkennen und behandelt sie ausführlicher. Liutwin habe Mettlach der Trierer Kirche testamentarisch vermacht. Es handle sich um ein adliges Eigenkloster, über das die Karolinger wie Allodialbesitz verfügten. ${ }^{320}$ Herrmann faßt 1993 kurz den Forschungsstand zusammen und geht für Lothar von königlichen Rechten am Kloster aus. ${ }^{321}$ Brigitta Merta hebt 1994 für die Karls-Urkunde die besondere Stellung des Königsgerichtes hervor. Wie die vorausgehende Literatur betont sie die innere Abhängigkeit der Mettlacher Urkundengruppe und geht fest vom Doppelepiskopat Liutwins in Reims und Trier aus. ${ }^{322}$

Zum ersten Mal äußert Schmal dann ganz grundsätzliche Zweifel an allen vier Urkunden. ${ }^{323}$ Der Verdacht begründe sich durch die engen textlichen Übereinstimmungen der Diplome von 842, 884 und 888. Alle drei erwähnten Vorgängerurkunden zu Mettlach von Pippin (751-768), Karl dem Großen (768-814) und Ludwig dem Frommen (813/4-840). Doch nur das Diplom Karls sei erhalten. Es berühre sich inhaltlich aber nicht mit den anderen. Welche Urkunden seien dann aber gemeint? Schmal will deshalb darin andere Diplome für die Trierer Kirche erkennen, die aber unmittelbar nichts mit Mettlach verbinde. Zunächst einmal sei es eine im Original erhaltene Privilegienbestätigung Ludwigs des Frommen von 816 für Trier $\left(\mathrm{BM}^{2}\right.$ 626), ${ }^{324}$ dann sowohl eine auf ihrer Basis später gefälschte Urkunde Pippins für Trier von 760 (DKarol. I $\dagger 36)^{325}$ als auch eine weitere, in dieser Weise konzipierte Fälschung auf Karl den Großen von 772/4 (DKarol. I †226). ${ }^{326}$ Diese drei Urkunden stimmten deshalb in großen Teilen wörtlich überein. Die beiden Fälschungen seien nicht vor dem 10. Jahrhundert entworfen worden, wobei sie sich den Überlegungen von Dopsch und Oppermann dazu anschließt. Eine mit dieser Gruppe inhaltlich ebenso verbundene, auf den Merowingerkönig Dagobert (†638/9) 634 datierende Fälschung klammert sie aus, weil sie später entstanden sei. - Allerdings

320 Vgl. Anton, Liutwin, S. 33, 36-45. Anton, Trier im frühen Mittelalter, S. 156-158, 169, 183, 200. Er hält Liutwin für einen möglichen Mettlacher Abtbischof. So auch schon Gauthier, Évangélisation, S. 358, 361 f. Vgl. dagegen RaAch, Mettlach, S. 12. Vgl. zu Mettlach hier auch Germ. Pont. 10, ed. Boshof, S. 246 ff.

321 Vgl. Herrmann, Mettlach, Sp. 585.

322 Vgl. Merta, Durchsetzung von Besitzansprüchen, S. 172-179.

323 Vgl. Schmal, Mettlach, S. 36-43.

324 Vgl. MRUB I 50, S. 55-57. BM 626, S. 262. Eine Abbildung bietet KöLzer, Studien, Taf. 29.

325 Vgl. DKarol. I †36, S. 50-52. MRUB I †12, S. 15 f. Die Urkunde existiere nur noch als spätere Kopie.

326 Vgl. DKarol. I †226, S. 304-306. MRUB I †26, S. 30-32. Von der Urkunde sei nur noch eine Nachzeichnung vorhanden. Eine Abbildung davon findet sich bei KöLzer, Studien, Taf. 26. Schmal, Mettlach, S. 38, datiert die Urkunde auf 772 und folgt dabei dem MRUB, während die MGH-Edition 774 angibt. 
verschweigt sie, daß allen diesen Urkunden gemeinsam ist, daß sie den Trierer Bischof Modoald als Gründer des Trierer Klosters Oeren nennen, worauf später zurückzukommen ist. ${ }^{327}$ - Zwischen der Fälschung auf Pippin zu 760, dem echten Ludwigs-Diplom von 816 und dem DKIII. 102 von 884 ließen sich ebenfalls längere identische Passagen erkennen. Auch in DKarol. I $† 226$ sowie in DArn. 39 seien solche Passagen zu finden. Schmal sieht ferner kleinere Übereinstimmungen mit DLoI. 67. Da nun die Urkunden von 760 und 772/4 falsch seien, gelte das auch für alle Mettlacher Karolingerdiplome des 9. Jahrhunderts. DKIII. 102 und DArn. 39 nennten Erzbischof Liutwin als Donator des Klosters an Trier. Da DLoI. 67 daraus wohl in einem zweiten Manipulationsschritt noch den origo Widos von Spoleto zum Schenker mache, sei die intendierte Fälschungsabsicht, Liutwin zum Stammvater der Widonen zu erheben und damit eine nachträgliche Verbindung zwischen Liutwin und Wido herzustellen. ${ }^{328}$ Es handle sich um eine komplette Fälschungsserie. Zu dieser gehöre auch die KarlsUrkunde von 782 mit ihren starken inhaltlichen Widersprüchen, die als letztes Glied dieser Kette entstanden sei. ${ }^{329}$

Schmals grundsätzliche Kritik ist berechtigt. Allerdings übersieht sie bei ihrem Abhängigkeitsmodell, daß sich DKIII. 102 und DArn. 39 auch ganz einfach allein aus der echten $\mathrm{BM}^{2} 626$ von 816 entwerfen ließen. Der dann noch fehlende Inhalt ergäbe sich aus den umfangreichen Übereinstimmungen mit dem ebenfalls zeitlich vorher datierenden DLoI. 67 von 842, das Schmal wegen des origo-Bildes jedoch fast ans Ende der Fälschungskette und damit nach den Urkunden Karls III. und Arnulfs plaziert. DDKarol. I $† 36$ und $† 226$ beziehen sich dagegen in keiner Form inhaltlich auf Mettlach und sind zur Erklärung der Mettlacher Diplome in keiner Weise erforderlich. Deshalb drängt sich förmlich die Frage nach dem Wie der Überlieferung unserer vier Mettlacher Rechtstexte auf.

327 Auch Kölzer, Studien, S. 140, hält die Ludwigs-Urkunde für echt. Zum Fälschungsnachweis der anderen beiden Urkunden vgl. die Edition sowie die Ergebnisse von Dopsch, Trierer Urkundenfälschungen, S. 321-323, 332, 337, 342 f., und OppermanN, Rheinische Urkundenstudien 2, S. 132 f., 161, 191, der von einer Entstehung um 1100 ausgeht. Schmal, Mettlach, S. $27-29,38$ u. Anm. 247, merkt an, daß sie nicht vor dem 10. Jahrhundert entstanden sein können. Sie seien frühestens 973 und spätestens 1139 zustande gekommen. Dopsch weist zudem auf eine Verbindung dieser Urkunden zum DZw. $\nmid 4$ hin, das damit gleichzeitig konstruiert worden sein müsse. Da die manipulierten Urkunden - abgesehen von der Ludwigs des Frommen - auch Oeren als Trierer Besitz und Gründung Modoalds erwähnen, dürften sie nicht vor dem Konflikt zwischen dem Erzstift und Oeren am Ende des 10. Jahrhunderts entstanden sein. Vgl. dazu auch Schieffer, Lothringische Kanzlei, S. 71, 82-92, sowie insgesamt oben Kap. D.II.6. Vgl. zur Dagobert-Urkunde sowie zu dem die Urkunden insgesamt verbindenden Bild des Gründers Modoald unten S. 218 f. u. Anm. 377.

328 Vgl. Schmal, Mettlach, S. 39, Anm. 251 u. S. 40 f., 259, 261.

329 Vgl. Schmal, Mettlach, S. 41-43. 


\section{Die Überlieferung der Karolingerdiplome}

Schmal berücksichtigt bei ihrer Argumentation kaum, daß die Urkunde Lothars I. von 842 als einzige der vier Karolingerdiplome zu Mettlach im Original erhalten ist. ${ }^{330}$ Das Diplom befindet sich heute im Landeshauptarchiv Koblenz. Zwar ist es mutiliert, denn nur die linke Hälfte ist noch vorhanden. Es besteht jedoch kein Anlaß, sie für manipuliert zu halten. Verdächtige Spuren weist sie nicht auf (vgl. Abb. 2 im Anhang). ${ }^{331}$ Mehrfache Veränderungsstufen an diesem Dokument sind deshalb unwahrscheinlich. Allerdings fehlen mit der rechten Seite etwa zwei Drittel des Pergaments und damit entscheidende Teile des Rechtsinhalts. ${ }^{332}$

Die Fehlstellen lassen sich ergänzen. Denn für Trier liegen weitere, wenn auch spätere wichtige Quellen vor: Es handelt sich um eine Gruppe von vier Chartularen, die unter Erzbischof Balduin in der Mitte des 14. Jahrhunderts angelegt wurden, die sog. Balduineen. ${ }^{333}$ Drei davon enthalten den Text aller Mettlacher Urkunden und ebenso den von $\mathrm{BM}^{2}$ 626, DDKarol. I †36 und $\dagger 226 .^{334}$

Diese drei Balduineen ordnen die Rechtstexte nach einzelnen Abteilungen. Alle unsere Diplome finden sich unter: Privilegia regum et imperatorum putrefacta. Neben einer weiteren Gruppe für unbesiegelte Urkunden sonderte man hier vermeintlich verderbte Dokumente aus. Es handelte sich dabei um Urkunden, die den Kompilatoren zum einen grundsätzlich verdächtig erschienen, aber wohl auch um solche, die mutiliert waren und deshalb Anlaß zu Bedenken boten. Von den heute aus der Gruppe noch erhaltenen „Vorlagen“ für die Abschriften finden sich Beispiele für beides. In dieser Aussonderung erkennt Мӧтsсн (1980) gar Ansätze zu einer frühen Quellenkritik. Von 30 Urkunden dieser Gruppe seien sechs Fälschungen. Allerdings wird man die Zahl der Fälschungen inzwischen nach oben korrigieren müssen. So befinden sich in dieser Abteilung nahezu alle Königsurkunden für die Trierer Kirche aus dem 7. und 8. Jahrhundert, auch DDKarol. I †36 und $† 226$. ${ }^{335}$

330 Vgl. Schmal, Mettlach, S. 37, Anm. 230. Sie weist in einer Anmerkung kurz darauf hin, bezieht das aber nicht mehr weiter in ihre Überlegungen ein.

331 Vgl. Koblenz, Landeshauptarchiv, Best. 1 A Nr. 4 (= LBA 5125).

332 Aber auch das Original Ludwigs von $816\left(\mathrm{BM}^{2}\right.$ 626), das in die Urkunden Karls III. und Arnulfs einging, ist stark beschädigt. Vgl. dazu oben S. 202 u. Anm. 324.

333 Vgl. dazu insgesamt Möтsсн, Balduineen, bes. S. 3-63, zu den verschiedenen Handschriften, der Entstehung, den verwendeten Urkunden und der Datierung. Hiersemann, Balduineum Kesselstatt. Heyen, Balduin.

334 Vgl. Мӧтsсн, Balduineen, S. 90-92.

$335 \mathrm{Zu}$ diesen Kategorien vgl. Мӧтsсн, Balduineen, S. 44 u. Anm. 152. Bei der Einordnung der Urkunden übersieht er (ebd., S. 41-46, bes. S. 42), daß es sich bei der Urkunde Pippins an Weomad von 760 und der Karls des Großen an Weomad von 774 um Fälschungen handelt. Vgl. dazu oben S. 202 f. u. Anm. 325 ff. - Die Urkunden dieser 
An deren siebter und achter Stelle stehen DKarol. I 148 und DKIII. 102 hintereinander als Paar. An elfter Stelle befindet sich $\mathrm{BM}^{2}$ 626. Gleichsam an 14. und 15. Position erscheinen DLoI. 67 sowie DArn. 39 wieder als Paar. Echte und falsche Urkunden sind gemischt, auch chronologisch. Anordnungskriterium sind offensichtlich die Königsnamen. Deshalb folgt als Aussteller Karl III. (876-888) auf Karl den Großen (768-814) und Ludwig das Kind (893-911) auf Ludwig den Frommen (813/4-840). ${ }^{336}$ Zwar sind für den Text des Lothar-Diploms Interpolationen vor seinem Weg in die Balduineen nicht auszuschließen, doch insgesamt ist dem dort wiedergegebenen Inhalt zu trauen. ${ }^{337}$

Wenn aber DLoI. 67 noch als Original vorliegt, dann steht es nicht am Ende einer Fälschungsserie. Es ist vielmehr das vertrauenswürdigste der vier Karolingerdiplome. Gerade deshalb muß es am Anfang einer Untersuchung der Mettlacher Urkunden stehen, gefolgt zunächst von dem inhaltlich stark aus ihm

Gruppe lassen sich bei Мӧтsсн, S. 81 ff., schnell über seine chronologische Urkundenliste zusammenstellen. Enthalten sind in dieser Abteilung in folgender Reihenfolge: 1. die falsche Urkunde Dagoberts für die Trierer Kirche von 634 (MRUB I †5); 2. Pippins falsche Urkunde vom 17. Juni 760 für Weomad von Trier (DKarol. I †36); 3. eine Urkunde Pippins II. von Aquitanien ( $\dagger$ nach 864) für Hetti vom 25. Juli 847 (MRUB I 78); 4. Karls des Großen echtes, doch teils verdächtiges Diplom vom 1. April 772, in dem er Weomad die Immunität für Trier verleiht (DKarol. I 66); 5. die falsche Urkunde Karls des Großen für Weomad vom 1. September 772/4, in der er die Immunität bestätigt (DKarol. I †226); 6. eine falsche Urkunde Karls des Großen für Weomad vom 1. September 802 (DKarol. I †268). Vgl. dazu ferner Anm. 336.

336 Der weitere Verlauf ist 9. die Urkunde Karls III., des Einfältigen (893/98-923), für Erzbischof Ruotger vom 13. Juni 919, in der er die Abtei Maastricht restituiert (MRUB I 160; Koblenz, Landeshauptarchiv, Best. 1 A Nr. 11); dann 10. eine ähnliche Urkunde Karls III. vom 9. Juli 919 (MRUB I 161; kein Original erhalten); 11. BM² 626 für Erzbischof Hetti von 816 mit der Privilegienbestätigung; danach zwei Urkunden von Ludwig dem Kind, nämlich: 12. die erste vom 19. September 902 für Erzbischof Radbod mit der „Restitution der Münze und anderer entfremdeter Rechte“ (DLdK 17, S. 120-122; kein Original erhalten); 13. die zweite vom 11. Februar 908 für Radbod mit einer Güterschenkung zu Enkirch (DLdK 59, S. 187-189; Koblenz, Landeshauptarchiv, Best. 1 A Nr. 9). - Soweit entsprechende Vorlagen existierten bzw. existieren, finden sich heute schwarz-weiß Aufnahmen dieser Urkunden abrufbar in der Online-Datenbank des Forschungsinstituts Lichtbildarchiv älterer Originalurkunden (LBA) der Philipps-Universität Marburg unter http://lba.hist.uni-marburg.de/lba/pages/ [10.03.2009].

337 Das gilt auch für $\mathrm{BM}^{2}$ 626. Von der Ludwigs-Urkunde ist noch umfangreicherer Text erhalten, der verglichen mit dessen Wiedergabe in den Balduineen keinen Anlaß zu grundsätzlichen Zweifeln bietet. - Schmal, Mettlach, S. 22, 37, 41, Anm. 128-130, $231 \mathrm{f}$., 265, weist auf die litteras putrefactas in den Balduineen hin, für sie ein Indiz für die Manipulation der Diplome. Doch muß man zur Kenntnis nehmen, daß sich ebenso echte Urkunden in dieser Gruppe befinden. Auch bezieht sich Schmal dabei nur auf die Ausführungen des MRUB und übersieht die umfassende Arbeit von Мöтsch zu den Balduineen. 
schöpfenden DKIII. 102 sowie dem wiederum daraus schöpfenden DArn. 39. Auf der Basis der dabei gewonnenen Erkenntnisse gilt es endlich, das widersprüchliche DKarol. I 148 genauer in den Blick zu nehmen.

\section{Die als Original erhaltene Urkunde Lothars I. von 842 (DLoI. 67)}

Am 29. August 842 stellte Kaiser Lothar I. (817/40-855) in Mötsch, das dem Kloster Prüm gehörte und bei Bitburg in der Eifel liegt, diese Urkunde für die Trierer Kirche unter Erzbischof Hetti aus. Die Urkunde stamme von der Hand des Remigius, so der Editor Theodor Schieffer. Verhandelt wurde der Rechtsgegenstand des Diploms zuvor in Trier. Es entstand während der Beratungen vor dem Teilungsvertrag von Verdun 843 zwischen Lothar und seinen Brüdern, Karl dem Kahlen von Westfranken und Ludwig von Ostfranken, wodurch die verlustreichen karolingischen Bruderkriege zunächst beendet wurden. ${ }^{338}$

Zum Inhalt des Diploms: ${ }^{339}$ Lothar habe wegen des überaus schwierigen Teils seiner eingeengten und beschränkten Herrschaft aus dem Besitz der Kirche

338 Vgl. dazu den Kommentar von Schieffer zum DLoI. 67, S. 178 f. Zu den Bruderkriegen und deren Vorgeschichte vgl. auch Nelson, Search für peace. Schieffer, Karolinger, S. 117 f., 125-143. Fried, Weg, S. 350-378. Boshof, Ludwig der Fromme, S. 129-134, 178 ff. Hartmann, Ludwig der Deutsche, S. 27-44. Nelson, Charles, S. 105-136. Lothar I. erhielt ein konstruiertes Mittelreich, das als Landstreifen von Friesland bis nach Italien reichte.

339 Vgl. MRUB I 69, S. 77 f. DLoI. 67, S. 179 f. (In Klammern stehen die aus den Balduineen ergänzten Textstellen. Die Numerierung in fetten Lettern entspricht der Zeilenzählung des Originals.): [1] In nomine domini nostri Iesu Christi dei aeterni. Hlotharius divina [ordinante providentia imperator augustus. Si enim ea, que contra racionis ordinem et divinam ammonicionem propter humanarum rerum nos] [2] egisse cognoverimus et ea summa cum diligentia ad emendationem perducere studuerimus, id nobis procul du[bio ad regni nostri stabilitatem et eterne felicitatis gloriam minime pertinere diffidimus. Proinde omnium sancte dei ecclesie nostrorumque tam presentium quam et futurorum] [3] noverit industria, quia nos propter arduam et strictam regni nostri partem angustati et constricti [concessimus ex rebus sancti Petri Treuerensis ecclesie quoddam monasterium quod vocatur Medelacus cuidam ex proceribus nostris Witoni Spolitanorum duci, cuius origo ad prefatam ecclesiam propter dei amorem memoratum contulit] [4] monasterium. Sed dum nos propter totius regni nostri utilitatem atque suscipiendam [G]recorum legationem Treueris civi[tate una cum multis ex fidelibus nostris venissemus, adiens celsitudinis nostre clementiam Heti iam dicte sancte ecclesie venerabilis archiepiscopus una cum clero et populo illius urbis aures nostras pulsans] [5] atque praedecessorum nostrorum auctoritates nostris obtulit obtutibus. [Cum autem eiusdem auctoritates in nostra vel procerum nostrorum presentia relegi fecissemus, repperimus, qualiter a propinquis iam dicti Witonis ducis idem monasterium ad memoratam fuisset delegatum ecclesiam vel quomodo] [6] a praedecessoribus nostris, regibus videlicet et magnis imperatoribus Pippino glorioso regi, Karolo invictissimo [augusto atque pie recordationis domni et genitoris nostri Hludowici prestantissimi augusti, ibidem fuisse con- 
des hl. Petrus in Trier ein Mettlach (Medelacus) genanntes Kloster einem gewissen Wido, Herzog der Spoletaner, aus dem Kreis seiner Vornehmen überlassen. Dessen origo habe das Kloster aus Liebe zu Gott der genannten Kirche übertragen. Aber während Lothar zum Nutzen seiner ganzen Herrschaft und, um eine Gesandtschaft der Griechen zu empfangen, in die Stadt Trier mit vielen seiner Vasallen gekommen war, wandte sich Hetti, der Erzbischof der schon genannten ehrwürdigen hl. Kirche, an die Milde von Lothars Erhabenheit. Gemeinsam mit dem Klerus und Volk jener Stadt richtete er eine Bitte an Lothar und legte seinen Augen Urkunden von dessen Vorgängern vor. Als jedoch die Urkunden desselben in Lothars und seiner Vornehmen Gegenwart vorgelesen worden waren, habe Lothar erkannt, wie dasselbe Kloster von den Verwandten (a propinquis) des bereits genannten Herzogs Wido der erwähnten Kirche übertragen und wie dieses ebendarin von Lothars Vorgängern bestätigt worden war, Königen nämlich und großen Kaisern, dem ruhmreichen König Pippin, dem unbesiegbaren Kaiser Karl und von Lothars Herrn und Vater, dem vortrefflichsten Kaiser Ludwig, seligen Angedenkens. Da Lothar aber die ganze Wahrheit der Sache erkannt habe, gefalle es der Gunst seiner Erhabenheit wegen der Liebe Gottes, der Verehrung desselben hl. Ortes und der treuesten Ergebenheit des dortigen Bischofs, daß er das erwähnte Kloster mit all seinen Besitzungen der schon genannten Kirche des hl. Petrus in Trier zurückgibt. [Und deshalb] ${ }^{340}$ habe er beschlossen, daß [diese seine] kaiserliche Urkunde verfaßt

firmatum. Nos autem omnem rei veritatem cognoscentes propter amorem dei et] [7] convenerationem ipsius sancti loci seu fidelissimam eiusdem sedi praesulis devotionem placuit celsitudinis [nostre serenitati, ut prefatum monasterium cum omnibus suis pertinentiis iam dicte restitueremus sancti Petri Treuerensi ecclesie. ..............] [8] imperiales litteras fieri censuimus, per quas sanccimus modisque omnibus confirmamus, ut sicut ..................... [fuit idem confirmatum cenobium, ita nostris ac successorum] [9] nostrorum temporibus ad utilitatem praefatae ecclesiae absque alicuius contradictione vel repetitione seu qualibet refragatione [inviolabiliter per hanc nostram auctoritatem perseveret, quatenus clerus et populus ibidem deo deserviens pro nobis, coninge ac prole seu tocius imperii a deo nobis collati stabilitate] [10] domini misericordiam attentius exorare delectet. Et si quis contra hanc [confirmationem] nostram aliquid irrationabiliter [agere temptaverit aut a predicta sancte Treuerensi ecclesia illud auferre conaverit, anathema sit. Et ut hec nostre confirmationis atque concessionis auctoritas] [11] nostris et futuris temporibus inviolabilem atque inconvulsam obtineat firmitatem, manu propria subter eam firmavimus at anuli nostri inpres[sione adsignari iussimus.]

Signum (MF) Hlotharii serenissimi augusti.

[Remigius] notarius advicem Agilmari [recognovi].

Data IIII kal. septbr. anno Christo propitio imperii domni Hlotharii pii imperatoris in Italia XXIII et in Francia III, indictione IIII; actum MaLrciaco villa sancti Salvatoris de Prumia; in dei nomine feliciter amen.]

340 Die hier vorgenommenen Ergänzungen folgen DKIII. 102, S. 166, das diese Urkunde teilweise verwendete und dessem Verfasser wenigstens noch ein Teil der hier ausgefallenen Stelle vorgelegen haben muß. In diesem Fall: Et ideo has nostras. - Auch der Editor 
wird. Er bestimme durch sie und bestätige in allem, daß, wie [durch die Urkunden seiner Vorgänger] ${ }^{341}$ dasselbe Kloster bestätigt worden sei, es so zu seinen und seiner Nachfolger Zeiten unverletzlich bei der Nutznießung (ad utilitatem) der genannten Kirche durch diesen seinen Beschluß verharre ohne irgendjemandes Widerspruch, Klage oder irgendeine Anfechtung. Das gelte, solange der Klerus und das Volk, das Gott ebendort eifrig diene, sich damit beschäftige, die Gunst des Herrn für Lothar, seine Gattin, seinen Nachkommen und für die Stetigkeit seiner ganzen ihm von Gott übertragenen Herrschaft inbrünstiger zu erflehen. - Es folgt die Poenformel. Von den erwähnten vorgelegten Urkunden ist jedoch nur die Karls des Großen überliefert, aber offenbar inhaltlich nicht verwendet worden.

$\mathrm{Daß}$ den Balduineen das Original von DLoI. 67 vorgelegen haben muß, zeigt sich an einem selbst noch am erhaltenen Fragment erkennbaren, wohl schon alten Textverlust in der Mitte von Zeile acht. Er dürfte sich in den heute verlorenen Teil nach rechts fortgesetzt haben. Denn lediglich acht Worte vom Ende dieser Zeile sind noch in den Balduineen erhalten. Aber nicht nur dieser Ausfall ging in die Kopiarbücher ein. Auch am Schluß der Zeile sieben, den nur noch die Chartulare überliefern, fehlen mehrere Worte. Der Vergleich mit der weitaus größeren Länge der vorausgehenden Zeilen legt das nahe. Erst Zeile neun ist wieder vollständig aufgenommen. Das spricht dafür, daß bei der Abschrift im 14. Jahrhundert schon ein Schaden am Pergament vorlag, der das Ende der siebten und die Mitte der achten Zeile unlesbar machte. Offenbar wußte der Kopist mit dem dazwischenstehenden Text (also dem Beginn der achten Zeile) nichts Rechtes anzufangen und ließ ihn ebenfalls weg. Vielleicht wies man die Urkunde deshalb den litteris putrefactis zu. ${ }^{342}$ Damit ist der dort überlieferte echte Text aber verifizierbar.

Das gilt ebenso für den Inhalt. Denn für die erwähnte byzantinische Gesandtschaft gibt es weitere Belege: der Hinweis auf ihren Aufenthalt in Trier in den Annales Bertiniani zum Jahr 842 sowie ein Papyrusfragment eines byzantinischen Kaiserbriefs von St-Denis aus diesem zeitlichen Umfeld. ${ }^{343}$ Auch die

des Lothar-Diploms, Theodor Schieffer, bietet eine ähnliche Ergänzung an: Quapropter has nostras. Vgl. dazu DLoI. 67, S. 180, Anm. q.

341 Vgl. dazu nochmals DKIII. 102, S. 166, wo in unmittelbarem Zusammenhang mit dem von der Lothar-Urkunde übernommenen Text folgende Passage zu finden ist: per auctoritates antecessorum nostrorum plenius in dei nomine. In die hier paraphrasierende Übertragung wird jedoch nur eine davon gekürzte Version übernommen, um die Kernaussage zu verdeutlichen. - Auch Theodor Schieffer ergänzt ähnlich. Vgl. dazu DLoI. 67, S. 180, Anm. r: a praedecessoribus nostris praedictae Treuerensi ecclesiae.

342 Zum Textverlust in den Balduineen vgl. DLoI. 67, S. 189 u. Anm. q-r.

343 Vgl. Ann. Bert. ad a. 842, ed. Waitz, S. 28, sowie die Ausführungen Schieffers in den Vorbemerkungen zu DLoI. 67, S. 179. Zur byzantinischen Gesandtschaft vgl. auch Ohnsorge, Kaiserbündnis, bes. S. 107 ff. Offenbar wollte man Lothar bzw. über ihn 
formelhafte Passage mit der dringlichen Bitte um das Gebet für den Kaiser, seine Familie und dessen Herrschaft fügt sich bestens in die Zeit vor dem Vertrag von Verdun 843 ein. Im Jahr der Urkundenausstellung 842 war nämlich keineswegs klar, daß dessen Abschluß zunächst erfolgreich drei karolingische Teilreiche schaffen würde. Man erkennt förmlich Angst und Sorge Lothars vor der $\mathrm{Zu}$ kunft. ${ }^{344} \mathrm{Da}$ sich der Hinweis auf vorausgehende Urkunden zu Mettlach zumindest für Pippin und Karl den Großen auf dem Originalfragment befindet, handelt es sich dabei kaum um eine nachträgliche Manipulation. Es legt im Gegenteil eine glaubwürdige Grundlage nahe. ${ }^{345}$

Wido I. von Spoleto (842-ca. 859) und sein Vater, Graf Lambert I. von Nantes (†837), - Angehörige der mehrfach erwähnten fränkischen WidonenSippe - waren Anhänger Lothars. Sie begleiteten ihn mit zahlreichen anderen seiner Großen, als er - nach den Aufständen der Söhne gegen ihren Vater Ludwig den Frommen (813/4-840) 830 und 833 - vom Vater im Jahr 834 nach Italien verbannt wurde. Die alte Nachfolgeordnung von 817 , die für Lothar noch eine überragende Position als Kaiser vor seinen Brüdern Pippin (I. von Aquitanien, 814-838) und Ludwig (dem Deutschen, * 805, † 876) vorsah, mußte geändert werden. Die Geburt Karls des Kahlen $(* 823$, $† 877)$ als Kind von Ludwigs zweiter Frau Judith $(\dagger 843)$ hatte für erheblichen Zündstoff gesorgt, weil für Karl ein eigenes Teilreich eingerichtet wurde. Nach dem Tod Kaiser Ludwigs 840 aber kehrte Lothar mit seinen Anhängern über die Alpen zurück, um seine Ansprüche auf ein alleiniges Kaisertum gegenüber seinen Brüdern geltend zu machen. Vermutlich erhielt Wido bei dieser Gelegenheit für seine Treue den ehemaligen Vorfahrenbesitz Mettlach übertragen. ${ }^{346}$ Lothar setzte sich jedoch nicht gegen seine Brüder durch. Er verlor die Schlacht bei Fontenoy am 25. Juni 841. - Auch hier wäre an eine Übertragung Mettlachs an Wido in einer Zeit der Not zu denken oder schon 834/5 im Vorfeld von Lothars Gang ins italienische Exil. - Nach dem öffentlich vor den Anhängern beeideten Bündnis Karls und Ludwigs in Straßburg im Februar 842, das sich gegen Lothar

u. a. seinen Sohn Ludwig II. in Italien um Hilfe gegen die Sarazenen bitten. Vgl. dazu BM $^{2}$ 1091o-1092, S. 450. Dölger, Regesten 1, Nr. 442, S. 53.

344 Vgl. dazu auch nochmals oben Anm. 338.

345 Vgl. dazu nochmals oben Anm. 328. Auch die weiteren Argumente Schmals für eine Fälschung lassen sich nicht halten: So will sie an der Passage Heti iam dicte sancte ecclesie venerabilis archiepiscopus erkennen, daß Hetti ursprünglich einmal zu Beginn der Urkunde (dicte) erschienen sei, später aber entfernt wurde. Dabei übersieht sie, daß sich dies - schon aufgrund des Genus' - nicht auf Hetti, sondern die direkt nach ihm erwähnte Trierer Kirche bezieht. Schmal geht zudem von einer möglichen Manipulation durch Thiofrid von Echternach aus. Doch eine der beiden von ihr als Fälschungsindiz angeführten Stellen findet sich noch auf dem Originaldiplom. Vgl. dazu Schmal, Mettlach, S. 41 u. Anm. 261. - Die übrige Literatur hält das Diplom und seinen Inhalt für glaubwürdig. Vgl. dazu RaAch, Mettlach, S. 25 f. Anton, Liutwin, S. 43 u. Anm. 69. 346 Vgl. nochmals RAACH, Mettlach, S. 25 f. 
richtete, fanden sich schließlich alle Parteien im Juni desselben Jahres zu ersten Verhandlungen bereit. Nachdem Wido Mettlach 842 zugunsten von Lothars Memoria und dessen bischöflichen Vertrauten Hetti (814-847) wieder verlor, kehrte der Adlige bald nach Italien zurück. Seine Familie aber sollte einmal selbst Kaiser stellen. ${ }^{347}$ Hetti stand im Konflikt zunächst auf Seiten Ludwigs des Frommen. Nach dessen Tod aber wechselte er dauerhaft auf Lothars Seite, wohl weil sein Bistum nun zu Lothars Herrschaftsbereich zählte. ${ }^{348}$

Die Art, wie Lothar hier mit Mettlach umging, erinnert in der Tat mehr an königlichen, als an kirchlichen Besitz. ${ }^{349}$ Auch daß Mettlach mit seiner Ortsbezeichnung und nicht seinen Patrozinien genannt wird, unterstreicht diesen Eindruck. Warum überträgt Lothar ferner das Kloster ad utilitatem? Dem stehen die von Hetti vorgelegten Urkunden entgegen: Lothars Vorgänger hätten der Trierer Kirche immer wieder den Besitz Mettlachs bestätigt. Aber auch das könnte man als wiederholte Lehensvergabe interpretieren. Ist das aber gemeint? Oder stattete Lothar den Wido tatsächlich mit entfremdetem Kirchengut aus? Oben haben wir bereits gesehen, daß auch Reims im Zuge der Bruderkriege erheblichen Besitz verloren hatte, um dessen Rückerwerb Erzbischof Hinkmar (845-882) bemüht war. Dabei wählte er so manchen außergewöhnlichen Weg und scheute vor weitreichenden Konstruktionen nicht zurück. ${ }^{350}$ Muß man das auch für den Trierer Erzbischof Hetti annehmen? Auszuschließen ist es nicht. Vielleicht aber ist der Hinweis auf die Vorgänger nur topisch gebraucht.

Das Diplom bot - wie gesehen - immer wieder Anlaß, in Liutwin den Stammvater der sog. ,Widonen-Lambertiner-Miloniden' und den Gründer Mettlachs zu sehen. Einmal heißt es ja, Widos origo habe das Kloster Trier übertragen. Etwas später wird wiederholt, Mettlach sei a propinquis des Wido an Trier gegeben worden. ${ }^{351}$ Liutwin selbst bleibt unerwähnt. Doch hat man ihn hinter origo vermutet und sich nicht an der zweiten Stelle gestört. Sie aber kann

347 Vgl. zu Wido ausführlicher Hlawitschka, Wido I., Sp. 67 f. Hofmeister, Markgrafen, S. 349-356. Hlawitschka, Die Widonen im Dukat von Spoleto, S. 27-44. Hlawitschka, Politische Intention, S. 126-129. Zur politischen Gesamtsituation vgl. nochmals oben Anm. 338.

$348 \mathrm{Zu}$ Hetti vgl. Anton, Trier im frühen Mittelalter, S. 167-171, 199-201. Depreux, Prosopographie, Nr. 150, S. 244-246. Unter Ludwig war Hetti auch kaiserlicher Legat im Missatwesen, unterstützte dessen Kirchenreform und fand sich an Ludwigs Sterbebett in Ingelheim 840. Als Dank erhielt er wohl von Ludwig die Abtei Echternach. - Zu Hetti vgl. auch DLoI. 87, S. 211 f., vom 1. Januar 845. Es handelt sich um einen Tausch Hettis mit dem Prümer Abt, der im Liber aureus von Prüm erhalten ist. Vgl. dazu Hioki, Stadtherrschaft, S. 22 f. Goerz, Regesten der Erzbischöfe von Trier, S. 1.

349 Vgl. Herrmann, Mettlach, Sp. 585, der von königlichen Rechten am Kloster spricht, die noch Lothar I. ausübte.

350 Vgl. dazu oben Kap. B. u. C.

351 Vgl. z. B. RaAch, Mettlach, S. 25, Anm. 13. Schmal, Mettlach, S. 40, geht davon aus, man habe origo hier später eingefügt, um einen Bezug zu Liutwin herzustellen. 
nicht eine Person meinen, denn dann müßte es a propinquo heißen. Vielmehr sind hier mehrere Verwandte gemeint. Und das muß kein Widerspruch sein. Denn origo kann ebenfalls im Sinne von „Sippe“, „Familie“ oder „Verwandte“ gebraucht werden. ${ }^{352}$ Ebenso wäre auch an eine Verlesung des Kopisten im 14. Jahrhundert zu denken. Vergleicht man die Handschrift des Remigius im Original dieser Urkunde und in dem von DLoI. 70 könnte im Text ursprünglich einmal stirps, also Sippe, gestanden haben. In jedem Fall muß die Bedeutung des verwendeten Begriffs a propinquis entsprochen haben. ${ }^{353}$ Das heißt also, die Familie Widos hatte Mettlach noch zu Zeiten Pippins an Trier übertragen. Berücksichtigt man allein den Text dieser Urkunde, liegt das näher, als vom bischöflichen Stammvater Liutwin auszugehen. An einen solchen Ahnen hätte man sich doch sonst noch namentlich in Widos Familie, in Trier oder Mettlach erinnern müssen. ${ }^{354}$ Wußte man überhaupt noch genaueres über die Schenker-Vorfahren? Wenn die Lothar vorgelegten Urkunden glaubwürdig waren, mußten sie darüber Informationen enthalten. Doch keiner dieser Vorfahren scheint so bedeutend gewesen zu sein, daß er eigens genannt wird. Wahrscheinlich erwähnten die Urkunden mehrere Personen. Gegen Liutwin spricht auch, daß die erste Übertragung unter Pippin III. erfolgt sein soll. Denn Liutwins Episkopat ist immer in die Zeit des frühen 8. Jahrhunderts datiert worden. ${ }^{355}$ Und hätte nicht auch Erzbischof Hetti mit einem namentlich bekannten früheren Trierer Bischof als Schenker Mettlachs argumentieren müssen? Das Lothar-Diplom legt also nahe, daß Mettlach das Eigenkloster von Widos Vorfahren war oder sie damit wenigstens eng verbunden waren und daß diese es - aus welchem Anlaß auch immer - unter König Pippin an die Trierer Kirche gaben.

Fassen wir zusammen: DLoI. 67 ist echt. Seinen Inhalt sollte man für die Mettlacher Frühzeit deshalb ernst nehmen. Mettlach wurde danach von Vorfahren bzw. der Familie Widos I. von Spoleto - und keinem Bischof Liutwin unter König Pippin an Trier geschenkt. Vielleicht war es Eigenkloster dieser

352 Vgl. dazu den Artikel ,Origo', in: Novum Glossarium Mediae Latinitatis O, ed. BLAtт/ Lefèrre, Sp. 795-800. - Laut dem Artikel ,origo', in: Georges, Handwörterbuch 2, Sp. 1399, kann das Wort im Singular auch für „Stammväter, Urväter, Ahnherren, Ahnen“ stehen. $\mathrm{Zu}$ einem Verständnis im Sinne von „Herkunftsgemeinschaft“ vgl. schließlich auch Wolfram, Origo gentis. 1. Allgemeines, S. 174-178.

353 Vgl. dazu nochmals die Abbildung von DLoI. 67 im Anhang (Abb. 2) sowie auch die Abbildung des ebenso von Remigius verfaßten DLoI. 70, S. 184 f., vom 20. März 843 für Graf Esich, in: 799. Kunst und Kultur 1, S. 332 f. Dabei könnte eine S-t-Ligatur zu einem o-r verlesen worden sein. Stehen $s$ und der Schaft des t bei Remigius zu dicht beieinander, ergibt sich eine Form, die einem o ähnelt. Auffällig ist bei der Schrift des Remigius ferner, daß das ligaturlose , s' bei ihm über keine Oberlängen verfügt.

354 So erinnerten sich die Karolinger schon früh an ihren Vorfahren Ansegisel, der dann dem hl. Arnulf Platz machte. Vgl. dazu ausführlich Oexle, Arnulf.

355 Vgl. dazu Ewig, Milo. Anton, Liutwin. 
Familie. Was also genau bestätigten Lothars Vorgänger? Die weiteren Mettlacher Diplome vermögen womöglich mehr Aufschluß darüber zu geben.

4. Die kopial überlieferte Urkunde Karls III. von 884 (DKIII. 102)

Das nächste Karolingerdokument, das Mettlach und nun plötzlich auch einen Liutwin erwähnt, ist die Urkunde Kaiser Karls III. (876-888) für den Trierer Erzbischof Radbod (883-913) vom 9. Juni 884. Der Text findet sich - wie erwähnt - unter den litteris putrefactis der Balduineen. Die Datierung ist unvollständig. Eine Ortsangabe fehlt, was der kopialen Überlieferung geschuldet sein mag. ${ }^{356} \mathrm{Da}$ die zeitlich unmittelbar vorausgehende und folgende Urkunde vom 23. Mai und 11. Juni in Worms ausgestellt wurde, könnte dies auch hier naheliegen. ${ }^{357}$

Zum Inhalt: ${ }^{358}$ Kaiser Karl macht bekannt, wie sich der ehrwürdige Radbod, Erzbischof der Trierer Kirche, an die Milde von Karls Erhabenheit wandte und seinen Augen Urkunden von dessen Kirche über eine gewisse Abtei ( $a b$ bacia) vorlegte, deren Name Mettlach (Medelacha) sei. Als jedoch dieselben Urkunden in Karls und seiner Vornehmen Gegenwart vorgelesen worden waren, habe Karl erkannt, wie vom hl./seligen (beato) Liudono, einem gewissen Erzbischof der Trierer, dasselbe Kloster der erwähnten Kirche übertragen, aber auf Anstiften eines gewissen Wido zeitweilig entzogen worden war; wie es aber dennoch von Karls Vorgängern zurückgegeben und durch deren Beschluß bestätigt wurde, von Königen nämlich und großen Kaisern, dem ruhmreichen König Pippin, dem unbesiegbaren Kaiser Karl, dem Kaiser Ludwig seligen Angedenkens und auch dem Kaiser Lothar seligen Angedenkens. Da Karl aber die ganze Wahrheit der Sache erkannt habe, gefalle es der Gunst seiner Erhabenheit wegen der Liebe Gottes, der Verehrung desselben heiligen Ortes und dem treuesten Anliegen des dortigen Bischofs, daß er das erwähnte Kloster der schon genannten Kirche in Trier mit all seinem Zubehör durch die Verordnung seines Beschlusses bestätigt. Und deshalb habe er entschieden, daß diese seine kaiserliche Urkunde verfaßt wird. Er bestimme durch sie und bestätige in allem, daß - wie das genannte Kloster, das Mettlach (Medelachus) heiße, vom erwähnten hl./seligen Mann, nämlich Liudono, an die erwähnte hl. Trierer Kirche übertragen und durch die Urkunden von Karls Vorgängern häufiger im Namen Gottes bestätigt worden sei - es so zu seinen und seiner Nachfolger Zeiten unverletzlich bei der Nutznießung (ad utilitatem) der genannten Kirche durch

356 Vgl. DKIII. 102, S. 165 f.

357 Vgl. DDKIII. 101, 103, S. 163-167. Die erste wurde am 23. Mai 884 für das Kloster Honau ausgestellt, die zweite am 11. Juni 884 für das Kloster Lorsch.

358 Vgl. MRUB I 123, S. 129 f. DKIII. 102, S. 165 f. Zum Urkundentext vgl. unten S. 213 f. 
diesen seinen Beschluß verharren soll - ohne irgendjemandes Widerspruch oder irgendeine Anfechtung, damit der Klerus und das Volk, das Gott ebendort eifrig diene, die Gunst des Herrn für Karl, seine Gattin und für die Stetigkeit seiner ganzen ihm von Gott übertragenen Herrschaft inbrünstiger erflehe. Es folgt die Poenformel.

Die erhebliche inhaltliche Abhängigkeit dieser Urkunde von DLoI. 67 von 842 ist unübersehbar. ${ }^{359}$ SCHMAL kann sich allerdings nicht vorstellen, daß dieses über 40 Jahre später wiederaufgegriffen wurde, und geht deshalb - wie gesehen - von einer Fälschungsserie aus. Man erkenne beim Diplom Karls III. nicht nur Übereinstimmungen mit den Mettlacher Urkunden, sondern auch mit dem echten $\mathrm{BM}^{2} 626$ von $816^{360}$

Um die parallelen Stellen von DKIII. 102 mit den echten Urkunden von 816 und $842 \mathrm{zu}$ verdeutlichen, folgt der vollständige lateinische Text. Fett markiert sind die übernommenen Passagen aus der Lothar-Urkunde (DLoI. 67), unterstrichen die aus dem Ludwig-Diplom $\left(\mathrm{BM}^{2}\right.$ 626). Doppelt unterstrichen finden sich die bereits früh durch Mutilation ausgefallenen Stellen von DLoI. 67, die nicht mehr in die Balduineen eingingen, aber noch in das Diplom Karls III. ${ }^{361}$

In nomine sancte et individue trinitatis. Karolus divina favente clementia imperator augustus. Si nos, qui imperiali magnitudine prelati sumus, causas ecclesiarum dei ad peticiones venerabilium presulum nostro relevamus iuvamine atque imperiali tuemur munimine, id nobis ad mortalem vitam temporaliter transiendam et ad eternam feliciter obtinendam profuturum liquido credimus. Ideoque noverit omnium fidelium nostrorum tam presentium sagacitas quam et futurorum industria, qualiter venerabilis Rathbodo Treuerensis ecclesie archiepiscopus adiens celsitudinis nostre clementiam auctoritates sue ecclesie de quadam abbacia, cuius vocabulum est Medelacha, obtulit obtutibus nostris. Cum autem easdem auctoritates in nostra procerumque nostrorum relegi fecissemus presentia, repperimus, qualiter a beato Liudono quondam Treuerorum archiepiscopo eundem monasterium ad memoratam fuisset delegatum ecclesiam, sed instinctu cuiusdam Widonis pro tempore abstractum, et tamen quomodo a predecessoribus nostris regibus videlicet et magnis imperatoribus Pippino glorioso regi, Karolo invictissimo augusto atque pie recordacionis Hludowico augusto nec non et bone memorie Hlotario imperatore ibidem fuisset restitutum atque illorum auctoritate confirmatum. Nos autem omnem rei veritatem inde cognoscentes propter amorem dei et venerationem ipsius sancti

359 Vgl. hier nur DKIII. 102, S. 165. Anton, Liutwin, S. 40, 43 f. u. Anm. 49. Merta, Durchsetzung von Besitzansprüchen, S. 175.

360 Vgl. Schmal, Mettlach, S. 37, 40 u. Anm. 234, 254. Vgl. nochmals zum LudwigsDiplom MRUB I 50, S. 55 f. Die Urkunde von 816 sicherte Hetti Königsschutz, Immunität und Abgabenfreiheit der Trierer Kirche zu.

361 Vgl. zu den doppelt unterstrichenen verderbten Stellen auch oben S. $207 \mathrm{f}$. u. Anm. 340-342. - Schmal hat in ihrem Abstammungsmodell noch einige weitere Übereinstimmungen ausgelassen. Vgl. zu den von ihr herausgearbeiteten Passagen die Tabellen bei Schmal, Mettlach, S. 37, 39. 
loci seu fidelissimam eiusdem presulis postulationem placuit celsitudinis nostre serenitati, ut prefatum monasterium iam dicte Treuerensi ecclesie cum omnibus suis adiacentiis per auctoritatis nostre preceptum confirmaremus. Et ideo has nostras imperiales litteras fieri censuimus, per quas sancimus modisque omnibus confirmamus, ut, sicuti a memorato viro beato scilicet Liudono prefatum cenobium, quod dicitur Medelachus, ad prescriptam sanctam Treuerensem ecclesiam fuit traditum atque per auctoritates antecessorum nostrorum plenius in dei nomine confirmatum, ita nostris ac successorum nostrorum temporibus ad utilitatem prefate ecclesie absque alicuius contradictione seu qualibet refragatione inviolabiliter per hanc nostram auctoritatem perseveret, quatenus clerus et populus ibidem deo deserviens pro nobis ac coniuge nostra seu tocius imperii a deo nobis collati stabilitate domini misericordiam attentius exorare delectet. Et si quis contra hanc auctoritatem ac confirmacionem nostram aliquid irrationabiliter agere temptaverit aut a predicta sancta Treuerensi ecclesia illud monasterium auferre conaverit, anathema sit. Et ut hec nostre confirmacionis auctoritas pleniorem in dei nomine obtineat firmitatem et per futura tempora a cunctis sancte dei ecclesie fidelibus et nostris verius credatur et diligentius observetur, manu propria nostra subter eam firmavimus et bulla nostra iussimus sigillari.

Signum Karoli serenissimi augusti.

Segoinus notarius advicem Liutuuardi archicancellarii recognovit.

Data Vid. iun. anno ab incarnatione DCCCLXXXIIII, indictione II, anno vero Karoli VIII.

Während das Diplom Lothars die inhaltliche Vorlage bildet, findet sich die Ludwigs-Urkunde nur in Arenga, Promulgatio, den ersten und letzten Worten der Dispositio sowie der Corroboratio, also im äußeren formalen Teil. Allerdings bleiben davon die Invocatio, Intitulatio, die ersten Worte der Arenga, die Signum- und Rekognitionszeile völlig unberührt. Dazu gleich mehr. ${ }^{362} \mathrm{Da}$ die verwendeten beiden Vorlagen als Originale in Trier erhalten blieben - trotz der Verwüstungen 882 - spricht einiges dafür, daß sie in DKIII. 102 zusammenfanden. Vielleicht bewahrte man sie sogar gemeinsam auf, weil beide für Erzbischof Hetti ausgestellt worden waren.

Die Urkunde Karls III. verändert jedoch die inhaltliche Aussage von DLoI. 67 durch kleine Textergänzungen. Zunächst wird Mettlachs Status als Abtei besonders hervorgehoben. Die Stelle könnte eingeschoben sein: Die grammatische Form Mettlachs wechselt plötzlich das Genus ins Femininum (Medelacha), während sie weiter unten wieder maskulin (Medelachus) ist. Denkbar wäre aber auch eine Verlesung bzw. Verschreibung bei der Kopie der Urkunde, vielleicht war diese beschädigt.

In DLoI. 67 wird Wido noch als Nachkomme der Schenkersippe Mettlachs und Herzog von Spoleto behandelt. Hier ist davon keine Rede mehr: Das Kloster sei Trier auf Anstiften eines gewissen Wido für eine gewisse Zeit entzogen worden. Die Karolinger Pippin, Karl, Ludwig, Lothar und schließlich wieder Karl hätten die rechten Besitzverhältnisse wiederhergestellt und bestätigt.

362 Vgl. dazu unten S. 216 f. u. Anm. 369-374. 
Damit ist zum einen überhaupt nichts mehr von Widos Vorfahren erkennbar. Sie werden geradezu verschleiert. Zum anderen verschwimmt die genaue Zeit des Besitzentzuges, den die Lothar-Urkunde noch relativ deutlich umreißt. Geschah er schon unter Pippin oder erst unter Lothar I..? ${ }^{363}$ Wido wird somit zu einem geradezu üblen Subjekt, das Trier einmal um Mettlach gebracht haben soll.

Zudem hätte auch Lothar II. (855-869), der namengebende, unglückliche Herrscher des nördlichen Mittelreiches, der Trierer Kirche ein Bestätigungsdiplom zu Mettlach ausstellen müssen. Bei seinen erfolglosen Versuchen, einen Nachfolger zu installieren, unterstützte ihn doch - wie gesehen - der ehrgeizige Trierer Erzbischof Thietgaud $(847-863, \dagger 868)$, der den Primat über die gesamte Belgica und damit über Reims anstrebte. ${ }^{364}$ Ging ein solches Diplom verloren? Und was geschah mit Mettlach bis zum Herrschaftsbeginn Karls III.?

Noch einige andere Kleinigkeiten stechen ins Auge: Das Trier zugeordnete Patrozinium des hl. Petrus wird an keiner Stelle aufgegriffen. Die Vorlage Lothars nannte es aber! Ging es mehr um eine Schenkung an Radbod als um eine an die Trierer Kirche selbst? In DLoI. 67 hatte Lothar noch wegen Hettis Ergebenheit das Kloster zurückgegeben. Von einer solchen Schwäche des Beschenkten ist nun nicht mehr die Rede. Im Gegenteil: Radbod fordert sein Recht auf Mettlach ein.

Die entscheidendste Veränderung aber ist, daß plötzlich ein hl. oder seliger Trierer Erzbischof Liodonus - mit dem wohl Liutwin gemeint ist - als Schenker des Klosters an Trier präsentiert wird. Aus Widos schenkender Verwandtschaft wird damit ein Trierer Erzbischof. Weshalb? Schon der Vorlagenvergleich zeigt, daß der Schreiber von DKIII. 102 sicher nicht die Diplome verwandte, die Lothar I. angeblich noch gesehen hatte. Nur die Passagen zu Wido und Liodonus sind wirklich völlig neu und eigenständig. Sie wirken deshalb eingeschoben und eingepaßt, als ob eine neue Wahrheit einer alten übergestülpt werden sollte. Von einer Klostergründung durch Liutwin, wie sie die späteren Viten berichten, ist allerdings überhaupt keine Rede. ${ }^{365}$ ANToN nennt die Übertragung zwar eine testamentarische Schenkung, doch gibt das der Text hier nicht her. ${ }^{366} \mathrm{Daß}$ Liodonus zu seiner Amtszeit noch kein Erzbischof, sondern nur Bischof gewesen sein kann, haben wir inzwischen mehrfach gesehen. ${ }^{367}$ Daß dieser Bischof mit beatus bezeichnet wird, könnte schlicht bedeuten, daß er nicht mehr lebte. Es

363 Darauf weist auch Anton, Liutwin, S. 43 f. u. Anm. 69, hin.

364 Vgl. zu Lothar II. zuletzt und mit der neuesten Literatur Schieffer, Karolinger, S. 139,

$152-155,160-164$. Vgl. zu ihm ferner die Überlegungen zu Milo und Thietgaud von Trier oben in Kap. C.III.4.

365 Vgl. dazu kurz oben Kap. D.I.2.a. sowie unten Kap. D.IX.2. u. D.IX.5.

366 Vgl. dazu Anton, Liutwin, S. 40 u. Anm. 61.

367 Vgl. zur Einführung der Metropolitanverfassung um 800 bereits ausführlich oben Kap.

C.III.2. 
mag aber ebensogut Anzeichen eines beginnenden Heiligenkultes sein. Liutwin wird - wie die Trierer Quellen ja zeigen - seit dem ausgehenden 10. Jahrhundert als solcher verehrt. ${ }^{368}$

Die Frage ist nun, ob diese Veränderungen noch unter Radbod erfolgten oder später, vielleicht im Zuge eines erstarkenden Liutwinkultes. Blicken wir dazu auf den Beginn und das Eschatokoll der Urkunde. Während Invocatio und Intitulatio den anderen Diplomen Karls III. entsprechen, gilt das nicht für den ersten Satz der Arenga. Mit Si nos, qui imperiali magnitudine prelati sumus, [...] eröffnen ausschließlich noch zwei erhaltene Diplome des Kaisers: eine Besitzbestätigung für das Kloster Reichenau vom 22. April $884^{369}$ sowie eine Restitution von thüringischen u. a. Besitzungen für die Reimser Kirche, ausgestellt in Metz am 30. Juni desselben Jahres. ${ }^{370}$ Die Formulierung wurde also nur 884 verwendet. Auch der Notar Segoin erscheint nur in diesem Jahr in Karls Urkunden als Aussteller. ${ }^{371}$ Gäbe es nicht die inhaltlichen Manipulationskriterien, spräche dieser Teil des Formulars für die Echtheit des Dokumentes. In Trier muß man deshalb über ein Segoin-Diplom als Vorlage verfügt haben, das man für den äußeren Rahmen von DKIII. 102 verwendete. Denkbar wäre eine Bestätigungsurkunde von DLoI. 67, die sich am Text der Vorlage vielleicht recht genau orientierte und die erst zu späterer Zeit entsprechend (z. B. durch eine Nachzeichnung) sinnentstellt, interpoliert bzw. inhaltlich verändert wurde.

Warum ging DKIII. 102 aber in die litteras putrefactas der Balduineen ein? Was machte es verdächtig? War es beschädigt? KeHrs Editionstext bietet be-

368 Vgl. dazu unten Kap. D.V.ff.

369 Vgl. DKIII. 99, S. 160 f. Dabei handelt es sich um ein nicht vollzogenes Originaldiplom, das sich heute in Karlsruhe, Generallandesarchiv, Selekte der älteren Urk. Nr. A 18, befindet. - Nach Kehr (DKIII. 99, S. 160 f.) geht die Arenga dieser Urkunde, der auch mit noch etwas mehr Text DKIII. 102 fast wörtlich folgt (bis etwa: Ideoque noverit omnium fidelium nostrorum praesentium scilicet et futurorum industria, quia [....]; insgesamt DKIII. 99, S. 161, Z. 11-14), eben auf Segoins Vorlage in DKIII. 102 zurück (oder in DKIII. 106, das aber deutlich weniger übereinstimmenden Text bietet). Das würde bedeuten, daß Segoin sie entweder aus $\mathrm{BM}^{2} 626$ übernommen haben könnte oder noch durch eine andere Vorlage im Jahr 884 inspiriert wurde. Allerdings weist die Urkunde falsche Herrscherjahre auf. - Auch hier und im folgenden sei zu schwarz-weiß Abbildungen noch einmal auf die Online-Datenbank des Forschungsinstituts Lichtbildarchiv älterer Originalurkunden (LBA) der Philipps-Universität Marburg unter http://lba.hist.uni-marburg.de/lba/pages/ [10.03.2009] hingewiesen.

370 Vgl. DKIII. 106, S. 170 f. Erhalten ist es aber nur noch in einer Abschrift des 17. Jahrhunderts aus dem verlorenen Chartular von St-Rémi.

371 Vgl. DDKIII. 94, 97, 100 f., 103, 106-108, S. 153-155, 157 f., 162-167, 170- 173. Er tritt dabei in Kolmar, Worms, Metz und Regensburg auf. Segoin ist auch der Schreiber, aber nicht Verfasser und Rekognoszent von DKIII. 98, S. 158-160 (15. April 885 in Bodman). - Vgl. ferner KeHr, Kanzlei Karls III., S. 25-28 u. Taf. 7. Es dürfte sich um einen Romanen, einen Westfranken oder Lothringer gehandelt haben. Er war wohl ein Kalligraph. 
dauerlicherweise nicht die Version der Balduineen, sondern eine leicht korrigierte und den anderen Karls-Diplomen angepaßte Fassung. Die Rekognitionszeile lautet in zwei der drei Trierer Chartulare des 14. Jahrhunderts hingegen: Segon notarius advicem Liuttardi cancellarii recognovit im dritten: Segoin notarius advicem Luictardi cancellarii recognovit. ${ }^{372}$ Doch Liutward von Vercelli war zu dieser Zeit Erzkanzler. Die Abschreiber müssen also bei Segoins und Liutward von Vercellis Namen erhebliche Schwierigkeiten gehabt und noch dazu aus dem Erzkanzler einen Kanzler gemacht haben. Entweder war die Vorlage nur schwer lesbar, oder sie muß bereits fehlerhafte Angaben enthalten haben. Vermutlich war sie kein Original mehr. Man hätte ja, wie gesagt, das Formular einer Karls-Urkunde von 884, vielleicht einer noch vorhandenen Segoin-Urkunde für Trier verwenden können. Zwei weitere Dokumente Karls III. sind zudem für den Trierer Raum erhalten: 1. eine Privilegienbestätigung für Prüm vom 22. Mai 884 mit Segoin als Notar, ${ }^{373}$ 2. ein Diplom für St. Maximin vom 1. Oktober 885, das den dortigen Mönchen das Privileg der Abtwahl zurückgibt, mit Inquirinus als Notar. ${ }^{374}$ In beiden erscheint jedoch Liutward als Erzkanzler. Nahm man hier vielleicht Anleihen? Sicher klären läßt es sich nicht.

Welchen Zweck aber verfolgt der Versuch, Widos Vorfahren als Schenker Mettlachs durch Liudonus zu ersetzen und damit zu verschleiern? Wäre dieser Rechtstext in der vorliegenden Form zeitgenössisch, böte sich ein von BüTTNER erwogenes Erklärungsmuster an, das auch RAACH wieder aufgegriffen hat. Als der italienische Markgraf Wido II. von Spoleto 888 von Langres aus versuchte, das Königtum nördlich der Alpen zu erwerben, wobei er scheiterte, habe man in Trier einen erneuten Verlust Mettlachs befürchtet. Da hätte sich ein Trierer Bischof als weit zurückliegender Schenker angeboten, um die Erinnerung an die Besitzverhältnisse unter Lothar I. auszulöschen. ${ }^{375}$ Doch 884 war Wido II. kaum schon aktiv. Oder hatte man grundsätzlich Bedenken vor neuen Ansprüchen dieser Familie? Allerdings kann Liutwin durchaus erst später Eingang in diese Urkunde gefunden haben.

Denkbar wäre nämlich auch eine Verbindung des als beatus bezeichneten Bischofs mit Liutwins Trierer Kult, der deutlich ab dem 10. Jahrhundert auflebte. Sollte DLoI. 67 nachträglich durch ein anderes oder interpoliertes Diplom ersetzt oder ergänzt werden, das dessen Sinn entstellte und das spätere Trierer Liutwinbild vorprägte? Bereits bei Irminas „Ur-Testament“ haben wir

372 Vgl. dazu DKIII. 102, S. 166, Anm. r-t. Die ursprüngliche Fassung findet sich auch noch im MRUB I 128, S. 130.

373 Vgl. DKIII. 100, S. $162 \mathrm{f}$.

374 Vgl. DKIII. 133, S. 212 f. Sie bietet jedoch nur wenige wörtliche Übereinstimmungen.

375 Vgl. Büttner, Wanderweg, S. 38 f. Raach, Mettlach, S. 26. Schieffer, Karolinger, S. 181, 185 f., 188 f., 191 f. Fried, Weg, S. 139, 431 f., 441 f. 
solche Textentlehnungen mit Inhaltsveränderungen beobachtet. ${ }^{376}$ Auch bei den Informationen über die Gründung und die Frühzeit des Klosters Oeren läßt sich ein ähnliches Phänomen erkennen. Denn die oben erwähnten, von Schmal in die Argumentation eingebrachten, manipulierten Urkunden Pippins von 760 (DKarol. I †36), die Karls des Großen von 772/4 (DKarol. I †226) und die dabei nicht berücksichtigte Urkunde Zwentibolds von 895 (DZw. †4) basieren nicht nur alle auf $\mathrm{BM}^{2}$ 626. Darüber hinaus nennen oder restituieren sie auch Oeren als Trierer Besitz. Ja noch mehr: Sie alle konstruieren den Trierer Bischof Modoald als Erbauer und Gründer dieses Klosters, um deutlich zu machen, daß Oeren schon lange zu Trier gehörte. Wie gesehen, handelt es sich dabei um eine Tradition, die zunächst im Trier des späten 10. oder frühen 11. Jahrhunderts unter Erzbischof Egbert (977-993) oder Liudolf (994-1008) im Zuge des Streits um Oeren und das Servatiusstift in Maastricht aufkam. ${ }^{377}$ Da sowohl die Mettlacher als auch die Oerener Urkundengruppe ein für das jeweilige Kloster aktiv werdender Trierer Erzbischof und schließlich $\mathrm{BM}^{2} 626$ verbindet, dürften sie auf der Basis dieses Modells durchaus gleichzeitig konstruiert worden sein. Zumindest das Modell eines solchen vermeintlich wichtigen Trierer Bischofs in der Frühzeit der Klöster wird parallel entstanden sein.

Erzbischof Radbod (†915) übernahm 883 das Bistum nach dem Normannensturm und begann mit dem Wiederaufbau. Unter ihm kam Regino von Prüm in die Stadt. Erzbischof Radbod wurde auch zum Erzkanzler des neu geschaffenen lothringischen Sonderkönigtums unter König Zwentibold (895900), dem Sohn Arnulfs von Kärnten (887-899). Radbod blieb auch Erzkanzler unter der sich diesem König anschließenden, wechselnden ost- und westfränkischen Herrschaft. Von Arnulf erhielt er am 1. Juli 889 das Servatiusstift in Maastricht für die Trierer Kirche übertragen. Die Urkunde ist noch im Original erhalten. ${ }^{378}$ Für Radbod sind zudem zahlreiche echte Urkunden und Trierer Fälschungen des 10.-12. Jahrhunderts überliefert: so das erwähnte DZw. †4 vom 25. Oktober 895 zu Oeren. In einer weiteren Fälschung auf

376 Vgl. dazu oben Kap. D.II.4.b.

377 Die hl. Irmina wird erst später als erste Äbtissin mit dem Kloster von den Oerener Nonnen in Verbindung gebracht. Vgl. dazu auch KöLzer, Studien, S. 129 f., 144-148 u. Anm. 183, oben S. 177 u. Anm. 235 sowie insgesamt zu Irmina Kap. D.II.6. In diesen Zusammenhang gehört auch die unechte Dagobert-Urkunde MRUB I $\uparrow 5$, S. 4 f., bzw. DMerowinger I †33, S. 89-92, von 634, die ebenfalls Modoald als Gründer Oerens sieht. Schon Oppermann, Rheinische Urkundenstudien 2, S. 160 u. 191, ging aufgrund inhaltlicher Kriterien davon aus, daß sie später entstanden sein muß. SchmaL, Mettlach, S. 27 f., 38 u. Anm. 171 f., 239, 248, folgt ihm darin.

378 Vgl. zu Radbod Bauer, Radbod, Sp. 386. Schieffer, Lothringische Kanzlei, S. $23-$ 148, bes. S. 43 ff. Anton, Trier im frühen Mittelalter, S. 175-178, 204-207. - Zur Schenkung des Servatiusstiftes in Maastricht an Trier vgl. MRUB I 129, S. $136 \mathrm{f}$. DArn. 53, S. 75-77. - Später erhielt Trier dann das reichsunmittelbare Oeren und gab dafür Maastricht ab. Vgl. dazu oben S. 174. 
Ludwig das Kind (893-911) vom 22. März 902 will dieser dem Kloster Oeren auf Bitten Erzbischof Radbods Friede und Bann für seine Besitzungen verliehen haben. Sie stammt aber erst aus dem frühen 12. Jahrhundert. ${ }^{379}$ Man sieht, daß sich der Episkopat Radbods aufgrund seiner Länge als Projektionshorizont für Konstruktionen in der Vergangenheit anbot und genutzt wurde. ${ }^{380}$ Echte Originale ließen sich als Vorlagen für neue Entwürfe einsetzen.

379 Zu DZw. †4, S. 24 f. vgl. nochmals oben S. 177 u. Anm. 235, 327. - Vgl. DLdK †80, S. 218-221. Diese Fälschung entstand gemeinsam mit DMerowinger I $\uparrow 52$, die bereits oben besprochen worden ist. Auch für diese ist als graphische Vorlage $\mathrm{BM}^{2} 626$ verwendet worden. Vgl. zur Urkunde Ludwigs des Kindes ausführlich oben in Anm. 233, mit einem Abbildungsnachweis und Hinweisen zur Literatur.

380 Vgl. hier nur noch MRUB I 132, S. 139 f. DArn. 113, S. 166 f., worin Arnulf am 7. Februar 893 dem Trierer Domkapitel unter Radbod alle seine Einkünfte und Präbenden schenkt. Erhalten ist das Privileg in einer fast gleichzeitigen Abschrift, was es etwas fragwürdig macht. - MRUB I 136, S. 201 f. DArn. 124, S. 183 f. In diesem Diplom schenkt Arnulf dem Trierer Domkapitel unter Radbod am 16. April 894 das Dorf Méry in der Grafschaft Verdun. Der Text ist aber nur in einer Abschrift des 12. Jahrhunderts erhalten, was auch ihn verdächtig macht. - MRUB I 140, S. 205 f. DZw. 13, S. 39-41. König Zwentibold soll am 28. Januar 896 auf Bitten seines Kanzlers Radbod aus den Wäldern des Erzstifts und der Abtei St. Maximin einen Bannforst gemacht haben. Die Urkunde ist jedoch äußerst umstritten und nur in den Balduineen überliefert. - MRUB I 143, S. 208 f. DZw. 18, S. 49-51. Am 5. Februar 898 bestätigt Zwentibold Radbod die Besitzungen seiner Kirche und Abgabenfreiheit bis auf jährlich sechs Pferde, weil das Bistum zu einer Grafschaft geworden sei. Das erhaltene Original befindet sich in Koblenz, Landeshauptarchiv, Best 1 A Nr. 7. - MRUB I 144, S. 209 f. DZw. 20, S. 53-56. Zwentibold spricht am 13. Mai 898 dem Trierer Erzstift unter Radbod die Abtei St. Servatius in Maastricht anstelle des unrechtmäßigen Entwenders Reginar zu. Das Original befindet sich in Koblenz, Landeshauptarchiv, Best. 1 A Nr. 8. - MRUB I 145, S. 210 f. DZw. 21, S. 56 f. Diese Urkunde Zwentibolds für Radbod vom 13. Mai 898 entspricht inhaltlich, aber nicht im Wortlaut, der Vorgängerin. Sie ist nur in den litteris putrefactis der Balduineen erhalten und scheint verdächtig. - MRUB I 148, S. $212 \mathrm{f}$. DZw. 27, S. 65 f. Zwentibold befreit am 23. Januar 899 die Leute der Trierer Kirche von der Pflicht der Königsgastung und die Villen von der Gerichtsbarkeit der königlichen Richter. Das Privileg ist in den Balduineen überliefert. - MRUB I 149, S. 213 f. DLdK 2, S. 97 f. König Ludwig das Kind bestätigt am 22. März 900 dem Trierer Domkapitel unter Radbod die Privilegien und die Güter zu Méry wie sein Vater Arnulf. Erhalten ist der Rechtstext nur in einer um einiges späteren Abschrift aus der Mitte des 12. Jahrhunderts, was ihn verdächtig macht. - MRUB I 150, S. 214 f. DLdK 17, S. 120-122. Ludwig das Kind restituiert am 19. September 902 Radbod die bisher vom Bistum (episcopatum) getrennten, zu einer Grafschaft gemachten Münzen, Zölle und Zinsleute etc. Dies solle unter Bischof Weomad geschehen sein. Erhalten ist das Diplom in den litteris putrefactis der Balduineen. - MRUB I 152, S. 216. DLdK 59, S. 187-189. Ludwig das Kind schenkt Radbod am 11. Februar 908 die Güter Ruothards in Enkirch. Das Original befindet sich in Koblenz, Landeshauptarchiv, Best. 1 A Nr. 9. - MRUB I 157, S. 220 f. DKdE 74, S. 165 f. König Karl der Einfältige erläßt am 13. August 913 auf Radbods Bitte, daß dessen Nachfolger durch Klerus und Volk frei gewählt werden dürfen. Das Original befindet sich in Koblenz, Landeshauptarchiv, Best. 1 A Nr. 10. - 
Ganz ausschließen läßt sich freilich nicht, daß Radbod selbst Bischof Liutwin als Schenker Mettlachs konstruierte. Dann wollte er damit vielleicht Mettlach beim Neuaufbau nach der Zerstörung für Trier sichern. Wo jedoch hätte er die Informationen zu Liutwin gefunden? Und weshalb reichte Radbod nicht die klare Besitzaussage der Lothar-Urkunde, die er sich doch nur bestätigen lassen mußte? Weshalb hätte es jetzt schon eines Liodonus bedurft? Oder verfälschte Radbod selbst erst später die echte Bestätigung? Vielleicht standen in einer für Radbod ausgestellten Originalurkunde auch ein oder mehrere ganz andere Schenkernamen, die nachträglich durch Liutwin ersetzt wurden.

Zusammenfassend kann man feststellen, daß es sich bei der Behauptung, Liudonus habe Mettlach an Trier geschenkt, um eine Manipulation handelt. DKIII. 102 verwendet fast ausschließlich den Text von DLoI. 67 und BM² 626 sowie wohl auch Teile einer Originalurkunde, ausgestellt vom Notar Segoin. Es beseitigt aber die Verbindung zwischen Wido von Spoleto und den Schenkern Mettlachs und ersetzt sie durch den hl./seligen Liutwin. Wido wird zum Entfremder Mettlachs vor unbestimmbarer Zeit. Die Verwendung von $\mathrm{BM}^{2} 626$ von 816 bei den im späten 10. oder frühen 11. Jahrhundert gefälschten DDKarol. I $† 36$ und $\uparrow 226$ sowie DZw. $\uparrow 4$, das mit den beiden eng verbunden ist, weist aber noch in eine andere Richtung. Der in diesen drei falschen Diplomen konstruierte Trierer Gründerbischof Modoald für Oeren paßt bestens zum Schenkerbischof Liutwin für Mettlach. Man wählte also ein ganz ähnliches Bild für die Frühzeit zweier Klöster im Trierer Raum. Damit gehört - so die hier vertretene These - DKIII. 102 in der vorliegenden Form (als Neuschöpfung oder nachträglich interpoliertes Original) ebenfalls in diese Zeit und nicht ins ausgehende 9. Jahrhundert. Ganz ausschließen läßt sich aber nicht, daß schon Erzbischof Radbod beim Wiederaufbau der Stadt einen Trierer Bischof Liutwin mit diesem Diplom erstmals als Schenkerbischof für Mettlach postulierte, um das Kloster für Trier zu sichern. Doch hätte Radbod eigentlich auch die inhaltliche Bestätigung von DLoI. 67 ausreichen müssen. Vielleicht standen an Liutwins Stelle ursprünglich in einem möglichen Original auch einmal ganz andere Schenkernamen.

\section{Die kopial überlieferte Urkunde König Arnulfs von 888 (DArn. 39)}

Auch die Urkunde König Arnulfs (887-899) vom 22. Oktober 888 zum Kloster Mettlach steht in enger Verbindung mit den beiden zuvor besprochenen Dokumenten. Auch ihr Text findet sich allein in den litteris putrefactis der

An dieser Stelle sei erneut auf die Online-Datenbank des Forschungsinstituts Lichtbildarchiv älterer Originalurkunden (LBA) der Philipps-Universität Marburg unter http://lba.hist.uni-marburg.de/lba/pages/ [10.03.2009] hingewiesen. 
Balduineen. Es fehlt allerdings die Signumzeile, ein großer Teil der Rekognitionszeile, ein Teil des Datums, das gesamte Actum und schließlich die Apprecatio. Vermutlich kürzte man hier die Vorlage bei der Abschrift in die Kopiarbücher - so der Editior KEHR. ${ }^{381}$ - Oder war das Stück zu diesem Zeitpunkt beschädigt? - Die unmittelbar vorausgehenden und nachfolgenden Urkunden Arnulfs könnten eine Ausstellung in Regensburg nahelegen. ${ }^{382}$

Zum Inhalt: König Arnulf macht bekannt, wie sich der ehrwürdige Radbod, Erzbischof der Trierer Kirche, an die Milde seiner Erhabenheit wandte und Arnulfs Augen Urkunden seiner Kirche über eine gewisse Abtei vorlegte, deren Name Mettlach (Medelacha) sei. Als jedoch dieselben Urkunden in Arnulfs und seiner Vornehmen Gegenwart vorgelesen worden waren, habe Arnulf erkannt, wie vom hl./seligen (beato) Ludwino, einem gewissen Erzbischof der Trierer, dasselbe Kloster der erwähnten Kirche übertragen, aber auf Anstiften Widos zeitweise entzogen worden war; es aber dennoch von Arnulfs Vorgängern, Königen nämlich und Kaisern, dem Pippin, Kaiser Karl, Ludwig, Lothar und

381 Vgl. MRUB I 128, S. 135 f. DArn. 39, S. 57 f. Fett wiedergegeben sind hier die aus DKIII. 102 übernommenen Passagen: In nomine sancte et individue trinitatis. Arnolphus divina favente gratia rex. Si nos, qui regali magnitudine prelati sumus, causas ecclesiarum dei ad peticiones venerabilium presulum nostro relevamus iuvamine atque regali tuemur munimine, id nobis ad mortalem vitam temporaliter transigendam et ad eternam feliciter obtinendam profuturum liquido credimus. Ideoque noverit omnium fidelium nostrorum tam presentium quam et futurorum sagacitas, qualiter venerabilis Rathbodo Treuerensis ecclesie archiepiscopus adiens celsitudinis nostre clementiam auctoritates sue ecclesie de quadam abbacia, cuius vocabulum est Medelacha, obtulit obtutibus nostris. Cum autem easdem auctoritates in nostra presentia relegi fecissemus, repperimus, qualiter a beato Ludwino quondam Treuirorum archiepiscopo idem monasterium ad memoratam fuisset delegatum ecclesiam, sed instinctu Widonis pro tempore abstractum, at tamen a predecessoribus nostris regibus videlicet ac imperatoribus Pippino, Karolo augusto, Ludowico, Hlotario nec non Karolo augusto ibidem fuisset restitutum atque illorum auctoritate confirmatum. Nos vero hoc idem prefatum monasterium cum omibus suis adiacentiis propter amorem dei ac postulationem eiusdem loci presulis ad iam dictam ecclesiam Treuerensem isto nostre auctoritatis precepto fecimus confirmari, per quod decernimus atque iubemus, ut hoc stabile per cuncta tempora permaneat, manu propria subtus eam firmavimus at anuli nostri impressione sigillari iussimus.

Asbertus cancellarius etc.

Data XI kal. novembris anno dominice incarnationis DCCCLXXXVIII, indictione VII.

382 Vgl. dazu DDArn. 38, 40, S. 56-59. Es handelt sich um ein im Original erhaltenes Diplom vom 9. Oktober 888, in dem er einem Gubo eine Schenkung macht, sowie um eine weitere Schenkung an Reginbert vom 8. November 888, überliefert im Lorscher Kodex. - Auch hier und im folgenden noch einmal der Hinweis auf die Online-Datenbank des Forschungsinstituts Lichtbildarchiv älterer Originalurkunden (LBA) der Philipps-Universität Marburg unter http://lba.hist.uni-marburg.de/lba/pages/ [10.03.2009]. 
auch dem Kaiser Karl ebendarin zurückgegeben und durch deren Beschluß bestätigt wurde. Arnulf aber veranlaßte, daß dieses gleiche erwähnte Kloster wegen der Liebe zu Gott und dem Anliegen des Bischofs desselben Ortes der schon genannten Kirche in Trier mit all seiner Umgebung durch diese Verordnung seines Beschlusses bestätigt werde. Dies solle für alle Zeit geschehen.

Die Forschung hat sich kaum mit dieser Urkunde beschäftigt, bietet sie doch fast ausschließlich und wörtlich den Text ihrer Vorgängerin Karls III. von 884. ${ }^{383}$ RAACH weist auch in diesem Zusammenhang auf eine mögliche Verbindung mit dem Versuch Widos II. von Spoleto hin, im Jahr 888 das Königtum nördlich der Alpen von Langres aus zu erlangen. ${ }^{384}$ S CHMAL betrachtet sie als Teil ihrer angenommenen Fälschungsserie. ${ }^{385}$

Da das Mettlacher Diplom Arnulfs DKIII. 102 von 884 nur verkürzt wiedergibt, ist ein Zusammenhang mit Widos Plänen wenig wahrscheinlich. Steht aber die Vorlage schon unter erheblichem Manipulationsverdacht, muß das auch für dieses Dokument gelten. Nicht ganz grundlos dürften es die Balduineen separiert haben.

Die Übernahme der Vorlage, die mit wenigen Auslassungen erfolgt, bricht nach dem Hinweis auf die karolingischen Herrscher ab, die eine Bestätigung vornahmen. Man fügte lediglich noch Karl III. hinzu, ohne aber die Lücke zwischen ihm und Lothar I. zu füllen. Dann wird umgehend verkündet, daß das Kloster allezeit bei Trier verbleibe. Von einer Gabe ad utilitatem ist keine Rede mehr. Die bisher mit der Bestätigung einhergehende Bedingung des Gebets für den Herrscher und das Reich fehlt. Waren diese Bedingungen für die Trierer Kirche zu bedrohlich geworden? Vielleicht wollte man ja sein Heil nicht mehr vom König oder Kaiser abhängig machen, oder die gewundenen Ausführungen der Vorlage schienen zu kompliziert. Der Trierer Erzbischof Radbod, als Fordernder, und Erzbischof Liutwin (beato Ludwino), als hl./seliger Schenker, treten damit um so deutlicher in den Vordergrund.

Seltsamerweise entfällt die Poenformel. Da die Rechtsverkündung unmittelbar in die Anordnung zur Besiegelung übergeht, dürfte sie kaum vom Kopisten weggelassen worden sein. Sie fehlte bereits. Die ebenso entfallene Signumzeile wirft zudem die grundsätzliche Frage auf, was bei der Abfassung der Balduineen vorlag: ein Original oder - wie häufiger in Trier - bloß eine spätere und meist schon deshalb nicht unverdächtige (womöglich interpolierte)

383 Vgl. so z. B. Anton, Liutwin, S. 43 f., der vermutet, daß keine weitere Urkunde mehr verwandt wurde. Andernfalls hätte man annehmen können, beim genannten Wido möge es sich um eine andere Person handeln als um den Wido der Lothar-Urkunde.

384 Vgl. RaACH, Mettlach, S. 26.

385 Vgl. Schmal, Mettlach, S. 38-41. 
Urkundenabschrift? Auch DKarol. I $\uparrow 36$ und DZw. $\nmid 4$ sind nur in derartiger Form erhalten. ${ }^{386}$

Das Urkundenformular Arnulfs dieser Zeit ist zwar korrekt wiedergegeben, ebenso der Kanzler Asbertus. Doch verfügte man in Trier über das Original der Schenkung des Servatiusstiftes in Maastricht durch Arnulf im Jahr 889 an die eigene Kirche unter Radbod, mit dem hier der Schluß der Corroboratio und sogar die Indiktion übereinstimmen. ${ }^{387}$ Eine Vorlage wäre also schnell zur Hand gewesen. Ebenso lassen sich erneut kleinere Ähnlichkeiten mit BM² 626 erkennen. ${ }^{388}$

DArn. 39 dürfte also manipuliert sein. Offenbar sollte es nur den Inhalt der Vorgängerurkunde durch die wiederholende Ausstellung unterstreichen und gleichsam auf die Kernaussage verdichten. Während man sich bei der Konstruktion von DKIII. 102 in der bekannten Form durch die Übernahme echter Vorlagen noch redlich bemühte, daraus einen neuen Text mit der gewünschten Botschaft zu schaffen, ließ sich die nun bestätigend zusammenfassen. Diese Arbeitsweise wird - wie gesehen - auch im Umfeld des Oerener Konfliktes mehrfach greifbar. ${ }^{389}$ Ein neu konzipiertes bzw. interpoliertes Dokument alleine reichte nicht aus, um der eigenen Wahrheit zum Recht zu verhelfen. Vielmehr schien die Häufung von Belegen, Erfolg zu versprechen. Nach dieser Methode arbeiteten auch die Schöpfer der Pseudoisidorischen Fälschungen, und die

386 Vgl. dazu nochmals oben S. 177, 202 f., 204 f. u. Anm. 235, 325, 327, 335, sowie die Abbildungen bei KöLzer, Studien, Taf. $26 \mathrm{f}$.

387 Vgl. MRUB I 129, S. 136 f. DArn. 53, S. 75-77. Der Schluß der Corroboratio und die Datierung lauten darin: Et ut haec donationis nostrae auctoritas nullo umquam successore nostro irrumpente solidissimam in dei nomine per omnia mundi volventis saecula obtineat stabilitatem munimine nostro roborata, manu nostra subtus eam firmavimus et anuli nostri impressione iussimus siggillari.

Signum domni Arnolfi (MF.) largissimi regis.

Aspertus cancellarius advicem Theotmari archicappellani recognovi et (SR. NN.) (SI. 2.) Data KAL. IVL. anno dominicae incarnationis DCCCLXXXVIIII, indictione VII, anno secundo regni domni ARNOLFI, piissimi regis; actum Franchonofurt palacio regali; in dei nomine feliciter amen.

388 Vgl. MRUB I 50, S. 56: per quod praecipimus atque iubemus ut [...]. Ferner ebd.: etiam manu propria subter firmauimus et anuli nostri impressione signari iussimus. Diese Formulierungen finden sich bei den wenigen neuen Ergänzungen am Ende des ArnulfDiploms.

389 Vgl. zum Oerener Konflikt nochmals die Fälschungsserie, die Modoald zum Gründer machte, oben in Kap. D.II.6. sowie S. 218 u. Anm. 377. Vgl. in diesem Zusammenhang insgesamt die Maximiner Fälschungen zuletzt bei KöLzer, Studien. Doch auch von anderen Urkunden gibt es solche Mehrfachausfertigungen. Vgl. dazu nur die Zweifachausstellung der Urkunde Zwentibolds vom 13. Mai 898 zum Servatiusstift in Maastricht oben in Anm. 380. Ähnlich entstand auch die falsche Irmina-Urkunde vom 1. November 697/8 als Ableitung des Irmina-Testaments vom 1. Dezember desselben Jahres. Vgl. dazu oben Kap. D.II.4.b. 
Rechtsgutachten Hinkmars von Reims machten sie sich ebenso zu eigen. Das haben wir oben ja schon ausführlich gesehen. ${ }^{390}$ Völlig ausschließen läßt sich allerdings nicht, daß Radbod selbst versuchte, die Zugehörigkeit Mettlachs zu Trier zu sichern. So hätte er sich nach der Urkunde Karls III. hier erneut auf einen von ihm eingeführten Trierer Erzbischof Liutwin als Schenker in der Vorzeit berufen. Wollte er die Nutznießung (ad utilitatem) von DLoI. 67 in endgültigen Besitz umwandeln? Vielleicht standen in einem möglichen Original aber auch ein oder mehrere ganz andere Schenkernamen, die später ersetzt wurden.

Faßt man zusammen, so läßt sich an dieser Urkunde deutlich ein Verformungsprozeß nachvollziehen. Die Bestätigung Mettlachs ad utilitatem unter der Bedingung des Gebets wandelte sich in eine Gabe für alle Zeit. Bischof Liutwin wird unangefochtener heiliger Schenker, Mettlach bedingungsloser Trierer Besitz. Da das Arnulf-Diplom - auch in der vorliegenden Form - nicht vor der Urkunde Karls III. entstanden sein kann, kommt als Manipulations- bzw. Interpolationszeit wahrscheinlich frühestens das späte 10. Jahrhundert in Frage. Vielleicht entstanden beide parallel zu den Urkunden, die Modoald zum Gründer Oerens machten. ${ }^{391}$ Allerspätestens um 1100 jedoch lagen DKIII. 102 und DArn. 39 vor. Denn die Redaktion A der Gesta Treverorum berichtet über die Zeit Bischof Hettis: „Einige sagen, daß er Kirchengut [...] des heiligen Ludwin seinen Großen zu Lehen gegeben habe. ${ }^{\text {“392 }}$ Diese Aussage war nur durch die Verknüpfung des Inhaltes von DLoI. 67, DKIII. 102 und DArn. 39 möglich. Doch hatte sich deren Bild inzwischen weiter verschoben. Nicht mehr der Kaiser, sondern nur der Trierer Bischof war imstande, dortiges Kirchengut zu vergeben. Wido und seine Sippe waren längst dem Vergessen anheim gefallen. Nicht ganz auszuschließen ist jedoch, daß schon Erzbischof Radbod selbst mit Liutwin einen Schenkerbischof aus weit zurückliegender Zeit konstruierte, um Mettlach mit dieser zweiten Urkunde in der Aufbauzeit nach dem Normannensturm fest an Trier zu binden. Doch wie oben angemerkt, hätte hier erneut eine Wiederholung des Inhalts der Lothar-Urkunde ausgereicht. Vielleicht standen in einem möglichen Original an Liutwins Stelle auch ein oder mehrere ganz andere Namen.

390 Vgl. dazu die Überlegungen oben in Kap. A.IV. - Je mehr Zeugnisse, um so überzeugender wirkte diese Wahrheit, die durchaus mit einem tiefen Glauben an die Rechtmäßigkeit der eigenen Sache postuliert werden konnte.

391 Denkbar wäre, daß das im Original erhaltene DLoI. 67 mit den darin erwähnten Bestätigungen von Lothars namentlich genannten Vorgängern als Anregung u.a. für DDKarol. I $\dagger 36$ u. $\dagger 226$ diente.

392 Vgl. Zenz, Taten der Trierer, S. 52. Vgl. dazu Gesta Treverorum cap. 25, ed. Wartz, S. 164, Z. 4 f.: Dicunt eum aliqui res ecclesiarum [...] sancti Liutwini principibus suis in beneficium tradidisse. Vgl. dazu auch Schmal, Mettlach, S. 40, Anm. 254. 
6. Die kopial überlieferte Urkunde Karls des Großen von 782 (DKarol. I 148)

Die Bemerkung der Lothar-Urkunde, mehrere Verwandte Widos I. von Spoleto hätten Mettlach an die Trierer Kirche geschenkt, ist also glaubwürdiger als ein alleiniger, später herangezogener hl. oder seliger Schenker Liutwin, dem es an Familie fehlte. Was bedeutet das für die einzige vorgeblich im 8. Jahrhundert entstandene Mettlacher Urkunde? Nachdem sie bereits kurz zur Person Milos herangezogen worden ist, muß sie jetzt umfassender geprüft werden. ${ }^{393}$

\section{a. Ein Diplom mit Unstimmigkeiten}

Nach einem in Diedenhofen abgehaltenen Königsgericht stellte Karl der Große (768-814) ein Diplom über das gefundene Gerichtsurteil aus. Karl weist darin der Trierer Kirche unter Erzbischof Weomad (762-791) das Kloster Mettlach nach vorausgehenden Besitzstreitigkeiten zu. Die früheste Überlieferung in den litteris putrefactis der Balduineen bietet einen vielleicht kopial oder schon früher verkürzten bzw. veränderten Text. Womöglich war die Vorlage beschädigt. Es fehlen die Corroboratio sowie das Eschatokoll und damit Datum und Actum. Als Gerichtsort wird zu Beginn aber die erwähnte Pfalz angegeben. Die bischöflichen Zeugen - Angilram von Metz, Petrus von Verdun und Borno von Toul - machen - wie oben gesehen - das Jahr 782 für das Geschehen wahrscheinlich. Es handelt sich bei ihnen um die Trierer Suffragane, worauf schon Oexle hingewiesen hat. ${ }^{394}$ Der Text diente - nach dem bisherigen Kenntnisstand - nicht unmittelbar als Vorlage für die besprochenen Mettlacher Urkunden, auch wenn diese ein älteres Dokument Karls angeben. ${ }^{395}$ Es folgt hier eine Übersetzung: ${ }^{396}$

393 Vgl. dazu bereits oben Kap. C.II.3., mit dem Ergebnis, daß Milo recht neutral beschrieben wird und Hinkmar sie für seine Konstruktion zu Milo kaum herangezogen haben kann.

394 Vgl. dazu oben zu Beginn von Kap. C.II.3., Anm. 22.

395 Das haben bereits die Editoren dieser Diplome so gesehen. Vgl. dazu die in der Edition oben aufgeführten Kommentare zu den jeweiligen Urkunden.

396 Die Übersetzung beruht in einigen Teilen auf RAAсн, Mettlach, S. 13 f., nimmt aber deutliche Veränderungen vor. Vgl. dazu DKarol. I 148, S. 201 f. Die im Text durch Klammern und Fettdruck als nachträgliche Einfügungen ausgewiesenen Stellen finden sich so nicht in der Edition. Der Editor KeHr weist sie alle als gewöhnlichen Urkundentext aus. Der Verfasser hält sie hier jedoch für nachträgliche Interpolationen:

Karolus gratia dei rex Francorum et Longobardorum ac patricius Romanorum. Cum nos in dei nomine Theodonevilla palatio nostro una cum optimatibus et fidelibus nostris ad universorum causas audiendas vel recta iudicia terminanda resederemus ibique veniens Wicbertus missus noster una cum scabinis et testibus Moslinses, qui detulerunt nobis, eo quod res proprietatis nostre, id est monasterium quod dicitur Medolago, quod avus noster Karolus quondam maiorum domus Miloni beneficiavit et postea domnus et genitor noster Pippinus quondam rex ipsius Miloni beneficiavit et post discessum Miloni Harthamo episcopo, et 
„Karl, von Gottes Gnaden König der Franken und Langobarden und ,patricius Romanorum'.

Als wir uns im Namen des Herrn in unserer Pfalz in Diedenhofen zusammen mit unseren Optimaten und Gefolgsleuten aufhielten, um die allgemeinen Rechtsstreitigkeiten anzuhören und hierüber gerechte Urteile zu fällen, da kam dorthin auch unser missus Wicbert zusammen mit Schöffen und Zeugen aus der Moselgegend. Sie erhoben bei uns Klage, weil (eo quod) unser Eigenbesitz (res proprietatis nostre), das ist das Kloster, das Mettlach genannt wird, das unser Großvater Karl [Martell], einst Hausmeier, dem Milo zu Lehen gab (beneficiavit) und das später unser Herr und Vater Pippin, einst König, demselben Milo als Lehen gab und nach

adseruerunt, ut $<$ Leodonius quondam episcopus genitor $>$ Milo $<\boldsymbol{n i}>$ et Wido $<\boldsymbol{n i}>$ partibus ecclesie sancti Petri, que est constructa infra muros Treverice urbis, per sua strumenta delegasse[n]t; et dixerunt, qualiter Milo, qui < fuit successor ipsius Leodoni episcopi et> eo tempore episcopio sancti Petri Treverice urbis regebat, abbates in ipso monasterio de ipsa civitate misisset, id est Ebreo et post Ebreo Ratbertum episcopum et post Ratbertum Harthamum, qui et post discessum Miloni exinde vestitus fuit per beneficium Pippini regis, et tales testes vel scabini ibidem in presentia adfuerunt, qui per sacramenta hoc adfirmaverunt, ut vidissent et certissime cognovissent iusticiam esse sancti Petri ad episcopium Treverice urbis. Et ibidem de hac re contentio fuit inter Wicberto misso et filios Lantberti Widoni et Hrodoldo vel Warnario; nam agentes sancti Petri vel scabini dicebant, ut Lambertus genitor eorum per forcia potestate Pippini regis malo ordine ipsum monasterium invasisset et Harthamum episcopum exinde expoliasset. Et taliter iudicaverunt, ut per legem et iusticiam illa vestitura partibus nostris atque sancti Petri adesse debuisset, pro eo quod Milo et Harthamus ipsum monasterium per beneficium Karoli maioris domus et domni Pippini regis semper habuissent; sed Wido atque germani sui Hrodoldus et Warnarus contradixerunt, ut eorum fuisset vestitura, quia genitor eorum Lantbertus in legitima alode eos vestitos dimisisset et pro hac causa magna ibidem fuit contentio. Unde nos una cum fidelibus nostris totos scabinos de ducato Moslinse coniunximus, qui unanimiter iudicaverunt, ut Wido et germani sui tales auctoritates non habuissent, qualiter genitor eorum contra Pippinum regem ipsum monasterium evindicasset, nostra legitima ad partes sancti Petri esse deberet vestitura. Sed dum Wido et germani sui de vestitura legitima nec testes neque scabinos habere potuerunt, tunc eis iudicatum fuit, ut in presentia nostra iam fato monasterio partibus nostris in causa sancti Petri Treverensis cum fide facta reddere deberent; quod ita et fecerunt et per missum eorum vestitura a partibus sancti Petri Treverecensis, ubi Weomadus <archiepiscopus $>$ pontifex esse videtur, presentialiter fecerunt, sicuti eis a nobis vel fidelibus nostris indicatum fuit, id sunt Angalramno, Petro et Bornoni episcopis, Erhardo, Walarano, Ernust, Warnario, Huncelino, Warlando, Waltario, Rimigaudo, Hainrico, Gaeroni et Hieronimo comitibus nec non et a reliquis fidelibus nostris scabinos Theutfrido, Waltario, Hildrado, Theuthario, Ebreardo, Baldoino, Gerhac, Gundacro, Gisleberto, Buou, Theodo, Fulcoino, Hadegario, Alpcario, Gunihario, Aldmanno, Folrado, Bolso, Gundolando, Odilhario, Ricfrido, Teutberto, Helengario, Ravangario, Odilberto, Unifrido, Ebrehelmo, Herardo, Audo, Barigaudo, Warmado, Hereberto, Rotfrido, Beregrimo, Adalingo, Regulo, Obbon, Thietdingo, Trutberto, Walanco, Ricgaulo, item Guniario, Gunilaigo et Walachario seu comiti palatii nostri Woradi vel ceteris quam plures fidelibus, qui ibidem aderant, visi sumus iudicasse, ut suprascriptus Weomadus <archiepiscopus> tale preceptum vel iudicium evindicatum de iam dicto monasterio Medolaco una cum rebus et hominibus suis ad se pertinentibus vel aspicientes partibus sui Treverensium accipere deberet. Quod ita et fecimus, ut ipse et successores sui, qui fuerint rectores ipsius episcopati, suprascripto monasterio omni tempore habeant elidiatum atque evindicatum et sit in postmodum ex hac re inter ipsos subita ac definita causatio. 
Milos Tod dem Bischof Harthamus [dem Nebensatz fehlt Schluß und Gegenstand der Klage] ; sie behaupteten, $\mathrm{da} \beta<$ Leodonius, einst Bischof und [vielleicht stand hier auch Lambertus] Vater des $>$ Milo und Wido [es - gemeint ist wohl das Kloster, vielleicht wurde aber auch etwas ausgelassen] dem Besitz (partibus) ${ }^{397}$ der Kirche des hl. Petrus, die innerhalb der Mauern der Stadt Trier errichtet wurde, durch seine/ihre Urkunden (per sua strumenta) zugewiesen/abgetreten/übertragen hätte[n]; sie erzählten, wie Milo, der $<$ desselben Bischofs Leodonius [auch hier könnte Lambert bzw. Lamberts gestanden haben] Nachfolger war und $>\mathrm{zu}$ dieser Zeit die Wirtschaftsgebäude/die Wirtschaft (episcopium) vom hl. Petrus der Stadt Trier leitete, in dasselbe Kloster Äbte aus derselben Stadt geschickt hätte, und zwar Ebreo und nach Ebreo Bischof Ratbertus und nach Ratbertus den Harthamus, der auch nach Milos Tod darauf mit dem Lehen des Königs Pippin investiert wurde. Und solche Zeugen und Schöffen waren ebendort anwesend, die das mit Eiden bekräftigten, daß sie gesehen und ganz sicher erkannt hätten, daß das Eigentumsrecht (iustitia) des hl. Petrus zum episcopium der Stadt Trier gehöre. Und wegen dieser Sache herrschte dort Streit zwischen dem missus Wicbert und Lamberts Söhnen Wido, Hrodold und Warnar. Denn agentes des hl. Petrus und die Schöffen sagten, daß sich deren Vater Lambert mit Gewalt potestate Pippini regis malo ordine dieses Kloster angeeignet habe und dadurch den Bischof Hartham völlig seines Besitzes beraubt hätte. Und sie urteilten so, daß nach Gesetz und Recht jene Belehnung/Gewere (vestitura) uns sowie dem hl. Petrus hätte gehören/zustehen müssen, weil Milo und Harthamus dasselbe Kloster immer durch das Lehen des Hausmeiers Karl und des Herrn Königs Pippin gehabt hätten. Aber Wido und seine Brüder Hrodold und Warnar erhoben den Widerspruch, daß ihnen die Belehnung/ Gewere (vestitura) gehöre/zustehe, weil ihr Vater Lambert sie vestitos in ihr rechtmäßiges Eigentum/Erbe (allode) hinterlassen/zurückgelassen hätte. Und wegen dieser Sache gab es dort großen Streit. Deshalb haben wir uns zusammen mit unseren Getreuen allen Schöffen aus dem Moseldukat angeschlossen, die einmütig urteilten, daß Wido und seine Brüder solche Urkunden nicht hätten, wie ihr Vater dasselbe Kloster gegen König Pippin erstritten hätte, und unsere rechtmäßige Belehnung/Gewere zum Besitz des hl. Petrus gehören müsse. Aber da Wido und seine Brüder für die rechtmäßige Belehnung/Gewere weder Zeugen noch Schöffen anführen konnten, wurde dann über sie geurteilt, daß sie in unserer Gegenwart das schon genannte Kloster uns stellvertretend für den hl. Petrus von Trier unter Eid zurückgeben sollen. Das machten sie auch so, und sie nahmen/lösten sogleich durch den missus ihre Belehnung/Gewere (vestitura) vom Besitz des hl. Petrus von Trier, wo $<$ Erzbischof $>$ Weomad Bischof ist, wie über sie von uns und unseren Getreuen geurteilt wurde. ${ }^{398}$ Das sind die Bischöfe Angalramnus [v. Metz], Petrus [v. Verdun] und Borno [v. Toul], die Grafen [es folgen elf Namen] und von unseren übrigen Getreuen die Schöffen [es folgen 44 Namen], unser Pfalzgraf Woradus und die

397 RaAch, Mettlach, S. 13, übersetzt partibus mit „Teile“, die vermacht werden. Herrn Präsident Professor Dr. Rudolf Schieffer verdanke ich den freundlichen Hinweis, daß es sich dabei um den Ort, an den das Geschenkte übertragen wird, handelt, nämlich den „Besitz der Kirche des hl. Petrus“.

398 Diese Stelle ist verderbt oder verändert worden. Was eigentlich wie zurückgegeben werden soll, wird nicht deutlich. Offenbar sollen Wido und seine Brüder nur ihre Teile zunächst an Karl zurückgeben, der gleichsam die Trierer Kirche vertritt. Eigentlich hätte dafür aber doch Weomad zugegen sein müssen. 
zahlreichen übrigen Getreuen, die dort anwesend waren. Wir haben geurteilt, daß der erwähnte <Erzbischof $>$ Weomad eine solche Königsurkunde und das erstrittene Urteil über das schon genannte Kloster Mettlach gemeinsam mit seinen Besitzungen und Leuten, die dazu gehören, für die Trierer Seite annehmen solle. ${ }^{399}$ Das haben wir auch gemacht, damit er selbst und seine Nachfolger, die Leiter/ Bischöfe desselben Bistums (episcopatum) sein werden, das genannte Kloster für alle Zeit unbestritten und erstritten haben sollen. Und es sei von nun an in dieser Sache zwischen denselben [Beteiligten] ein beendeter und vorschriftsmäßiger Prozeß.“

Der Text selbst ist schon auf den ersten Blick verderbt, voller erkennbarer Unstimmigkeiten und schwer übertragbarer Stellen. Die hier nun wiedergegebene Version versucht, nahe am lateinischen Text zu bleiben, kann aber selbstredend nicht umhin zu bewerten. Das angewandte Klammersystem zeigt, daß Interpolationen als Ursache für die komplizierten und widersprüchlichen Aussagen angenommen werden, worauf gleich zurückzukommen ist. Denkbar sind ferner Beschädigungen an der Vorlage, die man durch interpretierende Ergänzungen nachräglich stimmig zu machen versuchte.

\section{b. Bisherige Interpretationsversuche}

Diese Widersprüche hat die bisherige Forschung durch teils ebenso widersprüchliche und komplexe Interpretationsversuche zu erklären und aufzulösen versucht. Allesamt gingen davon aus, daß Milo Trierer Bischof war, und bezogen das in ihre Überlegungen ein. Inzwischen wissen wir aber, daß dies nicht der Fall gewesen sein kann. Schon ABEL und Simson hielten deshalb 1888 Bischof Hartham für Milos unmittelbaren Trierer Nachfolger. ${ }^{400}$ Ewig verwandte einmal mehr - wie schon bei seinen Reimser Überlegungen - das Deutungsmuster von Chorbischöfen für Hartham und Ratbert. ${ }^{401}$

Das Namensgut der Urkunde zog genealogische Überlegungen zur schon erwähnten Familie der sog. ,Widonen-Lambertiner-Miloniden' nach sich. Neben dem als Spitzenahn der Sippe postulierten Bischof Liutwin - ganz abgesehen von seinem Onkel Basin - bekam Milo einen Bruder Wido zugeordnet. Man versuchte dann, Lambert und seine Söhne in das Familienstemma zu

399 Die Stelle ist erheblich verderbt, vielleicht interpoliert oder auch falsch kopiert. Die hier wiedergegebene Übersetzung ist nur eine Interpretation. - Sinngemäß soll es wohl bedeuten, daß Weomad für Trier das Kloster Mettlach mit all seinem Besitz und Hörigen zugesprochen bekam.

400 Vgl. Abet, Jahrbücher 1, S. 435-438. Schon Leonardy, Rückgabe, der eine interpretierende Übersetzung des Diploms lange vor Raach anfertigte, formulierte 1872 erstmals die These, bei Bischof Hartham müsse es sich um Milos Nachfolger handeln. Allerdings hält er die Bischöfe Ratbert und Hartham zunächst für Hilfs- bzw. Weihbeschöfe. Doch vermutet Leonardy ferner zurecht, der/die Abschreiber der Balduineen hätten den verderbten Text der Urkunde vielleicht durch eigene interpretierende Zusätze stimmig zu machen versucht.

401 Vgl. Ewig, Milo, S. 419 u. Anm. 40. 
integrieren und sah in ihm einen Sohn dieses Wido. Unumstritten ist inzwischen, daß Lamberts Kinder die Vorfahren der bedeutenden Widonen des 9. Jahrhunderts waren: darunter auch Wido I. (842-ca. 859) und II. (†894) von Spoleto. ${ }^{402}$

RAACH hat sich erstmals intensiv mit diesem Diplom beschäftigt. Er sieht darin das spätere Trierer Geschichtsbild bestätigt, daß Liutwin Mettlach an Trier geschenkt hätte. Nach dieser Übertragung an St. Peter und noch vor Milos Belehnung müsse das Kloster jedoch einem rechtlichen Wandel unterworfen worden sein. Karl Martell ( $† 741)$ habe es wohl säkularisiert, es aber formal im von Liutwin gewünschten Zustand belassen. In Trier habe Liutwins Testament vorgelegen. Milo stehe für die Verbindung zu Karl Martell. Mettlach sei folglich kein Reichskloster geworden. Die ,Enteignung' durch Karl Martell werde im Diplom jedoch nicht verurteilt, weil Karl der Große (768-814) den Widonen nahegestanden habe. Die Mettlacher „Kloster- oder Chorbischöfe“ könne man aufgrund von Milos kirchenrechtlich problematischer Position erklären. Endlich aber sei mit Mettlach doch aus einem adligen ein bischöfliches Eigenkloster geworden. ${ }^{403}$ RAACH hält Milos Bruder Wido für den 738/9 erwähnten Laienabt der Klöster St-Wandrille (Fontenelle) und St-Vaast in Arras, einen angeblichen Verwandten Karl Martells. Aufgrund seines weltlichen Lebenswandels und einer Verschwörung gegen Karl sei er verurteilt und hingerichtet worden. Sein Verhalten entspreche auffällig den negativen Beschreibungen von Milo. Doch nicht Wido, sondern Milo sei der Vater Lamberts. Schon EwIG habe nämlich auf mögliche Kinder Milos hingewiesen. Da die aber sicher illegitim waren, habe die Urkunde auf einen Verwandtschaftshinweis verzichtet. Vielleicht erkläre eine denkbare Verwandtschaft zwischen Widonen und Karolingern auch einen ge-

402 Zur Literatur zu dieser Familie vgl. Mitterauer, Markgrafen, S. 64-72, hier S. 67-72, der die älteren Forschungsthesen 1963 zusammengefaßt hat, die vor allem additiv die bekannten Quellen verbinden. Ja, man wollte sogar eine widonische Bischofsdynastie von Basin über Liutwin, Milo bis zu Weomad am Werk sehen. Vgl. ferner Metz, Miszellen. Hlawitschka, Kaiser Wido und Lambert. Schneider, Fulco von Reims, S. 1-21. Hlawitschka, Widonen im Dukat von Spoleto, geht den Verwandtschaftsbeziehungen und der Geschichte der Familie im 9. Jahrhundert weiter nach. BRUNTERC'H, Duché du Maine, S. 46 ff., behandelt die Widonen in der bretonischen Mark. Erstmals hielten wohl Wartz, Herkommen des Grafen Wido, S. 153, und Wüstenfeld, Herzöge von Spoleto, S. 391, schon in der Mitte des 19. Jahrhunderts Wido für den Vater Lamberts.

403 Vgl. RaAch, Mettlach, S. 12-18, 21. Die Mettlacher Äbte müßten dennoch nicht unbedingt bischöfliche Würden innegehabt haben, wie der titellose Ebreo zeige. - Für die rechtliche Doppelstellung des Klosters beruft er sich auf Semmler, Traditio, S. 3, der sie im Rahmen der „durch Konfiskation dem König zugefallenen Klöster“ einordnet. 
meinsamen Besitz an Mettlach. Wir erinnern uns dazu an Hinkmars Denkschrift von 863, die als einzige Quelle von Nachkommen Milos spricht. ${ }^{404}$

BECKER vermutet in den drei genannten Mettlacher Äbten gar Besitzer eines Afterlehens von Milo. ${ }^{405}$ Auch AnTon hält Wido für den Abt von Fontenelle sowie Hartham und seine beiden Vorgänger Ratbert und Ebreo für Klosterbischöfe. Karl Martell habe das von Liutwin an Trier übertragene Mettlach indirekt konfisziert und verfügte vielleicht über verwandtschaftliche Mitrechte am Kloster. Denkbar seien auch Rechtsstreitigkeiten nach Liutwins Tod. Mettlach entstehe ursprünglich als Eigenkloster. Mischbesitzverhältnisse seien grundsätzlich unwahrscheinlich. Doch DKarol. I 148 verschleiere das, indem es Karl Martell und Pippin darüber wie über Allodialbesitz verfügen lasse. DKIII. 102 und DArn. 39, die nur noch Liutwin nennten, harmonisierten aber später die Darstellung der Karls-Urkunde. Doch danach will Anton - dem widersprechend - eine gemeinsame Gewere der Karolinger und der Trierer Kirche am Kloster erkennen. Lambert habe dann beim Tod seines Vaters Milo versucht, seine Allodansprüche unter König Pippin durchzusetzen. ${ }^{406}$

Nonn betont 1998 die Interpretationsschwierigkeiten und behandelt das Diplom kurz. Er hält die Zahl der Beteiligten für auffällig. Lediglich Rimigaudus und der Pfalzgraf Woradus seien noch ein weiteres Mal zu finden. Auf den

404 Vgl. Raach, Mettlach, S. 26-35, mit der entsprechenden Literatur. Er verweist für Wido u.a. auf die bereits oben besprochene, im späteren 12. Jahrhundert gefälschte Schenkung über Stain von 706 (MRUB I 7a), die einen Diakon Milo und Grafen Wido als Zeugen nennt, sowie auf die ebenfalls gefälschte Urkunde für das Apostelkloster in Metz (später St. Arnulf) von 715, die einen Milo und Grafen Wido in ihrer Zeugenliste aufführt (ebd., S. 28 f.). Wie wir gesehen haben, dürften diese Listen erst später entstanden sein. Vgl. dazu oben Kap. C.II.1. u. D.III.1. - Zu Wido als Laienabt in Fontenelle vgl. die vermutlich nach 833 entstandenen Gesta sanctorum Patrum Fontanellensis coenobii cap. VII, ed. Lohier/Laporte, S. 56-58. Vgl. dazu Chronique, ed. Pradié, S. 42-47, 214, der auch auf chronologische Unstimmigkeiten hinweist. Der Verfasser der Chronik behauptet, seine Informationen einem bereits verstorbenen Bruder zu verdanken, der Wido noch gekannt habe. Zu den Gesta vgl. genauer oben Kap. C.III.1. - Vgl. zu Milos vorgeblichen Kindern Ewig, Treverensia, S. 229 f. u. Anm. 6, der die Übertragung Mettlachs an Trier als Entschädigung dafür sieht, weil in Trier unter Weomad eine Grafschaft errichtet worden sei. Doch gehen die Hinweise auf diese Grafschaft nur auf zwei nicht unumstrittene Urkunden Zwentibolds und Ludwigs des Kindes zurück. Vgl. MRUB I 143, 150, S. 208 f., 214 f., bzw. DZw. 18, S. 49-51, sowie DLdK 17, S. 120-122, vom 5. Februar 898 und 19. September 902. - Daß die Angabe zu Milos möglichen Kindern zu Hinkmars Konstruktion gehört, haben wir bereits oben in Kap. C.I. bei Anm. 12 gesehen.

405 Vgl. Becker, Mettlacher Äbte, S. 43 f., 51 f. Doch dann müsse für die geistige Leitung schon für diese Zeit ein Propst angenommen werden, wie ihn die Miracula s. Liutwini allgemein vor der Einführung des ersten regulären Abtes im 10. Jahrhundert angäben. Becker folgt insgesamt den Thesen Raachs und stellt auch eine Abtliste zusammen.

406 Vgl. Anton, Liutwin, S. 33, 36-40, 43-45, bes. Anm. 53. Eine Verbindung zu den Gründern Hornbachs hält er immerhin für möglich. 
ebenfalls öfter erscheinenden Wicbertus verweist er in einer Fußnote. Besonders merkwürdig sei die hohe Schöffenzahl, die eine spätere Interpolation vermuten lasse. Gleiches gelte für den Gang des Missus' mit Schöffen und Zeugen vor den König. Die Rolle Wicberts als Partei für Trier sei schwer einzuordnen, der Hausmeiertitel für Karl Martell finde sich in keiner weiteren Urkunde Karls des Großen. Die Beschreibung Milos als Nachfolger Bischof Liutwins, indem er das Trierer episcopium regiere, mute eigenartig an, zumal dieser Terminus sonst nur in gefälschten Karls-Urkunden begegne. Er regt deshalb eine weitere Untersuchung an. Einiges deutet also auf Eingriffe in den Text hin, doch interpretiert NonN das Dokument auf der Basis des gängigen Trierer Forschungsstandes zu Milo und Liutwin, den er im Inhalt der Urkunde nicht wiedererkennt. ${ }^{407}$

Schmal verwirft dieses Diplom dann endgültig aufgrund des Inhalts und seiner fehlenden Datierung als Trierer Fälschung nach 1077. Denn es fänden

407 Vgl. Nonn, Moseldukat, S. 13-33, bes. S. 17-22, der sich vor allem mit einem möglichen Moseldukat beschäftigt. Die früheste, scheinbar zeitgenössische Quelle eines solchen Dukats bilde diese Urkunde. Ein zweiter Beleg finde sich in einer Schenkung Karls des Großen an Metz vom 1. Mai 783 (DKarol. I 149, S. 202-204, hier S. 203), ein dritter in der Divisio imperii von 839. Nonn stellt auch die bisherige Forschungsliteratur zusammen. Zu Wicbert vgl. unten S. 238 f. u. Anm. 419-424. Nonn zweifelt nicht zu Unrecht an einem Moseldukat. Doch läßt sich der Befund auch nicht von der Hand weisen, daß dieser schwammige Terminus nur in den Quellen der Zeit von 782 839 auftaucht. Warum nur jetzt? Und welchen Sinn hätte eine Manipulation in einem späteren Zusammenhang gemacht? Der Begriff läßt sich also nicht ganz wegdiskutieren und müßte für eine spätere Zeit erklärt werden. Wenn Nonn dann darauf verweist, Pfalzgraf Woradus erscheine nur noch als Waraldus in einer weiteren Urkunde just ebenfalls von 782 (DKarol. I 138), ist dies doch eher ein Beleg für als gegen das Vorhandensein dieses Pfalzgrafen. Die Verschreibung des Namens läßt sich problemlos mit der kopialen Überlieferung erklären. Woher hätte denn ein Fälscher wissen sollen, daß ausgerechnet in diesem Jahr dieser Pfalzgraf wirkte, denn DKarol. I 138 ist nur im Pariser Umfeld überliefert. Die hohe Schöffenzahl von DKarol. I 148 könnte sich allerdings durchaus aufgrund nachträglicher Interpolationen erklären lassen. Daß die Verwendung des Hausmeiertitels in den Karolingerurkunden nicht völlig obsolet war, zeigen die von Nonn selbst angeführten DDKarol. I 43, 88, 124, von 769 (Karlmann), $774 / 5$ und 779 , in denen immerhin zweimal Grimoald der Jüngere $(\dagger 714)$ und einmal Pippin der Mittlere ( $\uparrow 714)$ als solche bezeichnet werden. Auf den auffälligen Begriff des episcopiums wird unten noch genauer einzugehen sein. Vgl. dazu S. $236 \mathrm{ff}$. u. Anm. 413-418. Nonn kritisiert zudem den Begriff der rectores episcopati, der sich aber just nur noch in dem als Original erhaltenen DKarol. I 147, S. 200, von 782 findet. Er erscheint also im selben Jahr wie im für die Mettlacher Urkunde angenommenen Entstehungsjahr. Das deutet dann jedoch eher auf eine vielleicht kurze Mode des Begriffs in der Kanzlei und nicht vollständig gegen die Echtheit des Diploms. Vielmehr spricht dieses Argument für die Datierung eines bestehenden alten Kerns von DKarol. I 148 in genau dieses Jahr 782. Nonns Argumente zeigen also berechtigte Unstimmigkeiten im Diplom auf, müssen aber weiter überprüft werden. - ANTON, Raumbestimmende Voraussetzungen, S. 163, Anm. 67, hält dagegen und spricht lediglich von „modernisierende[n] Verfälschungen“. 
sich weder in den anderen Mettlacher Urkunden noch in den Liutwin-Viten, dem Libellus de rebus Treverensibus oder den Gesta Treverorum Hinweise darauf. Von einem Sohn Liutwins namens Wido sei in diesen Quellen ebensowenig die Rede. Hätte nicht vielmehr Trier wegen der Entfremdung Mettlachs durch Karl Martell klagen müssen? Verdacht erregten ferner die Erwähnung des Trierer Mauerberings, der gleichzeitige Gebrauch des Titels Bischof und Erzbischof sowie der angehängt wirkende Rechtsspruch am Ende der Urkunde. Endlich gebe es Textparallelen zu DDKarol. I $† 36$ und $† 226$. Vielleicht habe ja ein echtes oder bereits verfälschtes Diedenhofener Diplom als Vorlage gedient. Die genannten Äbte sprächen zwar für eine alte Abtliste als Vorlage, Ratbert und Hartham seien aber erst nachträglich zu Bischöfen gemacht worden. Doch muß Schmal eingestehen, daß sich immerhin Lambert und seine Söhne auch als gemeinsamer Eintrag im zeitnahen Verbrüderungsbuch der Reichenau finden. ${ }^{408}$ Zwar nimmt Schmal die Widersprüche des Diploms nicht einfach hin. Doch kann es deshalb vollständig als Fälschung verworfen werden? Gibt es vielleicht einen anderen Weg, diese Ungereimtheiten aufzuheben?

\section{c. Versuch einer Neuinterpretation}

Die zentralen Punkte der inhaltlichen Widersprüche, an denen sich die Forschung immer wieder gerieben hat, sind unverkennbar: Wie konnten Karl Martell und Pippin das Kloster Mettlach an Milo verleihen und Pippin dies an Bischof Hartham wiederholen, wenn doch Milos und Widos Vater, Bischof Liutwin, es in irgendeiner Form dem Besitz der Kirche des hl. Petrus in Trier übertrug? Warum nannte es Karl der Große Eigenbesitz? Wie erklären sich die merkwürdigen Passagen, die von gemeinsamen Rechten der Karolinger und der Trierer Kirche am Kloster sprechen? Wer waren die von Milo nach Trier entsandten Äbte? Wie erklärt sich deren Bischofstitel, wenn doch angeblich Milo seinem Vater Liutwin als Nachfolger im Trierer episcopium folgte? Weshalb konnte Lambert ohne den Widerstand König Pippins Mettlach besetzen? Schließlich setzte man sich auch erst später dagegen zu Wehr. Schwer zu klären ist auch Lamberts Verhältnis zu den anderen Personen, die in der Urkunde genannt werden. Die Angaben zum Schenker-Bischof Liutwin erinnern darüber hinaus weniger an den Inhalt der im Original erhaltenen Urkunde Lothars I. von 842 als an DKIII. 102 sowie DArn. 39, die vielleicht im Kern aus dem späten 9. Jahrhundert stammen, aber eher am Ende des 10. oder zu Beginn des 11. Jahrhunderts ver- oder gefälscht sein dürften. Doch reicht das alles schon ergänzt um Schmals Argumente - aus, eine Ganzfälschung anzunehmen?

408 Vgl. Schmal, Mettlach, S. 41-43. Die Frage ist dann aber, warum ausgerechnet das Jahr 1077 der Terminus post quem sein soll. 
Um dies zu prüfen, empfiehlt es sich, die von Merta zusammengetragenen weiteren Grafengerichtsdiplome Pippins und Karls des Großen zum Vergleich zur Hand zu nehmen. ${ }^{409}$ Schnell wird deutlich, daß man vorsichtiger urteilen muß. Denn der gesamte Urkundenaufbau von DKarol. I 148 folgt dem äußeren, sich wiederholenden Formular dieser Urkundengruppe: Zu Beginn erwähnt der König, er habe sich zur Versammlung an einem meist namentlich genannten Ort aufgehalten. Dann seien Personen zu ihm gekommen, die um Rechtssprechung baten. Die Standpunkte der verschiedenen Parteien werden beschrieben, schließlich auch die Art der Rechtsfindung. Dann folgen namentlich die dabei Anwesenden bzw. Zeugen oder Schöffen, an deren Ende der Pfalzgraf. Sodann wird das Urteil erneut explizit verkündet. Vor allem der von Schmal bei DKarol. I 148 als angehängt angenommene Schluß stimmt teilweise wörtlich mit diesen Vergleichsdokumenten überein. Der als Pfalzgraf genannte Woradus begegnet zudem in einer, sicher auf 781 datierten Gerichtsurkunde Karls des Großen für Ado, den Vogt des Klosters St-Denis. Darin lautet die Schreibweise Waraldus. ${ }^{410}$ Angesichts der kopialen Überlieferung von DKarol. I 148 läßt sich die Variation durchaus erklären. Auch die Namen der frühen, nur hier erwähnten Mettlacher Äbte können kaum erfunden sein. Wer verfügte über ein Motiv, sie zu konstruieren? Später schien sich doch niemand mehr für diesen Rechtsstreit zu interessieren. Deshalb muß DKarol. I 148 in mehreren Teilen auf einem echten Kern beruhen.

Da der zu Beginn der Urkunde beschriebene Sachverhalt wohl auf dem Erinnerungszeugnis der erwähnten Zeugen beruhte, sollte man zudem erwarten, daß diese wenigstens ein jeweils für ihre Partei kohärentes Bild präsentierten.

409 Vgl. dazu oben Anm. 322. Vgl. ferner Merta, Durchsetzung von Besitzansprüchen, S. $172-176$. Sonst folgt sie der älteren Literatur. Neuere Studien, z. B. Anton, übergeht sie. Sie spricht aufgrund der Urteilerzahl im Dokument von einer wichtigen Entscheidung. Neben dieser Urkunde erwähnten noch zwei Diplome ein vorausgegangenes Grafengericht. Auch sie böten ähnlich viele Namen. Vgl. DDKarol. I 138 u. 204, S. 188 f., 273 f. Beide sind für St-Denis ausgestellt. Die erste datiert vom 16. Dezember 781 für Abt Fulrad (12 Urteiler + Pfalzgraf), die zweite vom 17. August 806 für Abt Fardulf (19 Urteiler), den der Text aber mit Fulrad verwechselt. Sie sind in einem Chartular aus dem 12./13. Jahrhundert erhalten. Darüber hinaus fänden sich noch mehr Gerichtsurkunden Pippins III. und Karls des Großen, doch keine davon nenne so viele Zeugen wie die für Trier. Vgl. hierzu noch DKarol. I 1, S. 3 f., für St-Denis (6 Urteiler + Pfalzgraf); ebd. 12, S. 17 f., für St-Denis (6 Urteiler + Pfalzgraf); ebd. 63, S. 91-93, für Fulda (keine Namen); ebd. 65, S. 95 f., für Lorsch (4 Grafen + 5 Vasallen Karls); ebd. 102, S. 146 f., für St-Denis (11 Urteiler + Pfalzgraf); ebd. 110, S. 155 f., für Honau (7 Urteiler + Pfalzgraf); ebd. 197, S. 265 f., für Nonantola (keine Namen); ebd. 216, S. 288 f., (11 Urteiler + Pfalzgraf). - Eine Urkunde wäre noch zu ergänzen: ebd. 6, S. 9-11, für St-Denis vom 8. Juli 753 (14 Urteiler + Pfalzgraf). - Allerdings sollte man bei einer Zahl von über 45 Zeugen doch nachträgliche Ergänzungen nicht ausschließen.

410 Vgl. DKarol. I 138, S. 188 f., vom 16. Dezember 781 aus Quierzy. 
Dabei müssen die von ihnen dargebotene chronologische Reihenfolge sowie die erwähnten Argumente nicht mit einer faktischen Wirklichkeit übereinstimmen. Sie können, ja werden vielmehr auf einem Aushandlungsprozeß unter den Vertretern der jeweiligen Partei beruhen, der erst jetzt vor Gericht oder im Vorfeld der Verhandlung erfolgte. Doch sollte dieser eigentlich zu einem für die eigene Partei in sich stimmigen Ergebnis geführt haben, wie es üblicherweise in einem solchen Fall im kollektiven Gedächtnis konstruiert wird. Das jedoch ist gerade für die hier vorzufindenden unstimmigen Angaben der Trierer Seite keineswegs der Fall. ${ }^{411}$

Die inneren Widersprüche deuten deshalb auf nachträgliche Konstruktionen und Interpolationen in den Text. Daß der Rechtsinhalt sich so nicht mehr in der Trierer Überlieferung wiederfindet, muß nicht bedeuten, daß er frei erfunden ist. Auch das echte DLoI. 67 wird nicht mehr rezipiert, sondern behutsam in Richtung eines hl. oder seligen Schenkerbischofs Liutwin verändert. Das wäre auch für das Diplom Karls des Großen denkbar, hätte man einen Weg gefunden, es später anzupassen oder zu bearbeiten. Letztlich muß es einen Grund dafür geben, warum es in die litteras putrefactas gelangte. Auch hier stellt sich deshalb die Frage, ob dem Kopisten im 14. Jahrhundert ein Original oder nur eine Abschrift vorlag. Waren Original oder Abschrift beschädigt? Wenn es darin aber nachträgliche Manipulationen gab, könnten im Text noch Hinweise darauf erhalten geblieben sein. Gehen wir auf Spurensuche und prüfen dazu noch einmal genau den Inhalt.

$\mathrm{Zu}$ Beginn wird der Grund für das Aufsuchen des Königsgerichtes erläutert, nämlich weil (eo quod) Karl Martell das Kloster Mettlach an Milo als Lehen gab, darauf Pippin nochmals an Milo und dann an Bischof Hartham, ... Folgt man der Intention und Konjunktion dieses Nebensatzes, so müßte im Anschluß daran etwas geschehen sein, was diese Belehnungen vielleicht in Frage stellte, zumindest aber einen Anlaß für eine Klage am Königsgericht bot. Doch läuft der Satz ins Leere und schweigt darüber. Stattdessen folgt geradezu abrupt der Hinweis auf Milos und Widos Vater Bischof Liutwin, der etwas nicht genauer Erläutertes (gemeint ist wohl das Kloster) an den Besitz der Trierer Kirche übertragen habe. Allerdings stehen Milo und Wido nicht im Genitiv, wie es erforderlich wäre, sondern im Dativ. Schenkte also Liutwin ursprünglich gar nicht an Trier, sondern an die beiden? Vielleicht aber handelt es sich um den Fehler eines Kopisten, und der Genitiv ist gemeint.

Diese Stelle macht aus mehreren Gründen keinen Sinn: Einmal wird dem beschriebenen Eingangssachverhalt zeitlich vorgegriffen und damit erst das vieldiskutierte Problem geschaffen, weshalb über ein Gut, das an den Besitz der

$411 \mathrm{Vgl} . \mathrm{zu}$ solchen Aushandlungsprozessen, an deren Ende ein einheitliches Bild steht, Fried, Schleier, S. 85 f., 173, 175, 178 ff., 183 ff., 197 ff., 216 ff., 227 f., 295, 367 ff., mit Beispielen. 
Kirche des hl. Petrus in Trier verschenkt worden war, plötzlich wieder der König als Eigenbesitz verfügte. Auch die Urkunde bleibt eine Antwort schuldig, was nicht einfach Verschleierungstaktik gewesen sein kann. Denn die Trierer agentes hätten doch gerade vor dem König Beschwerde über eine solche königliche Enteignung führen müssen. Seltsamerweise kommt in der Urkunde dem Wido, Milos Bruder und vermeintlichen weiteren Sohn Liutwins, überhaupt keine Funktion zu. Man hätte auf diesen bedeutungslosen Wido hier problemlos verzichten können. Und doch tat man es nicht. An ihn wird in keiner Quelle, die von einem Bischof Liutwin spricht, jemals wieder erinnert, auch nicht in den Liutwin-Viten. ${ }^{412}$

Liutwins Rolle in DKarol. I 148 folgt hingegen zwei Funktionen: einmal ist er Vater und Vorgänger Milos, zum anderen Überträger an den Besitz der Trierer Kirche. Doch über eine solche zentrale Bedeutung kann er im 8. Jahrhundert kaum verfügt haben, wenn nicht einmal DLoI. 67 Liutwins Namen nennt. Die Stelle paßt viel besser in den Kontext von DKIII. 102 und DArn. 39, die vielleicht im Kern aus dem späten 9. Jahrhundert stammen, aber eher am Ende des 10. oder zu Beginn des frühen 11. Jahrhunderts ver- oder gefälscht worden sein dürften. Laut DKarol. I 148 verwandte Liutwin für sein Vorgehen mehrere Urkunden (sua strumenta), was nicht näher erläutert wird. Allerdings stimmten mehrere Dokumente ganz im Gegenteil bestens mit der Aussage über mehrere Schenker in DLoI. 67 überein. All das legt den Schluß nahe, daß ein Bischof Liutwin nicht im Original des Diploms zu finden war, sondern in dieses zu einer späteren Zeit als Vater Milos und Widos interpoliert wurde, als man Liutwin mit Mettlach zu verbinden begann und er deshalb folgerichtig auch in diese Urkunde zu gehören schien.

Da Milo siebenmal im Text genannt wird, fällt ihm die eigentlich bedeutende Rolle neben Bischof Hartham zu, dessen Name viermal fällt. Durch den zweimal kurz eingefügten Liutwin wird aber geradezu die Bedeutung Milos auf diesen abgeleitet. Nimmt man Liutwin aus der Passage heraus, erhält die Stelle eine Aussage, die der echten Lothar-Urkunde ähnlich ist: In diesem Fall schenkten nämlich Milo und Wido durch ihre Urkunden etwas (wohl Mettlach) an den Besitz der Trierer Kirche. Man muß dazu nur das Dativ-i an beider Namen als nachträgliche Interpolation sehen. Widos Erscheinen machte dann plötzlich Sinn. Wido müßte nicht einmal Milos Bruder gewesen sein. Beide sind jedoch aufgrund ihrer Namen sicher Mitglieder der Widonen-Familie. Die Stelle bereitet jetzt weniger Schwierigkeiten. Dies ist eine erste mögliche Lesart, die jetzt durchgespielt werden soll. Auf eine zweite, davon etwas abweichende, denkbare Lesart kommen wir noch weiter unten zu sprechen.

Das stellt konsequenterweise auch die zweite Passage in Frage, in der Milo als "Nachfolger" (successor) Bischof Liutwins erscheint. In diesem Zusammen-

412 Vgl. dazu die Liutwin-Viten ausführlich unten in Kap. D.IX.2. u. D.IX.5. 
hang muß besonders auffallen, daß Milo in DKarol. I 148 an keiner einzigen Stelle explizit als Bischof bezeichnet wird. Dagegen erhält Ratbert das Attribut des episcopus' einmal, Hartham sogar zweimal. Milo dagegen, der Nachfolger seines vermeintlichen Vaters, habe das episcopium der Stadt Trier regiert oder geleitet (regebat). Es wird also absichtlich vermieden, ihn Bischof zu nennen. Liest man hingegen den Anfang des Diploms frei von solchem Vorwissen, entsteht der Eindruck, ein Adliger sei mit Mettlach belehnt worden, dem sodann ein Bischof folgte. Das bedeutet entweder: 1. Milo wurde nachträglich seines Bischofstitels beraubt, oder 2. Milo war überhaupt kein Bischof.

Der Begriff des episcopiums bietet dafür einen Anhaltspunkt. Zweimal verwendet ihn die Urkunde. Bei der Urteilsverkündung am Ende benutzt der Text dann jedoch den Terminus episcopatus und meint dabei zweifellos das Trierer Bistum. Episcopium aber bedeutet zunächst auch etwas ganz anderes: „die Gesamtheit der Gebäude, in der die Geistlichen einer Kathedrale leben“ oder Bischofssitz bzw. die Verwaltungs- und Wirtschaftsgebäude eines Bischofs. ${ }^{413}$ Im 8. Jahrhundert wird der Begriff im Karolingerreich kaum gebraucht. Keine weitere echte Urkunde dieser Zeit benutzt das Wort. Wenige Belege sind überhaupt nachweisbar, dieser hier eingeschlossen. Davon verwenden einige episcopium im Sinne dieser Verwaltungs- und Wirtschaftsgebäude, einer auch als die „Geistlichen einer Kathedrale“. ${ }^{414}$ Beherrschte Milo also die

413 Vgl. dazu den Art. ,episcopium', in: Niermeyer/van de Kieft, Mediae Latinitatis Lexicon minus 1, S. 494 f. - Es handelt sich um eine Übersetzung aus dem Griechischen. Dabei wird wohl Bezug auf die Kanones genommen. Ich habe hier für die freundlichen Hinweise von Herrn Professor Dr. Wolfram Brandes (Frankfurt a. M.) zu danken. Vgl. zu diesen hier nur Ecclesiae occidentalis monumenta iuris antiquissima, ed. Turner (vgl. auch unten Anm. 415). Vgl. ferner den inzwischen vorliegenden Art. ,episcopium', in: Mittellateinisches Wörterbuch 3, Sp. 1319-1321. Auch BAuER, Lotharingien, S. 188211, hier S. 199, versteht episcopium in diesem Zusammenhang als „bischöfliche[...] Rechte und Besitzungen“. Zur Problematik des Begriffs vgl. ferner ebd., S. 94 f. Vgl. dazu auch Anton, Verfassungsgeschichtliche Kontinuität, bes. S. 18-21. Boshof, Kloster und Bischof, S. 216.

414 Vgl. zum Gebrauch im Sinne einer Gebäudegruppe: Epp. Bonifatii 24 f., ed. TANGL, S. 41-44, hier S. 42, Z. 32-34: Igitur Thuringis et Germaniae populo ea, que ad anime respiciunt utilitatem et salutem, scribere non omisimus, inter alia, ut construant episcopia et aeclesias condant, iniungentes (Brief Papst Gregors II. [715-731] vom 4. Dezember 724 an Bonifatius). Ebd., S. 44, Z. 4-6: Facite ergo et domum, ubi debeat ipse pater vester episcopus habitare, et ęcclesias, ubi orare debeatis, [...] (Papst Gregor II. im Dezember 724 an die Thüringer). Willibald, Vita Bonifatii cap. 8, ed. Levison, S. 47, Z. 23-26: [...] suo chorepiscopo Eoban baptizavit, - quem ad subveniendum suae senilis aetatis debilitate Fresonis, iniuncto sibi episcopio in urbe qui vocatur Trecht, subrogavit, - [...]. Die Admonitio generalis (a. 789 m. Martio 23) cap. 72, ed. Boretius, Nr. 29, S. 60, Z. 3 f.: Psalmos, notas, cantus, compotum, grammaticam per singula monasteria vel episcopia et libros catholicos bene emendate; [...]. Als Geistliche einer Kathedrale verstehen es die Karoli epistola de litteris Collendis, ed. Boretius, S. 79, Z. 8-12: [...], quia nos una 
Wirtschaftsgebäude des Trierer Bischofssitzes und war dortiger Verwaltungschef, also ein oeconomus oder vicedominus? ${ }^{415}$ Und lag, wie es etwas weiter unten im Text heißt, das Eigentumsrecht über Mettlach ebenfalls bei diesen Verwaltungsgebäuden bzw. der Bischofspfalz? Warum gebrauchte man nicht durchgehend episcopatus? Episcopium kommt im Gegensatz zu episcopatus als Terminus erst ab dem 9. Jahrhundert wirklich häufiger zum Einsatz. ${ }^{416}$ Dabei nimmt es auch die Bedeutung von Bistum an, in der es die Forschung hier bisher immer gelesen hat. Dann aber war Milo sicher kein Bischof. ${ }^{417}$

Wenn hier episcopium tatsächlich im Sinne von Wirtschaftsgebäuden verwendet wurde, ist folgende Lesart denkbar: Milo wäre nicht nur mit Mettlach belehnt worden, sondern er verfügte über das Trierer episcopium vielleicht als Allod, also Eigenbesitz, für das er Pflichten wie den Heeresdienst zu leisten hatte. Und dann hätte bei Milo als Inhaber des Trierer episcopiums, also dortigem Verwalter und zugleich Lehnsnehmer Mettlachs, auch die iustitia, also das Eigentumsrecht des hl. Petrus über Mettlach, gelegen. Vielleicht ging dieses Recht nach Milos Tod dann auf andere Familienangehörige über oder durch die neue Belehnung an Bischof Harthamus. Womöglich herrschte aber auch genau darüber der Streit, den die Urkunde thematisiert. Denn vielleicht waren die Verwandten Milos verärgert darüber, daß nun plötzlich nicht mehr sie damit belehnt wurden, was sie eigentlich erwarteten. Und womöglich bietet das Bild dieses Verwalters Milo dann die Grundlage für das negative Milobild Erzbischof Hinkmars von Reims $(845-882) .{ }^{418}$ Denn nach Hinkmar hatte Milo das

cum fidelibus nostris consideravimus utile esse, ut episcopia et monasteria nobis Christo propitio ad gubernandum commissa praeter regularis vitae ordinem atque sanctae religionis conversationem etiam in litterarum meditationibus eis qui donante Domino discere possunt secundum uniuscuiusque capacitatem docendi studium debeant impendere, [...]. Vgl. auch nochmals die vorausgehende Anm. - Vgl. dazu auch Oelsner, Jahrbücher Pippins, S. 467 f., Anm. 9, mit weiteren, späteren Belegen.

415 Vgl. zu diesem Amt Kreiker, Vicedominus, Sp. 1621. Der vicedominus entstamme „regelmäßig dem Diözesanklerus“. War der Bischof abwesend oder während einer Vakanz des Bischofssitzes, konnte er als Bistumsverweser agieren. Seit dem 9. Jahrhundert habe das Amt an Bedeutung verloren. Das Decretum Gratiani bestimmt die Aufgaben des vicedominus so: Offitium uicedomini est episcopium disponere. (D. 89 c. 2; sowie D. 89 c. 3 und C. 1 q. 3 c. 8 ).

416 Vgl. nochmals oben Anm. 413 f., sowie den Art. ,episcopatus', in: Niermeyer/van de Kieft, Mediae Latinitatis Lexicon minus 1, S. 493 f. Vgl. zuletzt den Art. ,episcopatus', in: Mittellateinisches Wörterbuch 3, Sp. 1317-1319.

417 Vgl. DKarol. I. 148, S. 201, Z. 14-17: [...], et tales testes vel scabini ibidem in presentia adfuerunt, qui per sacramenta hoc adfirmaverunt, ut vidissent et certissime cognovissent iusticiam esse sancti Petri ad episcopium Treverice urbis. - Dann hätte hier die iustitia von St. Peter bei der Trierer Bischofspfalz gelegen, die Milo verwaltete.

418 Für ein episcopium könnte auch sprechen, daß eine Urkunde Ludwigs des Kindes (900911) erwähnt, daß zur Zeit Bischof Weomads (762-791) dem Trierer Bistum u.a. die Münzrechte entzogen und einer Grafschaft zugeschlagen wurden. Vielleicht wandelte man den Einflußbereich des episcopiums jetzt in eine Grafschaft um. Vgl. dazu DZw. 18, 
Trierer und Reimser episcopium inne gehabt. Dann wäre Milo vielleicht auch Verwalter der Reimser Bischofspfalz gewesen und ganz sicher kein Bischof. Hinkmar aber interpretierte den Terminus episcopium als Bistum und nicht als Wirtschaft und konstruierte damit nun seine eigenen Bilder.

Eine weitere Spur bietet ein Hinweis auf ein gemeinsames Handeln Milos und Widos in Bezug auf Mettlach ohne Beteiligung eines Liutwin. In einer Königsgerichtsurkunde Pippins für St-Denis vom 30. Oktober 759 aus Compiègne finden sich Protagonisten mit dem gleichen Namen wie im Karls-Diplom als Zeugen wieder: Tunc illis iudicatum fuit a Uuidone, Raulcone, Milone, Helmgaudo, Rothardo, Gislehario vel reliquis quam plures seu et Uuicberto comite palatii nostro, [...]. ${ }^{419}$ Ein Wido, ein Milo und ein Pfalzgraf Wicbert stehen hier fast nebeneinander. Da das Amt des Pfalzgrafen nicht unbedingt auf Lebenszeit vergeben wurde, ${ }^{420}$ kann es sich durchaus um unseren späteren Wicbertus missus handeln. Die Urkunde enthält Wicberts letzten nachweisbaren Auftritt als Pfalzgraf. 775 übte ein Anselm dieses Amt aus. ${ }^{421}$ Sind beide Wicberte aber identisch, war dieser Wicbert dazu prädestiniert, in der Mettlacher Sache aufzutreten. Er kannte als ehemaliger Pfalzgraf das Rechtsverfahren und zudem zwei Personen namens Milo und Wido. Waren sie nicht dieselben wie in DKarol. I 148, kam Wicbert hier sicher mit ihren Verwandten in Kontakt. Auch in zwei vorausgehenden Urkunden des Königsgerichts für Abt Fulrad von StDenis amtiert Wicbert als Pfalzgraf, während ein Milo jeweils die Liste der Zeugen anführt. Das erste Diplom datiert vom 1. März 752, das zweite vom 8. Juli $753 .{ }^{422}$ Das paßt übrigens bestens zum vielzitierten Bonifatiusbrief von November 751, der gegen einen Milo schwere Vorwürfe erhebt, ohne dessen Funktion genauer zu bestimmen. ${ }^{423}$

S. 49-51, vom 5. Februar 898, sowie besonders DLdK 17, S. 120-122, vom 19. September 902. Auch die echte Urkunde Zwentibolds (895-900) beschreibt eine Umwandlung der bischöflichen Grundherrschaft unter Bischof Radbod in eine Grafschaft. Vgl. dazu auch oben Anm. 380 u. 404.

419 Vgl. DKarol. I 12, S. 17 f., hier S. 18. Die Urkunde ist im Original erhalten.

420 Vgl. dazu Eberl, Pfalzgraf, Sp. 2012 f.

421 Vgl. DKarol. I 102, S. 146 f., bes. S. 147. Auch diese Urkunde ist im Original erhalten.

422 Vgl. DKarol. I 1, S. 3 f., bes. S. 3: [...], id est Milone, Rotgario, Cheimgaudo, Crothardo, Gerichardo, Autgario et Wiberto comite palatii nostri vel reliquis quam pluribus [...]. Das Diplom ist in einem Chartular des ausgehenden 12. oder beginnenden 13. Jahrhunderts erhalten. - DKarol. I 6, S. 9-11, bes. S. 10: [...], unacum plures nostris fidelibus id sunt Milone, Helmegaudo, Hildegario, [C]hrothardo, Drogone, Baugulfo, [G]islehario, Leuthfredo, Rauhone, Theuderico, Maganario, Nithado, Uualthario, Uulfario et Uuicberto comite palati nostro [...]. Diese Urkunde ist im Original erhalten. - Vgl. zu diesem Milo der Urkunden auch Hennebicque-Le Jan, Prosopographica Neustrica, S. 259, Nr. 214. Nonn, Moseldukat, S. 21, Anm. 40, ist zwar auch dieser Pfalzgraf Wicbert aufgefallen, allerdings zieht er keine direkte Verbindung zwischen beiden Kontexten. Vielmehr sieht er in ihm ein Argument für eine Manipulation von DKarol. I 148.

$423 \mathrm{Vgl}$. dazu ausführlich oben Kap. C.II.2. 
Diese Urkunden hat man bisher nie mit dem Trierer Milo in Verbindung gebracht, weil dieser ja Hinkmar zufolge die Bistümer Trier und Reims gemeinsam okkupierte. Wenn Milo aber kein Bischof war, dürften beide ein und dieselbe Person sein. Milo verwaltete also nur die Bischofspfalz von Trier bzw. die dortigen bischöflichen Wirtschaftsgebäude, vielleicht auch die von Reims. War der Trierer Milo kein Kleriker, kann er ebenso der gleichnamige Schenker sein, der während Pippins III. Herrschaft (751-768) gemeinsam mit seiner Frau Ragentrud Besitz an das Kloster Echternach für ihr gemeinsames Seelenheil gibt. ${ }^{424}$

Kommen wir zur Urkunde zurück: Ohne den Inhalt der Interpolationen lösen sich entscheidende Verständnisprobleme auf: Wenn nämlich Liutwin Mettlach nicht an Trier schenkte, dann war das Kloster zunächst kontinuierlich in königlichem Besitz und die Belehnung von Milo sowie Bischof Hartham ist problemlos nachvollziehbar. Daß spätere Trierer Quellen ein bereits frühes Mettlacher Dionysiuspatrozinium erwähnen, ist ein weiterer Hinweis auf karolingischen oder königlichen Besitz. Es kann aber auch eine Verbindung Mettlachs über Milo und Wido mit St-Denis bedeuten, was die gerade eben erwähnten, für dort ausgestellten Urkunden denkbar erscheinen lassen. ${ }^{425} \mathrm{War}$ Milo aber kein Bischof, sondern ein Adliger oder vielleicht niederer Kleriker, der die Trierer Bischofspfalz verwaltete, benötigt man für die Mettlacher Äbte und Bischöfe Ratbert und Hartham nicht mehr das Erklärungsmodell von Kloster-, Abt- oder Trierer Chorbischöfen. ${ }^{426}$ Da Milo sie aus Trier nach Mettlach sandte, handelt es sich schlicht um die damals amtierenden Trierer Bischöfe.

424 Vgl. Wampach I 2, Nr. 56, S. 120 f.: Ego Milo et coniunx mea Ragentrudis pro Dei timore et anime nostre remedio vel remissione peccatorum nostrorum donamus terram nostram in villa Sumingen in pago Muslensi ad monasterium Epternacum, [...]. Von möglichen Kindern der beiden ist dabei nicht die Rede.

$425 \mathrm{Vgl}$. zum Dionysiuspatrozinium genauer unten S. $324 \mathrm{ff}$.

426 Vgl. dazu zunächst bereits oben S. 228 u. Anm. 400 f. - Vorsicht ist geboten, das Modell des Klosterbischofs als Erklärung für all die Fälle heranzuziehen, in denen man zwei gleichzeitige Bischöfe für eine Diözese oder für eine Diözese und ein ihr untergeordnetes Kloster vorzufinden glaubt. Das Modell von Doppelbischöfen oder versetzten Bischöfen korrespondierte schon seit dem Altertum nicht mit dem Kirchenrecht. Vgl. dazu OBer, Translation der Bischöfe, der bereits darauf hinweist. Ein Bischof sei üblicherweise fest mit seiner Diözese in einem eheähnlichen Verhältnis verbunden und dürfe kein anderes Bistum übernehmen bzw. sein Bistum wechseln. - Zu den sog. Klosterbischöfen vgl. zunächst immer noch grundlegend FRANK, Klosterbischöfe des Frankenreiches, der zahlreiche - auch zweifelhafte - Belege zusammenträgt. Ein Klosterbischof „hatte im Kloster unter Umgehung des zuständigen Diözesanbischofs die Weihefunktionen zu übernehmen." Er könne dabei zugleich Abt oder auch nur Mönch sein (ebd., S. 4). Für DKarol. I 148 geht er nicht von Klosterbischöfen aus (ebd., S. 144 f.). Vgl. ferner Angenendt, Monachi peregrini, S. 216-224, der sich vor allem mit Pirmin und dessen Klostergründungen beschäftigt. Pirmin sei es entgegen Bonifatius um die Stärkung der Klöster und ihrer Freiheiten im irisch-columbanischen Sinne gegangen, unabhängig vom 
zuständigen Ortsbischof. Die Klöster sollten sich ihren zuständigen Bischof für Weihehandlungen selbst bestimmen dürfen. Schieffer, Entstehung von Domkapiteln, S. 171-231, geht der Entstehung der überwiegend angelsächsisch geprägten Bistümer nach. Vor allem die Verbindung von neuem Bischofssitz und bereits zuvor bestehendem Kloster wird betont. Ewig, Spätantikes und fränkisches Gallien 2, S. 411-583, untersucht die merowingische Zeit des 6. bis zur Mitte des 8. Jahrhunderts. Er bezeichnet den Zustand der von der Diözesangewalt - auch auf sakramentalem Gebiet - freien Klöster als irisch-columbanische Klosterfreiheit bzw. große Freiheit'. Sie finde sich zusammengefaßt im Formular von Rebais (637) (ebd., S. 416 ff.). Prinz, Frühes Mönchtum, S. $60,109,170,180$ f., $211-218,225,258,329,432,449$, bietet allgemeinere Bemerkungen. Vgl. ferner Felten, Äbte und Laienäbte, S. 32 ff., bes. S. 38 f. u. Anm. 29. Dierkens, Abbayes et Chapitres, S. 297-299, bes. S. 298, verweist bei den Klosterbischöfen auf „les abbés ou les moines, qui dans le cadre de leur monastère, ont reçu la consécration épiscopale." Diese stammten aus der insularen oder angelsächsischen Klosterkultur. Angenendt, Willibald zwischen Mönchtum und Bischofsamt, bes. S. 167-169, hält Willibald von Eichstätt für keinen Klosterbischof. Dierkens, Willibrord und Bonifatius, S. 459-465, bemerkt: „Die Bischofswürde ist Äbten, sogar Mönchen verliehen worden - abbas-episcopus, monachus-episcopus -, die es gewohnt waren, ihre Funktionen, hauptsächlich die Weihe von Gotteshäusern und die Ordination von Priestern, dort auszuüben, wo es notwendig war, ohne Rücksicht auf den nicht vorhandenen Bischof der Diözese - ordinarius loci. Verbunden mit der Funktion des Missionsbischofs, episcopus ad praedicandum, schien diese dehnbare Konzeption offenkundig für die Christianisierung der jenseits des römischen Limes gelegenen Gebiete in Friesland, Sachsen, Hessen etc. sinnvoll zu sein.“ (Ebd., S. 459.) „Ist dementsprechend die Tätigkeit von Diözesanbischöfen oder von ,außerplanmäßigen` Bischöfen zu bevorzugen, ob es sich nun um Missionsbischöfe - episcopi ad praedicandum, um Abtbischöfe oder um Chorbischöfe handelt?“ (Ebd., S. 465.) - Dierkens zeigt damit die im Grunde verwirrenden und nicht klar zu scheidenden Bischofstypen. - Vgl. weiter Angenendt, Klosterbischof. Kloft, Das geistliche Amt, S. 885-917, bes. S. 893-896, weist darauf hin, daß Abt- und Klosterbischöfe häufig in den iro-fränkischen Klöstern der Merowingerzeit zu finden seien (ebd., S. 893). Vgl. zuletzt Jenal, Klosterbischöfe. Schließlich fällt LeHner, Abtbischof. Begriffsbestimmung eines Unwortes, S. 138, für das von ihm untersuchte Regensburger Beispiel das treffende Urteil: „Andererseits muß der Abtbischof als Ausdruck der Hilflosigkeit vieler Historiker angesichts der miserablen Quellenlage fürs spätantike und frühmittelalterliche Regensburg gewertet werden." Dies läßt sich auf viele andere Orte problemlos übertragen. Bewertet man den zusammengetragenen Befund nämlich kritisch, erklären sich die meisten Klosterbischöfe des 8 . Jahrhunderts als Bischöfe einer sedes, die später auch ein Abbatiat oder mehrere zusätzliche Abbatiate übernahmen (Abtbischöfe). Daneben läßt sich bei den wenigen dann noch verbleibenden Klosterbischöfen nahezu immer ein irischer Bezug herstellen. Meist handelt es sich um irische, in Irland geweihte Wanderbischöfe, häufiger auch um wandernde Missionsbischöfe ohne festen Bischofssitz, die dann nicht immer Iren sein müssen. Als diskussionswürdige Beispiele bleiben letztlich nur Bischof Virgil von Salzburg und Bischof Pirmin. Virgil ließ die Salzburger Bischofsrechte zunächst vom schon am Namen erkenntlichen irischen Klosterbischof Dobdagrec (Dub Dá Chrích) ausüben, bis er selbst zum Bischof geweiht wurde. Nur Pirmin scheint die Rolle eines Klosterbischofs übernommen zu haben. Er soll bei der Gründung der Reichenau, Murbachs und schließlich Hornbachs beteiligt gewesen sein. Allerdings ist die Quellenlage insgesamt nicht unproblematisch. Damit scheint Pirmins Tätigkeit aber eher mit der eines wan- 
Vielleicht ist Ratbert mit einem sonst nicht nachweisbaren Bischof Hartbertus identisch, der am 28. August 745 Güter an das Kloster Weißenburg schenkte. Ähnlich ließe sich dann auch der sonst nicht einzuordnende Trierer Bischof Hildulf in dieser Zeit erklären, der in der älteren Maximins-Vita genannt sein könnte. ${ }^{427}$ Die von Hinkmar angegebene bischöfliche Amtszeit Milos von über vierzig Jahren ist ja ohnehin ein Konstrukt. ${ }^{428}$ Da Triers Bischof Weomad erstmals für 762 sicher belegbar ist, können ihm also einige Bischöfe

dernden Missions- und nicht Klosterbischofs vergleichbar. - Zu Virgil vgl. Schmiedinger, Bonifaz als Gegenspieler Virgils, S. 92-102, bes. S. 97 f. Wolfram, Virgil als Abt und Bischof. - Zu Pirmin vgl. zuletzt Semmler, Pirmin(ius), der von einer romanischen Herkunft ausgeht. Antoni, Leben und Taten des Bischofs Pirmin. - Vgl. ferner zum Chorepiskopat Gоттlов, Der abendländische Chorepiskopat. FELten, Äbte und Laienäbte, bes. S. 39 f. u. Anm. 30. Koтtje, Chorbischof. Kloft, Das geistliche Amt, S. 895 f., verweist auf Isidors Definition, wonach sie in Dörfern und Höfen eingesetzt waren, die ihnen untergebenen Kirchen verwalteten und für die niederen Kirchenämter über Weiherechte verfügten, sonst aber dem Ortsbischof unterstellt waren. - Welche Schlüsse läßt das für Mettlach zu? Die oben gerade angesprochenen Abtbischöfe gab es häufig. Und eben eine solche Funktion muß man für Ratbert und Hartham annehmen. Hier dürften die zunächst Trierer Bischöfe dann zusätzlich noch Mettlacher Äbte geworden sein. - Vgl. zuletzt Apsner, Hoch- und spätkarolingische Zeit, S. 278 f.

$427 \mathrm{Zu}$ Bischof Hartbertus vgl. Traditiones Wizenburgenses 143, S. $346 \mathrm{f}$. Er ist als sein eigener Schreiber tätig. - Vgl. zu Hildulf als möglichem weiteren Trierer Bischof anstelle Milos die ältere Vita sancti Maximini episcopi Trevirensis cap. 9, ed. Henschen, S. 23, wo bei der Umbettung von Maximins Leichnam ein Bischof Hildulf genannt wird. Ein Bischof Hildulf findet sich auch als zeitgenössischer Nachtrag in Willibrords Kalender aus dem 8. Jahrhundert zum 11. Juli. Vgl. dazu auch oben Kap. D.III.3. Vgl. ferner Miesges, Festkalender, S. 68 f. u. Anm. 6. Erst ab dem 11. Jahrhundert beginne Hildulf, in Trier als Heiliger an Bedeutung zu gewinnen. In den ältesten Trierer Bischofslisten ab dem späten 10. Jahrhundert erscheine er nicht. Vgl. zu den Listen unten Kap. D.IV.3.e. $\mathrm{Zu}$ den drei überlieferten Viten Hildulfs vgl. Sauerland, Trierer Geschichtsquellen, S. $124 \mathrm{ff}$., die älteste stamme wohl aus dem 11. Jahrhundert. Die Gesta Treverorum cap. 25, ed. Wartz, S. 162, nennen ihn als Gründer einer Johanneskirche. Er sei von König Pippin eingesetzt worden und der Vorgänger Weomads gewesen. Dem folgen Brower/Masen, Antiquitates, S. 372-376, die Hildulf als Nachfolger Milos und Vorgänger Weomads nennen. Zu Weomad vgl. ebd., S. 376-384. - Handelte es sich um einen Nachfolger des Harthamus? - Vgl. ferner Ewig, Trier, S. $131 \mathrm{f}$. ANTon, Trier im frühen Mittelalter, S. 154, sieht Hildulf als Trierer Bischof um 690 und Gründer Moyenmoutiers. In Anton, Trier vom Beginn des 6. bis zum Ende des 8. Jahrhunderts, S. 66, nennt er ihn dann nur noch Trierer Chorbischof. Er habe mit St. Maximin in Verbindung gestanden. Ähnlich sieht das auch Frank, Klosterbischöfe, S. 111, mit der älteren Literatur. Vgl. zusammenfassend Bautz, Hildulf. Pfeiffer, Die frühe fränkische Zeit, S. 245 f. Vgl. zu den Quellenbelegen und weiteren Angaben auch oben S. 197 f. u. Anm. 303, sowie zuletzt BAuER, Spätmerowingische Zeit, S. 236 f., 245 f., der Hildulf im 8. Jahrhundert ansiedelt und ihn - trotz Willibrords Kalendereintrag - nicht für einen Bischof hält. Er sei vielmehr Bischofsgehilfe. Einen Hildulf im 8. Jahrhundert hält er für rein fiktiv. Bauer, Verehrung heiliger Trierer Bischöfe, S. 395 f., geht Hildulfs Verehrung in Trier nach, wobei Toul und Trier deren Zentren waren.

428 Vgl. dazu erstmals oben Kap. C.III.9. 
in den für Milo bisher angenommenen vierzig Jahren vorausgegangen sein. Das in Trier später rezipierte negative Milobild Hinkmars dürfte die Erinnerung an die Bischöfe Ratbert, Harthamus und vielleicht auch Hildulf überlagert und schließlich ausgelöscht haben.

Ohne Interpolationen wäre nicht Liutwin, sondern Milo neben Wido ein wesentlicher Überträger an den Besitz der Kirche des hl. Petrus in Trier gewesen. Dann erklärt sich ebenso die überaus positive Erinnerung, die man Milo in Mettlach noch im 11. Jahrhundert bewahrte. Sie ist sowohl in der älteren Liutwin-Vita (I) als auch in den Miracula s. Liutwini erkennbar, wenn es heißt, Milo habe viel Gutes für das Kloster getan, auch wenn man bei Hinkmar anderes über ihn lese. Erst nachdem er seinem Vater Liutwin gefolgt sei, habe sich sein Charakter langsam zum Schlechten gewandelt. ${ }^{429}$

Milo und Wido schenkten Mettlach kaum vollständig oder als Eigenbesitz an Trier. Schließlich handelte es sich um karolingischen Besitz, den Karl der Große auch als solchen bezeichnete. Was übertrugen sie also? Wenn Milo als Lehensnehmer Äbte in Mettlach einsetzte, handelte er gewissermaßen wie ein Eigenkirchenherr. Denkbar wäre deshalb, daß er eine Eigenkirche vom König als Lehen erhielt. Dies erklärt auch, warum DKarol. I 148 nicht die Patrozinien des Klosters, sondern den Ortsbegriff Medelagus verwendet. Wahrscheinlich verzichtete Milo - und mit ihm womöglich sein Verwandter Wido - zugunsten des Besitzes der Trierer Kirche auf ihr Recht, mit dem Eigenkloster belehnt zu werden. Die Vorfahren ihrer Familie hatten dieses Eigenkloster vielleicht in den Schutz des Königs oder der Karolinger gegeben, um es von diesen als Lehen wieder zurückzuerhalten. Eine solche Praxis des mundiburdiums war verbreitet. ${ }^{430} \mathrm{Da}$ Milo ohnehin Trierer Bischöfe in Mettlach als Äbte einsetzte, wäre das ein nur konsequenter Schritt. Resultierte dies vielleicht aus seiner Stellung als vicedominus bzw. oeconomus des episcopiums? Fehlten ihm als Adligen oder niederem Kleriker Nachkommen? Handelte es sich bei Wido um den 738 hingerichteten Abt von Fontenelle, hätte auch der wohl keinen Nachwuchs. ${ }^{431}$ Eine derartige Überlassung vermag dann auch zu erklären, warum König und Trierer Kirche über gemeinsame Rechte in Mettlach verfügten. Mettlach wäre jetzt an den Trierer Bischof nach dem Wunsch der ehemaligen Eigenkirchen-

429 Vgl. dazu oben bereits Kap. C.IV.2. u. C.IV.4. sowie unten Kap. D.IX.2. u. D.IX.4.b. 430 Vgl. dazu Cordes, Mundiburdium, Sp. 898 f., sowie die Art. ,mundiburdalis', ,mundiburdire', ,mundiburdis', ,mundiburditio', ,mundiburdus', ,mundilingus', ,mundium ‘ und ,mundius', in: Niermeyer/van De Kieft, Mediae Latinitatis Lexicon minus 2, S. 922-925. - Auch Willibrord übergab wohl Echternach an Pippin II. und Plektrud, um es von ihnen zurückübertragen zu bekommen. Vgl. dazu oben S. 170 f. - Zum Eigenkirchenwesen vgl. hier Schieffer, Eigenkirche, -nwesen. I. Allgemein. Hartmann, Der Rechtliche Zustand der Kirche. Stutz, Geschichte des kirchlichen Benefizialwesens. Stutz/Feine, Forschungen. Vgl. ebenso oben bei u. Anm. 124.

431 Vgl. dazu oben S. 229 f. u. Anm. 404. 
herrn vergebenes Lehen. ${ }^{432}$ Und das deckt sich mit dem Bild von DLoI. 67, nach dem Lothar I. Wido von Spoleto mit dem Kloster belehnt, dieses Lehen aber bald wieder Erzbischof Hetti (814-847) zurückgibt. Die darin angesprochenen Vorfahren Widos, die Mettlach an St. Peter gaben, waren dann Milo sowie Wido, und Mettlach kam tatsächlich unter Pippin III. - wie es dort ja heißt - an die Trierer Kirche. ${ }^{433}$

Dazu paßt ebenfalls der weitere Verlauf des Rechtsstreits in DKarol. I 148. Denn Lambert und seine Söhne werden ganz unvermittelt in das Geschehen eingeführt. Ihre Namen sprechen für Verwandtschaft mit Milo und Wido. Ein Gedenkbucheintrag der Reichenau belegt, daß es diese Gruppe gab, ohne aber weitere Hinweise auf andere männliche Familienangehörige oder gar auf Milo zu geben. ${ }^{434}$ Warum jedoch reagierte Lambert so massiv und eignete sich das Kloster an? Die Urkunde sagt nicht explizit, er habe Bischof Harthamus von dort vertrieben, sondern ihn dadurch seines Besitzes beraubt. Harthamus könnte also Abt geblieben sein, während Lambert das Kloster in Besitz nahm. Worauf gründete Lambert seinen Anspruch? Hatte er als Widone Rechte am Kloster? Seine Söhne behaupteten immerhin, ihnen stehe die vestitura zu, denn ihr Vater habe sie eingesetzt in ihrem rechtmäßigen Erbbesitz (alode) zurückgelassen. ${ }^{435}$ Endlich heißt es, die Söhne verfügten über keine Urkunden darüber, wie ihr Vater das Kloster gegen König Pippin erstritten habe. Es muß also schon einmal ein mit diesen wenigstens postulierten Belegen verbundenes, erfolgreiches' Rechtsverfahren gegeben haben. Ein Hinweis auf ein derartiges Verfahren stand mit großer Wahrscheinlichkeit am Ende des - zu Beginn der Urkunde ins Leere laufenden Nebensatzes und wurde später wohl entfernt oder fiel aus. Damit wäre nämlich Lambert als Person tatsächlich früher in den Text eingeführt worden und ein weiterer Widerspruch löste sich auf. Ja, sogar die Klage seiner Söhne macht jetzt deutlich mehr Sinn.

Was aber geschah dann in Mettlach nach Milos Tod? Lambert, ein Verwandter Milos und Widos, nahm die Übertragung der Belehnungsrechte des Familienklosters durch die beiden an Trier nicht einfach hin. Hätte er auch

432 Vgl. DKarol. I 148, S. 201, Z. 20-23, 31-34: Et taliter iudicaverunt, ut per legem et iusticiam illa vestitura partibus nostris atque sancti Petri adesse debuisset, pro eo quod Milo et Harthamus ipsum monasterium per beneficium Karoli maioris domus et domni Pippini regis semper habuissent; [...]. [...], tunc eis iudicatum fuit, ut in presentia nostra iam fato monasterio partibus nostris in causa sancti Petri Treverensis cum fide facta reddere deberent; quod ita et fecerunt et per missum eorum vestitura a partibus sancti Petri Treverecensis, [...].

433 Vgl. dazu oben S. $206 \mathrm{f}$.

434 Vgl. Verbrüderungsbuch der Abtei Reichenau, ed. Autenrieth/Geuenich/Schmid, S. $119^{\mathrm{A} 4}$ : lantbreth deotbric unito unerinheri ruadolt unerin ruadlind. Vgl. dazu METz, Miszellen, S. 8. Der Eintrag stamme von der ersten Hand und damit aus den ersten Jahrzehnten des 9. Jahrhunderts.

435 Dabei könnte der ältere Wido seine jüngeren und vielleicht noch unmündigen Brüder Hrodold und Warnar vertreten, da meist nur auf Wido Bezug genommen wird. 
zustimmen müssen? War er etwa kein Sohn, sondern ein Bruder eines der beiden? Klagte er deshalb beim König und eignete sich das Kloster trotz des dortigen Abts und Trierer Bischofs Hartham an? Es erklärte auch, warum dieser Vorgang zunächst ohne weitere rechtliche Folgen blieb. Denn erst durch Lamberts Tod entstand wieder Handlungsbedarf. Seinen drei Söhnen wollte man nicht mehr die Rechte des Vaters einräumen. Eventuell bekam dieser sie auch gar nicht für seine Nachkommen von König Pippin zugesprochen.

Widos starke Rolle bei den Verhandlungen in Diedenhofen könnte aber noch eine ganz andere Interpretation nahelegen. Damit kommen wir zur bereits angedeuteten zweiten möglichen Lesart: Vielleicht war nicht Liutwin, sondern der besagte Lambert der Vater Milos und Widos. Man hätte dann im Urkundentext nur die Namen ausgetauscht, die zudem beide mit einem „L“ anlauteten. Dies würde ebenfalls dafür sprechen, daß Lambert zuvor im ausgefallenen Satzteil genannt wurde. Da es nun dem anstatt seiner interpolierten Namen des Liutwin widersprach, ließ man die Passage mit dem eigentlichen Gegenstand der Klage aus. Übertrug Lambert vielleicht gar nicht alleine, sondern gemeinsam mit seinen beiden Söhnen? Beim Plural der Urkunden könnte es sich dann um jeweils ein eigenes Dokument der genannten Personen handeln. Oder überließ Lambert etwas ganz anderes als Mettlach dem Besitz der Kirche des hl. Petrus von Trier, woraus sich dann irgendwelche Rechte ergaben, vielleicht auch das des Wirtschaftsverwalters des episcopiums für Milo? Entsandte Milo deshalb vielleicht als ebensolcher - Äbte bzw. Bischöfe aus Trier nach Mettlach, von denen Bischof Harthamus das Kloster schließlich als Lehen von Pippin III. ganz übernahm? Dies könnte zum einen die alleinige Entscheidung Pippins gewesen sein. Vielleicht meint die Passage, daß das Eigentumsrecht (iustitia) der Kirche von St. Peter beim Trierer episcopium liege, aber auch das Folgende: Milo war als dortiger Verwalter für die Übertragung Mettlachs an die Trierer Bischöfe allein verantwortlich und diese deshalb rechtens. Hierauf trat Lambert - nach Milos Tod - als Anwalt seines (zweiten) dabei übergangenen Sohnes Wido auf und besetzte das Kloster, um die Rechte der Familie an einer weiteren Belehnung zu sichern. Es handelte sich dann bei diesem Wido um denselben, der mit seinen Brüdern beim Königsgericht auftrat. In diesem Falle ließe sich eine klare Verbindung zwischen Lambert und dem zuerst genannten Wido erkennen. Beiden wäre innerhalb der Urkunde eine klare Position zugewiesen. Auch deshalb könnte Pippin nichts Weiteres unternommen haben, als Lambert sich Mettlach aneignete. Dabei ging es insgesamt aber wieder um die Belehnungsrechte an Mettlach (als Eigenkirche). Es erklärte sich ebenso, warum Wido und seine Brüder behaupteten, sie folgten Lambert im Eigenbesitz (alode). Doch gäbe es in diesem Fall allenfalls einen, noch dazu umstrittenen Schenker Mettlachs an Trier: Milo. Einige Fragen bleiben offen: Da Milo schon von Karl Martell ( $\dagger$ 741) mit Mettlach belehnt wurde, wie alt wäre dann Lambert geworden, wenn er seinen Sohn überlebte? Welches war Lamberts Amt, und was genau überließ 
er dem Besitz der Kirche des hl. Petrus in Trier? Wie konnte Milo Lambert nachfolgen, wenn dieser bzw. sein Vater noch lebte? Wie ließen sich die weiteren Brüder Hrodold und Warnar erklären? Kamen sie erst nach Milos Tod zur Welt? Stammten sie von einer anderen Mutter? Allerdings stimmten in dieser Interpretationslesart die familiären Konstellationen nicht mit dem Eintrag im Reichenauer Verbrüderungsbuch überein, der einen Milo gänzlich verschweigt. War man über ihn verärgert? Jedoch würde diese Variante nur ganz geringe Veränderungen am ursprünglichen Original bedeuten. Schließlich könnten Lambert, Milo und Wido auch in irgendeinem Verwandtschaftsverhältnis zueinander stehen. Vielleicht schenkten/überließen sie gemeinsam als Familie ihr Familienkloster Mettlach, das unter dem mundiburdium der Karolinger stand, dem Besitz der Trierer Kirche, gingen aber fest davon aus, daß die Karolinger weiter einen Familienangehörigen mit dem Kloster belehnen würden; womöglich schon deshalb, weil auch Familienangehörige das Trierer episcopium verwalteten. Als dies aber nicht geschah, kam es zum Protest. Doch letztlich zeigen beide Lesarten - und das ist entscheidend -, daß die Urkunde ohne einen Bischof Liutwin weitaus mehr Sinn ergibt und dieser interpoliert wurde.

Am Ende des Diploms wird noch darauf verwiesen, daß Weomad gerade das Amt des archiepiscopus pontifex in Trier inne habe. Nun sind in der Tat zahlreiche Trierer Fälschungen seit dem 10. Jahrhundert auf Weomad ausgestellt worden. ${ }^{436}$ Deshalb bleiben bei seinem Namen Zweifel. Der Titel des Erzbischofs wirkt neben dem des pontifex interpoliert. Letzterer ist allerdings in dieser und auch der vorausgehenden Zeit häufig im Gebrauch. ${ }^{437}$ Etwas eigenartig wirkt es aber doch, daß Weomad nicht schon zu Beginn des Diploms für das eigentlich in seinem Namen verfochtene Anliegen auftritt, sondern erst bei der Rechtsfindung zur Sprache kommt. Vielleicht erstritt schon einmal Bischof Harthamus vor Weomad das Kloster Mettlach für Trier zurück. ${ }^{438}$

436 Vgl. nur DDKarol. I †36, †226, †268. - Eine echte Urkunde für Weomad von 772 nennt ihn episcopus und pontifex, aber nicht Erzbischof. Vgl. dazu DKarol. I 66, S. 96, Z. 2, 18, 28, 31, 34; S. 97, Z. 3 f., 11, 16.

437 Hier reicht ein Blick in die Register der einschlägigen Editionen, wie sie inzwischen auch auf CD-ROM und darüber hinaus online zugänglich sind. Vgl. dazu Quellensammlung/ Fontes, ed. Bogon/Müller/Pentzel. So findet sich der Begriff pontifex u. a. mehrfach bei Gregor von Tours. Vgl. auch den Art. ,pontifex', in: Niermeyer/van De Kieft, Mediae Latinitatis Lexicon minus 2, S. 1058 f., sowie die vorausgehende Anm.

438 Vielleicht stand an seiner Stelle einmal ein anderer Bischofsname, womöglich der Harthams. Doch dann müßte das Diplom bereits vor 782 ausgestellt worden sein, ja sogar vor 762, weil Weomad für dieses Jahr durch eine Prümer Urkunde (DKarol. I 16, S. 21-25) sicher als Trierer Bischof nachweisbar ist. König Pippin hätte das Diplom dann ausstellen müssen. Der Inhalt des Dokumentes spricht jedoch insgesamt dagegen. Denkbar wäre auch, daß die Initiative von Mettlach selbst gegen Lamberts Söhne ausging. 
Damit kommen wir zu einer letzten Überlegung: Wenn tatsächlich Milo (und vielleicht auch Wido) dafür sorgte, daß die Investitur Mettlachs von der eigenen Familie an Trier kam oder wenigstens nach Milos Tod Bischof Hartham unmittelbar damit belehnt wurde, dann ist es wahrscheinlich, daß Milo in Mettlach sein Grab fand. Die späteren Trierer Quellen überliefern die Peterskirche in Ehrang als seine Ruhestätte. Doch wurde ein erstes Gotteshaus an dieser Stelle erst frühestens 300 Jahre nach Milos Tod erbaut. ${ }^{439}$ Die in Mettlach nach so langer Zeit nachweisbare überaus positive Memoria Milos muß jedoch einen realen Sitz im Leben gehabt haben. ${ }^{440} \mathrm{Da}$ in Mettlach offenbar keine Schriftzeugnisse mehr aus der Frühzeit erhalten blieben, ist dafür ein Grab als kontinuierlicher Erinnerungsort wahrscheinlich. Wenn zudem Lambert bis zu seinem Tod Mettlach behielt, fand vermutlich auch er an diesem Ort seine letzte Ruhe. Vielleicht diente das Eigenkloster ohnehin als Widonische Grablege.

Fassen wir zusammen: Liutwin wurde - so die hier geäußerte These - als Vater Milos und Widos sowie Schenker Mettlachs an den Besitz der Kirche von St. Peter erst später in ein älteres Dokument interpoliert, das zunächst ein Königsgerichtsurteil zu einem Familienstreit über das Kloster Mettlach zum Inhalt hatte. Da Liutwin Mettlach gemäß der Interpolation aber nicht gründete, dürften diese Veränderungen vermutlich noch vor der Liutwin-Vita I und den Miracula s. Liutwini vorgenommen worden sein. Wahrscheinlich geschah das gemeinsam mit oder kurz vor der Verfälschung oder Fälschung von DKIII. 102 und DArn. 39 im 10. Jahrhundert. Denn diese bezeichnen Liutwin bereits als beatus. Sollten beider Angaben zu Liutwin aber noch aus dem späten 9. Jahrhundert stammen, was sich nicht völlig ausschließen läßt, kann es frühestens seit dieser Zeit geschehen sein. DKarol. I 148 wurde später aber nicht mehr genauer aufgegriffen, weil sich das Erinnerungsbild zu Mettlach in Trier und dem Kloster selbst schon weiter verformt hatte. Die Urkunde mag in der vorliegenden Form eine frühe Stufe eines mit Mettlach verbundenen Liutwinbildes markieren, das sukzessive entstand, ja konstruiert wurde. Sie könnte aber ebenso als späterer Reflex auf dieses Bild Liutwins nachträglich durch oder bei einer Abschrift entsprechend angepaßt worden sein. Die Spur weist in jedem Fall zum Trierer Erzstift. Welches Interesse aber konnte man dort an einem solchen Bild haben? Offenbar sollte in Vergessenheit geraten, daß einmal Milo und Wido ihre Rechte auf eine Belehnung mit dem unter karolingischem mundiburdium stehenden Mettlach an die Trierer Kirche übertrugen, was Streit mit dem weiteren Familienmitglied Lambert (und dessen Söhnen) verursachte. Oder nach der zweiten vorgeschlagenen Lesart: Man wollte die Erinnerung daran beseitigen, daß Lambert Vater (oder wenigstens Verwandter) von Milo und Wido war und sie in enger Verbindung zu Mettlach standen. Vielleicht überließ/en sie/er

439 Vgl. dazu schon oben Kap. C.I.

440 Vgl. zu dieser Tradition nochmals wie Anm. 429. 
das Familienkloster Mettlach, das unter dem mundiburdium der Karolinger stand, dem Besitz von St. Peter in Trier unter der Annahme, von den Karolingern damit weiter belehnt zu werden, zumal Angehörige der Familie auch das Trierer episcopium verwalteten. Denn Milo war kein Trierer Bischof, sondern Verwalter der dortigen bischöflichen Wirtschaft bzw. Bischofspfalz. Vielleicht bildete diese Funktion die Basis für Hinkmars negatives Bild Milos. Milo sandte vielmehr Trierer Bischöfe als Äbte nach Mettlach, deren letzter, Hartham, auch nach Milos Tod mit dem Kloster belehnt wurde. Lambert fand sich damit nicht ab, scheint gegen König Pippin sein Recht betont zu haben und eignete sich Mettlach bis zu seinem Tod wohl auch für seine Söhne Wido, Rodold und Warnar an. Karl der Große sprach dann Mettlach Trier zu. Wahrscheinlich fanden Milo und Lambert in Mettlach ihre letzte Ruhestätte.

\section{d. Exkurs: Die Verbreitung Widonischen Namensgutes}

Nach den Überlegungen zu DKarol. I 148 deutet alles für das 7. und 8. Jahrhundert auf eine andere Struktur und Verbreitung der Familie der sog. ,Widonen-Lambertiner-Miloniden' hin, als sie u.a. noch HLAwitschKa hat erkennen wollen. ${ }^{441}$ Ein Bischof Liutwin oder sein vermeintlicher Onkel Bischof Basin dürften kaum an deren Spitze gestanden haben.

In einer Urkunde Pippins III. (751-768), die dieser 768 unmittelbar vor seinem Tod für Abt Fulrad von St-Denis ausstellte, wurden diesem Güter im Elsaß und der Ortenau bestätigt. Es handelte sich dabei um Besitzungen, quas homo aliquus nomine Uuido eidem [Fulrad] delegaverat, [...]. Fulrad gab diese Güter an König Pippin, damit dieser sie ihm bestätigend zurückschenkte. Dieser Wido dürfte wohl der spätere Präfekt der bretonischen Mark gewesen sein (799-803/13). ${ }^{442}$ Widos Übertragung hatte wohl schon einige Zeit zurückgelegen. So könnte es sich u. a. um den neben Milo erwähnten Wido der KarlsUrkunde zu Mettlach und/oder Lamberts Sohn Wido handeln. Auch weist dieses Diplom neben den oben schon genannten Urkunden ${ }^{443}$ auf ein engeres Verhältnis der Widonen zu St-Denis und Fulrad hin.

Im Kloster St-Wandrille/Fontenelle an der Mündung der Seine in der Normandie finden sich weitere Angehörige dieser Sippe im 7. und 8. Jahrhundert. So soll der erste Nachfolger des hl. Gründers Wandregisil (†668) der Abt Lambert und Bischof von Lyon (ca. 677/9-683/8) aus edlem Geschlecht gewesen sein. Er stamme aus der Gegend von Calais. Sein Vater heiße Erlebertus. Sein Onkel Hrotbertus sei referendarius am Königshof gewesen, sein Onkel

441 Vgl. dazu Hlawitschka, Widonen (Lambertiner). Vgl. ferner oben Anm. 316 u. 402. 442 Vgl. DKarol. I 27, S. 37 f., hier S. 38. Die Urkunde ist im Original erhalten. Im folgenden werden die entsprechenden Besitzungen dann namentlich aufgeführt. Zu diesem Wido vgl. Hlawitschka, Wido, comes.

443 Vgl. dazu die Urkunden oben in Kap. D.IV.3. u. S. 238 f. 
Haltbertus Kleriker geworden. So berichtet wenigstens Lamberts um 800 verfaßte Vita. ${ }^{444} \mathrm{Zu}$ Beginn des 8. Jahrhunderts erschien ein Klausner Milo in Fontenelle, Sohn eines Hrotmundus und einer Wisla. Eine Schenkungsurkunde von Vater und Sohn, die in den wohl nach 833 entstandenen Gesta des Klosters wiedergegeben wird, datiert auf 713. Dieser Milo sei in St-Wandrille bestattet worden. ${ }^{45}$ Für 738 (oder zwischen 742 und 745) berichten die Gesta vom schon erwähnten Abt Wido. ${ }^{446}$ Etwa für 754 bis 787 nennen sie einen Wido laicus oder Vuitlaicus als Abt (wohl einen Laienabt), unter dem das Kloster gelitten habe. Er stamme aus der Gegend südlich von Caen; sein Vater heiße Irminus, seine Mutter Vuitbolda. ${ }^{447}$

Insgesamt zieht sich der Wirkungsbereich der Familie seit dem 7. Jahrhundert somit bald von der Bretagne, früh von der Normandie, über den Raum um Paris, Calais und Trier bis ins Elsaß und die Ortenau. Wir müssen uns hier beschränken. Zahlreiche weitere Beispiele ließen sich anführen. Das nachgewiesene Namensgut dieser vermutlichen Sippe deutet in keiner Form auf Liutwin.

Das heißt aber nicht, daß dieser Name ungewöhnlich wäre. In relativer geographischer Nähe zu Trier und Mettlach läßt sich in mehreren Weißenburger, im Saargau ausgestellten Urkunden von 712 bis 724 ein Notar Liutwin (Leodoinus, Leuduinus) nachweisen. Vielleicht ist es der Liutwin der IrminaUrkunden. Auch ein Diakon Basin findet sich in dieser Funktion. ${ }^{448}$ Häufig haben Memorialbücher Liutwine aufgenommen. Doch stehen diese nie in di-

444 Vgl. Vita Lantberti cap. 1, ed. Levison, S. 608. Vgl. dazu Wattenbach-Levison, Geschichtsquellen 1, S. 138 f. Fontain, Abbayes normandes, S. 31 - 54. Freise, Fontenelle. ELm, Macht der Weisheit, S. 219 ff.

445 Vgl. Gesta sanctorum Patrum Fontanellensis coenobii cap. III,2, ed. Lohier/Laporte, S. 25-27. Vgl. dazu Chronique, ed. Pradié, S. 90-93, 207. Zur Entstehung der Gesta vgl. Freise, Fontenelle, sowie bereits oben zu Beginn von Kap. C.III.1.

446 Vgl. dazu schon oben Kap. C.III.1. u. Anm. 40.

447 Vgl. Gesta sanctorum Patrum Fontanellensis coenobii cap. XI, ed. Lohier/Laporte, S. 79-83. Vgl. dazu Chronique, ed. Pradié, S. 128-133, 218 f. - Stammte vielleicht sogar die Echternacher Irmina aus dieser Familie? Vgl. dazu oben Kap. D.II.

448 Vgl. Traditiones Wizenburgenses 196, ed. GlöCKnER/Doll, S. 401 f., vom 27. Juni 717 (Besitzbestätigung des Hrodoin an Weißenburg); ebd. 194 f., 224, 227, S. 447-454, bes. S. 454, vom 3. Februar 718, vom 13. Februar 718 und vom 18. Mai 718 (Schenkungen Chrodoins an Weißenburg); ebd. 232, S. 460 f., vom 29. März 712 (Schenkung Chrodoins), hier nur der Name eines Liutwin ohne Amtsbezeichnung; ebd. 233, S. 461 f., vom 30. März 712 (Schenkung Weroalds), ohne Amtsbezeichnung Liutwins; ebd. 243, S. 479 f., vom 15. Januar 721 (Schenkung des Mönchs Weroald); ebd. 262, S. 503 f., vom 10. Juli 724 (Schenkung einer Luca); ebd. 267, S. 510 f., vom 12. Juli 712 (Schenkung Graf Adalhards), sowie auch insgesamt erläuternd ebd., S. 126128. Vgl. dazu auch Ebling, Prosopographie, S. 179 f., Nr. CCXXIV. - Zu Basin vgl. Traditiones Wizenburgenses 149, S. 351, vom 22. April 753; ebd. 221, S. 436 f., von November 755/6, sowie insgesamt erläuternd ebd., S. 132. 
rekter Verbindung mit widonischen Namen. Auch diverse Milos werden in den Weißenburger Urkunden genannt. ${ }^{449}$

\section{Ergebnis}

Da die Urkunde Lothars I. von 842 noch als Originalfragment erhalten ist, muß man ihren Quellenwert höher einschätzen als den der anderen nur im 14. Jahrhundert kopial überlieferten Diplome zu Mettlach. Nimmt man den Inhalt von DLoI. 67 ernst, ergibt sich ein völlig neues Bild von der Frühzeit des Klosters. Nach ihrem Inhalt übertrugen es nämlich mehrere Vorfahren Widos I. von Spoleto an die Trierer Kirche. Die Karolinger hätten dies seit Pippin III. immer wieder bestätigt.

Die Urkunde Kaiser Karls III. von 884 für Trier unter Erzbischof Radbod (DKIII. 102) muß schon deshalb wenigstens inhaltlich gefälscht sein. Denn ihr Verfasser übernahm fast vollständig den Text der Lothar-Urkunde, ergänzte ihn um Passagen aus einer weiteren in Trier vorliegenden Originalurkunde Ludwigs des Frommen von $816\left(\mathrm{BM}^{2}\right.$ 626), änderte aber die Kernaussage durch bewußte, kleine Eingriffe. Aus den Verwandten Widos wird plötzlich der beatus archiepiscopus Liutwin von Trier als Schenker Mettlachs. Ein möglicher Bezug zu Wido verschwindet absichtlich. Der tritt nun vielmehr als Entfremder und Räuber des Klosters vor unbestimmter Zeit auf. Immerhin will Karl seine Bestätigung unter der Bedingung des Gebetsgedenkens für Herrscher und Reich vorgenommen haben.

Die Urkunde König Arnulfs von 888 (DArn. 39) wiederholt den Inhalt von 884 fast wörtlich, verkürzt aber den Text ihrer Vorgängerin etwas. Damit wird

449 Vgl. Traditiones Wizenburgenses 247, ed. GlöCKnER/Doll, S. 487-489, hier S. 489, vom 20. November 727/31-736 (Schenkung des Mönchs Rodoin), wo ein Milo diaconus als Zeuge unterschreibt. Die weiteren dortigen Milo-Nachweise stammen erst aus dem 9. Jahrhundert. Vgl. ebd. 49, S. 235 f., vom 7. Oktober 860, u. a. mit Milo und seinem Bruder Adalhelm als Zeugen; ebd. 51†, S. 237-239, vom 18. Februar 830, wieder mit Milo und Adalhelm als Zeugen; ebd. 120, S. 323 f., von 782/90, mit einem Milo als Zeugen; ebd. 127, S. 329 f., vom 3. August 819, ebenso; ebd. 151, S. $352-$ 354, vom 23. Januar 849, eine Schenkung Milos und Adalhelms; ebd. 166, S. 366 f., vom 16. Juli 837, mit Milo als Zeugen; ebd. 172, S. 373-375, vom 17. November 839, eine Schenkung eines Priesters Milo; ebd. 173, S. 375 f., vom 13. März 826, mit einem Zeugen Milo; ebd. 174, S. 376 f., vom 1. Juni 809, eine Schenkung eines Priesters Milo; ebd. 177, S. 379-381, vom 10. Oktober 819, mit einem Zeugen Milo; ebd. 268, S. 511 f., hier S. 512, vom 24. April 84[6], ebenso. - Zu den Memorialbüchern vgl. u. a. Verbrüderungsbuch der Abtei Reichenau, ed. Autenrieth/Geuenich/Schmid, S. 54 ${ }^{\text {B4 }}$ (als Mönch des Klosters Lorsch neben seinem Mitbruder uuerinheri), $157^{\mathrm{A} 2}$ (ebenso als Mönch des Klosters Prüm; als weitere Mönche, aber an anderer Stelle, erscheinen auch zwei Lamberte und ein Milo). 
die Botschaft noch konzentrierter: Trier unter Erzbischof Radbod erhält Mettlach jetzt ganz bedingunglos und für alle Zeiten übertragen. Das entworfene Bild des Trierer Schenkerbischofs Liutwin korrespondiert ganz auffällig mit dem Bild des Trierer Bischofs Modoald als Gründer des Klosters Oeren, wie es etwa seit dem späten 10. oder frühen 11. Jahrhundert in Trier konstruiert wurde. Die es aufnehmenden manipulierten Urkunden geben vor, ins 7. und 8. Jahrhundert zu datieren. Auch bei diesen Diplomen stand die erwähnte echte Urkunde Ludwigs des Frommen von $816\left(\mathrm{BM}^{2}\right.$ 626) als Vorlage Pate. Eine Verbindung zwischen beiden Bildern und somit eine annähernd gleichzeitige Entstehung ist deshalb sehr wahrscheinlich. Für die Urkunden Karls und Arnulfs zog man in Trier wohl noch erhaltene zeitgenössische Originale heran. Allerdings wäre es ebenfalls denkbar, daß bereits Erzbischof Radbod Liutwin als Schenker Mettlachs ersann, um nach dem Normannensturm von 882 das Kloster als Trierer Besitz zu sichern. Auch läßt sich nicht ausschließen, daß man echte, für Radbod ausgestellte Diplome, die noch andere Schenker Mettlachs nannten, nachträglich manipulierte und einen Erzbischof Liutwin als solchen interpolierte bzw. dies bei Abschriften der Stücke geschah.

Liutwin fand als nachträgliche Interpolation, aus einem späteren Kenntnisstand heraus, auch Eingang in die ursprünglich echte Königsgerichtsurkunde Karls des Großen zu Mettlach (DKarol. I 148). Ein Bischof Liutwin wird darin zum Vater und Vorgänger Milos, was bereits auf der Trierer Rezeption von Hinkmars negativem Reimser Bild von Milo beruhen dürfte. Der eigentliche echte Kern von DKarol. I 148 steht aber DLoI. 67 in seiner Aussage nahe: Die beiden Widonen Milo und wahrscheinlich auch Wido überließen zur Zeit Pippins III. wohl das Kloster Mettlach dem Besitz der Trierer Kirche. Es handelte sich bei dieser Übertragung inhaltlich vermutlich um das Belehnungsrecht mit dem ehemaligen Eigenkloster ihrer Familie, das schon früher zum Schutz dem mundiburdium der Karolinger übergeben worden war. Damit wurde Mettlach Königsbesitz. Der mit Mettlach belehnte Milo war kein Bischof, sondern Adliger oder niederer Kleriker, der u. a. Trierer Bischöfe in Mettlach als Äbte einsetzte und selbst als Verwalter der bischöflichen Wirtschaft (episcopium) wirkte. Diese Funktion könnte die Vorlage für Erzbischof Hinkmars von Reims negatives Bild von Milo im 9. Jahrhundert geboten haben, die Milo dann auch für Reims übernommen haben soll. Hinkmar verstand den Begriff des episcopiums in diesem Zusamenhang nicht mehr als Wirtschaft im Sinne des 8., sondern als Bistum im Sinne des 9. Jahrhunderts. Nach Milos Tod übernahm Bischof Hartham - vielleicht sogar auf Milos Wunsch - Mettlach als Lehen. Der Widone Lambert wollte seine familiären Belehnungsrechte am Kloster jedoch nicht aufgeben, klagte bei Pippin und eignete sich das Kloster deshalb neben dem wahrscheinlich dort als Abt weiter amtierenden Hartham an. Doch Lamberts Söhnen gelang es nicht mehr, dieses Recht auch für sich in Anspruch zu nehmen bzw. zu belegen, obwohl sie ihrem Vater im Allod folgten. Karl der 
Große übertrug Mettlach wieder an die Trierer Kirche. In seiner ursprünglichen Fassung kann DKarol. I 148 also durchaus als Vorlage von DLoI. 67 verwendet worden sein. Aber noch eine zweite Lesart ist denkbar: Danach wäre in Lambert der eigentliche Vater Milos und Widos, vielleicht aber auch nur ein Verwandter der beiden, zu sehen. Liutwin hätte dann Lamberts Stelle - zum Bischof gewandelt - als nachträgliche Interpolation eingenommen. In diesem Fall wäre Lambert nach Milos Tod für seinen (zweiten) Sohn Wido, der mit seinen Brüdern auch vor dem Königsgericht auftrat, oder für seine Familie eingetreten und hätte dessen/deren Rechte gegen den Trierer Bischof Hartham vertreten. Einiges spricht schon deshalb dafür, daß Milo und wahrscheinlich auch Lambert in Mettlach bestattet wurden. Womöglich bestand der Streitgegenstand auch darin, daß die Widonen Lambert, Milo und Wido das Familienkloster Mettlach, das unter karolingischem mundiburdium stand, zwar an den Besitz der Trierer Kirche übertrugen, aber weiterhin davon ausgingen, daß das Belehnungsrecht bei ihrer Familie blieb. Stellte diese nicht auch die Verwalter des Trierer episcopiums?

Resümiert man aber die gewonnenen Ergebnisse, zeigt sich, daß die Urkunde ohne einen Bischof Liutwin weit mehr Sinn ergibt als mit einem solchen. Deshalb spricht inzwischen einiges dafür, daß Bischof Liutwin frühestens am Ende des 9., wahrscheinlicher aber erst im 10. Jahrhundert mit Mettlach in Verbindung gebracht worden sein dürfte.

\section{Liutwin-Einträge in der Mettlacher Güterrolle}

Wir haben gesehen, daß es zwar einige Dokumente gibt, die einen Bischof Basin sicher belegen, aber alle merowingischen und karolingischen Quellen zu einem Bischof Liutwin problematisch sind und keine Beweise für seine Existenz erbringen. Deshalb nehmen wir die Spur im 10. Jahrhundert wieder auf. Erst hier finden sich neue Hinweise. Die bisherigen Überlegungen haben gezeigt, daß auch einige der als ver- oder gefälscht erkannten Urkunden in diese Zeit deuten.

Die wenigstens in einigen Teilen scheinbar älteste Quelle, die zwar auf Liutwin, nicht aber einen Basin verweist, ist die sog. Mettlacher Güterrolle. Sie wird im Landeshauptarchiv Koblenz aufbewahrt. Es handelt sich um ursprünglich mindestens vier miteinander verbundene, wohl in Mettlach doppelseitig beschriebene Pergamentblätter mit urbarialen Aufzeichnungen und Traditionsnotizen von Mettlacher Gütern. Mindestens ein, durch eine Nahtstelle noch nachweisbares, viertes Blatt ist verloren. Die erhaltenen drei sind $15 \mathrm{~cm}$ breit und $99 \mathrm{~cm}, 99 \mathrm{~cm}$ und $85 \mathrm{~cm}$ lang. ${ }^{450}$ Abfassung und zeitliche Schichten der urbarialen Einträge untersuchten Karl Lamprecht 1885 sowie

450 Vgl. Koblenz, Landeshauptarchiv, Best. 143 Nr. 6. 
Charles-Edmond Perrin 1935 genauer. ${ }^{451}$ Während Lamprecht noch die ersten Teile des Urbars im 9. Jahrhundert entstanden sehen will, unternimmt PERrin eine paläographische Analyse. Er arbeitet Entstehungstufen und Struktur der Rolle heraus und datiert die Niederschrift des ersten Teiles überzeugend in die zweite Hälfte des 11. Jahrhunderts. Schließlich edierte Hartmut Müller 1965 die Rolle in der von Perrin angenommenen chronologischen Entstehungsfolge ihrer Einträge. ${ }^{452} \mathrm{Er}$ faßt den Befund folgendermaßen zusammen:

„Die urbarialen Teile der Mettlacher Güterrolle sind keine originale Aufzeichnungen, sondern eine Niederschrift des späten 11. Jahrhunderts, die ein Schreiber ([...] als A bezeichnet) aus Texten verschiedener Entstehungszeiten kompilierte, die nicht überliefert sind. Die urbarialen Aufzeichnungen erscheinen nicht in der Reihenfolge ihrer Entstehungszeit. In die Zwischenräume, die der Schreiber A bei der Aufzeichnung des ältesten Urbarteils aus der Mitte des 10. Jahrhunderts ließ, wurden spätere Nachträge vom gleichen Schreiber A und anderen Schreibern sowie bereits einige Traditionsnotizen eingeschoben, wodurch ein sachliches wie paläographisches Durcheinander entstand. [...]

In der Mitte des 11. Jahrhunderts wurde das Fragment des ältesten Urbars, das aus der Mitte des 10. Jh. stammt, zusammen mit den späteren Zusätzen von einem Mettlacher Mönch auf eine Rolle von mindestens vier Teilen geschrieben, ohne daß dieser versuchte, die einzelnen Aufzeichnungen, die ihm vorlagen, nach Inhalt oder Entstehungszeit zu klassifizieren. Es ist möglich, daß ihm damals die Fassung des 10. Jh. nur in verstümmelter Form vorlag, [...]. “453

Hieran zeigt sich bereits die ganze Problematik der Quelle. Aus der kopialen Abschrift, die frühestens ab der Mitte des 11. Jahrhunderts erfolgte, hat die Forschung auf ein Ursprungsurbar aus der Mitte des 10. Jahrhunderts zu schließen versucht. Doch dieses Vorgehen beruht auf PerRins Überlegungen, der davon ausgeht, daß das angenommene Ursprungsurbar nicht älter sein könne. Denn die vor 1091 verfaßten Miracula s. Liutwini berichteten, ein Wicelin, vicedominus des Trierer Erzbischofs, habe etwa zu Beginn des 10. Jahrhunderts das alte Mettlacher Urbar vor den Augen der Mönche vernichtet. Auf ihn wird unten in Verbindung mit den Miracula noch genauer einzugehen sein. ${ }^{454}$ Ist dieser Bericht aber glaubwürdig? Erstaunlich genug jedenfalls ist, daß

451 Vgl. Lamprecht, Deutsches Wirtschaftsleben 2, S. 105-109. Perrin, Recherches, S. 108-140, zur Entstehung und der ersten Stufe der Rolle bes. S. 116-118. Perrin datiert u. a. aufgrund der Handschrift des Schreibers A.

452 Vgl. MüLLER, Mettlacher Güterrolle. Eine ältere Edition findet sich bereits im MRUB II Nachtrag 10, S. 338-351. Darauf basiert der Druck bei Lager, Urkundliche Geschichte, S. $172-189$.

453 Vgl. MüLler, Mettlacher Güterrolle, S. 110-112.

454 Vgl. Miracula s. Liutwini auct. Monacho Mediolacensi cap. 8, ed. SAUERLAnd, S. 1263 f.: [...], afferri sibi librum iam notum petiit, in quo privilegii et cunctarum, que ad locum pertinebant, rerum inscriptio fuit. Vgl. dazu Perrin, Recherches, S. 122 f., 136. Vgl. zu Wicelin auch unten S. 351 und Anm. 734-736. 
die Abfassung der Miracula und die Niederschrift der ersten Teile der Rolle annähernd in dieselbe Zeit des späten 11. Jahrhunderts fallen. Besteht zwischen beiden Quellen ein Zusammenhang? Suchte man vielleicht nach einer Begründung für die neu anzulegende Güterrolle und fand sie in Wicelin? Letztlich muß doch die Abfassung einer solchen Rolle einem besonderen Anlaß geschuldet sein. Daß selbst der Schreiber A in mehreren Bearbeitungsstufen vorgegangen sei, wie Perrin meint, gründet sich allein auf der Vermutung des für die Mitte des 10. Jahrhunderts angenommenen Ursprungsurbars, mit dessen postuliertem Grundbestand einige weitere Einträge des Schreibers A zeitlich nicht zu harmonieren scheinen. Diese enthalten nämlich Dubletten, die man sich nicht schon im Urbar hat vorstellen, sondern erst durch spätere Ergänzungen aufgrund einer anderen Vorlage erklären wollen. Doch ebenso können die vermuteten, verlorenen älteren und wie auch immer aussehenden Vorlagen bereits mit Zusätzen und Erläuterungen versehen gewesen sein, bevor sie auf die Rolle übertragen wurden. Der Kopist hob diese sicher nicht mehr eigens hervor. Letztlich kann sogar der Kopist noch solche Änderungen bei der Übertragung vorgenommen haben. So läßt sich über den Zustand und die Entstehungszeit der Vorlagen und eines Ursprungsurbars nichts Sicheres sagen und damit auch nicht über den Mettlacher Grundbesitz im 10. Jahrhundert. Die Rolle spiegelt vielmehr den Mettlacher Besitz nach der Mitte des 11. Jahrhunderts und damit zur Zeit des Schreibers A. Diesem Schreiber, der wahrscheinlich Mönch des Klosters Mettlach war, ging es nicht darum, auf der Basis seines Materials ein strukturiertes Register anzulegen, vielleicht war das auch schlichtweg nicht möglich oder es überforderte ihn. Vielmehr wollte er zunächst Material zusammentragen und erhalten, um Mettlacher Besitz zu sichern, wie er sich für ihn und das spätere 11. Jahrhundert darstellte oder darstellen sollte. RAACH schließlich nimmt die Güterrolle als Grundlage seiner ausführlichen Untersuchungen des Mettlacher Güterbesitzes, dem aber an dieser Stelle nicht genauer nachgegangen werden soll. ${ }^{45}$

Auffällig ist, daß sich etwa zur selben Zeit wie in Mettlach zwei Mönche, einer in Novalese und einer in Benediktbeuern, daran machten, die Vergangenheit ihrer Klöster zu rekonstruieren bzw. zu konstruieren. Wenig Material war dazu erhalten. Dennoch verstanden sie es, neue mythendurchsetzte Geschichten zu formen, die kaum etwas mit dem zu tun hatten, was einst wirklich geschah. Dafür sollten sie um so mehr für die Bedürfnisse der Verfasserzeit hilfreich sein. Das Chronicon Novaliciense sowie das Breviarium Gotscalchi entstanden. Letztlich ging es auch ihnen darum, den eigenen Klosterbesitz gegen Forderungen von außen zu sichern. Konkrete Güteransprüche wurden in die Geschichten eingeflochten. Die eigenen Rechte sollten bereits in fernen Tagen begründet sein. Jeder der Mönche verwandte dazu ebenfalls einen rotulus, auch

455 Vgl. insgesamt RAach, Mettlach, S. $63 \mathrm{ff}$. 
wenn diese teils länger ausfielen (dreißig und fünf Blatt) als der in Mettlach. Dabei scheint es sich bei diesen beiden um eine Art Arbeitsfassung gehandelt zu haben, wie ihr teilweise notizenhafter Text vermuten läßt. ${ }^{456}$ Muß man für das Mettlacher Exemplar nicht einen ganz ähnlichen Hintergrund annehmen?

Von der Hand des ersten Schreibers A im 11. Jahrhundert finden sich nun einige Belege in die Mettlacher Rolle für einen hl. Liutwin eingetragen, die Perrin in Teilen auf die Mitte des 10. Jahrhunderts datiert. Beim Eintrag zu Beginn der Liste (Kap. 1) zum Besitz in Wadern, der nach Perrin dazu gehöre, würde erstmals überhaupt in einer Quelle bis dahin das Fest eines hl. Liutwin erwähnt (nach späterer Tradition gefeiert am 29. September), vor dem eine Woche Frondienst zu leisten sei. Doch wird dieser Liutwin, der hier nicht als Bischof bezeichnet wird, in keiner Form genauer mit Mettlach in Verbindung gebracht. Vielmehr erscheint im selben Eintrag völlig gleichwertig auch das Fest des hl. Andreas für zu erbringende Abgaben, ohne diesen einem genauen Ort zuzuweisen. ${ }^{457}$ Andreas aber wurde im 10. und 11. Jahrhundert in Mettlach nicht herausgehoben verehrt, wohl aber in Trier. Der Trierer Erzbischof Egbert (977-993) wies diesem Heiligen schließlich für seine Stadt eine ganz besondere Rolle zu. So ließ er im Dom eine Andreaskapelle erbauen und stiftete einen Andreas-Tragaltar mit der Sandale des Verehrten als Reliquie. ${ }^{458}$ Damit bietet

456 Vgl. Geary, Phantoms, S. $114 \mathrm{ff}$.

457 Es handelt sich auch nach dem Editor um den ersten Eintrag (Kap. 1). Vgl. MüLler, Mettlacher Güterrolle, S. 116 f., Nr. U 1: In villa Waderella habemus ecclesiam cum decimacione $X$ villarum didatam cum uno manso, ad nostras manus XLVIII mansos et dimidium habemus. In pasca solvit unaqueque aut $X$ denarios aut oves eiusdem precii et II pullos et XXX ova. In medio maio $V$ denarios. In natale domni III pullos et pro ligno II modia dominice avene et secundo anno IIII denarios pro porcis. In octobre angariam ad Mosellam de tribus obis plaustrum I faciunt. In aprili serviunt I epdomadam, in maio duas, in iunio unam. Insuper debent III dies de unaquaque domo unum ad urbis opus, alium ad fenum, tercium ad araturam. Messem ducunt ad monasterium quantumcunque sit. Ante festivitatem sancti Liutwini unam epdomadam serviunt. In novembre serviunt duas epdomadas. In decembre unam, in ianuario duas, in februario unam. I Dimidia oba in Badachenroth solvit in festivitate sancti Andree unciam unam. De dominicali terra habemus IIII carruades, due arantur ex nostro aratro et alie II cum familia. Preter ipsas in beneficio sunt date XII et dimidia, que omnes similiter solvunt et serviunt. Insuper ibi sunt II obe, quas tenent baiulatores, et solvunt $X$ denarios. Area quoque una solvit II denarios et dimidium. Ruocho habet unam obam ibi, que solvit unciam I et angarias II, unam sibi aliam nobis. Vgl. dazu MRUB II Nachtrag 10, S. 339. Perrin, Recherches, S. 113 f. Lamprecht, Deutsches Wirtschaftsleben 2, S. 106.

458 Vgl. zur Verehrung des Andreas in Trier mit dem Fest am 30. November zunächst Miesges, Festkalender, S. 9-11, 106 f., 144, der zeigt, daß Andreas schon im 9./ 10. Jahrhundert in St. Maximin verehrt wurde und seitdem in zahlreichen Kalendarien erscheint. Der früheste Eintrag finde sich in einem Kalendar in der Handschrift Vatikan, Bibliotheca Apostolica, Palatinus lat. 1448, fol. $6^{\mathrm{r}}-11^{\mathrm{v}}$, aus dem 9./10. Jahrhundert. Es sei in St. Maximin ,nach einer nordfranzösischen Vorlage aus der Gegend von SaintOmer verfasst“ (ebd., S. 10) worden. Zu dieser Handschrift vgl. auch Hoffmann, 
dieser Eintrag eines Liutwinfestes auf der Rolle keinen Beleg für eine unmittelbare Verehrung Liutwins in Mettlach, sondern nur im Trierer Raum. Darüber hinaus deutet die mit Egbert intensivierte Andreasverehrung auf eine nachträgliche Aufnahme dieses Festes in die ursprüngliche Vorlage der Güterrolle ab dem ausgehenden 10. Jahrhundert oder spricht sogar für eine Entstehung dieser Vorlage frühestens ab der Egbertzeit.

Ebensowenig läßt sich eine spätere Interpolation oder Ergänzung Liutwins ausschließen. Denn ein Liutwinfest schon im frühen 10. Jahrhundert findet sich in keinem der erhaltenen Trierer Kalendare belegt, auch nicht im Kalender des hl. Willibrord (†739), der ja - wie gesehen - ein Zeitgenosse Liutwins gewesen sein müßte. Erst in einem Trierer Kalender des späten 10. Jahrhunderts, in einer Sakramentarhandschrift, erscheint Liutwin. Es schließen sich nun weitere Nachweise des späten 10. und des 11. Jahrhunderts an, die Liutwin dann auch zum 29. September nennen. Ebenso folgt ein Kalendar angelsächsischen Ursprungs in einer Handschrift des 9. Jahrhunderts, das wohl nach St. Maximin in Trier gelangte und mehrere Trierer Nachträge vom Beginn des 11. Jahrhunderts enthält, darunter das Liutwinfest zu diesem Tag. ${ }^{459}$

Ferner weisen weitere, bisher auf die Mitte des 10. Jahrhunderts datierte Einträge der Güterrolle zu Valmünster, Udern, Vahl, Tincry und Losheim auf das Fest des hl. Martin hin, ${ }^{460}$ einer zu Damvillers zudem noch auf das der hll. Johannes und Remigius. ${ }^{461}$ Ein Eintrag zu Büdelingen erwähnt neben dem hl. Martin wieder Liutwin. ${ }^{462}$ In einem weiteren Eintrag erscheinen die Feste Martins und Andreas' gemeinsam, ${ }^{463}$ in einem anderen wieder Martin und Liutwin. ${ }^{464}$ Immerhin muß also Liutwin zur Abfassungszeit der Güterrolle nach der Mitte des 11. Jahrhunderts in einem weiteren Umfeld im Trierer Raum

Buchkunst 1, S. 260, der sie insgesamt ins 9. Jahrhundert datiert. Zu Egberts besonderer Verehrung des Andreas vgl. Westermann-Angerhausen, Goldschmiedearbeiten, S. 21-32, zum Andreas-Tragaltar. Vgl. ferner unten S. 289 f. u. Anm. 547, 552-554. 459 Vgl. zu Willibrord bereits oben Anm. 29 u. Kap. D.II. Zum Liutwinfest am 29. September vgl. vor allem Miesges, Festkalender, S. 8, 47, Anm. 3, 88 f., bes. S. 8. Zum Kalendar vgl. unten Anm. 571. - Vgl. zum Trierer Kalendar der Sakramentarhandschrift unten S. 292 f. u. Anm. 568 f. - Zu den weiteren Nachweisen des späten 10. und des 11. Jahrhunderts vgl. ausführlicher unten Kap. D.VII.

460 Vgl. MüLler, Mettlacher Güterrolle, S. 117-120, Nr. U 2-5, 7.

461 Vgl. MüLler, Mettlacher Güterrolle, S. 119 f., Nr. U 6.

462 Vgl. MüLlen, Mettlacher Güterrolle, S. 121, Nr. U 8: [...] In natale sancti Martini solvit unaquaque oba XII denarios, excepta una, que solvit III solidos. In festo sancti Luitwini victimam unam aut XII nummos debet villicus et IIII panes et II sextaria vini. [...]

463 Vgl. Müller, Mettlacher Güterrolle, S. 121, Nr. U 9.

464 Vgl. Müller, Mettlacher Güterrolle, S. 122, Nr. U 10: De Medelinga V solidi, de Minciche $V$ solidi, partim in maio, partim in festo sancti Martini. De Wintiriche in festo sancti Liutwini VI solidi, et duo solidi de Dalesdorfh. Vdo de Prumia eciam tunc solvere debet XII solidos de Hoinsceith. De Wala X solidi et XXX denarii. 
verehrt worden sein. Daneben finden sich noch die üblichen Kirchenfeste wie Weihnachten und Ostern.

In einem Nachtrag zum angenommenen ältesten Urbar nach 950 - so Perrin und Müller - zu Udern/Oudrenne sei die Kopie einer Weiheurkunde des Trierer Erzbischofs Rotbert (931-956) von einem 25./26. Februar für die dortige Kirche wiedergegeben. Es handle sich um den einzigen kurzen Bericht der Rolle. Da die Weiheurkunde zudem für das beschriebene Geschehen die Herrschaftszeit König Heinrichs I. (919-936) nenne, müsse die originale Vorlage zwischen 931 und 936 ausgestellt worden sein, urteilt die Forschung einhellig. Die Urkunde könne sich nicht schon im postulierten ältesten Urbar befunden haben, weil sie dann wohl dem darin befindlichen weiteren Eintrag zu Udern/Oudrenne unmittelbar zugeordnet worden wäre. Dieser ältere Eintrag zu Udern/Oudrenne befindet sich aber zu Beginn der Rolle (Kap. 4), während die Weiheurkunde weit davon entfernt aufgenommen wurde (Kap. 16). ${ }^{465}$

Doch handelt es sich tatsächlich um die Kopie einer Weiheurkunde? Werfen wir einen genaueren Blick auf ihren Inhalt: Den gegenwärtigen wie zukünftigen Untertanen der hl. Kirche Gottes wird bekannt gemacht (notum sit), daß die Feier der Kirchweih (ęclesie consecracionis dedicacio) in der Villa - nämlich Udern - an den V. Kalenden des März vorgenommen worden sei, ausgeführt durch Erzbischof Rotbert in einem Weihegottesdienst zu Ehren des hl. Erzbischofs Liutwin, dem (gemeint ist Rotbert) - wie man wisse - die Villa gehöre, und sie (die Kirche) sei ausgestattet worden mit einer Hufe mit den dort ansässigen Hörigen. Dann solle man wissen, daß der ganze Zehnt derselben Villa

465 Vgl. zu Kap. 4 Müller, Mettlacher Güterrolle, S. 118, Nr. U 3. Zu Kap. 16 vgl. ebd. S. 122 f., Nr. U 11: Notum sit sancte dei ecclesie fidelibus tam presentibus quam futuris, quod ęcclesię consecracionis dedicacio in villa videlicet Udera acta est $V$. kalendas marcii gerente Rvothperto archiepiscopo consecracionis ministerium in honore sancti Liutwini archiepiscopi, cuius eciam res ipsius ville esse noscuntur, et dotata uno manso cum mancipiis presencialiter super sedentibus. Nam et omnem decimacionem ipsius ville determinatam ibi cum largicione Rvoperti archiepiscopi scitote. Similiter et de villa Leimersthorf in silvis, in pratis et veneis et agris et omnibus illuc aspicientibus, et de aliis villis similiter, scilicet Bruningesdorfh, Duodenhofh, Lomerstorf, Hettinga, Huntinga et Mundelar, Wrentelinga, et quicquid de decimacione ad nostram parrochiam pertinere noscitur, totam cum integritate ad prefatam ecclesiam pertinentem scitote. Et qui hoc irritare amplus studuerit, idem beate memorie episcopus Rovtpertus anathematizavit. Sciant ergo se sub anathemate esse, quicunque hoc studuerit adnibilare. / Hec autem gesta sunt temporibus Heinrici regis et ducis Gisilberti et advocati Gozberti et prepositi Regilonis et decani Gagandhardi et Burginradi et Wolmundi fratrum de monasterio Mediolacensi et presbiteri Rvoperti eiusdem ecclesie. - Vgl. dazu MRUB II Nachtrag 10, S. 343 f. Perrin, Recherches, S. 125. Lamprecht, Deutsches Wirtschaftsleben 2, S. 106, zur Datierung. Goerz, Mittelrheinische Regesten I 883, S. 253, datiert die Weihe auf den einzigen Sonntag in dieser Zeitspanne und damit auf das Jahr 932, worin ihm Lamprecht folgt. Alle Autoren sind sich einig, daß es sich um eine Kopie der vorliegenden Weiheurkunde (eigentlich um eine notitia) handelt. Vgl. so zuletzt noch RaAch, Mettlach, S. 93 f., der ebenso die Datierung auf 932 übernimmt. 
zusammen mit einer Schenkung Erzbischof Rotberts dort festgelegt wurde. Man solle wissen, daß gleichermaßen auch von der Villa Leimersthorf an Wäldern, Wiesen, Weinbergen, Feldern und allem dort Dazugehörendem und von anderen Villen ebenso, nämlich Bruningesdorfh, Duodenhofh, Lomerstorf, Hettinga, Huntinga, Mundelar sowie Wrentelinga, und was immer auch bekannt sei, das vom Zehnt zu unserer Pfarrkirche gehöre, das alles (totam vielleicht aus totum oder tota verschrieben) solle ausschließlich der genannten Kirche gehören. Und wer das fürderhin/weiterhin (amplus, gemeint ist das Adverb amplius) bestreiten will, den hat derselbe Bischof Rotbert seligen Angedenkens verflucht. Sie sollen also wissen, daß sie unter dem Fluch stehen, wer auch immer sich bemüht, das für ungültig zu erklären/zu leugnen. Diese Dinge seien geschehen zu den Zeiten König Heinrichs, des Herzogs Gisilbert, des advocatus Gozbert, des Vorstehers oder Propstes (prepositus) Regilon, des Dekans Gagandhard, der Brüder Burginrad und Wolmund vom Kloster Mettlach und des Priesters Rvopert (Rotbert?) von derselben Kirche.

Das Stück bietet einige Auffälligkeiten, die sich so in den anderen erhaltenen Urkunden Rotberts nicht finden. ${ }^{466}$ Zwar stimmt der Beginn des Formulars mit den weiteren zeitgleichen Urkunden des Erzbischofs überein. Doch ist diese Wendung ohnehin im Trierer Raum des frühen 10. Jahrhunderts verbreitet, wie ein Blick ins MRUB zeigt. ${ }^{467}$ Es stellt sich aber grundsätzlich die Frage, wer eine solche Urkunde üblicherweise ausstellte. Man sollte doch annehmen, daß es der Bischof selbst war. Und so geht Rotbert auch in MRUB I 198 am 9. September

$466 \mathrm{Zu}$ den weiteren Urkunden Rotberts vgl. MRUB I 173, S. 236 f., den Prekarievertrag Rotberts für eine Ada, die Nichte seines Vorgängers Ruotger, von 936; ebd. 174, S. 237 f., den Prekarievertrag Rotberts für Berta von 938. Beide Urkunden sind in die Balduineen als glaubwürdige Stücke aufgenommen worden. Ebd. 178, S. 240 f., scheint keine echte Urkunde zu sein, sie folgt auch nicht dem Formular der beiden zuvor genannten Stücke. Beyer hält sie für einen Konzeptentwurf. Darin untergibt Rotbert 943 die Kirche in Welcherath der Pfarrei Nachtsheim und beschreibt deren Grenzen. Schon diese Grenzbeschreibung gemahnt zur Vorsicht. In ebd. 193, S. 254 f., verleiht Rotbert am 29. Februar 952 einem Wido Land als Erblehen. Auch diese Urkunde befindet sich in den Balduineen unter den glaubwürdigen Dokumenten. Die Familie der Widonen war also noch immer im Trierer Raum ansässig. In ebd. 198, S. 258 f., restauriert und dotiert Rotbert (hier Robertus) erneut das Marienkloster neben dem Trierer Dom am 9. September 955. Auch diese Urkunde stammt aus der glaubwürdigen Abteilung der Balduineen. In ebd. 201, S. 261 f., schenkt Rotbert am 15. September 956 dem Martinskloster im Weingau einen Weinberg mit Zehnt in der Umgebung. Diese Urkunde ist noch im Original erhalten.

467 Es handelt sich im wesentlichen um die Passage Notum sit sancte dei ęcclesię fidelibus tam presentibus quam futuris, die sich ähnlich in Rotberts zeitnahen Urkunden von 936 und 938 findet. Vgl. nochmals MRUB I 173 f., S. 236 f. Dort heißt es beide Male: Notum sit omnibus huius ęclesię fidelibus presentibus atque futuris. $\mathrm{Zu}$ beiden vgl. auch GoERz, Mittelrheinische Regesten I 898 f., S. 256. Ähnlich auch in MRUB I 193, S. 254. - Vgl. auch insgesamt MRUB I, S. $235 \mathrm{ff}$. 
955 bei der Neudotierung des Marienklosters neben dem Trierer Dom vor, wenn die Urkunde denn echt ist. Darin ist auch von einem Weihegottesdienst am 8. September die Rede, dem Geburtsfest Mariens, was beim Marienpatrozinium ja naheliegt. ${ }^{468}$ Selbst wenn das Stück manipuliert wäre, entspräche es doch der geläufigen Vorstellung. Sonst hätten die Redaktoren der Balduineen im 14. Jahrhundert - worin es allein überliefert ist - es sicher in die bekannte Abteilung der fragwürdigen Dokumente ausgesondert, was nicht geschah.

Liest man aber den Text der Weiheurkunde, so berichtet dieser von Erzbischof Rotbert in der dritten Person: Rotbert habe geweiht, den Zehnt übertragen und Zuwiderhandelnde verflucht. Diese letzte Stelle steht im Perfekt und spricht von ihm in seligem Angedenken, also als Verstorbenem. Hinzu kommt, daß die Personen und Zeugen am Ende nicht klar formal gegliedert - wie üblicherweise -, sondern geradezu zusammengefaßt werden. Merkwürdig ist auch, warum plötzlich von ad nostram parochiam pertinere die Rede ist. Handelt es sich dabei um eine Pfarrkirche oder um die Trierer Diözese? Meint „unser" den Trierer Bischof, der dann doch eigentlich als Aussteller in der ersten Person fungieren müßte, oder das Kloster Mettlach, das von seinem Besitz spricht? Wahrscheinlich ist Mettlach gemeint, denn der frühere Eintrag zu Udern (Kap. 4) spricht allein vom Mettlacher Besitz der dortigen Kirche. Diese Passagen zeigen, daß keine direkte Kopie einer Originalurkunde Rotberts vorliegt. Vielmehr griff der erste Redaktor der Güterrolle bzw. der Schreiber A hier entweder bei der Abschrift in den Text ein, oder dies war schon vor ihm geschehen, und er übernahm diese Zusammenfassung nur noch auf die Rolle. Es ist deshalb angebrachter, den Eintrag eine, Weihenotiz' zu nennen. Und dem Formular einer solchen notitia bzw. Privaturkunde entspricht das vorliegende Stück. Daß die darin vorgefundenen Namensformen schon bald Schwierigkeiten bereiteten, belegt der erwähnte Ort Lomerstorf, der sich erst als späterer interlinearer Nachtrag von anderer Hand als der des Schreibers A findet. Wahrscheinlich handelt es sich um eine Verwechslung mit Leimersthorf. ${ }^{469}$

Wie man es beim Formular einer notitia überwiegend findet, nennt der Text das Datum der Handlung gleich zu Beginn, in diesem Fall das Weihedatum: die V. Kalenden des März. Je nachdem in welches Jahr dieser Tag fällt, handelt es sich um den 25. oder 26. (nur 932 und 936) Februar. Merkwürdig aber ist das Weihedatum selbst, denn das Liutwinfest wird nach der Tradition, die seit dem späten 10. Jahrhundert in Trier belegbar ist, am 29. September gefeiert.

468 Vgl. MRUB I 198, S. 258: Quapropter karissimi qui natalia dei genitricis et intemerate uirginis et dedicationis officium hic frequentare gaudetis. quod hodie. id est.VI. Id. Sept. nostra est humilitate restauratum felici retinente memoria. et a nobis ad posteros eadem transmigret sollertia. et iugiter retinenda noticia.

469 Vgl. dazu Müller, Mettlacher Güterrolle, S. 122, Anm. h. Vgl. zur notitia hier nur Zielinski, Notitia. Gawlik, Privaturkunden. 
Wurde also die Kirche womöglich zunächst einem ganz anderen Patrozinium gewidmet und an dessen Stelle erst nachträglich der hl. Liutwin eingesetzt? Später einmal wird an diesem Tag des Trierer Bischofs Modestus gedacht. Beim Datum könnte es sich aber auch um eine Verschreibung aus den VI. Kalenden handeln. Dann wäre als Patrozinium der Apostel Matthias denkbar, der zu dieser Zeit im Trierer Raum verehrt wurde. ${ }^{470}$ Von einem Liutwinpatrozinium in Udern ist danach ebenfalls nicht mehr die Rede. Es kann sich also nicht durchgesetzt haben. Vielmehr erscheint im Visitationsbericht von 1560 ein Magarethenpatrozinium, für 1657 taucht ein Martinspatrozinium auf. ${ }^{471}$ Was in der Zwischenzeit geschehen ist, wissen wir nicht.

Wenn RAACH den Text so deutet, daß Liutwin Besitz an der Villa (also Udern) hatte, und dies als Hinweis dafür wertet, Mettlach habe bereits zuvor über diese Villa verfügt, so handelt es sich um einen Übersetzungsfehler. ${ }^{472}$ Denn die Villa gehörte vielmehr Erzbischof Rotbert, der die geweihte Kirche mit einer umfangreichen Ausstattung versah (eine Hufe und mehrere Zehnte). Von einer Schenkung der Villa an Mettlach ist nicht die Rede. Einzig das hier ganz und gar nicht passende Weihepatrozinium will eine klare Verbindung mit dem Kloster herstellen. Es kann nur interpoliert sein, um Mettlacher Ansprüche zu konstruieren. Vielleicht erfolgte die Interpolation eben mit dem Zweck, den Text so zu verstehen, wie RAACH es tat, nämlich zu glauben, daß nicht Rotbert, sondern Liutwin die Villa Udern gehörte. Vielleicht gab es auch einen späteren Versuch, Udern/Udrenne dieses Patrozinium zuzuweisen, den man mit dieser interpolierten Notiz nachträglich legitimieren wollte. Ähnlich argumentiert neuerdings BAUER, der das dortige frühe Liutwinpatrozinium für fragwürdig hält. Es sei nicht von Trierer, sondern Mettlacher Seite dorthin gelangt. ${ }^{473}$

Doch scheint die Kirche in Udern Mettlach zu gehören und einiges dafür zu sprechen, daß zumindest der Textkern der notitia echt sein dürfte. Denn während sie - wie gesehen - erst im zweiten erhaltenen Drittel (Kap. 16) der Mettlacher Rolle zu finden ist, steht gleich zu Beginn (Kap. 4) der Rolle ein weiterer Eintrag zu Udern. Wie aber konnte Mettlach bereits vor der Kirch-

470 Vgl. nochmals die vorausgehende Anm. Ganz ähnlich macht es beispielsweise auch das echte Testament der Irmina. Vgl. dazu oben Kap. D.II.4.a. Auch die für St. Maximin überlieferten Weihenotizen nennen die Datierung jeweils gleich zu Beginn. Vgl. dazu unten Kap. D.VI.1. Vgl. ferner Miesges, Festkalender, S. 32 f., 140. Modestus findet sich danach in den Trierer Kalendern aber erst ab dem 15. Jahrhundert.

471 Vgl. dazu Pauly, Siedlung und Pfarrorganisation. Landkapitel Perl und Remich. Das Burdekanat Trier, S. 170-173. Pauly sieht im Vorgängerpatrozinium Liutwins das des hl. Martin.

472 Vgl. RaAch, Mettlach, S. 94.

473 Vgl. Bauer, Verehrung heiliger Trierer Bischöfe, S. 399. - Vielleicht aber bestand auch in Udern wirklich einmal kurzfristig ein Liutwinpatrozinium, das man als Aufhänger benutzte, um den Ort mit Mettlach in Verbindung zu bringen, wo Liutwin erst um einiges später eine dominierende Rolle einnahm. 
weihe über Besitz in Udern verfügen? Die Inhalte beider Kapitel ähneln sich, auch wenn sie auf der Rolle räumlich auseinanderstehen. Im frühen Eintrag wird schon der Mettlacher Besitz mit einer Kirche (und eben keiner Villa) in Udern angegeben, ausgestattet mit einer Hufe sowie Zehnteinkünften in Laimmenestorf, Brunistorf, Duodinhof, Hettinga, Mundelar, Huntinga und Wrentilinga. Ein Zehnt in Udern fehlt dabei jedoch ebenso wie das in der Weihenotiz nachgetragene Lomerstorf. Doch folgen dann sehr ausführliche und umfangreiche Angaben zur genauen Besitzgliederung und den zu leistenden Diensten und Abgaben. ${ }^{474}$ Die Frage stellt sich, warum nicht der Hinweis auf Rotbert bereits an dieser Stelle in Kap. 4 der Rolle steht, wenn doch die Ausstattung der Kirche dort auf ihn zurückgehen soll. Aber im frühen Eintrag der Rolle wird Rotbert überhaupt nicht erwähnt, auch kein dortiges Liutwinpatrozinium, sondern, wie gesehen, als einer der Abgabetermine das Martinsfest. Und warum nennt wiederum die Weihenotiz (Kap. 16) nicht die genauen Abgaben und Leistungen, ergänzt aber den Zehnt in Udern als Ausstattung und später noch Lomerstorf? Zwei überlieferte Prekarieurkunden Rotberts von 936 und 938 gehen da ganz anders vor und sind geradezu minutiös in den Einzelheiten. ${ }^{475}$

Weshalb bietet also der Bearbeiter des späteren 11. Jahrhunderts die notitia noch zusätzlich an späterer Stelle? Platzgründe allein können nicht ausschlaggebend gewesen sein, sondern entweder die Absicht, den Inhalt von Kap. 4 zu modifizieren oder den eines ursprünglichen Textes der Weihenotiz. Die notitia ergänzt Kap. 4 - wie gesagt - vor allem noch um die Ausstattung des Zehnten in Udern sowie das Liutwinpatrozinium, das durch seine Plazierung im Text der Notiz durchaus den Eindruck vermitteln kann, nicht Rotbert, sondern eben Liutwin besitze Udern. Die Mettlacher Intention dürfte also sein, nicht nur über die Kirche in Udern zu verfügen, sondern vielmehr die gesamte Villa ans Kloster zu ziehen. Das aber bedeutet, daß einige Passagen der Weihenotiz entweder nachträglich (noch vor oder bei Abschrift auf die Güterrolle) interpoliert wurden und die notitia in der ursprünglichen Form Kap. 4 sehr nahestand bzw. dessen eigentliche Grundlage bildete oder die Notiz vollständig konstruiert wurde. Sie (Kap. 16) macht jedenfalls die Position Erzbischof Rotberts als Gönner Mettlachs verständlicher, wie ihn die Miracula s. Liutwini darstellen, worauf noch zurückzukommen sein wird. ${ }^{476}$

Gegen den Inhalt sowohl von Kap. 4 als auch Kap. 16 auf der Güterrolle, die zunächst nur Besitz Mettlachs an der Kirche in Udern belegen, spricht

474 Vgl. MüLler, Mettlacher Güterrolle, S. 118, Nr. U 3: In Vdera habemus ecclesiam cum una oba dotatam et cum decimatione villarum Laimmenestorf, [...]. Vgl. dazu RAACH, Mettlach, S. $92 \mathrm{f}$.

475 Vgl. dazu oben Anm. 466.

$476 \mathrm{Vgl}$. dazu ausführlicher unten S. $351 \mathrm{ff}$. 
jedoch die Darstellung von vier Schenkerpaaren, die auf der Rückseite des erst im frühen 13. Jahrhundert entstandenen Mettlacher Kreuzreliquiars zu finden sind. Eines davon, das RAACH noch vor der Mitte des 10. Jahrhunderts als tätig annimmt, zeigt einen Stephan mit seiner Gattin Bernowida, die Udera - also Udern - an Mettlach geben. Danach also verfügte Mettlach nicht nur über die dortige Kirche mit ihrer Ausstattung, sondern über die ganze Villa. Gemäß der bisherigen Forschung lebte das Paar am Ende des 9. Jahrhunderts. ${ }^{477}$ Weshalb aber wurde diese Schenkung nicht auf der Güterrolle erwähnt? Stand ein entsprechender Text vielleicht auf dem inzwischen verlorenen Teil der Rolle? Was genau schenkten Stephan und Bernowida? Lag noch eine Urkunde vor? Wie wäre Rotbert in den Besitz der Villa gelangt? Die überlieferten und variierenden Traditionen bieten einen nicht aufzulösenden Widerspruch, der Mißtrauen gegenüber dem erhaltenen Material weckt. Er ließe sich nur auflösen, wenn Stephan und Bernowida erst nach Rotbert in den Besitz der Villa gelangten. Andernfalls handelt es sich um ein fiktives Stifterpaar, um somit eine Schenkung der Villa möglichst weit in die Vergangenheit zurückzuverlegen bzw. zu konstruieren. Vielleicht bediente man sich dazu brauchbarer älterer Dokumente als Vorlage.

Man könnte diesen Befund damit erklären, daß der Besitz in oder sogar von Udern für Mettlach umstritten war und man versuchte, den Anspruch darauf durch verschiedene und nicht genau übereinstimmende Legitimationstraditionen immer wieder aufs neue geltend zu machen. Allerdings gibt es über die hier zusammengetragenen Belege hinaus keine weiteren, die auf Streitigkeiten um Udern hindeuten, bis auf eine Auseinandersetzung des dortigen parochus 1264 mit dem Mettlacher Abt um gerade erst nutzbar gemachtes Land. ${ }^{478}$

Vielleicht aber sammelte man in Mettlach auch lediglich ganz additiv das Material, paßte es gegebenenfalls einem immer neuen zeitgenössischen Wissensstand an und kümmerte sich nicht um derartige Widersprüche, weil sie schlichtweg für die jeweils eigene Gegenwart keine Rolle spielten. In jedem Fall aber muß Liutwin Ende des 11. Jahrhunderts in Mettlach bereits über eine gewisse Bedeutung verfügt haben, sonst hätten die Ergänzungen in der Rolle nicht vorgenommen werden können.

477 Vgl. zum Mettlacher Kreuzreliquiar zuletzt SAuER, Fundatio, S. 306 ff. u. Abb. 66-68, sowie nochmals unten Kap. D.IX.4.b. Vgl. ferner RaACH, Mettlach, S. 90-92. Hlawitschka, Anfänge des Hauses Habsburg-Lothringen, S. 154 ff. Hlawitschka, Lotharingien und das Reich, S. 163 ff., identifiziert Stephan mit einem gleichnamigen Bildgaugrafen am Ende des 9. Jahrhunderts.

478 Die interpolierte Weihenotiz Rotberts für Udern bestätigt also keinen älteren Besitz Mettlachs an diesem Ort, vielmehr schafft bzw. erweitert sie - nimmt man sie wörtlich solchen erst. Vgl. dagegen noch RAACH, Mettlach, S. 94; ebd., S. 95, zu möglichen Besitzstreitigkeiten. Vgl. zum beschriebenen Vorfall 1264 das Regest bei Lager, Urkundliche Geschichte, S. 301. 
Daß das Liutwinpatrozinium in Mettlach überhaupt erst allmählich seit dem späten 11. Jahrhundert eine überragende Bedeutung für das Kloster erlangt haben kann, zeigen die weiteren Einräge der Güterrolle und dabei besonders die Traditionsnotizen. Auch das stellt ein Liutwinpatrozinium in Udern/Oudrenne und dessen so frühe Verbindung mit Mettlach in der Rotbert-Notiz in Frage.

In den von Perrin und Müller auf nach 995 datierten Nachträgen erscheint nämlich kein Liutwinfest mehr, wohl aber die Feste der hll. Martin, Andreas, Johannes, Peter und Paul, Remigius und Maximin. ${ }^{479}$ Auch in den Ergänzungen, die auf die zweite Hälfte des 11. Jahrhunderts datiert werden, fehlt ein Liutwinfest. Stattdessen werden erneut die Gedenktage der hll. Martin, Petrus, Andreas, Remigius und Johannes genannt. ${ }^{480}$ In den urbarialen Nachträgen anderer Schreiber des 12. Jahrhunderts finden sich ebenso keine Hinweise auf Liutwin mehr, sondern wieder nur die Festtage der hll. Andreas, Martin, Petrus und Paulinus. ${ }^{481}$ Auch die auf der Rückseite der Rolle hinzugefügten Traditionsnotizen erwähnen einen hl. Liutwin erst ab etwa 1125/6, dann jedoch nahezu ausschließlich und als wohl eigentlichen Klosterheiligen. ${ }^{482}$

479 Vgl. hier insgesamt MüLler, Mettlacher Güterrolle, S. 123 f., Nr. U 12, zu Roden, wo die Feste der hll. Martin, Andreas, Peter und Paul erwähnt werden. Ebd., S. 124, Nr. U 13, zu Bliesen nennt das Martinsfest. Ebd., S. 124, Nr. U 14, zu Wadern erwähnt das Remigiusfest. Ebd., S. 124 f., Nr. U 15, zu Rech erwähnt die Feste der hll. Remigius, Martin und Andreas. Ebd., S. 125, Nr. U 16, zu Losheim erwähnt die Feste der hll. Maximin und Martin.

480 Vgl. Müller, Mettlacher Güterrolle, S. 125-127, Nr. U 17-22. Ebd., S. 125, Nr. U 17, zu Roden erwähnt kein Heiligenfest. Ebd., S. 126, Nr. U 18, zu Trier, Alsdorf und Mötsch erwähnt die Feste der hll. Martin und Petrus. Ebd., S. 126, Nr. U 19, erwähnt kein Heiligenfest. Ebd., S. 126, Nr. U 20, zu Nieder- (Ober-)mennig und Wiltingen nennt das Fest des hl. Remigius. Ebd., S. 126, Nr. U 21, zu Damvillers und Ornes nennt die Feste der hll. Johannes und Remigius.

481 Vgl. MüLler, Mettlacher Güterrolle, S. 127-129, Nr. U 23-27. Ebd., S. 127, Nr. U 23, zu Vic und Tincry nennt keine Heiligenfeste. Ebd., S. 127 f., Nr. U 24, zu Ihn und Hemmersdorf erwähnt die Festtage der hll. Andreas und Martin. Ebd., S. 128, Nr. U 25, zu Kirsch erwähnt das Martinsfest. Ebd., S. 128, Nr. U 26, zu Nieder- (Ober-)mennig und Mötsch erwähnt die Festtage der hll. Petrus, Paulinus und Andreas. Ebd., S. 128, Nr. U 27, zu Beringen nennt das Fest des hl. Martin.

482 Vgl. MüLler, Mettlacher Güterrolle, S. 129-146, bes. S. 135 f., Nr. T 8, aus der Zeit von September 1125 bis September 1126, worin Gumpert von Thailen auf dem Totenbett sein Allod zu Thailen Mettlach vermacht: [...] et allodium suum, quod in Teilna possederat, super altare beati Livtwini pro salute anime sue tradidit constituens inde dari [...]. Hoc facto vitam finivit et infra monasterium beati Livtwini sepulture traditus est (ebd., S. 135). In ebd., S. 136, Nr. T 9, von um 1126 führt neben den noch zuerst genannten hll. Peter und Paul bereits Liutwin gleichwertig auf: Ego Lambertus decanus ex precepto domini mei corepiscopi et peticione domni abbatis et fratrum coram predictis testibus et hominibus eosdem duos mansos incolentibus traditionem istam auctoritate beatorum apostolorum Petri et Pauli et beati Livtwini et domni pape et domni archiepiscopi Godefridi banno confirmavi. Ebd., S. 136 f., Nr. T 10, (nach dem 12. September 1126) erwähnt 
Zuvor erfolgen Schenkungen an Mettlach - wenn ein Patrozinium genannt wird - nur über dem dortigen Altar des hl. Petrus. Ja, Mettlach selbst wird noch als Kloster des hl. Petrus bezeichnet. ${ }^{483}$ So geschieht es auch in einer Schenkung (1095-1123) eines Hezelo von Pachtern, der mit seinen Söhnen Landbesitz in Tünsdorf zum Seelenheil seiner verstorbenen Frau übergibt. Doch hierin trägt der Schreiber H des frühen 12. Jahrhunderts bezüglich der Gattin etwas später den Satz que iacet sepulta in monasterio sancti Liutwini über dem Ende der ersten Zeile nach. ${ }^{484}$ Erst etwa seit 1126 also setzt sich Liutwin als Hauptpatrozinium in Mettlach tatsächlich durch. ${ }^{485}$

Dies zeigt, daß man zunächst noch den hl. Petrus als wichtigeres Patrozinium betrachtete und Liutwin seine Bedeutung bei Schenkungen erst im frühen 12. Jahrhundert erhielt. Doch spricht das eher gegen einen bereits lange be-

nur eine capsam sanctarum reliquiarum (ebd., S. 136). Doch dann setzt sich Liutwin als Hauptheiliger durch. Ebd., S. 137, Nr. T 11, (um 1126) verzeichnet eine Übertragung super altare sancti Liutwini. Ebd., S. 137 f., Nr. T 12, (1124-1127) verzeichnet wieder eine Übertragung nur super altare sancti Liutuuini (ebd., S. 137) und ein Begräbnis in monasterio sancti Liutuuini (ebd., S. 138). Ebd., S. 138, Nr. T 13, (1127-1130) spricht von einem monasterio Mediolacensi et sancto Livtwino fratribusque inibi deo servientibus. Ebd., S. 139, Nr. T 14, (1125-1136) nennt wieder einen Altar des hl. Liutwin. Ebd., S. 139 f., Nr. T 15, (zwischen 1131 und 1137) nennt gar ein oratorio sancti Liutvvini (ebd., S. 139). Die Beispiele lassen sich nun für die weiteren, späteren Traditionsnotizen fortsetzen. Vgl. ebd., S. 141 ff., Nr. T 18 ff. Nur einige wenige Male tritt neben Liutwin noch Petrus als Heiliger auf, doch nimmt er gegenüber Liutwin eine geradezu verschwindend geringe Rolle ein. Vgl. dazu auch unten Anm. 485. - Vgl. dazu schließlich Becker, Mettlach, S. 517, der Liutwin erst ab dem 12. Jahrhundert als Patron nennt.

483 Vgl. MüLler, Mettlacher Güterrolle, S. 129 f., Nr. T 1, (1095) Bernewinus custos monasterii sancti Petri emit in villa Waltinga IIII obas de Hezelone et patre eius Heimone VII talentis, quas et ipsi apud furtam coram scabinis et omni familia beati Petri in communi placito presente Wirico aduocato, domno Liboni abbati deinde per manus eiusdem Wirici aduocati super altare beati Petri tradiderunt (ebd., S. 129). Hier wird deutlich, daß man in Mettlach als Hauptpatrozinium den hl. Petrus führte. Ebd., S. 130, Nr. T 2, (um 1095) erwähnt kein Patrozinium. Ebd., S. 130, Nr. T 3, (Anfang 12. Jahrhundert) nennt eine Übertragung super altare sancti Petri. Ebd., S. 130-134, Nr. T 4 f., (um 1120) nennen keinerlei Mettlacher Patrozinien. Zu ebd., Nr. T 6, wo auch nur Petrus genannt wird, vgl. unten Anm. 484 und den Text oben auf dieser Seite. Auch in ebd., S. 134 f., Nr. T 7, (1102-1124) wird lediglich super altare sancti Petri (ebd., S. 135) geschenkt. 484 Vgl. Müller, Mettlacher Güterrolle, S. 134, Nr. T 6, (1095-1123): Hezelo de Pahta tradidit presente domno Libone abbate super altare sancti Petri pro uxore sua Bvoda, que [...].

485 Allerdings findet sich auch noch eine Schenkung über dem Petrusaltar. Vgl. MüLler, Mettlacher Güterrolle, S. 140 f., Nr. T 17, (von 1131-1137) wobei sich die Frage stellt, ob der Editor hier eine korrekte zeitliche Einordnung vorgenommen hat. In ebd., S. 141 f., Nr. T 18, (13. März 1139-März 1140) wird Liutwin gemeinsam mit Petrus genannt, wobei Petrus erst nach ihm aufgeführt wird. Nur noch ebd., S. 144, Nr. T 25, (1157-1163) erwähnt eine Schenkung sancto Petro et sancto Liwtwino und stellt Petrus damit nochmals vor Liutwin. Doch wird Petrus eben nicht mehr, wie es noch im 11. Jahrhundert geschah, allein genannt. 
stehenden lokalen Liutwinkult in Mettlach, als vielmehr für einen erst kürzlich erfolgten erheblichen Bedeutungszuwachs Liutwins, der dadurch das Petruspatrozinium auf den zweiten Platz verdrängen konnte. Und auch das wirft Zweifel daran auf, ob sich die Weihe der Kirche in Udern zu Ehren des hl. Liutwin und die Verbindung mit diesem Parozinium tatsächlich schon in der Vorlage der Rotbert-Notiz aus der Mitte des 10. Jahrhunderts befand oder erst vom Kopisten Ende des 11. Jahrhunderts ergänzt wurde. (Vielleicht benutzte dieser auch schon eine interpolierte Vorlage.) Denn in dessen Zeit muß sich Liutwins wachsende Relevanz in Mettlach bereits abgezeichnet haben.

Zusammenfassend läßt sich sagen, daß die Mettlacher Güterrolle den Stand ab der Mitte des 11. Jahrhunderts wiedergibt und keine wirklich sicheren Angaben zu früheren Zeiten in Bezug auf Mettlach bieten kann. Das nur in den vermeintlich frühen Einträgen erwähnte Liutwinfest kann dorthinein frühestens ab dem späten 10. Jahrhundert interpoliert oder ergänzt worden sein, beeinflußt durch die dann beginnende Liutwinverehrung im Trierer Raum. Eine direkte Verbindung zu Mettlach wird bei diesem Fest nicht hergestellt. Vielmehr erscheinen ganz gleichwertig die Feste der hll. Martin, Remigius, Peter und Paul, Paulinus, Johannes sowie Andreas.

Daß Liutwin für Mettlach zunächst keine wirklich überragende Rolle zugekommen sein kann, läßt sich an den wenigen frühen Nennungen eines Liutwinfestes in dem vom Schreiber A verfaßten Teil erkennen (dreimal in 22 urbarialen Einträgen). Hinzu kommt eine Kirchweih mit einem Gottesdienst zu Liutwins Ehren in Udern/Oudrenne, von der eine Weihenotiz (zwischen 931 und 936) zu Erzbischof Rotbert berichtet, der diese Villa besaß und der die Kirche in Udern ihr zufolge mit dem dortigen Zehnt und weiterem Besitz ausstattete. Doch handelt es sich hier sowohl bei Liutwin wie beim Zehnt in Udern um Interpolationen in diese Notiz, spätestens des Schreibers A; vielleicht ist sogar das ganze Stück konstruiert. Ein früherer Eintrag der Rolle zeigt, daß Mettlach zwar über die Kirche in Udern mit einer größeren Ausstattung verfügte, aber ohne den dortigen Zehnt und ohne, daß ein Liutwinpatrozinium genannt wird. Vor allem der nachträgliche Einschub zu Liutwin ist so geschickt plaziert, daß der Eindruck entsteht, nicht Rotbert, sondern Liutwin selbst hätte Udern bereits besessen. Man strebte in Mettlach offensichtlich an, die Villa vollständig an das Kloster zu ziehen.

Die weiteren fünf urbarialen Einträge anderer und späterer Schreiber erwähnen Liutwin mit keinem Wort. Die ebenfalls auf der Rückseite der Rolle überlieferten Traditionsnotizen zeigen sogar, daß bis etwa 1126 bei Schenkungen an Mettlach der Petrusaltar verwendet wurde, man Mettlach sogar Kloster des hl. Petrus nannte. Erst seitdem wird Liutwin plötzlich massiv für diesen Zweck herangezogen und vom Liutwinkloster gesprochen. Petrus erscheint wenn überhaupt - nur neben Liutwin. Liutwin setzte sich also erst in dieser Zeit in Mettlach als Hauptpatrozinium durch. Auch das spricht für spätere Inter- 
polationen oder Ergänzungen des erwähnten Liutwinfestes in die angeblich frühen Vorlagen der Rolle und vor allem für einen Liutwinkult in Mettlach, der noch nicht lange verstärkt verbreitet war. Dieser muß jedoch zum Zeitpunkt der ersten Abfassung der Güterrolle in der zweiten Hälfte des 11. Jahrhunderts immerhin schon über eine gewisse Bedeutung verfügt haben.

\section{Die frühen Trierer Bischofslisten}

\section{Eine Weihenotiz aus dem Kloster St. Maximin von 952}

Daß Erzbischof Rotbert (931-956) aber von einem hl. Trierer Bischof Liutwin gewußt haben könnte, belegt eine Weihenotiz aus dem reichsunmittelbaren Kloster St. Maximin in Trier zum Jahr 952. Es ist die früheste Quelle überhaupt, die von Reliquien eines Bischofs Liutwin berichtet. Doch sie nennt keinen Bischof Basin.

Rotbert selbst war eine bedeutende Gestalt zu Beginn des 10. Jahrhunderts. Er wirkte zunächst als Erzkanzler für Lothringen unter König Heinrich I. (919936), schließlich 937-953 als Erzkanzler bzw. Erzkaplan Ottos I. (936-973). Ob er ein Bruder Mathildes (†968), der Gemahlin Heinrichs I., war, ist umstritten und wird inzwischen eher verneint. Rotbert griff maßgeblich in den Streit um das Reimser Bistum 946-948 zugunsten des von dort vertriebenen Erzbischofs Artold und gegen den neuen Inhaber Hugo ein. HeHL vertritt dazu die plausible These, Rotbert berufe sich hierbei u. a. auf einen Trierer Primat über Reims in der Belgica, wie ihn schon Thietgaud von Trier im 9. Jahrhundert beanspruchte. ${ }^{486}$

Die Annahme, Rotbert habe 953 seine herrschaftlichen Rechte über das reichsunmittelbare Kloster St. Maximin verloren, beruht auf einer um 1000 auf Otto I. in St. Maximin gefälschten Urkunde. Sie sollte - so KöLZER - vielleicht im Umfeld des Oerener Streites erhobene Ansprüche des Trierer Erzstiftes auf

486 Im Jahr 951 zog Rotbert auch mit Otto I. nach Italien. - Zu Rotbert vgl. insgesamt Goerz, Regesten der Erzbischöfe zu Trier, S. 3 f. Heit, Ruotbert, Sp. 1104. Persch, Ruotbert, Sp. 1112 f. Finck von Finckenstein, Bischof und Reich, S. 106-108. Gierlich, Grabstätten, S. 63 f. Bönnen, Trier zwischen dem 10. und dem beginnenden 12. Jahrhundert, S. 205, 210, 216, 218. - Gegen eine Verwandtschaft mit Mathilde vgl. Hlawitschka, Kontroverse, S. 33-54. - Zum Reimser Streit vgl. Hehl, Erzbischof Ruotbert, S. 55-68. - Otto I. könnte Rotbert 947 die Herrschaftsrechte bestätigt haben, doch ist das umstritten. Zur Bestätigung der Herrschaftsrechte vgl. das nur in den Balduineen überlieferte DOI. 86, S. 168 f. Thomas, Ein kaisergleicher König, S. $91-$ 103, weist es als Fälschung des Mönchs Theoderich aus St. Eucharius in Trier nach. Zum Trierer Primat über Reims unter Thietgaud im 9. Jahrhundert vgl. bereits ausführlich oben Kap. C.III.4. 
St. Maximin abwehren und trage prophylaktischen Charakter. Denn die im Trierer Erzstift während des Streites gefälschten und schon besprochenen Urkunden über Modoald als Gründer Oerens enthielten ebenso die Bemerkung, St. Maximin sei auf dem Besitz der Trierer Kirche gegründet worden. Und wir haben im Zusammenhang mit den Mettlacher Diplomen gesehen, daß diese den Modoald-Urkunden inhaltlich nahe stehen und einige von ihnen vielleicht zur selben Zeit konstruiert worden sind, sie andernfalls aber einer ähnlichen Intention folgend verfälscht wurden. ${ }^{487}$ Besteht also eine Gemeinsamkeit zwischen den konstruierten Trierer Besitzansprüchen auf diese Klöster?

487 Zum Entzug der Rechte über das Kloster St. Maximin vgl. MRUB I †196, S. 256 f. DOI. †169, S. 250 f. Die Urkunde ist als Fälschungsoriginal erhalten. Zur Urkunde vgl. Wisplinghoff, St. Maximin bei Trier, S. 136 ff., der sie noch für echt hält. Eine Abbildung findet sich bei KöLzer, Studien, S. 44-57, 107-110, Taf. 6, der sie überzeugend als Fälschung vom Ende des 10. Jahrhunderts in St. Maximin nachweist. Die Rahmenurkunde vom gleichen Tag sei wohl echt, beziehe sich aber lediglich auf den im Diplom erwähnten Fischfang in der Ruwer und nicht auf Herrschaftsrechte über das Kloster. Die Fälschung erfolgte wohl parallel zu den Interpolationen desselben Schreibers in DArn. 114, DZw. 14, DKdE 69 und der Fälschung von DOI. †179. Freise, Merita patroni, will als ihren Fälscher Sigehard, den Verfasser der Miracula S. Maximini, erkennen, der im ausgehenden 10. Jahrhundert Abt von St. Eucharius war (vgl. dazu Heyen u.a., Trier, St. Maximin, S. 1020 u. Anm. 85). Vgl. zu den Miracula und Sigehard unten Anm. 489. Nach Kölzer, Studien, S. 57 ff. u. 109 f., wurde die St. Maximiner Abwehr gegen das Trierer Erzstift noch unterstützt durch eine gleichzeitig auf 950 gefälschte Urkunde Papst Agapets II. (946-955) (JL †3649). Vgl. dazu ZImmermann, Papsturkunden I †121, S. 212-214. Germ. Pont. 10, St. Maximin †5, ed. Bosнof, S. 201 f. Zwei Maximiner Mönche führen darin Klage gegen den Trierer Erzbischof Rotbert, der dem Kloster St. Maximin großen Schaden zufüge. In Rom entscheidet man deshalb, St. Maximin unterstehe nur dem König und dem selbst gewählten Abt. Dem Erzbischof und seinen Nachfolgern wird sogar bei Zuwiderhandlung mit Exkommunikation gedroht. - Zum Streit um Oeren vgl. nochmals oben S. $174 \mathrm{ff}$. Zum Bezug der St. Maximiner Fälschungen um 1000 zum Oerener Streit vgl. auch Kölzer, Studien, S. 69-89, 110-116, bes. auch S. 79. Dort weist er schon auf die bereits oben besprochenen - in Trier manipulierten Modoald-Oeren-Urkunden hin (DMerowinger I †32, DDKarol. I †36 u. †226). Diese Trierer Fälschungen sprechen nicht nur von einer Gründung Oerens durch Modoald, sondern auch einer bereits frühen Zugehörigkeit St. Maximins zum Trierer Erzstift. Die St. Maximiner KarolingerFälschungen DDKarol. I $\uparrow 39, \uparrow 276$ sowie $\mathrm{BM}^{2} \uparrow 754$, $\uparrow 755$ und DLoII. $† 39$ dagegen sind nach Kölzers minutiöser Beweisführung nicht schon im 10. Jahrhundert entstanden, sondern vielmehr erst zwischen 1056/65-1075/80 als Reaktion auf erneute und spätere Ansprüche des Trierer Erzbischofs. Die Maximiner Karolinger-Spuria betonen jetzt nämlich St. Maximins Position als Königsgut bis zurück in die Zeit Pippins und dessen Vorgänger. Das Kloster sei unmittelbar dem Abt untergeordnet. Abt und Kloster unterstünden wiederum dem mundiburdium des Königs. Die Diplome gingen also einen Schritt weiter. In diesen Zusammenhang gehöre auch das (bis 1084) entstandene St. Maximiner Merowinger-Spurium DMerowinger I $† 29$ als inhaltliche Reaktion auf das Trierer DMerowinger I †32. Die St. Maximiner machten darin jetzt endlich ihr Kloster zu einer Gründung Kaiser Konstantins als Johanneskirche. 
Rotbert pflegte Kontakte mit Flodoard von Reims (†966), einem Kleriker des Reimser Bischofs Artold, zugleich einem Beteiligten und Chronisten des Reimser Streites sowie dem Verfasser der „Reimser Kirchengeschichte“ und der Reimser Annalen. ${ }^{488}$ Deshalb ist es nicht unwahrscheinlich, daß Reimser Traditionen, die über Trier berichteten, nach Trier gelangten - wie eben Hinkmars Bild des Doppelherrschers Milo über die beiden Bistümer. Allerdings finden sich noch keine Reaktionen darauf in den Trierer Quellen.

Es hat sich nun eine Notiz erhalten über die Weihe eines doppelstöckigen Neubaus einer Außenkrypta in St. Maximin und die darin errichteten Altäre. Als Datum gibt die Notiz das Jahr 952 an. Bereits um 934 begannen in St. Maximin die Bauarbeiten an einer großen und beeindruckenden ottonischen Klosterkirche nach der Zerstörung des Vorgängerbaus. Ihre Ausmaße sind inzwischen durch Grabungen gesichert. ${ }^{489}$ Daran schloß sich im Osten besagte Außenkryptenanlage an, die sich inzwischen ebenfalls archäologisch genau rekonstruieren läßt. ${ }^{40}$ Der älteste Nachweis dieser Notiz allerdings findet sich in einer ehemals St. Maximiner, jetzt in Paris aufbewahrten Handschrift auf einer herausgerissenen und beschädigten Seite, ergänzt von einer Hand des 12. Jahrhunderts. Vor und nach ihr steht nur noch fragmentarischer Text mit Angaben zu anderen Weihen in dieser Kirche. ${ }^{491}$ Der Trierer Alexander Wiltheim verwendete um die Mitte des 17. Jahrhunderts diese Handschrift und eine zweite, inzwischen verschollene in seinem Werk „Origines et annales coenobii $S$. Maximini“. ${ }^{492}$ Aus dem zweiten Kodex übernahm er dann vollständig die im ersten nur bruchstückhaften Stellen der weiteren Weihen. Diese zweite Handschrift tauchte offenbar im späten 19. Jahrhundert bei einem Pfarrer Nick wieder auf, der sie ins 11. Jahrhundert datierte. Doch verschwand sie bald

$488 \mathrm{Zu}$ Flodoard vgl. bereits ausführlicher oben Kap. B.IV. u. C.III.12.

489 Vgl. dazu Neyses, Baugeschichte, S. 100-190. Zur Klostergeschichte vgl. WisplingHOFF, St. Maximin bei Trier, S. 31 ff., zu den Äbten S. 49 ff., der allerdings durch die Erkenntnisse von KöLzer, Studien, S. 29-117, in vielen Stellen revidiert wird. Als Quelle zur Klostergeschichte dienen u. a. Sigehard, Miracula S. Maximini, ed. Henschen, die dieser Mönch um 962/3 verfaßte. Vgl. dazu Wattenbach-HoltzmannSchmale, Geschichtsquellen 1,2, S. 172 f. - Vgl. schließlich zu diesem Teil der Geschichte St. Maximins auch Heyen u.a., Trier, St. Maximin, S. 1017 ff., 1047 ff., $1064 \mathrm{ff}$.

490 Vgl. Neyses, Baugeschichte, S. $139 \mathrm{ff}$.

491 Vgl. Notae S. Maximini Treverensis, ed. Waitz, S. 967.

492 Das Werk Wiltheims ist als Handschrift Trier, Rheinisches Landesmuseum, M1 (zuvor: Trier, Stadtbibliothek, 1621,2) erhalten. Vgl. zu dieser Handschrift und der weiteren Überlieferung der Weihenotizen auch ausführlich NeysEs, Baugeschichte, S. 157-168. 
wieder. Das Original der ursprünglichen Weihenotizen kann sie aber nicht gewesen sein. ${ }^{493}$

Die entsprechende Stelle der Handschrift enthielt zunächst Angaben zur Weihe des fertiggestellten Mönchschors der neuen Klosterkirche von St. Maximin mit dem Hochaltar zu Ehren des hl. Johannes sowie weiterer Altäre am 13. Oktober 942. Die Bischöfe Rotbert von Trier und Adalbero von Metz (929-962) nahmen sie unter Abt Ogon vor. Die leiblichen Überreste der frühen Trierer Bischöfe Agricius, Maximinus und Nicetius überführte man in die neue Innenkrypta und setzte sie in drei Steinsarkophagen bei. Es folgt eine Nachricht über weitere Weihen in der Kirche am 29. September 949 unter dem Abbatiat des Willer (945-957). Sodann schließt sich die besagte Notiz zur Weihe der Außenkrypta 952 an. Nach ihr stehen noch zwei Einträge, der eine über die Weihe eines Oratoriums als Abtkapelle zur Zeit Erzbischof Poppos (1016-1047) am 2. März 1018 sowie der andere über die Konsekration eines Oratoriums am 9. Januar 1072. ${ }^{494}$

Nun zur uns interessierenden Notiz: Im Jahr 952 erfolgte unter Abt Willer und auf Anordnung Erzbischof Rotberts die Weihe des Obergeschosses der Außenkrypta zu Füßen der hll. Bekenner Maximin, Agricius und Nicetius sowie eines Altares in (der Mitte) dieser Oberkrypta mit einem Salvator- sowie Allerheiligenpatrozinium. Es werden Reliquien aufgezählt, die man hineingelegt habe. Zu dessen Rechten sei ein Altar des hl. Sixtus geweiht worden, in dem sich dessen Reliquien und die weiterer Heiliger befänden. Zur Linken sei ein Altar zu Ehren des hl. Benedikt, der seine sowie weitere Reliquien enthalte. Der Altar, der sich genau zu Füßen der hll. Bekenner Maximin, Agricius und Nicetius befinde, sei zu Ehren der Trierer Bischöfe geweiht. Neyses lokalisiert ihn in der Innenkrypta direkt vor den drei Sarkophagen, unter der Chorapsis. Im Osten stoße der Bereich an das Untergeschoß der Außenkrypta. Der Altar enthalte nach der Notiz - Reliquien von Eucharius, Valerius, Maternus, Agricius, Maximin, Nicetius, Paulinus und Liutwin sowie Reliquien der hll. Quiriacus, Lubentius und Maxentius. Es folgen dann die Altäre der Unterkrypta. Am selben Tag sei in der Unterkrypta rechts des Eingangs ein Altar des hl. Papstes Kalixtus (217-222) geweiht worden, in dem sich seine und andere Reliquien

493 Vgl. Neyses, Baugeschichte, S. 157, 168. Die Publikation des Pfarrers Nick zu den ältesten bekannten Altarweihen in St. Maximin findet sich bei Nick, Altarweihen, S. $82-87$.

494 Während Wiltheim seine Vorlagen sorgfältig kopierte, hatte sie schon etwa hundert Jahre zuvor Nicolaus Novillanius in seinen Gesta der Äbte von St. Maximin benutzt, daran aber Ergänzungen und Veränderungen vorgenommen. Bei ihm ist noch eine weitere Weihenotiz zum Jahr 1231 erhalten. Das Werk von Novillanius ist in der Handschrift Trier, Stadtbibliothek, 282/1629, erhalten. Vgl. zur Handschrift Keuffer, Beschreibendes Verzeichnis 3, S. 79. Becker, St. Eucharius, S. 220, Nr. 362. Vgl. insgesamt Notae dedicationum s. Maximini Treverenis, ed. Sauerland, S. 1269-1272. 
befänden. Vier weitere Altäre werden beschrieben, einer davon ein Marienaltar in der Mitte der Unterkrypta. Es ist dabei schwer vorstellbar, daß alle Altäre mit so unzähligen Reliquien gleichzeitig in einer Messe konsekriert wurden. Vermutlich weihte man sie einzeln oder zunächst nur die Hauptaltäre und ließ dabei die Reliquien der Heiligen ein. Wahrscheinlich ist ferner, daß man beim Fortschreiten der Bauarbeiten immer wieder Weihen vornahm. Darauf deutet auch hin, daß entgegen den anderen Notizen kein genaues Tagesdatum, sondern nur ein Jahr (952) genannt wird. Binding spricht dazu von Weihen auf der Baustelle. Dies könnte zutreffen, denn die Notiz sagt nichts darüber, wie weit die Bauarbeiten gediehen oder ob diese bereits abgeschlossen waren. ${ }^{495}$

495 Vgl. Notae dedicationum s. Maximini Treverensis, ed. Sauerland, S. 1270 f.: Anno ab incarnatione Domini 952, abbate Willero regimen monachile gubernante, Ruperto vero presulatum disponente, dedicata est cripta superior ad pedes sanctorum confessorum Maximini, Agricii, Nicecii, et altare in ea in honore domini Salvatoris nostri et omnium sanctorum; atque in ipsum positae sunt reliquiae de mensa Domini in Chana Galileae, de pallio sanctae Mariae, de cruce Domini, de presepio Domini, de sepulchro Domini, de capillis sancti Petri, de corpore sancti Laurencii, de corporibus sanctarum Priscillae et Aquilae et aliorum multorum. A dextris huius altaris sanctificatum est altare sancti Sixti; in quo habetur de corpore eius, de corpore sancti Laurencii, de capite sancti Ypoliti et reliquiae sancti Quintini et sancti Clementis, de costa sancti Ciriaci, sancti Pancracii, sancti Georgii, sancti Simphoriani. A sinistris vero est altare in honore sancti Benedicti; in quo continentur reliquiae eius et sancte Scolastice, sororis ipsius, sancti Columbani, sancti Galli, sancti Wichberti, sancti Dissibodi, sancti Florini. Altare quod est ad pedes sanctorum confessorum M[aximini], A[gricii], N[icecii] sacratum est in honore episcoporum Treverensium; ac reliquie ipsorum in illo Eucharii, Valerii, Materni, Agricii, Maximini, Nicecii, Paulini, Liutwini, et reliquie sancti Quiriaci, Lubentis, Maxencii. I In inferiori cripta ipso die consecratum est altare sancti Calixti pape ad dexteram intrantibus; in quo est de corpore eius et reliquiis sanctorum Bonefacii, Cosme et Damiani, Iuliani, Modesti, Crescenciae, Valentini, Felicis, Adaucti, Ianuarii. Iuxta illud altare est ara sancti Mauricii; in qua eius reliquie sunt ac sanctorum Gereonis, Dionisii sociorumque eorum et sanctorum Marcelli, Vincencii, Apollinaris. I In medio supradictae inferioris criptae habetur altare sanctae Mariae genitricis domini nostri Ihesu Christi; ibique continentur reliquiae sancti Stephani papae et martyris et sanctae Felicitatis et septem filiorum eius. A sinistris vero huius consecratum est altare sancti Sebastiani, ipsius habens reliquias, de corporibus sanctorum Gervasii et Prothasii, Crisanti et Dariae, Proti et Iacincti, Gorgonii et sanctorum confessorum Ambrosii, Willibrordi, Amandi, Germani, Castoris. Prope illud est positum altare in honore sanctarum virginum, in quo sunt reliquie sancte Felicitatis, de corpore sanctae Agnetis, sanctae Ceciliae, sanctae Luciae, sanctae Walgisgae, sanctae Modestae, sanctae Brigidae, sanctae Agathae, sanctae Helenae, sancate Aldegundis. - Eine Edition unter Einbeziehung der Veröffentlichung des Pfarrers Nick findet sich auch bei NeYses, Baugeschichte, S. 157 ff., bes. S. 158 f. Zur genauen Lage des Altars der Trierer Bischöfe zu Füßen der drei Sarkophage vgl. ebd., S. $161 \mathrm{f}$. Offenbar bestand eine Fensternische zwischen beiden Anlagen zur Durchsicht. - Zur Kirchbzw. Altarweihe vgl. Benz, Kirchweihe, 1. Liturgie. Binding, Kirchweihe, 2. Baugeschichtlich. Als Beispiele für den Weiheritus dieser Zeit vgl. Vogel/Elze, Pontifical romano-germanique 1, Nr. XXXIIIff., S. 82 ff. Die Belege zeigen, wie die Altarweihe und Reliquienversenkung im Altar im Rahmen einer feierlichen Messe nach entsprechendem Ordo zelebriert wurden. 
Die Frage ist nun, wo dieser Text seinen Ursprung hatte. Befand er sich als Inschrift in der Nähe der Altäre oder in der Krypta und wurde dann in eine Handschrift übernommen? Doch welchem Nutzen hätte dies gedient? Oder handelte es sich um eine notizhafte, berichtende, urkundenähnliche Aufzeichnung, die ins St. Maximiner Archiv, vielleicht sogar darüber hinaus gelangte? Zeugen nennt sie jedenfalls keine. Neyses spricht von einem eher erzählenden Charakter. ${ }^{496}$ Die recht genauen Angaben, die in großen Teilen durch die Grabungsergebnisse bestätigt worden sind, legen zwar eine relativ zeitgenössische Entstehung nahe. Die Art der handschriftlichen Überlieferung schließt aber nicht aus, daß zu den Angaben und aufgeführten Heiligen später noch weitere ergänzt wurden. Darauf deuten Formulierungen dieser Notiz und auch derjenigen zum Jahr 949 hin. Die Notiz zum Jahr 949 spricht nämlich zunächst von der Weihe dreier Altäre, zählt diese dann auf und nennt den genauen Weihetag. Sodann aber ergänzt sie noch die Lage von fünf weiteren Älteren, die sich in deren Nähe befänden und nennt deren Reliquien. Diese fünf können kaum gleichzeitig mit den ersten dreien geweiht worden sein. Vielmehr müssen sie erst später hinzugekommen sein, und man ergänzte sie danach in der Notiz oder bei ihrer Abschrift an dieser Stelle aufgrund ihrer Lage und wohl auch ihre Reliquien.

Ganz ähnlich ist die Notiz zum Jahr 952 aufgebaut. Sie spricht zunächst nur von der Weihe der Oberkrypta und des Altars mit Salvator- und Allerheiligenpatrozinium, also des zentralen Altars. Daß die drei aufgeführten weiteren Altäre gleichzeitig geweiht wurden, ist eher unwahrscheinlich. Vielmehr wird - wie schon bei der Ergänzung zu 949 - deren Lage im Verhältnis zu dem zunächst genannten zentralen Altar beschrieben. Sie können also schon früher während des Baues geweiht worden sein, aber ebenso erst einige Zeit (vielleicht sogar Jahre) später. Gleiches gilt für die so zahlreichen Reliquien, die nach und nach ergänzt worden sein können. Die Ausführungen zur Unterkrypta klingen in diesem Zusammenhang geradezu angehängt und belegen, daß in den ursprünglichen Text der Notiz zweifellos eingegriffen wurde. Denn wenn der jetzt aufgeführte Kalixtusaltar „am selben Tag“ geweiht wurde, muß die ursprüngliche Notiz einmal eine genaue Tagesangabe enthalten haben, die heute fehlt. Oder man ergänzte die Weiheangabe mit dieser Wendung, ohne sich daran zu stoßen, daß ein Tagesdatum fehlte. Denkbar wäre, daß der Papstaltar gleichzeitig mit dem zentralen Altar der Oberkrypta konsekriert wurde und die weiteren Altäre der Unterkrypta später oder bereits früher hinzukamen. Denn auch bei diesen wird wieder die relative Lage beschrieben. Da die Unter- aber vor der Oberkrypta fertiggestellt worden sein muß, dürfte sie tatsächlich bereits früher geweiht worden sein. Der in ihrer Mitte gelegene Marienaltar wird ihr

496 Vgl. Neyses, Baugeschichte, S. 168. Zum Charakter einer Notiz/notitia vgl. nochmals Zielinski, Notitia. Gawlik, Privaturkunden. 
Hauptaltar (das Pendant des Salvator- und Allerheiligenaltars im oberen Stockwerk) gewesen sein. Auf eine vorausgehende Weihe der Unterkrypta verweist ohnehin, daß die Notiz eigentlich zentral von der Weihe der Oberkrypta spricht. So wäre diese Notiz - und wären wohl ähnlich die anderen mit ihr überlieferten Notizen - bereits eine nachträglich ergänzte und ausgeschriebene Fassung eines ursprünglich weitaus kürzeren Textes (wohl aus St. Maximin), der jetzt als Lage- und Reliquienbeschreibung dieses Klosters dienen sollte. Altäre und Reliquien, die neu hinzugekommen waren, hatte man einfach noch eingefügt. ${ }^{497}$

Bedenkt man ferner, daß sich nach Neyses der Altar der Trierer Bischöfe, der eine Liutwinreliquie beherbergen soll, nicht einmal in der Außen-, sondern der Innenkrypta befand, wird er wohl kaum gleichzeitig geweiht worden sein. Auch dies dürfte später, nach Abschluß der Bauarbeiten geschehen sein. Und eine Garantie, daß sich alle für den Altar aufgeführten Reliquien von Anfang an darin befanden, gibt es nach dem eben beschriebenen Gesamtbefund für die Notiz kaum.

Wäre diesen Angaben aber zu trauen, so böte sich mit ihnen so etwas wie die früheste Trierer Bischofsliste überhaupt, die zudem erstmals Liutwin nennte, nicht aber Basin. Was aber machte Liutwin dann so verehrungswürdig, daß seine Reliquien neben denen seiner Amtsvorgänger in einem Altar in St. Maximin eingelassen wurden? Spuren seiner Kanonisierung finden sich in der Mitte des 10. Jahrhunderts noch nicht. Die Reihenfolge der Bischöfe entspricht aber schon fast der Chronologie, wie sie die späteren Trierer Bischofslisten präsentieren werden, zu denen wir gleich noch ausführlicher kommen. ${ }^{498}$ Le-

$497 \mathrm{Zu}$ den Grabungsergebnissen vgl. nochmals oben Anm. 489 f. - Zur Notiz zum Jahr 949 vgl. Notae dedicationum s. Maximini Treverensis, ed. Sauerland, S. 1270: Anno ab incarnatione Domini 949, abbate Willero, erudito admodum viro, ipsum coenobium sapienter regente, consecratae sunt 3 arae in iam dicta basilica. Una, quae ad sanctam Crucem dicitur, in qua habetur de cruce Domini, de sepulchro, de praesepe, de capite sancti Iohannis baptistae, de columna ad quam ligatus est Dominus. Ad occidentalem partem ecclesiae a dextris locata est ara sancti Gregorii papae, continens ipsius reliquias et sancti Remigii et septem Dormientium. A sinistris vero tertia posita est ara sancti Stephani protomartyris, eius habens reliquias et sancti Laurentii, Vincentii, Lamberti. Istae ergo arae benedictae sunt 3. Kal. superius notato. I A dextris ipsius arae quae dicitur ad sanctam Crucem est altare, in quo habentur reliquiae sanctorum martyrum [Nerei, Achillei, Pancratii, Sebastiani, Ciriaci, Marci et Marcelliani. A sinistris autem est altare, in quo sunt reliquiae sanctorum martyrum] Cosmae et Damiani, Clementis, Nicasii et Eutropiae, sororis eius. In turri vero contra aram sanctae Crucis est altare in honore sancti Michaelis archangeli, continens reliquias Iohannis et Pauli martyrum, sancti Maxentii confessoris, de presepio Domini, de sepulchro Domini. A dextris huius arae est altare habens reliquias sanctorum apostolorum Bartholomei, Philippi et Iacobi, Thomae et Iacobi, fratris sancti Iohannis euangelistae. A sinistris vero est ara habens reliquias sanctorum Simonis et Iudae et omnium apostolorum. - Zur Notiz zum Jahr 952 vgl. nochmals oben Anm. 495.

498 Vgl. dazu unten Kap. D.IV.3.ff. 
diglich Nicetius und Paulin sind vertauscht. Während hier noch Nicetius vor Paulin auftritt, wird er später hinter ihn rücken. Man verfügte also in Trier zu den frühen eigenen Bischöfen über eine Überlieferung, während sie noch für zahlreiche andere fehlte. Bis auf Nicetius, der im 6. Jahrhundert lebte, und dem späteren Liutwin fallen die Amtszeiten der anderen Bischöfe alle in das 3. und 4. Jahrhundert. Eucharius und Valerius sollen die beiden ersten Trierer Bischöfe gewesen sein. ${ }^{499}$

Was jedoch bewahrte die Erinnerung ausgerechnet an diese acht, und warum finden sich keine weiteren Namen? Dazu ist die Suche nach einem verbindenden Element notwendig. Dieses besteht tatsächlich: die Verfügbarkeit von Reliquien. Sie bietet den Schlüssel. Denn von den hier genannten Bischöfen existierten im 10. Jahrhundert bekannte Gräber oder für solche gehaltene Orte. Die Bestattungsplätze der anderen frühen Trierer Bischöfe dagegen waren zu dieser Zeit unbekannt. ${ }^{500}$ Bei den acht Namen sind drei Gruppen zu unterscheiden: 1. Die Gruppe der Bischöfe, deren Gräber sich in der Kirche St. Eucharius befanden: Eucharius, Valerius und Maternus; 2. die Bischöfe, die man für in St. Maximin bestattet hielt: Agricius, Maximin und Nicetius; 3. Paulin und Liutwin.

Geht man von dieser Aufteilung nach Grabkirchen aus, erklärt sich plötzlich, warum Paulin und Nicetius vertauscht wurden. Denn Nicetius wurde, obwohl nach Paulin verstorben, auch in St. Maximin begraben. So nannte man diese Gruppen in der Weihenotiz jeweils nach der Grabkirche zusammenhängend. Daß man für Eucharius, Valerius und Maternus schon im 8./9. Jahrhundert von einer gemeinsamen Bestattung ausging, belegt die schon erwähnte ältere Maximin-Vita. Sie berichtet, die Gräber hätten sich nahe der Stadt in einer Kirche befunden, die von einem der drei gebaut worden sei. ${ }^{501}$ Ähnlich

499 Vgl. zu diesen Bischöfen zusammenfassend die Literatur bei PAuly, Geschichte des Bistums Trier 2, S. 11-23, 31 f. W InHELLER, Lebensbeschreibungen, S. 3-9 (Nicetius), 10-27 (Maximin), 28-55 (Eucharius, Valerius und Maternus), 121-145 (Agricius). Duchesne, Fastes 3, S. 34 f., 37 f. Ewig, Trier, S. 29-50, 97-106. Gauthier, Évangélisation, S. 43-58, 172-188. AnTon, Trier im frühen Mittelalter, S. 66-81, $98-$ 100, 131-138. Binsfeld, Geschichte des Bistums Trier, S. 28 ff., 48 ff. (Eucharius, Valerius, Maternus, Agricius, Maximin, Paulin). Pfeiffer, Die frühere fränkische Zeit, S. 202 ff. (Nicetius). Bauer, Lotharingien, S. 430-437 (Maternus). Pfeiffer, Mission, S. 191 - 196 (Maternus). BAuER, Verehrung heiliger Trierer Bischöfe, S. 354-367, 386390. Vgl. ferner Felten, Benediktiner II, S. 3-5.

$500 \mathrm{Vgl}$. dazu insgesamt Gierlich, Grabkirchen, S. $14 \mathrm{ff}$.

501 Vgl. Vita sancti Maximini episcopi Trevirensis cap. 7, ed. Henschen, S. 22E-F: S. Paulinus igitur civitatis Antistes, in basilicam S. Ioannis, quam antecessores ejus aedificaverant, ferri eum imperavit. Videlicet SS. Eucharius, Valerius, atque Maternus alium illic praeparaverunt sibi locum ad quiescendum: ibique vir beatissimus in ecclesia, cujus superius meminimus, honorifice conditus est. At Sancti Eucharius, Valerius, Maternus ex altera 
berichtet die zwischen 900 und der Mitte des 10. Jahrhunderts in Trier verfaßte Vita Eucharii, Valerii et Materni, die drei lägen in einer Kirche südlich Triers, außerhalb der Mauern. ${ }^{502}$ Daß Agricius, Maximin und Nicetius gemeinsam in der Krypta der eigentlichen Hauptkirche bestattet wurden, belegen sowohl die Weihenotizen zu 942 und 952 als auch der Grabungsbefund, der eine solche Mehrfachgrabanlage dort nachweist. ${ }^{503}$

quiescunt parte civitatis, infra ecclesiam quam sibi procul a civitate mirabili construxerunt opere. - Zur Vita vgl. bereits oben Kap. D.III.3.

502 Vgl. Vita Eucharii, Valerii et Materni IV,17, ed. Bolland, hier S. 921: [...], \& corpus eius in ecclesia, quae est extra moenia ciuitatis ad meridianam plagam sita, cum hymnis \& piis lacrymis sepulturae tradiderunt. - Zur Vita vgl. WattenbaCH-Holtzmann-Schmale, Geschichtsquellen 3, S. 57* (zu ebd. 1, S. 172 letzte Z.) (BHL 2655-2657). WINHeLler, Lebensbeschreibungen, S. 28-32, 36-45. Die Vita betone die Trierer Primatsansprüche. Die beiden ältesten Handschriften der Vita stammen aus dem 10. Jahrhundert. Es handelt sich um die Handschrift Brüssel, Bibliothèque Royale de Belgique, II 976 (Phillipps 367; de Gheyn 1370), fol. $114^{\mathrm{r}}-126^{\mathrm{r}}$, geschrieben im Zeitraum von 975-993 in Trier, aus St-Ghislain (sie enthält auch die älteste Trierer Bischofsliste, vgl. dazu unten bei und Anm. 585). Vgl. zu dieser auch De GheYn, Catalogue 2, S. 302 f. Hoffmann, Buchkunst 1, S. 499. Ferner handelt es sich um den Kodex Paris, BN, lat. 10864, fol. $1^{\mathrm{r}}-15^{\mathrm{r}}$, aus dem 10. bis 13. Jahrhundert aus Echternach. Zur Pariser Handschrift vgl. Delisle, Inventaire (1863), S. 97. Hoffmann, Buchkunst 1, S. 448-450, 502, meint (ebd., S. 502), die Hand A, die nur die Vita schrieb, aber auch Hand B (fol. $15^{\mathrm{v}}-29^{\mathrm{r}}$ ) und D (fol. $96^{\mathrm{r}}-118^{\mathrm{v}}$ ) ähnelten der Haupthand des Echternacher Kodex' Paris, BN, lat. 9433 (Echternacher Sakramentar) und seien deshalb schon „um 900 in Echternach anzusetzen“. Auch BAUER, Lotharingien, S. 418-427, geht von einer früheren Datierung (nach 900 bzw. erstes Drittel des 10. Jahrhunderts) als die jüngere Forschung aus, die die Vita zuletzt in die Mitte des 10. Jahrhunderts datiert hat. Zur Forschungsliteratur vgl. ergänzend ebd. Zum Echternacher Sakramentar vgl. ferner Hoffmann, Buchkunst 1, S. 448, 476, 485, 502, 511. - Doch warum sollten hier Echternacher Schreiber nicht später in Trier tätig gewesen und die Texte dann nach Echternach gelangt sein? - Vgl. ferner Thomas, Studien, S. 158. Zum Begräbnisort der drei vgl. auch Gierlich, Grabkirchen, S. 14-20. Becker, St. Eucharius, S. 384-392. - Daß die Kirchen für Eucharius und Maximin bereits im 6. Jahrhundert bestanden, belegt ein Hinweis bei Gregor von Tours, Liber vitae patrum XVII,4, ed. KRusCH, S. 731: Ad unam enim portam Eucharius sacerdos observat, ad aliam Maximinus excubat, in medio versatur Nicetius; [...].

503 Vgl. dazu nochmals Anm. 494 f. Zu den Gräbern der drei vgl. auch Gierlich, Grabkirchen, S. 21-26, 42 f. Zur Kirche vgl. ebenso Pauly, Geschichte des Bistums Trier 1, S. 72-75. Zum Grabungsbefund der Innenkrypta vgl. Neyses, Baugeschichte, S. 133139 u. Abb. 68. - Beide Kirchen entstanden wohl auf spätantiken Gräberfeldern mit überwiegend christlichen Bestattungen. Vgl. dazu GierLich, Grabkirchen, S. 15 f., zu St. Eucharius, sowie Neyses, Baugeschichte, S. 20 ff., zu St. Maximin. Vgl. zuletzt insgesamt Weber, Archäologische Zeugnisse, S. 450 ff., 523 ff. - Für St. Eucharius wurde dies durch neueste Grabungen (2005) noch einmal bestätigt. Der dortige Friedhof stammt wohl noch aus der Zeit, bevor das Christentum unter Kaiser Konstantin im frühen 4. Jahrhundert römische Staatsreligion wurde. Vgl. dazu hier nur die Meldung „Erster christlicher Friedhof Deutschlands entdeckt" bei SPIEGEL ONLINE vom 21. 
Es bleiben Paulin und Liutwin. Paulin wurde 353 auf einer Synode in Arles exkommuniziert und von Kaiser Constantius (337-361) nach Phrygien verbannt, wo er starb. Dann schweigen die Quellen, bis sich um 600 der Nachweis des Festes seiner Trierer depositio findet. Fraglich bleibt aber, ob seine Leiche tatsächlich nach Trier zurückkehrte. ${ }^{504}$ Schon die ältere Maximin-Vita nennt ihn als Heiligen. ${ }^{505}$ Regino von Prüm spricht in seiner Chronik endlich von einer Rückführung Paulins von Phrygien nach Trier. Wußte er mehr? Hatte vielleicht der ihm vertraute Trierer Erzbischof Radbod die Finger im Spiel? Reginos Fortsetzer, der Weißenburger Abt und ehemalige St. Maximiner Mönch Adalbert, fügte zum Jahr 969 hinzu, die Leiche des Heiligen schwebe noch zu seiner Zeit in einer Krypta ohne Stütze in der Luft. ${ }^{506}$ Die noch etwas jüngere erste Vita Paulini aus der zweiten Hälfte des 10. Jahrhunderts schildert schließlich auch die Rückführung des Leichnams und benutzte als Vorlage die Translation des verstorbenen Maximin aus Aquitanien nach Trier in dessen Vita I. In der Vita Paulini wird erstmals St. Marien/St. Paulin nördlich vor Trier als Grabort genannt. ${ }^{507}$ Man hat somit Paulin im 10. Jahrhundert in Trier sicher verehrt und

Juli 2005 unter http://www.spiegel.de/wissenschaft/mensch/0,1518,366039,00.html [21.07.2005].

504 Vgl. zum Grab des Paulinus insgesamt Heyen, St. Paulin, S. 268-278. Beim Holz des noch erhaltenen Sarges handle es sich um Zedernholz des 4. Jahrhunderts, was für seine Echtheit spräche. Vgl. ferner Gierlich, Grabkirchen, S. 27-30. Das Fest findet sich im Martyrologium Hieronymianum, ed. De Rossi/Duchesne, zum 31.8., S. [113]: Treveris depositio s. Paulini episcopi. Vgl. zu Paulin grundlegend mit der Zusammenstellung aller, auch der zeitgenössischen Quellen WINHELLER, Lebensbeschreibungen, S. 55-73.

505 Vgl. dazu oben Anm. 501. Einen wörtlichen Beleg für eine Paulinus- bzw. Marienkirche in der Urkunde der Erkanfride für St. Maximin vom 1. April 853 (MRUB I 83, S. 88 f.), wie ihn Gierlich, Grabkirchen, S. 27, angibt, kann ich nicht finden.

506 Vgl. Regino, Chronicon ad a. 295, ed. Kurze, S. 15: Paulinus episcopus Treverorum, successor sancti Maximini episcopi, ob catholicam fidem a Constantio exilio religatur et usque ad mortem etiam ultra christianum nomen mutando exilia fatigatur, Ad ultimum apud Frigiam defunctus est, inde Treveris reportatur. Die Ergänzung im Autograph Adalberts lautet: Cuius corpus Treverim reportatum usque hodie in quadam cripta nullis aliunde sustentaculis nitens divino nutu mirabiliter in aere dependet. Vgl. zum Fortsetzer auch: Quellen zur Geschichte der sächsischen Kaiserzeit, ed. BAuER/RAu, S. 187 f. KöLzer, Studien, S. 61. - Da Regino seine Chronik Bischof Radbod widmete, versteckt sich vielleicht hierin ein Hinweis darauf, daß die Rückführung oder womöglich eine Fama um eine solche dem Umfeld dieses Trierer Bischofs zuzuordnen sein könnte. Zu Regino und zur Chronik vgl. nochmals oben Anm. 2.

507 Vgl. Vita Paulini prima cap. 12-15, ed. Pinius, S. 678. Zur Vita vgl. Winheller, Lebensbeschreibungen, S. 55 f., 59-66, der die Vita auf die zweite Hälfte des 10. Jahrhunderts datiert (ebd., S. 65). Heyen, St. Paulin, S. 9, 266-268. Zur Geschichte von St. Paulin von der Frühzeit bis ins 11. Jahrhundert vgl. ebd., S. 78-96. - Auch in St. Marien/St. Paulin stieß man bei Grabungen auf ein frühes christliches Gräberfeld unter der Kirche. Vgl. dazu ebd., S. 32 ff. Pauly, Geschichte des Bistums Trier 1, S. $102-105$. Gierlich, Grabkirchen, S. 29. Bauer, Verehrung heiliger Trierer Bischöfe, S. 365-367. Vgl. auch nochmals Germ. Pont. 10, ed. Boshof, S. $231 \mathrm{ff}$. 
sein Grab vielleicht schon mit der späteren Paulinskirche in Verbindung gebracht.

Zwar verfügte das Trierer Erzstift über St. Paulin. Auffälligerweise formulierte es diesen Anspruch aber auch zusätzlich in den bereits mehrfach besprochenen gefälschten Urkunden, die Modoald als Gründer Oerens nennen und St. Maximin als bischöflichen Besitz. ${ }^{508}$ Ganz offenbar bestand also am Ende des 10. Jahrhunderts in Trier ein großes Interesse daran, alte und bedeutende Kirchen in der Umgebung der Stadt als Besitz des Trierer Erzstiftes zu betonen und in Verbindung mit alten Trierer Erzbischöfen zu bringen. Nahm diese Entwicklung bzw. dieses Begründungsmodell vielleicht mit der Altarweihe in der Innenkrypta St. Maximins schon ihren Anfang? Oder wirkte sie bereits auf diese Weihenotiz nachträglich zurück?

Bei Liutwin ist nun die Forschung stets von einer Bestattung in Mettlach ausgegangen. ${ }^{509}$ Doch haben wir gesehen, daß eine derartige Tradition in keiner der bisher untersuchten frühen Quellen vorzufinden ist. Lediglich auf eine Übertragungstradition Mettlachs an St. Peter in Trier durch Liutwin sind wir gestoßen, die aber aus den schon gezeigten Gründen nicht zeitgenössisch gewesen sein kann, sondern frühestens ins späte 9. und noch wahrscheinlicher ins späte 10. oder frühe 11. Jahrhundert gehört. In der Maximin-Vita erscheint Liutwin nicht. Auch Liutwins für St. Maximin anzunehmende Reliquie weist in keiner Form auf das Kloster Mettlach hin, wenn ihr Eintrag denn zeitgenössisch ist und nicht später ergänzt wurde. Im Gegenteil, sie legt ebenfalls nahe, daß Liutwin sein Grab - wie die anderen aufgeführten Bischöfe - im direkten Umkreis von Trier fand und man deshalb auf seine Reliquie zurückgriff. Die Weihenotiz bietet einen Hinweis, daß Liutwin vielleicht in St. Maximin, St. Eucharius oder St. Marien/St. Paulin ruhte und seine Verehrung erst später nach Mettlach gelangte. Wie und warum das geschah, wird im folgenden noch zu untersuchen sein. Die Nennung neben Paulin könnte am ehesten für die Marienkirche sprechen. Verband man Paulin aber erst Ende des 10. Jahrhunderts sicher mit dieser Kirche, dann wußte man womöglich über beide Gräber erst seit kurzem oder nur ungenaues. ${ }^{510}$ Aber auch eine in St. Eucharius gefundene

508 Vgl. dazu nochmals die zur gleichen Zeit Ende des 10. oder zu Beginn des 11. Jahrhunderts gefälschten Urkunden Dagoberts I. von 634 (MRUB I †5, S. 4 f. DMerowinger I †33, S. 89-92), Pippins III. von 760 (MRUB I †12, S. 15. DKarol. I. †36, S. 51) und Karls des Großen von 772/4 (MRUB I †26, S. 31. DKarol. I †226, S. 305). Vgl. dazu bes. oben S. 218 u. Anm. 377.

$509 \mathrm{Vgl}$. dazu schon ausführlich oben Kap. D.I.2.a. u. D.I.2.c.

510 In den beiden späteren Weihenotizen nach 952 erscheinen dann auch Paulin und Liutwin nicht mehr unter den Bischöfen. Vielleicht war deren Bedeutung geschwunden, oder Liutwin wurde bereits nicht mehr mit Trier verbunden. Vgl. Notae dedicationum s. Maximini Treverensis, ed. Sauerland, S. 1271, Z. 15 f., zu 1018: [...] et sanctorum confessorum Maximini, Agricii, Nicecii, Eucharii, Valerii, Modoaldi, Firmini, [...]. Zu 
Grabplatte aus dem 8. Jahrhundert eines LVDVBERTVS DE NOBILE GENE$R E$, der seinen Besitz dem hl. Petrus übertrug und dann Kleriker wurde, erinnert an Liutwin. Zumindest ist eine gewisse Ähnlichkeit mit dem Bericht von Liutwins späteren Viten nicht zu leugnen. ${ }^{511}$ Sollte tatsächlich schon Radbod (883-915) einen Trierer Bischof namens Liutwin als Schenker Mettlachs konstruiert haben (vgl. DKIII. 102 u. DArn. 39), so könnte auch dies erklären, warum er im St. Maximiner Altar erscheint. Doch verwundert es dann, weshalb ein Liutwin erst in den folgenden Jahren tatsächlich seinen Platz im Trierer Gedächtnis findet und warum ganz andere Bischöfe nachhaltig vor ihm in dieses aufgenommen wurden, wie wir gleich sehen werden.

Zusammenfassend ist folgendes zu sagen: Wenn Liutwins Reliquie im Altar der Trierer Bischöfe in St. Maximin 952 authentisch und zeitgenössisch überliefert ist, woran durchaus Zweifel bestehen, spricht dies für seine Verehrung in Trier in der Mitte des 10. Jahrhunderts. Ein Begräbnis in Mettlach sowie die Gründung oder Schenkung des Klosters durch ihn beweisen sie hingegen nicht. Es liegt vielmehr nahe, daß Liutwin - wie die anderen gemeinsam mit ihm genannten Bischöfe - sein Grab in Trier fand. Der Altar zeigt zudem ein langsam wieder erwachendes Interesse an den Trierer Bischöfen und damit an der Vergangenheit der Stadt. Daß St. Maximin und St. Marien/St. Paulin aber auch in den Trierer Fälschungen des späten 10. oder frühen 11. Jahrhunderts erscheinen, deutet auf ein starkes Interesse des Erzstiftes an diesen Grabkirchen und den erwähnten früheren Trierer Bischöfen. Das könnte die St. Maximiner Mönche auch dazu bewegt haben, die Reliquien von Paulin und Liutwin erst einige Jahre nach der Altarweihe darin noch aufzunehmen oder in der Weihenotiz zu ergänzen. Womöglich reflektiert die Notiz auch die Konstruktion eines Schenkerbischofs Liutwin (und eine Wiederbelebung des Paulinkultes) schon durch Erzbischof Radbod. Vielleicht aber steht die Altarweihe auch mit Erzbischof Rotbert in Verbindung, der sich beim Reimser Streit 946/8 auf einen Trierer Primat in der Belgica berief. Womöglich erhielt er dabei von Flodoard auch erste Reimser Informationen über Triers Vergangenheit.

1072 vgl. ebd., Z. 22 f.: [...], sancti Modoaldi episcopi et sanctae Radegundis reginae, de pallio et stola sancti Maximini archiepiscopi. Hier erscheint aber Bischof Modoald, dem man nach einer Tradition des späten 10. oder frühen 11. Jahrhunderts auch die Gründung Oerens zuschrieb. Vgl. dazu allgemein oben Kap. D.II.6.

511 Vgl. Becker, St. Eucharius, S. 244. Gose, Katalog, S. 9, Nr. 29: Hic requiescit in | pace vir venera|biles Ludubertus $\mid$ de nobile genere, qui $\mid$ vixxit annus plus $\mid$ minus $L X V$, cuius de|posicio eius est XVI $\mid k(a) l($ endas) ian(uarias) et o(m)nes res suas $\mid s(a n) c(t) o$ Petro tradeldit et se clericu $(m)$ feci $(t)$. Vgl. auch Gauthier, Recueil des Inscriptions chrétiennes 1, Nr. I 29, S. 166-168. 


\section{Eine Urkunde Papst Johannes' XIII. von 969}

Kommen wir zum nächsten erhaltenen Beleg einer Trierer Bischofsliste. Ein Privileg Papst Johannes' XIII. (955-964) vom 22. Januar 969 bestätigte dem Trierer Erzbischof Dietrich I. (965-977) wesentliche Rechte seiner Kirche. Die Urkunde ist lediglich noch in einer Abschrift wahrscheinlich aus der Zeit um 1050 erhalten. In der Forschung hielt man sie aber zuletzt überwiegend für echt, was nicht ausschließt, daß gegenüber dem Original noch nachträgliche Veränderungen in der Kopie vorgenommen wurden. ${ }^{512}$ Auch die Päpste Benedikt VI. (973-974) und Benedikt VII. (974-983) bestätigten das Diplom. Auch diese Dokumente liegen nur als Kopien vor. ${ }^{513}$

512 Vgl. JL †3736. MRUB I 232, S. 288 f. Zimmermann, Papsturkunden I †195, S. $384-$ 387, hier S. 386: [...], quod Theoderico dilectissimo fratre nostro, Treuerensis ęcclesię archiepiscopo, veniente Romam oratum ad sanctorum apostolorum limina audivimus, sicut eciam pridem audiendo, immo et legendo compertum habuimus, eandem ipsam pre ceteris Galliarum ęcclesiis Christiane religionis exordium catholiceque fidei prima rudimenta percepisse per sanctissimorum virorum Eucharii, Ualerii ac Materni et cęterorum evangelicam doctrinam, quos tempore suo predictus beatissimus Petrus apostolus ordinavit et instruxit, necnon illuc ad predicandum direxit. Unde tocius ordinis nostre sedis apostolice consultu gratuitoque assensu iura privilegiorum, que a sancta Romana matre ęclesia prefatis sanctis eorumque reliquis successoribus, id est Agricio, Maximino, Paulino, Seuero, almificis et apostolicis viris, a primordio et usque nunc autentice concessa sunt queque eciam ipius civitatis excidio, incendio aliquove casu consumpta approbantur, eidem Treuerensi ęcclesie predictoque fratri nostro Theoderico et per eum cunctis successoribus suis reconfirmare, recorroborare et omnimodo restituere dignum duximus, [...]. Vgl. schließlich Germ. Pont. 10, Archiepiscopatus 69, ed. Boshof, S. 45-47. - Die Fälschungskriterien bei Oppermann, Rheinische Urkundenstudien 2, S. 139 ff., ließen sich nicht halten. BosHOF, Erzstift Trier, S. 49 ff., bes. S. 49-57 u. 70 ff., faßt den älteren Forschungsstand zusammen und plädiert für die Echtheit. RATHSACK, Fuldaforfalskningerne, S. $215 \mathrm{ff}$, in dt. Übers. Rathsack, Fuldaer Fälschungen, S. 277-313, will die Urkunde als Fälschung Erzbischof Megingauds (1008-1015) nachweisen. Er belegt Textabhängigkeiten zwischen der Vita Eucharii, Valerii et Materni und der Urkunde. Als Autor sieht er den Trierer Mönch Theoderich. Hussong, Studien 1, S. 210 ff., geht aber wieder von der Echtheit aus, worin ihm auch KöLzer, Studien, S. 85 u. Anm. 298, folgt. Auch Engels, Metropolit oder Erzbischof?, S. 268-270, hält die Argumente von Rathsack nicht für überzeugend.

513 Vgl. JL 3738, †3768. Vgl. ferner Zimmermann, Papsturkunden I †222, S. 434-436, vom 27. Januar 973, sowie ebd. $\dagger 235$, S. 468-470, vom 18. Januar 975, der die Kopien ins 11. Jahrhundert datiert. In ihnen wird die Vorlage Johannes' XIII. teils wörtlich übernommen. Hoffmann, Ottonische Handschriften aus Trier, S. 89 u. Abb. 4a, verweist die Kopie der Urkunde Benedikts VII. von 975 jedoch schon ans Ende des 10. Jahrhunderts in Egberts Umkreis. Vgl. ferner Germ. Pont. 10, Archiepiscopatus 71, †74, ed. Boshof, S. 47-49. - Vgl. dazu auch Boshof, Erzstift Trier, S. 73 ff. Rathsack, Fuldaer Fälschungen, S. 298 ff., hält beide für zeitgleiche Fälschungen mit der Urkunde Johannes' XIII. - Dietrich war es auch, der 966 von Otto I. das königliche Kloster Oeren im Tausch gegen das Servatiusstift in Maastricht erhielt. Vgl. DOI. 322. Er förderte 
Die Urkunde Johannes' XIII. verleiht - so sie denn in allen Teilen echt ist dem sich in Rom aufhaltenden Trierer Bischof Dietrich und seinen Nachfolgern den Primat in Gallien und Germanien sowie allgemeine Besitzrechte. Der Primat verstehe sich als Vorrang vor anderen Bischöfen auf Synoden - aber erst nach dem päpstlichen Legaten - und Vorrecht, nach Kaiser und Papst sowie bei Abwesenheit des Legaten, den Vorsitz zu führen und gefaßte Beschlüsse zu verkünden. Die Urkunde erscheint formal als Bestätigung der den frühen Trierer Bischöfen gewährten, inzwischen aber verlorenen Privilegien. Sie bezieht sich namentlich auf die im 10. Jahrhundert als erste Trierer Bischöfe bezeichneten Eucharius, Valerius und Maternus. Sie tut dies aber in einem Kontext, wie er erstmals sicher in der schon erwähnten Vita Eucharii, Valerii et Materni aus der Zeit zwischen 900 und der Mitte des 10. Jahrhunderts zu finden ist. Denn diese Vita nimmt jetzt ihre drei Protagonisten aus ihrer Wirkungszeit des 3. und 4. Jahrhunderts heraus und macht sie zu unmittelbaren Zeitgenossen des hl. Petrus, der Eucharius zum Bischof, Valerius zum Diakon und Maternus zum Subdiakon weiht und als Missionare über die Alpen schickt. Als Maternus stirbt, kehren die beiden Lebenden zu Petrus zurück, der ihnen nun seinen Bischofsstab mit auf den erneuten Weg nach Norden gibt. Damit erwecken sie Maternus nach 40 Tagen Totenruhe wieder zum Leben. Schließlich gelangen sie nach Trier, das sie missionieren und dessen erster Bischof Eucharius wird. Nach seinem Tod folgen ihm erst Valerius, dann Maternus in diesem Amt. ${ }^{514} \mathrm{Daß}$ die Vita deshalb wohl in gewisser Weise Pate bei der Urkunde stand, in der die drei Bischöfe auch von Petrus entsandt werden, ist in der Forschung mehrfach aufgefallen. ${ }^{515}$ Als weitere Nachfolger erwähnt die Papsturkunde dann noch: Agricius, Maximin, Paulin und Severus.

Man kann also auch hier von einer frühen Trierer Bischofsliste sprechen. Die Namen ähneln der Weihenotiz aus St. Maximin von 952. Allerdings fehlen die Namen von Nicetius und Liutwin. Hatten beide ihre Bedeutung verloren? Stattdessen wird nun ein Severus ergänzt. Diese Liste wuchs also an anderer

angeblich sogar das klösterliche Leben im Sinne der lothringischen Reformbewegung in den Klöstern St. Martin und St. Marien. Insgesamt zu Dietrich vgl. Goerz, Regesten der Erzbischöfe zu Trier, S. 5 f. Pauly, Geschichte des Bistums Trier 2, S. 55-57. Heyen, St. Paulin, S. 19, 26, 39, 92, 537. Boshof, Erzstift Trier. Heit, Dietrich I., Ebf. von Trier, Sp. 1331 f. Boshof, Trier, Oberlothringen und das Papsttum, S. 373-379. Bönnen, Trier zwischen dem 10. und dem beginnenden 12. Jahrhundert, S. $209 \mathrm{ff}$. Die Hinweise auf die Förderung des klösterlichen Lebens in St. Martin und St. Paulin finden sich allerdings erst in den Gesta Treverorum cap. 29, ed. WAITZ, S. 169. Zu Dietrichs Klosterpolitik vgl. Boshof, Erzstift Trier, S. $98 \mathrm{ff}$.

514 Vgl. dazu oben Anm. 502.

515 Vgl. dazu hier nur Winheller, Lebensbeschreibungen, S. 40 f., 44 f. Er will sogar im Trierer Bischof Dietrich den Auftraggeber der Vita erkennen. Boshof, Erzstift Trier, S. 55-59. Rathsack, Fuldaer Fälschungen, S. 277 ff., sieht es als Argument für eine Fälschung des Diploms. 
Stelle. Vielleicht ging es ihr um die ganz frühen Trierer Bischöfe, was für Nicetius und Liutwin nicht galt. So bietet das Privileg weder einen Beleg für noch gegen eine Liutwin- oder auch Basinverehrung in dieser Zeit. Severus aber ist in Trier - im Gegensatz zur oben formulierten These - mit keinerlei Grab nachweisbar. Bereits EwIG sieht jedoch einen möglichen Bezug zu einem Bischof Severus von Trier in der Kirchengeschichte Bedas, der in Britannien gepredigt habe. Dieser sei auch in die spätere Vita des Lupus von Troyes eingegangen. Man ergänzte also Severus in die Liste aus einer wohl bekannten literarischen Vorlage. ${ }^{516}$

In Trier bestand somit ein deutliches Interesse daran, die eigene Tradition mit dem hl. Petrus zu verbinden. Eine Bischofsreihe als Beweis der unmittelbaren Sukzession war da ein überzeugendes Hilfsmittel. Hauptsächlich wollte man damit wohl die eigene Vorrangstellung bei der ostfränkischen Königserhebung vor den Bischöfen von Köln und Mainz belegen, wie es die Forschung bereits ausführlich diskutiert hat. ${ }^{517}$ Diese Strategie verfehlte ihre Wirkung nicht. Denn selbst Widukind von Corvey, der nach neuesten Erkenntnissen in den Jahren vor Ottos I. Tod (973) schrieb, erwähnt sie. So nennt er als Argument des Trierer Erzbischofs für eine Beteiligung bei der Königskrönung Ottos I. 936 anstelle des Kölner Bischofs das hohe Alter des Trierer Bischofssitzes und eine Gründung gewissermaßen durch den hl. Petrus. Köln dagegen berief sich darauf, daß der Erhebungsort Aachen in seiner Diözese lag. Die Rolle des Mainzers war unumstritten. Merkwürdigerweise wird der Trierer von Widukind dann aber weder namentlich noch als an der Weihe beteiligt genannt, im Gegensatz zum Mainzer Hildebert und Kölner Wicfrid. ${ }^{518}$

516 Vgl. zu diesen wenigen Quellen Duchesne, Fastes 3, S. 36. Ewig, Trier, S. 41 ff. BosHOF, Erzstift Trier, S. 50 f. Der Hinweis auf Beda und die Vita des Lupus von Troyes findet sich bei Ewig, Trier, S. $41 \mathrm{f}$., Anm. 150: „Nach dem Zeugnis der Vita des Germanus von Auxerre, die von Constantius um 480 in Lyon verfaßt wurde, begleitete ein Bischof Severus den hl. Germanus auf seiner zweiten Reise nach Britannien, wo beide Bischöfe gegen den Pelagianismus predigten. Diese Nachricht wurde von Beda auf Severus von Trier bezogen. Sie ging dann von Beda in die Vita des Lupus von Troyes über, dessen Schüler Severus gewesen war." Zu Severus vgl. zuletzt Pfeiffer, Mission, S. 191 f., 205 f. Heinen, Bistum Trier, S. 96 f., 102-104. Bauer, Verehrung heiliger Trierer Bischöfe, S. 374-377.

517 Vgl. zu diesem sog. Primatsstreit Boshof, Köln, Mainz, Trier, S. 19-48. Boshof, Trier, Oberlothringen und das Papsttum. Sснмidt, Metrolpolit und Primas. Engels, Metropolit oder Erzbischof?, S. 19-48.

518 Vgl. Widukind, Sachsengeschichte II,1, ed. Hirsch/Lohmann, S. 65 f.: [...], quia antiquior sedes esset et tamquam a beato Petro apostolo fundata; [...]. Überhaupt erwähnt Widukind in seiner Sachsengeschichte keinen Trierer Erzbischof namentlich. Zur Datierung auf diese Zeit vgl. Fried, Gedächtnis der Zeugen, S. 51-55 u. 58-61. Fried geht aufgrund einer Neubewertung der Handschriftenfassungen davon aus, daß Widukind sein Werk erst nach dem Tod Ottos I. abschloß, sehr wohl aber noch einige Zeit 
Doch muß die Königserhebung Ottos I. keinesfalls so abgelaufen sein. Vielmehr dürfte es sich um Rechtfertigungsmuster oder Probleme handeln, die bei der Aachener Königssalbung Ottos II. (961-983) am 26. Mai 961 eine Rolle spielten. Davon wurde sicher auch Widukind in seinem sächsischen Kloster berichtet, doch schwieg er darüber. Widukind projizierte stattdessen die Berichte über das Ereignis 961, soweit er sie zu ordnen verstand, auf das von 936 zurück. ${ }^{519}$ Doch wenn Widukind seinen Bericht an der Salbung Ottos II. orientierte, was tat dann der Trierer Bischof? Wahrscheinlich wußte Widukind schlichtweg nicht genau, was aus ihm wurde oder blieb absichtlich undeutlich. Wenn es aber im Vorfeld von 961 erneuten Streit darüber gab, dürfte der Trierer doch gerade jetzt seine Rolle gegenüber Köln mit dem Petrus-Argument behauptet haben.

Deshalb könnte man die Vita Eucharii, Valerii et Materni im unmittelbaren Zusammenhang mit diesem Ereignis sehen. Sie wäre, sollte sie tatsächlich um die Jahrhundertmitte und nicht schon früher verfaßt sein, mit einer gewissen Wahrscheinlichkeit unter dem dazu zeitgenössischen Trierer Erzbischof Heinrich I. (956-964) entstanden, der mit dem ottonischen Herrscherhaus wohl verwandt war. Wenigstens aber wurde sie von ihm herangezogen. ${ }^{520}$ Die Vita diente dann als Argument für Heinrichs Recht auf Teilnahme neben oder gegen den einflußreichen Kölner Erzbischof und Bruder Ottos I.: Brun. ${ }^{521}$ Folgt man der Darstellung der Vita Brunonis des Ruotger von 968/9, in der der Kölner Brun, der Mainzer Wilhelm und der Trierer Heinrich den Otto gemeinsam salben, dann war diese Strategie erfolgreich. ${ }^{522}$ Vielleicht sah der Trierer Erzbischof Dietrich I. (965-977) nach dem Tod Bruns (965) und Wilhelms (968) die Gelegenheit, sich diese besondere Tradition nun 969 in einem Papstprivileg bestätigen zu lassen. ${ }^{523}$ Das würde nochmals deutlich für die Echtheit der Petrus-Legitimation und der Bischofsliste des Privilegs sprechen.

davor damit begann, mit der klaren Absicht, es Ottos Tochter Mathilde von Quedlinburg einmal zu übersenden.

519 Vgl. dazu Fried, Weg, S. 481-485.

$520 \mathrm{Zu}$ Heinrich I. vgl. Goerz, Regesten der Erzbischöfe zu Trier, S. 5. Heit, Heinrich I. Ebf. von Trier, Sp. 2086. BöNNEN, Trier zwischen dem 10. und beginnenden 12. Jahrhundert, S. 204 f., 207 f., 214, 218.

521 Letztlich behauptet die Vita ja, daß der eigentlich Kölner Bischof Maternus Bischof von Trier war. Zwar findet sich dieses Bild schon in der älteren Maximin-Vita, doch ließ es sich in diesem Zusammenhang erneut bestens einsetzen. Vgl. zum Bild in der MaximinVita bereits oben S. 197 f. u. Anm. 303. Zu Brun von Köln vgl. zuletzt ausführlich Schwenk, Brun.

522 Vgl. Ruotger, Vita Brunonis cap. 41, ed. Отт, S. 43: [...], unxeruntque Ottonem, equivocum patris, Bruno archiepiscopus, Wilhelmus et Heinricus ceterique sacerdotes Domini regem in Aquisgrani palatii et exultavit maxima gratulatione populus dicens: Vivat rex in aeternum! Zu Ruotger vgl. Lotтer, Ruotger von Köln, Sp. $1104 \mathrm{f}$.

523 Vgl. so auch Boshof, Erzstift Trier, S. 70 ff. Er weist darauf hin, daß auch der bedeutende Mainzer Erzbischof Wilhelm zu diesem Zeitpunkt verstorben war. 
Zusammenfassend wird deutlich, daß der Konflikt zwischen dem Trierer und Kölner Erzbischof um die Beteiligung an der Königserhebung erst eigentlich dazu führte, daß man sich in Trier auf seine bischöfliche Vergangenheit besann. Vielleicht entstand unter Erzbischof Heinrich (956-964), womöglich aber auch schon früher die Vita Eucharii, Valerii et Materni, die die ersten Trierer Bischöfe zu Petrusschülern machte und damit das Interesse an einer Trierer Bischofsliste unterstreicht. Wenigstens jedoch wurde die Vita hierzu argumentativ eingesetzt. Eine solche Liste findet sich dann bereits in knapper Form erstmals im Privileg Johannes' XIII. (955-964) für Erzbischof Dietrich I. (965-977) von 969. Liutwin oder Basin aber nahm sie nicht auf. Beider Bedeutung als spätere Trierer Bischöfe war entweder nicht bekannt oder in diesem Zusammenhang noch uninteressant.

\section{Basin und Liutwin in den Bischofslisten Erzbischof Egberts von Trier}

a. Erzbischof Egbert, Mettlach und die Vergangenheit seines Bischofssitzes

Auch Erzbischof Egbert von Trier (977-993), Dietrichs Nachfolger, interessierte sich sehr für die Vergangenheit seines Bistums und versuchte, dessen Geschichte weiter auszuarbeiten. Letztlich mußte ihn schon sein Mainzer Gegenüber Willigis (975-1011), der die ottonische Politik entscheidend mitbestimmte, dazu veranlassen. ${ }^{524}$ Für die weiteren Überlegungen zu Liutwin und Basin ist es notwendig, Egberts Rolle im Hinblick auf die Trierer Geschichte knapp zusammenzufassen. Dabei gilt es auch, sein Verhältnis zum Kloster Mettlach zu berücksichtigen, das angeblich Liutwin an St. Peter geschenkt hatte.

Egbert war Sohn des Grafen Dietrich von Holland, Westfriesland und Gent $(† 988) .{ }^{525}$ Er wurde wohl zunächst im Kloster Egmont in Nordholland erzogen, dann durch Brun von Köln geschult, gelangte vermutlich unter Otto I. (936973) in die Hofkapelle und wirkte seit 976 erstmals nachweisbar als Kanzler Ottos II. (†983). Im Jahr 977 wurde er Trierer Erzbischof. ${ }^{526}$ Egbert begleitete

524 Vgl. zu Willigis hier nur GerLich, Willigis, sowie die aktuellste Literatur und Ereignisgeschichte über das Register in: Althoff, Ottonen.

525 Vgl. Goerz, Regesten der Erzbischöfe zu Trier, S. 6 f. Steinruck, Erzbischof Egbert, S. 197. Egberts Mutter war Hildegard, eine Tochter des Grafen Arnulfs II. von Flandern. „Über die Familie seiner Mutter war Egbert mit dem angelsächsischen Königshaus, mit den westfränkischen Karolingern und mit den deutschen Königen und Kaisern aus dem Haus der Ottonen verwandt." Vgl. zu Egbert insgesamt die zweibändige Gedenkschrift zu seinem 1000. Todestag: Egbert. Erzbischof von Trier, ed. Ronig. Vgl. auch die älteste Quellenzusammenstellung bei Brower/Masen, Antiquitates, S. 480-493.

526 Vgl. dazu zuletzt Ronig, Anmerkungen. Ronig, Erzbischof Egbert von Trier. - Zu Egberts Wirken als Trierer Bischof vgl. Seibrich, Egbert, S. 187 ff. Bienert, Besiedlung Triers, S. 125, $137 \mathrm{f}$. BönNEN, Trier zwischen dem 10. und dem beginnenden 12. Jahrhundert, S. 208, 214-218, 227. - Zu Egberts Vorfahren vgl. Laufner, Vor- 
den Kaiser nach Italien, nahm 983 am Reichstag von Verona teil und gehörte nach Ottos II. Tod - wohl auch aus Opposition zum Einfluß Willigis' zunächst der Partei Heinrichs des Zänkers an. Doch bald versöhnte er sich mit der Gegenseite um Otto III. (983-1002). Er starb 993 mit etwas mehr als vierzig Jahren. ${ }^{527}$

Egbert förderte Kunst und Schulwesen in Trier. Dabei gibt es deutliche Mettlacher Verbindungen. So ließ er von Mettlacher Mönchen eine Vita des in Egmont verehrten Adalbert verfassen, so deren letztes Kapitel. ${ }^{528}$ Er korrespondierte intensiv mit Gerbert von Aurillac, dem Leiter der Reimser Domschule, kurzfristigen Reimser Erzbischof und späteren Papst Silvester II. (9991003), sowie mit den folgenden Reimser Erzbischöfen Adalbero (969-989) und Arnulf $(\dagger 1021)$. Man tauschte dabei Handschriften aus. ${ }^{529}$ Das heißt,

fahren. Steinruck, Erzbischof Egbert, S. $197 \mathrm{f}$. - Vgl. zu Egberts Position in der Hofkapelle Fleckenstein, Hofkapelle 2, S. 56. - Nach der gerade publizierten, umfangreichen Studie Wolfgang Huschners zu den ottonischen Herrscherdiplomen und deren Entstehung gehörte Egbert damit dem Kreis der führenden Politiker am Hof an. Vgl. insgesamt Huschner, Transalpine Kommunikation.

527 Vgl. Ronig, Anmerkungen, S. 11, 14 f. Erkens, Egbert von Trier, bei Anm. 78-80 u. 99 f., zum Verhältnis Egberts gegenüber Heinrich dem Zänker. STEInRuck, Erzbischof Egbert, S. 198.

528 Zum Hinweis auf die Mettlacher Mönche vgl. Ruotper, Vita S. Adalberti cap. 28, ed. Henschen, S. 103. Doch erst die späteren Miracula s. Liutwini auct. Monacho Mediolacensi cap. 10, ed. SAUerLand, S. 1264, nennen dann als Verfasser namentlich einen Mönch Ruotpert, der von Egbert zum Abfassen der Vita nach Egmont geschickt wurde: Ex eorum condiscipulatu Ruopertus quidam fuit, qui ad Ekmundam missus Vitam sancti Adelberti luculento sermone conscripsit. - Vgl. zu dieser Vita Емвасн, Adalbert-Vita, S. 15-36. Embach hält Ruotpert für den Verfasser, betont aber, daß darüber hinaus so gut wie nichts über ihn bekannt sei. Zu Ruotpert vgl. zusammenfassend auch FLESCH, Monastische Schriftkultur, S. 27-36, der in ihm den Stifter des Egbert-Psalters vermutet.

$529 \mathrm{Zu}$ Briefen von Gerbert an Egbert selbst vgl. Gerbert, Briefsammlung 13, ed. Weigle, S. 35 f., vom November 983 aus dem Kloster Bobbio an Egbert (über die Entsendung von Schülern nach Bobbio). Ebd. 172, S. 199, aus Senlis von Mai/Anfang Juni 990 (nachdem er die Partei Arnulfs von Reims verlassen hatte). - Zu den Briefen Erzbischof Adalberos von Reims an Egbert vgl. ebd. 26, S. 48 f., aus Reims von Februar/März 984, mit der Bitte, die Partei der Gegner Ottos III. zu verlassen. Ebd. 38, S. 65 f., aus Reims von Juli/August 984. Ebd. 54-56, S. 83-86, von April und Mai 985. Ebd. 68, S. 98, aus Reims von Mitte Juni 985. Ebd.73, S. 103 f., aus der ersten Märzhälfte 986. Ebd. 104, S. 134, vor Oktober 987, mit der Bitte um Anfertigung eines Kunstwerkes, wohl eines Kreuzes. Ebd. 106, S. 135 f., von Anfang Oktober 987, worin Adalbert u.a. einen Besuch in Trier ankündigt. Ebd. 108, S. 137, von 987, worin u. a. der Austausch von Büchern geregelt wird. Ebd. 109, S. 137 f., von Oktober/November 987, worin Adalbert u. a. sein Kommen in Trier anmeldet. Ebd. 114, S. 141 f., von Mitte April 988. Ebd. 121, S. 148 f., von Anfang/Mitte August 988, worin er über Kriegshandlungen berichtet, die zur Aufhebung der Belagerung Laons geführt haben. Ebd. 125, S. 152 f., aus Reims von August/September 988 mit der Bitte um Hilfstruppen - vermutlich für Laon. Ebd. 126, S. 153 f., aus Reims von Juni/August 988. Ebd. 131, S. 158 f., aus 
allerspätestens jetzt dürften entscheidende Reimser Texte, in denen auch Trier erwähnt wurde, in der Moselmetropole bekannt geworden sein - wie Hinkmars Remigius-Vita und Flodoards „Reimser Kirchengeschichte“. Und damit erfuhr man von einem schwarzen Fleck in der eigenen Vergangenheit: einem Milo, der die Bistümer Trier und Reims gemeinsam beherrscht haben sollte. Das hatte Konsequenzen, wie wir bald sehen werden.

Die gegen Ende des 11. Jahrhunderts entstandenen Miracula s. Liutwini, gleichsam eine Mettlacher Klostergeschichte, aber mit manchen chronologischen und sachlichen Fehlern, berichten über weitere Verbindungen zwischen Egbert und dem Kloster. Egbert habe den hochgelehrten Mettlacher Abt Remigius, der Mettlachs Licht in der ganzen Gallia zum leuchten gebracht und über viele bedeutende Schüler verfügt haben soll, mit einer historia über die hll. Eucharius, Valerius und Maternus beauftragt. Remigius habe sie um eine Homilie zu einem Evangeliumstext (Lk. 10,1) ergänzt. ${ }^{530}$ Mit der historia ist ein

Reims vom 10. September 988, worin es nochmals um die Truppen geht. Ebd. 132, S. 159 f., aus Reims aus der Zeit August/Oktober 988, worin es auch um die Rücksendung eines Buches geht. Ebd. 135, S. 162 f., von Anfang Oktober 988, worin er um Unterstützung für die wiederaufgenommene Belagerung von Laon bittet. Ebd. 144, S. 170 f., aus Reims vom Dezember 988. Ebd. 146, S. 172 f., aus Reims nach dem 28. Dezember 988. - $\mathrm{Zu}$ den Briefen Erzbischof Arnulfs von Reims, einem Karolinger, an Egbert vgl. ebd. 156, S. 184 f., vielleicht aus Reims von April 989. Ebd. 157, S. 185 f., aus Reims von Juni/Juli 989, worin um ein Zusammentreffen mit Egbert gebeten wird. Ebd. 168, S. 196 f., aus Laon (?) von März/April 990. - Auffällig ist dabei, daß seit der Wahl Arnulfs in den Briefen zum ersten Mal Bezüge auf Werke Hinkmars von Reims erfolgen. Vgl. dazu die Anmerkungen ab ebd. 155, S. 184 ff. sowie den Registereintrag auf S. 281. - Vgl. dazu auch Gerbert, Letters 34, 46, 60, 75, 80, 110, 113, 118, 122, 127, 130, 135, 140, 143, 164 f., 177, 181, ed. Latтin. Zu Gerbert vgl. zuletzt Riché, Gerbert.

530 Vgl. Miracula s. Liutwini auct. Monacho Mediolacensi cap. 16, ed. SAuerland, S. 1266: Post hunc Remigio committitur regimen Mediolacensium, in cuius cordis sacrario sapientia sibi placidam edificaverat domum. Talis etenim scientie plenitudo illi inerat, et ita secularium ac divinarum exercitionibus litterarum proprios et ad se confluentes ubertim imbuerat, ut multi monachi et clerici ex omnibus Gallie partibus ad suum magisterium convenerunt, ut de tali fonte sapientie arida corda rigarent. Tanta etiam discipulis eius provenerat perfectio, ac sic in cordibus eorum pii magistri fructificabat affectio, ut ad summam scientie arcem attingerent et ad propria redeundo confines et omnium Galliarum regiones luce Mediolacensis seminarii perfunderent. Quidam itaque ex illis ad episcopatum sunt promoti, alii abbates sunt effecti. Fecit siquidem de proprio patrono Liutwino sermonem ad eiusdem patris legendum annuam festivitatem. Rogatus insuper a Stephano et eius socio, Blandiniensibus monachis, de sancto Bavone cantum composuit nocturnalem, quem illi ad propria reportabant gaudentes omni thesauro cariorem. Iussu etiam Eckberti episcopi de confessoribus Christi Euchario, Valerio, Materno dulci modulatione composuit historiam, cui de euangelio: Designavit Dominus in illo die, legendam annexit omeliam. Illi autem Remigio abbati Ottho imperator camenam misit gracilis avene munus ob suavitatem musice artis in illo iam probate. Fecit et regulas de divisionibus abaci; fecit et excerptionem Prisciani super 
Reimoffizium für den liturgischen Gebrauch gemeint. ${ }^{531}$ Es ist noch in einer Handschrift des 12. Jahrhunderts aus St. Eucharius und einer zeitgenössischen, für die Domkirche entstandenen (heute Wolfenbüttel), erhalten. ${ }^{532}$ Und auch diese historia betont - wie zuvor die Urkunde Johannes' XIII. - deutlich die Gallia und Germania als den geographischen Tätigkeitsbereich des Eucharius und formuliert damit erneut den Trierer Primatsanspruch. ${ }^{533}$ Nach Angabe der Mettlacher Miracula verfaßte Remigius ebenso eine Predigt (sermo) über den hl. Liutwin, um diese bei dessen Fest verlesen zu können. Es wäre der erste Text, der

octo partes Donati, ipsas octo partes octonis incipiens verbis metrica lege sic ligatis: / Aurora, doceo, vigilans, ego, per, satis, o, si.

531 Vgl. dazu Leuchtmann, Reimoffizium, Sp. 656 f. Becker, St. Eucharius, S. 681.

532 Aus der erwähnten Handschrift aus St. Eucharius sind zwei Homilien des Remigius auf Eucharius sowie eine weitere auf den hl. Celsus bekannt. Es handelt sich um den Liber lectionarius des Euchariusklosters. Vgl. zu mehreren ersten Auszügen aus der zweiten Homilie zu Ehren des hl. Eucharius Sauerland, Geschichtsquellen, S. 107 f. (S. 23 ff. der Handschrift). Thomas, Studien, S. 159 f. u. Anm. 27, bemerkt, bei der Handschrift handle es sich heute um Trier, Priesterseminar, 4. Vgl. zu ihr Marx, Veröffentlichungen, S. 10 f. Zuletzt hat Becker, St. Eucharius, S. 66 f., den Inhalt dieser Handschrift aus dem 12. Jahrhundert beschrieben. Danach finden sich „S. 15-23 Abt Remigius von Mettlach, In natali s. Eucharii; S. 23-30? < Abt Remigius von Mettlach $>$, De festivitate s. Eucharii; S. 30-35 Theoderich <von St. Eucharius>, De festo s. Eucharii; S. 197200 Abt Remigius < von Mettlach>, In natali s. Celsi; [...].“ Diese Homilien heben Triers Würde hervor sowie den Trierer Primat über Gallien. - Vgl. auch eine Sequenz des Remigius auf den hl. Eucharius in: Analecta hymnica 42, S. 200 f., Nr. 217 (aus der Handschrift Trier, Bistumsarchiv, Abt. 95, Nr. 133a, fol. $141^{\mathrm{r}}-141^{\mathrm{v}}, 1191-12 . /$ 13. Jahrhundert. Vgl. zur Handschrift Becker, St. Eucharius, S. 115 f., Nr. 43). - Zu Remigius vgl. auch FlesCH, Monastische Schriftkultur, S. 44 ff., bes. S. 56-59 u. 6569, wo er sich der historia und der Homilie widmet. Ebd., S. 174-183, bietet er die Edition der Homilie des Remigius zu Lk. 10,1 nach der zur Amtszeit Erzbischof Liudolfs von Trier (994-1008) entstandenen Handschrift Wolfenbüttel, Herzog August Bibliothek, Guelf. 1109 Helmst., fol. 61 ${ }^{\mathrm{r}}-84^{\mathrm{v}}$. Die historia bzw. das Offizium des Remigius folge darin unmittelbar auf fol. $85^{\mathrm{r}}-92^{\mathrm{v}}$, die FLESCH, S. 184-194, vollständig ediert hat. Ebd., S. 60, weist er darauf hin, daß die Homilie auf Lk. 10,1 mit dem Euchariustext in Trier, Priesterseminar, 4, S. 15-23, übereinstimme. Ebd., S. 67, merkt Flesch endlich an, daß in der Wolfenbüttler Handschrift der Homilie die Vita Eucharii, Valerii et Materni vorausgehe. Zu Remigius vgl. ferner BeCKer, Mettlach, S. 522, 538, der dessen Abbatiat auf um 995-998/1008 datiert. Zur Wolfenbüttler Handschrift vgl. HoffManN, Buchkunst 1, S. 496. Vgl. zu dieser historia in der Handschrift Trier, Stadtbibliothek, 436/1913, fol. $182^{\mathrm{r}}-184^{\mathrm{r}}$, vom Ende des 15. Jahrhunderts, auch RosENTHAL, Fest, S. 110-114, der in seinem Abdruck des Textes die zahlreichen aus der älteren Vita Eucharii, Valerii et Materni übernommenen Passagen kenntlich macht. Vgl. zur Trierer Handschrift auch Keuffer, Beschreibendes Verzeichnis 4, S. 56-58. Becker, St. Eucharius, S. 68, Nr. 19.

533 Vgl. Flesch, Monastische Schriftkultur, S. 66 u. 185, Z. 53 f.: Preterea plurima pars Germanie atque Gallie [...]. Ebd., S. 189, Z. 195 f.: [...], ut, quem post se secundum presidem in Germania atque Gallia haberi decreverat, [...]. Ebd., S. 191, Z. 291 f.: [...], sanctus autem pater noster principatum in Germania atque Gallia evangelizandi primus assumpserat. 
sich explizit und ausführlicher mit Liutwin beschäftigt. Das spräche aber dafür, daß eine Liutwinverehrung in Mettlach erst jetzt, zu Egberts Zeit, im Entstehen begriffen war bzw. forciert wurde. Sonst hätte man eine solche Predigt doch bereits früher benötigt. Ziemlich wahrscheinlich ist, daß es sich bei dieser Predigt um die Liutwin-Vita I handelt, wie sich weiter unten bei der Analyse der Vita noch zeigen wird. Von weiteren Remigiuswerken ist in den Miracula die Rede, von denen man in Mettlach noch über Handschriften verfügt haben muß. ${ }^{534}$ Ferner liegen fünf Schreiben Gerberts von 989/90 an einen Trierer Mönch Remigius vor, die auch auf Gerberts Besuch in Trier deuten, ohne jedoch einen Mettlacher Bezug herzustellen. ${ }^{535}$

Da die späteren Miracula aber auch davon sprechen, daß vom Mettlacher magister Germanus schon früher zwei Brüder zu Gerbert entsandt wurden, der dabei fälschlich als Bischof bezeichnet wurde, ${ }^{536}$ vermutet die Forschung folgendes: Remigius sei zunächst Mönch in Mettlach gewesen und dann als einer der beiden Brüder nach Reims gereist. Nach seiner Rückkehr könnte er zunächst nach Trier gegangen sein, wegen seiner Euchariustexte vielleicht in dessen Kloster. In den späten Jahren Egberts oder nach dessen Tod (993) müsse er Mettlacher Abt geworden sein. ${ }^{537}$

534 Vgl. dazu nochmals oben Anm. 530. Zum sermo vgl. Thomas, Studien, S. $158 \mathrm{ff}$. RaAch, Mettlach, S. 8, Anm. 21 u. S. 59, Anm. 130. FlesCh, Monastische Schriftkultur, S. 51-55, hält den sermo und die Liutwin-Vita I für identisch. Er versucht zu zeigen, daß die Begriffe sermo und vita durchaus synonym gebraucht wurden. - Zu den weiteren Werken, die Remigius von den Miracula zugeschrieben werden, vgl. ebd., S. 55 f., $60-$ 65, 69-71. - Vgl. zur Vita Liutwini I und deren Entstehung auch ausführlich unten Kap. D.IX.2.

535 Vgl. dazu Gerbert, Briefsammlung 134, ed. Weigle, S. 161 f., vom Herbst 988. Ebd. 148, S. 174 f., von Januar/Februar 989. Ebd. 152, S. 178 f., etwa Mitte April 989. Ebd. 162, S. 190 f., aus Reims im November/Dezember 989. Ebd. 169, S. 197, aus Reims im Frühjahr 990. Im wesentlichen geht es in den Briefen um einen von Remigius bei Gerbert bestellten Himmelsglobus. Der letzte Brief behandelt eine medizinische Anfrage. Die Briefüberschriften sprechen eindeutig von einem Mönch Remigius bzw. Mönch Remigius von Trier. Da aus Trier auch eine Korrespondenz mit Abt Nithard von Mettlach geführt wurde (vgl. dazu unten Anm. 538), hätte man es in Reims doch wissen müssen, wenn Remigius inzwischen Abt von Mettlach geworden wäre. Gerbert befand sich laut diesen Briefen 989 in Trier. Vgl. dazu u. a. LAGER, Urkundliche Geschichte, S. 32-34. - Zum Schriftwechsel vgl. auch FLESCH, Schriftkultur, S. 45-47.

536 Vgl. Miracula s. Liutwini auct. Monacho Mediolacensi cap. 10, ed. SAuerland, S. 1264: Quorum magister extitit quidam Germanus, vir tunc temporis circumquaque omnium peritissimus. Duos igitur ex suis secularium disciplinarum gratia discendarum Remis ad Gerbertum episcopum misit, quia summa pericie illo in tempore in illo pre cunctis effulsit. Qui in talem sapientie plenitudinem ab eo sunt instructi ac tanti negocii thesauro redierunt referti, ut omnes affines et contemporales luce sciente perfunderent et radii talis ingenii usque ad nostre etatis tempora pertenderent. - Konkrete Namen fallen nicht.

537 Vgl. dazu Lager, Urkundliche Geschichte, S. 25 f. u. 32-37. RaAch, Mettlach, S. 47 u. Anm. 60 f. sowie S. 51-53 u. Anm. 92. Nach Trithemius, dem aber nicht zu trauen ist, 
Den zweiten Bruder will man im Mettlacher Abt Nithard/Nizzo I. erkennen, an den immerhin zwei Reimser Schreiben erhalten sind. Eines handelt von der sich verzögernden Rückkehr des Mettlacher Mönchs Gausbert (985). ${ }^{538}$ Auch auf diesem Weg könnten Reimser Texte in den Trierer Raum gelangt sein. Eine Verbindung, ja ein Gedankenaustausch, zwischen Egbert, Mettlach und Reims läßt sich also kaum leugnen, auch wenn die Miracula in ihrer Rückschau sicher einiges verformten. Die Dinge stellen sich nach ihnen für Mettlach sogar noch wesentlich merkwürdiger und komplizierter dar. Egbert soll dort Äbte abgesetzt und andere eingesetzt haben. Darauf wird später noch genauer einzugehen $\operatorname{sein}^{539}$

Das alles deutet auf sein großes Interesse an den Trierer Klöstern. Erinnert sei hier nochmals an den Konflikt um Oeren und das St. Servatiusstift in Trier. Als besonderes Beispiel seiner Klosterpolitik sticht ferner St. Eucharius heraus, die Grabkirche der ersten Trierer Bischöfe. Egbert gilt als deren zweiter Gründer. ${ }^{540}$ Die frühesten Nachrichten hierüber bietet die zwischen 1010 und 1023 verfaßte Translatio s. Celsi des Trierer Mönchs Theoderich. Darin erwähnt dieser den Neubau der desolaten kleinen Kirche, den Kaiser Otto II. (†983) auf Bitten Egberts unterstützt habe. Bei den Bauarbeiten fand man dann - auf welch wundersame Weise auch immer - 980 die Reliquien des bislang unbekannten hl. Celsus. Von Egberts Bestrebungen u.a. auf einer Synode in Ingelheim (vielleicht 980) um dessen Kanonisierung handelt die Translatio. ${ }^{541}$ Egbert ar-

sei er 998 gestorben. Vgl. dazu Thomas, Studien, S. 158 f., der Remigius für einen Mönch in St. Eucharius hält. Vgl. dazu auch Becker, St. Eucharius, S. 95, 112 f., 115, 399 f., 413, 457, 467, 681. Auch er geht von einem Aufenthalt Remigius' in St. Eucharius aus und datiert sein Abbatiat auf 995-1008. Vgl. zu Remigius zuletzt FLesCH, Monastische Schriftkultur, S. 44, 48, 56-58, 65 ff., der auch auf die Schwierigkeiten seiner Biographie hinweist, aber schon aufgrund der zahlreichen Werke, die Eucharius zum Thema machen, deutliche Bezüge zu St. Eucharius in Trier sieht.

538 Vgl. Gerbert, Briefsammlung 64, ed. Waigle, S. 95, aus Reims von Mitte Juni 985 an Abt Nithard, in dem Erzbischof Adalbero die sich verzögernde Rückkehr des Mönchs Gausbert aus Reims nach Mettlach anspricht. Ebd. 72, S. 103, aus Reims von Sommer/ Herbst 986, worin Gerbert Nithard um Bescheid wegen einer Abreise bittet. - Zur Rückkehr des Mönchs Gausbert vgl. auch die Briefe ebd. 56 u. 68, S. 86, 98, von Erzbischof Adalbero an Erzbischof Egbert von 985. Die Forschung zu Gausbert vgl. bei FlesCH, Monastische Schriftkultur, S. 16-20. - Zum Abt Nithard/Nizzo I. der Miracula vgl. RaAch, Mettlach, S. 46 u. Anm. 57. Lager, Urkundliche Geschichte, S. 31 f. u. 201, übergeht ihn als Abt. Vgl. schließlich Becker, Mettlach, S. 520.

539 Diese Verbindung betonen auch Margue/Schroeder, Ausstrahlung Triers unter Erzbischof Egbert, S. 116-118. Vgl. dazu ausführlich unten Kap. D.IX.4.b.

540 Vgl. dazu oben S. 174 ff. - Zu Egbert als Pfleger der Klöster vgl. auch STEinruck, Erzbischof Egbert, S. 198-200. - Zu Egbert und St. Eucharius vgl. Becker, St. Eucharius, S. 397 -399. Rosenthal, Fest, S. 99, 119 f. Vgl. zuletzt Ronig, Anmerkungen, S. 11.

541 Vgl. dazu Theoderich, Translatio s. Celsi cap. 2-4, 10, ed. Wartz, S. 205 f., hier in den wesentlichen Auszügen: 2. Anno dominicae incarnationis 978, [...], sanctae Trevirensi a 
Deo conservandae ecclesiae praefuit beatae recordationis vir virtutum Egbertus archimandrita lampabilis, clarus quidem parentelae generositate, sed clarior totius probitatis impretiabili dote. Et revera, quia ipsa gemina claritudine pollucibiliter viguit, uti honor debitus poposcit, totius regni pontificibus atque optimatibus ipsa sui reverentia praecelluit. Denique statura procerus, vultus autem rutila formositate prae omnibus tunc temporis primatibus enituit venustius. Erat enim monachorum praecipuus tutor ac nutritor ac regularis disciplinae specialis amator, quippe qui sub habitu episcopi humile pectus occultavit devotissimi monachi, sicque cum Martha foras profudit ad explendum frequens ministerium Domini, ut tamen cum Maria totum se conferret ad studium verbi divini, faciens se divinitati gratam hostiam, in practica videlicet columbam, in rethorica autem turturem. De liberalitate vero eius, qua unice opimatus extitit, quid condignum eloquar? Novum quippe in illo Iohannem quem Eleimonem vocant videres, quia opes quas ei Deus profusius largitus est, pleno ut ita dixerim cornu per manus egentium transmisit in coelum. / 3. Monasteria namque, quae Trevericae subiacent exedrae, ante ipsius sane tempora ultra communem Deo servientium modum erant indigna atque asperrima victualium necnon utensilium confecta inopia, et ob hoc religio monastica non minimum passa est deliquium. Sicque rarescente morum perfectorum ventilatore, ignis ille divini amoris, quem Veritas misit in terram et voluit vehementer accendi, iam abundante quoquo locorum iniquitate, non modo frigescere, verum quod pericolosius est, modis omnibus coepit extingui. Nam venerandae memoriae antecessor eius Theodericus doctor quidem extitit facundissimus atque familiae Domini procurator industrius; sed quia temporis angustia ob multiplices rei publicae exactiones totiens totiensque erat coartatus, minus monasteriorum necessitudinibus consuluit; quia nec unde, obvium sibi fuit. At iste summo veneramine nominandus regiam viam a dextris et a sinistris incedens, militum ambitionem refrenare non timuit, conprovincialium tyrannidem aequus arbiter auctoritate compressit, et omnia quae monasteriis hostili fuerant invasione subtracta manu potestativa undecumque recollegit ac monasteriorum partibus sub magna vigilantia reconsignavit, et ut pius paterfamilias neglecta atque aetate consumpta resarcire tantopere curavit. / 4. Cumque paterna lumina et ad septa beati Eucharii contorqueret monachorumque illius paupertatulae nimium condoleret, sapienti usus consilio, primum monasterio dignum delegit dispensatorem, abbatem videlicet nomine Gotherium, unice apud Gandense coenobium disciplinatum. Cui tantum supplementi sumptuum in agris vineisque, exceptis aliis perplurimis donariis ornamento monasterii conducibilibus, contulit, ut quamdiu firmamenti sphaera volvitur eius perenne meritum proinde capiat incrementum. Quanta autem aliis monasteriis, suae pastoralitati aeque subactis et agente inopiae pressura pene collapsis, ad restaurationis gratiam larga manu concesserit, qualiterve monasticae religioni, quae tunc temporis ubique pessumdari videbatur, utpote favorabilis animarum languentium archiater, auctorali antidoto succurrerit, modum atque calculum excedunt, ideoque ad narrandum sermo succumbit. Adeo denique virtutum paedagoga caritas in eius pectore vigorabili imperio sceptrum obtinuit, quatenus cum beato Iob hand iniuria dicere posset, quia ex utero matris meae egressa est caritas mecum. [...] / 10. [...] Cui necessario interfuit Trevericae ecclesiae metropolitanus bene meritus Egbertus, cuius memoria, quamdiu hodie dicitur, semper est in benedictione habenda, quia piis eius studiis asscribitur, quod suae ecclesiae clerus scientia ac religione nobilitatur. Discussis sane inibi multis quae synodica postulat rubrica, postquam tantus archipraesul, qui inter omnes illos primatum tenuit, vacuum sibi fore ad loquendum pervidit, [...]. - Theoderich selbst gibt in den Miracula s. Celsi an, 1006 als bejahrter Mann in das Euchariuskloster gekommen zu sein. Dort habe man ihn schließlich gebeten, die genannten Texte zu verfassen. Vgl. Theoderich, Miracula s. Celsi, ed. Waitz, S. 208. Becker, St. Eucharius, S. $681 \mathrm{f}$. Thomas, Mönch Theoderich, S. $42 \mathrm{ff}$. Theoderich lebte zuvor unter Abt Werdolf in Lüders und wanderte von Burgund nach Trier. Vgl. ferner Tномаs, Ein kaisergleicher 
beitete also an der Stärkung der bischöflichen Tradition und kreierte dazu auch einen neuen Heiligen. Der Kirchenneubau ist archäologisch belegbar. Grabungen im Jahr 2005 haben sogar dessen Krypta nachgewiesen. ${ }^{542}$ Der erwähnte Remigius fügt sich nicht nur mit seinen Euchariustexten hier ein, er verfaßte ebenso eine noch recht inhaltsleere Predigt über diesen hl. Celsus nach dessen Erhebung, die erneut Trierer Ansprüche auf die Gallia Belgica formuliert. Nach FLESCH ist dieser Terminus von Hinkmar übernommen. ${ }^{543}$ Inzwischen drängt sich deshalb der Eindruck auf, daß dieser Remigius Egberts politisches Konzept deutlich unterstützte, wohl einer seiner engeren Mitstreiter war und zudem die importierten Reimser Texte bei ihm ihre Wirkung entfalteten.

Gedächtnis und Erinnerung späterer Jahre steigerten Egberts Ruhm und die Farben seiner Bilder. Während der im dritten Viertel des 11. Jahrhunderts entstandene Libellus de rebus Treverensibus zu ihm nur den Inhalt zweier Urkunden wiedergibt, ${ }^{544}$ beziehen ihn die erwähnten, vor 1090 verfaßten Miracula

König. - Zum Celsuskult vgl. Donckel, Kult. - Vgl. zum Neubau von St. Eucharius und zu Egberts Fürsorge für das Kloster auch Becker, St. Eucharius, S. 29 f., 243, $246-$ 248, 343-346, $388 \mathrm{f}$. (zu den Bauten und politischen Beziehungen), S. 79 (zur Bibliothek). Vgl. zum Auffinden der Celsusgebeine auch Clemens, Umgang mit der Antike, S. 196 u. Anm. 104, der vom Fund einer frühchristlichen marmornen Grabtafel ausgeht.

542 Vgl. dazu Weiner, Katalog der Kunstwerke, S. 46 f. u. Taf. 185-187. Vgl. ähnlich Seibrich, Egbert, S. 188-190, auch zu weiteren, nicht ganz gesicherten Reliquientranslationen Egberts. U.a. soll er Reliquien der hll. Märtyrer Felix und Regula aus dem Züricher Großmünster mitgebracht haben sowie aus Spoleto die Gebeine der hll. Märtyrer Gregor und Pontianus. - Zu den neuesten Grabungsergebnissen aus St. Eucharius vgl. hier nur die Meldung „Trier - Erster christlicher Friedhof Deutschlands entdeckt" bei SPIEGEL ONLINE vom 21. Juli 2005 unter http://www.spiegel.de/ wissenschaft/mensch/0,1518,366039,00.html [21.07.2005].

543 Vgl. dazu nochmals oben Anm. 532 sowie Flesch, Monastische Schriftkultur, S. 6971. Zur Celsuspredigt sowie deren Edition vgl. ebd., S. 195-199. Diese Predigt ist überliefert in den Handschriften Trier, Priesterseminar, 4, S. 197-200 (12. Jahrhundert), und Trier, Bistumsarchiv, Abt. 95, Nr. 133c, fol. 43 $-45^{v}$ (11. Jahrhundert). - Zur letztgenannten Handschrift vgl. Hoffmann, Buchkunst 1, S. 506. Becker, St. Eucharius, 112 f., Nr. 30. - Zum hier erneut artikulierten Anspruch auf die Gallia Belgica vgl. Flesch, Monastische Schriftkultur, S. 70 u. Anm. 169, wo er auf die Prägung dieses Begriffes für Lothringen erstmals bei Hinkmar hinweist. Sein Werk müsse in Mettlach vorhanden gewesen sein, wie schon die Rezeption des negativen Milo aus diesem Text zeige. Vgl. ebd., S. 197, Z. 67, die entsprechende Stelle aus der Predigt, wo über Celsus gesagt wird: [...], qui Belgicam Galliam industris actibus illustris autem studiis irradiavit [...]. Er vermutet zudem (ebd., S. 70), daß Remigius einen weiteren Hymnus auf Celsus sowie eine Sequenz auf Maternus verfaßt haben könnte, die bisher Theoderich zugeschrieben werden. - Zum Begriff der Belgica Gallia bei Hinkmar vgl. auch LugGe, Gallia, S. 101 f., 129, 183 f. Vgl. zur Gallia Belgica als Bezeichnung für Lothringen auch BAuER, Lotharingien, S. 83-90.

544 Vgl. De rebus Treverensibus saec. VIII-X libellus cap. 14 u. 18, ed. Wartz, S. $104-$ 106. Bei der einen handelt es sich um die gefälschte Restitution des Klosters Oeren an 
s. Liutwini entscheidend in die Mettlacher Klostergeschichte ein. ${ }^{545}$ Vor allem die $1101 \mathrm{im}$ Kloster St. Eucharius abgeschlossene Redaktion A der Gesta Treverorum widmet Egbert eine ausführlichere, doch auch rückblickend verklärende Schilderung. Er habe sich um die Klöster der Stadt bemüht und den Dom mit zahlreichen wertvollen liturgischen Geräten und weiteren Wohltaten bedacht. ${ }^{546}$

„Als einst das Fest des heiligen Eucharius bevorstand, ist er persönlich zu dessen Kloster gereist, um dort das heilige Meßopfer zu feiern. Als er nun nach Beendigung der Feierlichkeiten von den Mönchen beharrlich gebeten wurde, doch auch eine Bewirtung mit Speise und Trank anzunehmen, da lehnte er die von den Mönchen angebotene Gastfreundschaft ganz und gar ab und beschleunigte seine Rückkehr in die Stadt, $[\ldots]$.

Als er aber zum Olewiger Bach kam, versagten infolge ernster Erkrankung seine Kräfte und, ohne Verzug noch in seinen Wohnsitz gelangend, endete er seinen letzten Tag. Er wurde in einer kleinen Kapelle bestattet, die er selbst zu Ehren des heiligen Andreas erbaut hatte. ${ }^{\text {} 547}$

Selbst im Tod findet sich nach dieser Fama noch die Verbundenheit mit Triers erstem Bischof und damit der Bistumsgeschichte. Deren Grundlage könnte eine vielleicht seit Egbert vorgenommene Prozession des Trierer Domkapitels zur Euchariuskirche sein. ${ }^{58}$ Egberts Bezug zu seiner Bischofskirche zeigt sich auch in den - von den Gesta angedeuteten - von Egbert in Auftrag gegebenen und teils heute noch erhaltenen Kunstwerken aus der sog. Egbert-Werkstatt. ${ }^{549}$ Man

Trier unter Egbert (DOIII. †368, vgl. dazu oben Anm. 224), bei der anderen um eine Schenkung Egberts an das Nonnenkloster St. Maria im Jahr 988. Zur Entstehung des Libellus'vgl. oben Kap. C.1., Anm. 1, Kap. C.IV.3. sowie unten Kap. D.IX.3.

545 Vgl. dazu ausführlicher unten Kap. D.IX.4.b.

546 Vgl. dazu Gesta Treverorum cap. 29, ed. Wartz, S. 169 f.: Cui successit aeternae memoriae Eckebertus, nobilitate et virtute insignis. Hic ecclesiam suam, paganorum et christianorum rapina exinanitam, largissima liberalitate ditavit, aureis et argenteis crucibus, plenariis, casulis, dalmaticis, tunicis, palliis, cappis, velis cortinisque et possessionibus auxit; monasteria urbis, rapina comprovincialium praediis exaustas, recollectis ubique manu potestativa possessionibus, reparavit; abbatiam sancti Servatii dono secundi Ottonis recepit. Ieiunium in sua parrochia tercia post pascha ebdomada fieri praecepit; corpus sancti Celsi confessoris in cimiterio sancti Eucharii repperit.

547 Vgl. Zenz, Gesta, S. 57. Vgl. dazu Gesta Treverorum cap. 29, ed. Wartz, S. 170 f.: Adveniente quondam festivitate sancti Eucharii, ipse pro celebrando ibidem divino officio ad eius monasterium perrexit. Cumque post expleta missarum sollempnia a fratribus obnixe peteretur cibi potusque karitatem sumere, ne eis onerosum fortasse existeret si tanta comitatus ambitione ibidem reficeretur, coepit oblatam a fratribus karitatem omnino refutare et reditum suum in urbem maturare. Cumque venisset ad fluvium Oleviam, coepit infirmitate gravi deficere, nec mora ad suam sedem veniens, diem clausit extremum. Sepultus est ibidem in parva ecclesia, quam ipse construxerat in honore sancti Andreae. - Die Berichte der Redaktionen B und C wissen dann plötzlich noch mehr. Vgl. dazu die Anm. ebd.

548 Vgl. Becker, St. Eucharius, S. 388 f., 426.

549 Vgl. zusammenfassend Westermann-Angerhausen, Goldschmiedearbeiten, S. 9-21. Vgl. zu den Bildhandschriften Egberts auch insgesamt Sauerland/Haseloff, Psalter, S. $58-80$. 
denke nur an den Egbert-Kodex ${ }^{550}$ oder eine Handschrift der Briefe Gregors des Großen. ${ }^{51}$ Von besonderem Interesse für unser Thema ist jedoch der sog. Andreas-Tragaltar bzw. Egbert-Schrein mit einer Sandale des hl. Andreas, ${ }^{552}$ der in Zusammenhang mit dem Neubau der Andreaskapelle am Trierer Dom stehen dürfte, in der sich Egbert bestatten ließ. ${ }^{553}$ Ganz offensichtlich sollte neben Petrus und Eucharius mit dem hl. Andreas Triers apostolische Tradition noch erweitert und verstärkt werden. ${ }^{554}$ Ferner erhielt Egbert einen Teil des sog. Petrusstabes für Trier und ließ ihn dort mit einer Trierer Bischofsliste verkleiden. ${ }^{55}$ Eine weitere Bischofsliste findet sich im berühmten Egbert-Psalter in Form ganzseitiger Abbildungen früherer Trierer Bischöfe. ${ }^{556}$ Schließlich ließ Egbert auch eine umfangreiche Liste der Bischofsnamen von Eucharius bis zu ihm selbst abfassen. ${ }^{557}$ All das kann man aber nicht nur als Trierisches Selbstbewußtsein gegenüber Köln lesen. Vielmehr zeigt es ebenso eine Argumentation gegen Mainz unter seinem mächtigen Bischof Willigis. Auch dort war man um Bischofslisten bemüht, die möglichst weit in die Vergangenheit zurückreichten. ${ }^{558}$ In diesen Trierer Listen, die im folgenden behandelt werden, erscheinen nun wieder Liutwin und erstmals auch Basin.

Zusammenfassend wird erkennbar, daß Egbert mit einer massiven Aufwertung des Kultes der ersten Trierer Bischöfe - u. a. in St. Eucharius - sowie des Apostels Andreas die Bemühungen um Vergangenheit und Selbstdefinition seines Bistums forcierte. Dabei fallen die Kontakte Egberts nach Reims und Mettlach auf. Aber auch die Beziehungen von Mettlach nach Reims und zu Egbert sind nicht zu übersehen. So spricht einiges dafür, daß jetzt die Rezeption Reimser Traditionen und Texte in Trier und dem Saarkloster erfolgte, u. a. die des Reimser Milobildes. Eingebettet in diese vielfältigen Wechselwirkungen und

550 Vgl. Weiner, Katalog der Kunstwerke, S. 23 f. u. Taf. 34-54. Vgl. dazu zuletzt den umfangreichen Ausstellungsband Der Egbert-Codex, ed. Franz.

551 Vgl. Weiner, Katalog der Kunstwerke, S. 21 f. u. Taf. 29 f. Weiner faßt in diesem Band noch die Beschreibungen zahlreicher weiterer Handschriften und Kunstobjekte aus dem Trierer Raum dieser Zeit zusammen.

552 Vgl. Weiner, Katalog der Kunstwerke, S. 36 f. u. Taf. 146-159.

553 Dort soll Egbert auch ausgerechnet seinen Vorgänger Heinrich, den möglichen Verfasser der Vita Eucharii, Valerii et Materni, - nach den Redaktionen B und C der Gesta beigesetzt haben. Vgl. Gesta Treverorum cap. 19, ed. Waitz, S. 168. Die Red. A spricht vom Tod Heinrichs in Italien und der Überführung der Leiche auf den Trierer Domfriedhof. Die Redd. B u. C lassen die Überführung dann aus, ergänzen aber in ebd. cap. 19, S. 171, zum Grab Egberts in der Andreaskapelle, daß er dort zuvor habe Heinrich beisetzen lassen.

554 Vgl. dazu Steinruck, Erzbischof Egbert, S. 204. Boshof, Köln, Mainz, Trier, S. 32.

555 Vgl. dazu unten Kap. D.VI.3.c.

556 Vgl. dazu Kap. D.VI.3.d.

557 Vgl. dazu Kap. D.VI.3.e.

558 Vgl. hier nur STEInRuck, Erzbischof Egbert, S. $204 \mathrm{f}$. 
das Interesse an den Trierer Bischöfen muß man auch den sermo des Mettlacher Abtes Remigius über Liutwin für den liturgischen Gebrauch im Kloster sehen, der mit der Liutwin-Vita I identisch sein dürfte. Er ist ein Indiz für den beginnenden und sich intensivierenden Liutwinkult im Mettlach dieser Jahre wohl unter Egberts Einfluß. Denn Remigius unterstützte Egberts Fürsorge für St. Eucharius nachweislich mit eigenen Texten, die auch Triers Primatsanspruch über die Gallia und Germania postulierten.

\section{b. Frühe Bischofslisten aus Egberts Umfeld}

Einen Beleg, daß Liutwin tatsächlich erst unter Egbert Eingang in die Trierer Bischofsliste fand, bietet die schon in anderem Zusammenhang herangezogene Handschrift Köln, Dombibliothek, 88. Das nach einer Kölner Vorlage in Fulda angefertigte Sakramentar enthält an verschiedenen Stellen einige Trierer Ergänzungen vom Ende des 10. Jahrhunderts. Sie sind eingetragen von Schreibern aus dem Umkreis des Trierer Egbert-Kodex'. Darunter befindet sich der oben erwähnte früheste Nachweis des Geburtstages einer Irmina. ${ }^{559}$

Winfried BöHNe hat vor einiger Zeit nochmals thematisiert, daß in einer darin enthaltenen Litanei sieben Namen in der Gruppe der Bekenner ausradiert und durch folgende ersetzt wurden (ebd., fol. $9^{\mathrm{r}}-10^{\mathrm{v}}$, hier fol. $9^{\mathrm{v}}$ ): Eucharius, Valerius, Maternus, Agritius, Maximinus, Paulinus, Hilarus. ${ }^{560}$ Diese Personen sind bereits bekannt. Nur die letzte fügt sich nicht ein. BöHNE hält sie für eine Verwechslung mit Bischof Hilarius von Poitiers aus der Mitte des 4. Jahrhunderts. ${ }^{561}$ Die Namensanordnung entspricht ansonsten der im Privileg Johannes' XIII., nur Severus fehlt. ${ }^{562}$ Die Liste paßt somit bestens in die Zeit der 970er Jahre.

Doch sind das noch nicht alle Trierer Zusätze. Im Kalendar (fol. $\left.3^{r}-8^{v}\right)$ ist zum 27. April der Gedenktag Maximins eingetragen (fol. $4^{\mathrm{v}}$ ), zum 31. August Sci. Paulini archiepi (fol. 6v), zum 8. Dezember die Oct[ava] s. Andree und zum Folgetag die Depos. S. Eucharii epi. in Trev. (fol. $\left.8^{v}\right) .{ }^{563}$ Eine andere Trierer Hand ergänzte auf fol. $15^{\mathrm{v}}-22^{\mathrm{r}}$ Meßformulare zu Heiligen, darunter Gebetstexte zu Maximin, Paulinus und Nicetius, eine weitere Hand fügte ,auf den fol. $22^{\mathrm{v}}-23^{\mathrm{r}}$

559 Vgl. zu dieser Handschrift und zu ihrem Nachweis einer Oerener Irmina bereits ausführlich oben S. $173 \mathrm{f}$. u. Anm. 221. An dieser Stelle sei nur nochmals Hoffmann, Buchkunst 1, S. 156-158, kurz erwähnt, der die Handschrift nach St. Maximin verweist.

560 Der Eintrag findet sich unmittelbar nach dem Namen siluesteri, sicher nicht ohne Absicht.

561 Vgl. BöHNe, Erzbischof Egbert, S. 102 f. u. Anm. 27. - Dies zeigt, daß wohl auch dieser Liste literarische Nachforschungen zugrunde lagen, die in jenem Fall fehlerhaft waren.

562 Vgl. dazu Kap. D.VI.2.

563 Vgl. BöHne, Erzbischof Egbert, S. 103. 
Formulare für die Trierer Bischöfe Marus [...] und Felix [...]“ hinzu. ${ }^{564}$ Nach BöHNE sprechen die Bischöfe und die auffällige Betonung des Apostels Andreas dafür, daß die interpolierte Bischofsliste in Egberts früher Amtszeit entstand. ${ }^{565}$ Eine mit diesem Namensgut fast identische Bischofsliste auf einem Missalefragment, das Hoffmann neuerdings dem Umkreis des Egbert-Kodex' zuweist, unterstützt diese These sogar noch. ${ }^{566}$

Es fällt auf, daß - obwohl die Zahl der Namen im Vergleich zu den vorausgehenden Listen um Marus und Felix angewachsen ist - Liutwin und auch Basin hier gänzlich fehlen. Sie verfügten also noch über keine so durchschlagende Bedeutung wie jene beiden. Diese Beobachtung weckt darüber hinaus begründete Zweifel daran, ob tatsächlich eine Reliquie Liutwins schon 952 ihren Platz im St. Maximiner Bischofsaltar fand. Zumindest nahm Egberts Umfeld davon noch keine nachweisbare Notiz.

Auch ein Kalendar aus einem St. Maximiner Psalter der Mitte des 10. Jahrhunderts, das von Hontheim im 18. Jahrhundert publizierte, enthält keinen Liutwin oder Basin, sondern die folgenden Namen: Eucharius, Valerius, Agritius, Maximinus, Paulinus, Marus. ${ }^{567}$ Offenbar verfügte man lediglich über einen Grundstock bekannter heiliger Trierer Bischöfe. Doch warum nahm man in St. Maximin Liutwin nicht auf? Ruhte denn seine Reliquie nicht in der eigenen Krypta?

Auf Egberts frühes Episkopat bei den Nachträgen in den Kölner Kodex weist auch ein Trierer Kalender hin, der sich in einem Sakramentar befindet, das in Paris (BN, lat. 18005, fol. $4^{\mathrm{v}}-10^{\mathrm{r}}$ ) aufbewahrt wird. Hoffmann datiert die ganze Handschrift ins ausgehende 10. Jahrhundert. Sie sei auf der Reichenau für eine Trierer Kirche entstanden. Eine beteiligte Hand fände sich im EgbertPsalter wieder. ${ }^{568}$ Daraus lassen sich bereits die folgenden Trierer Bischöfe zusammentragen: Eucharius, Valerius, Agritius, Maximinus, Paulinus, Marus, Maternus, Felix, Nicetius, Modoald, Liutwin. ${ }^{569}$ Die um Modoald und Liutwin erweiterte Liste macht damit wahrscheinlich, daß sie etwas nach, aber kaum vor dem Missalefragment und der Kölner Handschrift entstand. Bedenkt man

564 Vgl. Böhne, Erzbischof Egbert, S. 103 f. Hoffmann, Buchkunst 1, S. 157 f.

565 Vgl. BöHNe, Erzbischof Egbert, S. 105-107.

566 Vgl. Hoffmann, Ottonische Handschriften aus Trier, S. 88 f. u. Abb. 3a, zum Fragment Erfurt, Stadtarchiv, Mappe 5/205-6/14. Die Liste befindet sich im Libera nos und lautet: Euchario, Valerio, Materno, Agricio, Maximino, Paulino, Felice, Maro.

567 Vgl. BöHne, Erzbischof Egbert, S. 106. Von Hontherm, Prodromus, S. 373-379. Es handelt sich um die Handschrift $\mathrm{M}^{1}$ bei Miesges, Festkalender, S. 11. Die Handschrift ist verschollen.

568 Vgl. Hoffmann, Buchkunst 1, S. 338. Die Hand des Egbert-Psalters ist die Hand B dieser Handschrift. Vgl. auch Sauerland/Haseloff, Psalter, S. 156 f. Delisle, Inventaire (1871), S. 77.

569 Vgl. dazu BöHNe, Erzbischof Egbert, S. 106. - In der Litanei des Sakramentars finden sich die Namen allerdings nicht. Vgl. dazu Sauerland/Haseloff, Psalter, S. 194-197. 
Egberts spätere Bischofslisten, gehört auch Paris, BN, lat. 18005 noch in seine frühe Zeit.

Die Kölner und Pariser Kodizes sichern die These, daß Egbert nach weiteren Trierer Bischofsnamen suchte und sie allmählich ergänzte. Doch wo fand er sie? Forschte er in Trier gezielt nach Gräbern oder Grabsteinen? Auf die meisten Namen konnte man im Umkreis des Erzstifts auch sukzessive durch Studien in Viten, erhaltenen Konzilsakten oder anderen Quellen gestoßen sein. Diese Nachweise lassen sich teilweise heute noch rekonstruieren. Die betreffenden Texte waren außerhalb Triers greifbar, falls die eigenen Exemplare den Normannensturm 882 nicht überstanden hatten. Vielleicht halfen hier die Reimser Kontakte. ${ }^{570}$

570 So lassen sich solche Texte für Felix, Marus, Nicetius und Modoald nachweisen. - Zu Felix ( $\dagger$ ca. 399) vgl. Duchesne, Fastes 3, S. 36. Winheller, Lebensbeschreibungen, S. 73-84. Felix von Trier wird u. a. bei Sulpicius Severus, Dialogi III, 13,2, ed. Halm, S. 208-211, hier S. 211, erwähnt und ist für die Zeit von 386-401 durch einige zeitgenössische Quellen bezeugt (WINHELLER, S. 75 f., mit den genauen Quellennachweisen). Felix' erste Vita, die sich aber schon auf die Bischofsliste bezieht und auch Sulpicius Severus verwendet, wurde wahrscheinlich Ende des 10. oder Anfang des 11. Jahrhunderts in St. Paulin verfaßt. Danach soll er eine Marienkirche (St. Paulin?) in Trier erbaut haben, in der er auch begraben wurde (WINHELLeR, S. 76 f., $82 \mathrm{f}$.). Vgl. ferner Heyen, St. Paulin, S. 283 f. Gauthier, Évangélisation, S. 64 ff., auch zum Abhängigkeitsverhältnis der Viten aus dem St. Pauliner Bereich. Anton, Trier im frühen Mittelalter, S. 80 f. Gierlich, Grabkirchen, S. 33 f. Binsfeld, Geschichte des Bistums Trier, S. 58 ff. Heinen, Bistum Trier, S. 92-95. BAuer, Verehrung heiliger Trierer Bischöfe, S. 369 f., weist darauf hin, daß seine Verehrung in der Zeit Egberts beginnt. Felix' angebliches Grab ist für St. Marien/St. Paulin überliefert. Vgl. auch Anton, Führungsschicht Galliens, S. 17-45. - Zu Marus ( $\dagger$ ca. 480) vgl. DuchesNe, Fastes 3, S. 37. Ewig, Trier, S. 46, Anm. 170 u. S. 51, 60. Heyen, St. Paulin, S. 290 f. Anton, Trier im frühen Mittelalter, S. 85-87. GauThier, Évangélisation, S. 80, 135 f. Gieruich, Grabkirchen, S. 39. Heinen, Bistum Trier, S. 114. PFeiffer, Die frühe fränkische Zeit, S. 197. BAuER, Verehrung heiliger Trierer Bischöfe, S. 378 f. Marus' Verehrung ist seit dem Ende des 10. Jahrhunderts nachweisbar. Nach den Gesta Treverorum cap. 23, ed. Waitz, S. 158 (um 1100), wird Marus die Restaurierung des von den Franken verwüsteten Klosters St. Paulin zugeschrieben, wo er auch begraben sei. Die Erinnerung an Marus könnte aber an Felix und die St. Paulinskirche gekoppelt worden sein. Die Miracula S. Mari, ed. A.T., S. 730 f., finden sich erst in einer viel späteren Trierer Handschrift. - Zu Nicetius († nach 561) vgl. bereits oben S. 272 u. Anm. 499 sowie seine Lebensbeschreibung bei Gregor von Tours, Liber vitae patrum XVII, ed. KR UsCH, S. 727-733. - Zu Modoald vgl. Duchesne, Fastes 3, S. 38 f. Winheller, S. 145-158. Modoald erscheint in Konzilsakten, die sich bei Flodoard II,5, ed. StRATMAnN, S. 142, finden. Darüber hinaus gibt es noch weitere, unmittelbare zeitgenössische Quellen (ein Brief des Desiderius von Cahors sowie die Vita des Abtes Germanus von Granfelden, vgl. WinHELLER, S. 146-148). Die Modoald-Vita stamme erst aus dem frühen 12. Jahrhundert (Winheller, S. 148 ff.). Vgl. ferner Gauthier, Évangélisation, S. 347-356. Anton, Trier im frühen Mittelalter, S. 143-149. Gierlich, Grabkirchen, S. $47 \mathrm{f}$. Anton, Raumbestimmende Voraussetzungen, S. 153-158. BaUER, Spätmerowingische 
Für Liutwin existieren solche frühen Belege nicht. Die Pariser Handschrift bietet vielmehr den ersten erhaltenen Nachweis Liutwins überhaupt in einem Kalendar. Alle weiteren finden sich danach bzw. ab dem 11. Jahrhundert. Basin wird sogar noch viel später aufgenommen. ${ }^{571}$ Der Befund unterstreicht, daß erst zu Egberts Episkopat der entscheidende Schritt zur Aktivierung eines Liutwinkultes in Trier und damit wohl auch in Mettlach gemacht wurde.

Es ist nicht zu übersehen, daß Modoald und Liutwin ihren Weg gemeinsam in die Liste fanden. Bestand damit ein unmittelbarer Zusammenhang zwischen beiden? Immerhin tauchen sie am Ende des 10. oder zu Beginn des frühen 11. Jahrhunderts in manipulierten und miteinander in Verbindung stehenden Trierer Texten jeweils als Schenker- bzw. Gründerbischöfe eines Klosters im Trierer Raum (Oeren und Mettlach) auf. Es sei denn, ein Schenker Liutwin wäre schon Ende des 9. Jahrhunderts vom Trierer Erzbischof Radbod (883915) konstruiert worden. Doch warum geriet er dann zunächst wieder in Ver-

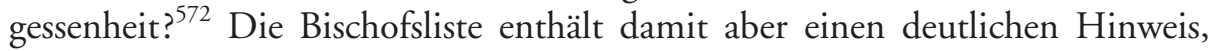
daß wohl Egbert selbst der Erfinder dieser komplementären Bilder und womöglich auch der Veranlasser der sie enthaltenden Dokumente war.

Fassen wir zusammen: Die Namen von Trierer Bischöfen im St. Maximiner Psalter aus der Mitte des 10. Jahrhunderts, die unter Egbert erfolgten Einträge solcher Namen zunächst in den Kölner Kodex (Dombibliothek, 88) und das Missalefragment (Erfurt, Stadtarchiv, Mappe 5/2005-6/14) sowie dann in

Zeit, S. 221-234. BAuER, Verehrung heiliger Trierer Bischöfe, S. 392-394, bemerkt, Modoalds Verehrung sei erst seit dem ausgehenden 10. Jahrhundert nachweisbar. Die vor der Vita entstandenen Gesta Treverorum cap. 24, ed. Wartz, S. 160, berichten, Modoald habe die Symphorianskirche am Moselufer erbaut und sei dort bestattet worden. Heyen, St. Paulin, S. 295-299, weist darauf hin, daß Modoald später nach St. Paulin umgebettet wurde. - Insgesamt zeichnet sich dabei also ab, daß jeder dieser Bischöfe in der späteren Tradition der Trierer Geschichte einmal besonders mit dem Schicksal einer dortigen Kirche verbunden war, wo er dann meist zunächst begraben lag.

$571 \mathrm{Zu}$ Liutwins Erscheinen in weiteren Handschriften seit dem späten 10. Jahrhundert vgl. unten Kap. D.VII. - Vgl. dazu ferner u. a. Miesges, Festkalender, S. 34 f., zu Basin, der nach seinem Eintrag im Willibrord-Kalendar nach langer Zeit in einem St. Maximiner Kalendar des 13. Jahrhunderts nachweisbar ist. Vgl. ebd., S. 8 , 88 f., zu Liutwin. Liutwin finde sich als einer mehrerer Nachträge vom Anfang des 11. Jahrhunderts in einer nicht aus Trier stammenden Handschrift des 9. Jahrhunderts (Berlin, Staatsbibliothek, lat. 131, Phillipps 1869). Das Kalendar (fol. $1^{\mathrm{r}}-11^{\mathrm{r}}$ ), in dem der Eintrag ergänzt ist, sei angelsächsischen Ursprungs. Die Nachträge des 11. Jahrhunderts wiesen meist Trierer Bezüge auf. Zum 29. September ist vermerkt (fol. $\left.8^{v}\right)$ : et in medeloco. depos sci Liutuuini treverensis archiepi. Daß Liutwin danach erst wieder in einem Kalendar des 14. Jahrhunderts zu finden sei, ist inzwischen widerlegt. - Zur Berliner Handschrift vgl. Rose, Verzeichniss 1, S. 293-295, Nr. 131, hier S. 294. Diese Handschrift enthält auf fol. $9^{\mathrm{r}}$ zu den 15. Kalenden des November auch den Nachtrag zum Tod Abt Nithards/Nizzos von Mettlach: O(biit) Nithað abbas mediolacensis. Vgl. dazu ausführlicher oben S. $286 \mathrm{u}$. Anm. 538.

572 Vgl. dazu ausführlich schon oben Kap. D.II.4.a.-c. 
erweiterter Form in das Pariser Sakramentar (BN, lat. 18005) dokumentieren ein langsames Anwachsen einer Trierer Bischofsliste. Unter Egberts Pontifikat kommen in mindestens zwei nachweisbaren Stufen sukzessive neue Bischöfe hinzu. Erst in der zweiten Stufe finden sich Modoald und Liutwin. Egbert dürfte damit maßgeblich für die Belebung ihres Kultes verantwortlich gewesen sein. Die einander entsprechenden Bilder eines Gründer- bzw. Schenkerbischofs bei Modoald und Liutwin, wie sie sich in manipulierten und voneinander abhängigen Trierer Texten in enger zeitlicher Nähe zu Egbert finden, deuten darauf hin, daß jener selbst am Entwurf dieser Bilder mitwirkte, wenn nicht schon Erzbischof Radbod am Ende des 9. Jahrhunderts einen solchen Liutwin für seine Zwecke konstruiert hatte.

\section{c. Die Bischofsliste des Trierer Petrusstabes}

Die nächste, dritte Stufe der Bischofsliste Egberts überliefert der sog. Petrusstab, der nun Liutwin fest in das Namensprogramm aufgenommen hat, während Basin weiter fehlt.

Zwei Kupferbänder an den Längsseiten des mit Goldblech verkleideten Stabes enthalten eine Datierung auf das Jahr 980 sowie eine Inschrift, die die Geschichte der Reliquie wiedergibt:

„(Dies ist) der Stab des heiligen Petrus, ehemals von ihm selbst zur Auferweckung des Maternus entsandt und vom heiligen Eucharius hierher gebracht. Lange war er im Besitz dieser Kirche. Später, in der Hunnenzeit, wurde er mit den restlichen Schätzen dieser Kirche nach Metz gebracht. Dort blieb er bis in die Zeit des frömmsten Kaisers Ottos des Älteren [I., 936-973]. Dann wurde er auf Forderung seines Bruders, des Erzbischofs Bruno, nach Köln übertragen. Aber in der Zeit Kaiser Ottos des Jüngeren [II., 961-983] wurde er auf Bitten des Erzbischofs Egbert von Trier und unter Zustimmung des ehrwürdigen Kölner Erzbischofs Warin [976-985] - vor allem aber, damit diese Kirche eines solchen Schatzes nicht länger beraubt bliebe - in zwei Teile zerschnitten. Ein Teil, nämlich der obere, wurde dieser Kirche zurückgegeben und vom Herrn Bischof in dieser Hülle geborgen. Der andere Teil und der elfenbeinerne Knauf wurde in Köln behalten. ${ }^{9573}$

573 Vgl. zur Übersetzung Westermann-Angerhausen, Goldschmiedearbeiten. S. 36. Vgl. ebd. zum Wortlaut der Inschrift: BACVLVM BEATI PETRI QVONDAM PRO RESVSCITATIONE MATERNI AB IPSO TRANSMISSVM. ET A SCO EVCHARIO HVC DELATVM. DIV HAEC AECLESIA TENVIT. POSTEA HVNORVM VT FERTVR TEMPORIBVS METTIS CVM RELIQVIS HVIVS AECLESIAE THESAVRIS DEPORTATVS. IBI VSQ. AD TEMPORA OTTONIS PIISSIMI IMPERATORIS SENIORIS PERMANSIT. INDE A FRATRE EIVS BRVNONE ARCHIEPO EXPETITVS COLONIAE EST TRANSLATVS. IVNIORIS AVTE OTTONIS IMPERATORIS TEPORE PATENTE ECEBERTO TREVIRORV ARCHIEPO ET ANNVENTE VENERABILI VVERINO COLONIAE ARCHIEPO. NE ET HAEC AECLESIA TANTO THESAVRO FRAVDARETVR. IN DVAS EST PARTES TRANS'SECTVS. VNA SVPERIORI VIDELICET HVIC AECLESIAE REDDITA ET A DOMNO EPO IN HAC THECA RE- 
Man sieht, wie Egbert die Euchariuslegende jetzt mit dem aus Köln geholten Reliquienteil verband und visuell inszenierte. Der Stab wurde schließlich auch bei Prozessionen eingesetzt. Die Forschung ist zu seiner Geschichte letztlich immer dieser Inschrift gefolgt. Doch über seine frühere Geschichte ist im Grunde nichts bekannt, auch nicht, wie er nach Metz gelangt sein soll. Die bisherige "Inaugenscheinname“ des Holzes deutet zwar auf ein hohes Alter, allerdings sind danach die Hölzer des Kölner und Trierer Stabes nicht identisch. $^{574}$

Die Reliquie, die sich heute im Limburger Domschatz befindet, wird neben der goldenen Hülle von einem mit Edelsteinen und Emailarbeiten verzierten Knauf geschmückt. Beides wurde in der Trierer Egbert-Werkstatt angefertigt. Am Knauf sind als Emails am oberen Teil die Symbole der vier Evangelisten angebracht. Unten befinden sich komplementär die Brustbilder von SCS PETRUS, SCS VALERIUS, SCS MATERNUS und SCS EUCHARIUS. Unmittelbar darunter, am Hals des Stabes, sind in zwei untereinander liegenden Reihen die Apostel dargestellt. ${ }^{575}$ Auf der anschließenden langen Umhüllung aus Goldblech befinden sich in Form von Treibarbeiten jeweils untereinander die namentlich bezeichneten Brustbilder von zehn Päpsten und zehn Trierer Bischöfen mit Nimbus. Die erwähnten Kupferbänder trennen beide Reihen voneinander: $:^{576}$

SCS CLEMENS PAPA

SCS LINVS PAPA

SCS CLETVS PAPA

SCS ANACLETVS PAPA

SCS KAL(i)STVS PAPA
SCS AGRITIVS ARCHIEPS

SCS MAXIMINVS ARCHIEPS

SCS PAVLINVS ARCHIEPS

SCS FELIX ARCHIEPS

SCS SEVERVS ARCHIEPS

CONDITA. RELIQVA CV APICE EBVRNEO IBIDEM RETENTA. ANNO DOMINICAE INCARNAT • DCCCCLXXX INDI ... (VIII).

574 Vgl. zum Stab und seiner Geschichte zuletzt Kloft, Dom und Domschatz, S. 82-88, der auch (ebd., S. 83) auf die unterschiedlichen Hölzer der Stabfragmente hinweist. Vgl. ferner Boshof, Erzstift Trier, S. 58 f. Lauer/Hefele, Petrusstab, S. 305-310. Bauer, Lotharingien, S. 411-429, der ebd., S. 342 ff., auch Bistumsgründungen und Stablegenden vor allem in Lotharingien untersucht und sich (ebd. S. 405-465) intensiv dem lotharingischen Stablegendenzyklus widmet. Von Trier habe die Legende ihren Ausgang genommen. Er geht (ebd., S. 412 f.) von einer, trotz aller Wirren, lückenlosen Bischofsliste aus. Nilgen, Amtsgenealogie, S. $221 \mathrm{f}$. - Zur Verehrung eines Petrusstabs in Köln vgl. Ruotger, Vita Brunonis cap. 31, ed. Отт, S. 31: Baculum et catenam sancti Petri, qua diligencia, quo fervore, quo gaudio Coloniam, alterum Metti, alteram Roma adduxerit, omnes noverunt. AсHTER, Petrusreliquien, S. 941-998.

575 Vgl. Westermann-Angerhausen, Goldschmiedearbeiten, S. 36 f.

576 Vgl. zu den Darstellungen des Stabes Westermann-Angerhausen, Goldschmiedearbeiten, S. 34-40, 125 f., 129-134, die dargestellten Bischöfe, S. 34. Vgl. ferner Egbert. Erzbischof von Trier 1, ed. Ronig, S. 38 f. u. Taf. 160-164. Kloft, Dom und Domschatz, S. 82 f., 86-88. Kraus, Bischofskataloge, S. 166 f. 
SCS FABI(i)ANVS PAPA

SCS CORNELIVS PAPA

SCS SYLVESTER PAPA

SCS GREGORIVS PAPA

BENED(ic)TVS SEPTIMUS PAPA
SCS MARVS ARCHIEPS

SCS NICETIVS ARCHIEPS

SCS MODOALDVS ARCHIEPS

SCS LIVDOVVINVS ARCHIEPS

EGBERTVS ARCHIEPS

Die Liste der Päpste nimmt die ersten vier direkten Nachfolger des Petrus auf und ergänzt drei Märtyrer-Päpste des 3. Jahrhunderts sowie Silvester und Gregor bis zum unmittelbaren Zeitgenossen Egberts: Benedikt VII. (974-983). Alle bis auf diesen sind Heilige. ${ }^{577}$

Die Liste der heiligen Trierer Bischöfe steht gleichwertig daneben und wird von Petrus über die inzwischen bekannten Namen bis zu Egbert selbst weitergeführt. Sie parallelisiert damit die Papstreihe. Das Trierer Namensgut der beiden zuvor besprochenen Handschriften (Köln, Dombibliothek, 88; Paris, BN, lat. 18005) findet sich hier wieder, ergänzt um eine Person: Severus. Damit wurde der bisher fehlende Bischof aus dem Diplom Johannes' XIII. in die Liste aufgenommen.

Es läßt sich also zusammenfassend sagen, daß diese Version der Bischofsliste relativ zeitgleich mit dem Pariser Kodex oder bald danach entstand. Liutwin gehört ihr inzwischen als feste Größe und letzter bekannter heiliger Bischof vor Egbert an. Seine Bedeutung stabilisierte sich. Die Liste zeigt, wie intensiv sich Egbert allein in den ersten vier Jahren seines Pontifikats mit seinen Vorgängern beschäftigte, was auch Liutwins Rolle erheblich aufwertete.

\section{d. Die heiligen Bischöfe des Trierer Egbert-Psalters}

Eine weitere Fassung der Bischofsliste, die wiederum Liutwin aber nicht Basin enthält, findet sich in Egberts berühmtem Prachtpsalter, der heute in Cividale aufbewahrt wird. ${ }^{578}$ Er entstand - nach Meinung der Forschung - als Trierer Auftragsarbeit auf der Reichenau zwischen 977 und 980. Die Handschrift stellt den Mönch Ruodprecht als Donator an Egbert dar. Als Illustrationen enthält sie nach jeder Psalmdekade jeweils ganzseitige Darstellungen von vierzehn heiligen Trierer Bischöfen in folgender, chronologisch jedoch nicht korrekter Reihenfolge: ${ }^{579}$

$577 \mathrm{Zu}$ diesen Päpsten vgl. hier nur ihre Biographien im Liber pontificalis 1, ed. Duchesne. Vgl. dazu auch Book of Pontiffs to AD 715, ed. Davis. Zu Benedikt VII. vgl. zuletzt Zimmermann, Benedikt VII.

578 Vgl. Cividale, Museo Archeologico Nazionale, 136. Vgl. dazu ausführlich Scalon/Pani, Codici, S. 337-349.

579 Zur Widmungsseite vgl. Cividale, Museo Archeologico Nazionale, 136, fol. 16 ${ }^{\mathrm{v}}-17^{\mathrm{r}}$. Zu Abbildungen aus dem Psalter vgl. Egbert. Erzbischof von Trier 1, ed. Ronig, Taf. 8-15. Sauerland/Haseloff, Psalter, Taf. 1 ff., zu den Bischöfen ebd. Taf. 7-33. - Zur 

S. Eucharius (3. Jh.)
S. Marus († um 480)
S. Valerius (3. Jh.)
S. Felix (368-398)
S. Maternus (4. Jh.)
S. Modualdus (ca. 622-647)
S. Agricius $(\dagger 330)$
S. Liutuuinus (angebl. $† 715$ )
S. Maximinus (330-347)
S. Legontinus († um 409?)
S. Paulinus (347-358)
S. Magnericus (570-596)
S. Nizetius (525-566)
S. Abrunculus († um 527) ${ }^{580}$

Am Ende der Handschrift sind die Namen dieser Bischöfe noch einmal in derselben Abfolge in eine Litanei aufgenommen. Sie eröffnen darin die Reihe der heiligen Bekenner und sind durch in Gold gehaltene Majuskelbuchstaben gegenüber den anderen Einträgen hervorgehoben. ${ }^{581}$

Die Anordnung entspricht bis zu Paulin derjenigen der Urkunde Johannes' XIII., die allerdings Nicetius nicht mehr enthält. Dafür fehlt im Psalter Severus. ${ }^{582}$ Dann folgen die im Pariser Sakramentar (BN, lat. 18005) zu findenden Ergänzungen bis zu Liutwin. Am Ende aber kommen erstmals Legontius, Magnerich und Abrunculus neu hinzu. Auch ihre Namen ließen sich in literarischen Quellen wiederfinden. Da sie als Heilige bezeichnet werden, ist nicht auszuschließen, daß man sich auf die Suche nach ihren möglichen Gräbern machte. ${ }^{583}$ So kann man an dieser Liste die einzelnen Ergänzungsstufen Egberts

Datierung und Lokalisierung vgl. erstmals ausführlich und bisher unwidersprochen Sauerland/Haseloff, S. 3-36, bes. S. 3-23; ebd., S. 45-57, auch mit der genauen Zuweisung der Illustrationen; ebd., S. 142-171, zur kunsthistorischen Datierung. Ebd., S. 37-42, ist das Kalendar des Psalters wiedergegeben, in dem sich von den Bischöfen aber nur Eucharius und Paulin finden. Zum Psalter vgl. Weiner, Katalog und Kunstwerke, S. 20. Ronig, Psalter, S. 163-168. Inzwischen liegt eine italienische Faksimileausgabe mit umfangreichem Kommentar (Psalterium Egberti, ed. BARBERI) und einer Zusammenfassung des Forschungsstandes (ebd., S. 105-177) vor. Vgl. zur Bischofsliste des Psalters auch schon Kraus, Bischofskataloge, S. $165 \mathrm{f}$.

580 Vgl. diese Genealogie mit den allerdings nur annähernd korrekten Pontifikatszeiten bei Weiner, Katalog und Kunstwerke, S. 20. Vgl. ferner Hoffmann, Buchkunst 1, S. 315.

581 Vgl. die Handschrift Cividale, Museo Archeologico Nazionale, 136, fol. 210 ${ }^{\mathrm{v}}-211^{\mathrm{r}}$. Egbert. Erzbischof von Trier 1, ed. Ronig, Taf. 16b. Zum Text der Litanei vgl. Coens, Recueil, S. 204-213, Nr. 9, hier S. 205 f.: Euchari, Valeri, Materne, Agrici, Maximine, Pauline, Nizeti, Mare, Felix, Modualde, Liutwine, Legonti, Magnerice, Abruncule.

582 Vgl. dazu Seibrich, Egbert, S. 188 u. Anm. 13, der darauf hinweist, daß einige Namen der Liste wohl umstritten waren und sich Severus nur auf dem Petrusstab als Heiliger finde. Vielleicht habe die Papsturkunde von 969 dazu geführt, Severus zunächst aufzunehmen.

583 Vgl. zu Legontius/Leontius Duchesne, Fastes 3, S. 36. Ewig, Trier, S. 39-42. Überliefert ist ein Bischof Leontius, allerdings ohne Bistumsbezeichnung, als „Alterspräsident“ der gallischen Kirche in einem Brief Papst Leos des Großen (440-461) von 444 (S. Leonis Magni Epistola 10, Sp. 628-636) sowie in einem Reskript Kaiser Valentinians an Aëtius (ebd., Sp. 636-640). Heyen, St. Paulin, S. 284-289. Gauthier, Évangélisation, S. 128, 131. Anton, Trier im frühen Mittelalter, S. 81-83. Gierlich, Grabstätten, 
geradezu ablesen. Die Schreiber und Illustratoren auf der Reichenau brachten diese in keine chronologische Reihenfolge, wie es auf dem Petrusstab geschah. ${ }^{584}$ Das heißt, der Auftrag für den Psalter muß noch vor der Arbeit am Stab an die Reichenau gegangen sein. Vermutlich erhielt man dort das neue, noch ungeordnete Material, das mit einiger Verzögerung um die drei letzten Namen ergänzt wurde. Merkwürdig bleibt, warum Severus fehlt. War sein Status als Heiliger inzwischen wieder oder noch umstritten? Jedenfalls dürften Stab und Psalter zeitlich parallel entstanden sein, wobei der Psalter später vollendet wurde.

Zusammengefaßt verdeutlicht der Psalter, daß Liutwin während einer zweiten Stufe der Sammelarbeiten Egberts zur Liste hinzukam, danach aber noch weitere Trierer Bischöfe (Legontius, Magnerich und Abrunculus) ausfindig gemacht und ergänzt wurden.

S. 34-36, gibt an, im frühen 12. Jahrhundert finde sich eine undeutliche Grabtradition in St. Paulin. Heinen, Bistum Trier, S. 95 f. Bauer, Verehrung heiliger Trierer Bischöfe, S. 371-374, bemerkt, seine Verehrung sei erst ab dem späten 10. Jahrhundert nachweisbar. - Vgl. zu Magnerich Duchesne, Fastes 3, S. 38. Winheller, Lebensbeschreibungen, S. 106-121. Er ist in einem Gedicht des Venantius Fortunatus erwähnt, in dem er ihn als Nachfolger des Nicetius nennt (Carmina X,7 u. Appendix, ed. Leo, S. 239 ff. u. 291 f., sowie Epistolae Austrasicae 14, ed. W. Gundlach, S. 128 f.). Auch Gregor von Tours, Libri historiarum X (VIII,12 u. 37; IX,10, ed. KRusCh/Levison, S. 378, 405, 424 f.), nennt ihn. Vgl. ferner Ewig, Trier, S. 89, 107-111. Gauthier, Évangélisation, S. 189-204, 248 f. ANTON, Trier im frühen Mittelalter, S. 100 f., 108 f., 138-142. Anton, Trier vom Beginn des 6. bis zum Ende des 8. Jahrhunderts, S. 25-28, 37-43. Gierlich, Grabstätten, S. 44-46. Anton, Raumbestimmende Voraussetzungen, S. 136 f., $141 \mathrm{f}$, 154 (datiert ihn auf 566 bis nach 568). Pfeiffer, Die frühe fränkische Zeit, S. 207f., 211-218. BAuER, Verehrung heiliger Trierer Bischöfe, S. 390 f., bemerkt, auch seine Verehrung sei erstmals seit dem späten 10. Jahrhundert nachweisbar. Nach der zu Beginn des 11. Jahrhunderts verfaßten Vita Magnerici cap. 52 f., ed. Pinius, S. 191, soll er die Martinskirche in Trier erbaut haben, in der er auch begraben liege. Die Vita berichtet, Erzbischof Rotbert (930-956) habe eine Umgestaltung des Grabes vornehmen lassen. Dann verwundert es aber, warum sich Magnerichs Reliquien nicht schon 952 im Altar der St. Maximiner Krypta finden. Egbert habe die Gebeine dann nach Eposium überführt. - Vgl. zu Abrunculus Gregor von Tours, Liber vitae patrum VI,3, ed. Кrusch, S. 682. Duchesne, Fastes 3, S. 37. Ewig, Trier, S. 89, 96 f. Heyen, St. Paulin, S. 291-294. Gauthier, Évangélisation, S. 170-172. Anton, Trier im frühen Mittelalter, S. 85-88. Gierlich, Grabstätten, S. 41. Anton, Raumbestimmende Voraussetzungen, S. 133. Pfeiffer, Die frühe fränkische Zeit, S. 202 f. Bauer, Verehrung heiliger Trierer Bischöfe, S. 384-386, bemerkt, nur für ihn sei eine Verehrung bereits 835/42 auf der Reichenau nachweisbar. - Gerade dieser Befund würde aber bestens dazu passen, daß Abrunculus ausgerechnet in dem auf der Reichenau angefertigten Psalter an letzter Stelle der Trierer Bischöfe noch angehängt wurde. Vielleicht also waren dafür tatsächlich die Reichenauer Mönche verantwortlich. Abrunculus ruhte zunächst vielleicht in St. Symphorian und wurde Mitte des 11. Jahrhunderts nach St. Paulin überführt.

584 Die Unordnung muß also gar nicht von den Reichenauer Mönchen verschuldet sein, wie Sauerland/Haseloff, Psalter, S. 9 f., 45 f., 144, vermuteten. 


\section{e. Egberts ausführliche Bischofsliste}

Spätestens am Ende seiner Amtszeit hatte Egbert dann sogar eine ihm vollständig erscheinende Bischofsliste zusammengestellt, die er mit seinem eigenen Namen - wie schon auf dem Petrusstab - enden ließ. Davon sind zwei verschiedene Versionen handschriftlich auf uns gekommen, die jeweils 44 Namen enthalten: die eine auf dem letzten Folio eines Kodex' aus dem Kloster StGhislain, entstanden aber in Trier, von einer Hand des späten 10. Jahrhunderts, die andere in einem Manuskript des Liber Floridus Lamberts von St-Omer aus dem frühen 12. Jahrhundert nach einer Vorlage des 11.: ${ }^{585}$

St-Ghislain
Eucharius.
Valerius.
Maternus.
Agritius.
Maximinus.
Paulinus.
Bonosius.
Britto.
Felix.
Mauricius.
Legontius.
Severus.
Quirillus.
Lamnecius.
Emerus.
Marus.
Volusianus.
Miletus.

\author{
$\underline{\text { Lambert, Liber Floridus }}$ \\ Sanctus Eucharius. \\ Sanctus Valerius. \\ Sanctus Maternus. \\ Sanctus Agritius. \\ Sanctus Maximinus. \\ Sanctus Paulinus. \\ Bonosius. \\ Britto. \\ Sanctus Felix. \\ Mauricius. \\ Legoncius. \\ Severus. \\ Quirillus. \\ Iamnerius. \\ Emerus. \\ Sanctus Maurus. \\ Volusianus. \\ Miletus.
}

585 Bei der Handschrift aus St-Ghislain handelt es sich um den Kodex Brüssel, Bibliothèque Royale de Belgique, II 976 (Phillipps 367; de Gheyn 1370) (vgl. dazu auch oben Anm. 502), bei der Lamberts um Gent, Universiteitsbibliotheek, 92 (früher 16), fol. 240. Vgl. dazu zunächst Kraus, Bischofskataloge, S. 163 f. Duchesne, Fastes 3, S. 30-34, zu den Handschriften. Zur Lamberthandschrift vgl. auch Derolez, Inventaris, S. 8. Vgl. ferner Series archiepiscoporum Treverensium, ed. Holder-EgGer, S. 296-299. Gauthier, Évangélisation, S. 10 f. - Kraus, Bischofskataloge, S. 163, weist darauf hin, daß Pertz die Lamberthandschrift ins erste Viertel des 12. Jahrhunderts datiert. Kraus sieht im Manuskript eine Kopie des im 11. Jahrhundert geschriebenen Originals, worin ihm auch Holder-EgGer, S. 296, gefolgt ist. - Die Liste wurde nach dieser Fassung Egberts bald in mehreren Stufen weiter ergänzt, wie es sich anhand der Editionen von Duchesne und Holder-Egger nachvollziehen läßt. - Vgl. zu Egberts ausführlicher Liste auch BöHNE, Erzbischof Egbert, S. $106 \mathrm{f}$. 
Modestus.

Maximianus.

Fibicius.

Abrunculus.

Rusticus.

Nicecius.

Ma[gnericus].

Gun[d]er[icus].

S..b...

Modualdus.

Numerianus.

Basinus.

Liutwinus.

Milo.

Wiomadus.

Rimbodus.

Wizo.

Hetti.

[...]

Ekbertus.
Modestus.

Maximianus.

Fabicius.

Abrunculus.

Rusticus.

Sanctus Nicetius.

Sanctus Magnericus.

Gundericus.

Sabaudus.

Modoaldus.

Numerianus.

\section{Basinus.}

Sanctus Leudoinus.

Milo.

Wiemadus.

Ribbodus.

Witzo.

Hatto.

[...]

Egbertus. ${ }^{586}$

Die Bischöfe sind nun in eine chronologisch plausible Reihenfolge gebracht. Dabei orientierte man sich wohl annäherungsweise an den erwähnten erhaltenen Schriftquellen. Eine tatsächlich sichere Zuweisung war jedoch kaum möglich. ${ }^{587}$ Bei der Liste aus der Lamberthandschrift fällt auf, daß elf der vierzehn im Egbert-Psalter genannten heiligen Bischöfe auch hier als solche gekennzeichnet sind. Die fehlenden Legontius, Abrunculus und Modoald verbindet immerhin, daß bei ihnen die Grabsituation im späten 10. und frühen 11. Jahrhundert nicht genau geklärt war. ${ }^{588}$ Die Heiligkeit mußte sich womöglich aus Reliquien ergeben. Die wachsende und uneinheitliche Zahl heiliger Bischöfe deutet also auch auf Egberts Suche nach wirklichen oder scheinbaren Gräbern Trierer Bischöfe hin. Doch wußte man nach dem Normannensturm 882 wohl kaum noch, wo diese alle begraben lagen. Deshalb ist anzunehmen,

586 Zum hier wiedergegebenen Text vgl. Series archiepiscoporum Treverensium, ed. HoLDER-EgGer, S. 298 f.

587 Vgl. zu den bestehenden Problemen, die Trierer Metropolitanrechte am Ende des 8. und zu Beginn des 9. Jahrhunderts zu bestimmen, OexLE, Arnulf, S. 329 ff.

588 Vgl. zu diesen dreien und ihren Gräbern in dieser Zeit nochmals oben Anm. 570 u. 583. Auch SeIbrich, Egbert, S. 188, vermutet, daß noch nicht endgültig geklärt war, wer zum Kreis der heiligen Bischöfe gehören sollte. - Entweder setzten sich nicht alle als solche durch, oder dieses Attribut wurde andernorts oder erst mit einiger Verspätung aufgrund eines anderen Wissensstandes hinzugesetzt. 
daß Egbert einige nicht sicher zu bestimmende Bischofsgräber erst zu solchen machte. Das variierende Namensgut zeigt, daß er dabei nicht immer Erfolg hatte.

Daß Liutwin auf dieser Liste erscheint, überrascht nicht. Allerdings finden sich hier zum ersten Mal überhaupt Basin und Milo als Trierer Bischöfe und zugleich Vorgänger und Nachfolger Liutwins. Basin war wohl Trierer Bischof, wie der zeitgenössische Nachtrag in Willibrords Kalendar belegt, doch seit langer Zeit kaum mehr erinnert. Von seinem Grab wußte man zu Egberts Zeit ganz sicher nichts mehr. Sonst hätte er ihn als Heiligen aufgenommen. Erst im 12. Jahrhundert wurde Basin mit St. Maximin in Verbindung gebracht. ${ }^{589}$

Milo kann nach den bisherigen Untersuchungen aber kein Bischof gewesen sein, sondern allenfalls ein niederer Kleriker oder nicht ganz unbedeutender Adliger unter den Karolingern. Er verwaltete die Trierer Bischofspfalz, hatte in irgendeiner Form Anteil am Kloster Mettlach, war mit diesem belehnt worden und lag mit einiger Sicherheit auch dort begraben. Milo entsandte Trierer Bischöfe nach Mettlach, um das Amt des Abtes zu übernehmen. Doch die Namen dieser Bischöfe - Ratbertus und Harthamus sowie ein wahrscheinlich ebenfalls in dieser Zeit amtierender Hildulf- finden sich nicht in Egberts Liste. ${ }^{590}$ Wußte er nichts mehr von ihnen? Oder ließ er sie absichtlich aus?

Milos Aufnahme als Bischof in die Liste kann nur auf der Rezeption Reimser Texte in Trier beruhen, nämlich Hinkmars Remigius-Vita sowie Flodoards „Reimser Kirchengeschichte“. Das heißt, spätestens jetzt mußte man in Trier - überrascht - zur Kenntnis nehmen, daß ein Milo ein dunkles Kapitel für die eigene Bistumsgeschichte darstellte, sie geradezu beschmutzte. Denn er belastete das Verhältnis zu Reims darüber hinaus. Ging man in Trier seit Erzbischof Rotbert (†956) wieder mit einiger Selbstsicherheit vom eigenen Primat in der Kirchenprovinz Belgica und bald auch der Gallia aus, wie es die Papsturkunde von 969 u.a. formulierte, hatte man nun ein Problem. ${ }^{51}$ Hinkmars anklagendes Beispiel eines Milo, der die beiden Bistümer Reims und Trier okkupierte, das schon einmal erfolgreich gegen den von Thietgaud von Trier (847-863/8) postulierten Primat in der Belgica zum Einsatz kam, entfaltete ein zweites Mal seine fatale Wirkung. Das Beispiel des so verwerflichen Räubers und Entfremders von Kirchengut mußte alle Trierer Primatsansprüche bedrohen und konnte sogar als Argument gegen sie eingesetzt werden!

Für Mettlach, wo man sich - wie wir gesehen haben - positiv an Milo als Förderer des eigenen Klosters erinnerte und wohl noch über sein Grab ver-

589 Vgl. die Angaben zu Basin bereits oben in Kap. D.I.2.b. sowie bei Gierlich, Grabstätten, S. $50 \mathrm{f}$.

590 Vgl. dazu ausführlich oben Kap. D.IV.6.c.

591 Vgl. dazu schon oben Kap. D.VI.1.-2. 
fügte, ${ }^{592}$ entstanden damit kaum geringere Schwierigkeiten. Denn der adlige Milo ließ sich nicht einfach - mit dem Hinweis auf seine Ruhestätte - als weiterer heiliger Trierer Bischof ausrufen. Im Gegenteil: Der eigene Gönner war plötzlich zum Frevler geworden.

Wie aber konnte man sich aus der Affäre ziehen? Vermochte man in Trier, Milos anprangernde Rolle als Doppelbischof von Reims und Trier zu überspielen? Und wie gingen die Mettlacher jetzt mit ihrer eigenen Milotradition um? Die im folgenden zu untersuchenden Quellen bieten Aufschluß darüber, wenn man sich auf die Suche nach Hinweisen und Spuren macht. Dem hl. Liutwin kommt dabei eine ganz besondere Rolle zu. Denn die Geschichte, die seine Viten über ihn erzählen, ist ohne die Konstellation der Bischofsliste nicht möglich. Seine älteste Lebensbeschreibung kann folglich kaum früher entstanden sein. Ja, so wie Egbert für das Bild Liutwins als Schenker Mettlachs an Trier verantwortlich gewesen sein dürfte oder es wenigstens von Erzbischof Radbod (883-915) übernahm, so war er wohl auch an der Lösung des Milo-Problems entscheidend beteiligt.

Zusammengefaßt wird an den beiden Varianten der ersten Trierer Bischofsliste erkennbar, daß unter Egbert die Heiligkeit einiger Bischöfe vielleicht aufgrund problematischer Gräber umstritten war. Erstmals aber finden sich Basin und Milo, dafür fehlen die in DKarol. I 148 überlieferten Bischöfe Ratbert und Hartham sowie der an anderer Stelle genannte Hildulf. Dem Platz Milos als Bischof auf der Liste muß das Bild eines die Kirche schädigenden und über 40 Jahre amtierenden Doppelbischofs zugrunde liegen, das inzwischen aus Reims rezipiert wurde. Dieses Bild unterdrückte deshalb die Namen der eigentlichen Trierer Bischöfe dieser Zeit und ließ sie in Vergessenheit geraten. Im Erzstift Trier bedrohte es gar die eigenen Primatsansprüche. In Mettlach stellte es das positive Bild des Adeligen Milo in Frage, der dort begraben lag. Erst die Bischofsliste ermöglichte also ein Liutwinbild, wie es dessen Viten überliefern und an dem Egbert nicht unbeteiligt gewesen sein kann.

\section{f. Ergebnis}

Es ist deutlich geworden, wie sehr sich Erzbischof Egbert (977-993) damit beschäftigte, die Vergangenheit seines Bistums und die seiner Vorgänger zu pflegen und aufzuwerten. Er unterstützte massiv die Grabkirche der ersten drei Trierer Bischöfe St. Eucharius, stärkte den Kult des Apostels Andreas in Trier, in dessen neu erbauter Kapelle er sich selbst bestatten ließ, und recherchierte die früheren Trierer Bischöfe sowie deren Gräber. In prachtvollen Handschriften, Litaneien, dem Petrusstab und in lokalen Kalendaren wurde ihre Erinnerung im Gedächtnis der Stadt intensiviert oder neu gestiftet.

592 Vgl. dazu oben S. 246. 
Egbert pflegte enge Verbindungen mit Reims, über das Trier mit seinem Primatsanspruch über die Belgica, Gallia und Germania seine Vorrangstellung postulierte, sowie mit dem Reimser Gelehrten Gerbert. Von dort bezog Egbert einige Texte für seine Nachforschungen über Triers Vergangenheit. Diese Kontakte verbanden das Erzstift auch mit dem Kloster Mettlach an der Saar, von dem aus Mönche zur Ausbildung nach Reims gingen. Einer von ihnen war der spätere Mettlacher Abt Remigius, der vor seinem Abbatiat auch unter Egbert in Trier wirkte und dessen Politik für St. Eucharius und die Trierer Primatsansprüche mit eigenen Werken nachweislich unterstützte. Remigius verfaßte den ersten bekannten Text über Liutwin: eine Predigt zum liturgischen Gebrauch. Mit ihr muß die Liutwin-Vita I gemeint sein. Diese Predigt weist aber in jedem Fall auf Egberts Episkopat für den Beginn eines greifbaren Mettlacher Liutwinkultes hin.

Die Liste der heiligen Trierer Bischöfe wuchs sukzessive. Liutwin wurde gemeinsam mit Modoald in einer zweiten Stufe in sie aufgenommen. Daß die beiden als Gründer- bzw. Schenkerbischof eines Klosters in manipulierten Trierer Dokumenten auftreten, legt einen Einfluß Egberts auf die Konstruktion dieser Bilder nahe, wenn auch ein solcher Erzbischof Radbods (882-915) für das Bild Liutwins nicht völlig auszuschließen ist. Doch nicht alle heiligen Kandidaten waren so unumstritten wie sie. Beim Wiederauffinden mancher Bischöfe und ihrer Gräber bestand noch Diskussionsbedarf. Alle ihre vorweisbaren Bestattungsplätze dürften aber in Trier gelegen haben.

Erst die letzte Stufe der Bischofsliste nahm Basin und Milo auf. Doch verschwieg sie die Namen weiterer Bischöfe, die in deren unmittelbarer zeitlicher Nähe in anderen Quellen überliefert werden: Ratbert, Hartham und Hildulf. Milo aber war kein Bischof, sondern vielmehr niederer Kleriker oder Adliger, der die Trierer Bischofspfalz verwaltete und über einen engen Bezug zu Mettlach verfügte, wo er auch begraben lag. Deshalb kann Milos Eintrag nur auf der Rezeption von Reimser Texten beruhen, die das von Hinkmar geschaffene Bild eines Doppelbischofs von Reims und Trier vermittelten. Offenbar war dieses Bild so dominant, daß die Namen der eigentlichen Trierer Bischöfe ausfielen. Dieser ,neue' Milo, den man im Trierer Raum zuvor nicht kannte, bedrohte die Trierer Primatsansprüche über die Belgica, Gallia - und damit auch über Reims - sowie die Germania, aber ebenso die bisherige Wertschätzung des ,alten' Milo in Mettlach. Milos scheinbarer Amtsvorgänger Liutwin versprach einen Weg aus dieser Misere zu weisen, den Egbert nach allen bisher zusammengetragenen Belegen mitgestaltete. 


\section{Liutwin und Basin in liturgischen Texten seit dem späten 10. Jahrhundert}

Abgesehen vom zeitgenössischen Nachtrag Basins zum 3. März in das Kalendar Willibrords $(\dagger 739)$ setzte die Erinnerung an ihn erst wieder Ende des 10. Jahrhunderts mit den Trierer Bischofslisten ein, um die sich Egbert so bemühte. Für die Mitte des 11. Jahrhunderts hat BAuER einen Beleg seiner Verehrung zum 3. März in der elsässischen Abtei Honau nachgewiesen. Ebenso sei eine solche Verehrung in dieser Zeit in Pfalzel und Klausen zu finden. ${ }^{593}$ Sie stimme auch mit dessen sanctus-Vermerk auf der dritten, schon nach Egbert verfaßten Trierer Bischofsliste überein, die wahrscheinlich in der ersten Hälfte des 11. Jahrhunderts entstand. ${ }^{594}$ Der eigentliche Kult setzte - nach Basins Abbildung auf dem Willibrord-Tragaltar des späten 12. Jahrhunderts - schließlich mit dem Beginn des 13. Jahrhunderts ein, wobei die Trierer Abtei St. Maximin ein eigenes Zentrum bildete. ${ }^{595}$ Man sieht also auch hier, daß Basins Verehrung maßgeblich durch Egberts Nachforschungstätigkeiten möglich gemacht wurde.

Für Liutwin machte Peter Miesges - neben den bereits oben erwähnten liturgischen Handschriften - nur einen Trierer Kalendereintrag des frühen 11. Jahrhunderts ausfindig, dem erst im 14. Jahrhundert weitere folgten. ${ }^{596}$ Inzwischen läßt sich dieser Befund weiter modifizieren. Flesch hat nach KurzejA nochmals betont, daß die aus St. Gallen stammende Litanei Humilie prece in Trier zu Egberts Zeit den lokalen Bedürfnissen angepaßt wurde. Dazu ersetzte man einige ihrer ursprünglichen Heiligen durch die heiligen Trierer Bischöfe, die etwa der zweiten Stufe der Egbertschen Bischofsliste entsprechen. Der in der Litanei zunächst erwähnte hl. Gallus wurde dabei in Strophe 11 unter Beibe-

593 Vgl. Bauer, Verehrung heiliger Trierer Bischöfe, S. 397. - Zum Eintrag im WillibrordKalendar vgl. bereits oben S. 118 u. Anm. 29.

594 Vgl. Bauer, Verehrung heiliger Trierer Bischöfe, S. 397. - Zur dritten Trierer Bischofsliste mit dem sanctus-Vermerk vgl. Series archiepiscoporum Treverensium, ed. Holder-Egger, S. 298 f.: [...] / Sanctus Modoaldus. / Numerianus. / Sanctus Basinus. / Sanctus Leudowinus. / Milo. / Wiemadus. / [...]. Duchesne, Fastes 3, S. 30-34. Überliefert ist sie in der Handschrift Wolfenbüttel, Herzog August Bibliothek, Guelf. 1109 Helmst., aus dem späten 10. oder frühen 11. Jahrhundert. Sie stammt aus der Abtei St. Maria in Reichenbach in der Diözese Regensburg. Der letzte Trierer Bischof dieser Liste ist Egberts Nachfolger Liudolf (994-1008). Die Namen seiner beiden Nachfolger waren bereits eingetragen, doch wurden sie durch Rasur getilgt, was auf die Streitigkeiten im Trierer Bistum zu Beginn des 11. Jahrhunderts deutet. Vgl. auch oben Anm. 532.

595 Vgl. Bauer, Verehrung heiliger Trierer Bischöfe, S. 397 f. - Zum Basinkult in St. Maximin vgl. auch oben Kap. D.I.2.b. u. D.III.2.

596 Vgl. dazu oben Anm. 571. 
haltung des übrigen Textes gegen Liutwin ausgetauscht. ${ }^{597}$ Kurzeja schloß aus dem Eingriff an einer solch zentralen Stelle, daß dies in Mettlach selbst, also Liutwins Grabesort, geschah, worin ihm neuerdings Bauer folgt: Man habe die Gründungsheiligen förmlich ausgewechselt. Dann sei die Litanei nach Trier gelangt. FLESCH hält sogar Remigius von Mettlach für den Verantwortlichen. ${ }^{598}$ Diese Argumente haben einiges für sich. Doch läßt sich nicht sicher ausschließen, daß dieser Eingriff zunächst in Trier selbst unter Egbert erfolgte oder von ihm erwünscht war und dann nach Mettlach gelangte, wie die anwachsenden Stufen seiner Bischofsliste nahelegen. In jedem Fall ist die Litanei in seiner Amtszeit angepaßt worden.

Im kürzlich (2003) erschienenen Frühmittelalterband der Trierer Bistumsgeschichte hat BAUER erste Ergebnisse seiner Studie zur „Verehrung heiliger Trierer Bischöfe aus Spätantike und Frühmittelalter"vorgelegt. Darin präsentiert er weiteres Material zu Liutwin. ${ }^{599}$ Dessen Verehrung „erreichte [...], nach dem Befund der liturgischen Quellen, erstens in Trier selbst einen erheblich intensiveren Grad, durchdrang zweitens die Diözese Trier engmaschiger und fand drittens darüber hinaus eine sehr weiträumige, hierbei freilich punktuelle Verbreitung. ${ }^{"}{ }^{600}$ Allerdings bietet BAUER zu den bereits bekannten Belegen keine vor dem 10. Jahrhundert: Bei der „Weihe einer Salvatorkirche in Luxemburg am 5. November 987 “ fänden sich Liutwinreliquien bezeugt. Noch aus der Zeit

597 Vgl. dazu Flesch, Monastische Schriftkultur, S. 27, 70 f. Die ursprüngliche Form der St. Gallener Litanei finde sich in der Handschrift Vatikan, Bibliotheca Apostolica, Palatinus lat. 489, aus dem 10. Jahrhundert, die wohl für das Kloster Hornbach verfaßt wurde. Zur Handschrift vgl. Berschin, Palatina, S. 66-68. - Vgl. die Litanei Humilie prece, in: Analecta Hymnica 50, Nr. 191, S. 253-256 (= Sylloga codicis Sangallensis CCCLXXXI, ed. Winterfeld, Nr. 4, S. 319-321). Die abgewandelte Trierer Version findet sich in Würdtwein, Commentatio, S. 240-243, bes. S. 241: Eucharius, Primus, Maternus Valeriusque, I Maximinus \& Agritius atque Marus. I Paulinus, Felix, Severus Nicetiusque, / Treverici Patres nos foveant inopes. [...] (Strophe 8). Ebd., S. 242: O Lutwine Dei summi venerande sacerdos, / Nobis nunc famulis auxiliare tuis, / Nil sic perspicuum poterat vox clara referre (Strophe 11). Vgl. ferner Kurzeja, Liber Ordinarius, S. 314-317.

598 Vgl. Kurzeja, Liber Ordinarius, S. 315 f., Anm. 1444 f. Er zeigt aber auch, daß die Litanei über Mainz nach Trier vermittelt wurde. Denn in Mainz ergänzte man noch eine Strophe zu Disibod, der in Trier durch den dort verehrten Quiriacus ersetzt wurde. Auch seien noch im 11. Jahrhundert weitere Trierer Heilige zusätzlich in diese Litanei ergänzt worden. - Vgl. dazu die entsprechenden Strophen der Litanei in Analecta Hymnica 50, Nr. 191, S. 254. Vgl. ferner Bauer, Spätmerowingische Zeit, S. 242. Bauer, Verehrung heiliger Trierer Bischöfe, S. 399. Flesch, Monastische Schriftkultur, S. 70 f.

599 Vgl. Bauer, Verehrung heiliger Trierer Bischöfe, S. 341 ff., bes. S. 398-400. Die vollständige Publikation ist als Monographie unter dem Titel „,Laudate Dominum in sanctis eius'. Die heiligen Bischöfe von Trier in ihrer Verehrung“ in der Reihe „Veröffentlichungen des Bistumsarchivs Trier" in Vorbereitung. Darin werden noch weitere Ausführungen zur Verbreitung der Patrozinien der Trierer Bischöfe ergänzt.

600 Vgl. BAuEr, Verehrung heiliger Trierer Bischöfe, S. 398. 
unmittelbar vor der Jahrtausendwende müsse ein Eintrag seines Festes am 29. September aus einem Essener Kalendar stammen - der älteste außerhalb Triers. Vom Beginn des 11. Jahrhunderts gebe es dann einen Nachweis aus Verdun, dem bald einer aus St. Gallen folge. Die Liutwinverehrung habe im 10. Jahrhundert sogar England erreicht (dies muß im Hinblick auf den Essener Eintrag allerdings später oder zeitgleich geschehen sein). In Trier sei seine liturgische Verehrung ebenfalls stärker ausgeprägt, eine wirkliche Intensivierung jedoch erst ab dem 14. Jahrhundert feststellbar. In der Trierer Diözese existierten Einträge aus Pfalzel und Klausen sowie einer aus einem Echternacher Martyrolog des (frühen) 12. Jahrhunderts. ${ }^{601}$

Zusammengefaßt unterstreichen alle genannten neuen Belege jedoch den bisherigen Befund: Eine nachweisbare Basinverehrung in Trier sowie eine Liutwinverehrung in Trier und Mettlach wird nicht vor dem Episkopat Egberts faßbar. Liutwins Kult muß also in dieser Zeit und von dieser Gegend seinen Ausgang genommen haben. Dabei ist nicht an eine Verbreitung von Mettlach nach Trier, sondern umgekehrt an eine vom Erzstift zum Kloster zu denken. Das baldige Auftauchen Liutwins in Essen läßt sich wahrscheinlich durch die nicht unwesentliche Rolle Egberts in der ottonischen Reichspolitik erklären. So wäre es nur verständlich, wenn sich ein Reflex heiliger Trierer Bischöfe im so bedeutenden ottonischen Damenstift fände. ${ }^{602}$

\section{Liutwin-Spuren in Urkunden des späten 10. Jahrhunderts}

\section{Liutwin in der Egbert-Fälschung für St. Paulin}

Die nächste und inhaltlich sogar erste konkretere Spur zu Liutwin findet sich in der sog. Egbert-Fälschung zum Jahr 981 (MRUB I †255). Diese Sammelurkunde für St. Paulin enthält eine Liste von Besitzungen, die diesem Stift verlorengegangen waren und die auf angeblichen Schenkungen zurück bis in die Zeit König Dagoberts $(\dagger 638 / 9)$ beruhten, darunter auch eine Liutwins. Da Egbert die verlorenen Güter nicht restituieren kann, gibt er andere an St. Paulin. Eine Urschrift des Textes existiert nicht. Erhalten sind nur mehrere Bestätigungen: die erste als Transsumpt Erzbischof Theoderichs/Dietrichs II. (1212-

601 Vgl. Bauer, Verehrung heiliger Trierer Bischöfe, S. 398-400. - Beim Essener Kalendar handelt es sich um die Handschrift Düsseldorf, Universitäts- und Landesbibliothek, D3, fol. 3 . Vgl. dazu Hoffman, Buchkunst 1, S. 504 u. ebd. 2, Abb. 300 f., der die Schreiberhand jedoch einem Trier Skriptorium zuweist. Vgl. ferner Handschriftencensus Rheinland 1, ed. Gattermann, Nr. 755, S. 446.

$602 \mathrm{Zu}$ Egbert vgl. nochmals oben Kap. D.VI.3.a. 
1242) von $1215 .{ }^{603}$ Oppermann bezeichnete deshalb dessen zitierte Vorlage als Fälschung, doch hielt EwIg wenigstens einige Teile für glaubwürdig. ${ }^{604}$ Heyen untersuchte sie genauer und schloß, daß der äußere formale Rahmen auf einer echten Urkunde Erzbischof Egberts von 981 beruhe. Eine Urkunde Erzbischof Eberhards (1047-1066) habe dann wenigstens einen Teil der verlorenen Güter beinhaltet. $\mathrm{Ob}$ sich darunter auch die mit Liutwin verbundenen befanden, lasse sich nicht sicher klären. An der Echtheit dieser Verlustliste - vielleicht eines Traditionsregests oder chronikalischen Nachweises - bestehe kaum Zweifel, weil sie nicht dem eigentlichen Fälschungszweck der Egbert-Fälschung diente. Um 1207 sei deren Urfassung wohl aus den genannten Vorlagen entstanden, um die Rechte an den „Kompensationsgütern“ zu sichern. ${ }^{605}$

Das Traditionsregest der Verlustgüter in der Fälschung ist weder chronologisch noch nach Personen geordnet. Seinen Anfang macht aber die Gabe Liutwins. Entscheidend sind hier weniger die übertragenen Güter als vielmehr, daß ganz knapp von einem gewissen Herzog Liutwin die Rede ist, der Mönch wurde und später heiliger Erzbischof dieses Sitzes, also Trier. Heyen und Anton halten entgegen Gauthier diese Dotation für glaubwürdig. Die Echtheit der Vorlage soll an dieser Stelle nicht überprüft werden. Doch ist sie, schon weil sich ihr unmittelbar eine Dagobert-Schenkung anschließt, nicht wirklich vertrauenserweckend. ${ }^{606}$ Allerdings wird hier erstmals so etwas wie eine ,Kurzvita' Liutwins greifbar. Sie erinnert in gewisser Weise an die umfangreichere Erzählung der Vita Liutwini I, bringt Liutwin jedoch überhaupt nicht mit dem Kloster Mettlach in Verbindung.

Damit ist die Egbert-Fälschung keinesfalls eine Bestätigung für die frühe und zeitgenössische Existenz eines hl. Bischofs Liutwin. Sie zeigt nur, daß die Fama Liutwins bei der Niederschrift der regestenhaften Vorlage über die angeblich verlorenen St. Pauliner Güter oder sogar erst bei der eigentlichen Fäl-

603 Vgl. zur Fälschung MRUB I $\nmid 255$, S. 311. Weitere Bestätigungen haben Erzbischof Arnold II. (1242-1259) am 9. Januar 1258 (MRUB III 1451, S. 326) und Erzbischof Boemund I. (1289-1299) am 1. Februar 1295 (Koblenz, Landeshauptarchiv, Best. 213 Nr. 17) ausgestellt.

604 Vgl. Oppermann, Rheinische Urkundenstudien 2, S. 227-239. Ewig, Trier, S. 124, 135.

605 Vgl. Heyen, Egbert-Fälschung. Heyen, St. Paulin, S. 23-26. Zur echten Egbertschen Urkundenvorlage vgl. auch SEIBRICH, Egbert, S. 194.

606 MRUB I $\nmid 255$, S. 311: Hoc etiam pacto. quicquid Liutwinus dux in monachum conuersus. et postea huius sedis sacer archiepiscopus. in Branbach. et in Birkenuelt in ecclesiis. aut in omnibus appendiciis aliis. ad habendum fratribus. deo et s. Paulino servientibus contulit. et quidquid Dagobertus orthodoxus rex francorum scilicet Billike cum Sulmana et Rula. et Niuelae. cum ecclesiis ac cum omnibus rite ad eadem loca pertinentibus de suo hereditario iure. eidem beatissimo confessori contradidit. Vgl. HeYen, Egbert-Fälschung, S. 145. Heyen, St. Paulin, S. 83 f. Anton, Liutwin, S. 32 u. Anm. 29. Gauthier, Évangélisation, S. 360, Anm. 104, meint, die Urkunde hänge von der Vita ab. 
schungskompilation bekannt war. Vielleicht war diese ,Kurzvita' Vorstufe oder auch nur Reflex der Vita. Der früheste daraus resultierende Beleg dafür, daß das Bild des zum Mönch gewordenen Herzogs und späteren heiligen Bischofs existierte, ist das Datum der angenommenen echten Urkundenvorlage Egberts von 981, wenn diese denn einen Hinweis auf Liutwin beinhaltete. Erst unter Egbert jedenfalls gehörte Liutwin sicher dem Kanon der heiligen Trierer Bischöfe an. Sein Bild in der Fälschung entspricht bereits dem angesprochenen Modell eines Schenkerbischofs. Sollte es tatsächlich die Schenkung eines Liutwin an St. Paulin gegeben haben, was sich weder beweisen noch ganz sicher widerlegen läßt, so tätigte diese allenfalls ein Liutwinus dux. Die Anmerkungen zu seinem Leben waren interpretierende Zusätze - frühestens aus dem späten 10. Jahrhundert.

Zusammengefaßt belegt die Egbert-Fälschung nur, daß frühestens ab 981 aber eher später - ein Bild greifbar wird, das einen Mönch gewordenen Herzog und baldigen heiligen Trierer Bischof Liutwin beinhaltet. Ihm könnte - was aber nicht sehr wahrscheinlich ist - die Schenkung eines Liutwinus dux an St. Paulin zugrunde gelegen haben.

\section{Die Schenkung Bertas an Mettlach 995}

Die Schenkung einer Berta aus dem Jahr 995 bietet da schon wesentlich konkretere Angaben zu Liutwin (MRUB I 270). ${ }^{67}$ Berta überträgt für sich und ihren verstorbenen Ehemann Folkmar, auch auf dessen Anordnung, an das

607 Vgl. MRUB I 270, S. 326: Cum cuncta que temporaliter possidentur ueluti fumus et umbra depereant. in hoc tamen possidenti erunt utilia, si ea decreuerit ad anime sue dispensare remedia. atque in hoc supra modum miranda et laudanda propitia deitas. quod inmensa ipsius annuenta gratia decidius semper acquirere statura transitoriis comparare semper possimus eterna. quod ego Berta peruicaci uersans animo. statui pro anime mee nec non et defuncti coniugis mei Uolkmari salute. ipso uidelicet dum uiueret hoc iubente et constituente. ad monasterium nomine Mediolacum. ubi s. Lutuinus corpore requiescit. quod ipse dum uita uiguit. in honore dei genitricis semperque uirginis Marie et bb. Petri \& Pauli apostolorum atque Andree construxit. quid in uilla Rodena uocabulo sita in pago Sarensi. in comitatu Uualdrauingensi a prefato coniuge meo dotis firmitudine possidendum suscepi. XV. scilicet mansos. preter dominicabilem terram. et quicquid illuc silue. pratorum. aque siue nanigii uel aquarum decursus appendet. ea uidelicet ratione. ut ab hac die id retinendi. possidendi. quocunque libuerit uertendi. liberam monachi ibi degentes habeant potestatem. Et ut cunctis palam fiat quomodo perniciose huic donationi contradicitur. ueraci relatu depromo ac plurium suffragio testium confirmo quod ipse predictus maritus meus hoc allodium quondam ab ipsius regis manibus magno pretio comparauit. et sine ullius contradictione legaliter et firmissima traditione possidendum suscepit. unde quisquis hiis contraire nititur. iram dei quam sibimet ipsi accendit incurrat. insuper ad regalem fiscum, quantum inuasores ac legum effractores competit. soluat. Actum Mediolacensi cenobio. V. Kal. Martii. anno incarnat. domin. DCCCC.XC.V presente ipsius loci domino uenerabili Ludolpho archiepiscopo. tra- 
Kloster Mettlach, wo der Körper des hl. Liutwin ruhe, der es selbst zu seinen Lebzeiten zu Ehren der Gottesmutter und Jungfrau Maria, der hll. Apostel Petrus und Paulus sowie des Andreas erbaute, ihren Besitz in der Villa Roden im Saargau, in der Grafschaft Wallerfangen. Diesen Besitz habe sie von ihrem Gatten erhalten. Es handle sich dabei um 15 Mansen, außer dem Herrenland, und was auch immer dort an Wald, Wiesen und Gewässern dazugehöre. ${ }^{608}$ Die Mettlacher Mönche sollen frei darüber verfügen. Berta teilt wahrheitsgemäß mit und bestätigt durch die Unterstützung zahlreicher Zeugen, daß ihr Gatte dieses Allod einst aus den Händen des Königs selbst gegen einen großen Betrag erworben und ohne irgendjemandes Widerspruch rechtmäßig durch eine äußerst sichere Schenkung zum Besitz empfangen habe. Die Handlung sei in Mettlach am 25. Februar 995 erfolgt in Gegenwart des Trierer Erzbischofs Liudolf (9941008). Es schließen sich die Namen der Überträger, Bürgen und Zeugen an.

Damit wäre diese Urkunde die früheste greifbare Quelle (abgesehen von der Liutwin-Vita I), die Liutwin etwa 300 Jahre nach seiner angeblichen Lebenszeit nicht nur erstmals als Gründer des Klosters Mettlach nennt, sondern ebenso von seinem dortigen Grab spricht. Überliefert ist sie - nach BEYER - als erstes Dokument des Mettlacher Diplomatars. Dessen letzte Einträge reichen bis 1678, doch sei jede dort aufgenommene Abschrift notariell beglaubigt. ${ }^{609}$ Zwar finden sich zwei Einträge über Roden auf der Mettlacher Güterrolle des späten 11. Jahrhunderts, sie nennen aber keine Schenker. Auch stehen beide an unterschiedlichen Stellen und verzeichnen, neben anderen Abweichungen, als Besitz einmal 15, ein anderes Mal 12 Mansen, wobei beim damit verbundenen Eintrag sogar Text getilgt wurde. ${ }^{610}$ Erst die Rückseite des Mettlacher Kreuz-

ditores Uodilo \& Heckinrich. fideiussores Uuetel. Helidrich et frater eius Henno. Testes. Wetel comes et nepos eius Wetel. Cuono. Gerunc. Bruonicho. Frizzo. Winigo. Friderart. Mazzo. Cuono. Gozichin. Hupichin. Thederich.

608 Die Stelle ist etwas mißverständlich. RAACH, Mettlach, S. 114, rechnet das Herrenland mit zur Schenkung, doch scheint es ausgenommen.

609 Vgl. MRUB I, S. VI u. 326. Vgl. dazu auch die Mettlacher Regesten bei Lager, Urkundliche Geschichte, S. 291.

610 Vgl. zur Mettlacher Güterrolle insgesamt bereits oben Kap. D.V. - Auf der Mettlacher Güterrolle finden sich Leistungen zu Roden unter Kap. 6 und $13^{1}$ eingetragen. $\mathrm{Zu}$ Kap. 6 vgl. Müller, Mettlacher Güterrolle, S. 125, Nr. U 17. MRUB II Nachtr. 10, S. 341, das für die Abgaben überwiegend hohe Geldzahlungen und keine Heiligenfeste, sondern lediglich den Weihnachtstermin nennt. Auch erwähnt das Kapitel nur 12 Hufen. Der Eintrag ist kurz und knapp, weil seine letzten sieben Zeilen durch Rasur getilgt sind. - Vgl. zu Kap. $13^{1}$ MüLler, Mettlacher Güterrolle, S. 123 f., Nr. U 12. MRUB II Nachtr. 10, S. 343. Dieses Kapitel erwähnt zu Roden 15 Mansen mit zahlreichen differenzierten Natural- und Geldleistungen sowie als Fälligkeitstermine u.a. auch die folgenden Heiligenfeste: Martin, Andreas, Peter und Paul. Die sich mit Kap. 6 deckenden Forderungen fallen hier noch niedriger aus. - Perrin, Recherches, S. 113 f., 117-119, 121 f., 125 f., hält den Eintrag von Kap. $13^{1}$ für den älteren, weil er noch gemäß der Urkunde 15 Mansen nennt und umfangreichere Naturalabgaben. Orientiere 
reliquiars zu Beginn des 13. Jahrhunderts bildet Berta und Folkmar dann als gemeinsame Überträger Rodens und letztes der insgesamt vier Stifterpaare ab. ${ }^{611}$

Die Urkunde, die von der Forschung bisher für echt gehalten wurde - nur Schmal äußerte einen Fälschungsverdacht -, bietet aber einige Auffälligkeiten. ${ }^{612}$ Zunächst einmal nennt sie keinen amtierenden Mettlacher Abt. Entgegen den späteren Mettlacher Quellen, die ein Marien-, Petrus- und Dionysiuspatrozinium für den Klosterkomplex angeben, ${ }^{613}$ wird hier noch Paulus, aber vor allem anstelle des Dionysius der Apostel Andreas angeführt. Nun ist es nach dem Mettlacher Ausgräber Martin KLewitz undenkbar, daß gleich drei Kirchen bei Gründung des Klosters gleichzeitig gebaut wurden, wenn das hier denn gemeint ist. ${ }^{614}$ Wir haben es also mit einer Fama zu tun. Kaum denkbar ist aber vor allem, daß Mettlach schon im späten 7. Jahrhundert ein Andreaspatrozinium erhielt. Denn nur in dieser Urkunde und einem Ablaßbrief von 1451 ist es überhaupt für das Saarkloster nachweisbar. (Im Brief war Andreas ein weiteres Patrozinium der Peterskirche.). ${ }^{615}$ Vielmehr verstärkte erst Erzbischof Egbert wieder den Andreaskult im Trierer Raum, wie wir gesehen haben. ${ }^{616}$ Somit böte auch diese Urkunde einen Hinweis auf eine direkte Verbindung des Mettlacher Liutwinkultes mit Egbert. Der Trierer Andreaskult bildete den Anlaß, diesen

man sich an der Urkunde, müsse er nach 995 in die Vorlage der Güterrolle aufgenommen worden sein. Mit dem Fortschritt der Geldwirtschaft stehe dann der rationalisierende Eintrag in Kap. 6 in Verbindung. Die geringere Mansenzahl könne auch für Besitzverlust sprechen. Vgl. auch RAACH, Mettlach, S. 114-116. - Die verschiedenen Angaben von 12 und 15 Mansen lassen sich vielleicht aber einfach als Verschreibung von XV zu XII erklären, wenn sich die beiden Schäfte des V an der Unterseite nicht mehr berührten.

611 Vgl. dazu Sauer, Fundatio, S. 311 u. Abb. 68. Henze, Kreuzreliquiare, S. 71-73.

612 Vgl. zu ihrer Echtheit FlesCh, Monastische Schriftkultur, S. 29, 48. Zu Roden vgl. auch RAACH, Mettlach, S. 113-118. Aus dem Jahr 996 ist eine weitere Übertragung dieser Berta überliefert, diesmal für das Kloster St. Maximin. Berta erscheint darin wieder als Witwe Graf Folkmars und zusätzlich sogar als Schwester eines Trierer Chorbischofs Beringer. Erhalten war der Nachweis der Schenkung wohl im Kopiarbuch von St. Maximin. Vgl. dazu MRUB I 273, S. 328 f. Schmal, Mettlach, S. 23 u. Anm. 137, geht aufgrund des aufgeführten Andreaspatroziniums von einer Fälschung allerdings noch vor dem Kreuzreliquiar aus. - Vgl. dazu aber die Überlegungen im folgenden.

613 Vgl. dazu zuerst die Vita Liutwini I unten in Kap. D.IX.2.

614 Vgl. hierzu nochmals die freundliche Auskunft des Saarländischen Landeskonservators i. R. Dr. Martin Klewitz oben in Anm. 25 u. 314.

615 Vgl. dazu Junges, Mettlacher Gotteshäuser, S. 92. Es handelt sich beim zweiten Nachweis um einen Ablaßbrief des Nicolaus Cusanus. Ab Ende des 15. Jahrhunderts habe Andreas keinesfalls mehr zu den Mettlacher Klosterpatronen gehört. Doch tauche der Gedenktag des Andreas in Mettlach mehrfach als Zinstag auf. Auch sei die zu Mettlach gehörende Pfarrkirche in Wadern Andreas geweiht. Ebenso befinde sich ein Andreasaltar in St. Gangolf. Lager, Urkundliche Geschichte, S. 219, weist das Andreaspatrozinium der Peterskirche zu.

616 Vgl. dazu oben S. 289 f. 
Heiligen nun auch für Mettlach stark zu machen, vielleicht fand auch eine Reliquie ihren Weg dorthin. ${ }^{617}$ Wo genau jedoch in Mettlach Liutwins Leichnam ruhen soll, verrät die Berta-Urkunde nicht.

Das Mettlacher Kreuzreliquiar aus dem frühen 13. Jahrhundert weist Andreas dagegen keine hervorgehobene Rolle zu. Auf den Außenseiten der Flügeltüren wird durch die Darstellung der Verkündigung und der Epiphanie Jesu die Klosterpatronin Maria stark betont. Als besondere Heilige Mettlachs zeigen die Innenseiten der beiden Türen die weiteren Patrone Petrus und Liutwin. Um die Kreuzreliquie herum sind dann mehrere Emailplättchen mit Heiligen auf kleinen Türchen in Form einer Staurothek angebracht, hinter denen sich wahrscheinlich einmal Reliquienfragmente befanden. Über dem Kreuzquerbalken werden Maria, Johannes der Täufer, Agatha und Dionysius dargestellt. Andreas findet sich zwar ebenfalls, allerdings unterhalb des Balkens inmitten der hier abgebildeten zwölf Apostel. Damit wäre immerhin eine Reliquie in Mettlach denkbar. ${ }^{618}$ Es ist nicht auszuschließen, daß Andreas seine Stellung als Patron nur kurzfristig, Ende des 10. Jahrhunderts, halten konnte und dann wieder verlor. Auf solche „Patrozinienverschiebungen“ hat bereits Peter Moraw hingewiesen. ${ }^{619}$

Die Berta-Urkunde erweckt dennoch nicht vollstes Vertrauen: Warum betont sie so stark, daß Bertas Gatte Folkmar Roden vom König selbst gekauft habe und das ohne irgendwelche Probleme? Und wer war dieser König? Die Urkunde bleibt eine Antwort schuldig. Gerade das deutet auf Schwierigkeiten hin. Die zwei voneinander deutlich abweichenden Einträge der Güterrolle lassen vermuten, daß es solche Schwierigkeiten tatsächlich gab. Setzte Mettlach die Urkunde vielleicht als nachträglich konstruiertes Mittel dagegen ein? Oder nahm man an einem vorliegenden Original noch Interpolationen vor? Ferner fällt auf, daß die Urkunde mit den V. Kalenden des März exakt dasselbe Tagesdatum nennt wie die oben erwähnte interpolierte notitia zu Erzbischof Rotberts Ausstattung der Kirche in Udern (931/6) in der Version der Güterrolle. Die beiden ältesten noch überlieferten Mettlacher Urkunden datierten also auf denselben Tag. ${ }^{620}$ Das kann kaum ein Zufall sein. Sie müssen einander beeinflußt haben, was mindestens für Interpolationen spricht. Vielleicht griff man auch auf eine gemeinsame Vorlage zurück.

617 Folgt man den Überlegungen von Moraw, Patrozinienforschung, S. 22 f., dann deutet ein ergänztes drittes Patrozinium häufig auf neu hinzugekommene Reliquien hin. Maria und Petrus waren dagegen im Trierer Raum verbreitete Gründerpatrozinien. Man denke hier nur an die ersten Patrozinien des Klosters Echternach.

618 Vgl. Sauer, Fundatio, S. 306-311 u. Abb. 67. Henze, Kreuzreliquiare, S. 53-74, bes. S. 58-65.

619 Vgl. Moraw, Patrozinienforschung.

620 Vgl. zum Text der Kopie auf der Güterrolle oben Anm. 465. 
Sollte es sich bei der Urkunde aber um eine vollständige spätere Manipulation handeln, warum setzte man dann an Andreas' Stelle nicht Dionysius ein? Ist die Urkunde jedoch wenigstens in diesem Teil echt, so zeigt sie eine der ersten greifbaren Stufen eines Mettlacher Liutwinkultes.

Zusammenfassend bietet die Berta-Urkunde für Mettlach von 995, wenn sie in diesem Punkt echt ist, den ersten chronologisch greifbaren Nachweis, daß Liutwin sowohl Mettlach gegründet haben als auch dort bestattet sein soll. Da dabei der in Trier unter Egbert geförderte Andreas als eines der von Liutwin gewählten Mettlacher Gründungspatrozinien erscheint, anstelle des später einmal an dieser Stelle genannten Dionysius, bietet die Urkunde einen weiteren Hinweis für Egberts Rolle beim Aufbau des Mettlacher Liutwinkultes am Ende des 10. Jahrhunderts. Allerdings ist sie nicht über alle Zweifel erhaben. Daß sie betont, das Schenkungsgut in Roden sei sicher und widerspruchsfrei durch den verstorbenen Gatten der Schenkerin aus königlichem Besitz erworben worden, deckt sich nicht mit den sehr widersprüchlichen und teils getilgten Angaben zu diesem Ort auf der Güterrolle. Für eine mögliche Manipulation oder Interpolation spricht vor allem die Tagesdatierung, die mit der interpolierten notitia zu Rotberts Ausstattung der Kirche in Udern exakt übereinstimmt.

\section{Ergebnis}

Die beiden untersuchten Urkunden bieten weitere Hinweise auf eine Rolle Egberts beim Aufleben eines Mettlacher Liutwinkultes. Die auf 981 datierende Egbert-Fälschung (MRUB I †255) zeigt, daß das Bild eines Herzogs Liutwin, der zunächst Mönch und später Trierer Erzbischof wurde, frühestens ab 981, aber eher noch später aufkam. Grundlage war vielleicht eine - dann wahrscheinlich manipulierte - Donationsurkunde eines dux Liutwinus an das Trierer Stift St. Paulin. In der Schenkung Bertas an Mettlach (MRUB I 270) von 995, die allerdings nicht frei von jedem Fälschungsverdacht ist, läßt sich erstmals das Bild eines Liutwin nachweisen, der Gründer Mettlachs und zugleich dort begraben ist. Daß Liutwin in dieser Urkunde Mettlach - entgegen der übrigen Überlieferung - auch mit einem Andreaspatrozinium ausstattete, weist deutlich auf den von Egbert in Trier massiv forcierten Kult dieses Apostels hin. Liutwins verstärkte Verehrung in Mettlach kann nach diesen Dokumenten erst während oder nach Egberts Amtszeit eingesetzt haben. Dazu würde auch bestens die für das ausgehende 10. oder frühe 11. Jahrhundert angenommene Fälschung oder Manipulation der beiden Urkunden passen, die für Erzbischof Radbod (883915) ausgestellt wurden und die einen hl. oder seligen Trierer Erzbischof Liutwin als Schenker Mettlachs an Trier nennen (DKIII. 111 u. DArn. 39), wenn 
nicht schon Erzbischof Radbod Ende des 9. Jahrhunderts diese Bild konstruierte. $^{621}$

\section{Liutwin und Basin in der Trierer Geschichtsschreibung des 11. Jahrhunderts}

\section{Zur Chronologie der Texte}

Bevor nun die Überlieferung zu Liutwin und Basin in der Geschichtsschreibung und Hagiographie des Trierer Raums untersucht wird, sind zunächst einige wenige grundsätzliche Bemerkungen erforderlich. Die Forschung ging - wie bereits oben erläutert - seit Kölzers Untersuchungen zu St. Maximin von folgender relativer Chronologie der Quellen aus, die in diesem Rahmen überliefert sind. Inhaltliche Argumente spielen dabei eine wesentliche Rolle: 1. die anonyme, in Mettlach verfaßte Liutwin-Vita I, 2. der im Trierer Erzstift aufgezeichnete Libellus de rebus Treverensibus, 3. die in Mettlach geschriebenen Miracula s. Liutwini, 4. die Liutwin-Vita II des Thiofrid von Echternach, 5. die in St. Eucharius in Trier verfaßte Redaktion A der Gesta Treverorum. ${ }^{622}$ Daran soll hier auch festgehalten werden, wobei absolute Datierung sowie Entstehungsort und -umstände im einzelnen jeweils dezidiert zu prüfen sein werden.

Der erst kürzlich gemachte Vorschlag von Schmal, in Thiofrid von Echternach $(\dagger 1110)$ auch den Verfasser der Miracula zu sehen, scheint nicht unbegründet. ${ }^{623}$ Dabei erwog sie ebenso eine Umdatierung der Vita I in die Zeit nach dem Libellus sowie nach den Miracula, wie die inneren Abhängigkeiten der genannten Quellen zeigten. ${ }^{624}$ Gegen diese These spricht jedoch eine schon

621 Vgl. dazu nochmals oben Kap. D.IV.3.-4.

622 Vgl. dazu bereits ausführlicher oben Kap. D.I.2.c. - Zuletzt hat Kölzer, Studien, S. 252-260, den Libellus de rebus Treverensibus in die Episkopatszeit Erzbischof Eberhards von Trier (1047-1066) umdatiert.

623 Vgl. dazu Schmal, Mettlach, S. 12 f., sowie auch unten Kap. D.IX.4.a.

624 Vgl. dazu Schmal, Mettlach, S. 11-21. Sie geht davon aus, daß der Vitenverfasser, weil er von einer Marienbasilika und keinem Oratorium spreche sowie ein dem Liutwin würdiges Grabmal nennt, bereits den Ende des 10. Jahrhunderts erbauten ,Alten Turm meine bzw. diesen schon vor Augen habe. Wenn die Vita I von Wundern Liutwins spreche, beziehe sie sich damit auf die Miracula. Die Miracula nähmen dagegen in keiner Form auf die Vita I Bezug. Sie berichteten nicht einmal von Liutwins Eltern Gerwin und Gunza, die die Vita I nenne. Auch werde das von Liutwin angeblich erbaute Dionysiusoratorium verschwiegen. Schmal datiert die Miracula zwischen 1063 und 1070, die Vita II des Thiofrid zwischen 1072 und 1077. Die Vita I wäre zwischen 1063 und 1077 entstanden. Sie habe auch Informationen zu Liutwins Leben aus dem Libellus entnommen. Im Libellus fehlten aber noch einige Mettlacher Patrozinien und Liutwins Eltern, die in der Vita I erscheinen. Deshalb sei er früher entstanden. - Dabei übersieht 
weiter oben gemachte Beobachtung: Die Mettlacher Vita I weiß noch nichts über die Todesart Milos, des angeblichen Sohnes Liutwins, zu berichten, obwohl sie Milo ein ganzes, teils positives Kapitel widmet. ${ }^{625}$ Der Trierer Libellus bietet dagegen plötzlich eine sagenhafte Erzählung über den verdorbenen Milo, der auf der Jagd von einem Eber getötet und in Ehrang bestattet worden sei. ${ }^{626}$ Die Mettlacher Miracula s. Liutwini nehmen das zwar auf, wollen aber den immer noch auch positiv erinnerten Milo von möglicher Schuld reinwaschen: Sein Ende sei nicht deshalb offenkundig verdächtig, weil ihn ein wilder Eber tötete, als er den Hunden folgte; sondern weil er gerecht war, befinde er sich in der ewigen Glückseligkeit, wie auch immer sein Tod gewesen sei. ${ }^{627} \mathrm{Daß}$ ausgerechnet die Vita I, die eine positive Mettlacher Milotradition spiegelt, keinerlei Bezug auf diese Geschichte nimmt, spricht für ihre Entstehung noch vor dem Libellus. Ja, das Bild von Milos unwürdigem Tod dürfte zunächst im Trierer Erzstift entstanden und erst dann nach Mettlach gelangt sein.

\section{Die Vita Liutwini I aus Mettlach}

Bereits ganz zu Beginn dieses Kapitels zu Basin und Liutwin findet sich eine knappe Inhaltsangabe der Liutwin-Vita I. ${ }^{628}$ Im folgenden sollen deshalb nur wesentliche Passagen und Aussagen dieser Quelle behandelt werden, die ebenso die ersten genaueren Angaben zu Basin enthält.

Die beiden ältesten greifbaren Kodizes, die die Vita überliefern, stammen aus dem 15. bzw. 16. Jahrhundert: der eine aus dem Kloster St. Eucharius/St. Matthias (frühes 16. Jahrhundert), der andere aus Mettlach selbst. ${ }^{629}$ Ihre ein-

Schmal aber, daß der Libellus aus der Perspektive des Erzstiftes geschrieben ist, während die Vita I eine Mettlacher Position einnimmt. So dürfte es nicht verwundern, daß man sich in Trier nur auf den inhaltlichen Kern der Vita I und die wichtigsten Patrozinien beschränkte. Im übrigen ist eine derart massive Textproduktion zu Liutwin und Mettlach in der von Schmal favorisierten knappen Zeit kaum wahrscheinlich. - Vgl. dazu ausführlicher die Überlegungen zu den Datierungen der Texte unten in Kap. D.IX.2.ff.

625 Vgl. dazu unten Anm. 641.

626 Vgl. dazu schon oben Kap C.I., Anm. 2.

627 Vgl. dazu bereits oben Kap. C.IV.4. sowie unten S. 345 ff. Vgl. hier auch nochmals die Darstellung der Miracula s. Liutwini auct. Monacho Mediolacensi cap. 3, ed. SAUERLAND, S. 1262, Z. 7-9: Cuius etiam finis non ideo infamis extitit, quod canes sequentem aper silvaticus extinxit; quia iustus, quacunque morte preoccupatus fuerit, in refrigerio erit. 628 Vgl. dazu oben Kap. D.I.2.a.

629 Vgl. dazu WinhelLer, Lebensbeschreibungen, S. 84 f. Bei der Handschrift aus St. Eucharius/St. Matthias handelt es sich um Trier, Stadtbibliothek, 1376/141, fol. $149^{\mathrm{r}}-156^{\mathrm{r}}$; bei der Mettlacher um Trier, Stadtbibliothek, 2002/92, fol. $175^{\mathrm{r}}-179^{\mathrm{r}}$. In beiden Handschriften folgen der Vita unmittelbar die Miracula s. Liutwini. Vgl. dazu W INHeller, Lebensbeschreibungen, S. 95 u. Anm. 45. Vgl. zu den Handschriften auch 
zige Edition in den Acta Sanctorum aus dem 17. Jahrhundert ist für heutige Zwecke unbefriedigend. ${ }^{630}$ Die Vita läßt sich nur aufgrund inhaltlicher Kriterien datieren. Nach den Teilübersetzungen von Briesens und Lagers versuchte dies zunächst WINHELLER 1935. Er hält die Vita für „recht unzuverlässig“ und geht von einer Entstehung zwischen der Amtszeit Erzbischof Rotberts (931-956), der nach einer späteren Urkunde eine jährliche Wallfahrt nach Mettlach angeordnet habe, und 1077 aus. Bis zu diesem Jahr nämlich sei die Liutwin-Vita II des Thiofrid von Echternach, der die Vita I verwandte, abgeschlossen gewesen. Als Vorlage für die Vita I habe vielleicht der erwähnte Liutwin-sermo des Mettlacher Abtes Remigius aus dem späten 10. Jahrhundert gedient. Für Liutwins Zeit verfüge die Vita über keinen Quellenwert. Da ihr Verfasser jedoch die Geographie Mettlachs ausführlich beschreibe und von „unserem besonderen Patron Liutwin" spreche, müsse er Mitglied des dortigen Konvents gewesen sein. ${ }^{631}$ Die weitere Forschung folgte ihm darin und vermutete, daß der Text in der Zeit des späten 10. oder frühen 11. Jahrhunderts verfaßt wurde. ${ }^{632}$

Die Ausführungen weiter oben zu den wachsenden Trierer Bischofslisten unter Egbert stützen das ebenso. Erst in seiner letzten, vollständigen Liste folgen die Trierer Bischöfe Basin, Liutwin und Milo aufeinander, wobei Milo seinen Platz allein den Reimser Quellen verdankte. Die Vita I kann deshalb nicht vor dem späteren Episkopat Erzbischof Egberts und der Langversion der Bischofsliste entstanden sein. ${ }^{633}$ Diesen terminus post quem unterstreichen auch die ersten und mit der Vita übereinstimmenden konkreteren Angaben zu Liutwin in der Egbert-Fälschung sowie der Berta-Schenkung. ${ }^{634}$

Keuffer/Kentenich, Beschreibendes Verzeichnis 8, S. 37 f., 51 f. Coens, Catalogus, S. 270. Becker, St. Eucharius, S. 220, Nr. 361.

630 Vgl. Vita Liutwini I, ed. Perier, S. 169-172.

631 Vgl. dazu von Briesen, Urkundliche Geschichte, S. 74-79. Lager, Urkundliche Geschichte, S. 1-12. Dabei bewegt sich von Briesen näher am Text, während Lager interpretiert und Informationen ergänzt, die darin nicht enthalten sind. WiNHELLER, Lebensbeschreibungen, S. 88-96, zur Entstehungszeit S. 92-94. Ebd., S. 87 f., bietet eine Zusammenfassung des Viteninhalts. - Zur Wallfahrtsurkunde vgl. unten S. 324326 u. Anm. 665, 668.

632 Vgl. zur Entstehungszeit der Vita Ewig, Trier, S. 133. Pauly, Landkapitel Merzig, S. 84 ff. RaACH, Mettlach, S. 8 f., Anm. 21 u. S. 51 ff., geht vom späten 10. Jahrhundert aus. Junges, Mettlacher Gotteshäuser, S. 81 u. Anm. 8, sieht im Verfasser der Vita schon Remigius von Mettlach. Da eine Wallfahrt zu Dionysius und keine zum Klostergründer Liutwin genannt werde, müsse die Vita noch vor dem Bau des ,Alten Turmes' am Ende des 10. Jahrhunderts entstanden sein. Gauthier, Évangélisation, S. 360 f. Anton, Liutwin, S. 34 f. u. Anm. 35, spricht sich für das spätere 10. Jahrhundert aus. BAUER, Spätmerowingische Zeit, S. 240-242, folgt mit der Datierung auf um 980 den jetzt zu erläuternden Thesen Fleschs in großen Teilen.

633 Vgl. dazu oben Kap. D.VI.3.e.

634 Vgl. dazu Kap. D.VIII. 
Schließlich hat Flesch mit einigen beachtenswerten Argumenten in der Vita I den erwähnten, bislang vermißten Sermo de proprio patrono Liutwino des Remigius erkannt. Man habe den sermo nach Angabe der Miracula jährlich zum Liutwinfest vorgelesen. Eine Liutwinpredigt - so FLESCH - sei aber nirgendwo überliefert, auch wenn man Handschriftenverluste nicht ausschließen könne. Die Begriffe sermo und vita würden in dieser Zeit aber häufig synonym gebraucht. Auch Thiofrid bezeichne seine spätere Liutwin-Vita II noch als sermo. Schließlich spreche die Klage des Verfassers der Vita I über fehlende Schriftquellen gegen eine noch vorausgehende Predigtvorlage. Vor allem falle die durchgängige und anspruchsvolle Reimprosa des Textes auf, auf die schon WinHELLER hinwies, sowie ein lebhafter Predigtstil mit rhetorischen Fragen (z. B. cap. 8 f.). Diese stilistischen Eigenarten fänden sich ebenfalls in den Euchariuspredigten des Remigius. Er müsse deshalb der Autor der Vita I sein. ${ }^{635}$

Diese Überlegungen überzeugen, wenn sie sich auch nicht mit letzter Sicherheit beweisen lassen. Für eine Verfasserschaft Remigius' spräche ferner, daß die beiden ältesten Handschriften der Vita aus St. Eucharius und Mettlach stammen, seinen Wirkstätten. ${ }^{636}$ Auch die von Winheller für die Vita I herausgearbeiteten Tautologien finden sich immer wieder bei Remigius. ${ }^{637}$ Die Reimform der Vita läßt eher keine oder allenfalls wenige nachträgliche Interpolationen und vielmehr Textstabilität vermuten. Nicht völlig ausschließen läßt sich, daß in Mettlach nachträglich in den sich anonym gebenden Vitentext bald die Verfasserschaft Remigius' hineininterpretiert wurde. Ganz offenbar reagierte der Text jedoch auf ein Bedürfnis, das in diesem Kloster seit der Zeit Egberts bestand. Mit dem oder für das Aufleben des dortigen Liutwinkultes wurde ein

635 Vgl. Flesch, Monastische Schriftkultur, S. 51-55, wo er auch zahlreiche Beispiele für seine Begriffsklärungen bietet. Flesch ediert auch den Schluß der Vita (ebd., S. 54), der sich in den Acta Sanctorum nicht findet. - Derartiges vermuteten schon die Bollandisten im Kommentar zur Edition der Vita I (AASS September 8, S. 179). Auch äußerte bereits LAGER, Urkundliche Geschichte, S. 36 f., einen ähnlichen Verdacht. - Vgl. zur Reimform W INHELLER, Lebensbeschreibungen, S. 95. Waisen sind selten, die Reime meist einsilbig, gelegentlich zweisilbig. Es fänden sich Reimpaare, aber auch Dreier- und Viererreime sowie häufiger Tiradenreim, ebenso Binnenreime. - Vgl. zur Bezeichnung sermo Thiofrid, Vita Liutwini II, Prologus, ed. Lampen, S. 3: [...] hoc opusculum nostrum potius esse sermonem quam textum historiae, [...]. - Vgl. den Vitentext zu den fehlenden Schriftquellen oben in Anm. 23. - RaAch, Mettlach, S. 8, Anm. 21, hält eine Übereinstimmung beider Texte nicht für wahrscheinlich. - Vgl. zum sermo auch nochmals oben S. 122, 284 f. u. Anm. 52, 534.

636 Vgl. zu Remigius nochmals oben S. 283 ff. u. Anm. 530-537.

637 Vgl. WinheLLER, Lebensbeschreibungen, S. 95. Man finde „sie meist in derselben Form: Nomen mit attributiver Bestimmung eines Synonymons im Genetiv, z. B. ,norma moderaminis' (c. 12), ,prodigium miraculi' (c. 14), ,humilitatis despectus' (c. 10), ,votum intentionis' (c. 7), ,collegium congregationis' (c. 17); nur selten setzt er zwei synonyme Nomina nebeneinander wie ,anfractus et latibulum' (c. 5).“ Die bei Flesch edierten Remigiustexte bieten ebenfalls einige dieser Tautologien. 
Mittel erforderlich, um das Wissen über den Heiligen zu verstärken und präsent zu halten. Gerade die Reimform der Vita prädestinierte sie für die einprägsame öffentliche Lektüre. Letztlich bittet der Verfasser ja alle, in deren Hände oder zu deren Ohren ihr Inhalt womöglich gelangen werde, sie mögen nicht neugierig nachforschen, von wem oder auf welche Weise all das gesagt worden sei. ${ }^{638}$

Schon das muß Mißtrauen gegen die eigentlichen Quellen des Liutwinkultes erregen. Der Hinweis auf fehlende Schriftzeugnisse und allenfalls bestehende mündliche Traditionen weckt den Verdacht, daß viele Informationen der Vita aus dem erwähnten Bedürfnis heraus konstruiert worden sind, den Kult zu stabilisieren. ${ }^{639}$ Was hätte man nach 300 Jahren noch überliefern können, zumal eine Plünderung Mettlachs durch die Normannen $882 \mathrm{sehr}$ wahrscheinlich ist? ${ }^{640}$ Deshalb soll die Vita im folgenden nicht auf ihre Aussagen zur Beschreibungszeit, sondern einmal genauer auf ihren Entstehungskontext um die Jahrtausendwende hin untersucht werden.

Dabei versprechen die inzwischen zusammengetragenen Erkenntnisse zu Milo einen besonderen Zugangsschlüssel, können sie doch das Bild Liutwins nicht unbeeinflußt gelassen haben. Beginnen wir deshalb am Ende der LiutwinVita, wo Milo in die Handlung eingeführt wird. Sogleich nimmt die Vita dabei Bezug auf Hinkmars Bild: Milo habe über 40 Jahre in Trier und Reims als Doppelbischof gewirkt. Milo sei vom Pfad der väterlichen Rechtschaffenheit zum Bösen abgeirrt, obwohl er von seinem Vater als Erbe der Besitztümer und Nachfolger seiner Ehren zurückgelassen worden sei. Daher habe er vom Vater die Bistümer Trier und Reims übernommen, nicht aber Laon, wo Liutwin zuvor auch das Bischofsamt inne gehabt habe. Als der Vater in Reims verstorben sei, habe Milo den Trierern recht erfolgreich dabei geholfen, dessen sterbliche Überreste von dort zum Sitz seiner ersten Braut, der Trierer Kirche, zurückzubringen. $^{641}$

Doch stimmt das alles schlechterdings nicht. Schon die ältere Forschung wies darauf hin, daß es sich bei den von Liutwin geleiteten Bistümern vielmehr

638 Vgl. dazu Vita Liutwini I cap. 2, ed. Perier, S. 169D: [...] lectorem prius consulente commoneo, omnesque, in quorum manus vel aures haec forte pervenerint, rogo, ne a quo vel qualiter haec eadem sint dicta, curiosi inquirant; [...].

639 Vgl. dazu nochmals oben Anm. 23.

640 Vgl. dazu oben S. 347 sowie unten S. 110.

641 Vgl. Vita Liutwini I cap. 16, ed. Perier, S. 171F: Cui erat jam filius, nomine Milo, qui, ut quidam dicunt, nimis degener a paternae rectitudinis semita oberraverat tramite malo; quamvis relinqueretur heres rerum \& successor honorum. Nam Patri succedens Treverensium \& Remorum pariter episcopatum per quadraginta annos tenuit, \& Trevericis Patris sui exuvias ad primae sponsae suae sedem revehendas satis efficax adjutor fuit. Treverici itaque comperto almi Praesulis obitu, paterno mox commoti affectu, ad Remensem concite urbem cum Milone properarunt, \& sacrum thesaurum, cum magna difficultate sed nutu Dei acquisitum, ad propria asportarunt. 
um eine Projektion von Milo auf den angeblichen Vater handle. ${ }^{642}$ Man muß aber noch weiter gehen: Wenn Milo nämlich ein solches episkopales Doppelamt niemals bekleidete, ist das erst recht für Liutwin unmöglich. Ebensowenig konnte es dann Milo von Liutwin qua Erbe übernehmen. Dann aber starb Liutwin nicht in Reims, wo zu dieser Zeit vielmehr Bischof Rigobert amtierte. ${ }^{643}$ Und deshalb holten die Trierer seine sterblichen Überreste kaum mit Milos Hilfe unter großen Schwierigkeiten, doch durch Gottes Fügung, von dort zurück. Dieses Bild floß vielmehr aus der älteren Maximin-Vita ein. Sie berichtet ganz ähnlich, wie die Leiche des Trierer Bischofs Maximin von seinem Bestattungsort in Aquitanien durch seinen damaligen Nachfolger Paulin unter einigen Schwierigkeiten nach Trier zurückgebracht wurde. Dabei sollen sich zahlreiche Wunder ereignet haben. ${ }^{644}$ Keinesfalls trifft daher die Fama zu, man habe Liutwin aufgrund plötzlicher Widrigkeiten nicht in Trier bestatten können, weil er nach dem Ort seiner Erniedrigung und nicht seiner Ehre strebte. Gleiches gilt für den Trierer Beschluß, seine Leiche in einem steuerlosen Schiff treiben zu lassen, wie ebenso für dessen Reise Mosel und Saar aufwärts bis Mettlach, wo bei seiner Ankunft die Kirchenglocken zu läuten begannen. Liutwin kehrte zu seinem Kloster heim. Dieses Bild findet sich ähnlich in den jüngeren MaternusViten und dürfte schlichtweg topisch sein. ${ }^{645}$ Dann entspricht es kaum der Wirklichkeit, daß Liutwin in dieser Weise zu seiner dortigen Ruhestätte fand und große Wunder wirkte. Wo genau Liutwin nun ruhte, verrät die Vita nicht. $^{646}$

Eine derart ausführliche Erinnerungssequenz kann sich keineswegs über drei Jahrhunderte im kulturellen Gedächtnis Mettlachs gehalten haben. Fehlende Schriftquellen und geringe mündliche Überlieferung vor Ort sprechen dagegen. Ohne die Rezeption von Hinkmars Milobild funktioniert die Sequenz zu Li-

642 Vgl. Winheller, Lebensbeschreibungen, S. 89 f. Anton, Liutwin, S. 51 u. Anm. 101 f. Zuletzt hat das auch BAuER, Spätmerowingische Zeit, S. 240, 242, nochmals betont. Daß Liutwin nicht Milos Vater war, ließ sich anhand von DKarol. I 148 von 782 nachweisen. Dann aber konstruierte die Vita dessen Vaterschaft für Milo, um absichtlich ein Familienverhältnis herstellen zu können. Deshalb muß Liutwin zu Beginn der Vita heiraten, wobei die Vita den Namen seiner Frau verständlicherweise verschweigt. Vgl. dazu Vita Liutwini I cap. 3, ed. Perrin, S. 169F: Qui jam adultus generis sibi consimilem duxit uxorem, [...].

643 Vgl. dazu bereits ausführlich die Überlegungen oben in Kap. B.V. sowie die umfangreichen Angaben zu Rigobert in Kap. C. Lager, Urkundliche Geschichte, S. 9 f. WinHeller, Lebensbeschreibungen, S. $84 \mathrm{f}$.

644 Vgl. dazu Vita sancti Maximini episcopi Trevirensis cap. 5-7, ed. Henschen, S. 22. Winheller, Lebensbeschreibungen, S. $14 \mathrm{f}$.

645 Vgl. dazu Vita Liutwini I cap. 16 f., ed. Perier, S. 171 f. Winheller, Lebensbeschreibungen, S. 45 ff. u. 91, erwähnt den Vergleich mit der Maternuslegende und spricht von hagiographischem Gemeingut.

646 Vgl. dazu insgesamt Vita Liutwini I cap. 17 f., ed. Perier, S. 172. 
utwins Tod und letztem Weg nach Mettlach überhaupt nicht. Warum aber war es notwendig, in der Vita unbedingt Liutwins langwierige Translation über Trier nach Mettlach zu erklären? Hätte man ihn nicht gleich ins Kloster bringen können? Und warum war es so wichtig, daß Milo daran mitwirkte? Beides weckt den Verdacht, daß es eine solche Translation entweder niemals gab oder daß sie ganz anders und vielleicht zu einer ganz anderen Zeit erfolgte. Keine einzige Quelle vor Egberts Episkopat berichtet jedenfalls davon. Vielmehr sollte es sie in der beschriebenen Form gegeben haben.

Eine weitere Unstimmigkeit der Vita bietet dazu einen Hinweis: Die Vita meldet Liutwins Tod in Reims zum 29. September, seinem späteren Festtag. Seine Überführung nach Trier und anschließend Mettlach dürfte nach diesem Erzählkonzept einige Tage in Anspruch genommen haben. Wie läßt es sich dann jedoch erklären, daß der erwähnte St. Maximiner Kalendarnachtrag aus dem frühen 11. Jahrhundert zu diesem Tag nicht Liutwins Tod, sondern seiner depositio in Mettlach gedenkt? ${ }^{647} \mathrm{Da}$ aber gerade die Bestattung in diesem Kloster von zentraler Bedeutung war, verdeutlicht der fiktive Bericht der Vita I. Liutwin wollte nicht in Trier bestattet werden, sondern in seinem Kloster, wie das Schiffswunder zeigte. Wenn ein solches Geschehen aber nicht im frühen 8. Jahrhundert stattfand, hatte es vielleicht seinen realen Hintergrund im 10. Jahrhundert, gar zu Egberts Zeit? Unternahm man hier eine Translation der Gebeine Liutwins von Trier nach Mettlach, oder bettete man die Gebeine im Kloster schlicht um? Der 29. September erinnerte dann tatsächlich an Liutwins depositio in seinem neuen Mettlacher Grab. Wenn Wissen darüber ausgerechnet in St. Maximin erhalten blieb, wo man doch 952 eine Liutwinreliquie in einem Altar deponiert haben wollte, deutet hier einiges auf Liutwins Erstbestattung in Trier selbst hin. ${ }^{648}$ Die Mettlacher Vita I hätte jedenfalls die Spuren dieser Translation zu verwischen gesucht, diese in die ferne Vergangenheit projiziert und den Tag der depositio zu Liutwins Todestag in Reims gemacht. Für eine solche depositio Liutwins in Mettlach gibt es ebenso archäologische Indizien, worauf unten genauer einzugehen sein wird. ${ }^{649}$

Nach den oben gewonnenen Erkenntnissen lag im Kloster Mettlach dagegen ein adliger oder niederer Kleriker namens Milo, Liutwins angeblicher Sohn, begraben. Doch über Milos weiteres Schicksal berichtet die Vita - die ihn ja zum Bischof macht - nichts mehr. Nach dem zeitgenössischen DKarol. I 148 war aber nicht Liutwin, sondern dieser, alte' vor-Hinkmarsche Milo längere Zeit intensiv mit Mettlachs Schicksal verbunden. Er entsandte als Äbte den Trierer Ebreo und die Trierer Bischöfe Ratbert sowie Hartham ins Kloster, dem er es

647 Vgl. dazu oben Anm. 58, zur Vita, sowie oben Anm. 571, zum Kalendarnachtrag. 648 Vgl. dazu oben Kap. D.VI.1.

649 Vgl. unten Kap. D.IX.4.b., S. 355 ff. 
schließlich möglicherweise übertrug und der damit auch von Pippin III. belehnt wurde.

Es ergibt sich deshalb für Milo und Liutwin ein auffälliger Befund in der Vita I: Liutwin erscheint als positives Gegenbild Milos. Während Milo die Bistümer Trier und Reims ausbeutete, ist Liutwin das strahlende Beispiel eines Bischofs, der sogar als Trierer bei der Erledigung der Amtsgeschäfte in Reims starb. Er verwaltete mit Laon sogar ein Bistum mehr als sein Sohn und besaß damit einen noch größeren Einflußbereich als dieser. Aber Liutwin übernimmt auch die oben erschlossenen positiven Attribute Milos, die die Vita inzwischen verschweigt. So findet jetzt Liutwin und nicht Milo sein Grab in Mettlach. Und nicht mehr Milo, sondern Liutwin sorgt sich nun intensiv um das Kloster, ja er gründete es sogar mit reicher Ausstattung, wie die ersten Kapitel der Vita ausführlich zeigen. ${ }^{650}$ Auch nicht Milo, sondern Liutwin übertrug - nach seiner Bischofserhebung - jetzt Mettlach an die Trierer Kirche und bestimmte, daß nur Leute der Trierer Erzbischöfe darüber verfügen dürften. Es handelt sich um ein Bild, wie es sich ebenfalls in den beiden wenigstens inhaltlich manipulierten Urkunden für Radbod von 884 und 888 findet (DKIII. 102 u. DArn. 39). ${ }^{651}$ Selbst Milos Rolle als Adliger könnte auf den Herzog Liutwin projiziert worden sein. Damit stößt man unübersehbar auf ein Phänomen, das in der historischen Gedächtnisforschung seit einiger Zeit als ,qualitative Inversion' bezeichnet wird. Es werden dabei gleichsam die Werte und Leistungen zweier Personen im Gedächtnis miteinander vertauscht bzw. von der einen auf die andere übertragen. ${ }^{652}$

Doch wie und warum könnte das geschehen sein? Erinnern wir uns noch einmal an die Rezeption des Reimser Milobildes in Trier und Mettlach sowie deren Auswirkungen. Wenn das gerade erst bekannt gewordene dunkle Bild des Doppelbischofs Milo tatsächlich die Trierer Primatsansprüche über die Belgica, Gallia und Germania bedrohte und Milos Grab sowie seine anzunehmende Erinnerung in Mettlach in Frage stellte, mußte das zwangsläufig zu Konsequenzen führen. Trier war verwundbar geworden. ${ }^{653}$ Dabei konnte das Argument eines Doppelepiskopats per se - entkleidet von allen negativen Konnotationen - dem Trierer Erzstift sowie Mettlach nicht nur schaden, sondern nutzen.

650 Vgl. dazu Vita Liutwini I cap. 7-10, ed. Perier, S. 170 f., sowie weiter unten in diesem Unterkapitel.

651 Vgl. dazu Vita Liutwini I cap. 13, ed. Perier, S. 171C: Qui etiam monasterii, in quo spiritualem exercebat militiam, non obliviscens, utilitati quoque inhabitantium in futurum consulens, idem cum appendiciis suis apostolorum principe, cujus cathedrae praesidebat, contradidit, ac de cetero episcoporum viris Trevirorum esse decrevit. - $\mathrm{Zu}$ den RadbodUrkunden vgl. oben Kap. D.IV.4.-5.

652 Vgl. dazu zuerst Fried, Geschichte und Gehirn, S. 29 f., hier S. 30, Phänomen Nr. 13. Fried, Schleier, S. 49-56, bes. S. 50 f., hier als Punkt 14.

$653 \mathrm{Vgl}$. dazu bereits oben S. $302 \mathrm{f}$. 
$\mathrm{Da}$ sich eine solche Sichtweise entwickelte, scheint die Vita I zu belegen. So gingen alle Attribute des inzwischen beschädigten Milo - sowohl die negativen Reimser als auch die positiven aus Mettlach - als gute Eigenschaften auf den unbelasteten und deshalb um so strahlenderen Liutwin über. Damit fand sich sowohl für Trier wie für Mettlach eine Lösung: Falls die bekannt gewordenen Angaben zu Milo tatsächlich stimmten, mußte das für dessen Vorgänger und Vater keinesfalls zutreffen. Das zeigt, daß dieses neue Liutwinbild nur aufgrund der Traditionen beider Orte entstanden sein kann. Alle bisherigen Indizien sprechen für Egberts Episkopat. Es wäre nicht sein einziger konstruierter Heiliger, denkt man an Celsus. Als Mediator dieses neuen Liutwinbildes zwischen Trier und Mettlach könnte der Vitenverfasser Remigius gewirkt haben. ${ }^{654}$

Auf Grundlage der bisherigen Überlegungen zur Vita I soll nun deren erster Teil nach weiteren Hinweisen zu einer Konstruktion ihres Inhaltes untersucht werden. Eine solche wird schon daran erkennbar, daß Liutwin unter König Childebert geboren und zu Zeiten König Childerichs (II.?, †675) sowie des Hausmeiers Grimoald (†714), Pippins des Mittleren Sohn, Bischof geworden sein soll. ${ }^{655}$ Selbst die ältere Forschung wies darauf hin, bei Childerich handle es sich für die Bischofserhebung um eine Verwechslung mit Childebert III. (678/9711). ${ }^{656}$ Daß Liutwin dem Basin erst nach dessen Tod als Bischof gefolgt sein kann, stimmt mit den Ergebnissen überein, die zu den Irmina-Urkunden gewonnen worden sind, in denen sich nur ein presbiter Liutwin neben Basin nachweisen läßt. Basins angegebener Todestag (4. März) entspricht dem zeitgenössischen Nachtrag im Willibrord-Kalendar. ${ }^{657}$

Bei Liutwins angeblichem Senatorenrang handelt es sich um einen Topos, der in Trier häufiger verwendet wurde. ${ }^{658} \mathrm{Daß}$ er königlichem Geschlecht entstamme, ließ sich bisher nicht nachweisen und mag ebenso topisch sein. Basin ist als Onkel Liutwins in keiner früheren Quelle anzutreffen, was ein konstruiertes Verwandtschaftsverhältnis nahelegt, das sich bis zu Milo fortsetzt. Liutwin wird so geradezu stemmatisch in der Trierer Bischofsliste zwischen Basin und Milo festgeklammert, als ob man befürchte, seine Existenz möge

$654 \mathrm{Zu} \mathrm{Remigius} \mathrm{vgl.} \mathrm{nochmals} \mathrm{oben} \mathrm{S.} 283$ ff. u. Anm. 530-537, 543 sowie S. 317 f. u. Anm. 635-638. Zu Celsus vgl. oben S. 286 u. Anm. 541.

655 Vgl. dazu Vita Liutwini I cap. 3 u. 11, ed. Perrin, S. 169F u. 171B.

656 Vgl. dazu bereits W InHeller, Lebensbeschreibungen, S. 88 f. - Vielleicht verwechselte der Verfasser auch beide Könige. Denn Childerich II. (ca. 655-675), der einzige Merowinger, der hier überhaupt in Frage kommt, könnte dann als König für Liutwins Geburt gemeint sein. - Vgl. auch Anton, Liutwin, S. $41 \mathrm{f}$.

657 Vgl. Vita Liutwini I cap. 11, ed. Perrin, S. 171B. - Vgl. zum Eintrag Liutwins neben Basin in den sog. Irmina-Urkunden bereits oben Kap. D.II.4.a.-c. Vgl. zum WillibrordKalendar bereits oben S. 118 u. Anm. 29.

658 Vgl. Vita Liutwini I cap. 3, ed. Perrin, S. 169. Zu den zahlreichen Beispielen vgl. nur Heyen, Fälschung und Legende, S. 403-415, bes. S. 410 ff. 
sonst angezweifelt werden. Ähnliches gilt für seine ehrwürdigen Eltern Gerwin und Gunza, bei denen bisher vergeblich nach überzeugenden historischen Vorlagen gesucht wurde und die ebenso Fiktion des Vitenverfassers sein dürften. Die Namen sind seltsam genug. ${ }^{659}$ Immerhin zeigt das Mettlacher Kreuzreliquiar aus dem frühen 13. Jahrhundert diese beiden auf seiner Rückseite, wie sie OBELIILGA an das Kloster übertragen. ${ }^{660}$ Doch könnte das ein schlichter Bezug auf die Erzählung der Vita sein, um mit beider Namen später Mettlacher Grundbesitz zu sichern.

Für die von DE RosiÈres im 16. Jahrhundert verfälschte Urkunde eines Moselherzogs Chlodulf, der Oblanga an Mettlach schenkt, wurde kürzlich als ursprüngliche Vorlage eine Schenkungsurkunde Gerwins und Gunzas über diesen Ort rekonstruiert. Da diese Vorlage aber immer noch auf 646 datiert und unter den Zeugen einen Basin nennt, der sicher nicht in diese Zeit gehört, ist anzunehmen, daß es sich schon dabei um eine gezielte Konstruktion handelt. Sie sollte absichtlich in die Jahre vor Liutwins Episkopat plaziert werden. Ihr Konstrukteur war sich der chronologischen Bezüge nicht mehr sicher. Die Urkunde nennt zwar die Mettlacher Heiligen Maria, Peter und Paul sowie Dionysius, läßt aber die eigentliche Schenkung an das Dionysiuskloster unter seinem Abt Renoldus erfolgen. ${ }^{661}$ Dahinter steckt vielleicht der Bericht der Vita I, daß Liutwin in Mettlach zunächst ein Dionysiusoratorium baute, womöglich nahm aber auch DE Rosı̇̀res selbst erst später diese Veränderung vor. ${ }^{662} \mathrm{Nach}$

659 Vgl. zu den bisherigen Deutungsversuchen WinheLLER, Lebensbeschreibungen, S. 90. RAACH, Mettlach, S. 35, Anm. 84, hegt Zweifel an der Glaubwürdigkeit. EwIG, Milo, S. $415 \mathrm{f}$, , vermutet in Liutwin zunächst einen der Großen Pippins des Mittleren in Neustrien. Haubrichs, Urkunde Pippins, S. 31, hält die Namen für verläßlich. Anton, Liutwin, S. 39 f. u. Anm. 57 f., geht von verworrenen Reflexen der Verwandtschaft Liutwins und seiner Familie mit den frühen Karolingern aus. BAuER, Spätmerowingische Zeit, S. 240 u. Anm. 71, bemerkt, häufig werde der Graf Warin von Poitiers als Vater Liutwins genannt.

660 Vgl. dazu nochmals SAuer, Fundatio, Abb. 68, unten links. - Vgl. zu den Eltern auch unten Anm. 684.

661 Vgl. die verfälschte Urkunde bei Pardessus, Diplomata 2, Nr. 310, S. 84 f., hier nur die folgenden Auszüge: [...], aliquid in gazophylacium Domini, cum vidua paupere mittere studentes, famulantibus in domo Domini scripta decrevimus conferre. Quapropter ob reverentiam Domini, et beatae Mariae ac beatorum apostolorum Petri et Pauli, ac beati martyris Dionysii, vivâ et sanâ mente, et corporeâ voluntate liberâ, sine omni haesitationis contradictione, villam nostram Oblagnam damus imperpetuum domno abbati Renoldo ac fratribus monasterii beati Dionysii, in Meteloch, super flumen Sarrae aedificati, [...]. Die Zeugenliste: Martino, Basino, Pipino, Arnoldo, Gunzâ, Ittâ, Gertrude, [...]. Die Urkunde nennt auffälligerweise keinen Merowingerkönig, dafür den Hausmeier Pippin den Älteren, seine Frau Itta und deren Tochter, die hl. Gertrud von Nivelles. Sie erschien erstmals bei de Rosières, Stemmatum, S. IIb. Vgl. dazu Goerz, Mittelrheinische Regesten I 84*, S. 39. - Vgl. zur Rekonstruktion Schmal, Mettlach, S. 22 ff.

662 Vgl. Vita Liutwini I cap. 6, ed. Perrin, S. 170. 
Schmals überzeugender Argumentation weisen einige im Text der konstruierten Vorlage erscheinende Namen und Begriffe auf Thiofrid von Echternach als ihren Verfasser in der zweiten Hälfte des 11. Jahrhunderts hin. Er könnte sie geschaffen haben, während er an seiner Liutwin-Vita II und den ihm vermutlich auch zuzuschreibenden Miracula s. Liutwini arbeitete. Dazu hätte er die Vita I herangezogen. ${ }^{663}$

So sagenhaft auch die Passage der Vita I über den Bau des Dionysiusoratoriums vor der eigentlichen Klostergründung ist, so kann sie nicht völlig aus der Luft gegriffen sein. Bei der Gründung dieser Kirche, die noch weitere, ungenannte Reliquien erhalten haben soll, in angeblich unbesiedeltem Gebiet handelt es sich zwar um einen Topos. Der anschließende Text berichtet aber sehr konkret über eine jährliche Dionysiuswallfahrt aus der Umgebung nach Mettlach zu dieser Kirche, wobei man Kerzen und andere Opfergaben mitbrachte. Nach Gebet und Messe sei den Pilgern vom custos Brot und Wein vor der Abreise gereicht worden. ${ }^{664}$

Diese Tradition muß zur Abfassungszeit der Vita I einen Sitz im Leben gehabt haben. Kürzlich ist vermutet worden, das entsprechende Kapitel habe man später interpoliert. Denn erst eine Urkunde Erzbischof Alberos (11311152) ordne die Wiederbelebung einer in Vergessenheit geratenen Wallfahrt nach Mettlach an, die angeblich unter Erzbischof Rotbert und Abt Ruodewicl

663 Vgl. dazu ausführlich und auch überzeugend SchmaL, Mettlach, S. 23-26, die allerdings davon ausgeht, daß Thiofrid bereits auf eine Vorlage zurückgriff. Da nach ihr die Vita I erst kurz vor der Vita II entstand, habe die Vita I schon die Grundstufe der Urkunde benutzt. Zu dem von Thiofrid gebrauchten Vokabular vgl. Lampen, Thiofrid, S. 61-84. Besonders auffällig ist der griechische Begriff gazophylacium, der bei Thiofrid mehrmals erscheint. - Dieser Begriff findet sich auch in Thiofrid, Vita Liutwini II cap. 2, ed. Lampen, S. 10. Ebd. cap. 4, S. 14 f., läßt er Liutwin eine Kirche ecclesia - und nicht ein Oratorium wie in der Vita I - in honorem egregii martyris Dionysii Areopagitae bauen. Es zeigt, daß er Dionysius eine wichtige Rolle zumaß. - Vgl. dazu aber auch DE Rosı̇̀res, Stemmatum, S. VIff., der bei weiteren Fälschungen auf der Basis heute noch überlieferter Mettlacher Urkunden immer wieder Dionysius als Hauptpatrozinium des Klosters betonte, so daß de Rosières durchaus in den Text eingegriffen haben könnte. - Vgl. zur möglichen Abfassung der Miracula s. Liutwini durch Thiofrid unten Kap. D.IX.4.a.

664 Vgl. Vita Liutwini I cap. 6, ed. Perrin, S. 170C: Cujus dedicationis dies ejusdem Kalendarii articulo annotatur, quo solemnitas martyrii ipsius martyris legitima consuetudine celebratur. Hujus etiam dedicationis solemnitatem secundum decreta, a posteris constituta, annua revolutione multitudo populi annua devotione frequentat, eademque ecclesiam, eo quod primitiva sit, in salutem non solum istius loci, sed \& regionis circumquaque jacentis constituta, cum cereis aliisque oblationibus certatim honorat. Qui oratione completa, Missaque festiva celebritate audita, singuli a custode monasterii frustum panis cum vino accipiunt; \& sic sancto Dionysio gratias agentes, locumque incolentibus fausta acclamantes, laeti quique propria repetunt. Es handelt sich dabei um dasselbe Kapitel, in dem auch der Bau des Dionysiusoratoriums erwähnt wird. - Anton, Liutwin, S. 42, betont, daß die Forschung im Bau der Kirchen, wie ihn die Vita berichtet, die historische Substanz des Textes gesehen habe. 
Rotwich Mitte des 10. Jahrhunderts ins Leben gerufen worden sei. Die Urkunde ist jedoch allein als Transsumpt in einem Privileg Erzbischof Theoderichs/ Dietrichs II. (1212-1242) von 1222 erhalten. ${ }^{665}$ Gegen eine Interpolation dieser Passage spricht aber, daß dieses Vitenkapitel in derselben Reimprosa verfaßt wurde wie der übrige Text. Den zuvor beschriebenen Bau des Dionysiusoratoriums durch Liutwin muß man deshalb vielmehr umgekehrt als Legitimation für die Wallfahrt lesen, die zur Abfassungszeit der Vita bestand: Nicht die Dionysiuskirche war das eigentliche Wallfahrtszentrum, vielmehr wäre diese Kirche ohne Liutwin gar nicht entstanden. Diese Legitimationsstrategie bedeutet aber das genaue Gegenteil: Dionysius war im 10. Jahrhundert in Mettlach ein wichtiges, wahrscheinlich das bedeutendste Patrozinium, und mit großer Sicherheit muß er das auch schon zuvor gewesen sein. Die für das Oratorium erwähnten weiteren Reliquien könnten u.a. die Johannes' des Täufers und die der hl. Agatha sein, die noch im Mettlacher Kreuzreliquiar des frühen 13. Jahrhunderts oberhalb des Kreuzbalkens einen Platz neben Dionysius und Maria einnehmen.

Liutwin selbst mußte nach der Logik der Vita die eigentliche Ursache für die Dionysiusverehrung und damit indirekt auch für die Wallfahrt nach Mettlach sein, sonst hätte der Dionysiuskult ja Liutwins postulierte neue alte Rolle für das Kloster in Frage gestellt. ${ }^{666}$ Denn eine Liutwinwallfahrt gab es ganz offen-

665 Vgl. Schmal, Mettlach, S. 16 ff., 26 ff. Sie vermutet, das Dionysiuspatrozinium sei erst später ergänzt worden, weil sich sonst keine früheren Hinweise darauf fänden. Es solle dem Bericht der Vita eine scheinbar zeitgenössische Note geben. Die Erzählung über den Bau des Dionysiusoratoriums beruhe auf der von ihr rekonstruierten ursprünglichen Fassung der Oblanga-Urkunde. - Vgl. zur Wiedereinführung der Wallfahrt MRUB I 550, S. 609 f. Zur Urkunde Theoderichs von 1222 vgl. MRUB III 189, S. 161 f. Allerdings erwähnen beide Urkunden weder Dionysius noch dessen Festtag in Verbindung mit der Wallfahrt. - Vgl. auch Goerz, Mittelrheinische Regesten I 908, S. 258 f., der die Einführung der Wallfahrt unter Rotbert auf 941 datiert. - Vgl. zur Wallfahrt auch RaACH, Mettlach, S. 42 f. Kyll, Pflichtprozessionen, S. 23-30, hier S. 24, Abb. 1, mit einer Fotografie der Theoderich-Urkunde. MaAs, Mettlacher Pfingstprozession, deutet sie als ursprüngliche Prozession zur Kathedrale, die dann nach Mettlach umgeleitet wurde. Doch hätte man in diesem Fall nicht den zentralen Heiligen austauschen müssen? - Schließlich versuchte Griebler, Mettlacher Wallfahrerliste, S. 56-64, sogar eine zeitliche Abschichtung der wallfahrenden Orte herauszuarbeiten. Er spricht auch von einer Wallfahrt am Liutwinustag. PAuly, Landkapitel Merzig, S. 87, nennt sie eine Wiedergutmachung Rotberts für die dem Kloster entstandenen Besitzverluste. - Vgl. zu Albero oben Anm. 295. Zu Ebf. Theoderich/Dietrich II. vgl. Goerz, Regesten der Erzbischöfe zu Trier, S. 31-44. Pundt, Erzbischof und Stadtgemeinde, S. 262-266, 270-275. Hirschmann, Civitas Sancta, S. 415, 420, $424 \mathrm{f}$.

666 Vgl. ähnlich schon Schmal, Mettlach, S. 180. - Der Logik der Vita folgt dagegen Prinz, Frühes Mönchtum, S. 349 u. 498, Anm. 138, der Liutwin gerade wegen der so bedeutenden Dionysiusreliquien eine wichtige Rolle im späten 7. Jahrhundert zusprechen will. 
sichtlich nicht zur Abfassungszeit der Vita. Dann jedoch ist die Vita I ein Zeugnis dafür, daß Liutwin erst am Ende des 10. Jahrhunderts allmählich neben Dionysius rückte oder rücken sollte und ihn als Patrozinium beiseite drängte. Ja, ihr Verfasser mußte seinen Hörern eine überzeugende Erklärung für Liutwins Bedeutung bieten, wenn doch Dionysius für sie alle noch von herausragendem rituell-liturgisch greifbarem Einfluß war. Als Konsequenz ebbte die Wallfahrt langsam ab, bis sie um die Mitte des 12. Jahrhunderts wiederbelebt wurde. Diese "neue“ alte Wallfahrt galt jetzt aber wohl Liutwin. Selbst im 19. Jahrhundert wurde sie noch zu Liutwins Ehren unternommen, war aber auf den Sonntag vor Pfingsten verschoben worden. ${ }^{667}$ Die Urkunde Alberos (11311152) legte sie undeutlich auf das Datum der Mettlacher Kirchweihe fest, womit in dieser Zeit aber lediglich Liutwin oder Petrus gemeint sein konnten. Dann zählt das Dokument alle einbezogenen Gemeinden auf. ${ }^{668}$ Und hierin ist der eigentliche Zweck der Wiederbelebung zu suchen: Man versprach sich Einkünfte für das Kloster, wobei man vielleicht auch mehr Orte verpflichtete, als es ursprünglich einmal waren. Das bedeutet aber, daß Liutwin bis zum Ende des 10. Jahrhunderts nicht herausragend wichtig gewesen sein kann. Zumindest übertraf ihn bis dahin das alte Mettlacher Dionysiuspatrozinium bei weitem.

Wie aber gelangte Dionysius nach Mettlach, wenn Liutwin dessen Kirche nicht errichtete? Einen Hinweis bieten die oben ausgeführten Überlegungen zur Rolle Milos und seiner weiteren Angehörigen bezüglich ihres Mettlacher Familienklosters. Milo nämlich und einige seiner Verwandten erscheinen in mehreren Urkunden für St-Denis unter dessen Abt Fulrad. Überhaupt sind Angehörige der sog. ,Widonen-Lambertiner-Miloniden' auch in geographischer Nähe des in dieser Zeit so bedeutenden Dionysiusklosters zu finden ${ }^{669}$ Es liegt also nahe, daß man aufgrund dieses engeren Verhältnisses für Mettlach eine Dionysiusreliquie erhielt, was die lange Bedeutung dieses Patroziniums nur unterstriche. Vielleicht stand Mettlach auch in direkter Verbindung zu St-Denis. Da Mettlach in DKarol. I 148 aber auch königlicher Besitz ist und als Lehen vergeben wird, könnten vielleicht schon die Karolinger dieses Patrozinium gestiftet haben.

Bei einem Gotteshaus blieb es nach der Vita bekanntlich nicht. Liutwin holte Künstler, ließ ein weiteres Oratorium für den hl. Petrus errichten und

667 Vgl. dazu von Briesen, Urkundliche Geschichte, S. 75 f., Anm. ****. Lager, Urkundliche Geschichte, S. 5 f. u. Anm. 1, der sie beschreibt. In den 1920er Jahren hat sich der Mettlacher Pfarrer Koll, Wallfahrt, S. 19 ff., nochmals ausführlich dieser Wallfahrt zugewandt. Auch er geht von einer Dionysiuswallfahrt aus, die erst später zu einer Wallfahrt zu Liutwins Ehren wurde.

668 Vgl. MRUB I 550, S. 609 f.: [...]. ut parrochiales ecclesie circumquaquam adiacentes. in dedicatione cenobii. prefate ecclesie bona deuotione conueniant. Es folgen die Ortsnamen. Vgl. zu Mettlachs Kirchweihfest nur die Überlegungen zur Güterrolle oben in Kap. D.V. 669 Vgl. dazu oben S. 238 u. Anm. 419, 422 sowie Kap. D.IV.6.d. 
schließlich eine Basilika zu Ehren der Gottesmutter Maria, womit er eigentlich erst das Kloster gründete. Die größte Kirche entstand danach am Schluß. Diese weiteren Sakralbauten bzw. das Kloster minderten jedoch die Bedeutung des Dionysiusoratoriums. Mettlachs Ausgräber Martin KLEwitz glaubt nicht an diesen Bericht, sondern geht von einem längeren, sich über mehrere Jahre hinziehenden Prozeß aus. ${ }^{670}$ Besonders fällt aber der Gebrauch der Begriffe Oratorium und Basilika auf. Und da bietet der archäologische Befund eine Überraschung.

Denn KLewitz stieß lediglich auf eine kleine Marienkirche, dagegen bei der ersten Peterskirche auf einen der im Hinblick auf seine Größe „aufwendigsten Kirchbauten" der Merowingerzeit mit drei Ostapsiden. U.a. gäben die Ostanlage sowie weitere Kleinfunde den Anlaß zu einer solchen Datierung. ${ }^{671}$ Diese Dimensionen werfen allerdings die Frage auf, warum ein solcher Ausnahmefall ausgerechnet in Mettlach und das schon bei der Klostergründung entstanden sein soll. Handelt es sich dabei also tatsächlich um einen der ersten dortigen Sakralbauten? Das wäre mehr als unwahrscheinlich, vergleicht man Mettlach etwa mit dem frühen Befund des Ende des 7. Jahrhunderts entstandenen

670 Vgl. Vita Liutwini I cap. 7, ed. Perier, S. 170C: Deinde omnem operam inibi monasterii aedificandi impenditur, \& aggregatis hujusmodi operis artificibus, ut citius perficeretur, studuit. Oratorium ergo in principis Apostolorum nomine, basilicamque summae Dei Genitricis semperque Virginis Mariae honori constituit, [...]. - Zur Einschätzung von Dr. Martin Klewitz vgl. bereits oben Anm. 25 u. 314.

671 Vgl. KLewitz, Baugeschichte, S. 83 f., zur Peterskirche: „Die Ausgrabungen [...] brachten die Fundamente des Gründungsbaues zutage. Es war eine dreischiffige Anlage mit drei Apsiden im Osten; im Westen konnte eine außerordentlich interessante Anlage mit Treppentürmen freigelegt werden. [...] Jedenfalls ist der Bau einer der aufwendigsten Kirchenbauten, die wir aus der Merowingerzeit kennen." Zur Marienkirche vgl. ebd., S. 84: „Der heutige ,Alte Turm' ist der fünfte Bau an dieser Stelle. Der ,Alte Turm` ist der erste Zentralbau, alle Vorgängerbauten waren Längsbauten. Die älteste Anlage [...] war ein einschiffiger Bau, kleiner und bescheidener als die Apostelkirche. Die beiden Kirchen lagen dicht beieinander." Die endgültige Publikation der Grabungsbefunde ist nach Auskunft des Ausgräbers nach dem jetzigen Stand in Kürze zu erwarten. - Die insgesamt aufwendigere Bauweise, die Ostapsiden sowie die Anlage im Westen mit den Treppentürmen sprechen jedoch für einen höheren zeitlichen Aufwand als für die Marienkirche und damit für eine um einiges spätere Entstehung. Zu den Baustufen der Marienkirche vgl. auch unten S. 356 f. u. Anm. 751, 753. - Zuletzt vgl. Polfer, Kirchenbauten, Anhang, S. 85 f., Nr. 30 f. - Herr Dr. Klewitz teilte in einem mir vorliegenden Schreiben vom 3. Mai 2005 freundlicherweise noch präzisierend mit: Die Marien- und Peterskirche seien zwar nicht gleichzeitig, doch in zeitlicher Nähe zueinander erbaut worden. Sie seien „wahrscheinlich nacheinander entstanden“. Dabei lasse sich archäologisch schwer sagen, „welche der beiden Kirchen die erste oder die zweite war“. Er habe die Dreischiffigkeit der ersten Peterskirche „nicht [...] sicher feststellen können.“ Die „sehr dünnen Mauerstärken“ dieses Baus von „,60 cm“ sprächen für eine „geringe Bauerfahrung“. „Kleinfunde im Brandschutt und der Ostgrundriss weisen in die vorkarolingische Zeit." 
Klosters Echternach. ${ }^{672}$ Auch Schmal lehnt einen gleichzeitigen Bau beider Kirchen ab. Ja, die Peterskirche gehöre nicht mehr in die Merowingerzeit. Sie begründet das mit Auskünften von Klewitz, es gebe auch einige Befunde eine „Westanlage und ein kryptenartiger Raum“ -, "die in die karolingische Zeit weisen" ${ }^{673}$ Eine Dionysiuskirche wurde in Mettlach nicht ergraben, was nicht heißt, daß sie nicht existierte. ${ }^{674}$ Damit weicht die Vita bei den Größenangaben der Gotteshäuser auch hier von den Tatsachen ab, ja kehrt den Grabungsbestand um. Vielleicht beschrieb sie lediglich den Befund, der zu ihrer Abfassungszeit bestand, mit dem gerade fertiggestellten Mettlacher ,Alten Turm ' - als Zentralbau und dem fünften Gebäude in Folge am Ort der Marienkirche. ${ }^{675}$ Vielleicht aber sollte damit eine beabsichtigte Wertung vorgenommen werden: Man hielt die Marienkirche inzwischen für wichtiger als die beiden anderen Gotteshäuser, zum einen womöglich, weil man sie bald als Ort des Liutwin-Grabes nennen sollte, oder zum anderen, weil sie wirklich die bedeutendste und vielleicht älteste Kirche des Klosters war. Nach den Grabungsergebnissen muß sie jedenfalls einer der ersten Bauten gewesen sein.

Nimmt man nochmals DKarol. I 148 zur Hand, findet sich darin eine Erklärung, die ein späteres Entstehen der großdimensionierten ersten Peterskirche noch wahrscheinlicher macht. Wenn das Kloster Mettlach, so wie es Milo von Karl Martell und dann von Pippin als Lehen erhielt, nämlich zunächst lediglich aus der Marien- und der Dionysiuskirche bestand, dann erklärte sich der Bau der Peterskirche aufgrund des Trierer Kathedralpatroziniums. Während der von Milo veranlaßten Mettlacher Abbatiate der Trierer Bischöfe Ratbert und

672 Vgl. zum Echternacher Grabungsbefund oben S. 130 f. u. Anm. 88.

673 Vgl. Schmal, Mettlach, S. 21 u. Anm. 117 u. S. 179 f., die sich auf ein Schreiben von Herrn Dr. Klewitz vom 6. Mai 1998 bezieht.

674 Vgl. dazu von Briesen, Urkundliche Geschichte, S. 76, Anm., der bemerkt, daß sich in Mettlach noch eine Erinnerung an Dionysius erhalten habe. Das Volk verehre ihn als den „Heiligen Schwindel“ zur Heilung von Kopfschmerzen. - Allerdings scheint dieser Bericht doch sehr legendenhaft. - Vgl. ferner KLEwitz, Baugeschichte, S. 82 f. Junges, Mettlacher Gotteshäuser, S. 81-85, weist darauf hin, daß sich noch heute in der Mettlacher Pfarrkirche Metall- und Holzkronen befänden, die auf eine Verehrung Dionysius' hindeuteten. RaAch, Mettlach, S. 9-11, 19, 120 f., lehnt Dionysius als Klosterpatron ab. Er spreche vielleicht für Liutwins Verbindung zur Königsfamilie. Das dem hl. Dionysius geweihte Bauwerk verschwinde nicht, sondern tauche noch in mehreren Quellen des 15. Jahrhunderts als Dionysiuskapelle auf. Vgl. zuletzt PoLfer, Kirchenbauten, Anhang, S. 85, Nr. 29. 1954-1965 sei südlich der Marienkirche „der Ostbereich einer sehr großen einschiffigen Saalkirche mit einer $12 \mathrm{~m}$ weiten Halbkreisapsis ergraben" worden. - Polfer hält hier fälschlicherweise den von Abt Hezzel begonnenen Neubau der Marienkirche Ende des 10. Jahrhunderts für die Dionysiuskirche. Vgl. dazu unten S. 356 f. u. Anm. 751. - Vgl. schließlich Becker, Mettlach, S. 517 f., 537, der eine knappe Zusammenfassung der Literatur zum Dionysiusoratorium gibt.

675 Vgl. dazu zuletzt Schmal, Mettlach, S. 16, 179, sowie oben Anm. 671. 
Hartham wäre dann der Baubeginn anzunehmen oder womöglich erst nach der Belehnung Bischof Harthams mit dem Kloster selbst. Da Hartham aber zunächst noch Schwierigkeiten mit Milos Verwandten bzw. seinem möglichen Vater Lambert hatte, der sich Mettlach aneignete, ${ }^{676}$ könnten sich die Arbeiten auch noch hingezogen haben. Vielleicht dauerten sie an, bis Trier unter Weomad das Kloster endgültig zugesprochen erhielt.

Wenn die Vita I berichtet, Liutwin habe in Mettlach einen Abt eingesetzt, so folgt das letztlich erneut Milos Vorgehen, das sich ja als ,qualitative Inversion auf Liutwin übertragen hat. Denn Milo sandte den Trierer Ebreo als ersten von drei Äbten nach Mettlach. Wenn es aber weiter heißt, Liutwin habe den Konvent angehalten, nach der Regel zu leben, steht dies wohl eher für die Rezeption der von Gorze beeinflußten lothringischen Klosterreform in Mettlach. ${ }^{677}$ Mit ihr läßt sich freilich auch der Hinweis auf den Abt verstehen. Liutwins baldiger Eintritt in das von ihm errichtete Kloster liegt nur noch in der Konsequenz des Erzählkonzeptes.

Schließlich wurde Liutwin zum Nachfolger seines Onkels Basin als Trierer Bischof an einem 21. November ordiniert. Ist es ein Zufall, daß ausgerechnet an Erzbischof Egbert im Kalendar einer Echternacher Handschrift des frühen 11. Jahrhunderts just einen Tag zuvor, am 20. November, erinnert wurde? Erst danach übertrug Liutwin Mettlach an St. Peter. ${ }^{678}$ Es könnte sich um einen weiteren Hinweis handeln, wer für den Beginn des Mettlacher Liutwinkults mitverantwortlich sein dürfte. Identifizierte sich Egbert vielleicht mit Liutwin? Denn nach der Vita sorgte sich Liutwin um Trier und seine Kirchen, wie es später über Egbert berichtet wurde und wie es sich anhand einiger zeitgenössischer Quellen ja auch für den Jüngeren nachweisen läßt. ${ }^{679}$

676 Vgl. nochmals die Überlegungen oben in Kap. D.IV.6.c.

677 Vgl. Vita Liutwini I cap. 7, ed. Perier, S. 170D: Quibus quoque abbatem, virum per omnia perfectis aequandum, praefecit, \& ut juxta regularis vitae instituta viverent, praecepit. Vgl. zum Wirken dieser nicht immer klar zu verfolgenden Klosterreform grundlegend Hallinger, Gorze-Kluny 1, S. 48, Anm. 13. Zur Wirkung im Trierer Raum und in Mettlach vgl. hier nur Volk, Klosterreform, S. 69 f., 75. CHoux, Décadence et réforme monastique, S. 204-223. WisplinghofF, Lothringische Klosterreform, S. 145-159, bes. S. 152, 154 f. Boshof, Kloster und Bischof, S. 197-245, bes. S. 215 ff., zur Diözese Trier, zu Mettlach ebd., S. 217 f., 222 u. Anm. 186. Wisplinghoff, Reform, bes. S. 65 f. Felten, Benediktiner II, bes. S. 35 f. - Vgl. ferner Raach, Klosterleben, S. $27-$ 42. RaAch, Mettlach, S. 40-45. Die Reform sei in Mettlach mit Abt Rotwich eingeführt worden.

678 Vgl. Vita Liutwini I cap. 12, ed. Perier, S. 171B-C: Ipso etiam die, quo sanctae conversionis habitum suscepit, illo utique eum divina electio ad archiepiscopum promovit, ut miro concordiae modo in undecimum Kalendarum Decembris diem, digne semper memorandum, tonsuratio ejus simul in unum concurrerent \& ordinatio. - Vgl. zu Egbert Miesges, Festkalender, S. 16, $102 \mathrm{f}$.

679 Zur Sorge Liutwins für die Trierer Kirchen vgl. Vita Liutwini I cap. 4, ed. Perier, S. 170 A: Primum namque sancta loca maximeque Trevericae urbis amplissimis donavit 
Da Liutwin neben Trier auch über die Bistümer Reims und Laon verfügt haben soll, ist es nur folgerichtig, daß die Vita zuvor erklärt, wie er zu diesen sedes kam und wie er dort wirkte. ${ }^{680}$ Letztlich verbirgt sich wohl auch dahinter ein Bezug zu Egbert. Neben den ohnehin bestehenden Trierer Primatsansprüchen gab es auch eine Verbindung des Erzbischofs nach Laon. Denn der Reimser Erzbischof Adalbero (969-989) bat Egbert in einigen Briefen, ihn bei der Belagerung der Stadt im Rahmen der westfränkischen Nachfolgestreitigkeiten mit Trierer Truppen zu unterstützen. Letztlich war Laon auch zentrale karolingische Residenz in Lothringen. ${ }^{61}$ Denkbar ist aber ebenso, daß der Konflikt Erzbischof Hinkmars von Reims (845-882) mit seinem Neffen Bischof Hinkmar von Laon (858-871), den man in Trier aus den Reimser Schriften kannte, hierzu anregte. ${ }^{682}$ In diesen Zusammenhang gehört zudem die merkwürdige Nachricht, Liutwin habe den ducatus totius regni Francorum innegehabt. Gemäß den Studien Lugges meint dieser Terminus im 10. Jahrhundert aber nicht das gesamte Frankenreich, sondern Lothringen, die alte fränkische Kernlandschaft. Die Richtigkeit dieser Beobachtung wird noch dadurch unterstrichen, daß Quellen, die der Vita chronologisch folgen, daraus das Herzogtum der Gallia Belgica machen. Damit bezieht sich Liutwins Herzogtitel auf die Trierer Primatsansprüche im 10. Jahrhundert. In gewisser Weise erinnert Liutwins Lebensbeschreibung sogar an das Leben Erzbischof Bruns von Köln ( $\dagger$ 965), der zugleich als Herzog Lothringens wirkte und sogar den Titel archidux führte. Sollte mit Liutwin etwa ein Trierer Gegenbild zu ihm in eine weit zurückliegende Vergangenheit projiziert werden, um Kölner Ansprüche in Frage zu stellen ${ }^{683}$ Der Dukat mag zudem an Milos ursprünglichen Einflußbereich

denariis, ceteraque cuncta, quae habuerat ad habitationes construendas erogare voluit aptis monachis. - Vgl. nochmals ausführlich zu Egbert oben Kap. D.VI.3.a.

680 Vgl. dazu Vita Liutwini I cap. 13-15, ed. Perier, S. 171C-D. Die Passage beschreibt u. a. auch, wie es Liutwin gelungen sein soll, an einem Tag in Reims und Laon eine Messe zu halten.

681 Vgl. zu diesen Briefen bereits oben Anm. 529. - Zum Gesamtgeschehen vgl. zuletzt Erkens, Egbert von Trier, S. 51. - Vgl. dazu auch Lusse, Laon, S. 230 ff., u. a. zur dortigen karolingischen Residenz.

682 Für diesen freundlichen Hinweis danke ich Herrn Professor Dr. Jörg W. Busch (Frankfurt a. M.). - Vgl. dazu hier nur oben zu Beginn von Kap. A.IV. sowie oben Kap. C.III.7.

683 Vgl. Lugge, Gallia, S. 108 ff., bes. S. 147-151, mit Belegen. - Daß hier Lothringen und damit auch die Trierer Primatsansprüche gemeint sind, vermutet auch BAUER, Lotharingien, S. 87. Bauer, Spätmerowingische Zeit, S. 240. - Vgl. zum Begriff der Gallia Belgica, der auf Hinkmar von Reims zurückgeht, oben S. 288 u. Anm. 543 unten. Vgl. zu den weiteren Quellen unten S. 330 f., 366, 371 u. Anm. 688, 781 f., 795. - Vgl. zu Bruns Funktion als Herzog Lothringens Schwenk, Brun, S. 9-42, 88-114. Fried, Weg, bes. S. 476, 501 f., 512, 516, 518, 520 f., 525, 534, 538-540, 556, 569, 651653, 680-682, 688, 691 f., 724-726. Althoff, Ottonen, bes. S. 102 f., 109-112, $122 \mathrm{f}$. 
erinnern. Doch dann dürfte sich auch Egbert mit einiger Sicherheit mit Liutwin identifiziert haben. Vermutlich war er im Zuge seiner Arbeit an der Trierer Bischofsliste maßgeblich mitbeteiligt, Liutwin als beispielhaften Amtsvorgänger zu konstruieren, wenigstens aber zu entwickeln.

Alle weiteren Passagen der Vita I beruhen auf hagiographischen Vorbildern bzw. Topoi. Dies gilt für Liutwins Dienst beim König und seine fromme Lebensweise, aber auch für die Adlervision, die ihn in Mettlach bauen ließ, sowie dafür, daß er sich aus der Welt zurückzog und sein Kloster und weitere Kirchen ausstattete. Dies alles bietet keine inhaltlich brauchbaren Informationen.

Am Ende bleibt die Erkenntnis, daß kaum eine Angabe der sog. ältesten Vita Liutwini der Wirklichkeit des späten 7. und frühen 8. Jahrhunderts entspricht. Vielmehr ging es um eine ganz eigene Trierer und Mettlacher Wahrheit, für die man in Liutwin eine Chance erkannte. Es war die Chance, Milo nicht ganz zu verlieren, den man im kulturellen Gedächtnis Mettlachs noch positiv erinnerte; ebenso die Chance, Hinkmars bedrohliches Geschichtsbild vom Doppelbischof Milo zu nutzen, um damit das völlig neue Bild eines dreifachen, vorbildlichen und glänzenden Erzbischofs Liutwin zu entwerfen. Dieses Bild konnte sowohl die Mettlacher Ansprüche befriedigen, vielleicht aber auch unterdrücken, weil Liutwins Grab seinen Platz im Saarkloster hatte. Das Bild erfüllte aber sicher die des Trierer Erzstiftes, verstand es doch in nahezu vollendeter Form, die dortigen Primatsansprüche wirkmächtig umzusetzen. Wer aber war Liutwin dann tatsächlich? Wir wissen wenig darüber: Vielleicht handelte es sich um einen Trierer Bischof, dessen Grab man noch in Trier kannte. Vielleicht folgte er Basin im Amt, wie der presbiter Liutwin neben dem Bischof Basin in Irminas „Ur-Testament“ zeigen könnte, das oben rekonstruiert wurde. ${ }^{684}$ Vielleicht schließlich regte die Grabinschrift eines verehrungswürdi-

684 Vgl. dazu oben Kap. D.II.4.d. - Vielleicht kam Liutwin ursprünglich aus derselben Region. Einige, wenn auch sehr spekulative Hinweise, könnten darauf hindeuten. Basin war ein alter thüringischer Königsname. Verstünde man den Namen von Liutwins Vater Gerwin als Warin, könnte auch das in diese Gegend deuten. Es gibt aber noch weitere Anhaltspunkte. Basin war - wie gesehen - neben einer Irmina an der Gründung des Willibrordklosters Echternach beteiligt, auch wenn Irminas Rolle umstritten bleibt. Willibrord unterhielt wiederum Kontakte zum wohl in Würzburg residierenden, aber vermutlich auch Thüringen beherrschenden Herzog Heden II. (vor 704-717), der ihm für Echternach auch Güter schenkte. Dieser Heden soll nun eine Tochter namens Immina gehabt haben, die Äbtissin in Würzburg (706/10-751/2?) wurde. Doch sind die Belege teils legendenhaft und alle nicht zeitgenössisch. Vielleicht jedoch bieten sie einige undeutliche Indizien dafür, daß Basins und Irminas Herkunft im Osten zu suchen ist, womöglich auch die Liutwins, dessen Name eher nach Sachsen passen würde als nur annäherungsweise in die Familie der sog. ,Widonen-Lambertiner-Miloniden'. - Die Urkunden Hedens für Willibrord finden sich bei Wамрасн I 2, Nr. 8, S. 27 f. (eine im Liber aureus erhaltene Urkundenabschrift, nach der Heden Willibrord mit seiner Gemahlin Theodora am 7. Mai 704 mehrere Schenkungen macht), sowie ebd. Nr. 26, 
gen Ludubertus aus St. Eucharius, der aus edlem Geschlecht stammte und sein Vermögen an die Trierer Kirche gab, um Kleriker zu werden, ${ }^{65}$ die Phantasie des Mettlacher Abtes Remigius an, der zur Feder griff. Merkwürdig aber bleibt bei der Vita I bei all ihrer Vorliebe für Mettlach, daß sie einen dem Trierer Erzstift nahen Standpunkt einnimmt. Man könnte geradezu meinen, ihr Verfasser versuche, beide Positionen miteinander zu harmonisieren. Im Anschluß wird das noch zu untersuchen sein. ${ }^{686}$

Zusammenfassend ergibt sich für die Vita I der folgende Befund. Alle bisherigen Indizien sprechen dafür, daß sie frühestens während des späten Episkopats Erzbischof Egberts entstand. Deshalb ist es wahrscheinlich, daß die Vita mit dem verlorenen Sermo de proprio patrono Liutwino des Remigius von Mettlach übereinstimmt. Die Reimform des Textes unterstreicht dies ebenso und legt eine Überlieferung als stabiles Korpus nahe. Die Vita verfügt für die Zeit Liutwins über keinen Quellenwert, wohl aber für ihre Entstehungszeit Ende des 10. Jahrhunderts. Das entworfene Liutwinbild ist ohne die Rezeption des Reimser Milobildes, das Hinkmar prägte, in diesen Jahren sowie die Bischofslisten Egberts in großen Teilen nicht möglich. Für das frühe 8. Jahrhundert ist es deshalb falsch. Die Vita ist unmittelbar mit dem unter Egbert aufkommenden Liutwinkult verbunden, den sie verbreiten und stabilisieren sollte. Geht man dagegen vom oben erschlossenen ,alten' Milo aus, der Adliger

S. 63-65 (eine als Abschrift im Liber aureus erhaltene Schenkung Hedens vom 18. April 717 an Willibrord); auch in Willibrords sog. Testament (ebd. Nr. 39, S. 97, von 727) wird Heden genannt. Zu den Namen Basin und Irmina vgl. in diesem Zusammenhang auch Förstemann, Personennamen, Sp. 249, 308 (Basinus, Bisinus - wobei vor allem der Thüringerkönig des 5. Jahrhunderts und unser Bischof aufgeführt werden; ebd. auch Basina). - Vgl. schließlich die Literatur bei Werner, Adelsfamilien, S. $148 \mathrm{ff}$, der freilich zu einem anderen Ergebnis kommt. - Zu Herzog Hedens II. Tochter Immina vgl. Werner, Adelsfamilien, S. 92 f., Anm. 272; S. 106, Anm. 326; S. 108, Anm. 335; S. 150-155. - Vgl. zu dieser Immina ferner Bendel/Schmitt, Vita sancti Burkardi Episcopi Wirziburgensis II cap. II,4 f., S. 54-59 (BHL 1484). Die Angaben zu Immina könnten auf einer älteren Urkunde beruhen, die damals noch vorlag. Die Vita sei von einem „Mönch des Klosters S. Stephan zu Würzburg“ verfaßt worden, „Eingelhardus oder Engelhardus, dem späteren Abt des Klosters S. Burkard.“ Entstanden sei der Text zwischen 1145 und 1150 (ebd., S. 19). Zu dieser auch Vita posterior genannten Lebensbeschreibung Burchards vgl. zuletzt Lebensbeschreibungen Bischof Burchards, ed. Barlava, S. 49 ff., die jetzt auf zwischen 1108/13 und 1125 datiert und Ekkehard von Aura für den Verfasser hält; zu Immina ebd., S. 13, 72-77 u. cap. II,4 f., S. 120, $162-$ 167. Vgl. schließlich auch Störmer, Herkunft, bes. S. 16. Mordek, Hedenen. - Für Gedanken und Hinweise in diese Richtung danke ich besonders Herrn Professor Dr. Wolfram Brandes (Frankfurt a. M.). - Auch Theodardus, Sohn des Theodar, der seinen Besitz in Echternach an Pippin den Mittleren (Urkunden der Arnulfinger 4, ed. Heidrich, S. 61-64) übertrug, gehört wohl in den familiären Umkreis Hedens II. So könnte Echternach zunächst im Besitz dieser Familie gewesen sein.

685 Vgl. dazu oben S. 275 f. u. Anm. 511.

686 Vgl. dazu die Ausführungen unten S. 360 f. u. Anm. 764-767. 
oder einfacher Kleriker war, sich intensiv um Mettlach sorgte und die Trierer Bischofspfalz verwaltete, läßt sich die Vita neu lesen: Beim Bild Liutwins handelt es sich dann um eine ,qualitative Inversion' der positiven und negativen Informationen, die Ende des 10. Jahrhunderts bekannt waren und die allesamt auf Liutwin übertragen werden. So ließ sich gegenüber Milo, der durch Hinkmars Bild beschädigt worden war, um so strahlender sein konstruierter Vater Liutwin hervorheben. Damit konnte man Milos ,alte' Attribute retten, indem man sie in gewisser Weise in ein neues Liutwinbild projizierte, ganz ähnlich, wie Hinkmar einmal umgekehrt Milos Bild entworfen hatte, um seine Reimser Ansprüche zu sichern. Das gilt sowohl für das Doppelbistum Trier und Reims, das für Liutwin aus aktuellem Anlaß um Laon ergänzt wurde, als auch für die enge Bindung zu Mettlach, die Entsendung dortiger Äbte, die Übertragung dieses Klosters an die Trierer Kirche, die Bestattung im Kloster und vermutlich ebenso das Herzogamt. Diese ,qualitative Inversion' wird zudem symbolisch darin deutlich, daß Milo im Text zunächst eine positive Rolle übernimmt, wenn er seinen in Reims verstorbenen Vater nach Trier zurückführt. Erst danach wandte er sich dem Bösen zu. Als Abt Remigius die Vita verfaßte, bediente er sich anderer Texte, um aus ihnen Motive und Topoi zu übernehmen. Realer Hintergrund für Liutwins Schiffsreise von Trier nach Mettlach könnte eine im 10. Jahrhundert tatsächlich dorthin ausgeführte Translation gewesen sein. Dafür spricht, daß Liutwins Gedenktag in St. Maximin als dessen depositio in Mettlach erinnert wurde. Die Vita machte aus diesem Datum den Todestag Liutwins in Reims. Liutwins Grab könnte sich also zunächst in Trier befunden haben. Liutwins Eltern Gerwin und Gunza sowie sein Onkel Basin banden ihn mit seinem Sohn Milo genealogisch in die Trierer Bischofsliste ein. Die Schenkungsurkunde seiner wohl fiktiven Eltern über Oblanga geht erst auf Thiofrid von Echternach in der zweiten Hälfte des 11. Jahrhunderts zurück. Die Vita richtete vor allem die frühe Mettlacher Geschichte auf Liutwin aus und ließ ihn deshalb drei Kirchen gründen. Durch den für ihn postulierten Bau der Dionysiuskirche sollte die bedeutende Dionysiuswallfahrt Ende des 10. Jahrhunderts letztlich auf Liutwin zurückgeführt werden und damit Liutwins nun wachsende Rolle nicht bedrohen. Nachdem die Wallfahrt zunächst erfolgreich verdrängt wurde, belebte man sie im 12. Jahrhundert als Liutwinwallfahrt wieder. Daß die Marienkirche als Basilika bezeichnet wird, könnte das für sie archäologisch nachweisbare hohe Alter reflektieren oder mit Liutwins dort bald erwähnter Bestattung zusammenhängen. Die auffällige Größe und aufwendige Bauart der Peterskirche weisen sie in die späte Merowinger- oder frühe Karolingerzeit. Sie könnte unter den Trierer Bischöfen Ratbert und Hartham begonnen und vielleicht unter Weomad fertiggestellt worden sein. Schließlich enthält die Vita I noch weitere Hinweise auf die Egbertzeit, wie Liutwins Titel als Herzog Lothringens, der die Trierer Primatsansprüche spiegelt, wie auch den Tag von Liutwins Bischofsweihe am 21. November, der fast genau mit der 
Memoria Egberts in Echternach im frühen 11. Jahrhundert (20. November) übereinstimmt. So könnte die Vita I dem Interesse Mettlachs und Triers gedient haben, um Hinkmars übles Milobild zu kompensieren und Milo in gewisser Weise für die eigene Tradition zu retten. Sie könnte aber ebenso ein Mittel für Trier gewesen sein, die Verehrung Milos in Mettlach zugunsten der von Liutwin zu eliminieren. Remigius, der Verfasser der Vita I, verbindet jedenfalls in seltsamer Weise Mettlacher Traditionen und Trierer Interessen, so daß es sich nicht sicher klären läßt, ob er einer der beiden Seiten eine besondere Präferenz entgegenbrachte.

\section{Der Libellus de rebus Treverensibus aus dem Trierer Erzstift}

Wie schnell dieses Bild Liutwins ins kollektive und darüber ins kulturelle Gedächtnis Triers einging, belegt der Libellus de rebus Treverensibus. Er war der erste Trierer Versuch, die eigene Geschichte ausführlich darzustellen, auch wenn er vor allem ausufernd viele Zitate sammelt und miteinander verbindet, die noch in Schriftzeugnissen vor Ort verfügbar waren. KöLzER hat ihn überzeugend in das Episkopat Erzbischof Eberhards (1047-1066) datiert, unter dem die konstruierte Urkunde Ottos III. (983-1002) (DOIII. †368) entstand, nach der Oeren an Erzbischof Egbert zurückgegeben worden sein soll. ${ }^{687}$ Auch Eberhard griff nach den Trierer Klöstern, bedrohte St. Maximin und beschäftigte sich noch dazu in besonderer Weise mit der Zeit Egberts. Eberhard erhob erneut Primatsansprüche für Trier. So erhielt er noch 1049 von Papst Leo IX. (1049-1054) in Rom den Primat der Trierer Kirche über Gallien (Gallia Belgica) bestätigt. Ferner wurden während seines Episkopats erstmals die Gebeine des Apostels Matthias um 1050 aufgefunden. ${ }^{688}$ Der Libellus formulierte genuin die Interessen des Trierer Erzstifts.

687 Vgl. KöLzer, Studien, S. 252 ff. Zum DOIII. †368, zu Oeren für Egbert vgl. nochmals ebd., S. 118 ff., sowie oben Anm. 224, 232. - Zu Eberhard vgl. ebd., S. 110-116, bes. S. $112 \mathrm{f}$, zu den Matthiasgebeinen. - Zu den bisherigen Datierungsversuchen, die vom frühen bis späten 11. Jahrhundert variierten, vgl. hier nur PoensGen, Geschichtskonstruktionen, S. $94 \mathrm{ff}$, , bes. S. $120 \mathrm{ff}$. Thomas, Studien, S. 75 ff., weist auch auf die Sammlung von Quellenexzerpten hin. Vgl. ferner oben Kap. C.I., Anm. 1 u. Kap. C.IV.3. - Die früheste Überlieferung des Libellus' findet sich im eigenständig entstandenen zweiten Teil einer Handschrift aus St. Eucharius des späten 12. Jahrhunderts: Trier, Stadtbibliothek, 1341/86, fol. $204^{\mathrm{r}}-218^{\mathrm{r}}$. Dieser Teil, der ebenso eine Passio sanctorum martyrum (fol. 193 $3^{\mathrm{r}}-204^{\mathrm{r}}$ ) sowie die Gesta Treverorum (fol. $218^{\mathrm{r}} \mathrm{ff}$.) enthält, wurde von Oerener Nonnen nach einer Vorlage verfaßt. Vgl. dazu KöLzer, Studien, S. 252. Zur Handschrift vgl. auch Keuffer/Kentenich, Beschreibendes Verzeichnis 8, S. 11-14. Becker, St. Eucharius, S. 120 f., Nr. 68.

$688 \mathrm{Zu}$ Eberhard vgl. Goerz, Regesten der Erzbischöfe zu Trier, S. 10 f. Zuletzt vgl. zu ihm ERkens, Trierer Kirchenprovinz am Vorabend des Investiturstreits, S. 109-158, bes. 
Liutwin wird darin nur knapp, aber präzise erwähnt. Die Passage, die ihn nennt, ist der schon oben besprochene Einschub zu Milo in ein Zitat aus Kapitel 53 des Liber historiae Francorum, das die Schlacht von Vinchy 717 schildert. Milo sei dabei, so lehre Flodoards "Reimser Kirchengeschichte" (II,12), ein Anhänger des siegreichen Karl Martell gewesen. ${ }^{689}$ Milo sei von edlem Geschlecht, aber hart und gottlos gewesen und habe bald darauf etwa 40 Jahre den Trierer und Reimser Bischofssitz (episcopatum) besetzt. Er sei Sohn eines gewissen Herzogs Liutwin. Nachdem Liutwin das Ordenskleid angenommen hätte, habe er an einem Mettlach genannten Ort als Mönch Gott gedient in der Kirche der Apostel Petrus und Paulus, die er selbst gegründet und reichlich beschenkt hatte, mit vielen anderen Mönchen, die er dort vereinigte. Als sein Onkel, der Trierer Erzbischof Basin, gestorben sei und Liutwin das Bischofsamt angenommen habe, habe er nicht allein diese Trierer, sondern darüber hinaus auch die Kirchen von Reims und Laon geleitet. ${ }^{690}$ Der Libellus kehrt dann zur Schilderung der Schlacht von Vinchy zurück und widmet sich im weiteren Verlauf an mehreren Stellen immer wieder Milo, dessen Treiben mit ausgiebigen zusätzlichen, teils redundanten Zitaten aus der Reimser Überlieferung dargestellt wird. ${ }^{691}$ Liutwin und Basin sucht man dabei jedoch vergeblich.

S. 143 ff. Gierlich, Grabstätten, S. 71 f. Er fand sein Grab in St. Paulin. Bönnen, Trier zwischen dem 10. und dem beginnenden 12. Jahrhundert, S. 220, 223-227. - Zur Urkunde Leos IX. vgl. JL 4158. MRUB I 329, S. 383-385. Germ. Pont. 10, Archiepiscopatus 97, ed. Boshof, S. 57 f. Die Urkunde ist im Original erhalten.

689 Vgl. Lib. hist. Franc. cap. 53, ed. Krusch, S. 326-328.

690 Vgl. De rebus Treverensibus saec. VIII-X libellus cap. 1, ed. WAItz, S. 99, Z. 25-33: Copioso igitur Karolus adunato exercitu, ut in Gestis Francorum legitur, Hilpericum in loco dicto Vinciaco cum multis regni sui nobilibus convenit; inter quos, ut [ab hier beginnt der neue Zusatz:] Remensis docet historia, erat Milo, genere clarus, sed acer et irreligiosus, qui postmodum circiter quadraginta annos Treverensem et Remensem episcopatum tenuit, filius domni Liutwini quondam ducis, qui, assumpto religionis habitu, in loco qui dicitur Medelocus in aecclesia apostolorum Petri et Pauli, quam ipse fundaverat et copiose ditaverat, cum multis aliis quos illuc congregaverat monachis monachus Deo militavit. Unde, decedente Basino avunculo suo, Trevirorum archiepiscopo, episcopus assumptus, non solum hanc Treverensem, sed et Remensem atque Ludunensem aecclesiam gubernavit.

691 Vgl. De rebus Treverensibus saec. VIII - X libellus cap. 1-3, ed. Waitz, S. 99-101. Es folgt dann ein Zitat aus Flodoard zur Vertreibung Rigoberts aus Reims durch Karl Martell sowie Milos Übernahme der Bistümer von Reims und Trier. Es schließt sich ein längeres Zitat aus dem Vorwort von Hinkmars Remigius-Vita zu Milo an, dann wieder Flodoard, der aber den Inhalt der Vita Rigoberti wiedergibt. In ebd. cap. 2, S. 100, wird ein Wunder aus einer Schrift Gregors von Tours berichtet, aber in die Zeit Milos datiert. In ebd. cap. 3, S. 100, folgt u. a. ein Auszug aus einem Brief Hinkmars an Papst Nikolaus I. (858-867) über Milo, in dem er wiederum aus der bekannten Milo-Passage des Bonifatiusbriefs (87, ed. TANGL) zitiert. Ferner habe Bonifatius als päpstlicher Vikar die Bistümer Reims und Trier verwaltet. - Vgl. dazu auch Poensgen, Geschichtskonstruktionen, S. 95 ff. Positiv erscheine dagegen der Reimser Bischof Rigobert. Im Zentrum stehe aber Milo (ebd., S. 99). 
Damit bestätigt der Libellus eine Beobachtung, die bereits bei der Vita I gemacht wurde. Liutwins und Basins Rolle für die Trierer Geschichte scheint sich über Milo zu definieren und nicht umgekehrt. Beide erläutern und konkretisieren Milos Person bzw. Herkunft. Aufgrund der umfangreichen Reimser Informationen ergab sich für den Libellus eine Schwierigkeit: Während Milo vom Mettlacher Verfasser der Vita I noch einige positive Attribute zugesprochen wurden, er seinen toten Vater aus Reims nach Trier überführte und ihm in den Bistümern Trier und Reims nachfolgte, ist hier gar nichts davon zu finden. Milo erhält im Gegenteil das Bistum Reims von Karl Martell, nachdem Bischof Rigobert von dort vertrieben wurde, und zugleich Trier. ${ }^{692}$ Aus Flodoard wußte man jedoch, daß Rigobert zuvor längere Zeit in Reims amtierte. Wie aber konnte dann Liutwin vor seinem Sohn Bischof in Trier, Reims und Laon gewesen sein? Der Libellus bleibt eine Antwort schuldig und will sie vielleicht gar nicht geben. Jedenfalls wurde Liutwins Bistumshäufung von der Milos abgekoppelt und eigenständig.

Mit Milo hatte man in Trier unter Eberhard - folgt man dem Libellus - ein größeres Problem als zur Abfassungszeit der Vita I. Milo bedrohte ebenso Eberhards Primatsansprüche. Doch wählte man nun einen anderen Lösungsweg als die Vita: Der Libellus erwähnt nicht nur die gleichzeitige Übergabe beider Bistümer durch Karl Martell an Milo, sondern auch das Unheil, das Milo über Trier selbst gebracht haben soll, während sich die Reimser Texte dabei auf die negativen Folgen für ihr eigenes Bistum beschränkten. Milo wird dazu in Trier als dessen pervasor bezeichnet. Auch Karl Martell erscheint in einem überaus ungünstigen Licht. ${ }^{63}$ Soweit ging die Vita I nicht. Durch die Gleichheit und Gemeinsamkeit im Leiden unter Milo in Trier und Reims wird im Libellus ein mögliches Reimser Argument gegen Trier amortisiert. Letztlich erbt Milo seine Ämter nicht mehr vom Vater, sondern erhält sie unrechtmäßig von Karl, der damit indirekt für dessen Umtriebe verantwortlich wird. Ja, man negierte dort ferner Milos Bindung an Mettlach, die man aus dem schon interpolierten DKarol. I 148 dennoch kennen mußte. Vielmehr distanziert sich der Libellus jetzt durch ein neues Bild vollständig von Milo: Man läßt ihn in Ehrang von einem Eber durchbohrt sterben, um ihm dort eine Ruhestätte - weit weg von

692 Vgl. De rebus Treverensibus saec. VIII-X libellus cap. 1, ed. WAItz, S. 99, Z. 37 f.: [Karl Martell habe] virum etiam Dei Rogobertum, qui eum de lavacro susceperat, episcopatu deturbavit et supradicto Miloni episcopatum Remensem cum Treverensi dedit.

693 Vgl. De rebus Treverensibus saec. VIII-X libellus cap. 2, ed. WAItz, S. 100: Huius aecclesiarum Dei pervasoris tempore, Milonis scilicet, contigit cuidam Trevericae urbis civi [...]. „Tempore“, inquit, „Milonis, quondam nostre Treverice civitatis pervasoris, [...]." Zur negativen Darstellung Karl Martells vgl. Poensgen, Geschichtskonstruktionen, S. 98 f. Der Libellus habe das schlechte Urteil über Karl nicht nur aus den Reimser Quellen übernommen, sondern auch die verwendeten positiven Passagen über Karl im Lib. hist. Franc. ins Negative gewendet. 
allen Trierer Bischofsgräbern - in der gerade erst erbauten Peterskirche rechts des Altars zuzuweisen. ${ }^{694}$ Er erleidet damit einen erwiesen konstruierten, seiner inzwischen bekannt gewordenen Lebensweise angemessenen Tod. Der Ort seines neuen Grabes erklärt sich damit. Die positive Memoria Milos, die in Mettlach noch verankert war, sollte durch diese Gegentradition des Erzstifts disloziert, ein altes durch ein neues Bild zunächst im kollektiven und somit im kulturellen Gedächtnis überdeckt werden. Verband man dies damit, auch Milos Gebeine aus Mettlach zu translozieren? Falls nicht, was wurde aus seinen sterblichen Überresten im Saarkloster? Erstreckte sich die ,qualitative Inversion auch auf sie? Es wäre nur konsequent, hätte man sie in die des hl. Liutwin umgedeutet. Eines jedoch ist unübersehbar: Die Angriffe des Libellus' auf Milo richten sich vor allem gegen Mettlach und das Milobild der Vita I.

Der Trierer Einschub zu Basin und Liutwin verfolgt damit mehrere Ziele: Zum einen steht er als positives Beispiel für eine gelungene Verwaltungstätigkeit von Milos Vater Liutwin sowohl in Trier wie in Reims. Diese habe vor der Zeit gemeinsamen Leids in beiden Städten unter Milo bestanden, der von Karl Martell eingesetzt worden sei. Basin ist dagegen nur neutraler Trierer Bischof. Zum anderen aber benötigt der Libellus Liutwins Beispiel offenbar, um nach Milo noch Ausführungen zum Primat in der Belgica und dem Verhältnis ihrer beiden Kirchenprovinzen Reims und Trier zueinander machen zu können. Der Libellus verwehrt sich gegen Argumente Hinkmars oder Passagen Flodoards, aus denen man einen Reimser Vorrang über Trier interpretieren könnte. Dagegen wird die von Flodoard überlieferte entscheidende Rolle des Trierer Erzbischofs Rotbert hervorgehoben, die dieser bei der Lösung des Reimser Bischofsstreits einnahm. Insgesamt betont der Text zwar eher die Gleichrangigkeit beider Bistümer, weist aber auf das höhere Alter Triers hin. ${ }^{695}$

694 Vgl. zu den Grabungsergebnissen, dieser Quellenstelle und den Überlegungen bereits oben Kap. C.I. - Vgl. hier ferner Poensgen, Geschichtskonstruktionen, S. 115 f.

695 Vgl. De rebus Treverensibus saec. VIII-X libellus cap. 4-7, ed. WArtz, S. 101 f. Zunächst argumentiert der Libellus gegen einen Mainzer Primat, ja die Mainzer Metropole sei bis zur Zeit des Bonifatius sogar Worms untergeordnet gewesen. Danach wird nochmals Hinkmars Brief an Nikolaus I. zitiert. Der Libellus wehrt sich gegen Hinkmars Primatsvorstellung, die sich durch die frühere Ordination vor dem weiteren Metropoliten begründet. Niemals habe ein Trierer einem Reimser Bischof gehorchen müssen. Dazu zitiert er das gefälschte Silvester-Privileg für Agricius von Trier. Danach habe der Papst Trier zu seiner Teilhaberin gemacht und den Primat in Gallien und Germanien verliehen. Vgl. zur behandelten Rolle Rotberts im Reimser Bischofsstreit schon oben S. 265 u. Anm. 486. Es folgt im Libellus schließlich eine Passage aus dem Testament des Reimser Bischofs Remigius zum besonderen Verhältnis von Reims und Trier. Schließlich wird auch noch Gregor von Tours zum Thema bemüht. - Vgl. Kölzer, Studien, S. 258. Poensgen, Geschichtskonstruktionen, S. 104 ff., bes. S. 109 ff. - Zum gefälschten Silvester-Privileg vgl. MRUB I 1, S. 1. 
In Trier berief man sich nicht auf eine dort neu geschöpfte Tradition zu Liutwin und Basin. ${ }^{696}$ Eine solche hätte sich sicher widerspruchsfreier in die vom Libellus verwendeten Schriftquellen eingefügt. Vielmehr griff man auf das Liutwinbild der Vita I zurück. Der knappe Einschub macht nichts anderes, als deren Inhalt zusammenzufassen. ${ }^{67}$ Gerade der Versuch, alle entscheidenden inhaltlichen Punkte in zwei Sätzen durch Aufzählungen zu komprimieren, spricht dafür, daß der Text der Vita I vorlag. Angesichts zahlreicher weiterer eingearbeiteter Quellenpassagen verwundert das nicht.

Die Gedrängtheit der kurzen Passage erklärt sich aus darstellerischen Gründen. Einmal wäre der Erzählkontext um Vinchy sonst zu sehr auseinandergerissen worden. Zum anderen blieben auf diese Weise problematische Aussagen der Vita ungenannt. Denn Milos herausragende Hilfe bei der Überführung seines toten Vaters von Reims nach Trier paßte nun wirklich nicht hierher. Unerwähnt bleiben auch das Dionysiusoratorium und die Marienbasilika, die Peter-und-Paul-Kirche ausgenommen. Das heißt keinesfalls, daß man in Trier nicht um die weiteren Patrozinien wußte. ${ }^{698}$ Vielmehr wurde nur dasjenige betont, das den engen Bezug Mettlachs zum Erzstift ausdrückte. Eine spätere Anmerkung des Libellus' unterstreicht die Verbindung zwischen beiden Orten: Hier wird die spätere Äbtissin von Pfalzel Warentrudis als soror Hetti primum abbatis in Medeloco, postea archiepiscopi Trevirorum genannt. ${ }^{699}$ Letztlich wird damit auch Liutwins Werdegang angesprochen sowie, daß er Mettlach an Trier übertrug, seine Vita also implizit zitiert. Hettis Abbatiat in Mettlach formulierte einen Anspruch auf das Kloster. ${ }^{700}$ Wahrscheinlich schloß der Verfasser des Libellus' das aus der echten Urkunde Lothars I. für Hetti von 842 (DLoI. 67), die diesem Mettlach wieder zusprach, ${ }^{701}$ so daß sich beides vermischte. Insgesamt aber tritt Liutwins Rolle weit hinter die des üblen Milo zurück. Eberhard jedoch formulierte damit seinen Anspruch auf Mettlach im Rahmen seiner Klosterpolitik, denn auch Oeren und Pfalzel sind im Libellus einige Kapitel gewidmet. ${ }^{702}$

696 Das vermutet Schmal, Mettlach, S. 15 ff., um die Vita Liutwini I nach den Libellus zu datieren. Die Vita habe den Libellus verwendet. Dafür spreche, daß der Libellus nur eine Peter-und-Paul-Kirche erwähne, erst die Vita schmücke das u.a. um das Dionysiuspatrozinium aus. - Daß Paulus nicht in der Vita genannt wird, bedeutet nicht, daß er nicht in Mettlach verehrt wurde, wo es auch ein Andreaspatrozinium gab, das der Libellus ausspart.

697 Vgl. ähnlich auch Poensgen, Geschichtskonstruktionen, S. 98 u. Anm. 2.

698 Vgl. dazu nochmals die Überlegung Schmals oben in Anm. 696.

699 Vgl. De rebus Treverensibus saec. VIII-X libellus cap. 17, ed. Wartz, S. 106.

700 Vgl. dazu oben Anm. 651.

701 Vgl. dazu oben Kap. D.IV.3.

702 Vgl. dazu De rebus Treverensibus saec. VIII-X libellus cap. 11-19, ed. WAITZ, S. 103106, die sich intensiv Oeren und Pfalzel widmen. 
Zusammenfassend zeigt der Libellus, daß das Bild Liutwins und Basins ins kulturelle Gedächtnis Triers aufgenommen wurde. Wie der knappe Einschub belegt, leitet es sich aber weiter von Milo ab, der den meisten Raum einnimmt. Die Kenntnis von Reimser Texten war in Trier inzwischen gewachsen und führte zu weiteren Verformungen der Trierer Bilder von Liutwin und Milo, die vor dem Hintergrund der Trierer Primatsansprüche unter Erzbischof Eberhard (1047-1066) zu sehen sind. Milo erhielt die Bistümer Reims und Trier nicht mehr als Erbe von Liutwin, wie es die in Trier bekannte Mettlacher Vita I berichtete. Vielmehr übertrug die Bistümer ein ausgesprochen negativ gezeichneter Karl Martell an Milo, nachdem Bischof Rigobert aus Reims vertrieben war. Milo schädigte nun nicht mehr nur die Reimser Kirche - wie es die Reimser Quellen beschrieben -, sondern wurde vom Libellus auch zum pervasor Triers erklärt. Damit ließ sich das gemeinsame und gleichwertige Leid in beiden Städten unter Milo betonen, für das letztlich nicht seine Trierer Heimat, sondern Karl Martell verantwortlich war. Das Trierer Erzstift versuchte die positive Milomemoria, die in Mettlach noch bestand und über die die Vita I Auskunft gab, durch ein Gegenbild zu überlagern. Ebenfalls sollte damit die in Trier noch bekannte Verbindung zwischen Milo und Mettlach überdeckt werden, von der man aufgrund von DKarol. I 148 durchaus wußte. Deshalb konstruierte man Milos Tod auf der Jagd und seine Bestattung in der - gerade erst erbauten Ehranger Peterskirche. Auf diese Weise ließ sich das bisher in Mettlach anzunehmende Grab Milos in Frage stellen bzw. dislozieren. Es wäre deshalb denkbar, daß seine dort bestatteten Gebeine in Folge der konstatierten ,qualitativen Inversion' in die des hl. Liutwin umgedeutet wurden oder dies bereits geschehen war. Die knappen Angaben zu Liutwin und Basin komprimieren die inhaltlichen Angaben der Liutwin-Vita I auf ihren Kern, wobei der Libellus Störendes ausließ. Dazu gehören einige der von Liutwin angeblich begründeten Mettlacher Patrozinien sowie Milos Rolle bei der Translation des Vaters von Reims über Trier nach Mettlach. Das weiter gewandelte Milobild trennte Liutwins Bistumshäufung in Trier, Reims und Laon von derjenigen seines Sohnes ab. Liutwins Mehrfachepiskopat vereigenständigte sich damit als positives Beispiel für Trier, auch wenn der Widerspruch zu Rigoberts gleichzeitigem Episkopat in Reims nicht aufgelöst wird. Die von Erzbischof Eberhard gewünschte enge Verbindung zwischen Mettlach und dem Erzstift wird hervorgehoben, indem der Libellus die Mettlacher Peterskirche sowie Hettis Abbatiat in Mettlach vor seinem Episkopat betont. Dieses Bild dürfte sowohl aus der Vita I als auch aus der Urkunde Lothars I. von 842 (DLoI. 67) geschöpft und deshalb kaum historisch sein. 


\section{Die Miracula s. Liutwini aus Mettlach}

\section{a. Entstehung und Verfasserfrage}

Am Ende des 11. Jahrhunderts meldete sich nach der Vita Liutwini I mit den Miracula s. Liutwini ein weiterer längerer Text aus Mettlach über Liutwin zu Wort. Von Basin schweigt er jedoch vollständig, was nur zeigt, wie wenig Bedeutung man ihm gegenüber Liutwin noch immer beimaß. Die Miracula berichten zunächst ausführlich die Geschichte Mettlachs von der Zeit Liutwins bis zur Gegenwart des sich anonym gebenden Verfassers. Im Anschluß daran sind mehrere Wundergeschichten zum Wirken des Heiligen im Kloster nach seinem Tod zusammengetragen. Auch diese Quelle ist in Reimprosa abgefaßt, was sie ebenfalls für die öffentliche Lektüre bestimmt haben dürfte. Im Rahmen der eigentlichen Wunder wird zum ersten Mal Liutwins Grab explizit mit der Mettlacher Marienkirche verbunden, und zwar in ihrer Gestalt als sog. ,Alter Turm', der heute noch als Ruine erhalten ist. Der Text muß unter dem Mettlacher Abt Nizzo III. entstanden sein, den die Miracula als noch lebenden Vorsteher nennen. Nizzo übernahm dieses Amt zwischen 1063 und 1077. Frühestens 1063 soll sein Amtsvorgänger Everhelm zurückgetreten sein. Während der Amtszeit Erzbischof Udos (1066-1078) übersandte Nizzo an diesen eine vom schon mehrfach behandelten Thiofrid von Echternach überarbeitete Liutwin-Vita (Vita II). Spätestens 1077 war Nizzo also Abt. Da sein 1095 zu fassender Nachfolger Libo in den Miracula fehlt, geht die Forschung dabei als terminus ante quem für die Niederschrift aus. ${ }^{703}$ Die älteste Handschrift aller-

703 Vgl. Miracula s. Liutwini auct. Monacho Mediolacensi, ed. Sauerland, S. 1261-1268. Die Wunder werden von Sauerland nur in Auszügen wiedergegeben. Eine vollständige Edition der Wunder findet sich in den Miracula s. Leodowini, ed. Perier, S. 176-179. Die beiden noch unedierten Wundererzählungen am Ende der Miracula hat inzwischen FLESCH, Monastische Schriftkultur, S. 25-27, veröffentlicht. - Vgl. dazu vON BRIESEN, Urkundliche Geschichte, S. 80-87. LAGER, Urkundliche Geschichte, S. 26 f. WInHELLER, Lebensbeschreibungen, S. 95, 98. Schmal, Mettlach, S. 12 ff., bes. S. 12-14, zu Everhelm ebd., S. 23-25. RAACH, Mettlach, S. 37 ff., bes. S. 56 f., 61 f., zu Everhelm und Nizzo III. Vgl. zuletzt Flesch, Monastische Schriftkultur, S. 12 ff., bes. auch S. 15 u. Anm. 20, der sogar von einer Entstehung der Miracula nach der Vita II ausgeht. Vgl. Becker, Mettlach, S. 522-527, zu Nizzo III. und seinen Vorgängern, wobei er Abt Udo für die Fehlinterpretation einer Handschriftenauffälligkeit hält. - Zu den Äbten Reginard (Evehelms Vorgänger), Everhelm und Nizzo vgl. auch Miracula s. Liutwini auct. Monacho Mediolacensi cap. 21-23, ed. Sauerland, S. 1267. Everhelm soll danach nicht lange im Amt gewesen sein. Als er wegen Verfehlungen von Bischof Eberhard (1047-1066) oder Udo von Nellenburg (1066-1078) vorgeladen wurde, verließ er das Kloster. - Zu Abt Libo vgl. eine auf 1095 datierende Urkunde bei MRUB II Nachtr. 10, S. 346 f. MüLLER, Mettlacher Güterrolle, S. 129 f., T 1. - Vgl. zu der von Thiofrid verfaßten Vita Liutwini II ausführlich unten Kap. D.IX.5. - Zur Lokalisierung des Liutwin-Grabes im ,Alten Turm 'vgl. nur die Miracula s. Leodowini cap. 7-11, ed. Perier, hier cap. 8, S. 178B: [...], eosdem cum processione ad ecclesiam sanctae Mariae 
dings, die den Text enthält, ist der schon erwähnte, aus Mettlach stammende Kodex des 16. Jahrhunderts, der ebenso die früheste bekannte Fassung der Vita Liutwini I beinhaltet. ${ }^{704}$

Kürzlich hat Schmal anhand einer vergleichenden Stilanalyse der Miracula mit Werken Thiofrids von Echternach (seiner Vita sanctae Irminae, der Vita Liutwini II sowie seiner Willibrord-Vita) dessen Verfasserschaft wahrscheinlich gemacht. Bei den Miracula handle es sich um ein Frühwerk. Die Formulierungen der Miracula wiesen vor allem zahlreiche Ähnlichkeiten mit einem der frühesten Texte Thiofrids auf: seiner Vita sanctae Irminae. Dieser Vita fehle noch der zunehmend „schwülstigere" Stil der späteren Werke. Daß Thiofrid auch die von Nizzo III. nach 1072 an Bischof Udo übersandte Liutwin-Vita II verfaßte, lege ihn ebenso als Autor nahe. Die Miracula müßten deshalb noch vor dieser Vita gegen 1070 entstanden sein. ${ }^{705}$

Diese These hat einiges für sich und läßt sich erweitern. Werner hält es aufgrund auffälliger Textberührungen für möglich, daß schon der Libellus die spätestens 1081 entstandene Irmina-Vita des Thiofrid benutzte, jedenfalls könne der Libellus der Vita nicht vorausgehen. ${ }^{706}$ Folgt man KöLzers Datierung

euntes, ac de omnibus Sanctis vesperas cantaturos, repetendo cantica sua est prosecutus, \& locum sepulchri sancti Luitwini saepius bacchando circuivit, [...]. Diese Stelle verbindet deutlich die Marienkirche und Liutwins Grab. - Weitere Belege finden sich unten in Anm. 765.

704 Vgl. die Handschrift Trier, Stadtbibliothek, 2002/92, die auf fol. $129^{\mathrm{r}}-143^{\mathrm{v}}$ die Vita Liutwini II des Thiofrid enthält, fol. $175^{\mathrm{r}}-179^{\mathrm{r}}$ die Vita I und fol. $179^{\mathrm{r}}-190^{\mathrm{r}}$ die Miracula s. Liutwini. Vgl. dazu schon oben Anm. 629. Weitere Handschriften der Miracula bei Winheller, Lebensbeschreibungen, S. 95, Anm. 45. Flesch, Monastische Schriftkultur, S. 12 f., weist darauf hin, daß die älteste Handschrift aus der Zeit des Bursfelder Reformabtes Tilmann von Prüm stamme, der 1480-1505 in Mettlach amtierte und sich um den Liutwinkult sehr bemüht habe.

705 Vgl. Schmal, Mettlach, S. $12-15$ sowie bes. Anm. 47 f., 68 u. 472, wobei hier ausgesprochen zahlreiche Belege für diese These zusammengetragen worden sind. Textaufbau, Wortwahl und Wortschöpfungen stimmten mit der Vita sanctae Irminae auffallend überein. Auch finde sich der von LAMPEN, Thiofrid, S. 61-84, herausgearbeitete Schreibstil mit zahlreichen Alliterationen, Wortspielen, ausschweifenden Darstellungen, Exklamationen, zahlreichen Superlativen, der Beschäftigung mit dem Seelenheil sowie Partizip-Präsens-Konstruktionen. Schließlich könne man aufgrund der erst späten handschriftlichen Überlieferung auch nicht ausschließen, daß der Text noch nachträglich bearbeitet wurde. - Vor ihr hielten bereits Nordenfalk, Abbas Leofsinus, S. 56 f. u. Anm. 11, und Pauly, Landkapitel Merzig, S. 84, Thiofrid für den Autor der Miracula. Dagegen jedoch spricht sich Thiofrid, Vita Liutwini II, ed. Lampen, S. XXVIII-XXX, aus, der in der Quelle zu wenige von Thiofrids typischen Wendungen findet sowie dessen häufige griechische Zitate vermißt. Dennoch erkannte er inhaltliche Parallelen bei der Darstellung Milos und der Echternacher Äbte, die nach ihrem dortigen Amt Trierer Bischöfe geworden seien. Darauf beruft sich ebenso FLESCH, Monastische Schriftkultur, S. 12. - Zu Thiofrids Irmina-Vita vgl. bereits oben S. 132 u. Anm. 91.

706 Vgl. Werner, Anfänge, S. 10-14 u. Anm. 48-50, wo er seine Argumente auf der Basis der wörtlichen Übereinstimungen weiter ausführt. Überzeugendstes Argument ist, daß 
des Libellus' in Eberhards Pontifikat (1047-1066) wird es jedoch mehr als wahrscheinlich, daß die Vita sanctae Irminae in unmittelbarer zeitlicher Nähe entstand. ${ }^{707}$ Schon WaмpaCH ging aus stilistischen Gründen von einer Entstehung der Vita „längere Zeit vor $1081^{\text {“ aus. }}{ }^{708}$ Vermutlich gehört die Vita also noch in Eberhards Zeit. KöLzer belegt ja überzeugend, daß unter Eberhard wohl 1065 das Falsum DOIII. †368 bezüglich Oerens entstand und dieser Bischof zugleich nach St. Servatius in Maastricht sowie St. Maximin ausgriff. Sein Tod 1066 habe allerdings seine diesbezüglichen Pläne verhindert. ${ }^{709} \mathrm{Im}$ übrigen gibt Thiofrid an, die Irmina-Vita im Auftrag der Oerener Nonnen geschrieben zu haben. Wahrscheinlich wollte man damit in Oeren eine eigene Irminatradition gegenüber Eberhards Trierer Ansprüchen stark machen. ${ }^{710}$

Eberhard griff nach dem Besitz der Trierer Klöster, was weder für seinen Nachfolger Konrad galt, der schon 1066 ermordet wurde, noch für den klosterfreundlichen Bischof Udo (1066-1078) und ebensowenig für dessen Nachfolger Egilbert (1079-1101), der sich in Trier nur schwer durchsetzte. ${ }^{71}$ Nun wehren sich die Miracula - wie wir gleich sehen werden - massiv und in vielfacher Form gegen den Einfluß der Trierer Erzbischöfe auf das Kloster und deren Übergriffe auf den Mettlacher Besitz. Diese auffällig starken Vorwürfe lassen sich deshalb kaum anders als mit einer auch gegen Mettlach gerichteten Politik Eberhards erklären, wie sie sich ja schon im Libellus abzuzeichnen scheint. ${ }^{712}$ Dann aber müssen die Miracula spätestens um 1065 begonnen oder wenigstens in Auftrag gegeben worden sein. Da Nizzo III. sein Amt vielleicht schon 1063 antrat, wäre dies durchaus denkbar. Er hätte das Werk dann von Thiofrid verfassen lassen, um sich gegen Eberhards Politik zur Wehr zu setzen. Die stilistischen Ähnlichkeiten zwischen den Miracula und Thiofrids IrminaVita sind dann mehr als nachvollziehbar.

Die Miracula bezogen sich bereits an einigen Stellen auf die Vita Liutwini I und den Libellus de rebus Treverensibus, wie wir ebenfalls im folgenden sehen

der Libellus als Gattin Dagoberts und Mutter Irminas eine Nanthild nenne, die in der Vita sanctae Irminae zunächst noch fehlte. Erst der Mönch Theoderich aus Echternach trug Ende des 12. Jahrhunderts Nanthilds Namen nach, als er die Vita in den Echternacher Liber aureus aufnahm. WERnER, Adelsfamilien, S. 180, weist darauf hin, daß in der Irmina-Vita erstmals die Verbindung Dagobert-Irmina-Oeren festgeschrieben werde.

707 Vgl. KöLzer, Studien, S. 255-260.

708 Vgl. Wampach I 1, S. 114 f., Anm. 4.

709 Vgl. dazu ausführlich KöLzer, Studien, S. 110 ff., 137, 259. Man habe in Trier dazu die Minderjährigkeit des Thronfolgers Heinrich IV. (1056-1065) genutzt, um diese Ziele zu verfolgen. In dieser Zeit seien die Maximiner Karolinger-Fälschungen gegen Trier entstanden.

710 Vgl. dazu nochmals oben Anm. 91.

711 Vgl. zusammenfassend zu diesen Bischöfen Goerz, Regesten der Erzbischöfe zu Trier, S. 11-13. Kölzer, Studien, S. 114, mit der älteren Literatur, sowie Bönnen, Trier zwischen dem 10. und dem beginnenden 12. Jahrhundert, S. 222-234.

712 Vgl. dazu schon oben Kap. D.IX.3. 
werden. ${ }^{713}$ Offenbar fühlte man sich vom Libellus direkt angegriffen. Der Verfasser der Miracula nahm sogar einen für Mettlach und Liutwin noch positiveren Standpunkt als die Vita I ein und zeigte, daß er über wesentliche klosterinterne Informationen verfügte, die ihn in enge Verbindung zu Mettlach bringen. Diese Perspektive fand dann interessanterweise Eingang in Thiofrids Vita II, die in einigen Punkten die Vita I geradezu an die Miracula anpaßte. ${ }^{714}$ Auch das deutet auf Thiofrid als Verfasser der Miracula. Über Thiofrids frühe Jahre ist bis 1081 nichts Sicheres bekannt, als der Echternacher Abt Reginbert starb und zuvor Thiofrid zum dortigen Nachfolger bestimmte. 1083 bis 1110 leitete er die Abtei. ${ }^{715}$ Wäre er der Autor der Wundergeschichten, so legten seine Kenntnisse nahe, daß er einmal Mönch in Mettlach war oder vielleicht die dortige Klosterschule besuchte, wenigstens aber intensive Kontakte zum Saarkloster pflegte. ${ }^{716}$

\section{b. Die Miracula und der Beginn des Liutwinkultes in Mettlach}

Alle inzwischen zusammengetragenen Ergebnisse weisen darauf hin, daß der Liutwinkult in Mettlach nicht schon im frühen 8. Jahrhundert einsetzte, sondern erst unter dem Episkopat Erzbischof Egberts von Trier (977-993). Davor haben keine gesicherten Informationen zu Liutwin vorgelegen. Sein Bild entstand vielmehr angelehnt an das seines angeblichen Sohnes Milo.

Die Miracula mit der einzig erhaltenen Darstellung der Mettlacher Klostergeschichte bieten nun die Möglichkeit, diese Ergebnisse an ihnen zu verifizieren und zu überprüfen. Dazu ist es erforderlich, die Angaben der Miracula von der vermeintlichen Zeit Liutwins bis etwa um das Jahr 1000 - soweit sie

713 Vgl. dagegen Schmal, Mettlach, S. 13 f., die schließt, die Vita I könne erst nach den Miracula entstanden sein.

714 Vgl. dazu nochmals oben Anm. 703, 705. Schließlich spricht der Text erneut von per specialem nostrum patronum Liutwinum. Vgl. dazu Miracula s. Liutwini auct. Monacho Mediolacensi cap. 1, ed. SAuerland, S. 1261, Z. 26. Dies müsse nach Schmal, Mettlach, S. 14, Anm. 61, Thiofrids Verfasserschaft der Miracula nicht ausschließen, denn in Thiofrid, Vita Liutwini II, Prologus, ed. Lampen, S. 2, spreche er von: Liutwini, specialis patroni et patris nostri, was auf der Vita I beruhe.

715 Vgl. zu Thiofrid nochmals Lampen, Thiofrid, S. 1-5. WInHeller, Lebensbeschreibungen, S. 98. Thiofrid, Vita Liutwini II, ed. Lampen, S. XI-XVI.

716 Letztlich fällt bei Thiofrid auf, daß sich seine Willibrord- und Irmina-Vita auch aus seinem Wirken in Echternach erklären, so daß schon aufgrund der Vita Liutwini II mit einem biographischen Bezug zu Mettlach zu rechnen ist. Dann könnten die teilweise deutlich verformten Angaben zu den Äbten vor Nizzo III. vielleicht aus eigener Anschauung bzw. aus dem Gedächtnis Thiofrids rekonstruiert sein. Vgl. dazu Miracula s. Liutwini auct. Monacho Mediolacensi cap. 17-21, ed. SAuerland, S. 1266 f. - Daß die Miracula in den Handschriften meist mit den Viten gemeinsam überliefert sind, mag darauf hinweisen, daß die Wunder letztlich als Ergänzung dazu geplant waren. Vgl. dazu nochmals oben Anm. 629, 704. 
sich zuordnen lassen - noch einmal vollständig zu analysieren und dabei ihre Entstehung in der zweiten Hälfte des 11. Jahrhunderts zu berücksichtigen. Was also berichten sie, und auf welcher Informationsbasis geschieht das? Da die Miracula über mindestens 70 bis zu knapp 400 Jahre zurückliegende Ereignisse referieren, ist ohnehin Vorsicht geboten. Bereits RaAcH wies bei seiner Untersuchung der Frühzeit des Saarklosters anhand der Miracula auf deutliche chronologische Unstimmigkeiten hin. ${ }^{717}$ BECKER folgte bei seiner knappen Klostergeschichte eng den Miracula. ${ }^{718}$

Der Text betont zu Beginn die Notwendigkeit, Liutwins Wundertaten zu überliefern, will aber zunächst etwas über das Kloster selbst berichten (cap. 1). ${ }^{719}$ Er erwähnt sodann (cap. 2) die bereits oben ausführlich besprochene, sicher manipulierte Liutwin-Urkunde, in der Bischof Liutwin all seinen ererbten und erworbenen Besitz an das Kloster Mettlach und die dortigen Mönche überträgt. Sie datiert widersprüchlich sowohl auf das zwölfte Jahr König Childeberts III. (706) als auch auf 696 nach Christi Geburt. In dieser Zeit habe Liutwin gelebt. Offenbar hatte der Verfasser Schwierigkeiten bei der genauen Zeitbestimmung. Nimmt man jedoch Thiofrid in Echternach als Verfasser der Miracula an, läßt sich das erklären. Denn im Echternacher Archiv fand sich mindestens eine Urkunde des Hausmeiers Pippin und seiner Frau Plektrud just aus dem zwölften Herrschaftsjahr Childeberts an das Kloster Echternach (Urkunden der Arnulfinger 4 u. 5). Thiofrid hätte also schlicht auf eine ihm zur Verfügung stehende alte Vorlage zurückgegriffen, die er, wie wir oben gesehen haben, zweifellos kannte. ${ }^{720}$ Vielleicht orientierte er sich dabei an der Angabe der Vita I, die Liutwin zunächst unter einem König Childebert leben läßt. Die Urkunde ist aber nicht nur aufgrund des Datums, sondern auch ihres Inhalts nicht glaubwürdig. Denn sie verkehrt die Aussage der Liutwin-Vita I und der beiden manipulierten Diplome für Erzbischof Radbod von 884 und 888 zu Mettlach (DKIII. 102 u. DArn. 39) ins Gegenteil, nach denen Liutwin Mettlach vollständig an das Trierer Erzstift übertrug. Diese völlige Umkehr kann nur mit der Absicht geschehen sein, die bestehende Tradition durch eine konstruierte Gegentradition in Frage zu stellen. Das bedeutet aber, daß der Verfasser wenigstens die Vita I, vielleicht sogar die beiden Diplome kannte. Die Miracula bieten an dieser Stelle deshalb keine vertrauenswürdigen Nachrichten über Mettlachs Frühzeit, sondern korrigieren das damals bestehende Liutwinbild in ihrem Sinne, der deutlich gegen das Trierer Erzstift zielt.

717 Vgl. Raach, Mettlach, S. 20 f., 37-62. Lager, Urkundliche Geschichte, S. 13-40.

718 Vgl. Becker, Mettlach, S. $518 \mathrm{ff}$.

719 Vgl. Miracula s. Liutwini auct. Monacho Mediolacensi cap. 1, ed. Sauerland, S. 1261.

720 Vgl. bereits oben S. 186 u. Anm. 262 f., auch mit dem Wortlaut der Miracula, sowie ferner oben S. 187 f. u. Anm. 266 f. Vgl. Miracula s. Liutwini auct. Monacho Mediolacensi cap. 3, ed. Sauerland, S. 1262. 
Weitere konkretere Angaben zu Liutwin fehlen in diesem Zusammenhang. Stattdessen schließt sich an die manipulierte Urkunde unmittelbar eine um einiges längere und ausführlichere Passage über Liutwins Sohn Milo an, die diesen in höchsten Tönen lobt (cap. 3). Milo muß also im kulturellen Gedächtnis Mettlachs eine immer noch zentrale positive Rolle gespielt haben. ${ }^{721}$

Milos Ende und Handeln sei der Erinnerung wert, auch wenn ihn Hinkmar als Zerstörer des Bistums Reims beschreibe, wie man im Prolog seiner RemigiusVita lesen könne. Er sei nicht deshalb berüchtigt, weil er auf der Jagd von einem wilden Eber getötet wurde. Denn weil er gerecht war, befinde er sich in der ewigen Seligkeit, wie auch immer er starb. Von ihm habe Mettlach viel Nützliches empfangen, und man habe viel Ehrenwertes von ihm gehört. Er habe nämlich das ihm Zurückgelassene nicht nur mit frommem Eifer fortgeführt, sondern das vom Vater zur Fürsorge Ererbte wie sein Eigentum angenommen. Allein aus Liebe zu ihm und dessen Vater hätte ein Feuer die Trierer entfacht. Und diese Zuneigung hätte sie gegenüber den Mettlachern verpflichtet, daß sie über den Zeitraum mehrerer Jahre wegen der Liebe zu ihm gleichsam das Recht des frommen Brauchs gehabt hätten, sich nach dem Tod ihrer Hirten aus Mettlach einen patronus zu wählen. Wer auch immer nämlich das Amt des Mettlacher Abtes bekleidete, wurde der Trierer Bischofswürde (episcopio) für würdig gehalten. Deshalb seien Weomad, Richbod, Hetti, Thietgaud, Bertolf und Radbod, nachdem sie durch die Anordnung der Mönche als Mettlacher Äbte eingesetzt worden seien, wegen des Verdienstes der Heiligkeit und des Vorrechts einzigartiger Weisheit in die Ehre der Bischofswürde der hl. Trierer Kirche nach der Ordnung eingesetzt worden. Diese hätten Pröpste unter sich gehabt, die das Kloster leiteten. Sie hätten ebenso durch den Titel beider Namen, des Bischofs nämlich und des Abtes, hervorgeleuchtet. Zwar habe das Kloster unter ihnen geblüht, doch sei durch sie der Mangel des Trierer Bistums aus der Fülle des Klosters gedeckt worden. Unter diesen Pröpsten lebten viele

721 Vgl. den Text oben in Kap. C.IV.4., Anm. 122. Der Text fährt dann fort: Unde Wiomadus, Ricbodus, Hetti, Thietgaudus, Bertolfus, qui Merciam de regia manu precio coemptam abbatie rebus coniunxit, et Rabodo, Mediolacensium quidem monachica ordinatione abbates constituti, pro sanctitatis merito ac singularis sapientie prerogativa ad honorem episcopatus sancte Treverensis ecclesie per ordinem sunt promoti. Qui tamen prepositos, qui locum regerent ac confratres vita moribusque ad spiritualis vite exercicia preirent, sub se habebant. Ipsi autem excellentia ordinis et titulo utriusque nominis, episcopi scilicet et abbatis, effective fulgebant. Quorum tempore Mediolacensis locus extitit floridus ex provectu honoris illorum, sed magnum in rebus propriis passus est dispendium, dum quisque illorum quod potissimum erat ex monasterio decerpsit et inopiam episcopii ex copia nostra supplevit. I Claruerant igitur in predicto monasterio multi monachorum sub hisdem prepositis, [...]. Qui primum illorum patrem Liutwinum pre oculis mentis habebant et ad conversationis eius et virtutum exemplar actus suos viteque ordinem reformabant et inter lubrica et aspera mundalium vestigiis [eius] illustrabant innitentes, ut secum pascuis viriditatis eterne fruerentur felices. 
ehrenwerte Mönche. Diese hätten zuerst ihren Vater Liutwin vor ihrem geistigen Auge gehabt und nach dem Beispiel seiner Lebensweise ihr Leben erneuert.

Dieses Kapitel geht noch weiter als das vorausgehende. Es erhebt nun massive Vorwürfe gegen namentlich genannte frühere Trierer Erzbischöfe, die ihre Position als Mettlacher Äbte ausnutzten, um mit Mettlachs Besitz den Wohlstand des Erzstifts zu mehren. Die Kritik wird besonders hart, wenn man den Weg verfolgt, wie den Trierer Bischöfen der Mettlacher Abbatiat zukam. Denn nicht Liutwin sorgte dafür. Vielmehr hätte das ehrenwerte Verhalten seines Sohnes und Erben Milo die Trierer dazu bewegt, Mettlacher Äbte zu Trierer Bischöfen zu wählen. Folgt man den Miracula, so erbte Milo Mettlach. Nach dieser Logik ergab sich dann aber für Trier überhaupt kein Rechtsanspruch auf das Kloster. Dieses Bild erinnert jedoch beinahe mehr an den eigentlichen Inhalt von DKarol. I 148, dem eines Milo nämlich, der die Trierer Bischöfe zu Mettlacher Äbten machte. Vielleicht wußte man in Mettlach noch davon, vielleicht war der Text sogar von Trierer Seite vorgelegt worden, um den eigenen Anspruch auf Mettlach zu unterstreichen. In jedem Fall belegt dieses Kapitel der Miracula eine nicht zu leugnende starke und positive Mettlacher Milomemoria, die wohl auf Milos Grab beruhte. Man wollte mit diesen Ausführungen das Erzstift treffen, von dem man sich unmittelbar bedroht fühlte. Diese Bedrohung muß von Trierer Ansprüchen ausgegangen sein, die von den Miracula auf der Basis eines Textes aufgegriffen werden: des Libellus' nämlich. Sein negatives Milobild und dessen Tod in Ehrang werden geradezu durch den positiven Mettlacher Milo konterkariert. Milo übernimmt letztlich sogar Liutwins Rolle. Man sieht an dieser Reaktion aber, daß der Libellus mit seinen Angaben zu Milo tatsächlich Mettlach angreifen wollte. Dem weiteren Trierer Anspruch, den der Libellus mit Hettis Mettlacher Abbatiat formuliert, ${ }^{722}$ stellen die Miracula dann den langwährenden Mißbrauch der Trierer Erzbischöfe darunter auch Hetti - an Mettlachs Wohlstand entgegen, eine geniale Konstruktion.

Schon Lager zeigte aber, daß keiner der erwähnten Trierer Bischöfe Mettlacher Abt gewesen sein könne. Im übrigen bestehe ein unübersehbarer inhaltlicher Widerspruch: Wer sollte denn nach dem Tod des Trierer Bischofs Mettlacher Abt sein, wenn doch beide Ämter in Personalunion verwaltet wurden? ${ }^{723}$ Die von den Miracula genannten Bischofs- bzw. Abtsnamen dürften somit schlicht einer Trierer Bischofsliste und nicht einer alten Mettlacher Klosterüberlieferung entnommen sein. Die bisher nur geringen Anmerkungen

722 Vgl. dazu oben S. 338 u. Anm. 699 f.

723 Vgl. Lager, Urkundliche Geschichte, S. 13 f. Darüber hinaus versucht er jedoch (ebd., S. 13 ff.), die Darstellung der Miracula an die Vita I anzupassen und mit ihr stimmig zu machen. RaAch, Mettlach, S. 20 f., weist darauf hin, daß die Namen dieser Trierer Bischöfe nicht mit der Reihenfolge der Gesta Treverorum übereinstimmen. 
der Miracula zu Liutwin lassen sich darüber hinaus einfach über die Kenntnis der Vita I erklären. Eine alte Tradition war dazu keineswegs erforderlich.

Im Kloster wußte man offenbar - Milos positive Memoria ausgenommen überhaupt nichts mehr über dessen frühe Zeit. Ein im folgenden (cap. 5) berichtetes Liutwinwunder könnte erklären, woran das lag. Die Hunnen hätten nämlich bei ihren Streifzügen durch das Trierer Land Mettlach angegriffen. Als es schließlich an die Plünderung der verschlossenen Marienbasilika ging, habe Liutwin Maria um ihr Eingreifen gebeten, die es dann verhinderte. Zwei der Angreifer seien als Mönche in Mettlach eingetreten. Jedoch suchten die Hunnen niemals Mettlach heim, gemeint waren vielmehr die Ungarn, die dem frühen Ottonenreich schwer zu schaffen machten. Doch sie kamen ebenfalls nicht nach Mettlach. Die Erzählung dürfte hingegen die dunkle Erinnerung an einen Normannenüberfall 882 widerspiegeln. Allerdings waren die Nordmänner längst im Gedächtnis des Verfassers der Miracula oder der Mettlacher Mönche und damit dem kulturellen Gedächtnis des Klosters durch die erst später in Aktion tretenden Ungarn „überschrieben“ worden. ${ }^{724}$ Daß ausgerechnet zwei Invasoren im Kloster blieben, mag vielleicht stimmen, kann aber auf anderem Weg in die Erzählung eingeflossen sein. Ebenso dürfte erst später Liutwin anstelle von Maria für die Rettung verantwortlich gemacht worden sein. ${ }^{725}$ Die Frühzeit des Klosters war also aufgrund eines Normannenüberfalls um 882 in Legende versunken. Eine normannische Zerstörung läßt sich für die Peterskirche durch den archäologischen Befund auch belegen. Für die Marienkirche ist der Nachweis schwieriger. ${ }^{726}$ Es wird also verständlich, warum die Vita I berichtet, man habe über Liutwin nichts Genaues mehr gewußt.

Für diese These spricht ebenso, daß die Miracula dann auffälligerweise (cap. 6) ihren Bericht mit dem Trierer Bischof Radbod (883-915) fortsetzen, dem ersten Bischof nach dem Normannensturm. ${ }^{727}$ Radbod habe Mettlach viele

724 Vgl. zum Phänomen der ,Überschreibung' FrIED, Geschichte und Gehirn, S. 30, der diese als „Nr. 12“ seiner Verformungsfaktoren aufführt. Fried, Schleier, S. 50, hier ebenfalls Nr. 12.

725 Vgl. Miracula s. Liutwini auct. Monacho Mediolacensi cap. 5, ed. SAuerland, S. 1262 f., hier S. 1263: [...], ad summae Dei genitricis basilicae concurrerunt portam [...]. Duo autem ex illis [den Hunnen] relicti post recuperationem celitus flagellorum omnem vitam apud nos exegerunt in servimine civium. VON BRIESEN, Urkundliche Geschichte, S. 80 f. Lager, Urkundliche Geschichte, S. 17. Vgl. dazu Nolte, Raubzüge der Ungarn, S. 365-371, der von einer Plünderung des Klosters durch die Ungarn ausgeht. Ähnlich auch Schmal, Mettlach, S. 145. RaAch, Mettlach, S. 37 f., meint, Mettlach sei von den Normannen verschont geblieben.

726 Vgl. zur Zerstörung der Peterskirche Klewitz, Baugeschichte, S. 83. Nach der kriegerischen Zerstörung sei im 10. Jahrhundert ein Neubau begonnen worden, der sich bis ins 11. Jahrhundert hingezogen habe.

727 Vgl. Miracula s. Liutwini auct. Monacho Mediolacensi cap. 6, ed. Sauerland, S. 1263: Ratbodo igitur, cuius mentionem fecimus supra, multa incommoditatis genera pro beneficiis a 
Unannehmlichkeiten bereitet, Villen und Besitz des Klosters unter seinen Leuten aufgeteilt sowie die Mönche durch eine tyrannische Herrschaft unterdrückt. Er habe ferner das Privileg des Klosters, in dem Stellung und Ehre des Ortes notiert waren, geraubt und die Einrichtungen, die vom hl. Liutwin und dessen Nachfolgern zur Versorgung der Brüder und der armen, dorthin kommenden Getreuen Christi hinzugefügt worden waren, völlig zerstört und diesen an Schätzen reichen und edlen Ort durch die entfernten Güter fast wüst und unbewohnbar gemacht.

Die Frage ist, woher die Miracula plötzlich - nach dem Überfall der Nordmänner - von einem solchen Privileg des Klosters wußten, wenn es nicht einmal die Vita Liutwini I kannte. Ebenso berichtet die Vita I nichts von Einrichtungen des Heiligen und seiner Nachfolger für die Brüder und die Armen. So kann es sich nur um einen erneut beabsichtigten Vorwurf gegen das Trierer Erzstift handeln, man habe auf Kosten Mettlachs gelebt, was Radbod dann auf die Spitze trieb. Der Vorwurf könnte aus der Gegenwart des Verfassers der Miracula motiviert sein, die geradezu auf die Überlegenheit Mettlachs pochen. Doch warum wird ausgerechnet Radbod zum Opfer so scharfer und fiktiver Polemik, die sich im Text noch fortsetzt? Die 1101 in St. Eucharius abgeschlossene Redaktion A der Gesta Treverorum dagegen rühmt ihn. Auch Regino von Prüm fand ja bei Radbod Zuflucht und wurde in St. Martin zum dortigen Wiederaufbau als Abt eingesetzt. ${ }^{728}$ Letztlich existiert überhaupt nur eine konkrete Verbindung zwischen Erzbischof Radbod und Mettlach: die beiden vermutlich Ende des 10. Jahrhunderts in Trier ge- oder verfälschten Diplome, die angeblich 884 und 888 für Radbod ausgestellt wurden (DKIII. 102 u. DArn. 39). Denn Radbod bekommt darin einmal von Karl III. und ein weiteres Mal von Arnulf Mettlach für Trier zugesprochen, wobei sich Radbod in beiden Diplomen darauf beruft, daß schon der hl. Liutwin das Kloster unmittelbar an St. Peter schenkte. Sollten die Stücke doch echt sein, was nicht völlig auszuschließen ist, muß schon Radbod diesen Liutwin für seine

se iure inferendis intulit Mediolacensibus. Namque villas resque monasterii in proprios divisit ac monachos tyrannico incumbens pressit dominio. Privilegium etiam cenobii, quo status et honor loci inerat annotatus, abstulit et instituta, que a sancto Liutwino et successorum eius providentia fratribus et pauperibus Christi supervenientibus fidelibus utiliter tradita fuerant, penitus divellit et usque ad id temporis divitiis locupletem ac nobilem rebus abstractis pene desertum fecerat et inhabitabilem.

$728 \mathrm{Zu}$ Radbod vgl. Gesta Treverorum cap. 28, ed. WAITz, S. 167 f.: Cui successit Radbodus, abbas de Mediolaco, venerabilis antistes, et eodem anno Robertum in Mettis episcopum consecravit. Hic adquisivit abbatiam sancti Servatii quae dicitur Mastreth ab Arnolfo imperatore, deinde etiam a Ludowico imperatore haec castella obtinuit, Sericum et Orkesvels cum villis sibi subiacentibus. Der Hinweis des Editors Waitz, das Mettlacher Abbatiat sei Reginos Eintrag zu 883 entnommen, ist falsch. Vermutlich geht dieser Vermerk in den Gesta ebenfalls auf die beiden Radbod-Urkunden zu Mettlach zurück. Vgl. ferner oben S. 218 u. Anm. 378. 
Zwecke konstruiert haben. ${ }^{729}$ Mit diesen beiden Urkunden dürfte Trier seine Besitzansprüche auf Mettlach sicher noch zur Abfassungszeit der Miracula geltend gemacht haben. Da die Miracula aber von einer Schenkung Liutwins an Trier nichts wissen wollten, konnte man diese beiden Urkunden ebensowenig akzeptieren. Deshalb griff man ihren gemeinsamen Empfänger so vehement an, um ihn zu desavouieren und darüber die beiden Diplome abzuwerten. Man darf diese Diplome also nicht auf der Basis der scheinbaren Informationen interpretieren, die die Miracula bieten, wie dies bisher meist geschehen ist, sondern man muß die Miracula vielmehr als Reaktion auf die Urkunden verstehen. ${ }^{730}$ Sollte Radbod tatsächlich schon Liutwin als Schenker erfunden haben, könnte sich auch deshalb der Ärger gegen ihn richten.

Die Vorwürfe der Miracula gegen Radbod setzen sich weiter fort (cap. 7). Erkenbert, ein Vorsteher des Klosters, soll beschlossen haben, gegen Radbods Vorgehen in Rom Klage zu führen. Die Miracula malen dies in einer lebendigen Szene aus. Erkenbert berichtet dem Papst (Hadrian III. [884-885] oder Stephan V. (VI.) [885-891]?), im Gebiet der Gallier gebe es einen Ort namens Mettlach, den ein sehr religiöser Laie und mächtiger Fürst zu Ehren der Gottesmutter und des Apostelfürsten Petrus gebaut habe, wo er, nachdem er in den geistlichen Stand eingetreten war, als Mönch mit Mönchen Gott zu dienen beschlossen habe. Dann sei er zum Trierer Bischof gewählt worden. Nach seinem Tod wollte er in Mettlach begraben werden. Dessen Nachfolger hätten sich jenen Ort als Besitz angeeignet. Sie seien aber mehr als Plünderer denn als Verwalter für den Besitz tätig gewesen. Dann beschreibt Erkenbert das Treiben des letzten Bischofs, Abtes und Plünderers Radbod. Die in cap. 6 gemachten Vorwürfe werden dabei in noch dunkleren Farben ausgemalt. Radbod habe den Namen des Abtes mißbraucht, Mönche und Besucher unterdrückt usw., ja Erkenbert selbst sei durch ihn von seinem Eigentum und Amt vertrieben worden. Seit sechs Jahren arbeite Erkenbert inzwischen für die Gesundung Mettlachs. Deshalb sei er nach Rom gezogen. Der darüber erzürnte Papst habe Erkenbert ein Schreiben für König Karl mitgegeben, in dem er diesen anzuordnen bat, dies alles rückgängig zu machen. Erkenbert sei damit zum König gegangen. Dieser habe ihn in sein altes Amt wiedereingesetzt und Bischof

729 Vgl. zu beiden Urkunden, ihrer Fälschung oder ihrem manipulierten Inhalt oben Kap. D.IV.4.-5. Auch RaAch, Mettlach, S. 38, sieht eine Verbindung zu diesen beiden Urkunden, die er aber für echt hält, die Vorwürfe damit für realistisch. Die Mönche hätten gehofft, daß die Widonen in diesen Jahren wieder die Fürsorge für das Kloster übernähmen.

730 Vgl. dagegen die Interpretation bei Lager, Urkundliche Geschichte, S. 17-19, der vermutet, Radbod habe Mettlach seiner Güter beraubt, um damit die übrigen im Normannensturm zerstörten Klöster wiederaufzubauen. Doch hält er die Kritik an Radbod für überzogen. RaAch, Mettlach, S. 37 f., meint ebenso, Radbod habe die Mettlacher Güter benutzt, um die anderen Trierer Klöster wiederaufzubauen. 
Radbod befohlen, von der Verletzung der Mettlacher abzulassen und das Entfremdete zurückzugeben. Was jedoch in den Schlund hungriger Hunde gelange, könne man nur schwer als Ganzes wiederherstellen. ${ }^{731}$

Diese Geschichte gibt insgesamt den Inhalt der Vita Liutwini I verkürzt wieder, verschweigt dabei aber - gemäß dem schon erkennbaren Konzept der Miracula - die entscheidende Schenkung Mettlachs durch Liutwin an Trier. Man berief sich somit nicht auf altes Mettlacher Wissen. Vielmehr werden die Invektiven gegen die Mißwirtschaft der Trierer Bischöfe, insbesondere Radbods, fortgesetzt. Diese Passage bezieht sich aber noch wesentlich dezidierter auf die beiden manipulierten Radbod-Urkunden. Erkenbert spricht nämlich von sechs Jahren, die er bereits gegen Radbod kämpfe. Bedenkt man Radbods Amtseinführung 883, kommt man auf 888, das Ausstellungsjahr von DArn. 39. Der Papstbrief an König Karl dürfte Karl den Dicken meinen, den Aussteller von DKIII. 102. Die Angaben beider Urkunden wurden schlicht vermischt. Wären diese den Mettlachern lediglich einmal vom Erzstift vorgelegt worden, wird eine solche Verformung in der späteren Erinnerung leicht erklärbar. Das Ziel dieser Erzählung liegt deshalb auf der Hand: Beide Diplome sollen durch das von den Miracula zeitlich nach ihnen eingeordnete päpstliche Schreiben sowie die königliche Anordnung ungeschehen gemacht und aufgehoben werden.

Bei Erkenbert könnte es sich um einen im Kloster noch erinnerten Namen, vielleicht den eines Abtes handeln. ${ }^{732}$ Vermutlich fand sich eine Grabinschrift. Vor ihm werden keine Vorsteher oder Äbte mehr namentlich erinnert, was bedeutet, daß man von solchen nichts mehr wußte. Vielleicht waren ihre Gräber beim Normanneneinfall zerstört worden.

Auch für das Erzählmuster dieses Kapitels gab es eine Vorlage, die der Verfasser vielleicht kannte. Die Urkunde Papst Agapets II. (946-955) von 950 für das Kloster St. Maximin, die KöLzer als Fälschung des ausgehenden 10. Jahrhunderts nachgewiesen hat, berichtete ähnliches: ${ }^{733}$ Zwei Maximiner Mönche, Asolf und Gunther, hätten sich vor dem Papst und dem römischen Klerus über Erzbischof Rotbert (931-956) beschwert, der versucht habe, das

731 Vgl. Miracula s. Liutwini auct. Monacho Mediolacensi cap. 7, ed. Sauerland, S. 1263. Lager, Urkundliche Geschichte, S. 18. Vgl. dazu auch Germ. Pont. 10, Mettlach *2, ed. Boshof, S. 252, der ein solches Schreiben jedoch auf ca. 911-915 datiert.

732 Vgl. RaAch, Mettlach, S. 38 f., der Erkenbert für den ersten Abt des Klosters hält. Ein Erkenbert lasse sich 885-891 als Abt von St. Maximin nachweisen. Vielleicht sei dieser dann nach Mettlach gewechselt (ebd., Anm. 13). Raach hält auch eine Inspiration des erwähnten Karl durch die Urkunde von 884 für möglich (ebd., Anm. 15).

733 Vgl. JL †3649. MRUB I †197, S. 257 f. Zimmermann, Papsturkunden I 121, S. $212-$ 214. Germ. Pont. 10, St. Maximin †5, ed. Boshof, S. 201 f. Kölzer, Studien, S. $57-$ 67. Vgl. dazu auch oben S. 265 f. u. Anm. 487. - Wenn man nach den Miracula später in Mettlach unter Abt Hezzel einen Neubau der Marienkirche begonnen habe, der St. Maximin nachempfunden worden sei, spricht das immerhin für Mettlacher Kontakte zu diesem Kloster. Vgl. dazu unten S. 355-357 u. Anm. 749, 751-753. 
reichsunmittelbare Kloster St. Maximin an die Trierer Kirche zu ziehen. Nach Vorlage einiger Urkunden sei dann vom Papst und dem römischen Klerus angeordnet worden, daß St. Maximin unter königlicher Gewalt verbleibe und keiner anderen Person unterstellt werde außer dem dortigen Abt, den die Brüder in Eintracht gemäß der Regel wählten.

Die Miracula beschreiben anschließend (cap. 8) das schädliche Wirken des Trierer vicedominus Wicelinus, der es gewohnt gewesen sei, Mettlacher Besitz unter seinen Rittern zu verteilen. Bei einem Aufenthalt im Kloster habe er sich das Mettlacher Güterverzeichnis vorlegen lassen. Als er durch dessen Lektüre Mettlachs Reichtum erkannte, sei er zornig geworden, habe das Buch in Stücke zerschnitten und verbrannt, um sich frei am Klostergut bedienen zu können, ohne den Mönchen die Möglichkeit zu geben, dieses durch Urkunden zurückzufordern. ${ }^{734}$

Erneut richtet sich die Kritik gegen Trier. Ein wenig erinnert dieser Wicelin allerdings an das Reimser Milobild, das vielleicht für dieses „Wichtlein“ Pate stand. Immerhin reflektiert die Geschichte einen wahren Sachverhalt. Denn aus Mettlachs Frühzeit gab es kein Polyptychon, um möglichen Güterbesitz zu rekonstruieren. Vielleicht war es dem Normannensturm zum Opfer gefallen. Diesen Makel wollte oder mußte das Wicelin-Kapitel erklären. Wahrscheinlich machte die Arbeit an der zeitnah zu den Miracula begonnenen Mettlacher Güterrolle, für die man offenbar nur über wenige Vorlagen verfügte, diese Erläuterung erforderlich. ${ }^{735}$ Einige davon konstruierte oder interpolierte man so haben wir oben gesehen - sogar, wie die von Thiofrid geschöpfte Schenkung Oblangas durch Gerwin und Gunza an Mettlach sowie die Notiz über die Weihe der Kirche in Udern/Oudrenne durch Erzbischof Rotbert. ${ }^{736}$

In den Miracula folgt dem ungeliebten Radbod dann Erzbischof Rotbert (931-956) (cap. 9), der Mettlachs Lage deutlich verbesserte. ${ }^{737}$ Er habe das Kloster bei Amtsantritt auf einer Visitationsreise besucht und nach seinem Gründer, den Gründungsumständen sowie der Besitzgeschichte gefragt. Man

734 Vgl. Miracula s. Liutwini auct. Monacho Mediolacensi cap. 8, ed. SAUERLAnd, S. 1263 f.: Fuit autem quidam vicedomnus Treverensium Wicelinus nomine, qui Mediolacensium proprias res militibus suis solitus erat distribuere. Qui etiam quondam ad monasterium venit sibique reficiendi copiam preparari iussit. Cibis itaque finitis, afferri sibi librum iam notum petiit, in quo privilegii et cunctarum, que ad locum pertinebant, rerum inscriptio fuit. Qui cum intente legeret et tantas res ad locum unum pertinere mirans invideret, eundem libellum cultello minutatim incidit ac flamme cremandum tradidit, reputans quidem se ultra liberiorem habiturum potestatem monachorum res auferendi, cum illis nulla relicta sint instrumenta easdem repetendi. Vgl. dazu LaGer, Urkundliche Geschichte, S. 18 f. Pauly, Landkapitel Merzig, S. 85. RaAch, Mettlach, S. 39 f.

735 Vgl. dazu oben Kap. D.V.

736 Vgl. zur Oblanga-Fälschung oben S. 323 f. u. Anm. 660-663. - Zur manipulierten Weihenotiz der Kirche in Udern/Oudrenne vgl. oben S. 256 ff. u. Anm. 465-478.

737 Vgl. zu Rotbert oben S. 265-267 u. Anm. 486-488. 
antwortete mit dem Verweis auf Liutwin, der das Kloster von seinem Besitz auf seinem Eigentum gegründet habe. Aber dessen (bischöfliche) Nachfolger hätten es zu einer kleinen Zelle heruntergewirtschaftet. Der Bischof habe das bedauert, aus dem Kloster Clinga Rotwich geholt und ihn in Mettlach zum Abt gemacht, um das Kloster zu erneuern. Dann sei dieser von Rotbert dem Kaiser Otto I. (936-973) und allen Fürsten vorgestellt worden, um ihn bekannt zu machen. Der Bischof habe ferner den König gebeten, eine Urkunde anfertigen zu lassen „über die Besitzungen des Klosters, welche er selbst (der Erzbischof) zurückgegeben habe oder zurückzugeben gewillt sei, sowie auch über die Bewilligung der Wahl der Brüder in der Nachfolge der Aebte, und dass kein Fremder sie angreifen aber auch kein Bischof oder Abt ohne die Zustimmung des Conventes etwas verschenken, vertauschen oder verkaufen könne. "“738 Die Miracula berichten im Anschluß (cap. 10 f.) über Rotwichs Reform im Kloster. Er habe es nicht nur geistig gefördert, sondern auch Gebäude im Hof errichten, es mit einer Mauer umgeben und Bücher verfassen lassen. Man habe die Benediktregel befolgt und viele Heranwachsende in den Wissenschaften ausgebildet. Ihr Lehrer war der in allem gebildete Germanus. Zwei seiner Schüler gingen zu Gerbert nach Reims. Die gute Zusammenarbeit Rotwichs und Rotberts zeige die Weiheinschrift des Petrusaltars. Sogar aus Rom habe man Schriften zum Geschenk erhalten. ${ }^{739}$

Daß der Verlust des Güterverzeichnisses durch Wicelin fiktiv sein muß, zeigt die Sukzession Rotberts auf Radbod, wobei der Episkopat Ruotgers (915-931) schlicht übersehen wird. Bei Erzbischof Rotbert (931-956) und Abt Rotwich wird die Erinnerung im Kloster erstmals durch greifbare Zeugnisse gelenkt. Die Mettlacher werden jedoch Rotbert kaum etwas davon berichtet haben können, wie ihr Patron Liutwin das Kloster gründete und dessen Nachfolger diesem Ort massiven Schaden zufügten. Dabei handelt es sich vielmehr um die fortgesetzte Polemik gegen Trier, die ohne Kenntnis der Vita I kaum denkbar ist und die wieder einmal Liutwins Schenkung an das Erzstift leugnete. Diesem Konzept folgt ebenso der Besuch beim Kaiser sowie dessen vermeintliches Besitzprivileg, das wieder gegen Trier zielt und Mettlachs Eigenständigkeit betont. Auch dieses

738 Vgl. Miracula s. Liutwini auct. Monacho Mediolacensi cap. 9, ed. SAuERLAnd, S. 1264. Vgl. dazu von Briesen, Urkundliche Geschichte, S. 83. Lager, Urkundliche Geschichte, S. 19 f., das Zitat ebd., S. 20. Zu Rotwich vgl. auch FlesCH, Monastische Schriftkultur, S. $14 \mathrm{f}$.

$739 \mathrm{Vgl}$. Miracula s. Liutwini auct. Monacho Mediolacensi cap. 10 f., ed. SAuerLand, S. 1264 f. Die Altarinschrift (ebd. cap. 11, S. 1265, Z. 3-6) lautet: Claviger alme poli, Ruopertus mente fideli / Hanc tibi preclaram presul devoverat aram, / Abbas quam Ruothwic devotus rite peregit, / Premia communis sibi quo sint equa laboris. Vgl. dazu von BRIEsEN, Urkundliche Geschichte, S. 83-86. LaGer, Urkundliche Geschichte, S. 22-24. Vgl. zu Rotwichs Zeit auch Germ. Pont. 10, Mettlach *3, ed. Boshof, S. 252, hier zu den aus Rom erhaltenen Schriften. 
konstruierte Diplom stellt letztlich die beiden Radbod-Urkunden (DKIII. 102 u. DArn. 39) in Frage. Vor allem aber werden Mettlach jetzt sogar seine vermeintlich alten Rechte auf Veranlassung eines Trierer Erzbischofs restituiert. Den historischen Kern dieses Berichts dürften zum einen Handschriften und Texte gebildet haben, die auf die Herkunft Rotwichs, eine Klosterschule sowie einige ihrer Schüler schließen ließen und die der Verfasser der Miracula kannte. Mit den angeordneten Reformen könnte deshalb durchaus die Einführung der lothringischen Klosterreform gemeint sein. ${ }^{740}$ Zum anderen aber bildete die eigentliche Basis für das harmonische Miteinander Rotberts und Rotwichs die Weiheinschrift des Petrusaltars, die damals ganz sicher noch vollständig erhalten war und die die beiden in gemeinsamer Eintracht nennt. Diese Inschrift bietet ein entscheidendes Indiz dafür, daß die zerstörte Mettlacher Peterskirche durch Rotbert und Rotwich wieder aufgebaut wurde. Darauf deutet ebenso die Rückseite des Mettlacher Kreuzreliquiars aus dem beginnenden 13. Jahrhundert hin, in deren oberer Reihe Rotbert mit dem Modell einer Kirche in den Händen dargestellt ist. ${ }^{71}$ Vor allem deshalb und nicht wegen einer Besitzrestitution dürfte Rotbert in Mettlach in positiver Erinnerung geblieben sein.

Als Rotwich - so die Miracula weiter (cap. 12) - durch seine Amtsgeschäfte ermüdet wegen der Beschwerlichkeit des Alters in einem Stuhl umhergetragen werden mußte, sei einem gewissen Hildibold, Abt von Sankt Marien (ad martyres?), die Mettlacher Abtei anvertraut worden. Brüder und Laien schmerzte es aber, zu Lebzeiten des eigenen Abtes von fremder Herrschaft gedrückt zu werden, und sie hätten Hildibold - zurecht verachtet und mit Schande überschüttet - gezwungen, zu seinem Eigentum zurückzukehren. Nach dreiundreißigeinhalb Jahren sei Rotwich gestorben, ebensolange wie Christus

740 Vgl. zum Wirken der lothringischen Klosterreform in Mettlach oben S. 329 u. Anm. 677. - Vgl. zu Ruotger, Rotwich und der Einführung der lothringischen Klosterreform auch RAACH, Mettlach, S. 40-45, 48 f., 58 f. Er weist darauf hin, daß die Miracula das Episkopat Ruotgers völlig übersehen, vielleicht weil zu seiner Zeit für Mettlach nichts Entscheidendes geschah. Dort findet sich ebenfalls (ebd., S. $41 \mathrm{f}$. u. Anm. 23) die Forschungsliteratur zur Benediktinerabtei Clinga, bei der es sich vermutlich um Klingenmünster in der Südpfalz handelt. Vgl. dazu auch Berger, Klingenmünster. - Vgl. zur Mettlacher Klosterschule, ihren Schülern und den Kontakten zu Remigius schon oben S. 282 ff. u. Anm. 528-539. - Vgl. zu Ruotger Goerz, Regesten der Erzbischöfe zu Trier, S. 3. Pokorny, Kanones. Meens, Fragmente. Anton, Trier in der hohen und späten Karolingerzeit, S. 82-85, 99-101, 113. Aspner, Hoch- und spätkarolingische Zeit, S. 279-282. - Eine Vorlage für diese manipulierte Urkunde Ottos I. könnte auch die gefälschte Urkunde Ottos I. von 947 sein (DOI. †86). Mit dieser will Otto auf Bitten des Trierer Erzbischofs Rotbert ein Immunitätsdiplom und Schutzprivileg für die Trierer Kirche ausgestellt haben. Doch dürfte es sich dabei um eine Fälschung aus dem Jahr 1006 handeln. Vgl. dazu Thomas, Ein kaisergleicher König.

741 Vgl. dazu Sauer, Fundatio, Abb. 68. Vgl. ferner nochmals Klewitz, Baugeschichte, S. $84 \mathrm{f}$., mit dessen Datierung des Neubaus ins 10. Jahrhundert dies übereinstimmen würde. Schmal, Mettlach, S. $142 \mathrm{f}$. 
gelebt habe, und von den Brüdern würdevoll begraben worden. ${ }^{742}$ Die Miracula fahren fort (cap. 13), daß Rotwichs Nachfolger Nizzo - ein Schüler Gerberts gerade einmal nach sechs Jahren im Amt aus dem Leben schied. ${ }^{743}$

Auch hier polemisieren die Miracula wieder gegen den Trierer Einfluß in Form des angeblich ,verordneten' neuen Abtes Hildibold. Ob er tatsächlich neben Rotwich amtierte oder man im späteren 11. Jahrhundert nur die Angaben zu mehreren Äbten chronologisch nicht zu deuten verstand, ist schwer zu klären. Bedenkt man die erheblichen Probleme, die der Verfasser selbst bei der Klosterchronologie seines eigenen Jahrhunderts hatte, verwundern etwaige Verwechslungen und Verzerrungen kaum. ${ }^{744}$ Rotwichs und Nizzos Amtsdauer könnte man immerhin ihren Grabsteinen entnommen haben. ${ }^{745}$ Doch weckt bei Rotwich der Vergleich mit Christus' Lebensdaten Zweifel. Gerade Thiofrid verwendete gerne solche Zahlenspiele. ${ }^{746}$ Eine absolute Datierung der Amtszeit

$742 \mathrm{Zu}$ seinem Gedächtnis hätten sie schließlich beschlossen, den Psalm De profundis (Psalm 130 bzw. 129, das Totengebet) immer nach der ersten Stunde zu singen gemeinsam mit dem Psalm Domine, ne in furore (Psalm 6), der nach der Gewohnheit für Bischof Egbert gesungen werde. Vgl. insgesamt Miracula s. Liutwini auct. Monacho Mediolacensi cap. 12, ed. Sauerland, S. 1265: [...] Postquam autem triginta et tres semis annos eundem locum regendo explevit iuxta numerum dierum, quo Christus dominus pro hominibus homo factus in mundo vixit, [...]. Vgl. dazu von BRIEsEn, Urkundliche Geschichte, S. 86. Lager, Urkundliche Geschichte, S. 23. RaAch, Mettlach, S. 45 f., 49. Nach ihm sei Hildibold dem Kloster von Erzbischof Egbert aufgezwungen worden.

743 Vgl. Miracula s. Liutwini auct. Monacho Mediolacensi cap. 13, ed. Sauerland, S. 1265 : Cui Nizo, Gerberti discipulus, sanctitate et sapientie flore preditus, successit, sed heu! nimis matura morte preventus, sex annis peractis discessit. Vgl. dazu LAGER, Urkundliche Geschichte, S. 24 f., der Nithard einfach aus- und einen Gerbert folgen läßt, den er mit Gerbert von Reims verwechselt. RaAch, Mettlach, S. 46 u. Anm. 57 sowie S. 49, 59, geht davon aus, daß Nizzo vom Konvent selbst gewählt wurde.

744 Vgl. Miracula s. Liutwini auct. Monacho Mediolacensi cap. 17-23, ed. SAuerLand, S. 1266 f. Vgl. dazu von Briesen, Urkundliche Geschichte, S. 87, 89. Lager, Urkundliche Geschichte, S. 26-28, der sich sogar durch die Angaben der Miracula verwirren läßt. RaAch, Mettlach, S. 47 f., 52-57, 61 f. Becker, Mettlacher Äbte, S. 51 f., zu den kaum zu rekonstruierenden Äbten dieser Zeit. FLESCH, Monastische Schriftkultur, S. 13 f. Schmal, Mettlach, S. 66-74, geht den Baunachrichten der Miracula aus dieser Zeit zum ,Alten Turm' und damit auch den Äbten nach und weist auf Unstimmigkeiten bei den Angaben zu Nizzo II. und einem Udo hin.

745 Vgl. auch Flesch, Monastische Schriftkultur, S. 41 f., der vermutet, die laut den Miracula von Abt Lioffin (vor/um 993?) auf den Gräbern seiner Vorgänger angebrachten Verse könnten sich paraphrasiert in den Miracula wiederfinden. Flesch vermutet in Lioffin auch den Verfasser der Grabinschriften von Rotwich und Nizzo. Vgl. zu Lioffin auch unten S. 357 u. Anm. 755.

746 Vgl. dazu Lampen, Thiofrid, S. 69 f. - Der für Rotwichs Memoria gesungene Psalm, der neben den für Erzbischof Egbert rückt, zeigt aber schon, wie für den Verfasser der Wundergeschichten inzwischen mehrere Erinnerungsebenen nebeneinander traten und sich nicht mehr problemlos entwirren ließen. Eine weitere dieser Ebenen bildete Nizzos außergewöhnliches und zeichenhaftes Begräbnis (bei der Bestattung war Wasser in das 
Rotwichs und Nizzos ist schon deshalb problematisch. Wenn Nizzo sechs Jahre amtierte und für 985 und 986 - wie gesehen - zeitgenössische Briefe an ihn erhalten sind, kann sein Abbatiat frühestens 980/1 begonnen und spätestens 990/1 geendet haben. Wir befänden uns damit teilweise schon in Egberts Episkopat. ${ }^{747}$ Dann könnte Rotwich - nimmt man die Angabe über $33 \frac{1}{2}$ Jahre dennoch ernst - frühestens 946, ja eher noch später ins Amt gekommen sein. Jedenfalls widerspräche es der in der Forschung bisher üblicherweise angenommenen Datierung von 941 bis 975 bzw. 940/5 bis nach 977, die so nicht gesichert ist. ${ }^{748}$ In Mettlach lag also selbst für Rotwich noch kein chronologisch zuverlässiges Material vor.

Nach den Miracula wurde nun Hezzel Vorsteher (cap. 14), ein unwürdiger, schlechter und ungeeigneter Mann, der unerlaubten Liebschaften nachging. Er habe das oratorium, das der hl. Vater Liutwin zu Ehren der hl. Maria erbaut hätte, auf den Rat gewisser Brüder vollständig abgerissen und begonnen, eine neue Kirche nach dem Beispiel des Klosters St. Maximin zu bauen. Die sei aber unvollendet geblieben, weil er seine Ehre verlor. Die Ratgeber seien durch den Tod bestraft worden. ${ }^{749}$ Bischof Egbert habe Hezzel für seine Verbrechen abund an seiner Stelle einen gewissen Engländer Lioffin eingesetzt (cap. 15). Zu

Grab eingedrungen), das wahrscheinlich die damit verbundene hohe Emotionalität im Gedächtnis hielt. Vgl. dazu die Rolle der Emotionalität der Erinnerung bei FrIED, Geschichte und Gehirn, S. 30, der sie als Faktor „8“ „des eigenen Beteiligt- oder Ergriffenseins" aufführt. Fried, Schleier, S. 50 f., hier ebenfalls Nr. 8.

747 Vgl. zu Nizzo oben Anm. 538. Becker, Mettlacher Äbte, S. 45, 51, datiert Nizzos Amtszeit auf um 980 bis um 986. Vgl. ähnlich RaACH, Mettlach, S. 46 u. Anm. 57. FlesCH, Monastische Schriftkultur, S. 16 u. Anm. 24, weist auf den Echternacher Nekrolog hin, wo sein Todestag zum 18. Oktober eingetragen ist. Man müsse ihn auf das Jahr des letzten Briefes (986) beziehen. BeCKer, Mettlach, S. 538, folgt seinem ersten Urteil. Vgl. zur Handschrift des Echternacher Obituars vom Anfang des 12. Jahrhunderts und dem Eintrag StefFen, Obituar, S. 12-22, 85. Das Obituar wurde wohl unter Abt Gottfried I. (1123-1156) angelegt. Vgl. zu Rotwich die nächste Anm.

748 Die früheren Datierungen basieren auf der ungesicherten Annahme, Rotbert habe 941 eine Dionysiuswallfahrt in Mettlach eingerichtet und dies decke sich zeitlich mit dem Amtsbeginn des Abtes Rotwich. Vgl. dazu von Briesen, Urkundliche Geschichte, S. 86. Lager, Urkundliche Geschichte, S. 23. Vgl. zuletzt zur Pflichtprozession RaAch, Mettlach, S. 42 f. Ebd., S. 46 u. Anm. 56, zur Amtszeit Rotwichs, die der Christusvergleich problematisch mache. Vgl. abweichend dazu Becker, Mettlacher Äbte, S. 45, 51, der auf 940/5 bis nach 977 datiert. FLESCH, Monastische Schriftkultur, S. 13, folgt ihm darin, ebenso BeCKer, Mettlach, S. 538.

749 Vgl. Miracula s. Liutwini auct. Monacho Mediolacensi cap. 14, ed. SAuERLAND, S. 1265: [...] Oratorium itaque a sancto patre Liutwino sancte Marie honori constructum, quorundam fratrum consilio casum minitans, a solo destruxit et ad exemplum monasterii Sancti Maximini aliud edificare cepit; sed imperfectum mansit, eo deiecto ex proprio honore; et vindictam consilii receperunt consiliatores morte. Vgl. dazu VON BRIESEN, Urkundliche Geschichte, S. 86. Lager, Urkundliche Geschichte, S. 24. RaAch, Mettlach, S. 46, 49 f., nimmt an, Hezzel sei vom Trierer Erzbischof ohne Wahl des Konvents eingesetzt worden. 
dessen Zeit blühte die Schule in Mettlach, ebenso die Einhaltung der Regel unter den Mönchen. Er habe die Gräber seiner Vorgänger mit Versen geschmückt und für das Wohlergehen der Brüder gesorgt. Das Häuslein, das Hezzel unvollendet zurückließ, habe er von Grund auf zerstört, dann zur Aachener Pfalz geschickt und nach deren Vorbild einen Turm errichtet, der bis heute stehe. Gemeint ist der ,Alte Turm' von Mettlach. Aber danach sei er angeklagt und von Bischof Egbert abgesetzt worden, schließlich als Verbannter in Echternach gestorben. Hezzel aber habe auf Vermittlung seiner Anhänger die Abtwürde wieder übernommen. Doch habe er, befleckt durch sein früheres Verbrechen, geschlagen und einsam seinen letzten Tag beendet. ${ }^{750}$

Was bedeutete das? Welche Entwicklungen spielten sich plötzlich in Mettlach ab? Wie erklären sich in so kurzer Zeit zwei vollständige Kirchneubauten und zwei Abtsabsetzungen? Da Nizzo noch 986 lebte, müßte all das in den wenigen Jahren bis zu Egberts Tod 993 geschehen sein, wenn denn der Chronologie der Miracula überhaupt zu trauen ist. Während diese zunächst ausschweifend und häufig Liutwin, Radbod, Rotbert und Rotwich in ihrer Darstellung nennen, werden diese unglaublichen und tiefgreifenden Ereignisse gerade einmal in zwei knappen Kapiteln paraphrasiert.

Warum ließ Hezzel ausgerechnet die Marienkirche abreißen, in der sich nach den später folgenden Angaben der Miracula Liutwins Ruhestätte befunden haben soll? Bestand ein Zusammenhang? Bei den Grabungen in Mettlach fand sich tatsächlich „ein Apsisbau mit einer Halbkreisapsis von 12 m Durchmesser etwa. Dieser Apsisbau befand sich als einziger nicht in Achse mit dem späteren ,Alten Turm‘." KLEwitz hält diese vierte sowie letzte Anlage vor dem ,Alten Turm ‘ für Hezzels Projekt. ${ }^{751}$ Deren Dimensionen erinnern in der Tat an den

750 Vgl. Miracula s. Liutwini auct. Monacho Mediolacensi cap. 15, ed. SAUERLAND, S. 1265 : Ecbertus autem, qui pro suis criminibus Heccelem deiecit, Lioffinum quendam Angligenam, artis medicine peritum, eius loco substituit. In cuius temporis spacio scolare exercitium in Mediolacu plurimum vigebat, et regularis discipline observatio inter monachos florebat. Precessorum eciam suorum sepulchra versibus adornavit. Necessaria quoque fratribus, quia rerum exuberantia sibi subpeditavit, copiose ministravit. Domunculam, quam Hezzel imperfectam reliquerat, ab imo eruit, et Aquisgrani palacium mittens et exinde similitudinem sumens, turrim, que adhuc superest, erexit. Sed postea accusatus, a prefato deponitur episcopo et exul moritur Efthernaco. Hezzel autem per quorundam suorum interventum prioris honoris iterum suscepit locum; sed priori crimine maculans vitam, pulsus et privatus meritis diem clausit ultimum. Vgl. dazu von Briesen, Urkundliche Geschichte, S. 86. Lager, Urkundliche Geschichte, S. 24 f. RaAch, Mettlach, S. 46 f. u. Anm. 58 f.; S. 50-52, 59, der unter Lioffin eine Spaltung des Konventes vermutet. Er sei von Egbert ernannt worden. Lioffins Absetzung falle ins Ende von Egberts Amtszeit.

751 Vgl. Klewitz, Freilegungen, S. 299. Nordenfalk, Abbas Leofsinus, S. 61, hält den Bau dagegen für eine Außenkrypta nach St. Maximiner Vorbild. 
beeindruckenden St. Maximiner Neubau des frühen 10. Jahrhunderts. ${ }^{752}$ Die veränderte Ausrichtung gegenüber den drei vorangegangenen Saalkirchen deutet auf ein verändertes Konzept. ${ }^{753}$ Es muß etwas Fundamentales und Einschneidendes in Mettlach geschehen sein, an dem wenigstens ein Teil des Konvents intensiven Anteil hatte. Weshalb sonst sollte es denen, die dazu rieten, den Tod gebracht haben? Nur schemenhaft konnte oder wollte man sich nahezu 100 Jahre später daran überhaupt noch erinnern.

Ebenso radikal beseitigte angeblich Lioffin den von Hezzel begonnenen Neubau und ließ den ,Alten Turm' errichten, der sich gegenüber dem projektierten Vorgänger geradezu winzig ausmachte. Auch bot der Turm architektonisch ein völlig anderes Konzept. Da die Aachener Pfalzkapelle auch eine Marienkirche war, kann er diese durchaus nachgeahmt haben. ${ }^{754}$ Vielleicht interpretierte man das aber erst später in den Bau hinein. Nimmt man den Bezug zu Aachen und dem reichsunmittelbaren Kloster St. Maximin jedoch ernst, orientierten sich beide Bauprojekte an Vorbildern, die letztlich eng mit dem König verbunden waren. Strebten die Mettlacher etwa die Reichsunmittelbarkeit an? Dies entspräche zumindest dem bisherigen Argumentationsmuster der Miracula. Erinnerte man sich gar daran - womöglich auf der Grundlage von DKarol. I 148 -, daß Mettlach einmal Königslehen war? Sichere Antworten gibt es nicht.

Was Hezzel so verabscheuungswürdig und Lioffin so lobenswert machte, entzieht sich unserer Kenntnis, scheint aber auf starke Spannungen im Kloster und mit dem Erzstift hinzuweisen. Lioffins Echternacher Exil wird tatsächlich durch eine Handschrift belegt, die er dort anfertigte. ${ }^{755}$ Verfolgten beide Neu-

752 Vgl. dazu bereits oben S. 267 u. Anm. 489 f. Schmal, Mettlach, S. 66 f., gemahnt beim Vergleich mit St. Maximin zur Vorsicht.

753 Vgl. dazu Klewitz, Freilegungen, S. 299: Ergraben wurden: „1. ein rechteckiger Bau, von dem nur die Ostseite faßbar war. 2. eine kreuzförmige Anlage, einschiffig mit Rechteckchor. 3. ein kleiner Rechteckbau im Osten, der im Erdgeschoß ein niedriges Tonnengewölbe hatte, er dürfte später von einem ottonischen Chor überbaut gewesen sein." Es folgen an vierter Stelle der große Apsisbau, der mit Hezzel verbunden wird, schließlich an fünfter Stelle der ,Alte Turm'.

754 Vgl. zum ,Alten Turm`z. B. Zimmermann, Mettlach, S. 124-132, sowie zuletzt zusammenfassend Schmal, Mettlach, S. 63-178, auch mit der älteren Literatur. Sie ist beim Vergleich mit Aachen vorsichtiger (ebd., S. 66 f.) und geht von einem Baubeginn am Turm unter Lioffin zwischen 977 u. 993 aus (ebd., S. 68). Untermann, Karolingische Architektur als Vorbild, S. 165-173, bes. S. 167. Bauer, Der Alte Turm in Mettlach im Spiegel der Denkmalpflege, S. 165-202, veröffentlicht Skizzen des frühen 19. Jahrhunderts, die den Zustand des Turmes - auch mit heute verlorenem Baubestand - vor seiner Restaurierung durch Eugen von Boch und August von Cohausen zeigen.

755 Vgl. zu Lioffin ausführlicher Nordenfalk, Abbas Leofsinus, S. 49-83, bes. S. 56-65, über das Wirken Lioffins in Echternach. Letztlich führt er den Bau des ,Alten Turms in Mettlach auf einige Lioffin bekannte englische Vorbilder zurück. RAACH, Klosterleben. Flesch, Monastische Schriftkultur, S. 36-43, mit der Zusammenfassung der neueren 
bauten je verschiedene Ziele? Wieso soll Erzbischof Egbert so massiv in die Klosterangelegenheiten eingegriffen haben? Den Verfasser der Miracula, der doch geradezu gebetsmühlenartig Mettlachs Autonomie gegenüber Trier betont, verärgerte das. Richtet sich die vorausgegangene Kritik an Trier vielleicht auch gegen Egbert?

Was wurde bei solch massiven Abrißarbeiten aus den Gräbern in der Kirche? Man konnte sie schwerlich vor Ort belassen haben. Wahrscheinlich stieß man sogar auf Sarkophage, die in Vergessenheit geraten waren und die man nicht mehr zuzuordnen verstand. Man hätte sie zwischenzeitlich in die Peterskirche schaffen können. Bei der Gruftöffnung 1072 in St. Paulin in Trier fand man ja solche Sarkophage, die man nachträglich mit Trierer Märtyrern in Verbindung brachte und das ganze zu einer Legende ausformte. ${ }^{756}$ Wenn eine verehrte Person - wie vielleicht Liutwin - tatsächlich in dieser Kirche ruhte, was wurde inzwischen aus ihr? Auch Milo und vermutlich Lambert wurden in der Marienkirche bestattet, wenn der älteste Bau der Peterskirche frühestens unter dem Einfluß der von Milo in Mettlach als Äbte eingesetzten Trierer Bischöfe Ratbert und Hartham begonnen wurde. ${ }^{757}$ Die starke Milomemoria spricht dafür, daß man Milos Grab sehr wohl kannte. Schließlich ist es kaum denkbar, daß der ,Alte Turm' innerhalb weniger Jahre errichtet wurde. Auch Schmal sieht das so. ${ }^{758}$ Vor allem darf eines im Zusammenhang mit den Neubauten nicht übersehen werden: Ausgerechnet jetzt tauchen in Trier und Mettlach zur Zeit Erzbischof Egberts plötzlich Spuren einer schnell anwachsenden Liutwinverehrung auf, wie die bisher untersuchten Quellen mehr als deutlich belegen. Daß parallel dazu ausgerechnet die Kirche, der bald erstmals Liutwins Grab zugeschrieben wurde, derart großen Veränderungen unterworfen war, läßt sich nur durch einen unmittelbaren und beabsichtigten Zusammenhang erklären: Hier fassen wir den Beginn von Liutwins Kult archäologisch-architektonisch. Man

Forschungsergebnisse. Er hält Lioffin für ein ehemaliges Mitglied des Klosters St. Peter in Gent. Zu Egbert sei er aufgrund seiner medizinischen Fähigkeiten gekommen, der ihn dann zum Mettlacher Abt machte. Becker, Mettlach, S. 521, 538, läßt seine Amtszeit 993, aber erst unter Egberts Nachfolger Liudolf (994-1008) enden. - Eine genaue Berechnung ist an dieser Stelle schwierig.

756 Vgl. dazu zusammenfassend nur Heyen, St. Paulin, S. 96 ff., 308 ff. Heyen, Fälschung und Legende. - Vgl. zum Grab in mittelalterlichen Kirchen auch Scholz, Grab. Zwar zeigen die Beschlüsse zahlreicher Synoden, daß man versuchte, Bestattungen in Kirchen nur Klerikern und Menschen mit herausragendem Lebensstil zu gewähren. Doch ließen sich gerade Eigenkirchenherren dieses Recht offenbar dennoch nicht nehmen. Vor allem die Häufigkeit, mit der solche Beschlüsse von Synoden wiederholt wurden, zeigt, daß man kaum in der Lage war, sie tatsächlich durchzusetzen.

757 Vgl. zum Bau der ersten Peterskirche oben S. 327-329 u. Anm. 670-676.

758 Vgl. insgesamt Schmal, Mettlach, S. 66-74, bes. S. 70-73. Der Turm sei erst unter Nizzo III. zwischen 1063 und 1077 fertiggestellt worden. 
errichtete seine Grabkirche. Das Gedächtnis Liutwins mußte stabilisiert werden. Man schuf einen Gedächtnisort, damit dieser als Gedächtnisstütze wirkte. ${ }^{759}$

Ob der Bau Hezzels schon dafür vorgesehen war oder erst der von Lioffin errichtete ,Alte Turm', ist schwer zu sagen. In jedem Fall sprechen Egberts angedeutete Eingriffe dafür, daß er an den Ereignissen in irgendeiner positiven oder negativen Form beteiligt gewesen sein dürfte oder man ihn beteiligt sehen wollte. In diesen Zusammenhang passen die wenigstens inhaltlich manipulierten Mettlacher Radbod-Urkunden (DKIII. 102 u. DArn. 39), nach denen Liutwin das Kloster an die Trierer Kirche geschenkt haben soll. ${ }^{760}$ War vielleicht Egbert deren spiritus rector? Immerhin wird Egbert auf dem Mettlacher Kreuzreliquiar aus dem frühen 13. Jahrhundert gleich rechts neben dem Bischof Rotbert dargestellt, die sich beide einander zuwenden. Es ist schwierig, vielleicht sogar unmöglich zu klären, von welcher Seite das Geschehen tatsächlich in Gang gesetzt wurde. Die bisherigen Ergebnisse haben allerdings gezeigt, daß Liutwin vor allem die Milomemoria kompensierte, ableitete oder überlagerte und hier der Ursprung der Entwicklung zu suchen sein dürfte. Zudem vermitteln die untersuchten Quellen den Eindruck, daß sowohl Trier wie Mettlach am Beginn des Kultes mitwirkten. So könnten sich durchaus beider Interessen vermischt oder beide Seiten ihre jeweils eigene Deutung dazu herausgearbeitet haben. ${ }^{761}$

Es bleibt in diesem Zusammenhang die Frage, woher die vermeintlichen Gebeine Liutwins stammten. Denkbar wäre: 1. daß im Zuge der ,qualitativen Inversion' der Leichnam Milos in den Liutwins umgedeutet wurde, 2. daß man Liutwingebeine (vielleicht solche, die man bei den Bauarbeiten fand) in Mettlach postulierte und zudem die Milos kannte oder daß 3. die Liutwingebeine ihren Weg aus Trier nach Mettlach fanden und man Milo dort dennoch weiter erinnerte. Für alle drei Modelle gibt es plausible Argumente. Für das dritte spricht aber ganz besonders die in St. Maximin für 952 genannte Liutwinreliquie. ${ }^{762} \mathrm{Daß}$ der St. Maximiner Kalendareintrag aus dem frühen 11. Jahrhundert zum 23. September eben nicht Liutwins Tod - wie die Vita I -, sondern

759 Vgl. zu diesem Prozeß Assmann, Religion und kulturelles Gedächtnis, S. 19.

760 Vgl. dazu oben Kap. D.IV.

761 Vgl. dazu bereits ausführlich die Überlegungen in Kap. D.IX.2. - Man könnte zum einen in Trier versucht haben, Liutwin dafür einzusetzen, Mettlach enger an das Erzstift zu binden. Ebensogut mögen die Mettlacher mit dem Hinweis auf einen bei ihnen bestatteten Erzbischof die Eigenständigkeit ihres Klosters aufgewertet haben wollen. Vielleicht plante Hezzel ja gar nicht, Liutwin, sondern Milo und seinen weiteren in Mettlach bestatteten Familienangehörigen einen großzügigen Neubau zu widmen. Womöglich erregte gerade das Unmut, weil die bekannt gewordenen Reimser Texte nun Hinkmars negatives Milobild vermittelten. Denkbar wäre ebenso ein Streit zwischen Mettlach und dem Erzstift um die Art der Kulteinführung. - Zu Egberts Darstellung auf dem Mettlacher Kreuzreliquiar vgl. SAuer, Fundatio, S. 309 u. Abb. 68.

762 Vgl. dazu oben Kap. D.VI.1. 
dessen depositio in Mettlach memoriert, unterstreicht ebenfalls eine Neubestattung von Liutwingebeinen an diesem Tag im Saarkloster. ${ }^{763}$

Verfolgt man die Miracula weiter, wird der Eindruck gefestigt, daß Liutwins Kult mit dem Bau des ,Alten Turms' seinen Anfang nahm. Denn nun wurde offenbar nach Egberts Tod - Remigius Abt (cap. 16). Und dieser Remigius, der wahrscheinlich aus St. Eucharius kam, soll ja neben zahlreichen anderen Werken einen sermo für das Fest Liutwins verfaßt haben, bei dem es sich - wie gesehen wohl um die Vita Liutwini I handelt. ${ }^{764}$

Es war kein Zufall, daß ausgerechnet jetzt der erste längere Text zu Liutwin entstand, denn dieser diente der Verbreitung des neuen Kultes. Man könnte meinen, die Gebeine seien gerade zur Ehre der Altäre erhoben worden und erhielten sogleich ein liturgisches Werk. Da die Vita I einige nun erklärungsbedürftige Phänomene des Kultes erläutert, dürfte sie tatsächlich mit dem sermo des Remigius übereinstimmen. Alle Angaben der Miracula zu Liutwin aus der Zeit vor Egbert beruhen ebenfalls allein auf der Vita I und sind Projektionen auf deren Basis. Der Verfasser der Miracula, Thiofrid, kannte keine anderen Quellen. Die am Ende der Miracula zusammengestellten Wunderberichte wissen ebenso lediglich von einem Turm als Grabort und nennen als einzigen Mettlacher Abt auffälligerweise Remigius namentlich. ${ }^{765}$ Auch hier reichte die Erinnerung nicht über das späte 10. Jahrhundert zurück. Man konstruierte also just in dieser Zeit mit Liutwin einen heiligen Trierer Bischof, der Mettlach gegründet haben sollte, den es aber in dieser Form niemals gegeben haben

763 Vgl. dazu nochmals oben S. 122, 294, 320 u. Anm. 58, 571, 647-649.

764 Vgl. Miracula s. Liutwini auct. Monacho Mediolacensi cap. 16, ed. Sauerland, S. 1266. Sogar Kaiser Otto III. solle Remigius ein liebliches Gedicht gewidmet haben. Vgl. dazu von Briesen, Urkundliche Geschichte, S. 84 f. Lager, Urkundliche Geschichte, S. 25 f. RAACH, Mettlach, S. 47, 52, 59-61, der Remigius' Amtsbeginn nach dem Tod Egberts annimmt. - Vgl. zur Übereinstimmung des sermo mit der Vita I bereits oben S. 122, 284 f., 316 ff. u. Anm. 52, 534, 631, 635-638. - Vgl. zu Remigius ausführlicher sowie zu seinen weiteren Werken oben S. 283 ff. u. Anm. 530-537, 543.

765 Vgl. dazu Miracula s. Leodowini cap. 3, ed. Perier, S. 177, wo ein Bauer aus Losma genannt wird, der sich an Abt Remigius wendet. Ebd. cap. 7, S. 178: [...], in una fornicum turris fero custos ecclesiae quiescere fecit, [...]. Ebd. cap. 8, identifiziert die Marienkirche mit Liutwins Grabeskirche: Dehinc in ipsa turri locum pausandi per noctem sumpserat. Ebd. cap. 9: [...], \& ad Mediolacum ductus ante altare sanctae Mariae sic irretitus exponitur. Sed meritis ejusdem gloriosae Dei Genitricis, precibusque sancti Luitwini in vespere facta vincula sunt ablata, [...]. Ebd. cap. 10: [...] Sed \& insidiator antiquus, ut pervigiles metu percelleret, illaqueari turris, quae imminebat capiti eorum, strepitum horroris fecit. [...] Ebd. cap. 11: [...] Hunc ergo pia Dei Genitrix proprium fecit honorem, nec passa est, coram se totiens effusam oblivisci fidelium precem: sed pii patris Luitwini precibus admonita \& ipsam se invocantibus ostendens pietatis viscera, in suorum die luminum pristinae eam redintegrando sanitati, ab ea retrusit ministrum principis tenebrarum. 
konnte. Vielleicht benötigte man im Zuge der lothringischen Klosterreform einen wirkmächtigen Heiligen, mit dem sich Mettlach erneuern ließ. ${ }^{766}$

Verfaßte der aus Trier kommende Remigius die Vita I, könnte er das als Auftragsarbeit für Egberts Nachfolger Liudolf (994-1008) getan haben, der Mettlach nahestand. Auffällig ist die Namensähnlichkeit der beiden. ${ }^{767}$ Denn die Vita verknüpft geschickt bestehende Mettlacher Traditionen - wie Milo und die Dionysiuswallfahrt - mit Liutwin, ja führt sie letztlich auf ihn zurück. Die seltsame Nähe der Vita I zu Standpunkten des Trierer Erzstiftes - z. B. Liutwins Schenkung an Trier - erschlösse sich dann, obwohl der Verfasser zu erkennen gibt, in welch engem Verhältnis er zu Mettlach steht. Die Vita versuchte somit, den Mettlachern ihr neues Patrozinium gleichsam schmackhaft zu machen, es in das kulturelle Gedächtnis des Klosters zu integrieren.

Nach der Mitte des 11. Jahrhunderts muß aber eine veränderte Entwicklung dazu Anlaß gegeben haben, sich erneut mit der Geschichte des eigenen Klosters sowie mit Liutwin zu beschäftigen und massiv Position gegen das Erzstift zu beziehen. Der Verfasser der in dieser Zeit entstandenen Miracula stellte dabei nicht die inzwischen gefestigte Rolle Liutwins für Mettlach in Frage, vielmehr trug er die ersten Wundererzählungen zusammen. Liutwin wurde nun ganz im Gegenteil zum Argument für die durch angebliche Privilegien gesicherte Mettlacher Eigenständigkeit. Man wollte nichts mehr davon wissen, daß er das Kloster an Trier schenkte. Vielmehr hätten die Trierer erst aus Anerkennung für Liutwins und Milos herausragendes Verhalten beschlossen, die Mettlacher Äbte zu Trierer Bischöfen zu machen. Diese Bischöfe hätten sich dann aber am Klosterbesitz vergriffen. ${ }^{768}$ Es kann kein Zufall sein, daß ausgerechnet jetzt mit der Güterrolle ein zweites Dokument geschaffen wurde, um den Mettlacher Besitz systematisch aufzunehmen. In die gleiche Richtung deutet, daß Liutwin in deren Traditionsnotizen allmählich gleichwertig neben das eigentlich Trierer Petruspatrozinium rückte und dieses bald sogar überflügelte. Ebenso weist dahin, daß Thiofrid eine überarbeitete Fassung der ersten Liutwin-Vita, die Vita Liutwini II, schrieb. Schließlich deutet auch die sog. Trinkschale des hl. Liutwin, die als Reliquie in Mettlach verehrt wird und deren ältere Inschrift vermutlich in dieser Zeit entstand, darauf hin. ${ }^{769}$ Es ging Mettlach offenbar darum, eindeutig

766 Vgl. Steinruck, Egbert, S. 199 f., der eine besondere Beteiligung Hezzels und Lioffins an der Klosterreform in Mettlach annimmt.

767 Das belegt zumindest Liudolfs Aufenthalt in Mettlach 995 anläßlich der Urkunde Bertas. Er war ein Sachse. Vgl. zu ihm hier nur Goerz, Regesten der Erzbischöfe zu Trier, S. 7. Bienert, Besiedlung Triers, S. 125 f. Bönnen, Trier zwischen dem 10. und dem beginnenden 12. Jahrhundert, S. 211, 220 f. Vgl. dazu bereits oben Kap. D.VIII.2.

768 Vgl. dazu schon RaAch, Mettlach, S. 57, dem diese Tendenz auffiel.

769 Vgl. ähnlich auch Becker, Mettlach, S. 527, 537. Schmal, Mettlach, S. 73. Beide halten diesen Turm für den von Lioffin begonnenen Bau. - Zur Trinkschale, die heute noch in der Mettlacher Pfarrkirche aufbewahrt wird, vgl. Schneider, Trinkschale. Die Schale 
den eigenen Besitz gegen das Trierer Stift mit Hilfe Liutwins zu sichern. Es gab - wie gesehen - nur einen Trierer Bischof dieser Zeit, der den Besitz des Klosters bedroht haben kann: Eberhard I. (1047-1066).

Der Mettlacher Abt Nizzo III. muß gegen ihn aktiv geworden sein. Wahrscheinlich vollendete er deshalb den Turm, der mit der Peterskirche verbunden und von den Vorfahren begonnen worden war, und ließ ihn schließlich mit einem dreifachen Dach abdecken. Auch Schmal erkennt darin den ,Alten Turm'. Und wohl aus diesem Grund legte er persönlich die Fundamente für ein Haus beim Altar der Gottesmutter und stellte dieses schnell und kunstvoll fertig. ${ }^{770}$ Erst Nizzo III. dürfte also die Arbeiten am ,Alten Turm' abgeschlossen und zugleich einen Erweiterungsbau errichtet haben. ${ }^{771}$ Der Liutwinkult war unter ihm in eine neue, entscheidende Phase eingetreten.

\section{c. Ergebnis}

Die Miracula bieten zwar keinerlei Angaben zu Basin, dafür aber um so mehr zu Liutwin. Einige inhaltliche Kriterien sprechen dafür, daß der Text unter Abt Nizzo III. während der letzten Jahre des Episkopats Erzbischof Eberhards I. († 1066) von Thiofrid von Echternach wenigstens begonnen wurde. Thiofrid könnte sogar einmal die Mettlacher Klosterschule besucht haben. Die Quelle

selbst besteht aus Ahornholz. Die ältere Inschrift, wohl aus der zweiten Hälfte des 11 . Jahrhunderts, befindet sich auf einem „einfachen Silberreif in lateinischen Majuskeln auf den ganzen Umkreis verteilt[...]" auf der Unterseite der Schale. In der Mitte des Reifs ist ein Kreuz angebracht. Die Inschrift lautet: + IN HOC VASCULO BEAT[US] LIUDUIN[US] ARCHIEP[ISCOPU]S BIBERE SOLEBAT (ebd., S. 12-14 u. Abb. 2). Die zweite Inschrift aus den frühen Jahren des 16. Jahrhunderts befindet sich auf dem silbervergoldeten Trinkrand der Schale. Der Hauptsatz steht auf der Außen-, der Nebensatz auf der Innenseite: IN · HOC . VASCVLO - BEAT[VS] - LVTWIN[US] - ARCHIEP[ISCOP]VS · TREVI[RENSIS] - BIBE[RE] - SOLEBAT . QVI . FVIT . FVNDATOR · HVIVS · [M]O[NA]STERII (ebd., S. 14 f. u. Abb. 1). Zur Schale vgl. ferner KolL, Wallfahrt, bes. S. 31-34. Koll behandelt auch die weitere Mettlacher Kloster- und Kirchengeschichte bis ins frühe 20. Jahrhundert. Aus dem frühen 16. Jahrhundert stammen zudem zwei Armreliquiare. Zur weiteren Geschichte Mettlachs vgl. auch Conrath, Mettlach. Zimmermann, Mettlach.

770 Vgl. Miracula s. Liutwini auct. Monacho Mediolacensi cap. 23, ed. SAuerLand, S. 1267: Turrim enim sancti Petri basilice inherentem et a prioribus inceptam perfecit et, consummato opere, decenter triplici tecto cooperuit. Domus etiam coram presentia altaris Dei genitricis fundamenta iecit et celeri instantia illam solerter edificando ad perfectum usque perduxit. Pallia miri decoris ad ecclesiasticum emit ornatum et in fonte salis multum laboravit causa honoris loci et utilitatis fratrum.

771 Vgl. dazu ähnlich Schmal, Mettlach, S. 66-74. - Ob es sich bei diesem Bau um einen West- oder Ostanbau handelte, ist schwer zu sagen. Für beides aber gibt es archäologische Nachweise. Vgl. dazu ausführlich ebd., S. 65 u. Anm. 433 sowie S. 72. Vgl. ferner KLewitz, Mettlach, S. 5: „Der Bau, heute der ,Alte Turm' genannt, hat im Westen eine Vorhalle gehabt, zu der er sich mit einem hohen Bogen öffnete. Im Osten war ein Chor angebaut, dessen Gestalt ungewiß ist." 
benutzte die Vita I und den Libellus, wandelte deren Angaben jedoch ab und lokalisierte Liutwins Grab erstmals in der Marienkirche. Die Miracula sind in ihrer Darstellung von erheblichen chronologischen Unstimmigkeiten durchzogen, was ihre Glaubwürdigkeit stark beeinträchtigt. Alle Angaben über Mettlach vor dem Normannenzug nach Trier 882 sind vollständig konstruiert und beruhen auf Rückprojektionen des Liutwinbildes der Vita I. Dieser Befund, die eigenwillige Wundergeschichte über einen Besuch der Hunnen im Kloster sowie eine für die Peterskirche archäologisch nachweisbare Zerstörung lassen deshalb kaum Zweifel an einem Überfall zu.

Die Miracula entfernen sich vom Bild der Vita I, Liutwin habe Mettlach unmittelbar nach seiner Bischofserhebung an St. Peter in Trier übertragen und bestimmt, daß es Leuten der Trierer Erzbischöfe gehöre. Die Miracula betonen vielmehr überdeutlich die Eigenständigkeit des Klosters gegenüber dem Erzstift, die dieses zur Abfassungszeit in Frage gestellt haben muß. Liutwin habe seinen Besitz nämlich an die Mönche des Klosters geschenkt, so der Inhalt des zu Anfang der Miracula wiedergegebenen, aber konstruierten Urkundenregests. Besonders Milo, der dann so positiv hevorgehoben wird, habe sich sehr um Mettlach gesorgt. Er sei eines gerechten Todes gestorben und habe gerade durch sein Verhalten dazu beigetragen, daß die Trierer überhaupt Mettlacher Äbte zu ihren Bischöfen machten. Milos Memoria in Mettlach war also sehr präsent und ungetrübt, wobei diese Ausführungen auch die schweren Vorwürfe des Libellus' gegen Milo unmittelbar aufnehmen und widerlegen wollen. Dazu könnten an dieser Stelle gar die Angaben von DKarol. I 148 etwas abgewandelt eingegangen sein.

Das neue Doppelamt, das schon aufgrund von logischen Brüchen unmöglich ist, soll dem Kloster zunächst zur Ehre gereicht haben, bis es zur Ausbeutung durch die Trierer Bischöfe führte, an deren Ende vor allem Radbod (883-913) steht. Die Vorwürfe, die gegen ihn gerichtet werden, müssen auf den wenigstens inhaltlich manipulierten DKIII. 102 und DArn. 39 beruhen, die einen hl. Trierer Erzbischof Liutwin als Schenker Mettlachs an Trier nennen, auf den sich Radbod in den Urkunden beruft. Die fiktive Reise des Mettlacher "Priors" Erkenbert zum Papst, um Klage gegen Radbod zu führen, zielt in die gleiche Richtung: Erkenbert stützt sich dabei auf inzwischen vermeintlich verlorene Privilegien des Liutwin für Mettlach. Diese Privilegien und das erhaltene Papstschreiben, das König Karl dann veranlaßt, alle Entfremdungen Radbods rückgängig zu machen, sollen die beiden Radbod-Diplome in Frage stellen und aufheben. Als Vorlage für die Erkenbert-Fama könnte der Inhalt eines ähnlich argumentierenden, gefälschten Rechtsprivilegs Papst Agapets II. (946-955) von 950 für St. Maximin gedient haben, das erst im späten 10. Jahrhundert entstand und gegen Bischof Rotberts unrechtmäßige Ansprüche auf St. Maximin polemisiert. 
Der Trierer Vicedominus Wicelin, den der Verfasser der Miracula ebenfalls konstruierte, soll erklären, warum es Trier zu verantworten hat, daß Mettlach bei der Anlage seiner Güterrolle kaum über schriftliche Besitznachweise seiner Frühzeit verfügte. Die Grundlage für das sodann beschriebene positive Wirken Erzbischof Rotberts (931-956) für Mettlach bildete im wesentlichen die damals noch erhaltene Weiheinschrift des Petrusaltars, der im Zuge des Neubaus der Peterskirche konsekriert worden sein dürfte. Der darauf neben Rotbert gelobte Abt Rotwich wird von den Miracula als vorbildlicher Reformator stilisiert, obgleich sich seine Amtszeit nicht einmal sicher bestimmen läßt. Wahrscheinlich aber wußte man von ihm noch durch im Kloster aufbewahrte Handschriften und Dokumente. Die konstruierte Urkunde für Rotwich, die Otto I. angeblich auf Rotberts Bitte für ihn ausstellte, gibt sich als weitreichendes Privileg für Mettlachs Selbständigkeit gegen äußere Eingriffe aller Art und richtet sich erneut gegen die beiden falschen, aber wenigstens inhaltlich manipulierten Radbod-Urkunden. Vielleicht nahm man deshalb die interpolierte Notiz über die Weihe der Kirche in Udern/Oudrenne durch Rotbert auf die Güterrolle auf.

Auch die Amtszeiten von Rotwichs Nachfolgern Nizzo und Hezzel lassen sich nicht genau bestimmen, doch werden Mettlacher Kontakte nach Reims und zu Erzbischof Egbert nun nachweislich faßbar. Egbert soll sowohl Hezzel sowie dessen Nachfolger Lioffin, den Egbert selbst einsetzte, aus dem Amt entfernt haben. Hezzel riß - nach den Miracula - die alte Marienkirche vollständig nieder und begann mit einem großdimensionierten Neubau, der sich archäologisch belegen läßt. Lioffin beseitigte diesen wieder und begann mit den Arbeiten am ,Alten Turm'. Die beiden vermutlich innerhalb von acht Jahren berichteten Ereignisse sind schwer durchschaubar, weisen aber auf Konflikte im Kloster sowie mit Egbert hin. Die massive Liutwinverehrung, die gleichzeitig einsetzte, muß damit unmittelbar zusammenhängen und läßt nur einen Schluß zu: Für Liutwins aufblühenden Kult wurde hier mit dem ,Alten Turm' ein Zentrum geschaffen. Dabei könnten Liutwins Gebeine in Folge einer ,qualitativen Inversion' in denen Milos wiedererkannt worden sein. Doch naheliegender ist, daß andere im Zuge einer Translation gezielt aus Trier herbeigeschafft wurden, womit dann deren depositio in Mettlach einherging, an die z. B. der St. Maximiner Kalendereintrag aus dem frühen 11. Jahrhundert erinnert. Dieser neue Kult diente vermutlich sowohl Trierer wie Mettlacher Interessen.

Die wenigstens inhaltlich manipulierten Radbod-Urkunden DKIII. 102 und DArn. 39 weisen aber darauf hin, daß man Liutwin in Trier benutzte, um Mettlach an das Erzstift zu binden, wie dies auch mit Oeren und St. Maximin versucht wurde. Das gilt sowohl für die Zeit Erzbischof Egberts (977-993) wie die des Episkopats Eberhards (†1066), an dessen Ende die Miracula in Auftrag gegeben wurden. Es läßt sich auch für die Zeit Radbods (883-913) nicht völlig ausschließen. Wenn tatsächlich der zunächst in Reims und dann unter Egbert in 
St. Eucharius tätige Mettlacher Abt Remigius die Liutwin-Vita I verfaßte, so verband er auf geschickte Weise Trierer Ansprüche auf das Kloster mit der in Mettlach bestehenden positiven Lokaltradition zu Milo und der Dionysiuswallfahrt. Egberts Nachfolger Liudolf (994-1008), der dem Saarkloster nahestand, könnte der Auftraggeber gewesen sein. Die Miracula distanzierten sich bald jedoch deutlich vom Vitenbild, postulieren Mettlachs Unabhängigkeit, die ja auf Liutwin zurückgehe, und scheinen massiv um Besitzsicherung gegen äußere Ansprüche bestrebt. Das konnte sich nur gegen Erzbischof Eberhards Klosterpolitik richten. Zweifellos hängt damit ebenso zusammen, daß Nizzo III. zugleich die Arbeiten am ,Alten Turm' beendete, diesen um einen Neubau ergänzte, die Güterrolle in Auftrag gab und bald eine neue Liutwin-Vita (II) anfertigen ließ. Man setzte nun den von Trier als Argument verwendeten Liutwin in eigener Sache ein, emanzipierte sich auf diese Weise vom Beginn des Kultes und überführte diesen in eine neue, zweite Phase.

\section{Die Vita Liutwini II des Thiofrid von Echternach}

Im Auftrag des Mettlacher Abtes Nizzo III. entstand auch die eben erwähnte sog. Vita Liutwini II, die dieser dem Trierer Erzbischof Udo (1066-1078) übersandte. ${ }^{772}$ Diese Vita konnte LAmpen vor längerer Zeit als Werk Thiofrids von Echternach nachweisen. Thiofrid selbst erwähnte in seinen Flores epitaphii Sanctorum, daß er eine solche Vita verfaßt hatte, die an Udo ging. Eine Stilanalyse des Textes brachte letzte Sicherheit. ${ }^{773}$ Winheller schränkte die Abfassungszeit aufgrund der benutzten Quellen weiter auf 1072-1077 (eigentlich nun 1178) ein. ${ }^{774}$ Die älteste erhaltene Fassung findet sich in einer aus Echternach stammenden Handschrift des 12. Jahrhunderts. ${ }^{775}$ Die Vita II war verbreiteter als die Vita I, die ihr als Vorlage diente.

772 Vgl. Thiofrid, Vita Liutwini II, Prologus, ed. Lampen, S. 1: Sacrario Spiritus Sancti, sanctae Trevericae sedis archipraesuli Udoni, eiusdem Spiritus adoptionis filiorum gratia id quod est abbas Nithardus et plantatio Domini ad glorificandum, pusillus grex Mediolacensium fratrum inter filios Dei inaestimabiles divitias supereminentis gloriae Dei.

773 Vgl. Lampen, Thiofrid, S. 7-11. Winheller, Lebensbeschreibungen, S. 96-105. Thiofrid, Vita Liutwini II, ed. Lampen, S. XI-XXXV, hier S. XXVI-XXVIII. Worstirock, Thiofrid, Sp. 804. Schmal, Mettlach, S. 11.

774 Vgl. Winheller, Lebensbeschreibungen, S. 98. Thiofrid habe die Bleitafel von St. Paulin benutzt. Deshalb könne das Werk nicht vor 1072 entstanden sein. Die Bleitafel wurde bei der Öffnung der Paulinusgruft 1072 „wiederentdeckt“. Sie enthielt die Thebäerlegende und war eine bald wieder verschwundene Fälschung. Vgl. dazu HeYEN, St. Paulin, S. $308 \mathrm{ff}$.

775 Vgl. zu den Handschriften Lampen, Thiofrid, S. 7 f. Bei der ältesten Handschrift handelt es sich um Paris, BN, lat. 9738, fol. $33^{\mathrm{r}}-47^{\mathrm{v}}$. Kodizes des 14. und 17. Jahrhunderts 
Thiofrid erweiterte deren Text auf fast das Fünffache, vor allem „mit Anspielungen und Texten der hl. Schrift, der Liturgie [...], der Mythologie [...]. “776 In zahlreichen inhaltlichen Punkten - vor allem der Erzählfolge stimmt Thiofrids Werk mit der Vita I überein. ${ }^{777}$ Darüber hinaus zieht es einige Angaben und Bilder der Miracula s. Liutwini heran und erweitert diese noch, was das höhere Alter der Miracula belegen dürfte. Da sich die Vita II aber an den Trierer Erzbischof Udo wandte, der eine klosterfreundliche Politik verfolgte, fehlt ihr die auffällige Schärfe der Wunderbeschreibungen. ${ }^{778}$

Die Vita II berichtet wieder über Liutwins Eltern Gerwin und Gunza sowie andere Details, die in den Miracula fehlen. ${ }^{779}$ Nur wenig Auffälliges ändert sich gegenüber der ersten Vita. Bereits zu Beginn wird bei der Geburt von Liutwins Sohn nun Milos Name genannt. ${ }^{780}$ Liutwins Herrschaftsbereich bezeichnete Thiofrid jetzt als Dukat der Belgica Gallia, was - wie das Herzogtum totius regni Francorum - Lothringen meint. ${ }^{781}$ Thiofrid machte Liutwins Onkel Basin folgerichtig sogar zum belgicae gallicae metropoleos archiepiscopum ${ }^{782}$ und verwechselte beim Bau der Dionysiuskirche diesen Heiligen - wie gesehen - mit Dionysius dem Areopagiten. ${ }^{783}$ Die Dionysiuswallfahrt fehlt inzwischen. Der verstärkte Liutwinkult muß sie verdrängt haben, sonst wäre Dionysius sicher noch korrekt zuzuordnen gewesen. ${ }^{784}$ Auf dem Bild der Miracula über Mettlachs Frühzeit beruht wohl die Bemerkung, man habe sichere Anzeichen dafür, daß nach Liutwins Tod diesem zehn oder mehr Mettlacher auf den Trierer Bischofsstuhl gefolgt seien. Diese hätten den Nachkommen ein inzwischen verlorenes Privileg hinterlassen, worin bestimmt sei: wer die Leitung jener Abtei erlange, der werde ebenso mit dem Trierer Bischofshut geschmückt. Einzelne

folgen. Vgl. ferner WINHELLER, Lebensbeschreibungen, S. 85. Thiofrid, Vita Liutwini II, ed. Lampen, S. XXX-XXXV.

776 Vgl. Lampen, Thiofrid, S. 9-11, das Zitat S. 10. Winheller, Lebensbeschreibungen, S. 99. Auch will er einen Bischofskatalog und einen Brief Papst Nikolaus' II. (10591061) gekannt haben.

777 Vgl. WinhelLeR, Lebensbeschreibungen, S. 99.

778 Eine Zusammenfassung der Vita findet sich bei Winheller, Lebensbeschreibungen, S. $98-104$. Zu Udo vgl. bereits oben S. 342 u. Anm. 711.

779 Vgl. Thiofrid, Vita Liutwini II cap. 1, ed. Lampen, S. 5-7. Vgl. dazu Winheller, Lebensbeschreibungen, S. $99 \mathrm{f}$.

780 Vgl. Thiofrid, Vita Liutwini II cap. 2, ed. Lampen, S. 7-10, hier S. 8: Ex qua genuit Milonem suum, ut competenti loco lector inveniet, in sancta Treverica sede successorem.

781 Vgl. Thiofrid, Vita Liutwini II cap. 2, ed. Lampen, S. 8: [...] et sub Childiberto rege Franciae ducatum Belgicae Galliae obtinens, [...]. - Vgl. dazu auch oben S. 288, 330 f. u. Anm. 543, 683.

782 Vgl. Thiofrid, Vita Liutwini II cap. 2, ed. Lampen, S. 10.

783 Vgl. Thiofrid, Vita Liutwini II cap. 4, ed. Lampen, S. 13-16, hier S. 14 u. Anm. 15. Vgl. dazu auch oben S. 324 u. Anm. 77, 663.

784 Vgl. dagegen Schmal, Mettlach, S. 17 f. Zur Wallfahrt vgl. auch oben S. 324-326 u. Anm. 664-668. 
Namen fehlen zwar - im Gegensatz zu den Miracula. Doch findet sich dieses Bild noch nicht in der Vita I und im Libellus allein auf Hetti bezogen. ${ }^{785}$ Liutwin überträgt nach Thiofrid jetzt all seinen Besitz bereits an Trier, bevor er selbst als Mönch in sein Kloster eintritt und nicht mehr unmittelbar nach seiner Bischofserhebung. ${ }^{786}$ Damit wird - wie W INHELLER richtig bemerkt - Milo der Möglichkeit beraubt, dieses Erbe zu übernehmen, weshalb ihn der Vater auch im folgenden daran für verlustig erklärt. ${ }^{77}$ Diese so frühe Schenkung soll ebenso dem Bild der Miracula zeitlich vorgreifen, wonach Liutwin seinen Besitz an das Kloster und dessen Mönche übertragen habe. Thiofrid dürfte damit sein eigenes Bild korrigiert haben, weil der neue Adressat dies erforderte.

Die noch gewachsene und herausragendere Rolle Milos in der Vita II ist nicht zu übersehen. Gott habe geschworen, ihn auf Liutwins Stuhl zu setzen. Auf königliche Anordnung hin hätten die Trierer ihn auf die väterliche Kathedra erhoben, damit er, von dem der Vater nicht wollte, daß er sein Erbe werde, nicht auf der Kathedra der Pestilenz sitze. So sei er dem Vater als Bischof gefolgt und habe auf dem Thron der höheren Ehre gesessen. Die Trierer ehrten den Vater im Sohn, der in vielem an den Vater erinnerte, und gingen mit ihm als Anführer nach Reims zum Grab des dort verstorbenen Bischofs Liutwin. Milo sei dabei auch Reimser Bischof geworden. Seine vierzigjährige Amtszeit an beiden Orten stehe für das ebensoviele Tage währende Fasten Christi und symbolisiere eine gewisse Vollendung in den guten Werken. Nach einer Debatte mit den Reimser Bürgern habe man Liutwins Körper schließlich mitgenommen. Dabei fällt Thiofrid sofort der Vergleich zur Rückführung St. Maximins aus Aquitanien und der Paulins aus Phrygien ein. ${ }^{788}$ Wenigstens nach der Maximin-Vita hatte ja

785 Vgl. Thiofrid, Vita Liutwini II cap. 5, ed. Lampen, S. 16-19, hier S. 18: Omnibus circumquaque coenobitis se religiosae conversationis exhibuerunt formam atque praeconii eorum haec certa habemus indicia, quod postquam ad Auctorem suum et antiquam possessionem gloriosissimi patris Liutwini revolavit anima, decem aut plures ex illis cum ingenti inthronizati gloria sibi successerunt in sancta sede Treverica et hoc posteris demiserant privilegium - heu, nunc abolitum - ut qui illius sortiretur abbatiae gubernacula, in ipsa metropoli etiam pontificatus decoraretur infula. - Vgl. dazu oben S. 338, 345-347 u. Anm. 699, $721-723$.

786 Vgl. Thiofrid, Vita Liutwini II cap. 6, ed. Lampen, S. 19-21.

787 Vgl. WinHelLer, Lebensbeschreibungen, S. 102.

788 Vgl. Thiofrid, Vita Liutwini II cap. 16 f., ed. Lampen, S. 37-39: XVI LQuod Treviri Milonem ipsius filium patri subrogaverunt et eo duce corporis eius thesaurum translaturi Remorum civitatem adierunt] Sanato tamen tantis doloris vulnere, infuso sensim oleo laetitiae, mox annuente Domino qui paravit lucernam Christo suo et iuravit de fructu ventris sui ponere super sedem suam Milonem filium eius, de quo supra praelibavimus, regali decreto in paternam sublimaverunt cathedram, ut quem pater dux in ducatus honore et in amplissima rerum temporalium hereditate sibi noluit heredem succedere, ne sederet in cathedra pestilentiae, idem eidem patri suo archiepiscopo in episcopatu succedens, sederet in solio augustioris gloriae. Patrem honorabant in filio, ut dum alter paterno fungeretur officio, alterius memoria altius imprimeretur animo et quia sic oculos, sic ille manus, sic ora ferebat 
schon die Vita I - wie oben herausgearbeitet - die Überführung von Reims nach Trier stilisiert, was man in Mettlach offenbar ahnte oder erkannte. ${ }^{789}$ Schließlich wird die Marienbasilika eindeutig als Liutwins Grabkirche genannt, wohin Milo dessen Leichnam verbracht habe und wo er in einem anmutig geschmückten Sarkophag aufbewahrt werde. ${ }^{790}$

Das Bild Liutwins festigte sich in Thiofrids Vita II aufgrund seines inzwischen ausgebildeten Kultes weiter: alte Mettlacher Traditionen wie die Wallfahrt hatte es verdrängt. Liutwins Sarkophag war allgemein bekannt. Liutwin begann, eine feste Position einzunehmen und sich von seiner ursprünglichen Existenz als ,qualitative Inversion' seines Sohnes Milo zu emanzipieren. Er mußte nicht mehr über Milo vermittelt werden, der ihn im Gegensatz zur Vita I und den Miracula auch nicht mehr unmittelbar beerbt. Vielleicht wollte Thiofrid das scharfe Milobild der Miracula etwas abschwächen. Wenn die Miracula vor allem Milo als wesentlichen Grund dafür nennen, daß die Mettlacher Äbte von den Trierern zu ihren Bischöfen gewählt werden, steht jetzt eine angeblich verschollene Urkunde, die die Äbte berechtige, zugleich Trierer Bischöfe zu werden, an dieser Stelle. Die im Vitentext - im Gegensatz zu den Wunderberichten verschwiegene Kritik an Trier bündelt sich stattdessen in diesem ungeheuren Privileg. Mettlach postulierte somit noch immer seinen Vorrang vor Trier.

Dennoch blieben das herausragende Bild Milos in Mettlach sowie dessen dortige Memoria ungetrübt und präsent. Der Liutwinkult überlagerte und verdrängte beides nicht, was dafür spricht, daß im Kloster noch ein Gedächt-

in vice patris filium dilexerunt illoque strenuo duce civitatem Remorum gloriosissimum egregii antistitis sepulcrum adierunt. I XVII LQuod idem Milo in Remensi quoque urbe suo successit patri et de altercatione utriusque populi super somate antistitis egregii] Deus autem cuius in sui dispositione non fallitur providentia, eius quoque urbis civium adeo in Milonem accendit studia, ut eum non adversum se, sed pro se venisse crederent ac ob patris sui reverentiam et dilectionem intimam communi et laeto consensu omnium sibi etiam archipraesulem inthronizatum cum ingenti gloria praeficerent. Sed quem pater exheredavit ut Dominus, qui dat omnibus affluenter et non improperat, esset eius pars et hereditas, sic, inquam, illum copiosae divinae munificentiae ditavit benignitas. [...] At qualis Christi miles Milo fuerit insignis an segnis non est huius loci ac temporis insinuare litteris, praesertim cum nos pavidos nautas Cyclopum praenavigantes littora, hinc Scylla prima hominis facies utero commissa luporum, hinc exanimet implacata Charybdis, sed hoc ad praesens de illo nosse sufficiat, quod utramque metropolim rexit XL annis, qui numerus abstinentiae dedicatur in ieiunio Salvatoris et significat quandam perfectionem in operibus bonis. [...] ac sicut maximi meriti Maximinum de Aquitania, Pauli passionum pro defensione catholicae fidei socium et nominis participem insignem Paulinum de Phrygia, sic inaestimabilis pretii margaritum, eminentissimi Liutwini corpus, de Francia transtulit.

789 Vgl. dazu oben S. 319 u. Anm. 644.

790 Vgl. Thiofrid, Vita Liutwini II cap. 23, ed. Lampen, S. 44-46, hier S. 44 f.: XXIII [Quod Mediolacenses ei summa occurrerunt devotione et Milo honorifice susceptum summo cum honore in basilica Sanctae Mariae tradidit sepulturael [...], sed in quo iam reconditus enituit thesaurus aeternae sapientiae et multiformis gratiae in sarcophago decenter ornato recondidit. 
nisort in Form eines Grabes existierte, der die Erinnerung an Milo stabilisierte. Das legt erneut nahe, daß Liutwins Gebeine nachträglich von Trier nach Mettlach geschafft wurden. Milos Bild in Mettlach wurde aber wieder eigenständiger und ließ den Milo des DKarol. I 148 endgültig hinter sich. Die Eigenschaften dieses ,alten', adligen Milo, der sich um das Kloster sorgte und es womöglich an Trier brachte, waren längst in Liutwin aufgegangen. Das Bild des ,neuen' Milo hatte inzwischen Hinkmars Vorwürfe adaptiert: die Einsetzung in zwei Bistümer durch Karl Martell sowie die lange Amtszeit. Doch wirkte Milos Ansehen im Saarkloster immer noch stark genug, um dies völlig ins positive Gegenteil umzudeuten: Milo spiegelte jetzt die Attribute des Vaters. Thiofrid entwickelte die Bilder seiner Vorlagen also weiter. Die Trierer Angriffe auf Milo, wie sie der Libellus massiv vorbrachte, wurden allerdings nicht mehr - wie noch in den Miracula - argumentativ richtiggestellt. Thiofrid setzte ihnen vielmehr ein ganz anderes Bild entgegen: die Trierer hätten in Milo nämlich vielfach dessen Vater wiedererkannt und ihn deshalb unterstützt. Die Art, in der Thiofrid die Milomemoria gegenüber Trier mitrug, kann nur einen Grund haben: Thiofrid gehörte einmal dem Mettlacher Konvent an.

Fassen wir zusammen: Die nach 1072 von Thiofrid verfaßte Vita Liutwini II greift sowohl auf die Vita Liutwini I wie auch die Miracula s. Liutwini als Vorlagen zurück. Liutwins Kult konnte sich inzwischen durchsetzen. Deshalb gewinnt sein Bild bei Thiofrid gegenüber dem Milos deutlich an Eigenständigkeit. Milo beerbt seinen vermeintlichen Vater nun nicht mehr direkt, sondern wird aufgrund der dem Vater ähnlichen Eigenschaften vom König sowie den Trierern verehrt und zum Bischof gemacht. Die Vorwürfe Hinkmars werden zwar aufgegriffen, aber in ihr positives Gegenteil umgedeutet. Die Vita II übt keine unmittelbare Kritik an Trier mehr. Sie formuliert vielmehr den Anspruch der Mettlacher Überlegenheit über das Erzstift auf der Grundlage einer konstruierten Urkunde, die den Mettlacher Äbten den Anspruch auf den Trierer Bischofssitz einräume.

\section{Die Redaktion A der Gesta Treverorum aus St. Eucharius}

Die erste Redaktion (A) der Gesta Treverorum, einer umfangreichen Darstellung der Geschichte Triers seit seiner Frühzeit, wurde 1101 im Trierer Kloster St. Eucharius abgeschlossen. ${ }^{791}$ Die Gesta bieten wie der Libellus die Sichtweise des

791 Vgl. dazu ausführlich Thomas, Studien, S. 23-39. Die drei frühesten Handschriften dieser Redaktionsklasse bieten die Darstellung der Trierer Geschichte bis zum Jahr 1101. Die älteste noch erhaltene Handschrift (A1) aus dem frühen 12. Jahrhundert komme aus dem Trierer Kloster St. Eucharius. Eine weitere, inzwischen verschollene noch etwas ältere stammte ebenso von dort. Thomas datiert diese verlorene Handschrift $\left(G^{*}\right)$ auf die 
Trierer Erzstiftes, entwerfen jedoch ein wieder verändertes Bild von Liutwin und Milo. Basin wird nur kurz als Onkel Liutwins und Bruder von dessen Mutter charakterisiert. ${ }^{792}$ Der Libellus nahm Liutwin noch in einem wenige Worte

Zeit zwischen 1072 und die letzten Jahre des 11. Jahrhunderts. A1 habe ihr gegenüber nur noch einige Zusätze vorgenommen. Ebd., S. 139-152, beschäftigt sich Thomas mit dem Publikum der Gesta, in dem er vor allem Laien sieht. Vgl. ferner BönNEN, Trier zwischen dem 10. und dem beginnenden 12. Jahrhundert, S. 231-234. - Zur Edition und dem ältesten noch erhaltenen Kodex vgl. Gesta Treverorum, ed. Wartz, S. $111-260$, bes. S. 123 .

792 Vgl. Gesta Treverorum cap. 24 f., S. 161 f.: [...] - Huic successit Numerianus; cui Basinus; post quem Liutwinus, Basini ex sorore nepos. Hic primo Belgicae Galliae dux, omnia monasteria huius urbis largissimis honoravit donariis et praediis auxit. Postea super fluvium Saroam in proprio suo congregationem monachorum instituit, ubi et ipse monasticae vitae habitum suscepit. Defuncto avunculo suo Basino episcopo successit, electus etiam a Remensibus et Laudunensibus praefuit; in quibus duobus uno die, Deo praestante, sacrorum ordinum consecrationem celebravit. Remis obiit, et a Milone filio et Treberensibus relatus, divino dato indicio, ad Mediolacum sepultus est. Post quem Milo, filius eius, sacerdotali functus est officio apud Trebiros et Remos, primo quidem imitator patris, deinde tirannus effectus est, nichilque in eodem de clericali honore vel vita nisi sola tonsura enituit. Eo enim tempore bella gravia et intestina parricidalia in hac provintia orta sunt, quando Karolus tirannus laicis episcopatus donavit, et episcopos nullam potestatem habere permisit. Cum hoc Karolo Milo supradictus ad bellum profectus est, sola tonsura iam clericus, habitu et moribus inreligiosus laicus, et post victoriam episcopatibus Trebirorum et Remorum ab eodem Karolo donatus est. Cuius infelici tempore de his ecclesiis multa sunt ablata, et res ab episcopiis divisae, domus religiosorum destructae, ecclesiastica disciplina dispertita, adeo ut clerici, sacerdotes, monachi et moniales sine lege ecclesiastica viverent et refugia indebita haberent. Patet huius calamitatis indicium in plurimis Treberensis parrochiae ecclesiis, in quibus singulis singulae fuerant olim congregationes, quae tam a praefato Milone quam ab aliis tirannis, ne dicam episcopis, rebus spoliatae, vix unum presbiterum possunt sustentare, sicut sunt ecclesia sancti Medardi quae sita est prope cellam sancti Eucharii, ecclesia super Saroam quae dicitur Tavena, ecclesia sancti Simphoriani a beato Modowaldo constructa, ecclesia in honore sanctae Crucis iussu beatae Helenae condita, ecclesia sancti Remigii ad litus Mosellae, [ecclesia ad palacium, ecclesia super montem sancti Beati, ecclesia] sancti Stephani extra castrum Andernacum. Forum quoque, quod erat ante portam Mediam constitutum et frequentia comprovincialium satis celebre et famosum, orta inter cives et negotiatores gravi simultate, ex eo loco in Wagasatiam translatum est. Et de his actenus.

25. Zacharias papa beatum Bonifacium, doctrina et operatione clarum, Treberensi et Remensi ecclesiis visitatorem et spiritualium negotiorum provisorem constituit, cum Milo tirannus res utrarumque teneret. Interea Karolus ecclesiarum destructor moritur. De quo nocte quadam revelatum est sancto Eucherio Aurelianensi episcopo, quia esset in inferno inferiori. Qui accito domno Bonifacio, Romanae sedis vicario, aliisque boni testimonii viris, sepulchrum Karoli aperuit. Sublato autem lapide, serpens mirae magnitudinis exivit de sarcophago, corpus autem Karoli non est ibi inventum. In his diebus domnus Zacharias papa audiens fidem et doctrinam domni Bonifacii, constituit eum archiepiscopum Mogontinae ecclesiae. Nam antea Mogontini episcopi et Colonienses suffraganei erant Wormaciensium episcoporum. Milo igitur tirannus, his ita peractis, venationi inserviens, ab apro percussus moritur in villa quae dicitur Arno primo a Treberi miliario, ubi et sepelitur post 40 annos suae tirannicae invasionis. 
umfassenden Einschub, der die Vita I paraphrasierte, in seine umfangreichen Quellenauszüge zu Milo auf, ohne innere Widersprüche zu beseitigen. ${ }^{793}$ In den Gesta erhält Liutwin dagegen einen eigenständigen Platz in deren Chronologie.

Es ist jedoch nicht sicher, ob diese Passage allein auf der Vita I beruht, wie bisher angenommen wurde. ${ }^{794}$ Denn es lassen sich einige Bezüge zu Thiofrids Vita II erkennen: So wird Liutwin als Belgicae Galliae dux bezeichnet. Ebenso tritt Milo nicht als unmittelbarer Erbe des Vaters auf, sondern habe vielmehr nach dessen Tod das bischöfliche Amt bei den Trierern und Reimsern bekleidet. Die Gesta bemerken ferner, Milo sei wenigstens zunächst als imitator des Vaters aufgetreten, was die Vita I so deutlich nicht formulierte. Allerdings weist die Vita II ganz ähnlich darauf hin. Die Gesta verschweigen damit im Gegensatz zum Libellus nicht mehr vollständig das bestehende positive Mettlacher Milobild. Sie heben es aber sogleich auf, indem sie einen baldigen Gesinnungswandel Milos zum Schlechten erkennen. Seine Tyrannei beschreiben sie darauf zwar etwas verkürzt, aber immer noch gemäß dem Libellus und den Reimser Quellen. ${ }^{795}$ Dieser zweite Teil wirkt allerdings angehängt. Denn die Gesta erinnern nun an Milos Einsetzung in die Bistümer Reims und Trier durch Karl Martell sowie an den durch Karl verschuldeten schlechten Zustand der Kirche. Daß Karl dazu Rigobert absetzen mußte, wird jetzt verschwiegen, weil es sonst Liutwins vorbildhaften Mehrfachepiskopat unglaubwürdig gemacht hätte. Während der Libellus lediglich betonte, daß nicht nur Reims, sondern auch Trier unter dem pervasor Milo zu leiden hatte, konkretisieren die Gesta diese Vorwürfe: Sie nennen namentlich mehrere kleinere Kirchen des Trierer Bistums, an denen es einmal klösterliche Gemeinschaften gegeben habe, die von Milo und anderen Tyrannen ihres Besitzes beraubt worden seien. Dann folgen weitere, aus den bekannten Vorlagen übernommene Vorwürfe gegen Milo und Karl, bis der Abschnitt mit Milos Tod durch den Eber und seinem Begräbnis in Ehrang schließt.

Insgesamt dominiert Milo also noch immer die Darstellung gegenüber Liutwin. Offenbar hatte man in Trier mit dem starken positiven Milobild aus Mettlach, das an die Liutwinüberlieferung gekoppelt war, weiterhin erhebliche Schwierigkeiten. Man ignorierte die dazu vorliegenden Texte keineswegs, sondern setzte sich mit ihnen auseinander. Auf diese Weise vermochte Mettlach, über Liutwin indirekt Stellung zu Milo zu beziehen, und beeinflußte damit das Bild, das man sich von ihm in Trier machte. Es mußte sich deshalb zwangsläufig

793 Vgl. dazu bereits oben Kap. D.IX.3.

794 Vgl. dazu Poensgen, Geschichtskonstruktionen, S. 121 u. Anm. 4.

$795 \mathrm{Ob}$ diese Gesta direkt aus dem Libellus, einer etwas überarbeiteten Version oder einer weiteren, beiden Texten gemeinsamen Quelle übernommen wurden, sei einmal dahingestellt. Vgl. dazu Thomas, Studien, S. 75-90. Poensgen, Geschichtskonstruktionen, S. 120-135. Kölzer, Studien, S. 252. Werner, Anfänge, S. 23. 
verändern. Die Gesta stellen die eigentlich widersprüchlichen Mettlacher und Trierer Sichtweisen nebeneinander und versuchen, sie einander anzupassen, um zu einem überzeugenden neuen Bild zu gelangen. So wird die Wahrhaftigkeit der verwendeten Texte grundsätzlich nicht in Frage gestellt und dennoch der eigenen Wahrheit in der Sache Geltung verschafft.

Auch der von Mettlacher Seite formulierte Anspruch für die eigenen Äbte auf das Trierer Bischofsamt, den die Miracula erstmals erwähnen und dabei auf Milo zurückführen, den die Vita II jedoch mit Liutwin selbst begründet, blieb im Erzstift nicht folgenlos. Während der Libellus eine solche Doppelfunktion wohl auf der Basis von DLoI. 67 nur für Hetti nennt und dies als Anspruch gegenüber Mettlach versteht, kennt die Redaktion A der Gesta schon drei Mettlacher Äbte, die später Trierer Bischöfe werden: Hetti, Bertolf und dessen Nachfolger Radbod. ${ }^{796}$ Hinter Radbod dürfte dabei wieder der Einfluß von DKIII. 102 und DArn. 39 stehen. Die Redaktion B der Gesta von 1132 ergänzt noch Hettis Vorgänger Wizzo. ${ }^{797}$ Damit werden jeweils nur die in den „Mettlacher Urkunden" erwähnten Trierer Erzbischöfe und ihre unmittelbaren Amtsvorgänger als Äbte des Klosters genannt. Das entspricht zwar nicht den Namen der Miracula sowie den ,zehn oder mehr“ Bischöfen der Vita II. Dennoch scheint dieses Mettlacher Bild aufgrund der verstärkten Liutwinverehrung auch in Trier an Einfluß gewonnen zu haben. Daß es sich einmal anders verhielt und Trierer Bischöfe tatsächlich als Äbte für Mettlach bestellt wurden, das hätte man im Erzstift an DKarol. I 148 noch nachvollziehen können. Wahrscheinlich aber ließ ausgerechnet der darin erwähnte Milo, der diesen umgekehrten Weg begründete, dieses Argument wegen seines Imageverlusts nicht mehr zu.

Zusammenfassend ist festzustellen, daß Liutwin unter Kenntnis der Vita Liutwini II sowie der Miracula in die bis 1101 in Trier verfaßte Redaktion A der Gesta Treverorum aufgenommen wurde. Mettlach nutzte über den im Erzstift geschätzten Liutwin die Gelegenheit, das eigene positive Milobild in Trier zu verbreiten. Die Gesta nehmen es zur Kenntnis und versuchen, dieses wiederum mit dem negativen Trierer Bild so zu verbinden, daß der Trierer Wahrheit Geltung verschafft wird. Dabei beansprucht Milo erneut mehr Raum als Liut-

796 Vgl. dazu Gesta Treverorum cap. 25, ed. Waitz, S. 163, Z. 17 f., sowie S. 164, Z. 4 f.: Post Fortunatum Trebirorum ecclesiae Hetti praefuit, abbas Mediolacensis. [...] Dicunt eum aliqui res ecclesiarum sancti Eucharii et sancti Liutwini principibus suis in beneficium tradidisse. Die letzte Bemerkung spiegelt noch die Kenntnis der Lothar-Urkunde. Ebd. cap. 27, S. 165, Z. 6 f.: Anno dominicae incarnationis 868. Bertolfus abbas Mediolacensis fit episcopus Treberis, [...]. Ebd. cap. 28, S. 167, Z. 21 f.: Cui [Bertolf] successit Radbodus, abbas de Mediolaco, venerabilis antistes, [...].

797 Vgl. Gesta Treverorum cap. 25, ed. Wartz, S. 163, Anm. **: [...]; deinde Wazzo qui ambo, alter alteri succedens, abbates extiterunt Mediolacensis coenobii; [...]. 
win. Der von Mettlach ebenso formulierte Anspruch für die eigenen Äbte auf den Trierer Bischofsstuhl geht somit in Teilen in die Gesta ein.

\section{Ergebnis}

Kurz nach dem Episkopat Egberts (977-993) in Trier, währenddessen sich plötzlich immer mehr Belege für einen hl. Trierer Bischof namens Liutwin finden, entstand der erste längere Text, der sich diesen Liutwin zum Thema wählte. Abt Remigius von Mettlach widmete ihm am Ende des 10. Jahrhunderts einen sermo, der mit der Vita Liutwini I identisch ist. Erzbischof Liudolf (9941008) dürfte ihn in Auftrag gegeben haben, der wie sein Vorgänger Egbert enge Kontakte zu Mettlach pflegte. Erst etwa 50 Jahre später wird Liutwin dann wieder im Libellus de rebus Treverensibus unter Erzbischof Eberhard (10471066) aufgegriffen. Der Bischof wollte u.a. mit Liutwin seine auch gegen Mettlach gerichtete Klosterpolitik legitimieren. Mettlach reagierte umgehend. Abt Nizzo III. (ab/nach ca. 1063-1095) gab noch vor Eberhards Tod 1066 die Miracula s. Liutwini bei Thiofrid von Echternach (†1110) in Auftrag, um die eigene Position klarzustellen. Die scharfen Vorwürfe der Miracula gegen das Trierer Erzstift fehlen dann in der Vita Liutwini II, die Thiofrid zwischen 1072 und 1078 für den klosterfreundlichen Erzbischof Udo (1066-1078) ebenfalls in Nizzos III. Auftrag verfaßte. Vielleicht wollte man die Wogen etwas glätten. Die um 1101 in Trier abgeschlossene Redaktion A der Gesta Treverorum versucht schließlich, die Mettlacher und Trierer Position einander anzunähern.

Wie die Vita I selbst zugibt, lagen weder in Trier noch in Mettlach genauere Informationen zu Liutwin vor. Anhand der Miracula läßt sich sogar zeigen, daß man in Mettlach im Grunde nichts mehr über die Zeit vor dem frühen 10. Jahrhundert wußte. Alles deutet deshalb auf eine Zerstörung wenigstens eines Teils des Klosters während des Normannensturms 882 hin. Ihr geringes Wissen über das 10. Jahrhundert schöpfen die Miracula aus den Handschriften, Dokumenten und Inschriften, die seitdem im Kloster entstanden. Dieses Material ermöglicht allerdings keine verläßlichen Schlüsse und gibt nur Hinweise auf die Namen einiger Mettlacher Äbte sowie die Länge ihrer vermutlichen Amtszeiten. Der Petersaltar, auf dem man noch von seiner Weihe durch Erzbischof Rotbert (931-956) und Abt Rotwich lesen konnte, belegt immerhin den Neubau der zerstörten Peterskirche unter den beiden.

Um so überraschender ist der umfangreiche Bericht der Vita I., mit dem sie Liutwin anhand hagiographischer Vorbilder erst erschuf: als lothringischen Herzog, Gründer Mettlachs, Neffen und Nachfolger Basins sowie Überträger Mettlachs an St. Peter in Trier. Unübersehbar hängt dabei Liutwins Bild mit dem seines vermeintlichen Sohnes Milo zusammen, das man sich so erst im ausgehenden 10. Jahrhundert machen konnte, nachdem man in Trier und 
Mettlach die Reimser Texte rezipiert hatte, die von Hinkmars negativem Milobild bestimmt wurden. Milo wurde nun auch in Trier als Okkupant des Reimser und Trierer Bistums zur Kenntnis genommen. Folgt man jedoch der ursprünglichen, nicht interpolierten Version des zeitgenössischen DKarol. I 148, war Milo einmal als Adliger oder niederer Kleriker mit Mettlach belehnt worden. Er sorgte sich um diesen Ort, bestellte Trierer Bischöfe dort zu Äbten, wollte das Kloster auf diese Weise womöglich auch an Trier übertragen sehen und wurde in Mettlach begraben. Alle diese negativen und positiven Attribute Milos finden sich nämlich verbunden miteinander als nun durchgängig positive Eigenschaften im Bild Liutwins wieder. In Form einer ,qualitativen Inversion wurde dieses Bild geradezu aus Milo heraus konstruiert. So sorgt sich Liutwin jetzt um Mettlach und soll es sogar errichtet haben. Liutwin überträgt das Kloster an Trier und bekleidet anschließend die Bistümer von Trier, Reims und Laon gemeinsam als fürsorglicher Hirte. Als schon Verstorbener signalisiert er noch zeichenhaft, daß er sich wünsche, im Kloster begraben zu werden. Um Bischof Liutwins konstruiertes Wirken als Gründer und Schenker Mettlachs an Trier abzusichern, wird er dann gleichsam genealogisch eingeklammert: zwischen seinem vermeintlichen Onkel und Vorgänger Basin sowie seinem Sohn und Nachfolger Milo.

Insgesamt scheinen bei der Projektion Milos auf Liutwin Trierer und Mettlacher Interessen ineinandergespielt zu haben. So ließ sich der unkanonische Doppelepiskopat Milos in Liutwin, vermehrt um ein weiteres Bistum, als Argument für die Trierer Primatsansprüche in der Belgica und Gallia retten. Deshalb wird Liutwin Herzog Lothringens. Doch gibt die Vita I das positive Milobild nicht ganz auf, das in Mettlach noch vorhanden war, sich wahrscheinlich wegen Milos Grab dort erhielt und vielleicht auch DKarol. I 148 reflektierte. Dieser Milo der Vita bringt den in Reims verstorbenen Vater zurück nach Trier, beerbt ihn in Besitz und Ämtern und wandelt sich erst dann zum Schlechten. Die Reimser Texte sehen das ganz anders. Die in Mettlach vorzufindenden lokalen Gegebenheiten - wie die vorhandenen Kirchbauten (St. Marien und St. Peter) sowie die Dionysiuswallfahrt - führt die Vita I jetzt alle auf Liutwin zurück. Der Heilige wird Mettlach förmlich übergestülpt. Tatsächlich entstand die Marienkirche als erster Sakralbau. Die Peterskirche kam wohl später unter den Trierer Bischöfen Ratbert und Hartham hinzu, die Milo als Äbte nach Mettlach entsandte, vielleicht sogar erst unter Weomad. Dionysius muß aber schon sehr früh in Mettlach verehrt worden sein. Darauf deutet die Wallfahrt, darauf deuten aber auch die engen Kontakte Milos und seiner weiteren Verwandten zum Kloster St-Denis hin, ebenso der einstige Rechtszustand Mettlachs als karolingisches Lehen.

Der Liutwin der Vita hat also niemals existiert, doch sollte dieser Text seinen gerade auflebenden Kult verbreiten. In Mettlach schuf man ihm dazu erstmals ein Zentrum: am Ort der alten Marienkirche. Nebulöse Angaben der Miracula 
weisen auf einschneidende Ereignisse im Kloster vermutlich während Egberts Episkopat hin. Gleich zweimal in kurzer Zeit sei die Marienkirche vollständig abgerissen worden, um Neubauten Platz zu schaffen. Ein angeblich von Abt Hezzel nur begonnener Bau, der sich an St. Maximin orientiert haben soll, konnte archäologisch nachgewiesen werden. Er wich von der Ausrichtung der Vorgängerkirchen deutlich ab und verfügte über eine Apsis von $12 \mathrm{~m}$ Durchmesser. Der ,Alte Turm', den Abt Lioffin gebaut oder begonnen haben soll, fand bald an dessen Stelle seinen Platz. Es handelt sich um einen Zentralbau, der wieder wesentlich kleiner ausfiel. Spätestens dieser Turm muß als Grabkirche Liutwins konzipiert gewesen sein. Egbert, der beide Äbte abgesetzt haben soll, scheint an all dem nicht unbeteiligt. Mit diesem Kirchenneubau verfügte man jetzt über einen Erinnerungsort, der als Gedächtnisstütze an Liutwin diente. Kult, Turm und Vita entstanden beinahe zeitgleich. Wie genau man zu den notwendigen Liutwinreliquien kam, bleibt im Dunkel der Trierer und Mettlacher Interessen verborgen. Vielleicht wurde Milos Grab in das Liutwins umgedeutet, vielleicht auch fanden sich weitere Gebeine neben denen Milos. Die meisten Indizien sprechen jedoch dafür, daß man solche Gebeine jetzt aus Trier herbeischaffte. Die in der Vita I geschilderte Translation Liutwins von Trier nach Mettlach und die in St. Maximin womöglich schon 952 verehrte Liutwinreliquie deuten darauf hin. Wenn in einem St. Maximiner Kalender des frühen 11. Jahrhunderts schließlich die depositio Liutwins in Mettlach zum 23. September erinnert wird, während die Vita I dieses Datum als Liutwins Todestag in Reims nennt, ist dies nur ein weiterer Hinweis.

Die miteinander verwobenen Bilder Liutwins, Basins und Milos begannen nun, intensiver weiterzuwirken und sich $\mathrm{zu}$ wandeln. Der Trierer Libellus übernimmt zwar das Bild Liutwins und Basins aus der Vita I, nennt beide aber nur in einem kurzen, erläuternden Einschub zu Milo, was wieder dafür spricht, daß Liutwin aus seinem vermeintlichen Sohn hergeleitet wurde. Milo steht dagegen im Zentrum und wird gemäß der Vorlage der Reimser Quellen in den dunkelsten Farben geschildert. Er beerbt seinen Vater nicht mehr wie in der Vita, sondern erhält seine Ämter von Karl Martell, der zuvor Bischof Rigobert in Reims absetzte. Doch nicht nur Reims leidet. Nach dem Libellus schädigt der pervasor auch Trier schwer. Schließlich stirbt Milo auf der Jagd durch einen Eber und wird in Ehrang bestattet. Daß der Reimser Bischof Rigobert eigentlich Liutwins vorausgehendes Reimser Episkopat unglaubwürdig machte, übersah der Verfasser, wie er ohnedies viele Widersprüche nicht auflöste, die durch das Verbinden der verwendeten Vorlagen entstanden. Die massiven Vorwürfe gegen Milo meinten ganz offenbar Mettlach mit seiner Milomemoria und sollten sein dortiges Grab in Frage stellen, ja dislozieren. Wahrscheinlich sah Erzbischof Eberhard (1047-1066) seine Primatsansprüche durch Milo bedroht, die er erneut auch gegenüber Reims betonte. Triers selbstbewußte Position dem Kloster gegenüber wird deutlich, wenn der Libellus bemerkt, Hetti sei dort 
zunächst Abt gewesen, bevor er Trierer Erzbischof wurde. Dies dürfte man aus DLoI. 67 geschöpft haben.

Wie sehr dieser Trierer Angriff Mettlach traf, zeigen die Miracula. Ihr Verfasser Thiofrid verwandte den Libellus sowie die Vita I und veränderte die Bilder Liutwins sowie Milos weiter, indem er die Vorwürfe aufgriff und ins Gegenteil kehrte. Liutwin schenkt demnach seinen Besitz gar nicht an Trier, sondern an Mettlach sowie die dortigen Mönche und stattet das Kloster mit Privilegien aus. Milo übernimmt das Erbe des Vaters in Würde und erweist sich als Wohltäter des Klosters. Der Tod durch den Eber besage deshalb gar nichts über Milo. Milo befinde sich vielmehr in der ewigen Glückseligkeit, weil er gerecht war. Hier reagieren die Miracula also direkt auf den Libellus. Letztlich veranlaßt Milo damit die Trierer, längerfristig Mettlacher Äbte zu ihren Bischöfen zu machen. Trier hat also keinen Anspruch auf Mettlach und verneigt sich vielmehr durch diese Geste vor Liutwin sowie Milo und damit vor dem Kloster. Dennoch entfremden und schädigen die Trierer Bischöfe bald den Klosterbesitz, indem sie ihn für Trier nutzen. Der Verfasser der Miracula betonte dagegen Mettlachs Eigenständig- und Unabhängigkeit. Deshalb stellte er auch die Glaubwürdigkeit der beiden wenigstens inhaltlich, wenn nicht sogar vollständig in Trier manipulierten Urkunden für Erzbischof Radbod (DKIII. $102 \mathrm{u}$. DArn. 39) in Frage, die berichten, daß ein Trierer Erzbischof Liutwin das Kloster an Trier schenkte. Thiofrid malte nun seinerseits ein düsteres Bild Radbods, wie er Mettlach noch schlimmer ausbeutet als seine Vorgänger. Ebenso konstruierte er Dokumente des Papstes, Karls des Dicken (876-888) und Ottos des Großen (936-973), die alle den Mettlacher Besitz gegen Fremdeinfluß schützen sollten, auch gegen den der Bischöfe. Die Kritik an Radbod meinte vor allem Eberhard. Wohl wegen ihm begann in Mettlach eine neue Phase der Liutwinverehrung. Jetzt unter Abt Nizzo III. (ab/nach ca. 1063) wurde der ,Alte Turm' vollendet sowie zugleich weiter ergänzt, und jetzt begann man damit, den Klosterbesitz auf der Güterrolle aufzuzeichnen, den das Erzstift bedrohte. Für die nur wenigen noch erhaltenen urbarialen Vorlagen machte Thiofrid Trier verantwortlich und erfand dessen vicedominus Wicelin, der das alte Güterverzeichnis einst dem Feuer übergeben habe.

$\mathrm{Zu}$ dieser zweiten Phase des Kultes gehörte ebenfalls eine neue und umfangreichere Vita, die Thiofrid anhand der älteren ausschrieb und veränderte. Liutwins Bild wurde darin eigenständiger und unabhängiger von Milo. Die Vorwürfe gegen Trier erübrigten sich, denn dort amtierte inzwischen der klosterfreundliche Erzbischof Udo (1066-1078). Liutwin gibt Mettlach in der Vita II nun bereits vor seinem Klostereintritt an Trier, was wiederum das Bild der Miracula relativieren sollte. Milo beerbt seinen Vater Liutwin deshalb nicht, sondern wird von den Trierern auf königliche Anordnung hin zum Bischof erhoben. Die Trierer verehren Milo als Spiegelbild seines Vaters. Die Vorwürfe Hinkmars gegen Milo werden deshalb in ihr positives Gegenbild verkehrt. Wie 
Mettlach seine Position gegenüber dem Erzstift aber sah, wird an einer angeblich verschollenen Urkunde deutlich, wonach die Äbte des Klosters Anspruch auf die Trierer Bischofskathedra hatten. Mindestens zehn Mettlacher Äbte, die Trierer Bischöfe wurden, hätte das Kloster nämlich hinterlassen.

Die Trierer Gesta Treverorum verwenden den Libellus und die Vita II. Sie versuchen, die Bilder der beiden lokalen Traditionen einander anzunähern und Unstimmigkeiten auszulassen. Dabei nimmt Milo wieder mehr Raum ein als sein vermeintlicher Vater Liutwin. Das positive Mettlacher Bild Milos wird in Trier zwar nicht mehr ignoriert, doch habe dieser bald den Pfad der Tugend verlassen. Auch der Anspruch der Mettlacher Äbte auf den Trierer Bischofsstuhl wird nun für Wizzo, Hetti, Bertolf und Radbod aufgegriffen, die beiden Bischöfe der „Mettlacher Urkunden“ (DLoI. 67, DKIII. 102 u. DArn. 39) sowie ihre jeweiligen Vorgänger im Amt.

Insgesamt also wandelten sich die Bilder Liutwins und Milos seit der Vita I im Zeitraum von etwas mehr als hundert Jahren erheblich durch die unterschiedlichen Interessen Mettlachs und Triers. Die Bilder reagierten jeweils aufeinander und entwickelten dabei immer komplexere Formen. Während Liutwin zunächst als ,qualitative Inversion' Milos entstand, begann er dann, zunehmende Eigenständigkeit zu gewinnen. Bei Milo konkurrierten sein positives Mettlacher mit dem negativen Trierer Bild, das sich vor allem auf die Reimser Texte berief. Beide Bilder übernahmen dabei zunehmend Elemente der opponierenden Seite und integrierten sie. Nur das Bild Basins blieb konstant, denn er interessierte lediglich in seiner Rolle als Onkel Liutwins.

\section{Zusammenfassung}

Am Ende dieses Kapitels zu Liutwin und Basin stehen ganz andere Bilder als diejenigen, die die Vita Liutwini I von den beiden zeichnet und die die Forschung bisher in weiten Teilen übernommen hat. Das kohärent erscheinende Gesamtbild von einem Bischof Liutwin läßt sich nicht mehr halten, nach dem dieser einmal Mettlach gründete, es an Trier schenkte, später Trierer Bischof wurde und schließlich in seinem Kloster sein Grab fand. Gleiches gilt für seinen vermeintlichen Onkel Basin und Liutwins Sohn Milo. Dieses große Bild zerfällt in zahlreiche Einzelbilder, die Liutwin und Basin aus verschiedenen Motivationen heraus aufgenommen haben. Einen solchen Liutwin gab es niemals, sondern nur einen Liutwin unterschiedlicher Einzelinteressen. Keine einzige zeitgenössische Quelle hat sich erhalten, die ein sicheres Zeugnis für ihn bietet. Basin dagegen läßt sich als historische Gestalt belegen. Im folgenden sollen nochmals die zentralen Erkenntnisse zu Liutwin, Basin sowie zu den über sie berichtenden Quellen in ihren wesentlichen Zügen zusammengefaßt und die Genese ihrer Bilder dabei nachvollzogen werden. 
Es hat sich bestätigt, daß der Normannenüberfall von 882 für das hier behandelte genuin Trierer Thema tatsächlich eine Zäsur darstellt. Denn eine große Zahl der Schriftzeugnisse vor diesem Ereignis ging in diesem Raum verloren. Für Trier sind bis heute gerade einmal zwei Originalurkunden (von 816 und 842) erhalten geblieben, die wohl deshalb bei späteren Fälschungen als Vorlage aus der Frühzeit eine zentrale Rolle spielten (BM² 626 u. DLoI. 67). Weitere Texte zur eigenen Geschichte mußte man überwiegend in auswärtigen Bibliotheken und Handschriften wieder zusammensuchen. Auch das Kloster Mettlach wurde von den Normannen heimgesucht und wenigstens dessen Peterskirche zerstört. Für die Zeit davor sind alle in Mettlach aufbewahrten Schriftquellen, darunter ein anzunehmendes Güterverzeichnis, verloren. Geblieben sind nur Legenden, die sich aber erst aufgrund späterer Bilder erklären lassen.

So kann man für das 8. Jahrhundert im Trierer Raum nur auf wenige, fragmentarische Zeugnisse zurückgreifen, die noch dazu von späteren Bildern oft massiv verformt und überlagert worden sind, weil sie für die Rekonstruktion der verlorenen Vergangenheit oft intensiv beansprucht wurden. Prüft man also die erhaltenen Quellen zu Liutwin und Basin chronologisch fortschreitend, stellt man fest, daß sich ein Bischof Basin im Kalender des hl. Willibrord von Utrecht bzw. Echternach (†739) als zeitgenössischer Nachtrag belegen läßt. Auch im rekonstruierten „Ur-Testament“ einer Nonne (oder Adligen) Irmina für Echternach (Wampach I 2, Nr. 4 + 2. Teil von Nr. 6) vom 1. Dezember 697/8 unterschrieb er als Zeuge. Einen Bischof Liutwin sucht man allerdings vergeblich. Allenfalls ein presbiter mit diesem Namen läßt sich für diesen Raum in dieser Zeit nachweisen. Die heute bekannten sog. Irmina-Urkunden, die einen Bischof Liutwin erwähnen, sind in dieser Form Fälschungen, die aufgrund anderer Bilder und Traditionen erst im 12. Jahrhundert entstanden. Auch die vermeintliche Liutwin-Urkunde über Stain/Etain für St. Eucharius (MRUB I 7a) von 706 ist inhaltlich eng mit diesen späteren Irmina-Fälschungen verbunden.

Die Nonne (oder Adlige) Irmina, die in ihrem „Ur-Testament“ einen Teil Echternachs mit weiterem Besitz an das dortige Kloster unter Willibrord schenkt, wird nämlich erst in der Vita sanctae Irminae mit einer gleichnamigen Oerener Äbtissin durch eine Analogiebildung zu einer Person verbunden. Der spätere Abt von Echternach, Thiofrid (1083-1110), verfaßte den Text spätestens 1066 im Auftrag der Oerener Nonnen. Eine hl. virgo Irmina taucht in Trier erst seit dem ausgehenden 10. Jahrhundert in Litaneien auf und ist vorher unbekannt. Ja, für Oeren ist als zentrale Heilige zunächst nur eine virgo Modesta belegt. Willibrord gedenkt in seinem Kalendar überhaupt keiner Irmina, sondern nur einer (Oerener?) Äbtissin Anastasia. Die Oerener Irmina soll nach ihrer Vita Tochter König Dagoberts I. (†638/9) gewesen sein und dieses Trierer Kloster gegründet haben. Die Echternacher Irmina wirkte jedoch erst 60 Jahre danach. Thiofrid mißverstand also die Bilder seiner Quellen gründlich. 
Die wenigen anderen frühen Quellen helfen nicht weiter: Die beiden Maximin-Viten aus dem ausgehenden 8. und frühen 9. Jahrhundert wissen weder etwas über Liutwin noch über Basin. Dafür bieten sie undeutliche Angaben über einen (Trierer?) Bischof Hildulf im frühen 8. Jahrhundert, der sich ebenso durch Willibrords Kalendar belegen läßt. Der echte Kern des Mettlacher Diploms DKarol. I 148 (ca. 782), in das Liutwin jedoch frühestens im späten 10. Jahrhundert interpoliert wurde, enthält dagegen die Namen anderer Trierer Bischöfe: Ratbert und Hartham.

Überhaupt bietet die zeitnahe Überlieferung zu Mettlach keine Hinweise auf einen Gründerbischof Liutwin oder einen einzelnen Schenker des Klosters an Trier. Folgt man dem glaubwürdigen Kern von DKarol. I 148 und dem im Original erhaltenen DLoI. 67 von 842, wurde Mettlach von mehreren Vorfahren Herzog Widos von Spoleto (842-ca. 859) unter (König?) Pippin III. (ab 741 Hausmeier, König 751-768) an Trier übertragen. In jedem Fall deutet alles auf massive Interessen der Sippe Widos am Kloster, ja auf ein Familienkloster hin, das sich unter dem mundiburdium der Karolinger befunden haben dürfte. Verschieden verstandene Besitzansprüche lösten in der Familie wohl auch Streitereien aus.

Die beiden auf 884 und 888 datierenden, für den Trierer Erzbischof Radbod (883-915) ausgestellten Urkunden über Mettlach (DKIII. 102 u. DArn. 39) wurden im späten 10. oder frühen 11. Jahrhundert in Trier manipuliert. Nicht völlig ausschließen läßt sich allerdings, daß womöglich schon Radbod selbst das darin erscheinende Bild eines als beatus bezeichneten Trierer Erzbischofs konstruierte. Jedenfalls ist dieses Bild eines Liutwin als Schenker Mettlachs an Trier, das die Diplome vermitteln, erst seither nachweisbar. Die beiden Urkunden verwenden formal BM ${ }^{2} 626$ und DLoI. 67 sowie eventuell noch andere zeitgenössische Urkunden als Vorlagen. Sie stehen inhaltlich in engem Zusammenhang mit weiteren falschen Trierer Urkunden des späteren 10. oder früheren 11. Jahrhunderts aus dem Erzstift, die einen Trierer Bischof Modoald (nach 614/626/7-vor 646/7?) das Kloster Oeren auf Trierer Besitz gründen lassen (DDKarol. I †36, †226 u. DZw. †4). Auch diese Stücke basieren auf $\mathrm{BM}^{2}$ 626. Dieser Modoald ist das beabsichtigte Gegenbild zum Oerener Bild, nach dem Irmina das Kloster gründete. Die erste ernstzunehmende Spur Liutwins führt also nach Trier in die Zeit Erzbischof Egberts (977-993) sowie seines Konfliktes mit Oeren und den dortigen Nonnen um die Rechtsstellung des Klosters, selbst wenn es vorausgehende Bezüge zu Radbod geben könnte. Ebenso gehört der Hinweis auf eine Liutwinreliquie, die in einer Notiz zur Weihe der Außenkrypta von St. Maximin im Jahr 952 erwähnt wird, in den Trierer Kontext. In die seitdem langsam wachsenden Trierer Bischofslisten wird Liutwin erst in den frühen Jahren Egberts aufgenommen, bezeichnenderweise gemeinsam mit Modoald. 
Jetzt setzt die Liutwinverehrung geradezu unvermittelt ein und verbreitet sich schnell. Neben dem Petrusstab und dem Egbert-Psalter findet Liutwin Eingang in mehrere liturgische Texte sowie Kalendare und erscheint als Heiliger. Auch Basin ist mit geringer Verzögerung nach Liutwin wieder zu finden, aber weitaus blasser, und wird noch nicht gleich mit dem Attribut der Heiligkeit belegt. Liutwin gehörte also zunächst nach Trier, doch das änderte sich bald.

Denn im ausgehenden 10. Jahrhundert erhielt er plötzlich in Mettlach eine neue Grabkirche anstelle der dortigen alten Marienkirche. Diesen sog. ,Alten Turm' begann Abt Lioffin - wohl unter Egbert -, wenn nicht schon ein um kurze Zeit vorausgehender, weitaus großdimensionierterer Bau mit Liutwin zusammenhängt, der bald aber aufgegeben und niedergerissen wurde. Parallel dazu - wohl aber schon unter Egberts Nachfolger Liudolf (994-1008) verfaßte der Mettlacher Abt Remigius, der zuvor engen Kontakt zu Erzbischof Egbert gepflegt und als Mönch u. a. in St. Eucharius gelebt hatte, die älteste Vita Liutwins (Vita I) in Form eines sermo in Reimprosa. Dabei gibt Remigius selbst an, sich allein auf - vermeintlich - mündliche Überlieferungen zu beziehen. Von nun an jedenfalls stößt man auf die Liutwintradition: in der Egbert-Fälschung, der Berta-Urkunde von 995 oder weiteren Kalendereinträgen. In St. Maximin erinnerte man dazu die depositio Liutwins in Mettlach zum 29. September.

Schon daran wird erkennbar, daß Liutwins älteste Lebensbeschreibung Unstimmigkeiten aufweist. Denn nach der Vita starb er am selben Datum in Reims als Bischof. Bei genauerer Betrachtung fällt auf, daß die Liutwin zugeschriebenen Attribute - wie z.B. sein Dreifachepiskopat in Trier, Reims und Laon - gar nicht möglich gewesen sein können. Denn in Reims amtierte nachweislich noch Bischof Rigobert. Die narratologische Struktur der Vita läßt vielmehr erkennen, daß die Angaben zu Liutwin überwiegend aus den wenigen und später im Text plazierten, teils positiven Angaben zu seinem vermeintlichen Sohn Milo entwickelt worden sein müssen. Milo ist letztlich Grund und Auslöser des Liutwinkultes.

Denn Milo wirkte ursprünglich als Verwalter der Wirtschaft des Trierer Bistums. Vielleicht hatte er diese Funktion ebenso in Reims inne. Jedenfalls war er um das Kloster Mettlach besorgt, mit dem er auch belehnt worden war. Die Trierer Bischöfe entsandte er als Äbte dorthin, bis der letzte dieser Bischöfe, Hartham, nach Milos Tod selbst mit Mettlach belehnt wurde, womöglich auf dessen Veranlassung. Milo fand schließlich sein Grab in Mettlach. Deshalb hielt sich seine positive Memoria dort bis ins 10. und 11. Jahrhundert hinauf, wie nicht zuletzt die Vita I zeigt.

Spätestens zur Egbertzeit müssen in Trier und Mettlach allerdings die Reimser Texte rezipiert worden sein, die Milo als einen Okkupanten der Bistümer Reims und Trier beschreiben. Wahrscheinlich deshalb wurde Milo überhaupt in die Trierer Bischofsliste aufgenommen. Das Trierer Bild paßte sich 
nun dem Reimser allmählich an. Milo mußte sich demnach also langsam zum Schlechten gewandelt haben, so berichtet die Vita I. Ein unrechtmäßiger Doppelbischof stellte zudem die Trierer Primatsansprüche über die Gallia Belgica und Germania in Frage, war also ein wirkungsvolles Argument für die Gegenseite.

Wohl aus diesem Grund wird Liutwin aus Milo heraus in Form einer ,qualitativen Inversion' entworfen. Alle positiven Mettlacher und negativen Reimser Attribute, die Milo auf sich vereinigt, finden sich jetzt völlig positiv gespiegelt auf Liutwin projiziert wieder. Nun erklärt es sich, weshalb Liutwin vor seinem vermeintlichen Sohn als vorbildlicher Mehrfachbischof gewirkt haben und zuvor schon Herzog von Lothringen gewesen sein sollte. Damit nimmt er der Ämterhäufung die bisherige negative Konnotation und kehrt sie in ein Argument für Trier um. Liutwin entsteht als unbeflecktes Gegenbild zu Milo: Liutwin sorgt sich jetzt um Mettlach, Liutwin wird dort bestattet, Liutwin bringt Mettlach an das Trierer Erzstift, Liutwin hat mehrere Bistümer inne. Die Reimser und Laoner bitten ihn aus freien Stücken darum, auch ihr Hirte zu werden. Voller Fürsorge stirbt er schließlich in Reims und soll von den Trierern in Begleitung seines Sohnes Milo über Trier nach Mettlach gebracht worden sein.

Da Liutwin tatsächlich aber niemals in Reims tätig war, fand diese Translation nicht statt. Vielmehr deutet einiges darauf hin, daß man „seine“ Gebeine erst im späten 10. Jahrhundert von Trier nach Mettlach in den ,Alten Turm“ verbrachte und sich diese Begebenheit hinter dem Bericht der Vita I und der depositio-Nachricht aus St. Maximin verbirgt. Wenn es tatsächlich einen Trierer Bischof Liutwin gab, dann hatte dieser wohl nichts mit dem Kloster Mettlach zu tun. Er dürfte, was ja naheliegt, in Trier oder einer der Kirchen vor dessen Stadtmauern begraben worden sein. Liutwin kann ebensowenig Milos Vater sein. Denn ein Liutwin findet sich kein zweites Mal im Namensgut der Familie der sog. ,Widonen-Lambertiner-Miloniden'. Um die Liutwinprojektion auch von anderer Seite genealogisch zu sichern, könnte Basin zu seinem vermeintlichen Onkel gemacht worden sein.

Ein frühes unmittelbares Interesse eines Trierer Bischofs am Zustand Mettlachs läßt sich durch die noch überlieferte, heute verlorene Weiheinschrift des dortigen Petersaltars aus der Mitte des 10. Jahrhunderts belegen. Sie nennt nebeneinander den Bischof Rotbert (931-956) und den Mettlacher Abt Rotwich. Man hatte offenbar die beim Normanneneinfall zerstörte Peterskirche wiederaufgebaut.

Liutwins Kult scheint in Mettlach sowohl aus Trierer als auch hauseigenen Interessen eingeführt worden zu sein. Vielleicht machte man an der Saar aus der gerade empfundenen Not eine Tugend, weil die Verehrung Milos nicht mehr unproblematisch war. Womöglich war der neue Heilige mit der Einführung der lothringischen Klosterreform in Mettlach verbunden. Doch diente Liutwins 
Kult zweifellos ebenso dazu, das Kloster enger an das Erzstift zu binden. Dennoch vermochte er es nicht, Milos positive Memoria zu verdrängen, obgleich es gelang, andere, weit zurückreichende und zur Zeit der Vita I noch greifbare Traditionen jetzt auf Liutwin zurückzuführen. So wird nun das alte Mettlacher Dionysiuspatrozinium durch ihn begründet: Liutwin habe zunächst ein Oratorium für diesen Heiligen erbaut. Tatsächlich aber scheint Dionysius lange vor Liutwin eine zentrale Bedeutung für das Kloster eingenommen zu haben. Denn die jährliche Dionysiuswallfahrt aus dem Umland nach Mettlach ebbte mit dem aufkommenden neuen Kult ab. Mettlachs „Gründerfamilie“, die Widonen, hatte Kontakte zum Kloster St-Denis, woher sie vielleicht die Dionysiusreliquie mitbrachte. Denkbar ist aber auch, daß Mettlach diese wegen seines Status' als ehemaliges Königslehen erhielt.

Mit Liutwin wurden in Mettlach somit in vielfacher Form neue Traditionen begründet. Als man unter Erzbischof Eberhard (1047-1066) in Trier den Libellus de rebus Treverensibus verfaßte, war dieser ,neue' Liutwin durch seine Vita bereits bekannt. Man zitierte sie in knappen Sätzen. Ein zentrales Problem stellte für Trier allerdings immer noch Milo dar, dessen Bild auch jetzt stärker als das Liutwins war. Nicht nur der Schaden, den Milo in Reims anrichtete, wird betont; er sei gleichermaßen pervasor Triers gewesen. Sein Grab befinde sich in Ehrang, nördlich der Stadt, wo er auf der Jagd durch einen Eber gestorben sei, was gegen die Milomemoria des südlich von Trier gelegenen Mettlach zielen dürfte. Doch die älteste Kirche in Ehrang läßt sich archäologisch erst für das 11. Jahrhundert belegen. Der Libellus beruft sich ferner auf das Mettlacher Lothar-Diplom von 842 (DLoI. 67) und behauptet, Hetti sei vor seinem Bischofsamt dort Abt gewesen. Beides formuliert klare Ansprüche auf das Kloster, was zu Eberhards aggressiver Politik auch gegenüber Oeren und St. Maximin paßt.

Der gerade ins Amt gekommene Mettlacher Abt Nizzo III. (ab/nach ca. 1063) gab aufgrund dieser Angriffe die Miracula s. Liutwini beim jungen Thiofrid $(\dagger 1110)$ in Auftrag. Dieser hatte schon mit der Vita sanctae Irminae (bis 1066) die Klostertradition und Eigenständigkeit Oerens gegenüber Trier betont. Nun verfolgte er dieselbe Strategie für Mettlach. Es ist deshalb nicht auszuschließen, daß Thiofrid Mettlach genauer kannte, ja dort sogar einmal Schüler oder Mönch war. Thiofrid betont in den Wunderberichten Mettlachs Selbständigkeit gegenüber Trier. Konsequenterweise soll Liutwin seinen Besitz nicht mehr an Trier, sondern direkt an das Kloster selbst und seine Mönche geschenkt haben, wie eine zu Anfang stehende, von Thiofrid gefälschte Urkunde behauptet. Milo wird entgegen den Vorwürfen des Libellus', die die Miracula erkennbar aufgreifen, noch positiver betont. Denn sein Tod auf der Jagd habe nichts mit schlechter Lebensführung zu tun. Vielmehr sei er gerecht gewesen und befinde sich in der ewigen Glückseligkeit. Letztlich trägt Milo nun dazu bei, daß Mettlach an Trier kommt, ja sogar dazu, daß die Trierer die Mettlacher 
Äbte für würdig befinden, ihre Bischöfe zu werden. Daraus spricht ein beachtliches Mettlacher Selbstbewußtsein. Die Trierer Bischöfe hätten sich allerdings bald am Klostergut vergriffen. Die massiven Vorwürfe gegen den vermeintlichen Mißbrauch Erzbischof Radbods (883-915) zeigen, daß Thiofrid die beiden für Radbod ausgestellten, wenigstens manipulierten Mettlacher Diplome (DKIII. 102 u. DArn. 39) kannte und auf sie anspielt. Die Miracula bieten darüber hinaus Anordnungen des Papstes und weitere fiktive Urkunden eines Königs Karl (III., 876-888) sowie Kaiser Ottos (I., 936-973) und Erzbischof Rotberts (931-956), die Mettlach alle in seiner Eigenständigkeit bestärken. Der Text will also ganz eindeutig Ansprüche der Trierer Kirche auf das Kloster desavouieren.

Die Miracula erwähnen ferner einen Trierer vicedominus Wicelin, ein ,Wichtlein', das das alte Mettlacher Güterverzeichnis verbrannt habe, damit das Kloster seinen enteigneten Besitz nicht mehr nachweisen könne. Doch offenbar hat diese Anekdote mehr damit zu tun, daß man unter Abt Nizzo III. in der zweiten Hälfte des 11. Jahrhunderts ebenso damit begann, ein neues Verzeichnis in Form einer Güterrolle anzulegen. Die nur wenigen dafür noch greifbaren Vorlagen mußten in irgendeiner Form erklärt werden. Wohl findet sich ein Fest Liutwins in den urbarialen Einträgen der Rolle, die angeblich auf älterem Material aus der Mitte des 10. Jahrhunderts beruhen. Auch die Notiz über eine Kirchweihe Bischof Rotberts in Udern spricht von einem Gottesdienst zu Liutwins Ehren und begründet damit dortigen Mettlacher Besitz. Allerdings legen es Unstimmigkeiten der Notiz im Vergleich mit einem weiteren Eintrag und fehlende Hinweise auf Liutwin in den vermeintlich jüngeren Einträgen nahe, hier mit Interpolationen oder Nachträgen in bestehende Vorlagen oder im Zuge der Kopie auf den rotulus zu rechnen. Der aufkeimende Liutwinkult muß dazu angeregt haben. Die auf der Rückseite eingetragenen Traditionsnotizen zeigen zudem, daß noch bis ca. 1126 Petrus das Mettlacher Hauptpatrozinium war, das erst danach von Liutwin überflügelt wurde.

Nizzo III. vollendet gemäß den Miracula ebenso den ,Alten Turm` und versieht ihn mit einem Anbau. Liutwins Kult tritt in eine neue, zweite Phase. Diese Zäsur wird auch durch eine neue, überarbeitete Vita (II) verdeutlicht, die ebenso Thiofrid von Echternach ca. 1072/7 verfaßte und die der klosterfreundliche Erzbischof Udo von Trier (1066-1078) erhielt. Thiofrid nimmt seine schweren, noch in den Miracula gemachten Vorwürfe gegen Trier in dieser Vita erkennbar zurück und formuliert moderater. Liutwin schenkt nun all seinen Besitz bereits vor seinem Klostereintritt an Trier. Milo kann ihn zwar nicht mehr beerben. Doch sorgen Karl Martell und die Trierer dafür, daß er dennoch Bischof wird, weil er die positiven Eigenschaften seines Vaters spiegele. Milos Memoria ließ sich offensichtlich nicht trüben, im Gegenteil. Liutwins Kult in Mettlach stabilisierte sich jetzt. Die Redaktion A der Gesta Treverorum (1101) greift sowohl die Mettlacher als auch Trierer Bilder auf und verbindet sie. 
Liutwin und Milo emanzipieren sich voneinander. Das positive Mettlacher Milobild ließ sich nun in Trier gekoppelt an Liutwins Bild verbreiten.

Zur selben Zeit begann sich ebenso Basins Kult auszuweiten. Basin erlangte als vermeintlicher Onkel Liutwins durch die beiden Viten wahrscheinlich zunehmend an Bedeutung. Zentrum seiner Verehrung war seit etwa der Mitte des 11. Jahrhunderts St. Maximin, als dessen früherer Abt er ausgegeben wird, um Besitzansprüche des Erzstifts gegen das Reichskloster abzuwehren. Auch will man dort bald über Basins Grab verfügen, obwohl die St. Maximiner Weihenotiz von 952 ihn nicht nennt.

Liutwins Kult hatte sich inzwischen soweit etabliert, daß er sich zudem anderweitig einsetzen ließ. Auf diese Weise fand Liutwin Eingang in die sog. Irmina-Urkunden. Thiofrid von Echternach hatte mit seiner Irmina-Vita (bis 1066) einen entscheidenden Schritt getan, den Kult der von ihm neu geschaffenen hl. „Doppel-Irmina“ weiter zu forcieren. Thiofrid kannte, wie seine Irmina- und auch seine Willibrord-Vita (1103/4) zeigen, nur das „Ur-Testament“ der Echternacher Irmina, das er jeweils als Regest wiedergibt. Nach diesen beiden Viten, aber ebenso den Urkunden Pippins und Plektruds von 706 (Urkunden der Arnulfinger 4 u. 5) sowie Alkuins Willibrord-Vita (785/97) gilt Willibrord allein als Gründer Echternachs, während Irmina sowie Pippin und Plektrud gemeinsam Grundbesitz für die Ausstattung des Klosters zur Verfügung stellen.

Das änderte sich nun. Das Bild der ,neuen“ „Doppel-Irmina“ ließ sich als wirkmächtiges Argument einsetzen, zumal sie nach ihrem Trierer Teilbild Königstochter gewesen sein sollte. So fälschte vermutlich der junge Mönch Theoderich in Echternach nach der Mitte des 12. Jahrhunderts zunächst Irminas Steinheim-Urkunde (Wамрасн I 2, Nr. 9), um diesen Ort vor den Übergriffen der Luxemburger Vögte zu sichern. In der Urkunde schenkt die Echternacher Irmina, die nun zur (Oerener) Äbtissin avanciert ist, Steinheim an Willibrord für sein Kloster. Als Vorlage für die Fälschung benutzte Theoderich das erwähnte „Ur-Testament“ und eine weitere, zu dieser Zeit noch erhaltene ältere Urkunde: die Weinberg-Schenkung einer Engela an Echternach (die ursprüngliche Fassung von Waмpaсн I 2, Nr. 10). Tatsächlich aber handelte es sich bei Steinheim um eine Karolinger-Schenkung, wie zwei echte Karolingerdiplome um 900 zeigen (DZw. 5 u. DKdE 76). Vielleicht wurde schon jetzt die Engela-Urkunde in eine Irmina-Urkunde verunechtet, indem man Irmina zur Empfängerin der Engela-Schenkung machte, die sie dann weiter an Echternach gibt.

Als der Trierer Erzbischof Johannes (I., 1189-1212) 1191/2 versuchte, Echternach unter Kaiser Heinrich VI. (1169-1197) an Trier zu ziehen und dessen Rechtsstellung als Reichsabtei aufzuheben, sah man sich im Sauerkloster erneut zum Handeln gezwungen. Der Mönch Theoderich erstellte deshalb auf Veranlassung seines Abtes Gottfried II. (1181-1210) ein Kopiarbuch der frü- 
hen Echternacher Urkunden als Chartularchronik: den Liber aureus. Darin macht er nun die hl. „Doppel-Irmina“ sogar zur Klostergründerin Echternachs. Er stellt die Vita sanctae Irminae dem Urkundenteil voran und läßt ihr die fünf ver- bzw. gefälschten sog. Irmina-Urkunden folgen (WАмрасн I 2, Nr. 3, 4, 6, 9 u. 10 in der jüngsten Fassung). Bei der ersten (Waмpach I 2, Nr. 4) handelt es sich um eine verkürzte Form des „Ur-Testaments“ vom 1. Dezember 697/8 (Waмpaсн I 2, Nr. $4+2$. Teil von Nr. 6), in der Irmina nachträglich aus einer Nonne (oder Adligen) zur Äbtissin gemacht und als weiterer Zeuge neben dem authentischen Bischof Basin noch Bischof Liutwin interpoliert wird. Vielleicht geschieht das, weil ein presbiter Liutwin im „Ur-Testament" unterschrieb, den der Mönch Theoderich für den hl. Trierer Bischof hielt. Die zweite Urkunde (Wамрасн I 2, Nr. 3) ist eine plumpe, auf den 1. November 697/8 vordatierende Fälschung, konstruiert aus dem Vokabular des „Ur-Testaments“. In ihr überträgt Irmina auf Anraten der Trierer Bischöfe Basin und Liutwin zwei Kirchen auf ihrem Echternacher Besitz an Willibrord sowie ein Klösterlein, das sie selbst einmal für Pilgermönche gegründet haben will. Sie tut dies aus Dankbarkeit Willibrord gegenüber; erst dann schenkt sie auch ihren Besitz in Echternach.

Es ist also das Ziel des Mönchs Theoderich, Irmina im Liber aureus zur eigentlichen Gründerin Echternachs noch vor Willibrord zu machen und dabei ganz entscheidend zwei Trierer Erzbischöfe beteiligt sein zu lassen. Dieses Motiv setzt sich in den drei weiteren Irmina-Urkunden fort, in denen sie sich nun selbst als Erbauerin des Klosters bezeichnet (WАмрасн I 2, Nr. 6, 9 u. 10). In der Urkunde, die als zweiter Teil vom „Ur-Testament“ abgespalten und um die Schenkung einer liturgischen Ausstattung ergänzt worden ist, treten nochmals Basin und Liutwin gemeinsam als bischöfliche Zeugen auf (WАмрасн I 2, Nr. 6). Da nach dieser Konstruktion die hl. Irmina, der hl. Liutwin und der hl. Basin bei der Schenkung des Klosters an Willibrord beteiligt gewesen sein sollten, mußte der Trierer Bischof Johannes sein Vorhaben schließlich erfolglos aufgeben. Echternach blieb Reichskloster.

In den Kontext dieser Fälschungen gehört ferner die erwähnte, vermeintliche Liutwin-Schenkung an das Kloster St. Eucharius (MRUB I 7a) von 706. Man nutzte den heiligen Bischof erneut, um Rechte und Ansprüche in eine weit zurückliegende Vergangenheit zu projizieren, und bediente sich einiger Echternacher Urkunden als Vorlage. Unter Abt Ludwig von Echternach und St. Eucharius (seit 1173) oder dessen Nachfolger Gottfried II. im Doppelabbatiat war ein solcher Informationsaustausch einfach möglich. Erst in dieser Zeit wurde die Urkunde vermutlich vom Mönch Theoderich gefälscht.

Damit sind wir am Ende der Bilder von Liutwin und Basin sowie wohl auch von Milo, Irmina und Willibrord angelangt. Die verschiedenen Einzelbilder, die die Forschung bislang zu einem Gesamtbild zusammengefügt hat, sind als Produkte einer langen Genese bzw. eines sich über mehrere Jahrhunderte hin- 
ziehenden dynamischen Prozesses deutlich geworden. Jede Zeit betrachtet diese Personen anders, erkennt in ihnen anderes und konstruiert sie in ihrem eigenen Kontext neu. Wie kontingent deren Bilder insgesamt sind, zeigt sich nicht zuletzt daran, daß die wenigen, bisher für zeitgenössisch gehaltenen Bilder Liutwins chronologisch vielmehr an der letzten Stelle des hier untersuchten Bilderflusses stehen. 